\title{
1,2,3-(NH)-triazoles: Its metal-free synthesis and application as ligands in transition metal catalysis
}

\author{
Sujata Sengupta \\ West Virginia University
}

Follow this and additional works at: https://researchrepository.wvu.edu/etd

\section{Recommended Citation}

Sengupta, Sujata, "1,2,3-(NH)-triazoles: Its metal-free synthesis and application as ligands in transition metal catalysis" (2010). Graduate Theses, Dissertations, and Problem Reports. 4653.

https://researchrepository.wvu.edu/etd/4653

This Dissertation is protected by copyright and/or related rights. It has been brought to you by the The Research Repository @ WVU with permission from the rights-holder(s). You are free to use this Dissertation in any way that is permitted by the copyright and related rights legislation that applies to your use. For other uses you must obtain permission from the rights-holder(s) directly, unless additional rights are indicated by a Creative Commons license in the record and/ or on the work itself. This Dissertation has been accepted for inclusion in WVU Graduate Theses, Dissertations, and Problem Reports collection by an authorized administrator of The Research Repository @ WVU.

For more information, please contact researchrepository@mail.wvu.edu. 


\section{1,2,3-(NH)-Triazoles: Its Metal-free synthesis and application as}

ligands in transition metal catalysis

\section{Sujata Sengupta}

Dissertation submitted to the Eberly College of Arts and Sciences at West Virginia University in partial fulfillment of the requirements for the degree of

\section{Doctor of Philosophy}

in

Organic Chemistry

Xiaodong Shi, Ph.D., Chair

Peter Gannett, Ph.D.

George O'Doherty, Ph.D.

Björn Söderberg, Ph.D.

Kung Wang, Ph.D.

C. Eugene Bennett Department of Chemistry

Morgantown, West Virginia

2010

Keywords: Lewis base catalysis, cross double-Michael addition, 1,2,3-triazoles, transition metal catalysis, hydroamination 


\section{Abstract \\ 1,2,3-(NH)-Triazoles: Its Metal-free synthesis and application as ligands in \\ transition metal catalysis}

Sujata Sengupta

An intermolecular cross-double-Michael addition between nitro and carbonyl activated olefins has been successfully developed through Lewis base catalysis. The reaction tolerates a large substrate scope with a variety of $\beta$-alkyl nitroalkenes and unsaturated ketones/esters being suitable, producing the allylic nitro compounds in good to excellent yields. This Lewis base approach was further expanded to a three component metal free cascade reaction for the synthesis of 4,5-disubstituted-1,2,3-(NH)-triazoles. More than 25 new $(\mathrm{NH})$-triazoles were prepared in good to excellent yields under mild reaction conditions. In addition, the availability of the C-4 vinyl group allows for the easy conversion into other triazole derivatives. The synthesized $(N H)$-triazoles were subsequently developed as promising ligands for $\mathrm{Rh}(\mathrm{I})$ and $\mathrm{Au}(\mathrm{I})$ metal cations. The 4,5disubstituted-1,2,3-(NH)-triazoles were applied to coordinate with $\mathrm{Rh}(\mathrm{I})$ metal cation, forming a new class of air and moisture stable triazole-bridged complexes in near quantitative yields. Furthermore, the X-ray crystallography studies revealed that the $\mathrm{C}-4$ substituted groups effectively controlled the triazole binding site, resulting in different coordination patterns. In addition a series of 1,2,3-triazole-bound cationic Au(I) catalysts have been synthesized, and their structures were characterized by X-ray crystallography. Variable-temperature NMR studies revealed a dynamic triazole-Au cation coordination in solution. Reaction profiles clearly indicate these new catalysts to possess much better thermal stability than literature-reported Au catalysts, including IPrAu NTf $_{2}$. 


\section{Dedicated to}

$$
\begin{aligned}
& \text { My OAmazing OParents } \\
& \text { Myy wonderful sister } \\
& \text { And my loving Mllisband }
\end{aligned}
$$




\section{Acknowledgments}

First and foremost, I am heartily thankful to my supervisor, Dr. Xiaodong Michael Shi, whose constant encouragement, guidance and support from the initial to the final level enabled me to develop a deep understanding and love for the science of organic chemistry. I owe my growth and maturation as a scientist to him. Without his help this thesis would truly not have been possible. I would also like to thank Dr. George O’Doherty, Dr. Björn Söderberg, and Dr. Kung Wang for their roles in my academic development. Their invaluable advice and suggestions throughout my years here in WVU are appreciated and acknowledged. In addition, I would like to thank the above mentioned and Dr. Peter Gannett for their roles on my Doctoral Research Committee.

I extend my gratitude to Dr. Jeffrey Petersen for his countless number of X-ray crystallographic analyses and Dr. Novruz Akhmedov for performing his NMR techniques in ${ }^{31}$ P-NMR. In addition, I would like to thank Dr. Petersen and Dr. Harry Finklea for their constant guidance and support during my graduate studies. Financial support from the C. Eugene Bennett Department of Chemistry, West Virginia University (particularly for a John. H. Trotter Scholarship), the Eberly College of Arts and Sciences (for Robert E. Stitzel Doctoral Travel Grant), WVNANO (for summer fellowships) and NSF is also gratefully acknowledged. In addition I would like to thank the Graduate Dissertation Fellowship from the Office of Graduate Student Affairs, WVU, for financial support during the writing of this thesis.

Also in my thoughts are my colleagues and fellow group members, past and present. I thank each one of them for their co-operation, guidance and help in my academics and research. I would particularly like to thank Dr. Haifeng Duan for teaching me all that I know in transition metal catalysis. I cannot thank him enough for his constant mentorship and friendship throughout the course of my graduate studies.

Most importantly, I would like to thank my family for their unconditional love, support and guidance throughout my life. Had it not been for you, Ma and Baba, I would have never been the person I am today. You are both the best role models, mentors, and parents a daughter can ever ask for. For all that you gave me and for all that you are to me, words 
are never enough to say how thankful and fortunate I am to have you both as my parents. To my sister Jayeeta, I would like to thank you for a lifetime of sisterhood and friendship. Though our careers prevent us from seeing each other as much as I would like, know that I will always be there for you and will always love you. Finally, to love of my life, my dear husband, Dibyo, I thank you for your constant and unconditional love and support throughout these past few years. We met and married during the course of my graduate studies here at WVU and I cannot thank you enough for all the sacrifices you have made during the past few years. As I am about to finish my time as a student here in Morgantown, I look forward to a wonderful lifetime of togetherness. 


\section{TABLE OF CONTENTS}

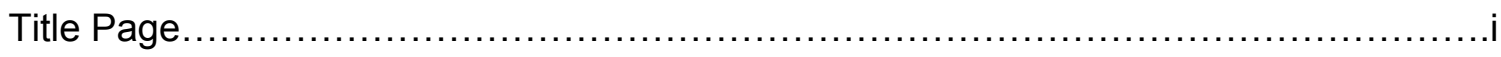

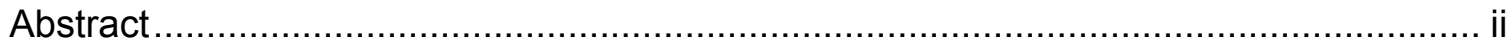

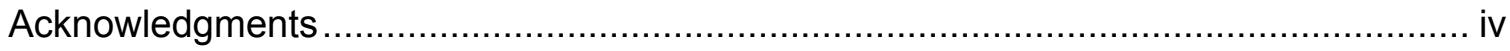

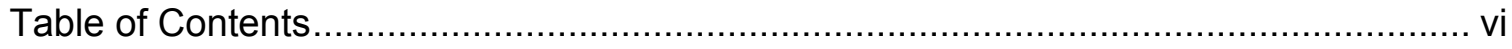

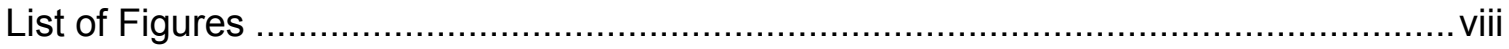

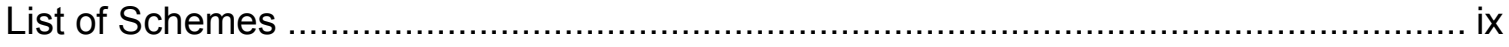

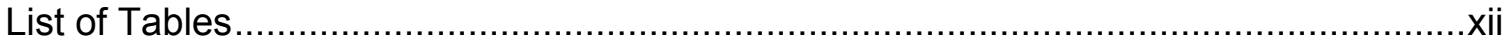

Chapter One: Intermolecular cross-double Michael addition between nitro and carbonyl activated olefins as a new approach in C-C bond formation

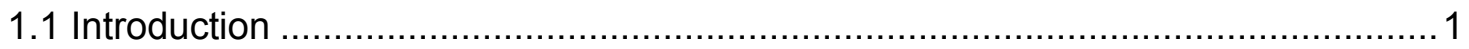

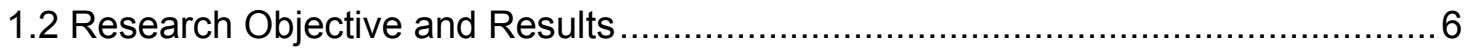

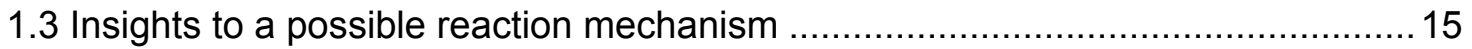

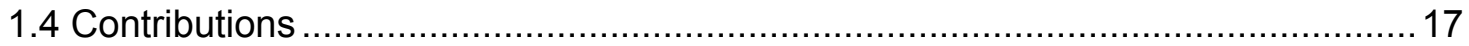

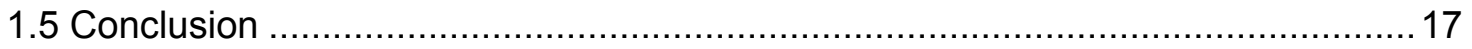

Chapter Two: One step cascade synthesis of 4,5-disubstituted-1,2,3-(NH)-triazoles

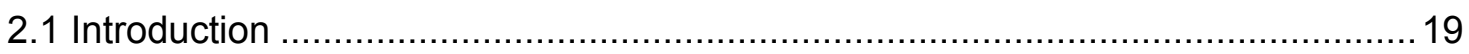

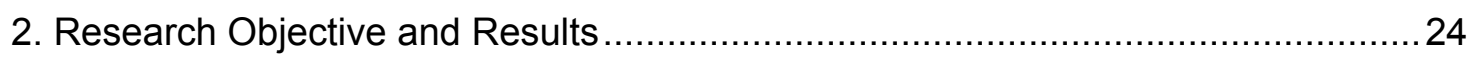

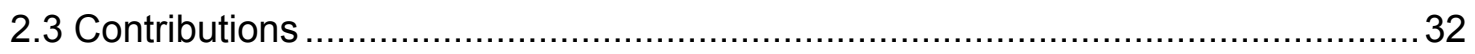

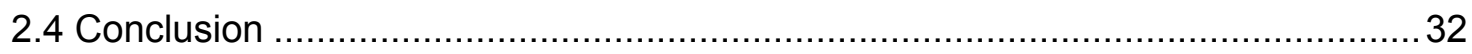

Chapter Three: Synthesis and Characterization of NH-triazole Coordinated Rh(I) complexes

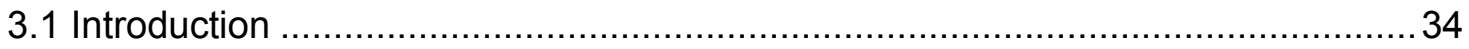

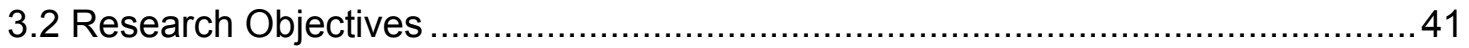

3.3 Results: Synthesis of $[\mathrm{Rh}(\mathrm{COD})(\mathrm{Triaz})]_{2}$ Complexes ............................42

3.4 Evaluation of Catalytic activity ..........................................................

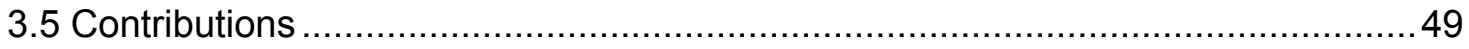

3.6 Conclusions 


\section{Chapter Four: Triazole-Au(I) complexes- A new class of catalysts with improved thermal stability and reactivity}

4.1 Introduction: Homogeneous Gold Catalysis ................................................. 51

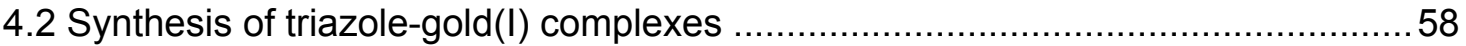

4.3 Efforts towards the synthesis of chiral triazole-gold(I) complexes ......................64

4.3 Determination of dynamic coordination nature of triazole-gold(I) complexes .......66

4.5 Catalytic reactivity of the triazole-gold(I) complexes. ..................................... 69

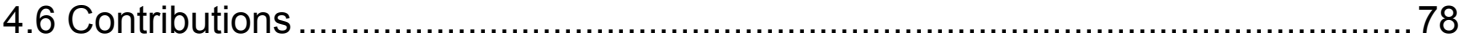

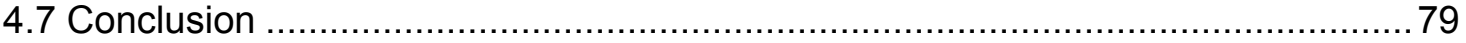

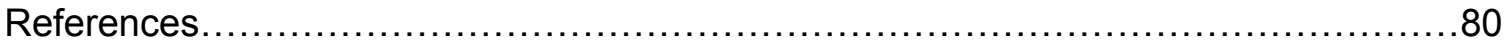

Supporting Information

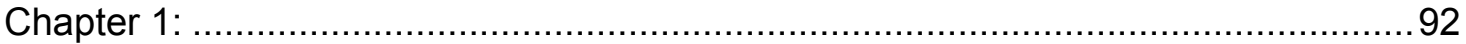

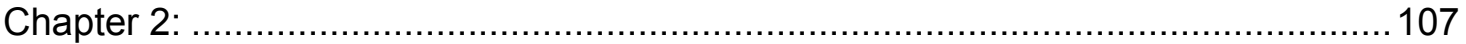

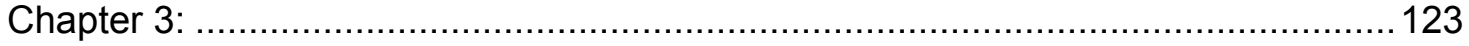

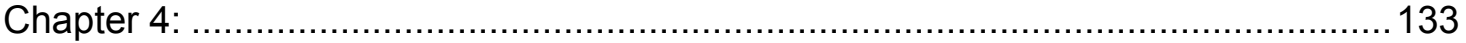

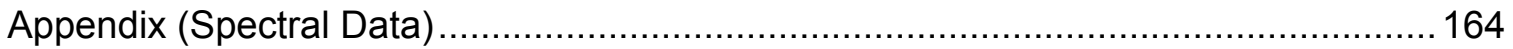




\section{LIST OF FIGURES}

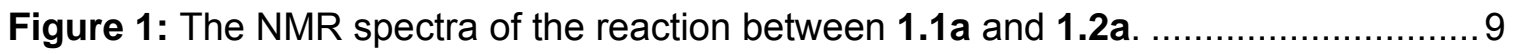

Figure 2: Popular ligands from organometallic catalysis.................................... 35

Figure 3: 1,2,3-triazole as neutral binding ligand. ........................................... 38

Figure 4: X-ray crystal structure for triazole bound $\mathrm{Rh}(\mathrm{I})$ complex $3.1 \mathrm{a} . \ldots \ldots \ldots \ldots \ldots \ldots \ldots . . . . . . . . . .43$

Figure 5: X-ray crystal structure for triazole bound $\mathrm{Rh}(\mathrm{I})$ complex $\mathbf{3 . 1 b} \ldots \ldots \ldots \ldots \ldots \ldots \ldots . \ldots . \ldots \ldots$

Figure 6: X-ray crystal structure for chiral triazole bound $\mathrm{Rh}(\mathrm{I})$ complexe $3.1 \mathrm{c} . \ldots \ldots \ldots . . . .44$

Figure 7: X-ray crystal structure for pyridine-triazole-Rh(I) complex $\mathbf{3 . 1 d} \ldots \ldots \ldots \ldots \ldots \ldots . . \ldots 6$

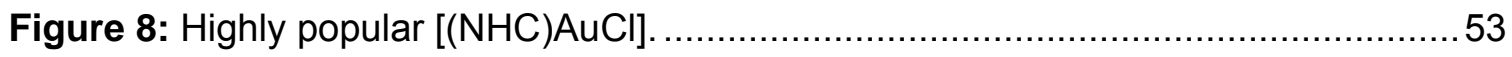

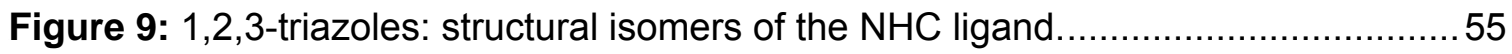

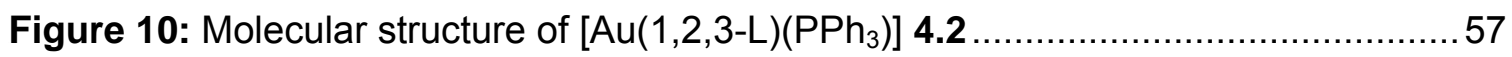

Figure 11: ${ }^{31} \mathrm{P}-\mathrm{NMR}$ spectra measured in $\mathrm{CD}_{2} \mathrm{Cl}_{2}$ of $\left[\mathrm{Au}(1,2,3-\mathrm{L})\left(\mathrm{PPh}_{3}\right)\right] 4.2 \quad \ldots \ldots \ldots \ldots . . .58$

Figure 12: X-ray crystal structure for triazole bound $\mathrm{Au}(\mathrm{I})$ complex $4.4 \mathrm{a} . \ldots \ldots \ldots \ldots \ldots \ldots . \ldots 1$

Figure 13: X-ray crystal structure for triazole bound $\mathrm{Au}(\mathrm{I})$ complex 4.4b...................61

Figure 14: X-ray crystal structure for triazole bound $\mathrm{Au}(\mathrm{I})$ complex $4.5 \mathrm{a} . \ldots \ldots \ldots \ldots \ldots \ldots . \ldots 3$

Figure 15: X-ray crystal structure for triazole bound $\mathrm{Au}(\mathrm{I})$ complex $4.6 \mathrm{f} . \ldots \ldots \ldots \ldots \ldots \ldots \ldots . \ldots \ldots$

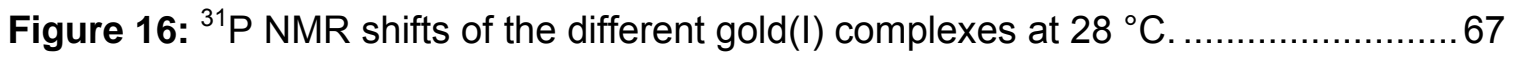

Figure 17: VT NMR studies $\left({ }^{31} \mathrm{P}\right.$ NMR spectra) complex 4.4b ..............................68

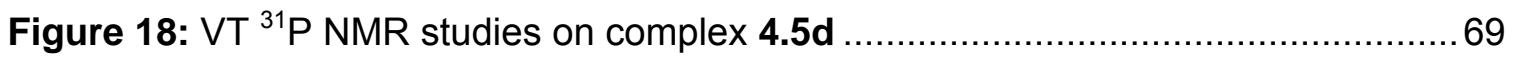

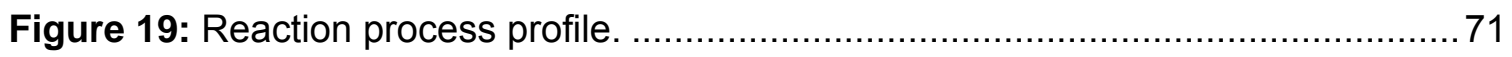




\section{LIST OF SCHEMES}

Scheme 1: The $\mathrm{BH}$ reaction and cross double-Michael addition reaction.

Scheme 2: The Intermolecular Rauhut-Currier reaction and its proposed reaction mechanism.

Scheme 3: $\mathrm{P}(\mathrm{Cy})_{3}$-catalyzed cross-coupling $\mathrm{RC}$ reaction reported by Morita and Kobayashi. 4

Scheme 4: Cross-coupling in the $\mathrm{RC}$ reaction by McClure and coworkers. 5

Scheme 5: Rauhut-Currier $(\mathrm{RC})$ reaction. 5

Scheme 6: Examples of asymmetric intramolecular $R C$ reaction by Krische $(A)$, Miller

(B) and Wang (C) groups.

Scheme 7: Challenges associated with a successful cross double-Michael addition reaction

Scheme 8: Initial reaction of $\beta$-nitrostyrene with cyclohexenone and observed polymerization of the nitroalkene.

Scheme 9: Successful cross double-Michael addition reaction involving $\alpha-m e t h y l-\beta-$

nitrostyrene and cyclohexenone.

Scheme 10: Further functional group transformation - easy steps to overcome the low diastereoselectivity

Scheme 11: Possible modes of reaction for the cross double-Michael addition.

Scheme 12: Computational studies revealing an unfavored equilibrium for the carbanion second Michael addition. 17

Scheme 13: $2^{\circ}$ amines as effective Lewis base for activation of nitroalkenes. 18

Scheme 14: Huisgen's 1,3-dipolar cycloaddition vs CuACC 20 
Scheme 15: Example of CuAAC by Sharpless and Folkin.................................... 20

Scheme 16: Proposed reaction mechanism of the CuAAC ......................................21

Scheme 17: Synthesis of N-substituted-triazoles through CuAAC ...........................22

Scheme 18: Zefirov's method for the synthesis of 1,2,3-triazoles............................22

Scheme 19: Zard's reinvestigation of Zefirov's method for the synthesis of 1,2,3-

triazoles.

Scheme 20: Thermal condensation of $\alpha$-nitroalkene and $\mathrm{NaN}_{3}$ for the synthesis of 1,2,3triazoles (Zard's method). 24

Scheme 21: Lewis base catalyzed intermolecular double-Michael addition reaction.....24

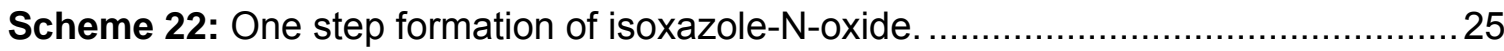

Scheme 23: Proposed reaction mechanism for the synthesis of isoxazole-N-oxides. $\ldots 25$

Scheme 24: One step metal free cascade synthesis of 4,5-disubstituted-1,2,3-(NH)triazoles. 26

Scheme 25: Side chain modifications of 4,5-disubstituted-1,2,3-(NH)-triazoles. 31

Scheme 26: Synthesis and resolution of enantiomerically pure hydroxyl-(NH)-triazole. 32 Scheme 27: Application of C3-symmetric polytriazoles as stabilizing ligands for $\mathrm{Cu}$ in "Click Chemistry". 36

Scheme 28: Triazoles as nitrogen donors in $\mathrm{P}, \mathrm{N}$-type ligands by van Marseveen and coworkers. 37

Scheme 29: Triazoles as monodentate Lewis-basic ligands for cationic Pd- and Pt-NCN pincer ligands by Gebbink and coworkers. 38

Scheme 30: Synthesis of $[\mathrm{Rh}(\mathrm{Btz})(\mathrm{COD})]_{2}$ complexes by Oro and co-workers........ 40

Scheme 31: Synthesis of 4,5-dicyanosubstituted-1,2,3-(NH)-triazole-Rh(I) complex by

Oro and co-workers and its proposed structure. 41

Scheme 32: Different binding sites for the $\mathrm{NH}$-triazole under basic condition. 42

Scheme 33: General method of synthesis for triazole-Rh(I) complexes. 
Scheme 34: The Inter- and Intramolecular Pauson-Khand reaction.

Scheme 35: General formation of active gold(I) species...................................5 52

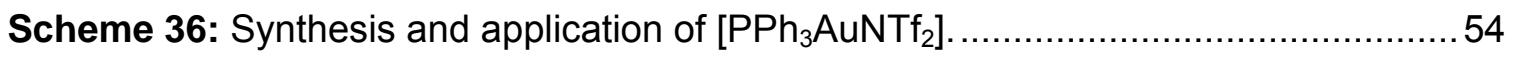

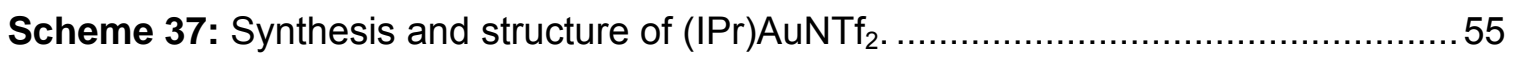

Scheme 38: Synthesis of triazole bound complexes by Nomiya and co-workers. .........56

Scheme 39: Synthesis of vinyl substituted triazoles through $\mathrm{Au}(\mathrm{I})$ alkyne activation. ....59

Scheme 40: Synthesis of triazole bound gold(I) complexes under basic conditions......60

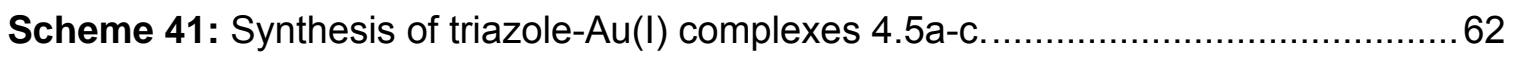

Scheme 42: Silver free method for the synthesis of active triazole-Au(I) complexes.....62

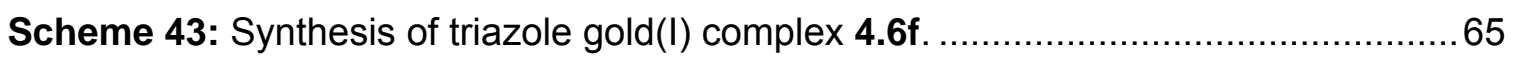

Scheme 44: Acid promoted hydroamination of alkynes by Tanaka et. al.....................70

Scheme 45: Triazole-Au(I) complex catalyzed synthesis of substituted pyrroles...........78 


\section{LIST OF TABLES}

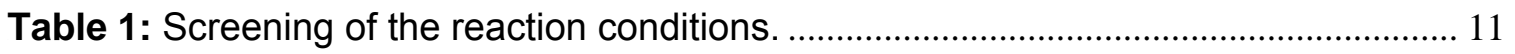

Table 2: Substrate scope of the cross double-Michael addition reaction.......................... 12

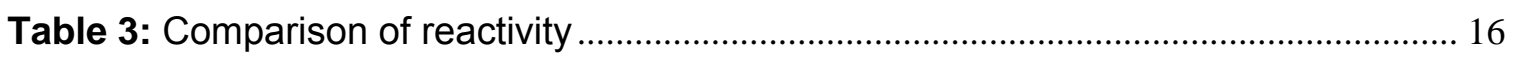

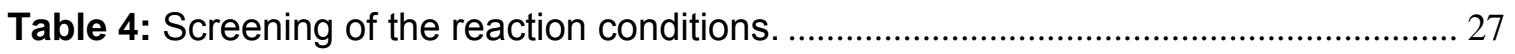

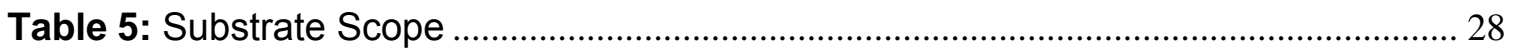

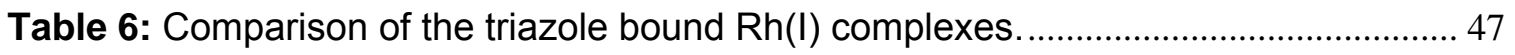

Table 7: Catalytic reactivity of the triazole bound $\mathrm{Rh}(\mathrm{I})$ complexes. .................................. 49

Table 8: Screening of the catalyst for triazole-alkyne addition. ...................................... 59

Table 9: Comparison of $\mathrm{Au}(\mathrm{I})$ catalysts in Internal Alkyne Hydroamination........................ 72

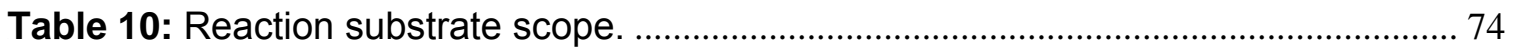

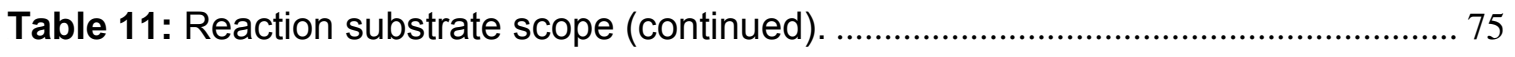

Table 12: Comparison of different gold(I) catalysts towards hydroamination of

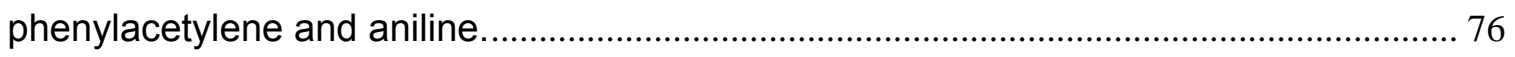

Table 13: Comparison of different gold(I) catalysts towards hydroamination of 1-propyne

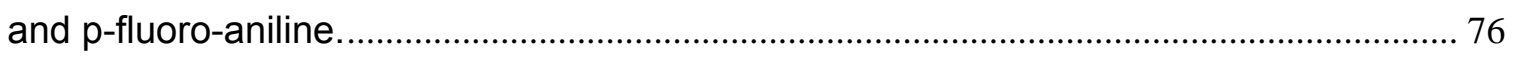

Table 14: Comparison of different gold(I) catalysts towards hydroamination of internal

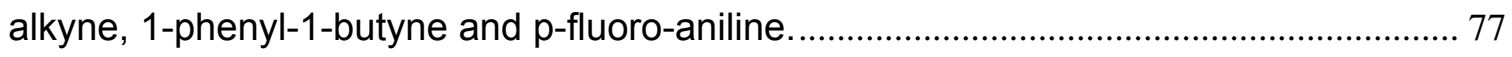

Table 15: Comparison of different gold(I) catalysts towards hydroamination of

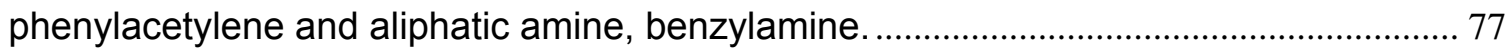




\section{Chapter One: Intermolecular cross-double Michael addition between nitro and carbonyl activated olefins as a new approach in $\mathbf{C}-\mathbf{C}$ bond formation ${ }^{\ddagger}$}

\subsection{Introduction}

Efficient $\mathrm{C}-\mathrm{C}$ bond formation and implementation of diverse functionality are two crucial aspects in organic synthesis ${ }^{1}$ with much research currently being focused on the control of reaction efficiency, stereoselectivity, and chemoselectivity. ${ }^{2}$ In addition, during the past two decades, tandem (or cascade or sequential) reactions of designated precursors have brought great attention to the construction of complicated organic molecules. ${ }^{3}$ Significant progress has been made using this strategy in the total synthesis of natural products and towards the synthesis of biologically activated molecules. ${ }^{4}$ The fact that tandem reactions of different substrates can rapidly combine organic functionalities within "one step" provides undeniable benefits as a simple, efficient, and atom economical approach in organic synthesis. Meanwhile, intermolecular sequential reactions across different reactants have been developed into many powerful methodologies, including the Mannich reaction, ${ }^{5}$ the Baylis-Hillman (BH) reaction, ${ }^{6}$ and the Robinson annulations ${ }^{7}$ etc. Among the many intermolecular sequential reactions established for the construction of a new $\mathrm{C}-\mathrm{C}$ bond, nucleophilic conjugate addition reactions (such as the Baylis-Hillman reaction) serve as a significant and synthetically useful method, with the ability to build rings, set multiple stereo centers and process a wide variety of substrates. ${ }^{8}$ Our interests in developing new organic reactions with the

\footnotetext{
${ }^{\dagger}$ Reproduced in parts with permission from Org. Lett. 2007, 9, 4495-4498. Copyright 2007 with permission from American Chemical Society.
} 
capability of rapid functional group construction originated from the Lewis base (LB) mediated Baylis-Hillman reaction (Scheme 1, reaction A). Similar to the BH-reaction, as shown in reaction B (Scheme 1), the successful intermolecular cross-double-Michael addition will also lead to highly attractive products in a single step and thereby provide a highly efficient methodology towards complex molecule synthesis.

Scheme 1: The Baylis-Hillman reaction and the cross double-Michael addition reaction.

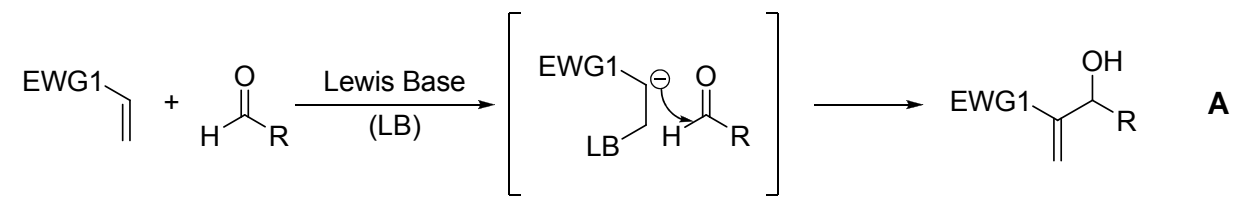

Baylis-Hillman Reaction

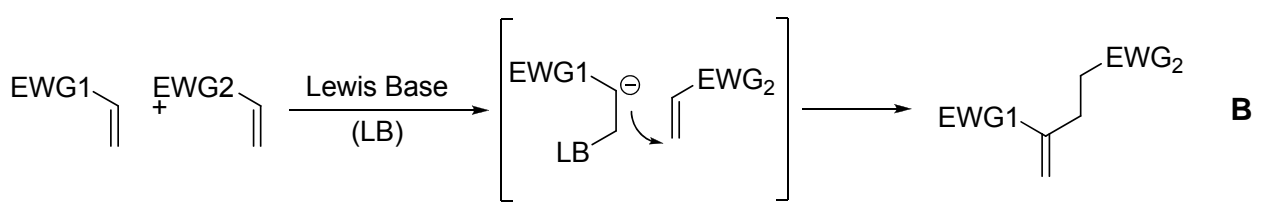

Intermolecular Cross Double Michael Addition

According to the literature, the only successful example employing this strategy is the homodimerization of enones by action of an organophosphine, which is commonly referred to as the Rauhut-Currier $(\mathrm{RC})$ reaction. ${ }^{9}$ While the $\mathrm{BH}$ reaction involves the coupling of the activated alkene/latent enolate with an aldehyde, the RC reactions (also known as the vinylogous $\mathrm{MBH}$ reaction), ${ }^{10}$ involves the coupling of one active alkene/latent enolate to a second Michael acceptor, creating a new C-C bond between the $\alpha$-position of one activated alkene and the $\beta$-position of a second alkene under the influence of a nucleophilic catalyst. Over the years, a vast array of literature has been established regarding the $\mathrm{BH}$ reaction, reflecting its potential to greatly affect organic 
synthesis by providing densely functionalized products with a new stereogenic center that serve as substrates for a multitude of subsequent transformations. ${ }^{11}$ The RC reaction, on the other hand, has received less attention due to low reactivity of substrates and difficulty in controlling the selectivity of the cross coupling reaction.

In 1963, Rauhut and Currier reported the phosphine-catalyzed dimerization of electron-deficient alkenes, acrylonitrile and ethyl acrylate, in what has become to be known as the RC reaction (Scheme 2). ${ }^{12}$ The transformation is believed to proceed via a reversible conjugate addition of a nucleophilic catalyst (either a trialkyl- or triarylphosphine) to an activated alkene to generate a zweterionic species. A Michael reaction on the enolate with a second equivalent of activated alkene followed by a prototropic shift and consequent extrusion of the phosphine catalyst generates the RC coupling product.

Scheme 2: The Intermolecular Rauhut-Currier reaction and its proposed reaction mechanism.
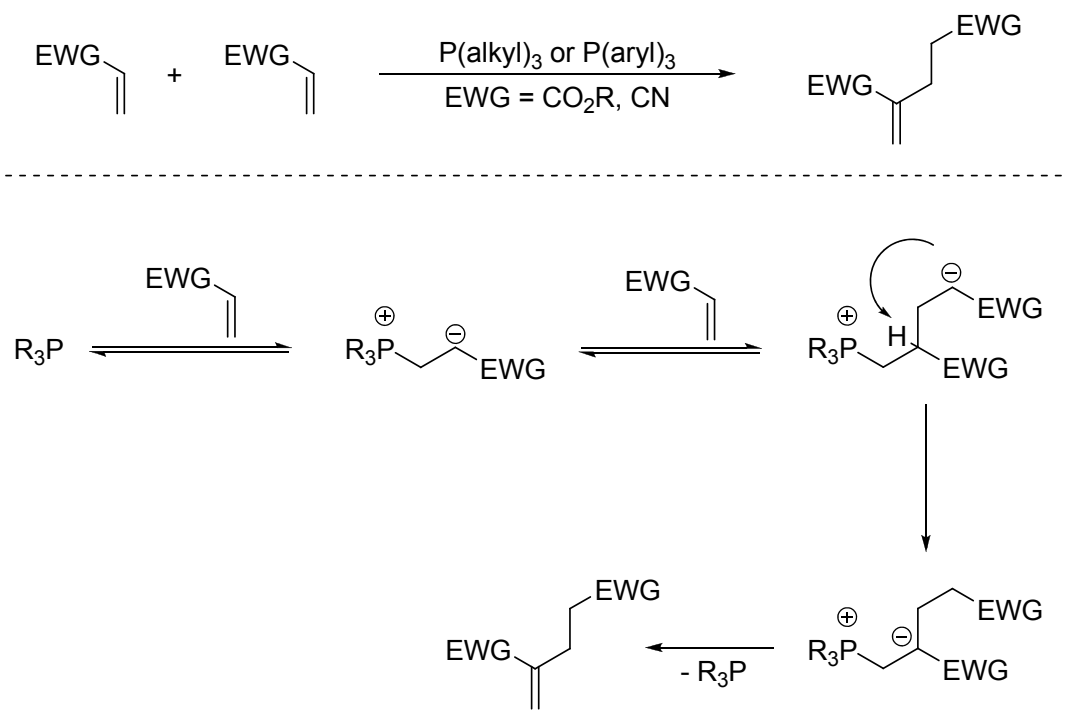
Although this reaction was first discovered in 1963, the development of this reaction has not been rapid and great advances have not been made until very recently, providing the synthetic community with an efficient method for the construction of C-C bonds. ${ }^{13}$ The earliest example involving the cross-coupling $\mathrm{RC}$ reaction was that of activated alkenes (methyl acrylate and acrylonitrile) with fumaric/maleic esters reported by Morita and Kobayashi and yields as high as $96 \%$ were achieved (Scheme 3). ${ }^{14}$

Scheme 3: $\mathrm{P}(\mathrm{Cy})_{3}$-catalyzed cross-coupling $\mathrm{RC}$ reaction reported by Morita and Kobayashi.
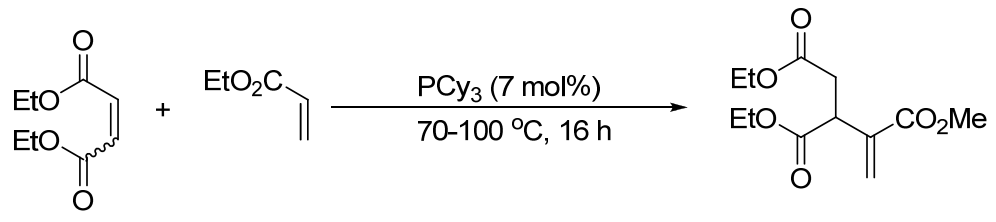

$95.5 \%$

Later on, McClure had presented a similar cross-coupling reaction of ethyl acrylate with acrylonitrile catalyzed by $\mathrm{PBu}_{3}($ Scheme 4$) .{ }^{15}$ However, only one of the two cross-coupled products was obtained along with the products corresponding to the homodimerization of both the reactants. Since then, various reports of $\mathrm{RC}$ reactions involving amine-based catalysts have since been reported, but most involve the homodimerization of the reactants. ${ }^{16}$ 
Scheme 4: Cross-coupling in the $\mathrm{RC}$ reaction by McClure and coworkers.

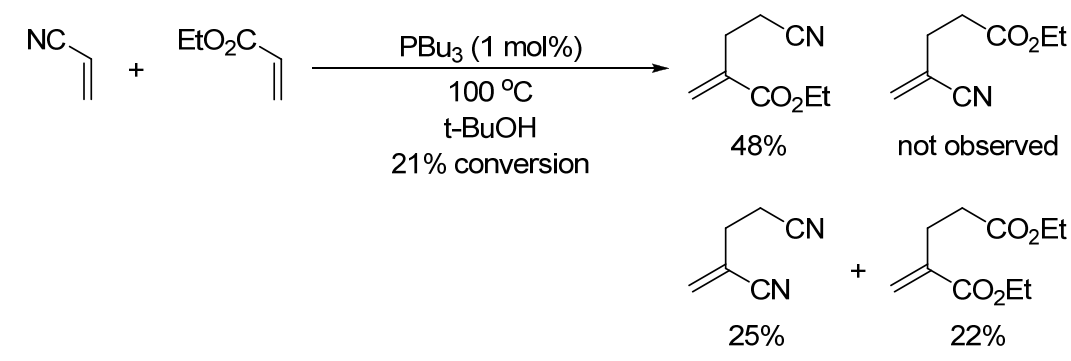

However, the lack of selectivity in cross-coupling reactions involving different activated alkenes was soon overcome when the groups of Roush ${ }^{17}$ and Krische ${ }^{18}$ presented detailed methodology studies where they cleverly resolved the issue of selectivity by tethering coupling partners of differing electrophilicity, thereby creating an intramolecular RC reaction (Scheme 5).

Scheme 5: Rauhut-Currier $(\mathrm{RC})$ reaction.

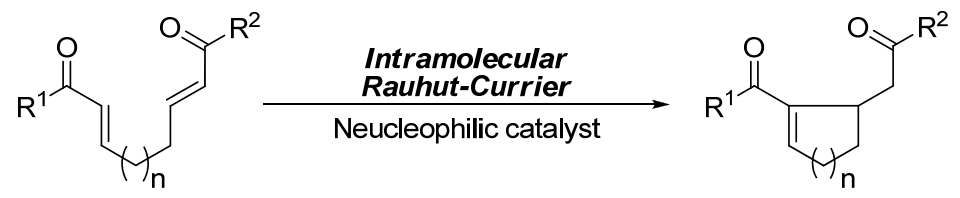

Consequently, along with Krische and co-workers, the Miller group, ${ }^{19}$ and the $W^{2} \mathrm{ang}^{20}$ group developed effective intramolecular asymmetric cyclization of $\alpha, \beta-$ unsaturated ketones (Scheme 6). Furthermore Kwon and co-workers successfully applied organophosphine catalysts to promote both intermolecular and intramolecular allene-alkene coupling. ${ }^{21}$ 
Scheme 6: Examples of asymmetric intramolecular $\mathrm{RC}$ reaction by Krische (A), Miller (B) and Wang (C) groups.

A

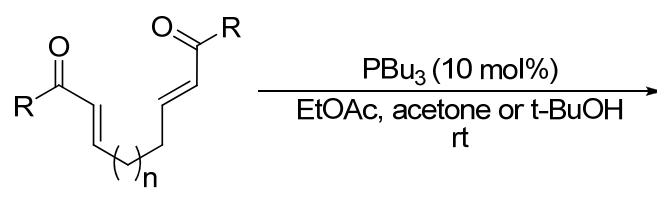<smiles>[R]C(=O)CC1C=CC=C1C([R])=O</smiles>

$$
\mathrm{n}=1: \mathrm{R}=\mathrm{Ph}, 2 \text {-furyl }
$$
$\mathrm{n}=2: \mathrm{R}=\mathrm{Ph}, 4-$ methoxyphenyl

$(n=1) 86 \%, 95 \%$

$(n=2) 60 \%, 90 \%$

B<smiles>O=C(/C=C/CCC/C=C/C(=O)c1ccccc1)c1ccccc1</smiles><smiles>COC(=O)C(CS)NCCCCC(C)C</smiles><smiles>O=C(C[C@@H]1CCCC=C1C(=O)c1ccccc1)c1ccccc1</smiles>
$70 \%$ yield, $95 \%$ ee

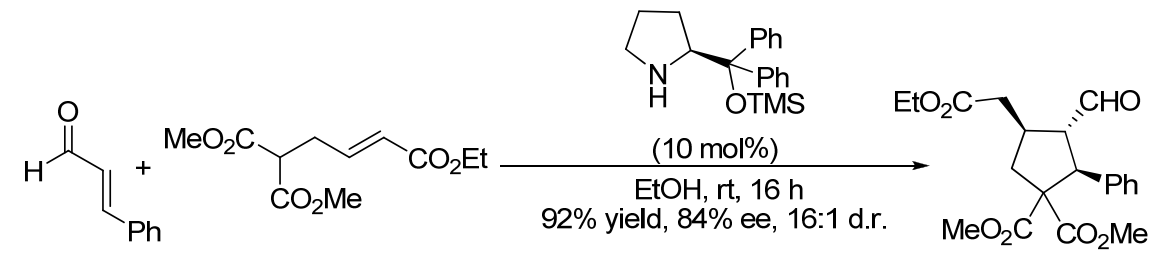

\subsection{Research Objective and Results}

The examples highlighted in the previous section, all re-emphasize the advantages of the Rauhut-Currier reaction as a very attractive approach in $\mathrm{C}-\mathrm{C}$ bond construction. However, to date, there is still a lack of effective methodology for efficient intermolecular cross-coupling of different activated olefins, especially with those involving nonketone/aldehyde Michael receptors, which essentially should provide more functionality to the final product. ${ }^{22}$ 
As seen from the numerous reports mentioned earlier, the biggest challenge for a successful cross-double-Michael addition is the control of sequential addition across the two Michael receptors. Assuming that the EWG1 activated alkene is more reactive than the EWG2 activated alkene, the nucleophilic addition of the LB catalyst will first attack the EWG1 olefin, forming the carbanion intermediate (Scheme 7). However, the carbanion intermediate will most likely react with the EWG1 activated olefin (homoaddition, Scheme 7, reaction A) rather than with the EWG2 activated olefins (desired heteroaddition, Scheme 7, reaction B). This fundamental challenge was associated with most of the previously mentioned examples and therefore resulted in no observation of a successful heterodouble-Michael addition.

Scheme 7: Challenges associated with a successful cross double-Michael addition reaction.

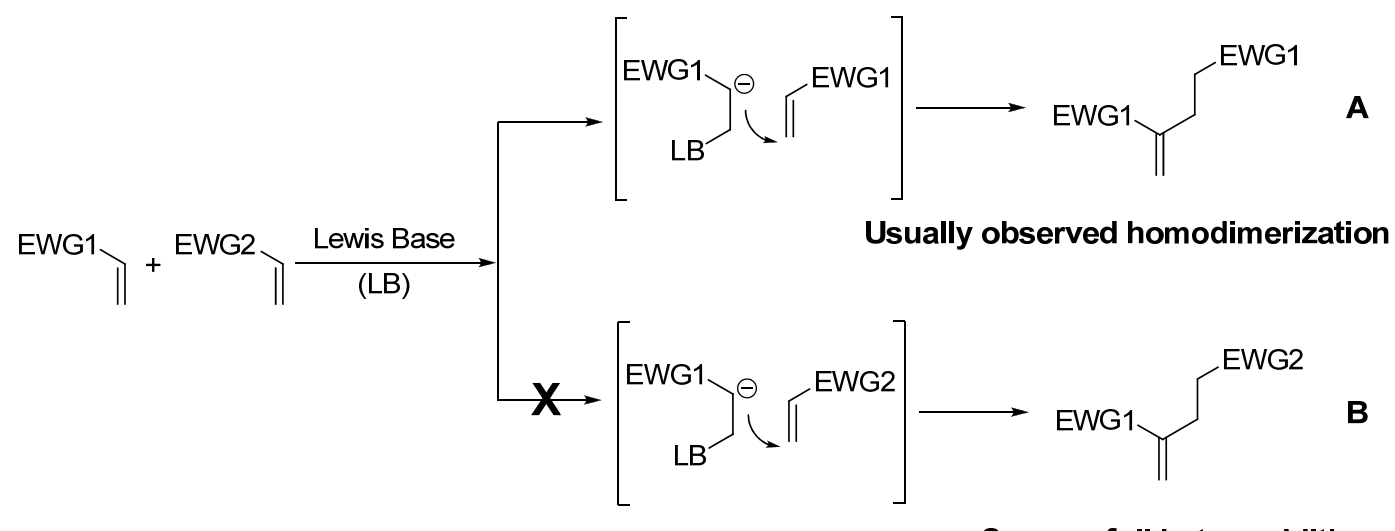

Successfull heteroaddition

To investigate this reaction, we first studied the reaction between the nitro and carbonyl activated olefins. It is well known that the nitroalkenes are more reactive Michael receptors than enones, which makes the sequential addition across the two alkenes 
possible. Our initial investigations began with the reaction of $\beta$-nitrostyrene with various carbonyl-activated alkenes, including cyclohexenone, methyl acrylate, and methyl vinyl ketone. Meanwhile, various Lewis bases were applied to promote this reaction, including DMAP, $\mathrm{PPh}_{3}, \mathrm{DABCO}$, imidazole, and NMI. However, among all the tested conditions, polymerization of the nitroalkene was dominant and only a trace amount of the desired product was obtained. However, when both L-proline and $\mathrm{NaN}_{3}$ were used as the catalysts, the desired product was obtained in $32 \%$ yield as a single $E$ isomer (determined by NOE) (Scheme 8). No product was isolated if only L- proline or only $\mathrm{NaN}_{3}$ was used as the catalyst.

Scheme 8: Initial reaction of $\beta$-nitrostyrene with cyclohexenone and observed polymerization of the nitroalkene.
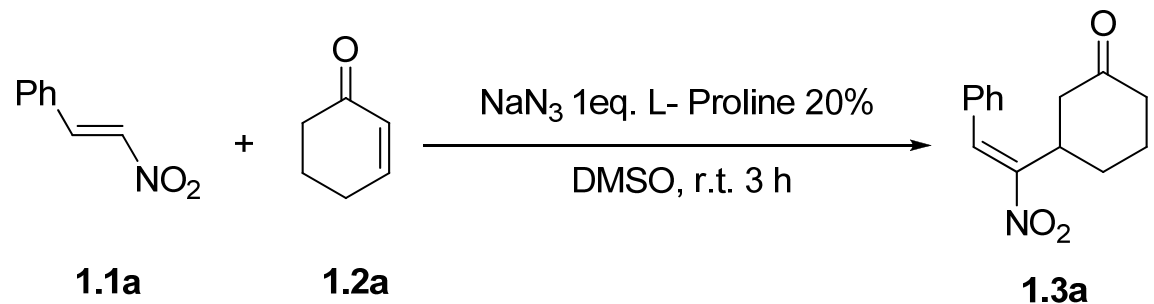

$$
\begin{gathered}
1.3 a \\
30 \% \text { Yield } \\
\text { Single isomer }
\end{gathered}
$$

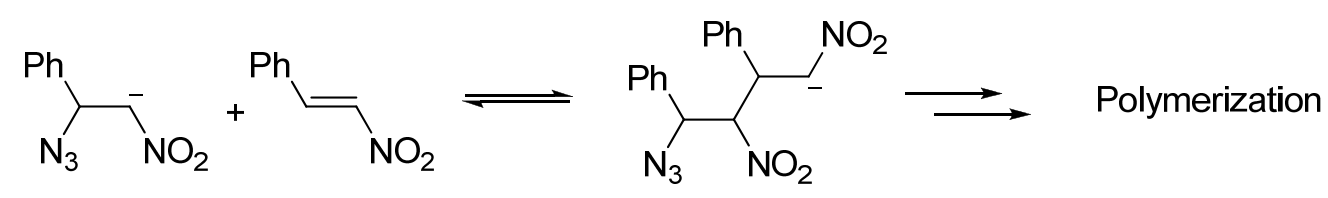

Monitoring this reaction in $d 6-\mathrm{DMSO}$ by NMR revealed that almost all the $\alpha$-nitrostyrene was consumed in $1 \mathrm{~h}$, and formation of product 1.3 was not observed until $2 \mathrm{~h}$ later, when most of 1.1a had already been consumed (Figure 1, g). 
Figure 1: The NMR spectra of the reaction between 1.1a and 1.2a: a) 1.2a; b) 1.1a; c) 1.3, a mixture of two double bond isomers with a ration of $2: 1$; $d$ ) reaction between $\mathbf{1 . 1 a}$ and 1.2a when time is 2 min.; e) 30 min.; f) 90 min.; g) 2 h.; h) 8 h.; i) 16 h.

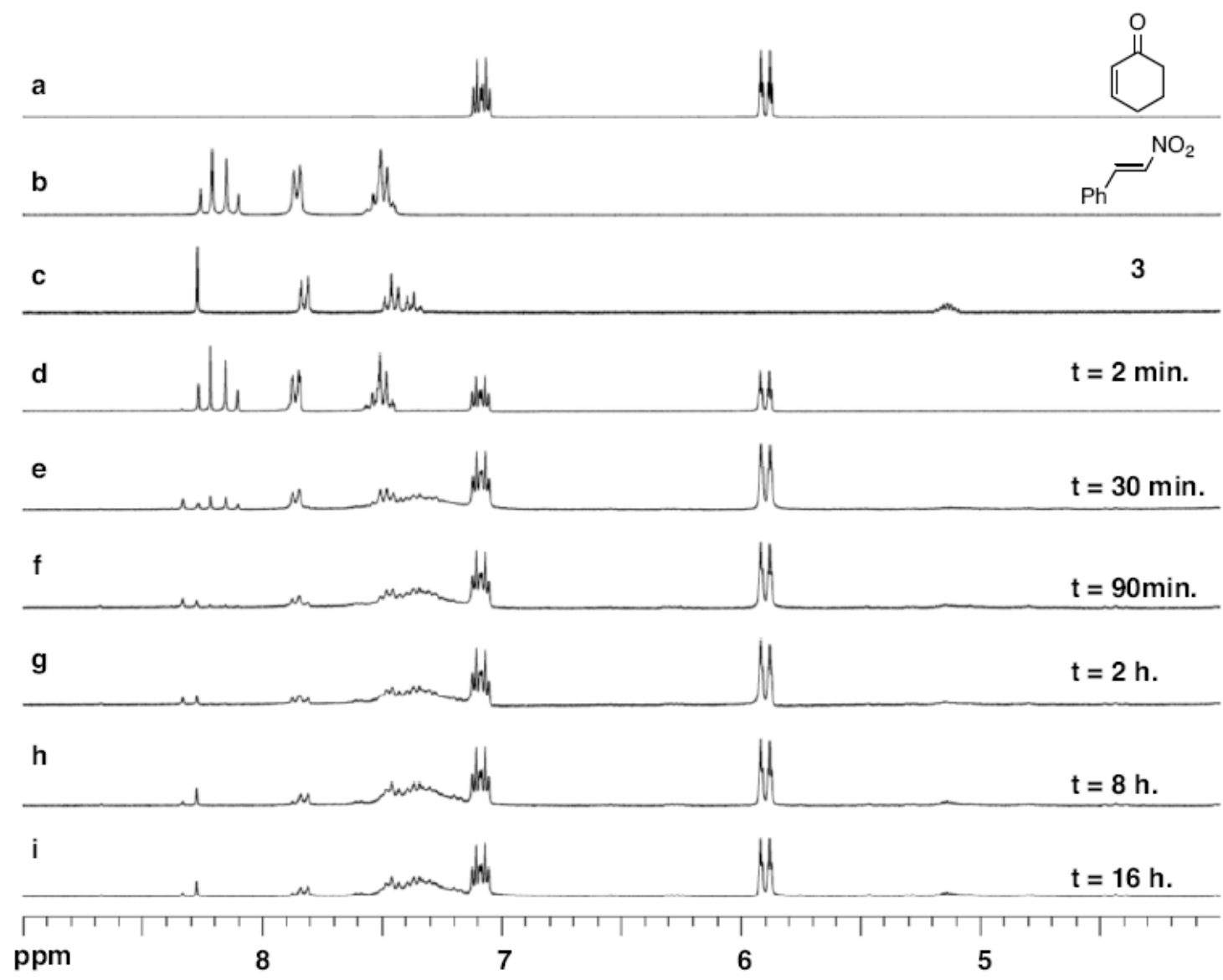

These results strongly imply that the addition of nitrocarbanion to $\beta$-nitrostyrene (which leads to the polymerization) is an equilibrium, and therefore the intermediate nitroalkene oligomers can dissociate and reform the nitrocarbanion, consequently leading to the addition to the less reactive Michael receptor (cyclohexenone in this case). Therefore, the key to a successful intermolecular hetero-double-Michael addition would be to avoid the polymerization of the nitrocarbanion and "quench" the equilibrium through a kinetically irreversible step. As a result, $\alpha$-methyl- $\beta$-nitrostyrene $\mathbf{1 . 1 b}$ was employed to 
react with enone $1.2 a$. The purpose of using $1.1 b$ was to: (a) slow down the polymerization of the nitroalkene and (b) introduce an irreversible step through an alkyl group $\beta$-elimination. As expected, the allylic nitro product 1.5a was now formed in good yield.

Scheme 9: Successful cross double-Michael addition reaction involving $\alpha-m e t h y l-\beta$ nitrostyrene and cyclohexenone.

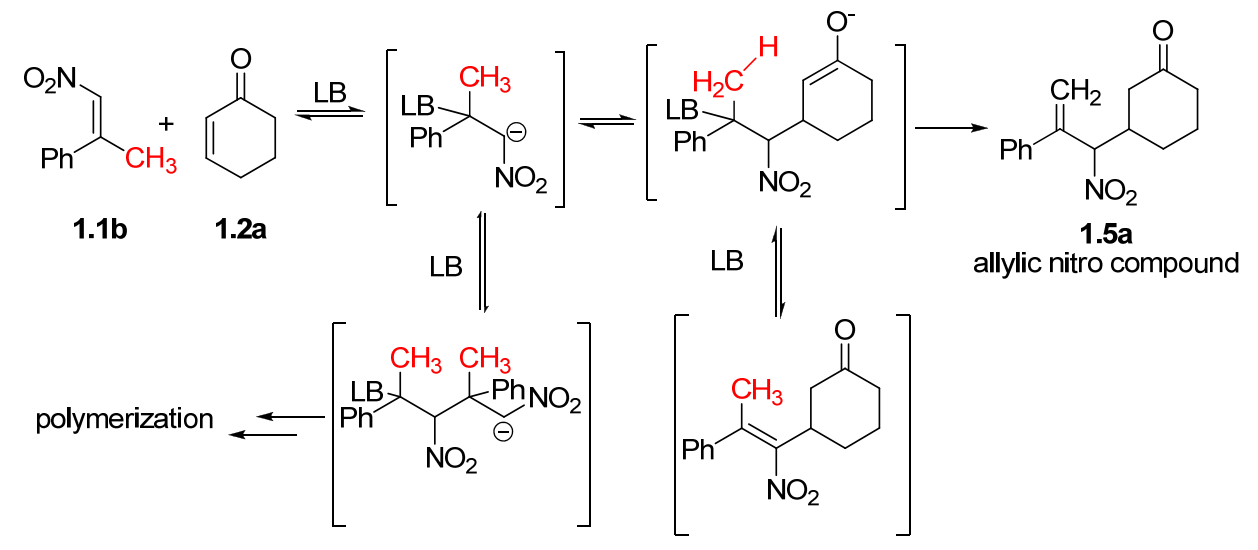

With the successful formation of the product allylic nitro-compound, we set forth to determine the best reaction conditions for this cross double-Michael addition, which is shown in Table 1. Among all of the tested Lewis bases, the secondary amines were the only effective catalysts that promoted this reaction (entries 1,4 , and 5). The nonnucleophilic amine, di-isopropyl-ethylamine (DIPEA, entry 7) and primary amine, glycine (entry 6) did not promote this reaction, while nucleophilic tertiary amines, such as DABCO (entry 3) promoted the reaction but with slow kinetics and poor yields. Inorganic bases such as $\mathrm{NaOt}$-Bu (entry 8) gave significant polymerization of 1.1b with no desired product formation. Meanwhile, other popular nucleophilic bases (entry 9), including DMAP, imidazole, $\mathrm{NMI}, \mathrm{PPh}_{3}$, and $\mathrm{P}(\mathrm{OMe})_{3}$ all proved to be non-effective catalysts for this reaction. A combination of L-proline ( 0.2 equiv) with other Lewis bases revealed 
modified reaction conditions (entries 10-14), providing higher yields of the allylic nitrocompound and shorter reaction times. However, $\mathrm{NaN}_{3}$ was selected as the best adduct, providing yields as high as $91 \%$. Finally, DMSO was found to be the solvent of choice.

Table 1: Screening of the reaction conditions.

\begin{tabular}{|c|c|c|c|c|c|c|}
\hline & & $1.2 \mathrm{a}$ & & 1. & & \\
\hline entry & solvent & $\begin{array}{l}\text { Lewis base } \\
\text { (equiv.) }\end{array}$ & $\begin{array}{l}\text { co-cat } \\
\text { (1equiv.) }\end{array}$ & $\begin{array}{c}\text { time } \\
\text { (h) }\end{array}$ & $\begin{array}{c}\text { conv. } \\
(\%)\end{array}$ & yield (\%) \\
\hline 1 & DMSO & L-proline $(0.2)$ & - & 4 & 93 & 80 \\
\hline 2 & DMSO & $\mathrm{NaN}_{3}(1.0)$ & - & 9 & 55 & 6 \\
\hline 3 & DMSO & DABCO (1.0) & - & 12 & 50 & 20 \\
\hline 4 & DMSO & pyrrolidine (0.2) & - & 4 & 72 & 60 \\
\hline 5 & DMSO & pyrrolidine (0.2) & $\mathrm{AcOH}$ & 4 & 100 & 81 \\
\hline 6 & DMSO & glycine (1.0) & - & 20 & trace & trace \\
\hline 7 & DMSO & DIPEA (1.0) & - & 20 & trace & trace \\
\hline 8 & DMSO & $\mathrm{NaOt}-\mathrm{Bu}(1.0)$ & - & 4 & 100 & trace \\
\hline 9 & DMSO & other bases & - & 20 & trace & trace \\
\hline 10 & DMSO & L-proline $(0.2)$ & DIPEA & 4 & 100 & 76 \\
\hline 11 & DMSO & L-proline $(0.2)$ & DMAP & 4 & 100 & 86 \\
\hline 12 & DMSO & L-proline $(0.2)$ & $\mathrm{PPh}_{3}$ & 4 & 100 & 83 \\
\hline 13 & DMSO & L-proline $(0.2)$ & $\mathrm{NaN}_{3}$ & 3 & 100 & 91 \\
\hline 14 & DMSO & L-proline $(0.2)$ & DABCO & 4 & 100 & 21 \\
\hline 15 & THF & L-proline $(0.2)$ & $\mathrm{NaN}_{3}$ & 20 & trace & trace \\
\hline 16 & $\mathrm{H}_{2} \mathrm{O}$ & L-proline $(0.2)$ & $\mathrm{NaN}_{3}$ & 20 & trace & trace \\
\hline 17 & $\mathrm{MeOH}$ & L-proline $(0.2)$ & $\mathrm{NaN}_{3}$ & 5 & 95 & 72 \\
\hline 18 & $\mathrm{MeNO}_{2}$ & L-proline $(0.2)$ & $\mathrm{NaN}_{3}$ & 20 & 40 & 31 \\
\hline 19 & acetone & L-proline $(0.2)$ & $\mathrm{NaN}_{3}$ & 5 & 9 & 8 \\
\hline
\end{tabular}


${ }^{a}$ Reactions were carried out at room temperature, 1.1b/1.2a $=1: 2 .{ }^{b}$ Reaction time was determined by TLC. ${ }^{c}$ Conversion based on the consumption of the starting material $\mathbf{1 . 1 b}$ from NMR. ${ }^{d} 1.5 \mathrm{a}$ as a mixture of syn/anti diastereomers $(\mathrm{dr}=1: 1)$, and the NMR yield was determined by 1,3,5-trimethoxybenzene as the internal standard. ${ }^{e}$ Other bases tested include 1.0 equiv of DMAP, imidazole, $\mathrm{NMI}, \mathrm{PPh}_{3}$, and $\mathrm{P}(\mathrm{OMe})_{3}$.

With the best reaction conditions, various nitroalkenes and $\alpha, \beta$-unsaturated ketones and esters were applied to investigate the reaction substrate scope, and the results are summarized in Table 2.

Table 2: Substrate scope of the cross double-Michael addition reaction

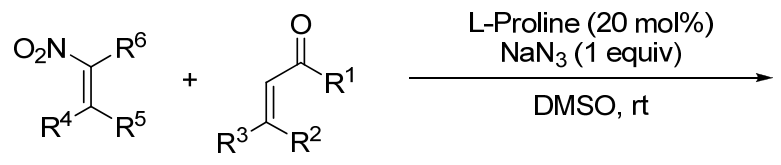<smiles>[R]C=C([R])C(CC([R])=O)C([R])([R])[N+](=O)[O-]</smiles>

allylic nitro compound

compound

time

$\mathrm{dr}$

(h)<smiles>C=C(c1ccccc1)C(C1CCC(=O)C1)[N+](=O)[O-]</smiles>

1.5a: $n=2$

3

1.0:1

1.5b: $n=3$

5

$1.2: 1$

72

1.5c: $n=1$

$8 \quad 1.1: 1$

55<smiles>C=C(c1ccccc1)C(C(CC(=O)c1ccccc1)c1ccccc1)[N+](=O)[O-]</smiles><smiles>[R]C(=O)C([R])CC1([N+](=O)[O-])C=CCCC1</smiles>

1.5e: $R^{1}=H, R^{2}=M e$

6

90

1.5f: $R^{1}=H, R^{2}=O M e$

6

85

1.5c: $R^{1}=R^{2}=M e$

6

$2: 1$

92 
<smiles>O=C1CCC(C2(C3C=CCCC3)C=CCC2)C1</smiles><smiles>O=C1C[Te]CC(C(C2=CCCCC2)[N+](=O)[O-])C1</smiles><smiles>[R]C(=O)CC([R])C(C1=CCCCC1)[N+](=O)[O-]</smiles><smiles>[R7]C(=O)CC([R8])C(C)(/C=C/CCCC)[N+](=O)[O-]</smiles><smiles>C=C(C)C(C1CCCC(=O)C1)[N+](=O)[O-]</smiles><smiles>C=C(c1ccccc1)C([N+](=O)[O-])C(C)(C)CC(C)=O</smiles>

\section{5h}

1.5i: $n=1$

1.5I: $n=2$

1.5j: $R^{3}=R^{4}=P h$

1.5k: $R^{3}=R^{4}=M e$

1.5m: $R^{5}=R^{6}=M e$

1.5n: $R^{5}=H, R^{6}=O M e$

1.50

$1.5 p$

3

1.3:1

76 
the reaction. Furthermore, this result is consistent with the fact that low enantioselectivity $(<5 \%$ ee) was observed in all the tested cases. Similar to other reactions involving the nitro group, low diastereoselectivity was obtained in all the examples due to the acidic nature of the proton on the nitro carbon (e.g., 1.5a and 1.5I) or because of the similar stereo effect by the alkyl and nitro groups (e.g., 1.5g and 1.5m). However, the low dr would be a small problem since the two diastereomers could either be separated through column chromatography or converted into the same product through readily available nitro group transformations. Three examples are highlighted in Scheme 10 to convert the allylic nitro compounds into its amine (lactam), allylic alcohol, and enone derivatives with good yields.

Scheme 10: Further functional group transformation - easy steps to overcome the low diastereoselectivity.

A

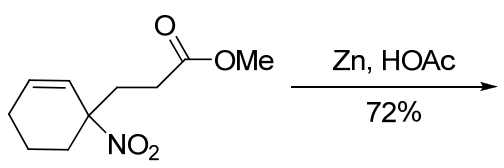

$1.5 f$

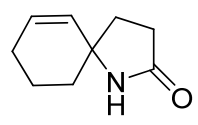

$1.6 a$

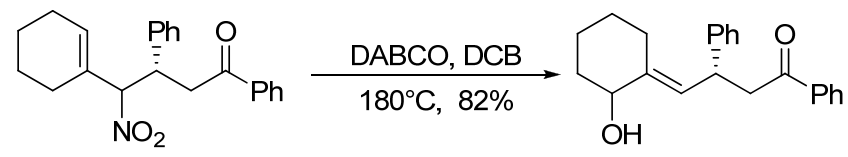

$1.5 j$

$1.6 b$

C

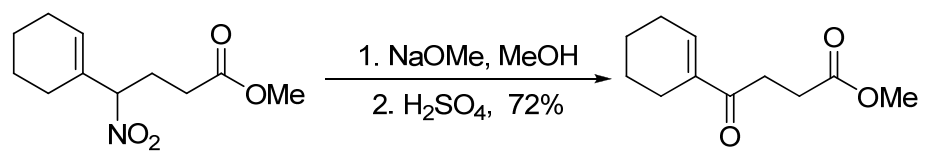

$1.5 q$

1.6c 


\subsection{Insights to a possible reaction mechanism}

Having established the wide accessibility of this cross double-Michael addition reaction, we then tried to determine a possible reaction mechanism for this reaction. Considering the fact that proline itself can promote this reaction without the presence of $\mathrm{NaN}_{3}$ ( $\mathrm{Table}$ 1, entry 1 ), the secondary amine most likely serves as the LB catalyst while $\mathrm{NaN}_{3}$ helps in tuning the reaction acidity for optimal performance. One key mechanistic question is whether this reaction proceeds with the nucleophilic addition of the LB to the nitroalkene followed by the second Michael addition or simply through a y-carbon deprotonation (Scheme 11).

Scheme 11: Possible modes of reaction for the cross double-Michael addition.

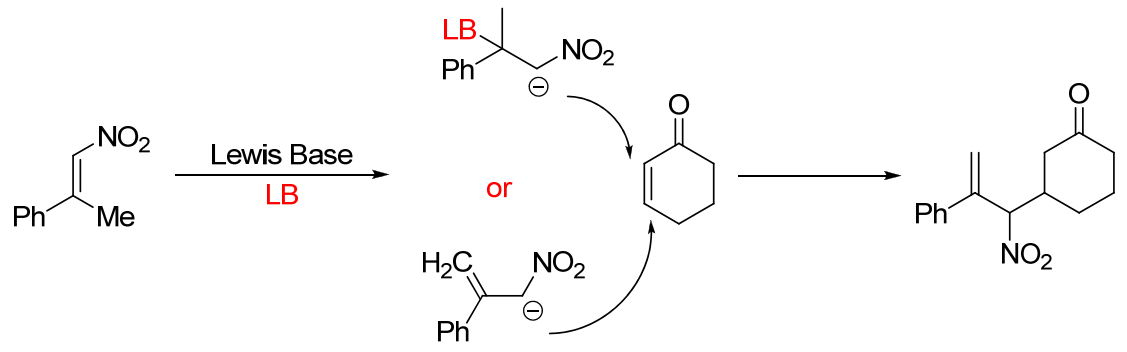

As indicated in Table 1, the secondary amines were the only effective catalysts for this cross double-Michael addition reaction. Both the non-nucleophilic amine, Hunig's base (DIPEA, entry 7) and the primary amine, glycine (entry 6) failed to catalyze the reaction, thereby revealing the importance of the nucleophilicity of the catalyst for effective promotion of this reaction. Meanwhile, the fact that addition of an acid to pyrrolidine accelerates the reaction (entry 5) provides additional evidence that disfavors the carbanion path. To further investigate the reaction mechanism, compound 1.1i was synthesized and applied to react with $\mathbf{1 . 2 a}$ (as a comparison to the reaction of that 
between 1.1b and 1.2a). As shown in Table 3, a clear kinetic difference was observed between 1.1b and 1.1i. This experimental result strongly suggests the LB nucleophilic mechanism as proposed earlier.

Table 3: Comparison in reactivity of $\mathbf{1 . 1 b}$ and $\mathbf{1 . 1 i}$.

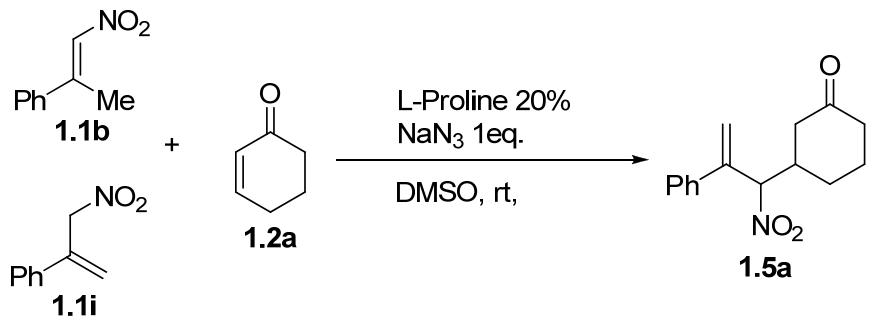

\begin{tabular}{cccc}
\hline Reactant & Catalysts & Reaction Time $(\mathrm{h})$ & Yield (\%) \\
\hline 1.1b & L-Proline $20 \%, \mathrm{NaN}_{3} 1$ equiv. & 3 & 90 \\
$\mathbf{1 . 1 i}$ & L-Proline $20 \%, \mathrm{NaN}_{3}$ 1 equiv. & 14 & 51 \\
\hline
\end{tabular}

Furthermore, this hypothesis was further supported by computational studies with the help of our collaborators at the Dept. of Physics, WVU. As shown in Scheme 12, an energetically unfavored equilibrium between the allylic nitro carbanion and the enone was observed, which may explain why the simple deprotonation of the $\gamma$-carbon could not lead to the desired product. 
Scheme 12: Computational studies revealing an unfavored equilibrium for the carbanion second Michael addition.

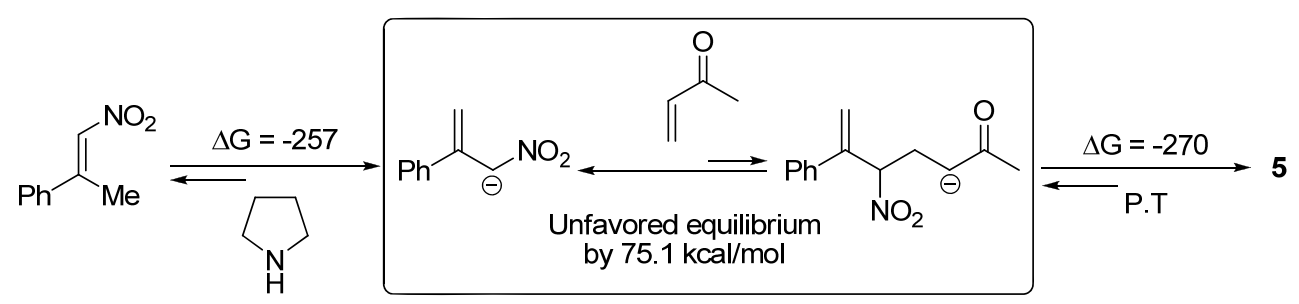

\subsection{Contributions}

Dr. Xiaohua Sun was the researcher who had first investigated the reaction. Together, Dr. Sun and Sujata Sengupta were responsible for the detailed NMR studies, determining the best reaction conditions and evaluating the substrate scope. All the computational data involved in the study of the reaction mechanism were done by researchers Hong Wang and Prof. James Lewis at the Department of Physics, West Virginia University. Detailed X-ray crystallographic data for compounds $\mathbf{1 . 5 d}$ and $\mathbf{1 . 6 a}$ were performed by Prof. Jeffrey L. Petersen at the C. Eugene Bennett Department of Chemistry, West Virginia University.

\subsection{Conclusion}

In conclusion, by introduction of the $\beta$-alkyl group on the nitroalkene, we have successfully expanded upon the intermolecular Michael/Michael cross-coupling reaction with the combination of L-proline and sodium azide $\left(\mathrm{NaN}_{3}\right)$ as catalysts. Among all the popular Lewis bases screened, L-proline was found to be the most effective catalyst and 
$\mathrm{NaN}_{3}$ as the co-catalyst for fine-tuning of the reaction acidity. This methodology is applicable to a wide range of $\beta$-alkyl nitroalkenes and enones, providing the homologated RC products in good to excellent yields. The products are synthetically attractive and can be readily converted into many other complex building blocks. We propose the reaction proceeds through a nucleophilic mechanism as opposed to a general base mechanism, as supported by both control experiments and computational studies. Although the reaction mechanism remains to be further elucidated, this reaction provides a new approach for $\mathrm{C}-\mathrm{C}$ bond formation under mild, efficient, and atomeconomical reaction conditions. Furthermore, the key to this new methodology was the fact that L-proline $/ 2^{\circ}$ amines may serve as a Lewis base to activate nitroalkenes, thereby generating a formal allylic nitro nucleophile under the mild reaction conditions (Scheme 13).

Scheme 13: $2^{\circ}$ amines as effective Lewis base for activation of nitroalkenes.

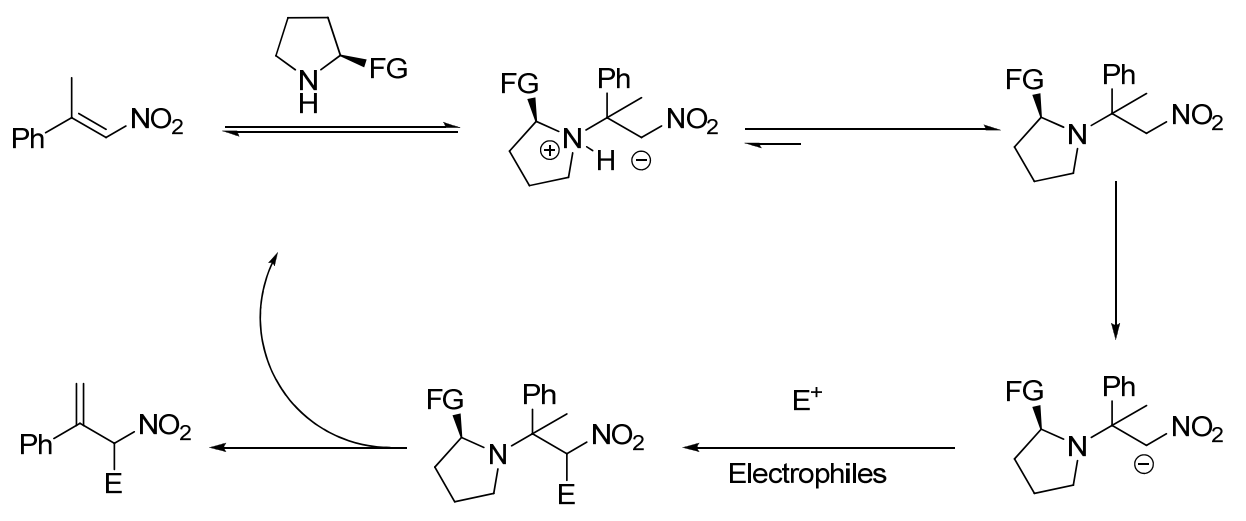




\section{Chapter Two: One step cascade synthesis of 4,5-disubstituted- 1,2,3-(NH)-triazoles ${ }^{\dagger}$}

\subsection{Introduction}

First pioneered by Huisgen in the early 1960 's,${ }^{23}$ the 1,3 -dipolar cycloaddition reaction between two unsaturated reactants provides an easy and efficient access to a wide variety of five-membered heterocycles. ${ }^{24}$ The cycloaddition of acetylenes and azides to synthesize 1,2,3-triazoles is by far the most useful member of this family. ${ }^{25}$ However, under thermal conditions and in the absence of any catalysts, the 1,3-dipolar addition reaction of terminal alkynes and organic azides affords both the 1,4- and the 1,5-triazole regioisomers (Scheme 14), ${ }^{26}$ since the activation energies for the concerted process leading to both isomers are very close. Furthermore, the reaction is usually extremely slow as alkynes are poor 1,3-dipole acceptors. However, Sharpless and Folkin have successfully discovered that in the presence of copper(I), the cycloaddition reaction is dramatically accelerated, highly regioselective to give exclusively the 1,4-disubstituted1,2,3-triazoles and highly efficient (yields are often $>95 \%$ ). ${ }^{27}$ Moreover, this copper catalyzed azide-alkyne cycloaddition (CuAAC, often referred to as "click-chemistry") can be performed in various solvents (including water) and is well tolerant to the presence of numerous other functional groups.

\footnotetext{
${ }^{\dagger}$ Reproduced in parts with permission from Org. Lett. 2008, 10, 1493-1496. Copyright 2008, with permission from American Chemical Society.
} 
Scheme 14: Huisgen's 1,3-dipolar cycloaddition vs CuACC.

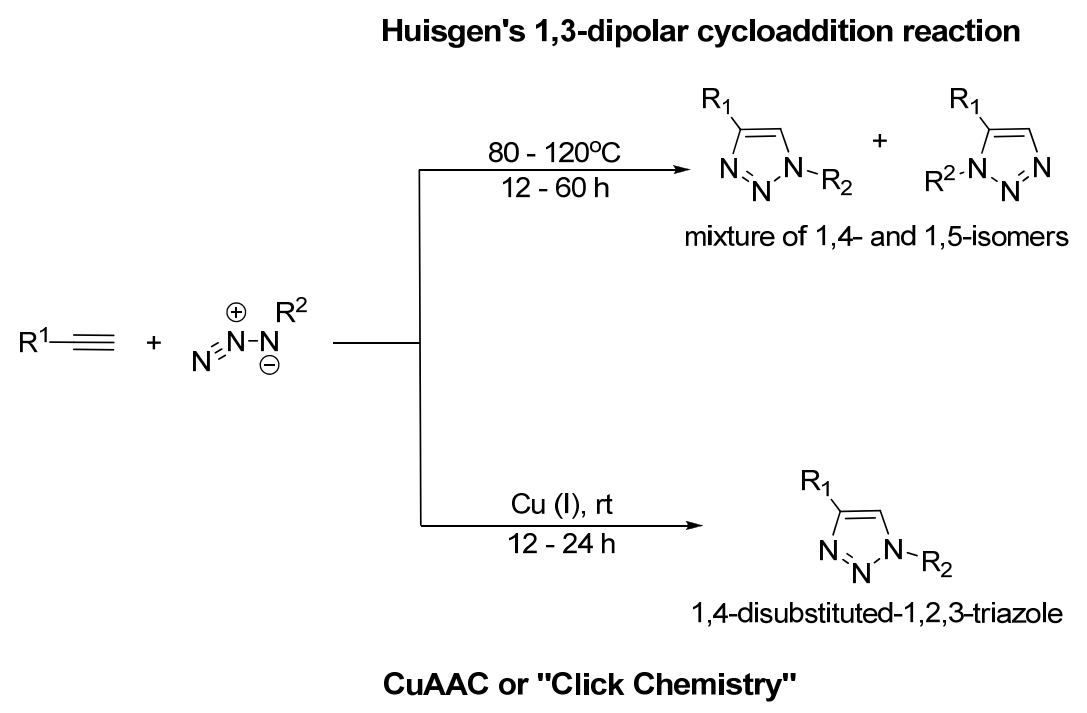

While a number of copper(I) sources can be used directly, the catalyst is better prepared in situ by the reduction of $\mathrm{Cu}(\mathrm{II})$ salts $\left(\mathrm{CuSO}_{4} \cdot 5 \mathrm{H}_{2} \mathrm{O}\right)$ with reductants such as ascorbic acid and/or sodium ascorbate. This process exhibits a broad substrate scope and provides` the 1,4-disubstituted 1,2,3-triazole products in excellent yields with near perfect regioselectivity (Scheme 15).

Scheme 15: Example of CuAAC by Sharpless and Folkin.

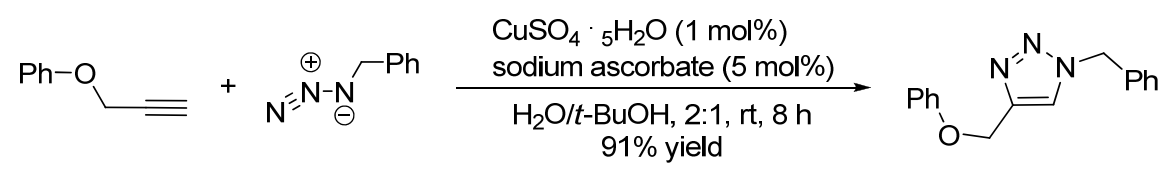

The reaction mechanism begins with the initial formation of a copper(I) acetylide intermediate (therefore indicating why internal alkynes fails to react by this process). Detailed density functional theory calculations (DFT) by the authors indicate a strong disfavor to the concerted [2+3] cycloaddition reaction and instead favor the involvement 
of a series of ligation steps with the formation of the interesting six membered coppercontaining intermediate (Scheme 16).

Scheme 16: Proposed reaction mechanism of the CuAAC.

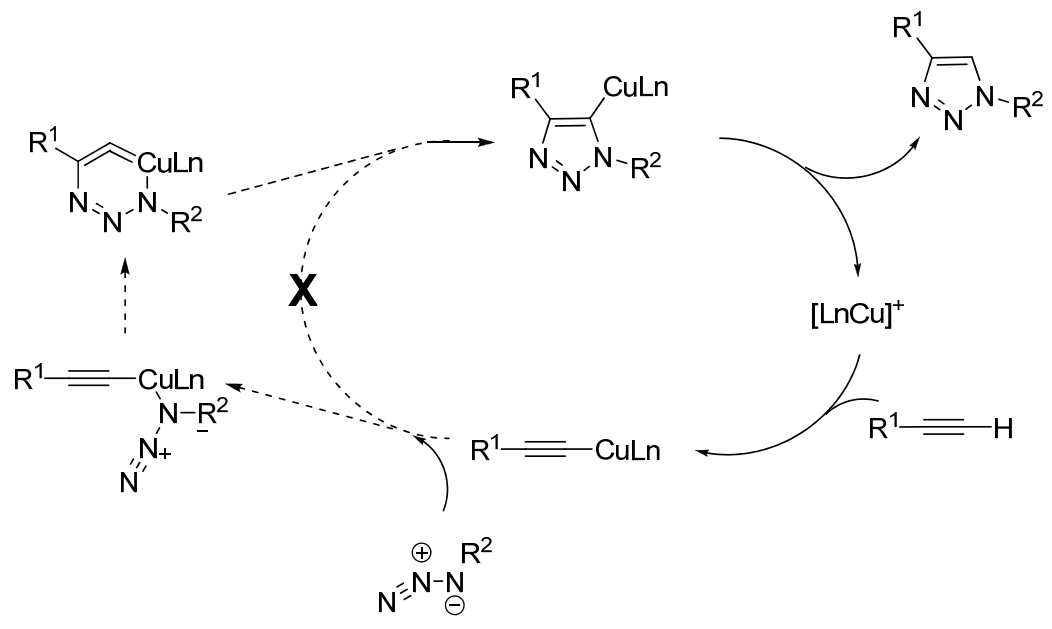

Since the recent discovery of the CuAAC reaction, the 1,2,3-triazole compounds have received considerable attention from scientists in various fields. ${ }^{28}$ Within the last 5 years, the importance of these compounds has been continuously demonstrated in research fields as diverse as material science ${ }^{29}$ chemical biology, ${ }^{30}$ and medicinal chemistry. ${ }^{31}$ However, despite being a very efficient method for the synthesis of $\mathrm{N}$-substituted triazoles (Scheme 17, reaction A), one limitation of the CuAAC is the lack of reactivity toward unsubstituted azides, such as $\mathrm{NaN}_{3}$ and $\mathrm{HN}_{3}$. Therefore, to prepare the unsubstituted triazoles ( $\mathrm{NH}$-triazoles) by CuAAC, the organic azides are usually applied with removable N-protecting groups followed by deprotection (Scheme 17, reaction B). ${ }^{32}$ Meanwhile, thermal reactions between the alkyne and $\mathrm{NaN}_{3} / \mathrm{HN}_{3}$ usually gave low yields, and the preparation of substituted alkynes is usually challenging and is 
associated with high costs. ${ }^{33}$ Therefore, an efficient method for the synthesis of substituted $\mathrm{NH}$-triazoles (as a complementary approach for the CuAAC reaction) would be highly desirable.

Scheme 17: Synthesis of N-substituted-1,2,3-triazoles through CuAAC.

A

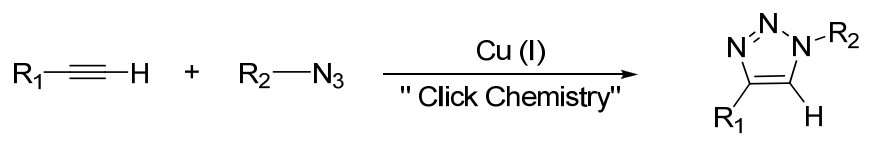

1,4-disubstituted-1,2,3-triazole

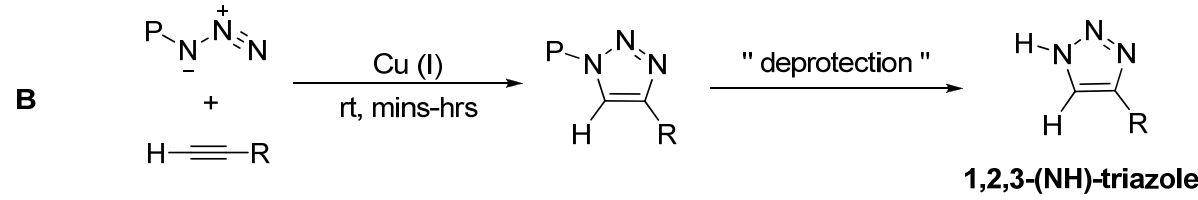

Besides the CuAAC approach, another popular method for the synthesis of 1,2,3triazole is the 1,3-dipolar cycloaddition between $\alpha$-nitrostyrene and $\mathrm{NaN}_{3}$, first reported by Zefirov in $1971 .{ }^{34}$ With DMSO as the solvent and at room temperature, the authors report the formation of corresponding triazoles $2.1 \mathrm{a}-\mathrm{c}$ in approximately $60 \%$ yield along with "considerable quantities" of the corresponding 1,3,5-triarylbenzenes (Scheme 18) .

Scheme 18: Zefirov's method for the synthesis of 1,2,3-triazoles.

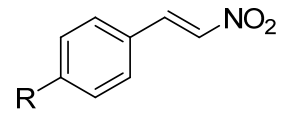

1.1a $(\mathrm{R}=\mathrm{H})$

$1.1 \mathrm{l}(\mathrm{R}=\mathrm{Cl})$

1.1m $(\mathrm{R}=\mathrm{Br})$
$\underset{\mathrm{DMSO}}{\stackrel{\mathrm{DaN}_{3}}{\longrightarrow}}$

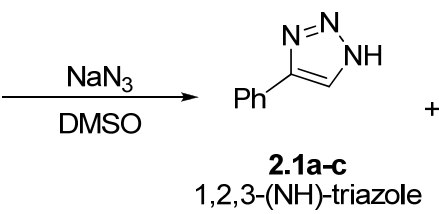

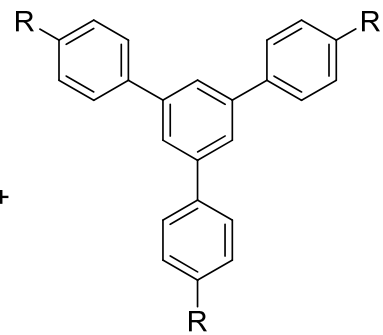

1,3,5-triarylbenzene 
However, a recent study by Quiclet-Sire and Zard to re-examine this reaction, indicated that the above result was not reproducible. ${ }^{35}$ Instead; performing an analogous series of experiments starting from 3-(2-nitrovinyl)pyridine, the authors indicate a different outcome, where both the phenyltriazole and 1,3,5-triphenylbenzene were obtained along with the triazole 2.2 (Scheme 19).

Scheme 19: Zard's reinvestigation of Zefirov's method for the synthesis of 1,2,3triazoles.

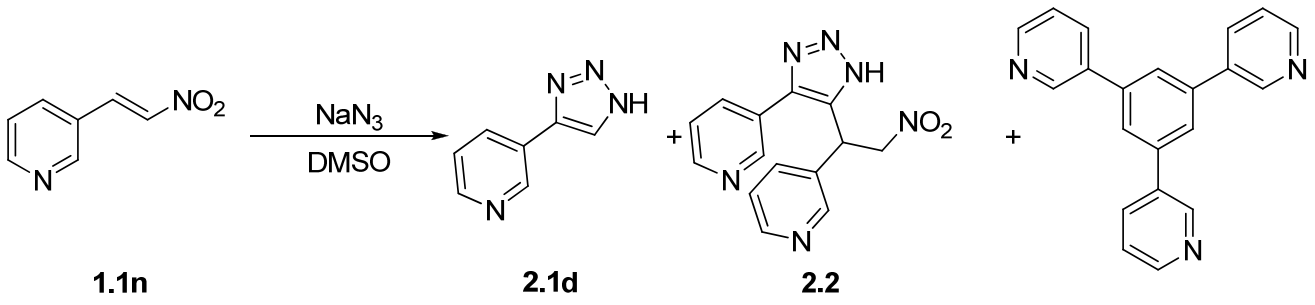

Under an optimized condition involving the slow addition of the a-nitroalkene to a hot solution $\left(80-90^{\circ} \mathrm{C}\right)$ of excess amount of sodium azide $(2-4$ equiv.), the $\mathrm{NH}-$ triazoles could be prepared in good to excellent yields (96\% in one single case) with very small amounts of the by products (Scheme 20). However, as pointed out by the authors themselves, the yields were dependent upon the substrates and the synthesis of the olefin precursor was challenging (probably due to an unfavored equilibrium in the Henry reaction) and therefore provided low yields in certain cases. Thus, as a general problem, all the thermal cyclization approaches suffered from a limited substrate scope. 
Scheme 20: Thermal condensation of $\alpha$-nitroalkene and $\mathrm{NaN}_{3}$ for the synthesis of 1,2,3$(\mathrm{NH})$-triazoles (Zard's method).

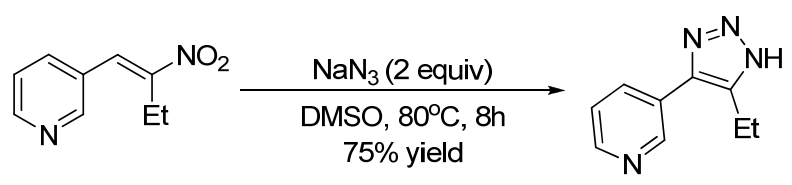

\section{Research Objective and Results}

As mentioned in the previous chapter, our interest in developing new synthetic methodologies by an organo catalyst promoted cascade reaction has recently led to the discovery of an intermolecular cross double-Michael addition between nitro and carbonyl activated olefins (Scheme 21). ${ }^{36}$ The key to this new methodology was the fact that Lproline may serve as a Lewis base to activate nitroalkenes, thereby generating a formal allylic nitro nucleophile under the mild reaction conditions.

Scheme 21: Lewis base catalyzed intermolecular double-Michael addition reaction.

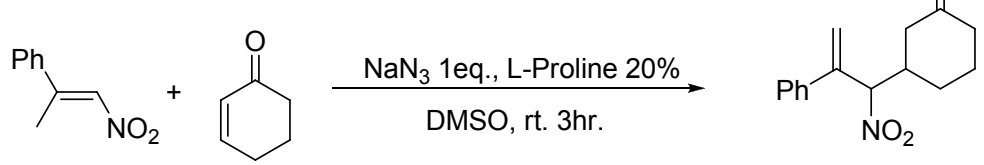

Cross Double Michael Addition product

$87 \%$ d.r. $=1.1: 1$

Moreover, in a separate study by fellow group members, Duan and Shi recently reported the reaction of nitroalkenes with electron enriched olefins to give isoxazole- $N$ oxides, as shown in Scheme $22 .^{37}$ 
Scheme 22: One step formation of isoxazole-N-oxide.

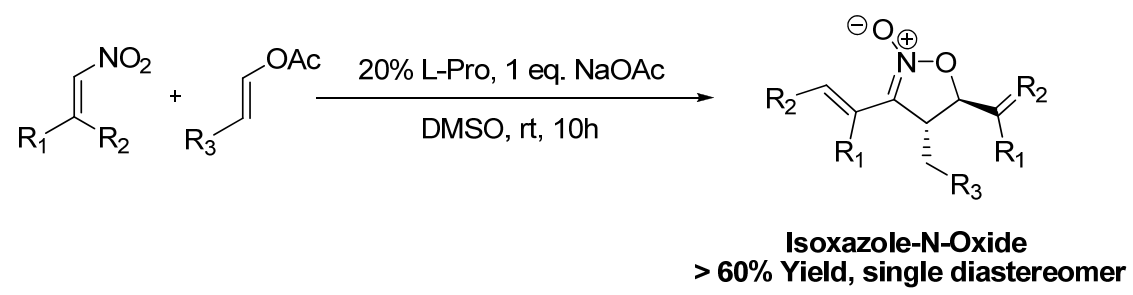

Mechanistic studies for this interesting transformation revealed that the $[3+2]^{38}$ cycloaddition of $\mathbf{1 . 1 b}$ with electron rich alkene $\mathbf{2 . 3}$ involve the formation of a 1,3-diene 2.A, as the active intermediate (Scheme 23). We then wondered whether the azide anion $\left(\mathrm{N}_{3}{ }^{-}\right)$could quench this active diene intermediate to produce $\mathrm{NH}$-triazole 2.6, which would avoid the synthesis of $\alpha$-nitroalkene starting material (more complicated 1,2disubstituted nitroalkenes) in the 1,3-dipolar cycloaddition and thereby significantly increase the reaction substrate scope.

Scheme 23: Proposed reaction mechanism for the synthesis of isoxazole-N-oxides.

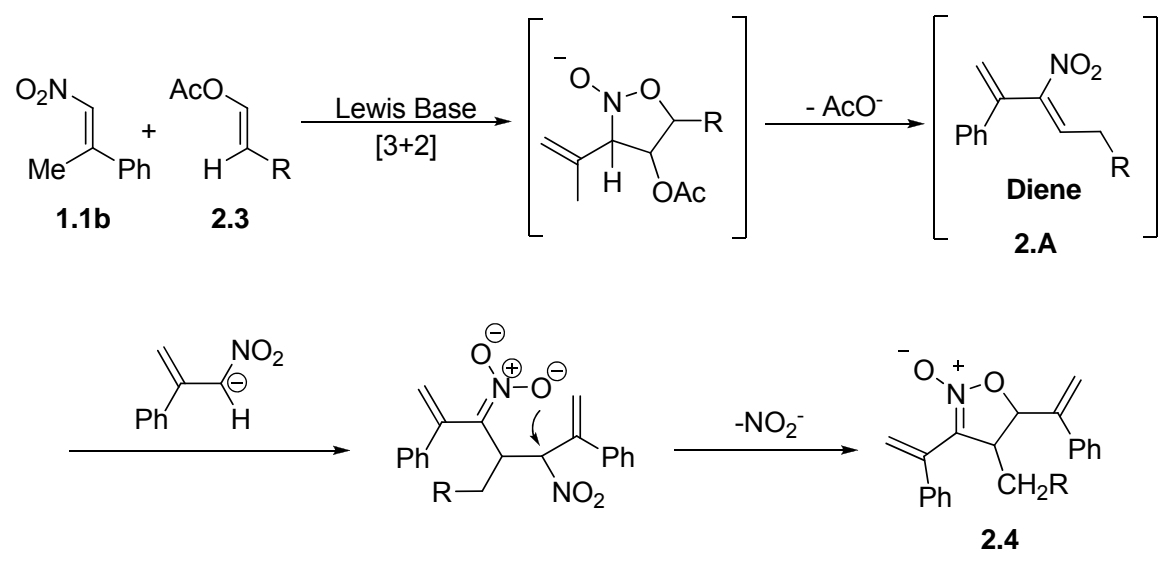


Our initial attempt was to treat $\mathbf{1 . 1 b}$ and 2.3 along with the addition of $\mathrm{NaN}_{3}$ to quench intermediate 2.A. However, isoxazole 2.4 was obtained exclusively without any trace of the triazole, even in the presence of excess $\mathrm{NaN}_{3}$. Therefore, this clearly suggests that the 1-alkyl diene intermediate 2.A is a highly reactive intermediate, which was fully quenched by allylic nitro carbanion and not by the azide anion $\left(\mathrm{N}_{3}{ }^{-}\right)$. To avoid this nitro carbanion addition, an alternate approach was designed by treating nitroalkene 1.1 with aryl aldehyde 2.5 to form the 1-aryl diene intermediate 2.B, followed by the $\mathrm{N}_{3}{ }^{-}$ 1,3-dipolar cycloaddition to give triazole 2.6. As expected, the reaction of nitroalkene 1.1b with benzylaldehyde $\mathbf{2 . 5 a}$ and $\mathrm{NaN}_{3}$ produced the desired 1,2,3-(NH)-triazole 2.6a at room temperature (Scheme 24).

Scheme 24: One step metal free cascade synthesis of 4,5-disubstituted-1,2,3-(NH)triazoles.

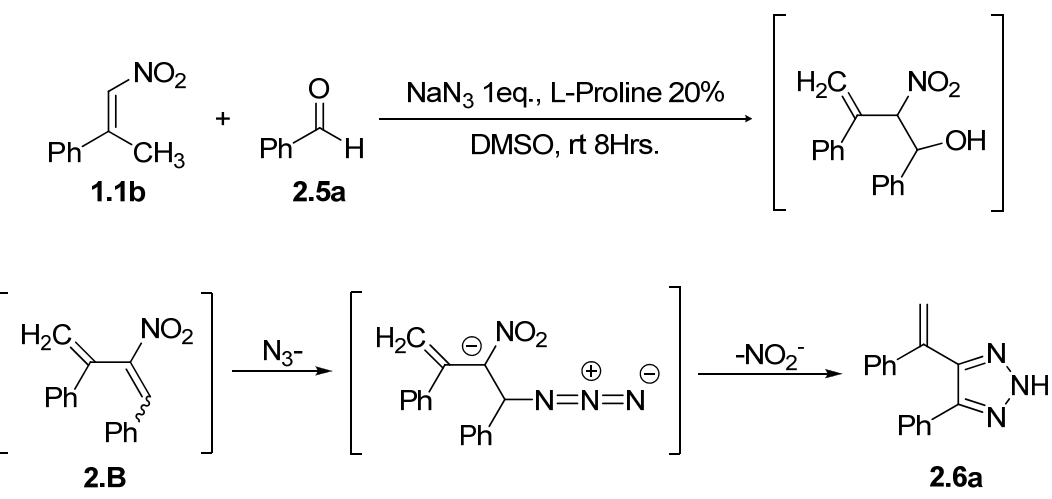

With the successful formation of the $\mathrm{NH}$-triazole, the reaction was further investigated to obtain the best reaction condition. The screening of the reaction conditions is summarized in Table 4. 
Table 4: Screening of the reaction condition.

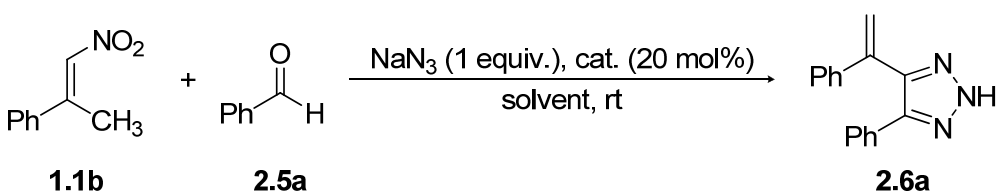

\begin{tabular}{ccccccc}
\hline entry & solvent & cat. $^{b}$ & $\begin{array}{c}\text { temp. } \\
\left({ }^{\circ} \mathrm{C}\right)\end{array}$ & $\begin{array}{c}\text { time } \\
(\mathrm{h})\end{array}$ & $\begin{array}{c}\text { conv. } \\
(\%)^{c}\end{array}$ & $\begin{array}{c}\text { yield } \\
(\%)^{d}\end{array}$ \\
\hline 1 & DMSO & - & $\mathrm{rt}$ & 12 & 40 & 28 \\
2 & DMSO & - & 80 & 10 & 100 & 35 \\
3 & DMSO & L-proline & $\mathrm{rt}$ & 8 & 100 & 90 \\
4 & DMSO & pyrrolidine & $\mathrm{rt}$ & 8 & 15 & 12 \\
5 & DMSO & pyrrolidine/AcOH & $\mathrm{rt}$ & 8 & 20 & 14 \\
6 & DMSO & DMAP & $\mathrm{rt}$ & 8 & 35 & trace \\
7 & DMSO & DIPEA (1.0) & $\mathrm{rt}$ & 8 & 30 & trace \\
8 & DMSO & NaOt-Bu $(1.0)$ & $\mathrm{rt}$ & 8 & trace & trace \\
9 & DMSO & glycine & $\mathrm{rt}$ & 8 & 90 & 20 \\
10 & DMSO & P(OMe) 3 & $\mathrm{rt}$ & 20 & trace & trace \\
11 & DMSO & imidazole & $\mathrm{rt}$ & 20 & 40 & trace \\
12 & THF & L-proline & $\mathrm{rt}$ & 12 & 58 & 45 \\
13 & MeCN & L-proline & $\mathrm{rt}$ & 12 & 58 & 55 \\
14 & MeOH & L-proline & $\mathrm{rt}$ & 12 & 65 & 64 \\
15 & Acetone & L-proline & $\mathrm{rt}$ & 12 & 48 & 40 \\
16 & MeNO 2 & L-proline & $\mathrm{rt}$ & 20 & 60 & 56 \\
\hline
\end{tabular}

${ }^{a}$ Reactions were carried out at room temperature, $1.1 \mathbf{b} / 2.5 a=1: 2 .{ }^{b} 20 \%$ of catalyst loading. Conversion based on the consumption of the starting material 1.1b from NMR. ${ }^{d}$ NMR yield was determined by 1,3,5-trimethoxybenzene as the internal standard.

As indicated in Table 4, treatment of sodium azide with 1.1b and 2.5a in DMSO without the presence of a Lewis base (LB), furnished the $\mathrm{NH}$-triazole $\mathbf{2 . 6 a}$ in poor yield (entry 1). As reported in the previous chapter, sodium azide is not only the reactant but may also serve as the Lewis base in the activation of 1.1b. However, as a less effective Lewis base catalyst, the reaction proceeds slowly at room temperature. However, 
increasing the reaction temperature resulted in significant polymerization of the nitroalkene 1.1b (entry 2). Further addition of different Lewis base catalysts revealed Lproline as the best catalyst (entry 3). Screening of the solvents gave DMSO as the solvent of choice. Considering the low cost, good reaction performance, and easy handling, L-proline was selected as the catalyst of choice. The optimal reaction condition is shown in entry 3.

With the optimal reaction condition, different nitroalkenes and aromatic aldehydes were applied to evaluate the reaction substrate scope, and the results are shown in Table 5.

Table 5: Substrate Scope

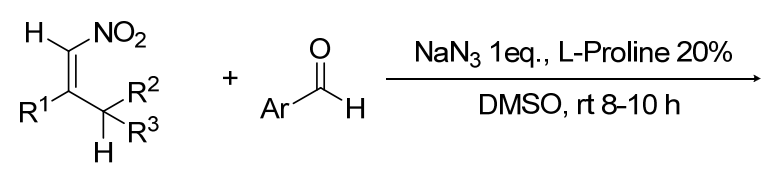<smiles>[R]C([R])=C([R])c1n[nH]nc1[Te]</smiles>
$R^{3}=H$ except $1 d$ where $R^{3}=M e$<smiles>C/C(=C/[N+](=O)[O-])c1ccccc1</smiles>

$1.1 \mathrm{~b}$<smiles>CC(C)=C[N+](=O)[O-]</smiles>

$1.1 \mathrm{e}$<smiles>CC(C)/C=C/[N+](=O)[O-]</smiles>

1.10<smiles>C/C(=C\[N+](=O)[O-])c1ccccc1</smiles>

$1.1 p$<smiles>O=Cc1cccnc1</smiles>

2.5b<smiles>O=Cc1ccncc1</smiles>

2.5c<smiles>O=Cc1cccc2ccccc12</smiles>

2.5d<smiles>O=Cc1ccc2ccccc2c1</smiles>

$2.5 \mathrm{e}$<smiles>O=Cc1ccccc1O</smiles>

$2.5 f$<smiles>O=Cc1c(O)ccc2ccccc12</smiles>

$2.5 \mathrm{~g}$

\begin{tabular}{ccccc}
\hline entry & 1.1 & $\mathbf{2 . 5}$ & $\begin{array}{c}\text { time } \\
(\mathrm{h})\end{array}$ & $\begin{array}{c}\text { yield } \\
(\%)^{b}\end{array}$ \\
\hline 1 & 1.1b & $\mathrm{Ar}=\mathrm{Ph}$ & 8 & $\mathbf{2 . 6 a : 8 9}$ \\
2 & $1.1 b$ & $\mathrm{Ar}=\mathrm{p}-\mathrm{NO}_{2}-\mathrm{Ph}$ & 8 & $\mathbf{2 . 6 b}: 88$ \\
3 & $1.1 b$ & $\mathrm{Ar}=\mathrm{m}-\mathrm{NO}_{2}-\mathrm{Ph}$ & 8 & $\mathbf{2 . 6 c :} 85$ \\
4 & $1.1 b$ & $\mathrm{Ar}=0-\mathrm{NO}_{2}-\mathrm{Ph}$ & 8 & $\mathbf{2 . 6 d :} 81$ \\
5 & $1.1 b$ & $\mathrm{Ar}=\mathrm{p}-\mathrm{CN}-\mathrm{Ph}$ & 8 & $\mathbf{2 . 6 e : ~} 78$ \\
\hline
\end{tabular}




\begin{tabular}{|c|c|c|c|c|}
\hline 6 & $1.1 \mathrm{~b}$ & $\mathrm{Ar}=\mathrm{p}-\mathrm{Cl}-\mathrm{Ph}$ & 8 & $2.6 f: 74$ \\
\hline 7 & $1.1 \mathrm{~b}$ & $\mathrm{Ar}=\mathrm{p}-\mathrm{OMe}-\mathrm{Ph}$ & 8 & 2.6g: $40^{d}$ \\
\hline 8 & $1.1 \mathrm{~b}$ & $\mathrm{Ar}=2,6-\mathrm{di}-\mathrm{Cl}-\mathrm{Ph}$ & 8 & 2.6h: 76 \\
\hline 9 & $1.1 \mathrm{~b}$ & $2.5 \mathrm{~b}$ & 8 & 2.6i: 76 \\
\hline 10 & $1.1 \mathrm{~b}$ & $2.5 \mathrm{c}$ & 8 & 2.6j: 75 \\
\hline 11 & $1.1 \mathrm{~b}$ & $2.5 d$ & 8 & 2.6k: 81 \\
\hline 12 & $1.1 \mathrm{~b}$ & $2.5 \mathrm{e}$ & 8 & 2.6I: 83 \\
\hline 13 & $1.1 \mathrm{~b}$ & $2.5 \mathrm{~g}$ & 8 & $2.6 \mathrm{~m}: 56^{d}$ \\
\hline 14 & $1.1 \mathrm{c}$ & $\mathrm{Ar}=\mathrm{Ph}$ & 8 & 2.6n: 72 \\
\hline 15 & $1.1 \mathrm{c}$ & $\mathrm{Ar}=\mathrm{p}-\mathrm{NO}_{2}-\mathrm{Ph}$ & 8 & 2.6o: 78 \\
\hline 16 & $1.1 \mathrm{c}$ & $\mathrm{Ar}=\mathrm{p}-\mathrm{Cl}-\mathrm{Ph}$ & 8 & 2.6p: 74 \\
\hline 17 & $1.1 \mathrm{c}$ & $2.5 \mathrm{c}$ & 8 & 2.6q: 71 \\
\hline 18 & $1.1 \mathrm{c}$ & $2.5 d$ & 10 & 2.6r: 73 \\
\hline 19 & $1.1 \mathrm{c}$ & $2.5 f$ & 8 & $2.6 \mathrm{~s}: 65^{d}$ \\
\hline 20 & $1.1 \mathrm{e}$ & $\mathrm{Ar}=\mathrm{p}-\mathrm{NO}_{2}-\mathrm{Ph}$ & 10 & 2.6t: $58^{c}$ \\
\hline 21 & $1.1 \mathrm{e}$ & $2.5 \mathrm{c}$ & 8 & 2.6u: 55 \\
\hline 22 & 1.10 & $2.5 \mathrm{c}$ & 8 & 2.6v: 56 \\
\hline 23 & $1.1 p$ & $2.5 \mathrm{c}$ & 8 & 2.6w: 51 \\
\hline
\end{tabular}

${ }^{a}$ Compounds 1.1 (1.0 equiv), 5 (2.0 equiv), L-proline (20 mol\%), and $\mathrm{NaN}_{3}$ (1.0 equiv) were dissolved in DMSO (0.2M of 1.1) and stirred at rt. Reactions were monitored by TLC. ${ }^{b}$ Isolated yields. ${ }^{c} 2.6 \mathrm{t}$ was characterized by X-ray crystallography. ${ }^{d}$ Heating at $80^{\circ} \mathrm{C}$.

As shown in Table 5, a large number of aryl aldehydes and $\beta$-alkyl nitroalkenes are suitable for this transformation. Various 4,5-disubstituted-1,2,3-(NH)-triazoles can be efficiently synthesized through this cascade process. Based on the reaction mechanism shown in Scheme 24, the major competing side reaction is the polymerization of the nitroalkene 1.1b. Therefore, less hindered nitroalkenes (1.1e and 1.10) gave moderate yields of $\mathbf{2 . 6}$ due to the decomposition of the nitroalkene. An excess amount of aldehyde (2.0 equiv) was also found to be important for the best product yields. The application of a stoichiometric amount of aldehyde (1.0 equiv) generally gave $10-20 \%$ lower yields of 2.6, varying by substrates. This may be due to the formation of oxidative $\mathrm{NO}_{2}{ }^{-}$ 
byproduct, which causes the decomposition of the reactant aldehyde. The electron density on the aryl group of the aldehydes was also found to influence the reaction performance. Non-substituted aromatic aldehydes and electron deficient aromatic aldehydes work well in this cascade approach. Electron-donating group substituted aryl aldehydes (entries $7,13,19$ ), on the other hand, gave poor yields at room temperature (less than $20 \%$ ). This is likely due to the slow kinetics in the initial Henry reaction along with the competition of compound $\mathbf{1 . 1}$ towards polymerization. Raising the reaction temperature to $80{ }^{\circ} \mathrm{C}$ produced the desired triazole 2.6 in good yields. Substituted azides (n-hexanyl azide and phenyl azide) have also been applied in this cascade process, however, no triazole product was observed. This is probably due to a slow 1,3-dipolar addition between the substituted azide and the diene intermediate 2.B, which could either be associated with the weaker nucleophilicity of the azide or slow elimination of $\mathrm{NO}_{2}{ }^{-}$

However, as a good nucleophile, the $\mathrm{NH}$-triazoles can be further functionalized in a regio- and enantioselective manner through readily available reactions, such as alkylation, ${ }^{39}$ acetylation, ${ }^{40}$ and Michael addition ${ }^{41}$ thereby allowing the formation of fully substituted 1,2,3-triazoles in simple steps. Compared to the thermal-1,3-dipolar addition (Zard's method), this cascade approach generates the activated intermediate in situ. Furthermore, this method successfully avoids the difficult synthesis of the a-nitroalkene reactants (i.e., 1 vinyl- 2-aryl nitroalkene), therefore significantly extending the reaction substrate scope. Moreover, the application of $\beta$-alkyl nitroalkene 1 allows the formation of a more reactive nitroalkene (1,3-diene) intermediate, which leads to mild reaction conditions and easy incorporation of other functional groups on the C-4, C-5 side chain. Some examples of side chain modification are shown in Scheme 25. 
Scheme 25: Easy side chain modifications of the 4,5-disubstituted-1,2,3-(NH)-triazoles.

A

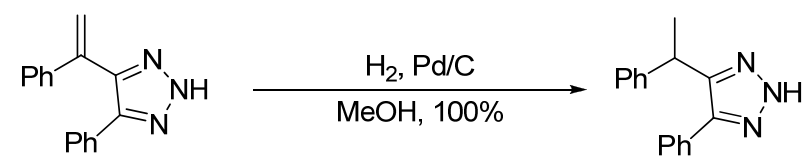

2.6a

2.7a

B

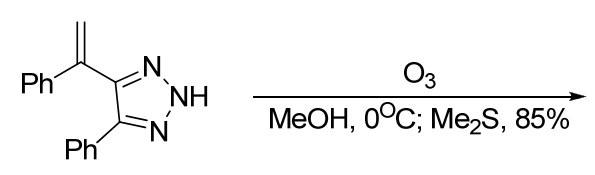

2.6a<smiles>O=C(c1ccccc1)c1n[nH]nc1-c1ccccc1</smiles>

2.7b

C

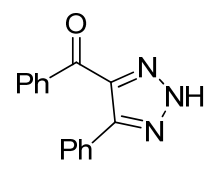

2.7b

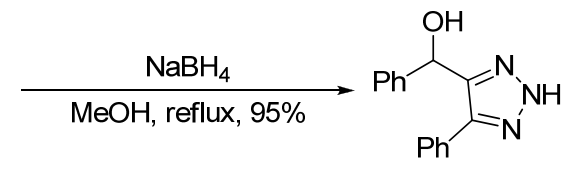

2.7c

Furthermore, through easy functional group transformations, the synthesis of chiral triazole complexes could also be achieved. For example, chiral resolution of the hydroxy-triazole $2.7 \mathrm{c}$ by refluxing with enantio-enriched quinine in a hot solution of methanol furnished the pure chiral triazole. Repeated recrystallization allowed the synthesis of the triazole with enantioselectivity as high as $99 \%$ (Scheme 26). This method of functionalization is of particular interest as it opens the path towards the synthesis of chiral triazole bound ligands in transition metal catalysis. 
Scheme 26: Synthesis and resolution of enantiomerically pure hydroxyl-(NH)-triazole.

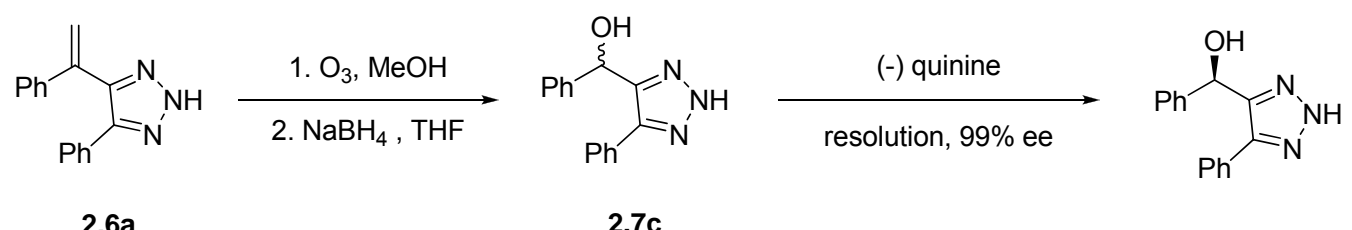

\subsection{Contributions}

Dr. Weibing Lu was the first researcher to identify the formation of the 4,5-disubstituted$(\mathrm{NH})$-triazole through the cascade reaction. Sujata Sengupta was involved in the determination of the best reaction conditions, the substrate scope and completion of the manuscript (including supporting information) for successful submission to Organic Letters. Dr. Haifeng Duan was involved in the functionalization reactions of the triazoles (synthesis of compounds $\mathbf{2 . 7 a - c ) . ~ T h e ~ d e t a i l e d ~ X - r a y ~ c r y s t a l l o g r a p h i c ~ d a t a ~ a n a l y s i s ~ o f ~}$ compound 2.6t was done by Prof. Jeffrey L. Petersen, at the C. Eugene Bennett Department of Chemistry, West Virginia University.

\subsection{Conclusion}

In conclusion, based on the Lewis base-catalyzed cascade nitroalkene-aldehyde-azide condensation, a new synthesis for $\mathrm{NH}-1,2,3$-triazoles was developed. The overall yields of this reaction are good, especially taking into consideration that this cascade method combines two reactions in "one-step". Notably, many of the products reported in Table 5 can neither be prepared from the CuAAC reaction (lack of reactivity of internal alkynes) nor by the thermal 1,3-dipolar cyclization (difficulty in the preparation of highly functionalized precursor nitro-olefins). With the advantages of readily available starting 
materials, mild reaction condition and high atom-efficiency, this method provides a complementary approach for the synthesis of substituted 1,2,3-NH-triazoles. 


\section{Chapter Three: Synthesis and Characterization of NH-triazole Coordinated Rh(I) complexes ${ }^{\dagger}$}

\subsection{Introduction}

Transition metal catalysis has currently evolved into a primary approach in modern synthesis, providing new and efficient routes for organic synthesis. ${ }^{42} \mathrm{~A}$ key correlation for successful transition metal mediated catalysis is the fundamental understanding of the ligand-metal coordination. ${ }^{43}$ In addition to the unique chemical properties of the individual metal elements, the binding ligands are crucial in determining the overall reactivity of the complexes. ${ }^{44}$ Ligand variation is perhaps the most powerful tool in transition metal catalysis and key features of transition metal catalysts such as activity, selectivity, and stability are dictated by the steric and electronic properties of the ligands

that are coordinated to the metal. ${ }^{45} \mathrm{It}$ is therefore no surprise that most efforts in the area of catalysis are put into the development/discovery of novel metal binding ligands. ${ }^{46}$ Successful examples include BINAP ${ }^{47}$ and salen ${ }^{48}$ complexes (Figure 2), both of which have been extensively and successfully applied in both the industry and academia. However, in comparison to the understanding of the properties of metal atoms/ions, the availability of ligands is significantly less developed. Therefore new and effective catalytic systems are still highly desirable.

\footnotetext{
${ }^{\dagger}$ Reproduced in parts with permission from Organometallics 2009, 28, 2352-2355. Copyright 2009, with permission from American Chemical Society.
} 
Figure 2: Popular ligands from organometallic catalysis.

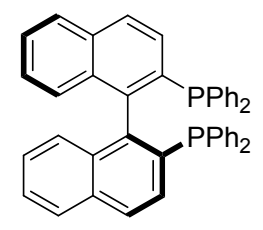

(S)-2,2'-bis(diphenylphosphino)-1,1'-binaphthyl (BINAP)

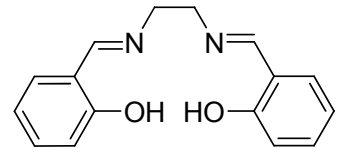

salen ligand

With a strong dipole moment, 1,2,3-triazoles are considered as potential ligands for coordination with transition metals. ${ }^{49}$ However few studies have been reported regarding triazole-metal binding before 2000 , probably due to the limited availability of functional triazole derivatives. ${ }^{50}$ The recent discovery of "click chemistry" by Sharpless and co-workers, allows for the facile synthesis of 1,4-disubstituted 1,2,3-triazoles. Since then, the application of 1,2,3-triazoles in research fields as diverse as material science and chemical biology have been widely studied. However, surprisingly, there are still very few examples or studies regarding the application of 1,2,3-triazoles as ligands in metal coordination.

In one of the earliest studies indicating the excellent metal binding ability of 1,2,3triazoles, Sharpless, Folkin and co-workers explored C3-symmetric polytriazolylamines (itself synthesized by the copper(I)-catalyzed ligation of azides and alkynes) as powerful stabilizing ligands for copper(I), protecting it from oxidation and disproportionation, while enhancing its catalytic activity in the click chemistry (Scheme 27). ${ }^{51}$ This new class of ligands is capable of binding to the Cu-metal by forming a five-member chelate between the $\mathrm{N}(3)$ of the triazole and the amine. From various ligands screened, polytriazolylamine, tris-(benzyltriazolylmethyl)amine, TBTA, showed the best stabilizing property to copper (I). It's tetradentate binding ability is believed to completely envelope the copper(I) center, leaving no free binding sites available for potential destabilizing 
interactions. $^{52}$ The tertiary amine and the 1,2,3-triazole functionalities likely work in concert to make TBTA so efficient: the former, more basic, and sterically encumbered nitrogen, accelerates the catalysis by providing additional electron density on the metal center, while the latter, being more labile, comes off the copper center only temporarily to allow the formation of the copper(I)-acetylide/ligand complex, which is then carried through the catalytic cycle.

Scheme 27: Application of C3-symmetric polytriazoles as stabilizing ligands for $\mathrm{Cu}$ in "Click Chemistry".

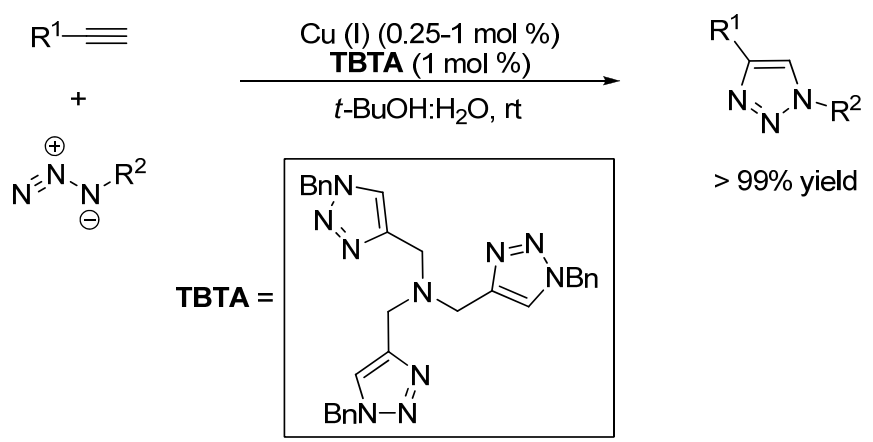

van Marseveen and co-workers have more recently developed the use of 1,2,3triazoles as nitrogen donors in P,N-type ligands (commonly referred to as ClickPhines). ${ }^{53}$ The triazole ligands were easily prepared using the $\mathrm{Cu}(\mathrm{I})$ catalyzed azide-alkyne "click" cycloaddition reaction. A diverse set of ligands were synthesized from readily available staring materials to give several homogenous and heterogeneous dendritic and polymeric catalysts (Scheme 28). The ${ }^{31}$ P NMR spectrum showed a broad signal at 20.6 ppm and crystal structure of Pd-triazole complex revealed a monodentate binding of the triazole ligand with the chloride still coordinated to the palladium. Furthermore, 
preliminary experiments found the efficiency of these ligands in the Pd-catalyzed allylic alkylation reaction.

Scheme 28: Triazoles as nitrogen donors in P,N-type ligands by van Marseveen and coworkers.

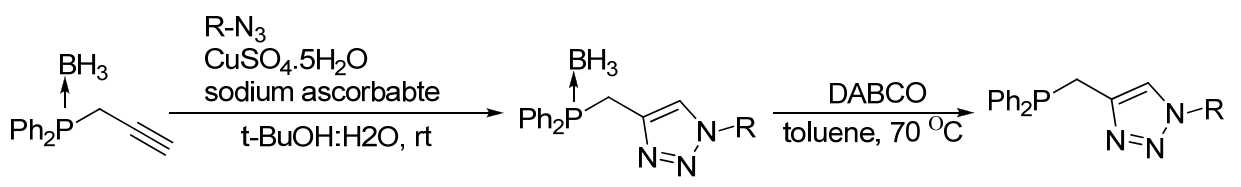

$\mathrm{R}=\mathrm{Ar}$, Alk, polystyrene, dendrimer, etc. $\quad$ "Click Phine" P, N-ligand

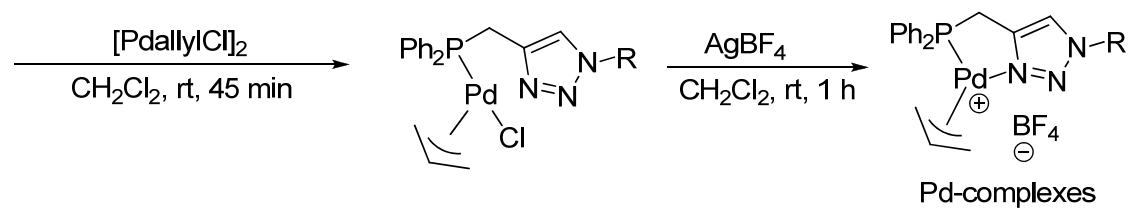

In a more recent example, Koten, Gebbink and co-workers, reported the first examples of 1,4-disubstituted 1,2,3-triazoles as monodentate Lewis-basic ligands for cationic Pd- and Pt- NCN-pincer complexes (Scheme 29). ${ }^{54}$ The 1,2,3-triazole coordinated complexes were synthesized by the addition of the triazole to the NCNpincer $\mathrm{Pd}$ and $\mathrm{Pt}$ cations, which is generated in situ upon reaction with $\mathrm{AgBF}_{4}$. Single $\mathrm{X}$ ray crystallographic structure of the complexes reveal an $M(I I)$ ion which is fourcoordinate and has a distorted square-planar ligand environment by virtue of the NCN donor atoms of the tridentate pincer ligand and the N-3 of the 1-benzyl-4-phenyl-1,2,3triazole. A comparison study of the coordination strength of these ligands with respect to more traditional ligands revealed that the coordination strength of the 1,2,3-triazoles towards NCN-Pt complexes can conveniently be tuned both sterically and electronically 
by the appropriate 1,4-functionalization, and coordination strengths similar to pyridine were obtained.

Scheme 29: Triazoles as monodentate Lewis-basic ligands for cationic Pd- and Pt-NCN pincer ligands by Gebbink and co-workers.

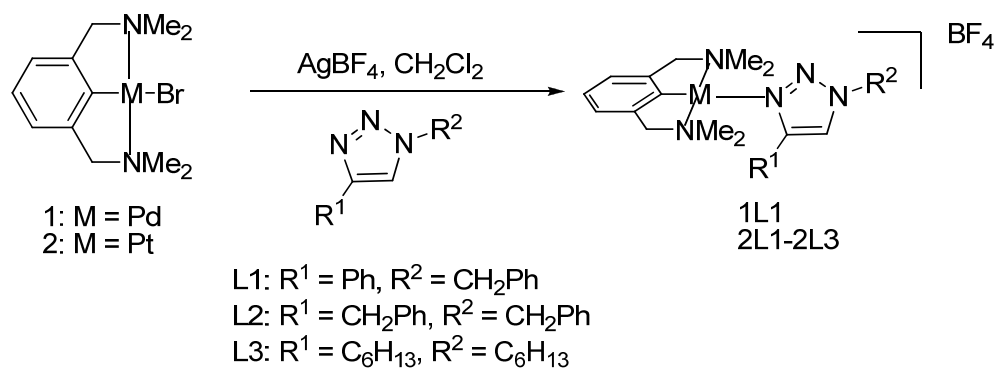

Overall, among the few literature reported catalytic systems, including the ones highlighted above, the N-substituted triazoles are dominant, which can be thought of due to the well developed click chemistry for the synthesis of the substituted triazoles.

However, the $\mathrm{NH}$-triazole, which has been reported as a stronger binding ligand even in the neutral form, ${ }^{55}$ is much less studied.

Figure 3: 1,2,3-triazole as neutral binding ligand.

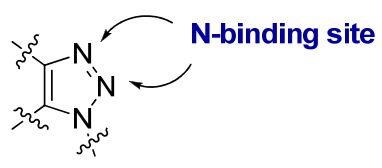

N-1-substituted 1,2,3-triazole:

neutral binding site 
In addition, compared to $\mathrm{N}$-substituted triazoles, the $\mathrm{NH}$-triazole possesses acidic $\mathrm{N}-\mathrm{H}$ protons $(\mathrm{pKa}<10),{ }^{56}$ therefore, they can be applied as anionic ligands with multiple binding sites. So far, all reported efforts regarding triazole anion binding focused on benzotriazoles, ${ }^{57}$ which decreased the overall interests in this class of complexes (limited functionality and hard to derivatize), especially due to the unlikely potential discovery of new chiral ligands. In one of the earliest example of benzotriazole as ligands with transition metals, particularly with rhodium (I) cation, Oro and co-workers explored the application of benzotriazole and benzotriazolate anion in $\mathrm{Rh}(\mathrm{I})$ complexes. ${ }^{58}$ In continuation with their interest in better understanding the structure and bonding patterns of rhodium (I) azolate complexes, the authors successfully synthesized mono- and di-nuclear rhodium complexes of the general formula $\mathrm{RhClL}_{2}(\mathrm{BtzH}),\left[\mathrm{Rh}(\mu-\mathrm{Btz}) \mathrm{L}_{2}\right]$, and $\left[\mathrm{Rh}_{2}(\mu-\mathrm{Btz})\left(\mu-\mathrm{N}_{3}\right)\left(\mathrm{L}_{2}\right)(\mathrm{L}=\mathrm{COD}\right.$, diolefin $)$. For example, the addition of benzotriazole to $[\mathrm{Rh}(\mu-\mathrm{Cl})(\mathrm{COD})]_{2}$ in acetone resulted in the formation of $[\mathrm{RhCl}(\mathrm{COD})(\mathrm{BtzH})]$ complex as stable yellow solid in $88 \%$ yield (Scheme 30). Though the authors were unsuccessful in obtaining an X-ray crystal structure, a square planar arrangement was proposed where the benzotriazole is coordinated through a pyridinic nitrogen atom. Furthermore, the addition of triethylamine to a solution of $[\mathrm{RhCl}(\mathrm{COD})(\mathrm{BtzH})]$ in methanol, led to elimination of the acidic proton on the benzotriazole ligand with the formation of $[\mathrm{Rh}(\mu-\mathrm{Btz})(\mathrm{COD})]_{2}$. Alternatively, a direct route to prepare $[\mathrm{Rh}(\mu-\mathrm{Btz})(\mathrm{COD})]_{2}$ could be achieved by the reaction of $[\mathrm{Rh}(\mu-\mathrm{Cl})(\mathrm{COD})]_{2}$ with benzotriazole and potassium hydroxide ( $>94 \%$ yield). Molecular weight measurements and X-ray crystallographic data on the $[\mathrm{Rh}(\mu-\mathrm{Btz})(\mathrm{COD})]_{2}$ complex indicated a dinuclear complex (Rh-Rh 3.27A), therefore showing that the nitrogen atoms of the bridging ligand involved in coordination are adjacent to each other. 
Scheme 30: Synthesis of $[\mathrm{Rh}(\mathrm{Btz})(\mathrm{COD})]_{2}$ complexes by Oro and co-workers.

$$
\begin{aligned}
& {[\mathrm{Rh}(\mu-\mathrm{Cl})(\mathrm{COD})]_{2}+\mathrm{BtzH} \underset{88 \% \text { yield }}{\longrightarrow}[\mathrm{RhCl}(\mathrm{COD})(\mathrm{BtzH})] \stackrel{\mathrm{Et}_{3} \mathrm{~N}}{\longrightarrow}[\mathrm{Rh}(\mathrm{Btz})(\mathrm{COD})]_{2}}
\end{aligned}
$$

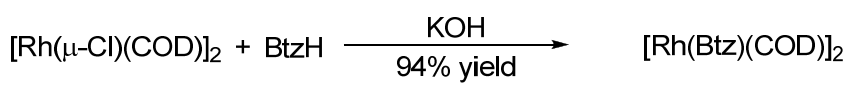

In addition, Oro and co-workers studied the only known example of a 4,5disubstituted-(NH)-1,2,3-triazole coordination with rhodium(I). ${ }^{59}$ The authors successfully synthesized neutral mono- and bi-nuclear dicyanotriazolate (DcTz) complexes of the general formula $[\mathrm{Rh}(\mu-\mathrm{Dctz})(\mathrm{L})]_{2}\left(\mathrm{~L}=\mathrm{COD}\right.$, diolefin, $\left.\mathrm{CO}, \mathrm{PPh}_{3}\right)$. Based upon a study by Rasmussen et al. ${ }^{60}$ indicating that the coordinating ability of ligands can be influenced by the presence of cyano substituents on the heterocyclic ring, the authors successfully investigated the coordinating ability of 4,5-dicyanosubstituted-1,2,3-(NH)-triazole (HDcTz). Treatment of [Rh(acac)(COD)] with dicyanotriazole, HDcTz, led to the formation of the rhodium dicyanotriazole complex in high yields (Scheme 31). Though the authors were unsuccessful in obtaining a single crystal for X-ray crystallographic analysis, molecular weight measurements indicated it to be a dinuclear complex, similar to the benzotriazole bridged complexes reported earlier. 
Scheme 31: Synthesis of 4,5-dicyanosubstituted-1,2,3-(NH)-triazole-Rh(I) complex by Oro and co-workers and its proposed structure.
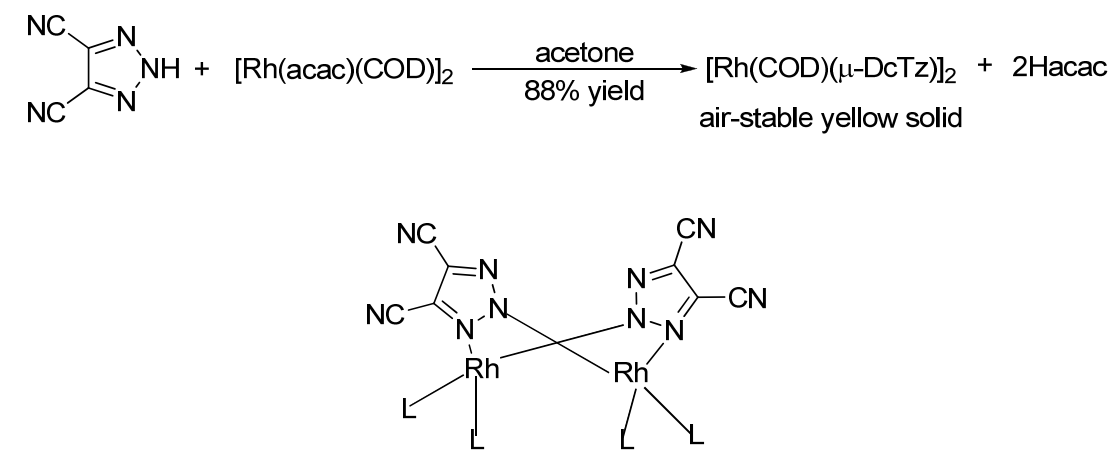

proposed structure of $\left[\mathrm{Rh}(\mathrm{DcTz}) \mathrm{L}_{2}\right.$

\subsection{Research Objective}

The initial study of the binding ability of benzotriazoles and dicyano triazoles with rhodium (I) provides a promising start to our interest in applying 1,2,3-(NH)-triazoles as novel ligands in various catalytic systems. To the best of our knowledge, $\mathrm{NH}$-triazoles have not been applied to any catalytic system, nor has any crystal structures of a $\mathrm{NH}$ triazole-bound transition-metal complex (besides that of benzotriazole reported by Oro et. al.) been reported so far. Moreover, the presence of multiple nitrogen biding sites in the triazole anion can result in complicated coordination systems, where, the two terminal nitrogens possess higher electron density while the internal $\mathrm{N}(2)$ nitrogen is more exposed for coordination (Scheme 32). Therefore, systems with regioselective coordination of the triazole anion are highly desirable. 
Scheme 32: Different binding sites for the $\mathrm{NH}$-triazole under basic condition.

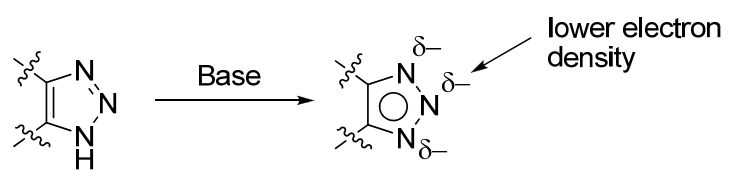

$\mathrm{NH}-1,2,3-$ triazole anion: anionic binding ligand with higher electron density on the terminal nitrogens

\subsection{Results: Synthesis of $\left[\mathrm{Rh}(\mathrm{COD})(\text { Triaz) }]_{2}\right.$ complexes}

With our new metal free synthetic methodology for the synthesis of 4,5-disubstituted$(\mathrm{NH})$-1,2,3-triazoles ${ }^{61}$ as mentioned in Chapter 2 and success in regioselective post $\mathrm{N}-2-$ triazole functionalization, ${ }^{62}$ our efforts turned to the possible application of these $\mathrm{NH}$ triazoles as new bridging ligands in the preparation of metal complexes with good regioselectivity. With the 4,5-disubstituted-(NH)-1,2,3-triazoles in hand, we examined the binding ability of the triazole anion with $\mathrm{Rh}(\mathrm{I})$ complexes by treating the $\mathrm{NH}$-triazole with $[\mathrm{Rh}(\mathrm{COD}) \mathrm{Cl}]_{2}$ under basic conditions (Scheme 33). As expected, the triazole anion effectively substituted the $\mathrm{Cl}^{-}$anion and triazole-Rh(I) complexes, $\left[\mathrm{Rh}(\mathrm{COD})(\text { Triaz) }]_{2}\right.$, were obtained in near quantitative yields. These new complexes showed excellent stability towards both air and moisture and could even be purified by column chromatography. ${ }^{63}$

Scheme 33: General method of synthesis for triazole-Rh(I) complexes.

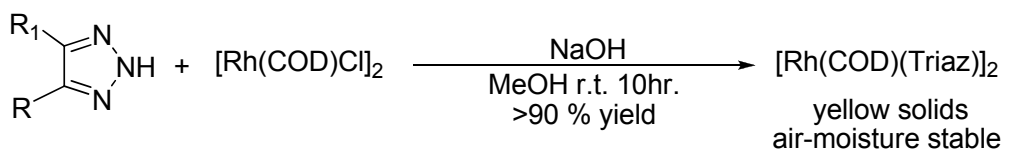


Single crystals of complexes $\mathbf{3 . 1 a}$ and $\mathbf{3 . 1 b}$, suitable for X-ray crystallographic analysis, were successfully grown from several solvent mixtures and are shown in Figures 4 and 5 respectively.

Figure 4: X-ray crystal structure for triazole bound $\mathrm{Rh}(\mathrm{I})$ complex 3.1a.
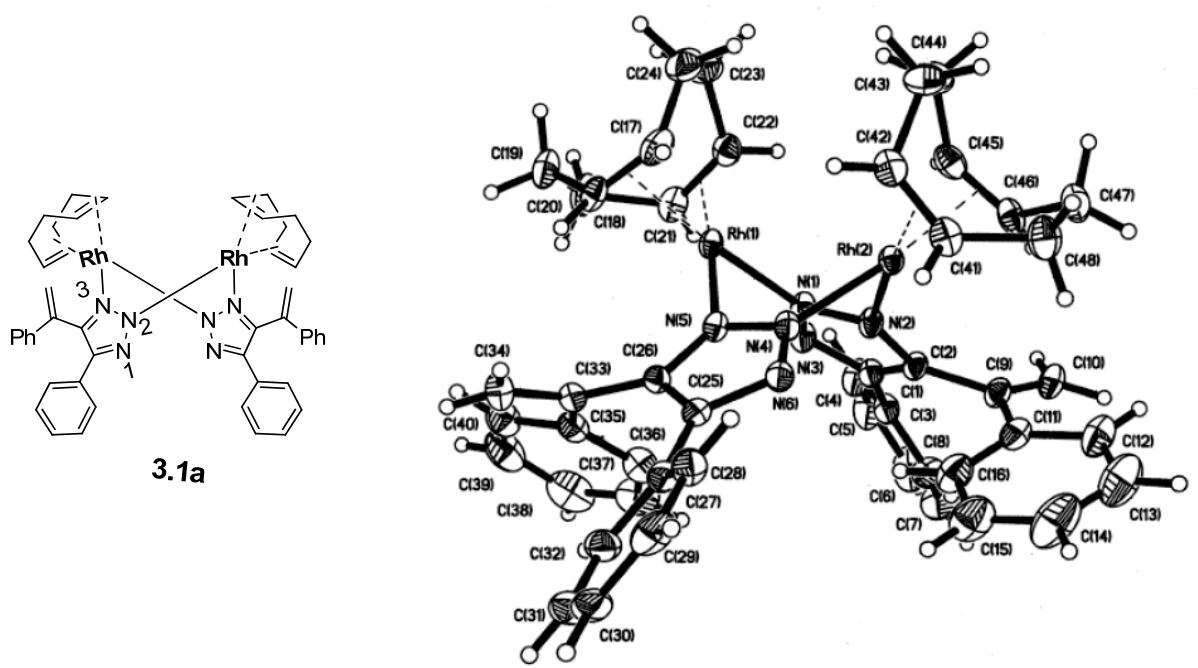

Figure 5: X-ray crystal structure for triazole bound $\mathrm{Rh}(\mathrm{I})$ complex 3.1b.
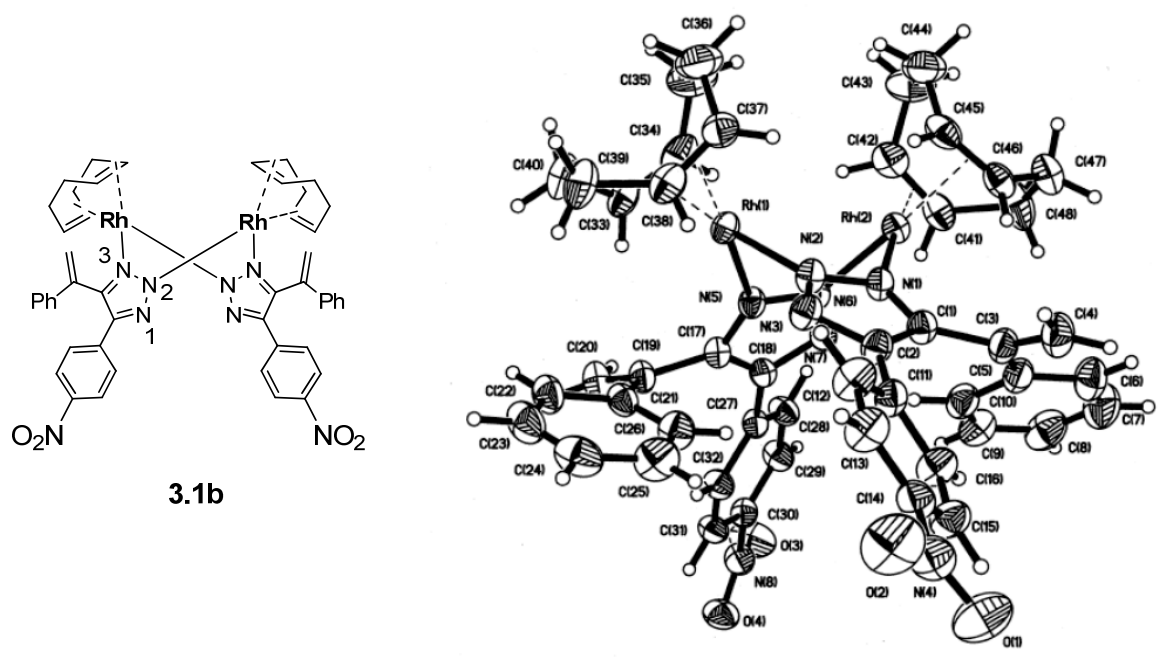
As revealed by the crystal structures, in both the complexes $\mathbf{3 . 1 a}$ and $\mathbf{3 . 1 b}$, two triazole anions coordinate with a $\mathrm{Rh}(\mathrm{I})$ cation as bridging ligands and link two $\mathrm{Rh}(\mathrm{I})$ cations forming bis-metallic complexes. The Rh cations with the COD ligands and nitrogen coordination adopt a 16-electron, square planar geometry. In these complexes, both the $\mathrm{N}(2)$ and $\mathrm{N}(3)$ nitrogens were bound to the metal, while the $\mathrm{N}(1)$ nitrogen was left uncoordinated. The presence of an electron withdrawing $\mathrm{p}-\mathrm{NO}_{2}$ group on the aromatic ring does not change the fundamental binding pattern (complex 3.1b). Both the complexes packed in a chiral lattice, where the two triazoles adopt a pseudo C-2 symmetry.

To evaluate the chiral selectivity of these complexes, the chiral triazole- $\mathrm{Rh}(\mathrm{I})$ complex 3.1c was prepared and the crystal structure suitable for X-ray analysis was grown by similar methods as above. The crystal structure of complex $\mathbf{3 . 1 c}$ is shown in Figure 6.

Figure 6: X-ray crystal structure for chiral triazole bound $\mathrm{Rh}(\mathrm{I})$ complex 3.1c.

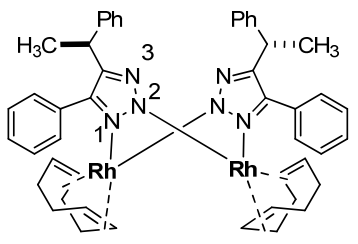

$3.1 c$

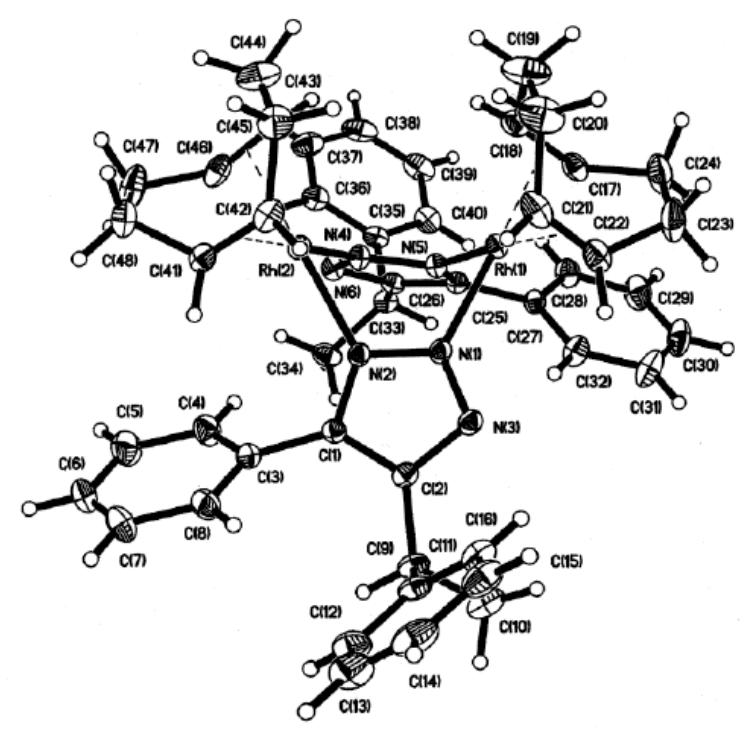


A similar triazole-bridged bis-Rh(I) complex was formed. However, rather than the $\mathrm{N}(2)$ and $\mathrm{N}(3)$ nitrogen's being involved in binding with the rhodium(I) cation as revealed in complexes $\mathbf{3 . 1 a}$ and $\mathbf{3 . 1 b}$, a completely different binding pattern was obtained in 3.1c, in which the $N(1)$ and $N(2)$ nitrogen's are bound to the metal leaving $N(3)$ uncoordinated. However, it must be noted that in all the cases, the triazole anions bound to two Rh cations. In general, the $\mathrm{N}(2)$ nitrogen, although with relatively lower electron density than the $\mathrm{N}(1)$ and $\mathrm{N}(3)$ nitrogens, is a favored $\sigma$-donor due to less steric hindrance. Meanwhile, since the C-4 and C-5 substituted groups are bearing significant steric repulsion, the conformation of these two groups' influences each other. As revealed in the post functionalization studies of the 4,5-disubstituted triazoles by fellow group members Chen and Liu et. al., the C-5 aryl group prefers to adopt a co-planar conformation with triazole ring to achieve the best m-conjugation. This key observation is again revealed in the complexes $\mathbf{3 . 1 a}$ and $\mathbf{3 . 1 b}$, where the C-4 strenyl group lies perpendicular to the triazole ring. As a result, the C-5 group blocks the $N(1)$ binding site, leaving the $\mathrm{N}(3)$ nitrogen as the preferred $\sigma$-donor. In contrast, with a more bulky alkyl group on the C-4 position (complex 3.1c), the C-5 aryl group now possesses a smaller dihedral angle with the triazole ring (less planar) and the $\mathrm{N}(1)$ nitrogen is now the preferred $\sigma$-donor. Therefore, an increase of steric hindrance on the $\mathrm{N}(3)$ position along with less protection on the $\mathrm{N}(1)$ led to different coordination pattern as observed in complex 3.1c.

In addition to the steric factor, another factor which maybe contributing to the triazole binding site is the electronic effect, which may provide different electron density on the $\mathrm{N}(1)$ and $\mathrm{N}(3)$ nitrogen. To investigate this effect, the pyridine-triazole-Rh(I) complex 3.1d was synthesized and its crystal structure is shown in Figure 7. 
Figure 7: X-ray crystal structure for pyridine-triazole-Rh(I) complex 3.1d.
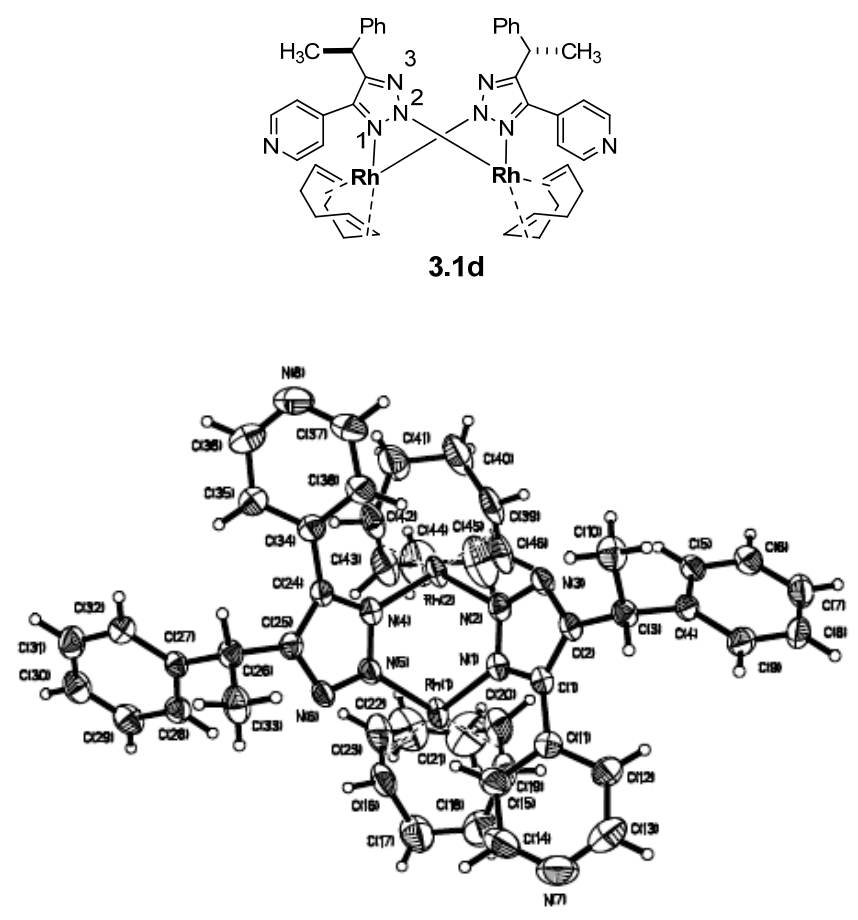

As indicated in the crystal structure, a similar $\mathrm{N}(1)$ binding was observed in $\mathbf{3 . 1 d}$, strongly suggesting that the steric effect discussed above is the dominant factor for the regioselective triazole-metal coordination. Notably, even with the presence of a strong $\sigma$ donor, pyridine, the triazole anion is still the preferred binding site and the complex is stable enough for purification through column chromatography. The direct comparison of all four complexes is provided in Table 6. 
Table 6: Comparison of the triazole bound $\mathrm{Rh}(\mathrm{I})$ complexes.

\begin{tabular}{cccccc}
\hline & & & & \multicolumn{2}{c}{ dihedral angle with triazole } \\
complex & N1-Rh $(\AA)$ & N2-Rh $(\AA)$ & N3-Rh $(\AA)$ & C-4 Ph & C-5 Ar \\
\hline 3.1a & - & $2.06 \pm 0.01$ & $2.12 \pm 0.01$ & $129 \pm 6$ & $33 \pm 1$ \\
3.1b & - & $2.06 \pm 0.01$ & $2.12 \pm 0.01$ & $131 \pm 1$ & $34 \pm 1$ \\
3.1c & $2.10 \pm 0.01$ & $2.08 \pm 0.01$ & - & $100 \pm 4$ & $49 \pm 1$ \\
3.1d & $2.12 \pm 0.01$ & $2.06 \pm 0.01$ & - & $99 \pm 1$ & $44 \pm 1$ \\
\hline
\end{tabular}

For complexes 3.1c and 3.1d, enantiomeric self sorting was observed. Similar to complexes 3.1a and 3.1b, complexes 3.1c and 3.1d are chiral with pseudo C2 symmetry between the two triazoles. With the stereogenic center on the C-4 position, the homo chiral coordination, where only R,R or S,S $[R h(C O D)(T r i a z)]_{2}$ was observed in the solid state. This result is crucial because it allows this new class of bis-metal complexes to be potential chiral catalysts for stereo selective functional group transformation. The solution NMR studies gave complex spectra even at low temperatures $\left(-50^{\circ} \mathrm{C}\right)$ due to the dynamic exchange of the COD ligands (see spectra in supporting information). However, considering the superior stability of these complexes, it is likely that the bismetal coordination should also exist in solution to maintain the 16-electron configuration on the rhodium. With the least steric hindrance, the $N(2)$ nitrogen should be of the most preferred binding site. It is possible that the $\mathrm{N}(1)$ an $\mathrm{N}(3)$ metal binding are dynamic in solution. The dissociation of the bis-metal skeletons is highly unlikely. 


\subsection{Evaluation of catalytic reactivity}

Finally, to evaluate the catalytic reactivity of this new class of $\mathrm{Rh}(\mathrm{I})$ complexes, the catalytic intramolecular Pauson-Khand reaction of enyne $\mathbf{3 . 2}$ was carried out to compare with the relatively air and moisture sensitive $\left[\mathrm{Rh}(\mathrm{COD}) \mathrm{Cl}_{2}\right.$ (Table 7). First reported in 1973 by I. U. Khand and P. L. Pauson, the cobalt-mediated carbonylative [2+2+1] inter/intramolecular cycloaddition of an alkyne, an alkene, and carbon monoxide to afford a cyclopentenone, is referred to as the Pauson-Khand reaction (PKR) (Scheme 34). ${ }^{64,65}$ Since its inception, the PKR has gained interest in the synthetic community and shows increasing use in synthesis of cyclopentenones. ${ }^{66}$ The original protocol for the PKR required stoichiometric amounts of a metal complex, which limits its utility. The first catalytic PKR was reported in $1994,{ }^{67}$ and shortly thereafter the first catalytic PKR where a metal other than cobalt, titanium was used.$^{68}$ Further development has produced catalytic, intramolecular PKRs that employ ruthenium ${ }^{69}$ and rhodium $(I)^{70}$ complexes, such as the relatively air and moisture sensitive $[\mathrm{Rh}(\mathrm{COD}) \mathrm{Cl}]_{2}$, catalysts.

Scheme 34: The Inter- and Intramolecular Pauson-Khand reaction.

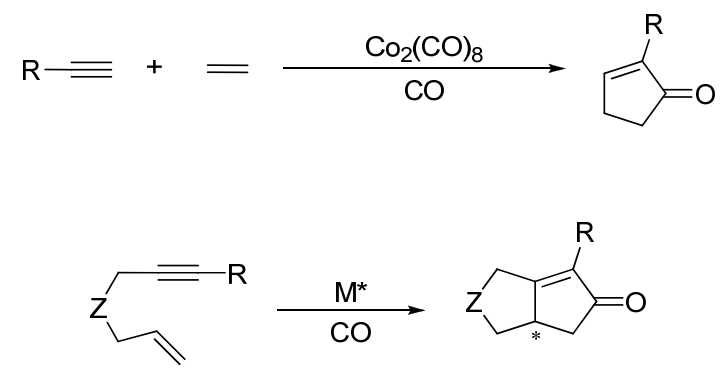


The results of the PKR of enyne $\mathbf{3 . 2}$ are shown in Table 7. Even with a greater stability toward air and moisture, all four Rh(I)-triazole complexes (3.1a-d) showed effective catalytic reactivity comparable to that of commercially available $[\mathrm{Rh}(\mathrm{COD}) \mathrm{Cl}]_{2}$.

Table 7: Catalytic reactivity of the triazole bound $\mathrm{Rh}(\mathrm{I})$ complexes.

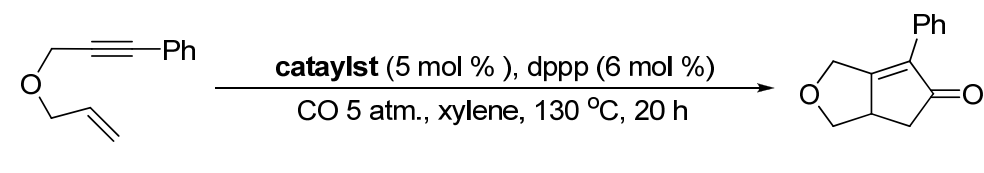

3.2

3.3

\begin{tabular}{cc}
\hline Catalyst & Yield (\%) \\
\hline$\left[\mathrm{Rh}(\mathrm{COD}) \mathrm{Cl}_{2}\right.$ & 82 \\
3.1a & 80 \\
3.1b & 88 \\
3.1c & 82 \\
3.1d & 60 \\
\hline
\end{tabular}

\subsection{Contributions}

Both Dr. Haifeng Duan and Sujata Sengupta were responsible for the synthesis of the various triazole- $\mathrm{Rh}(\mathrm{I})$ complexes and the determination of its catalytic reactivity through the Pauson Khand reaction. Furthermore, Dr. Haifeng Duan was particularly responsible for the successful growth of single crystal structures for the complexes. Dr. Jeffrey L. Petersen performed the detailed X-ray crystallographic studies on all the triazole-Rh(I) complexes (3.1a-d). Elemental analyses for all the four complexes were performed by 
Dr. Liviu Magean at the Department of Chemical Engineering, College of Engineering and Mineral Resources, West Virginia University.

\subsection{Conclusions}

In conclusion, we have successfully reported the synthesis and structural characterization of 4,5-disubstituted-1,2,3-(NH)-triazoles as organo-anionic ligands in coordination with $\mathrm{Rh}(\mathrm{I})$ complexes. One of the first examples of X-ray structure of $\mathrm{NH}$ triazole bound transition metal complexes is reported. With the application of chiral triazoles, enantiomeric self-sorting was observed, where only the homo chiral complexes were observed. As a new class of air and moisture stable compounds, these complexes showed effective catalytic reactivity in the Pauson-Khand reaction, further illustrating the great potential of these complexes as new catalysts in stereoselective reactions. 


\section{Chapter Four: Triazole-Au(I) complexes- A new class of catalysts with improved thermal stability and reactivity ${ }^{\dagger \ddagger}$}

\subsection{Introduction: Homogeneous Gold Catalysis}

Homogeneous catalysis with gold complexes has been one of the most rapidly developing fields of organometallic chemistry in the last few years and has gained immense popularity among the synthetic organic community. The unique versatility and efficiency of this metal is clearly evidenced by the countless number of reports of its use in organic transformations ${ }^{71}$ and its application in total synthesis. ${ }^{72}$ Though initial studies of gold catalysis has primarily involved the use of simple gold(I) and gold(III) salts, during the past few years, gold(I) salts with strongly coordinating phosphine ligands have gained much popularity. ${ }^{73}$ These ancillary ligands not only help to increase the solubility of the gold metal but in addition play a key role in both the reactivity and product selectivity. Key to the success of homogenous gold catalysis is the ability of gold $(\mathrm{I})$ and gold(III) to act as soft carbophilic Lewis acids towards the m-activation of C-C multiple bonds. This high carbophilicity also translates to a relatively low oxophilic character and a kinetically labile carbon-metal bond. In addition, the high oxidation potential of gold(I) to gold(III) makes the gold(I) reactions unaffected by air oxidation. As a result, compared to other transition metal catalyzed reactions, gold catalyzed reactions may be carried out under mild conditions (without the concern for air or moisture), provides good catalytic turnovers, excellent chemoselectivity with wide functional group compatibility and a high efficiency to generate products of significantly increased complexity.

\footnotetext{
${ }^{\dagger}$ Reproduced in parts with permission from J. Am. Chem. Soc. 2009, 131, 12100-12102. Copyright 2009, with permission from American Chemical Society.

$\ddagger$ This work was recently highlighted in ChemCatChem.2010, 2, 133-134.
} 
A significant number of the reported literatures in homogeneous gold catalysis, all focus with the use of cationic $\mathrm{Au}(\mathrm{I})$ complexes. ${ }^{74}$ In most reactions of this type, cationic gold(I) complexes paired with a weakly coordinating anion are used as catalysts. ${ }^{75}$ Generally, these compounds are generated by the reaction of the corresponding gold $(\mathrm{I})$ chloro complex with the silver, sodium, or potassium salts of anions such as $\mathrm{OTf}^{-}, \mathrm{BF}_{4}^{-}, \mathrm{PF}_{6}^{-}$, NTf or $\mathrm{B}^{-}\left(\mathrm{C}_{6} \mathrm{~F}_{5}\right)_{4}^{-}$(Scheme 35). Despite the remarkable reactivity of these cationic catalysts toward the electrophilic activation of C-C multiple bonds (allenes/alkynes/alkenes), they have the disadvantage of a lack of stability at higher temperatures, appearing in the formation of a gold mirror or gold nanoparticles. ${ }^{76}$ However, in order to activate some less reactive substrates, such as internal alkynes, harsher reaction conditions is usually required. ${ }^{77}$ As a result, new $\mathrm{Au}(\mathrm{I})$ catalysts that may overcome this reactivity-stability dilemma are highly desirable and would help to open new temperature ranges for this rapidly growing research field.

Scheme 35: General formation of active gold(I) species.

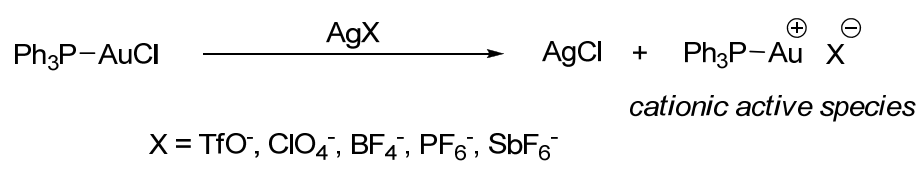

Among the reported systems, N-heterocyclic carbenes (NHC's), commonly described as excellent $\sigma$-donors, are becoming increasingly popular in this field. During the past decade, NHC's have impacted upon all fields of organometallic chemistry, becoming serious alternatives to the widely popular tertiary phosphines. ${ }^{78}$ They usually impart high stability and enhanced reactivity to the transition metals. ${ }^{79}$ The first NHC-gold(I) complex was isolated as early as $1973,{ }^{80}$ but it was only recently that these compounds, of the 
general formula $[(\mathrm{NHC}) \mathrm{AuCl}]$, have gained immense popularity, taking advantage of the straightforward synthetic routes developed recently (Figure 8). ${ }^{81}$

Figure 8: Highly popular [(NHC)AuCl].

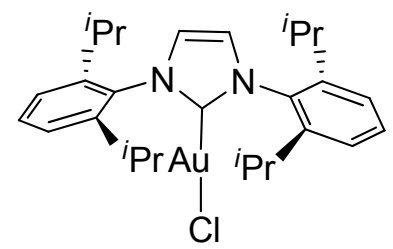

4.1c: $\mathrm{IPrAuCl}$

$(\mathrm{NHC})-\mathrm{Au}(\mathrm{I})$ catalyst with improved stability

As mentioned earlier, even with the high efficiency of phosphines gold(I) complexes in homogeneous gold catalysis, the catalytic system generally employed in these transformations involve the combined use of a phosphine gold(I) chloride complex $\left(\mathrm{Ph}_{3} \mathrm{PAuCl}, \mathbf{4 . 1 \mathrm { a }}\right)$ and a silver salt as a cocatalyst. This catalyst system has its certain limitations, for instance, silver salts are all very hygroscopic, causing difficulties in properly weighing the reagent and in keeping the reaction medium nonacidic. ${ }^{82}$ Moreover, the active gold(I) species is quite unstable, especially when a fluorine based counteranion is employed, ${ }^{83}$ and therefore in certain cases may not be isolable ${ }^{84}$ As a result, researchers are constantly on the outlook for alternate catalytic systems to generate the active gold(I) species. In continuation on their works in gold(I) catalysis, Gagosz and co-workers have developed the synthesis of new phosphines gold(I) complexes using the bis(trifluoromethanesulfonyl)imidate $\left(\mathrm{NTf}_{2}{ }^{-}\right)$moiety as a weakly coordinating counteranion (therefore forming a more dynamic Au-N coordination). These new air-stable complexes are convenient to prepare, store and handle and were found to 
be exceedingly active for the catalysis of a wide range of enyne cycloisomerizations (Scheme 36). ${ }^{85}$

Scheme 36: Synthesis of $\left[\mathrm{PPh}_{3} \mathrm{AuNTf}_{2}\right]$ and its application in enyne cycloisomerization.
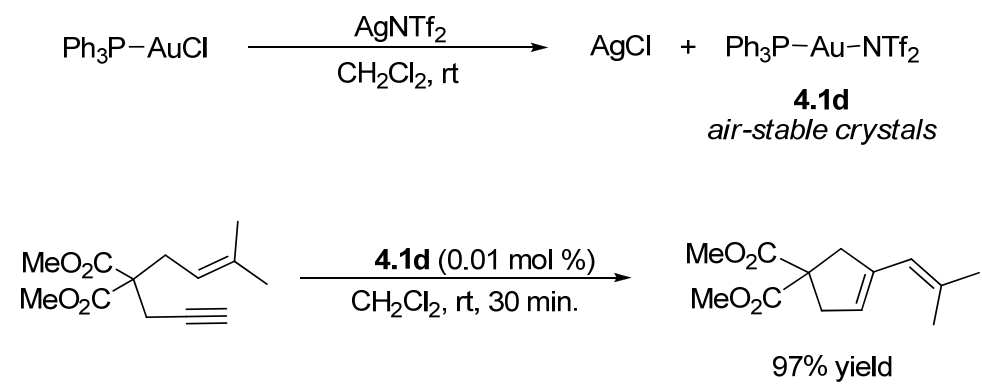

More recently, Gagosz and co-workers have successfully synthesized new Nheterocyclic carbene gold(I) complexes using the bis(trifluoromethanesulfonyl)imidate moiety $\left(\mathrm{NTf}_{2}{ }^{-}\right)$as a weakly coordinating counter anion. ${ }^{86}$ The recent success achieved in the use of strongly $\sigma$-donating NHC's ligands could be beneficial in cases where the use of phosphines led to a poor or moderate catalytic activity of the gold(I) complexes. By analogy to their previous work on the use of $\mathrm{NTf}_{2}{ }^{-}$as weakly coordinating counter anion for the synthesis of gold(I) complexes, the authors successfully synthesized stable yet catalytically active [(NHC)AuNTf $\left.{ }_{2}\right]$ complexes in high yields (up to 86\%) (Scheme 37). These new complexes were stable both in the solid and solution state and possessed a two coordinate gold(I) atom, in a linear arrangement with $\mathrm{C}-\mathrm{Au}-\mathrm{Cl}$ bond angles close to $180^{\circ}$ (from 177.4 to $178.0^{\circ}$ ). 
Scheme 37: Synthesis and structure of (IPr)AuNTf $4.1 e$.

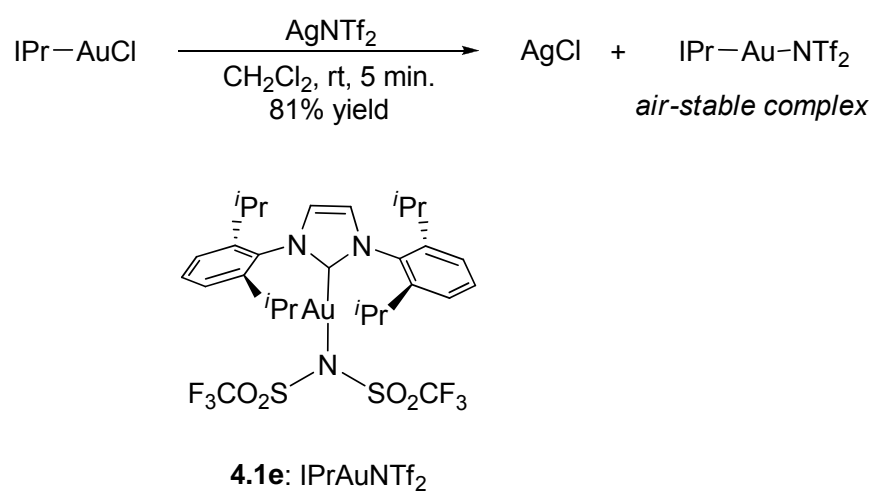

Our recent studies of the $\mathrm{Rh}(\mathrm{I})$-triazole complexes highlighted in Chapter 3 have indicated an improved stability along with a retention in its catalytic activity, ${ }^{87}$ therefore, our efforts then turned to the application of triazoles as ligands in gold(I) complexes. In comparison with the more expensive NHC ligands, the simple triazole compounds are also known to possess a nitrogen $\sigma$-donor and a lower LUMO aromatic antibonding orbital for potentially improved metal back-bonding. Therefore, we envisioned that triazoles may be applied as ligands to produce new cationic $A u(I)$ catalysts with improved stability and effective reactivity, especially at high temperatures (Figure 9). ${ }^{88}$

Figure 9: 1,2,3-triazoles: structural isomers of the NHC ligand.

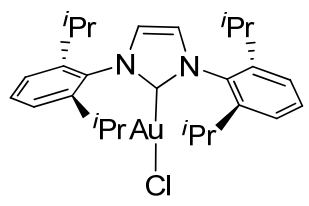

4.1e: IPrAuNTf $_{2}$ Cationic $\mathrm{Au}(\mathrm{I})$ caalysts with improved stability: $\mathrm{NHC}$ ligand and $\mathrm{NTf}_{2}^{-}$anion

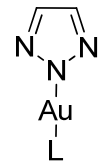

1,2,3-triazoles, structural isomer of $\mathrm{NHC}$ ligand: $\mathrm{N} \sigma$-donor and better $\pi$-receptor 
The affinity of gold for the nitrogen atom, in comparison with sulfur and phosphorus atoms, is very low and most compounds with gold-nitrogen bonds are of limited stability. ${ }^{89}$ But even then, a number of neutral or cationic gold $(\mathrm{I})$ complexes with nitrogen centers in the presence of ancillary P-donor ligands have been prepared, e.g., as neutral complexes such as $\left[\mathrm{Au}(\mathrm{im}-2-\mathrm{R})\left(\mathrm{PPh}_{3}\right)\right](\mathrm{R}=\mathrm{H}, \mathrm{Me}, \mathrm{Ph}),{ }^{90}$ and $\left[\mathrm{Au}(\mathrm{pz})\left(\mathrm{PPh}_{3}\right)\right](\mathrm{Hpz}=$ pyrazole), ${ }^{91}$ and cationic species such as $\left[\mathrm{Au}\left(\mathrm{NMe}_{3}\right)\left(\mathrm{PPh}_{3}\right)\right] \mathrm{ClO}_{4}$ and $\left[\mathrm{Au}(\mathrm{Q})\left(\mathrm{PPh}_{3}\right)\right] \mathrm{ClO}_{4}$ $(Q=2,6$-dimethyl-pyridine, naphthyridine, benzimidazole $) .{ }^{92}$ The first synthesis of a gold(I) triazole complex was described by Nomiya et. al. more than a decade ago. ${ }^{93}$ The authors successfully report the synthesis of two novel gold(I)-triphenylphosphine complexes, $\left[\mathrm{Au}(1,2,3-\mathrm{L})\left(\mathrm{PPh}_{3}\right)\right] 4.2$ and $\left[\mathrm{Au}(1,2,4-\mathrm{L})\left(\mathrm{PPh}_{3}\right)\right]_{2} \times \mathrm{H}_{2} \mathrm{O}(x=0.5-1.0) 4.3(\mathrm{HL}$ $=$ triazole) by the stoichiometric reaction of the precursor complex $\left[\mathrm{PPh}_{3} \mathrm{AuCl}\right]$ with the respective triazoles in the presence of $\mathrm{NaOH}$ (Scheme 38). The two complexes were isolated in $51 \%$ and $54 \%$ yields, respectively, as colorless crystals soluble in most organic solvents, by a vapor diffusion method with benzene/hexane as the internal/external solvents.

Scheme 38: Synthesis of triazole bound complexes by Nomiya and coworkers.

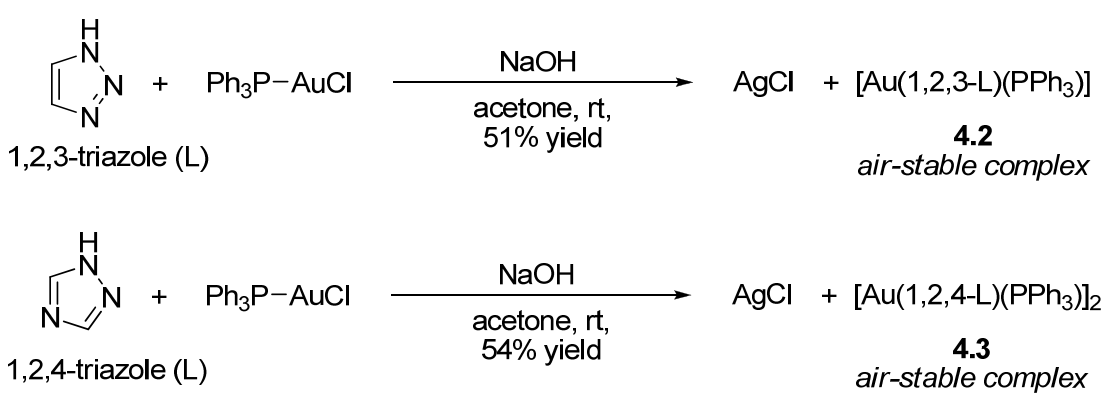

From the single-crystal X-ray analysis, the gold(I) compounds $\mathbf{4 . 2}$ and $\mathbf{4 . 3}$ are a monomer and dimer in the solid state, respectively, but molecular weight measurements 
in acetone revealed both $\mathbf{4 . 2}$ and $\mathbf{4 . 3}$ are present as a monomeric species. Furthermore, neutral complex 4.2 consists of an $\mathrm{AuL}\left(\mathrm{PPh}_{3}\right)$ core coordinated by a triazolate anion, in which the geometry around the gold $(\mathrm{I})$ atom is described as almost linear coordination, the P-Au-N angle being $178.75^{\circ}$ (Figure 10). Among the three nitrogen atoms of the 1,2,3-triazolate, the $\mathrm{N}(2)$ and $\mathrm{N}(3)$ atoms do not participate in the coordination.

Figure 10: Molecular structure of $\left[\mathrm{Au}(1,2,3-\mathrm{L})\left(\mathrm{PPh}_{3}\right)\right] 4.2$ with $50 \%$ probability ellipsoids.

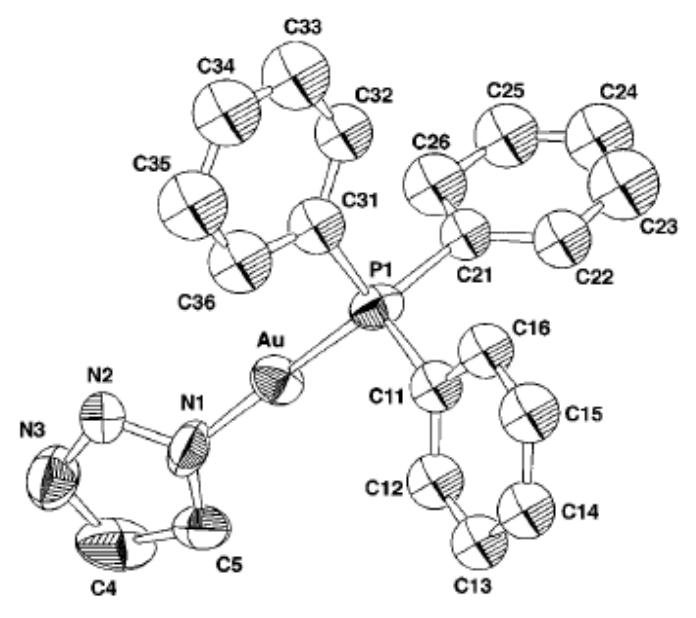

The ${ }^{31} \mathrm{P}$ NMR spectra measured at room temperature in $\mathrm{CD}_{2} \mathrm{Cl}_{2}$ of 4.2 indicated only one resonance at $\delta 31.1$ (Figure 11). However, the low-temperature ${ }^{31} \mathrm{P}$ NMR measurement showed (i) that the single peak in 4.2 was now split into two peaks at $\delta 30.6$ and 30.0 with an intensity ratio of $2: 1$ at $-90^{\circ} \mathrm{C}$, and (ii) the original single-line spectrum was recovered at room temperature from the low-temperature splitting ${ }^{31} \mathrm{P}$ NMR spectrum. Therefore, the low-temperature ${ }^{31} \mathrm{P}$ NMR measurements clearly indicate that, in solution at room temperature, the coordination of nitrogen atoms on the triazolate ligand to the 
gold(I) atom exchange dynamically; in 4.2 all three nitrogen atoms $[\mathrm{N}(1), \mathrm{N}(2)$, and $\mathrm{N}(3)]$ participate in coordination at room temperature.

Figure 11: ${ }^{31} \mathrm{P}-\mathrm{NMR}$ spectra measured in $\mathrm{CD}_{2} \mathrm{Cl}_{2}$ of $\left[\mathrm{Au}(1,2,3-\mathrm{L})\left(\mathrm{PPh}_{3}\right)\right] 4.2$ (a) at room temperature and $(\mathrm{b})$ at $-90^{\circ} \mathrm{C}$, indicating a dynamic exchange of the triazole-Au coordination system.

(a)
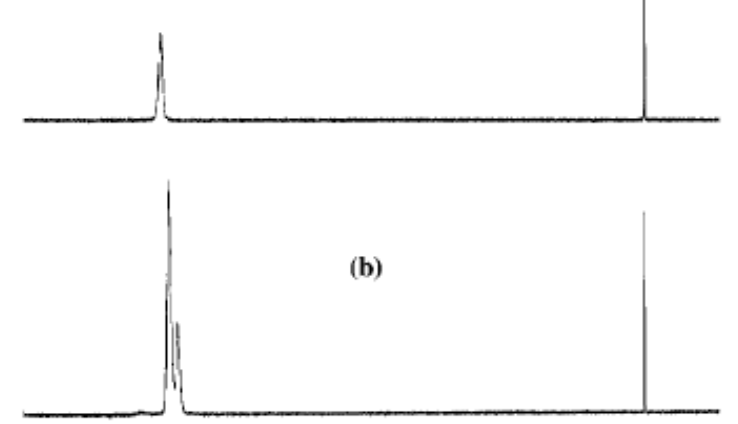

\subsection{Synthesis of triazole-gold(I) complexes}

In another separate study towards the selective functionalization of the 4,5-disubstituted triazoles, we had recently reported the highly efficient synthesis of vinyl substituted triazole through a gold(I) catalyzed alkyne activation (Scheme 39). ${ }^{94}$ 
Scheme 39: Synthesis of vinyl substituted triazoles through $A u(I)$ alkyne activation.

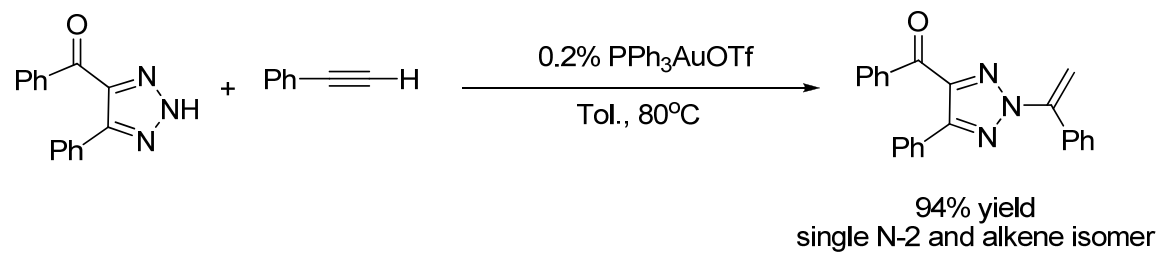

A large group of the substituted $\mathrm{NH}-1,2,3$-triazoles along with both internal and terminal alkynes were found to be suitable for this transformation and the $\mathrm{N}-1$ and $\mathrm{N}-2$ vinyl substituted 1,2,3-triazoles were prepared in good to excellent yields. Interestingly, while determining the best reaction conditions, we noticed that while only $0.2 \%$ of the gold triphenylphosphine catalyst loading was required, even at the high temperatures $\left(80^{\circ} \mathrm{C}\right)$ and prolonged reaction time $(12 \mathrm{~h})$, the gold catalyst failed to undergo any type of decomposition (no gold mirror formation was observed) and afforded the vinyl substituted triazole in excellent yield (92\%) (Table 8, entry 5), therefore, clearly suggesting that perhaps the triazole helps in stabilizing the active $A u(I)$ catalyst.

Table 8: Screening of the catalyst for triazole-alkyne addition.

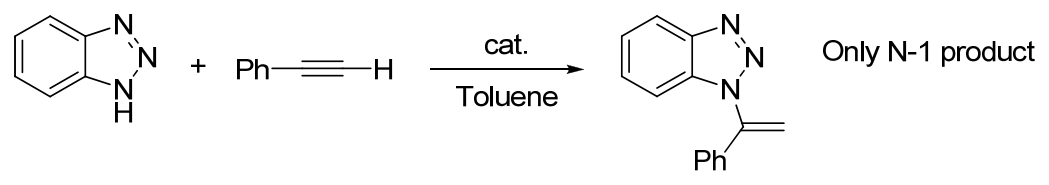

\begin{tabular}{cccccc}
\hline entry & catalyst & loading (\%) & temp. (C) & time (h) & yield (\%) \\
\hline 1 & $\mathrm{AuCl}$ & 5 & 80 & 6 & 82 \\
2 & $\mathrm{AuCl}_{3}$ & 5 & 80 & 6 & 88 \\
3 & $\mathrm{PPh}_{3} \mathrm{AuOTf}$ & 5 & rt & 12 & 15 \\
$\mathbf{4}$ & $\mathrm{PPh}_{3} \mathrm{AuOTf}$ & $\mathbf{5}$ & $\mathbf{8 0}$ & $\mathbf{5}$ & $>\mathbf{9 9}$
\end{tabular}




$\begin{array}{cccccc}\mathbf{5} & \mathrm{PPh}_{3} \mathrm{AuOTf} & \mathbf{0 . 2} & \mathbf{8 0} & \mathbf{1 2} & \mathbf{9 2} \\ 6 & \mathrm{Cul} & 5 & 80 & 12 & - \\ 7 & \mathrm{Cu}(\mathrm{OAc})_{2} & 5 & 80 & 12 & - \\ 8 & \mathrm{Sc}(\mathrm{OTf})_{2} & 5 & 80 & 12 & <5 \\ 9 & \mathrm{TfOH} & 5 & 80 & 12 & 10 \\ 10 & \mathrm{In}(\mathrm{OTf})_{3} & 5 & 80 & 12 & 68 \\ 11 & \mathrm{La}(\mathrm{OTf})_{3} & 5 & 80 & 12 & - \\ 12 & \mathrm{AgOTf} & 5 & 80 & 12 & 20 \\ 13 & \mathrm{Pd}(\mathrm{OAc})_{2} & 5 & 80 & 12 & -\end{array}$

${ }^{a}$ General reaction conditions: Reactions were carried out by dissolving benzotriazole (1 equiv), phenylacetylene (1.5 equiv) and catalyst in dry toluene $(0.2 \mathrm{M})$. The reactions were monitored by TLC. ${ }^{b}$ Determined by NMR analysis.

With the promising data reported by Nomiya, our facile method for the synthesis of $4,5-$ disubstituted-(NH)-1,2,3-triazoles, and our observations during the regioselective vinylation of triazoles, we turned our focus to the synthesis of triazole-Au(I) complexes. The triazole-Au complexes 4.4a $\left(\mathrm{PPh}_{3} \mathrm{Au} \cdot \mathrm{Btz}\right)$ and 4.4b $\left(\mathrm{PPh}_{3} \mathrm{Au} \cdot \mathrm{PTz}\right)$ were prepared in quantitative yields using a preparation procedure similar to the one reported previously for the triazole-Rh(I) complexes in Chapter 3 (Scheme 40).

Scheme 40: Synthesis of triazole bound gold(I) complexes under basic conditions.

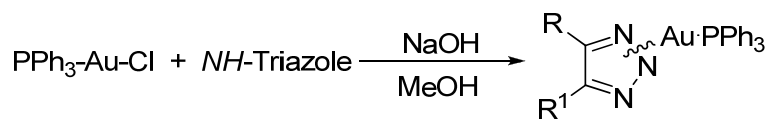


Single crystal structures were successfully grown by the vapor diffusion method using benzene/hexane solvent system and the structures of $4.4 \mathrm{a}$ and $\mathbf{4 . 4 b}$ were determined by X-ray diffraction [see the Supporting Information for details], which revealed $\mathrm{N}(1)$ coordination in 4.4a and N(2) coordination in 4.4b (Figures 12 and 13).

Figure 12: X-ray crystal structure for triazole bound $A u(I)$ complex 4.4a.

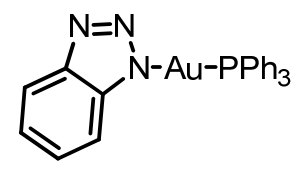

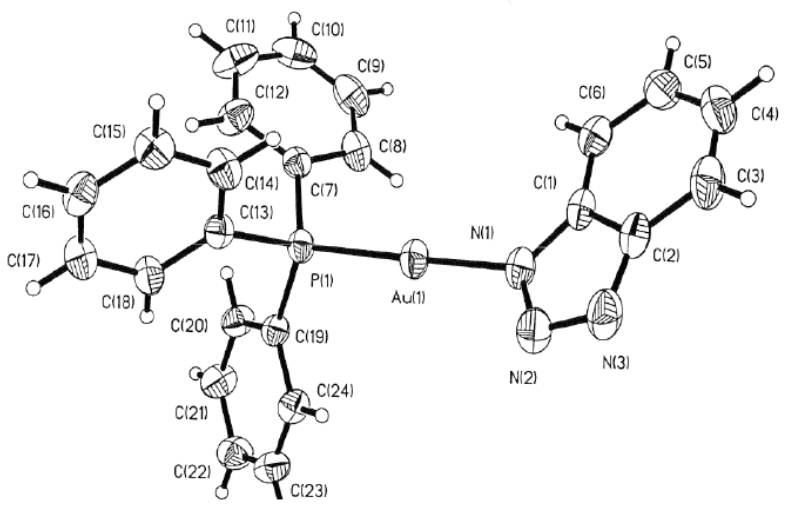

Figure 13: X-ray crystal structure for triazole bound $\mathrm{Au}(\mathrm{I})$ complex $\mathbf{4 . 4 b .}$
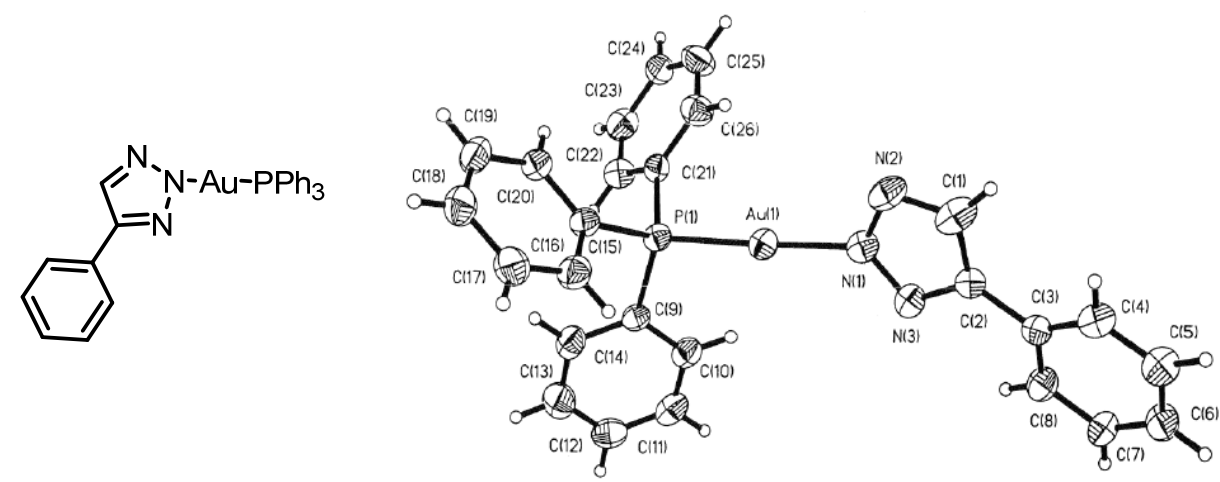
Neutral triazole bound $\mathrm{Au}(\mathrm{I})$ complexes were also successfully prepared by treating the corresponding triazole and $\mathrm{PPh}_{3} \mathrm{AuCl}$ mixtures with $\mathrm{AgOTf}$ (Scheme 38). Removal of the $\mathrm{AgCl}$ precipitate gave clear solutions, which were then concentrated to afford complexes 4.5a-c $\left(\mathrm{PPh}_{3} \mathrm{Au} \cdot \mathrm{BtzH}, \mathrm{PPh}_{3} \mathrm{Au} \cdot \mathrm{BtzMe}\right.$, and $\mathrm{PPh}_{3} \mathrm{Au} \cdot \mathrm{BtzBn}$, respectively) in nearquantitative yields (Scheme 41).

Scheme 41: Synthesis of triazole-Au(I) complexes 4.5a-c.

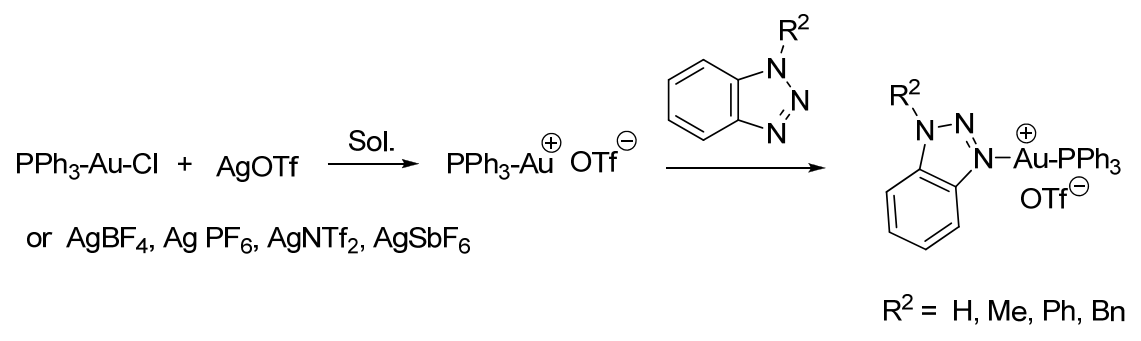

All of these triazole-Au complexes are white solids that are stable with respect to air and moisture, including the cationic gold complexes 4.5a-c. Moreover, complex 4.5a could also be prepared directly by the treatment of $4.4 a$ with HOTf (Scheme 42 ). This method of preparation of the active species is worth mentioning because it does not require the utilization of silver salts, which might under certain circumstances be active catalysts themselves. ${ }^{95}$

Scheme 42: Silver free method for the synthesis of active triazole-Au(I) complexes.

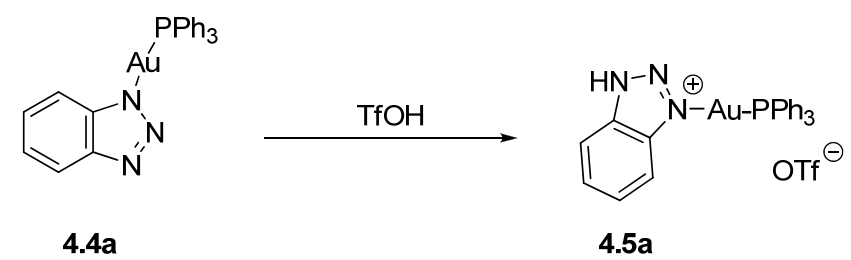


Importantly, X-ray structure of $4.5 a$ revealed coordination between the neutral triazole and the Au cation in the presence of a $\mathrm{TfO}^{-}$literal ion as the counteranion (Figure 14). This result provides strong evidence for the proposed neutral triazole-Au coordination in the presence of other counter anions. Furthermore, the solid state structure of $\left[\mathrm{PPh}_{3} \mathrm{Au}\right.$ (triazole)] revealed a Au-N bond length of $198 \mathrm{pm}$ which is much shorter than the Au-N bond lengths in other commonly available $s p^{2}-\mathrm{N}-\mathrm{Au}$ complexes (which are 203 pm or more). However, the above bond length are comparable to a typical Au-C bond length in a $[\mathrm{Au}(\mathrm{NHC})]$ complex, thereby indicating that from a structural point of view, 1,2,3-triazoles can be seen as analogues of $\mathrm{N}$-heterocyclic carbenes. ${ }^{96}$

Figure 14: X-ray crystal structure for triazole bound $\mathrm{Au}(\mathrm{I})$ complex 4.5a.

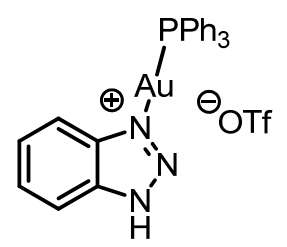

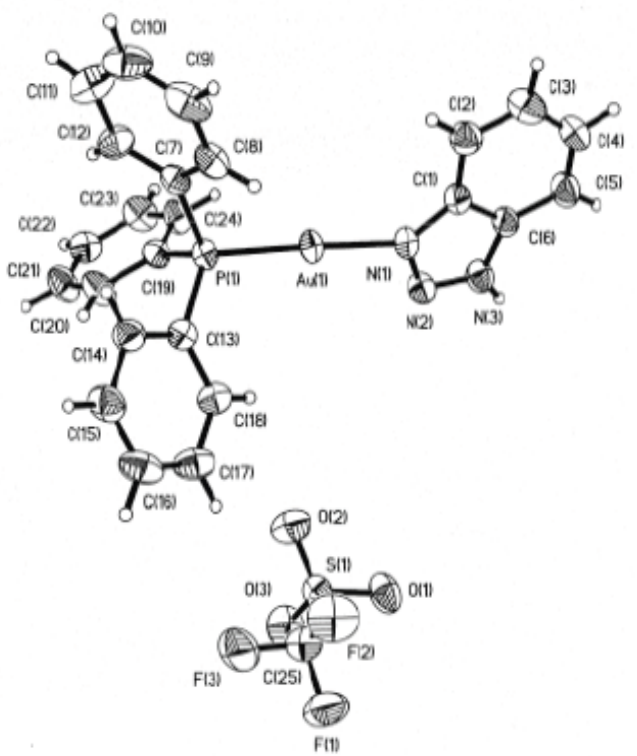




\subsection{Efforts towards the synthesis of chiral triazole-gold(I) complexes}

With the facile synthesis of the various triazole gold $(I)$ complexes highlighted in the previous section, we had also made efforts towards the synthesis of chiral triazole bound gold(I) complexes. Through easy functional group transformations on the 4,5disubstituted-(NH)-triazoles, we had successfully synthesized chiral hydroxyl triazole mentioned earlier in Chapter 2 (Scheme 38).

Our efforts then began with N-2-benzylated triazole $4.6 a$, which could be easily prepared by the regioselective alkylation of triazole 2.6a following the protocol reported by fellow group members Chen and Shi et. al. Hydroboration-oxidation with $\mathrm{BH}_{3}$.THF followed by $\mathrm{H}_{2} \mathrm{O}_{2}$ furnished hydroxyl triazole 4.6b (Scheme 43). However, all efforts to carry out chiral resolution on this hydroxyl triazole failed. Continuing with the achiral triazole, tosylation with p-toluenesulphonyl chloride followed by nucleophilic substitution of the primary alcohol with diphenylphosphine and oxidation with $\mathrm{H}_{2} \mathrm{O}_{2}$ furnished diphenylphosphine oxide triazole $\mathrm{X}$. Subsequent deoxygenation with silane $\left(\mathrm{HSiCl}_{3}\right)$ following standard procedures produced the diphenylpshophine triazole 4.6e. Unfortunately compound $4.6 e$ was highly unstable and all efforts to isolate it failed.

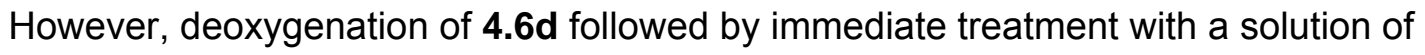
dimethyl sulphide gold $(\mathrm{I})$ chloride in DCM furnished the achiral triazole gold $(\mathrm{I})$ complex 4.6f, which was isolated as a white solid in near quantitative yield and was found to be completely stable to air and moisture. 
Scheme 43: Synthesis of triazole gold(I) complex 4.6f.
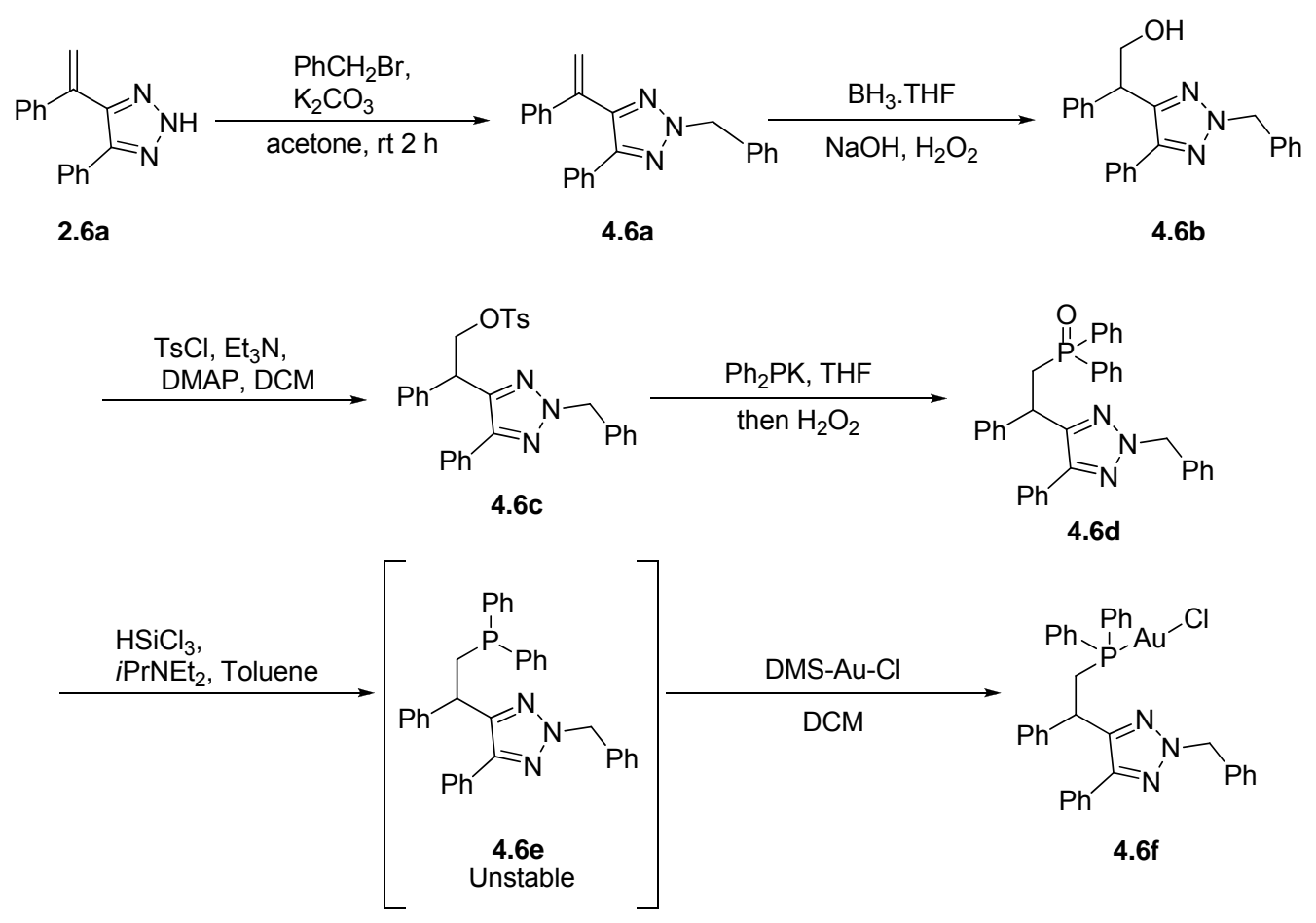

Furthermore, a single crystal of triazole gold(I) complex $4.6 f$ was successfully grown by the vapor diffusion method employing a mixture of benzene/hexane and was characterized through X-ray crystallography. Its structure is shown in Figure 15.

Figure 15: X-ray crystal structure for triazole bound $A u(I)$ complex 4.6f.
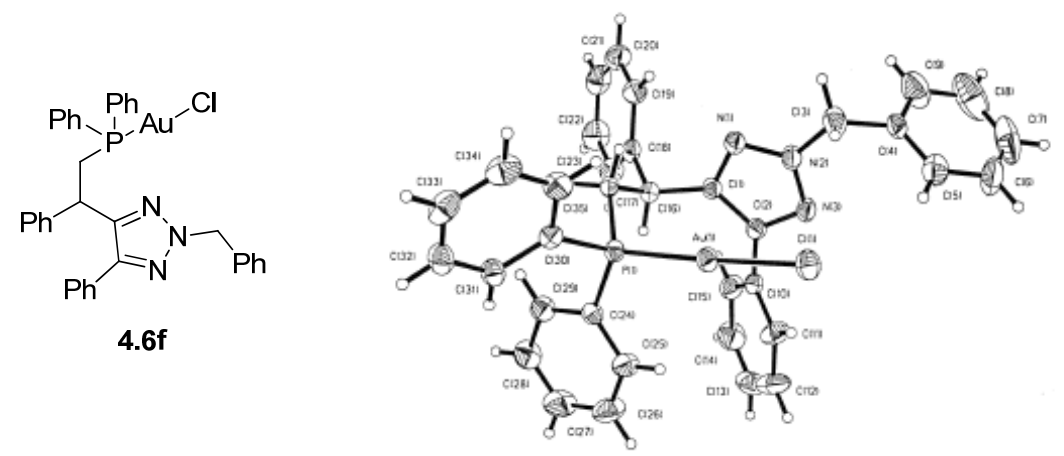


\subsection{Determination of dynamic coordination nature of triazole-gold(I) complexes}

Because triphenylphosphine $\left(\mathrm{PPh}_{3}\right)$ ligand was used in all these complexes, it stands to serve as a good probe for the measurement of covalence in the $\mathrm{PPh}_{3} \mathrm{Au}-\mathrm{X}$ bond.

According to the trans effect in linearly coordinated gold $(I)$ compounds, the ${ }^{31} \mathrm{P}$ NMR spectroscopic shift of the triphenylphosphine ligand might directly be attributed to the binding situation or rather to the degree of covalence in the Au-X bond, which may then directly correlate to its catalytic reactivity. A comparison of the ${ }^{31} \mathrm{P} N M R$ chemical shifts of different Au complexes is shown in Figure 16. The ${ }^{31} \mathrm{P}$ NMR spectrum of $\left[\mathrm{PPh}_{3} \mathrm{AuCl}\right]$ 4.1a showed a chemical shift at $34.31 \mathrm{ppm}$ (referenced to $\mathrm{H}_{3} \mathrm{PO}_{4}$ ). The $\mathrm{Au}-\mathrm{Cl}$ bond is expected to be mostly covalent, accounting for both the poor catalytic activity and the high stability of this complex. This is in good accordance to $\left[\mathrm{PPh}_{3} \mathrm{Aul}\right]$, which is known to give a signal approximately at $39 \mathrm{ppm}$. The highly active yet unstable literal ion complex $\mathrm{PPh}_{3} \mathrm{Au}^{+}$. OTf $4.1 \mathrm{~b}$ showed an upfield shift of the phosphorus signal at $28.80 \mathrm{ppm}$ (which can be attributed to the ionic character of the Au-OTf bond). As suggested by Gagosz et. al., the $\mathrm{Tf}_{2} \mathrm{~N}^{-}$anion forms a dynamic coordination with the Au cation, thereby improving the thermal stability and catalytic reactivity of the catalyst. ${ }^{97}$ This was supported by the ${ }^{31} \mathrm{P}$ NMR spectrum, where $\mathrm{Ph}_{3} \mathrm{PAu}^{+}$. NTf 4.1d gave a phosphorous chemical shift of $31.60 \mathrm{ppm}$, which is located in between that for the highly reactive $\mathrm{Au}^{+}$ literal ion and the strongly covalent complex $\mathrm{PPh}_{3} \mathrm{AuCl}$. We were subsequently pleased to observe a similar electronic influence for our triazole-bound Au complexes, (where the gold(I) triazole complex 4.4a showed a signal at $32.80 \mathrm{ppm}$ ), located between the two extremes of strong and weak covalence. 
Figure 16: ${ }^{31} \mathrm{P}$ NMR shifts of the different gold(I) complexes at $28{ }^{\circ} \mathrm{C}$.

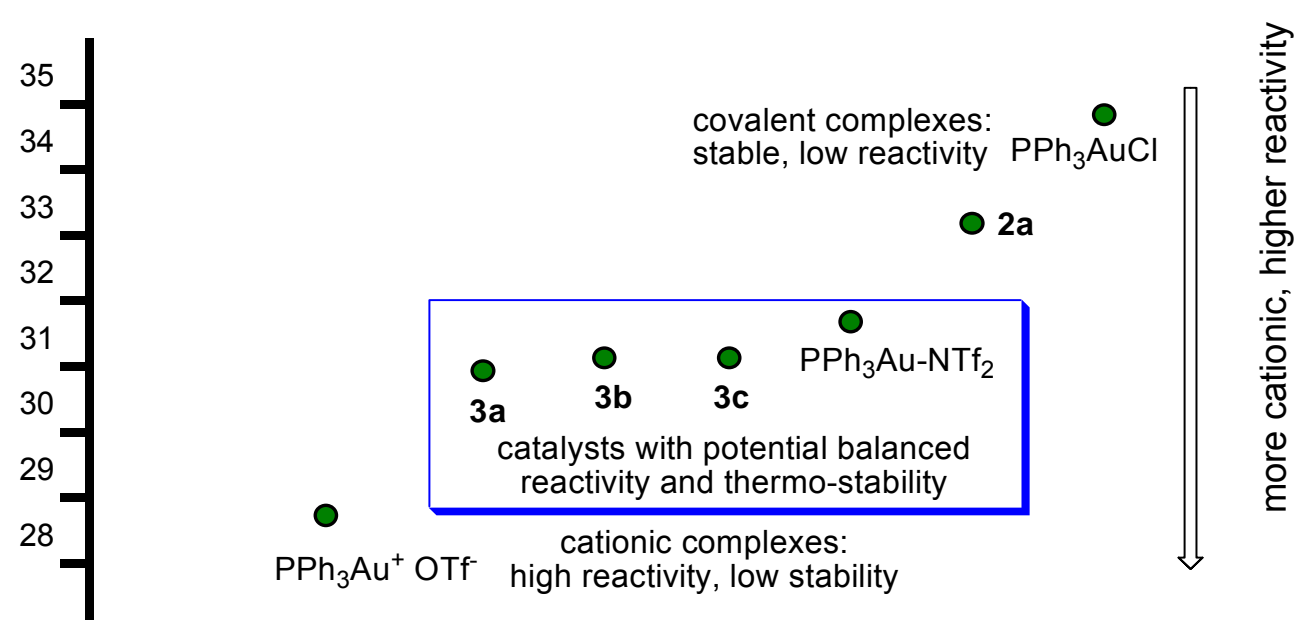

Thus, the complexes 4.4b and 4.5d (possessing similar binding affinities at the $\mathrm{N}(1)$ and $\mathrm{N}(2)$ positions) were then investigated by variable temperature (VT) NMR studies (note: different ${ }^{31} \mathrm{P}$ signals appear for various $\mathrm{N}$ isomers).

As shown in Figure 17, dissolving pure $\mathrm{N}(2)$ isomer $4.4 \mathrm{~b}$ gave a ${ }^{31} \mathrm{P} N M R$ spectrum consisting of two broad signals at around $32 \mathrm{ppm}$ at room temperature, indicating the rapid exchange between the coexisting $\mathrm{N}(2)$ and $\mathrm{N}(1)$ isomers in solution. The N(3) isomer was not observed because of C4-phenyl steric hindrance. However, lowering the temperature to $-50{ }^{\circ} \mathrm{C}$ led to sharpening of the signals, thereby indicating a diminished exchange rate between the to isomers. Signal line shape analysis (based on VT NMR data from -55 to $\left.+60^{\circ} \mathrm{C}\right)$ gave a good linear correlation $\left(r^{2}=0.99\right.$; see details in the supporting information). 
Figure 17: VT NMR studies $\left({ }^{31} \mathrm{P}\right.$ NMR spectra) complex $4.4 \mathrm{~b}$ at $-50{ }^{\circ} \mathrm{C}$ and $28{ }^{\circ} \mathrm{C}$, showing decrease in resolution due to dynamic exchange of triazole-Au binding system.
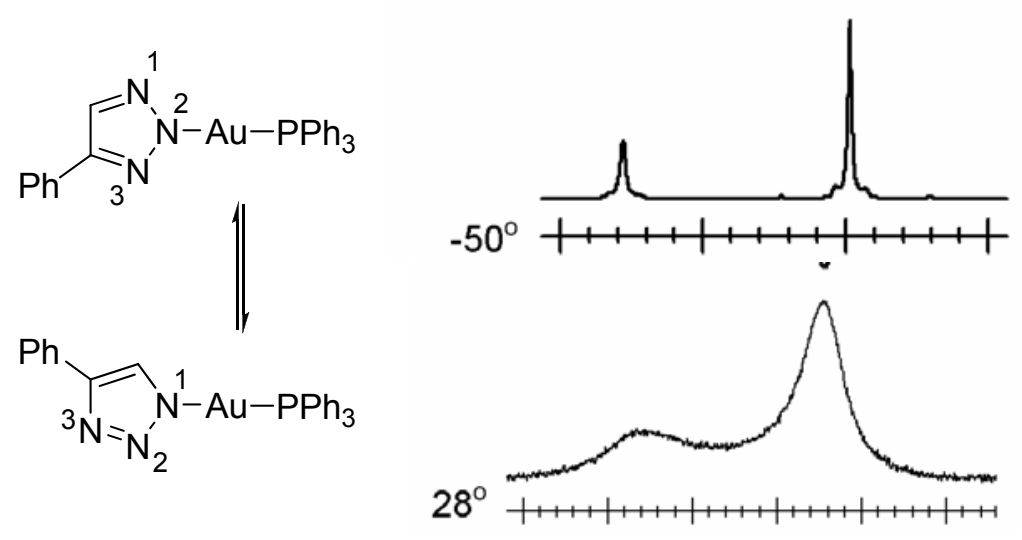

In comparison, dissolving cationic complex $4.5 \mathrm{~d}$ in solution gave one sharp signal at room temperature (Figure 18). With both $\mathrm{H}$ and $\mathrm{Au}$ coordinated on the triazole, theoretically, six regioisomers could be produced (i.e., $N(3)-H / N(1)-A u, N(3)-H / N(2)-A u$, etc.). As a result, multiple ${ }^{31} \mathrm{P}$ signals were obtained at lower temperatures. Because of the great complexity in $\mathbf{4 . 5 d}$, line shape analysis could not be applied. However, it was clear that faster exchange was associated with neutral triazole ligands, where a lower temperature was needed in order to obtain separated ${ }^{31} \mathrm{P}$ signals under the same conditions (detailed spectra's are provided in the supporting information). Notably, the benzotriazole Au complexes gave dominant $\mathrm{N}(1)$ binding between -55 and $60{ }^{\circ} \mathrm{C}$, which made them unsuitable for this VT NMR study. However, considering the fact that they possess the similar functional group, it is expected that complexes $4.4 \mathrm{a}$ and $4.5 \mathrm{a}-\mathrm{c}$ would possess the same dynamic coordination nature, which is crucial for the catalytic reactivity and potential Au cation stability. It must be noted that comparable properties 
were responsible for the improved thermal stability and reactivity of the $\left[\mathrm{PPh}_{3} \mathrm{AuNTf}_{2}\right]$ complex by Gagosz and co-workers.

Figure 18: VT ${ }^{31} \mathrm{P}$ NMR studies on complex $4.6 \mathrm{~d}$ at $-60{ }^{\circ} \mathrm{C}$ and $28^{\circ} \mathrm{C}$, showing dynamic exchange of triazole-Au binding.

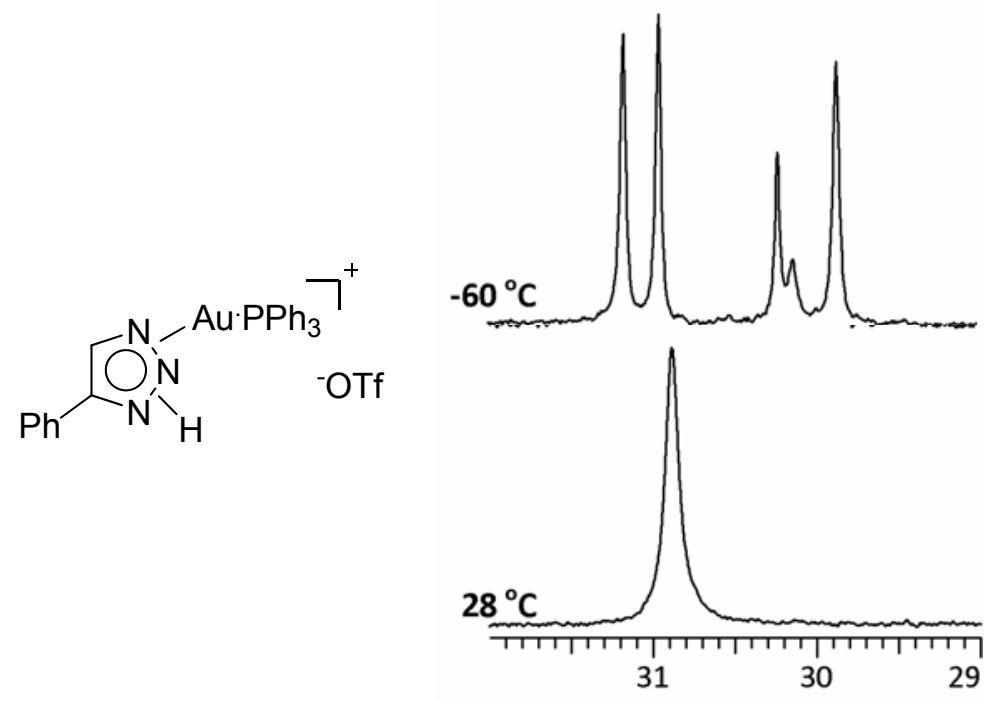

\subsection{Catalytic reactivity of the triazole-gold(I) complexes.}

To further test our hypothesis that this dynamic triazole-Au coordination may help the thermal stability of the Au catalyst, especially at high temperature, the hydroamination of internal alkyne $4.7 \mathrm{a}$ with aniline $\mathbf{4 . 8 a}$ was investigated in the presence of different $\mathrm{Au}(\mathrm{I})$ catalysts (Figure 19).

Due to both the importance of nitrogen containing compounds and the limitations associated with traditional methods for $\mathrm{C}-\mathrm{N}$ bond formation, the catalytic addition of an $\mathrm{N}-\mathrm{H}$ bond across a $\mathrm{C}-\mathrm{C}$ multiple bond (hydroamination) has received considerable 
attention as an atom-economical and potentially expedient route for the synthesis of amine derivatives. ${ }^{98}$ As stated earlier, gold complexes are Lewis acids that activate C-C multiple bonds towards nucleophilic attack. Among the reactions catalyzed by gold, hydroamination of C-C multiple bonds (alkynes, alkenes, and allenes) has received considerable attention for the synthesis of amine derivatives. ${ }^{99}$ However, general and efficient methods for the hydroamination of $\mathrm{C}-\mathrm{C}$ multiple bonds, particularly the intermolecular hydroamination of internal alkynes remain limited and extremely challenging, requiring elevated temperatures and harsh reaction conditions. ${ }^{100}$ Recently Tanaka has reported an acid-promoted, $\mathrm{Au}(\mathrm{I})$ catalyzed procedure for the intermolecular hydroamination of alkynes to form imines, ${ }^{101}$ based on the catalyst system optimized for the Au-catalyzed intermolecular hydration of alkynes. For example, treatment of a neat 1:1.1 mixture of phenylacetylene and p-bromoaniline with a catalytic $1: 5$ mixture of [(PPh $)$ AuMe] and $\mathrm{H}_{3} \mathrm{PW}_{12} \mathrm{O}_{40}$ at $70{ }^{\circ} \mathrm{C}$ for $2 \mathrm{~h}$ formed the ketimine in $94 \%$ yield $\left({ }^{1} \mathrm{H}-\mathrm{NMR}\right.$ yield) (Scheme 44). Both the gold and the acid were crucial for effective hydroamination and the reaction was quite sensitive to the nature of the acid promoter employed. Though the gold-catalyzed intermolecular hydroamination was effective for a variety of aryl- and alkyl-substituted terminal alkynes, the scope of di-alkyl substituted internal alkynes were extremely limited and required much longer reaction times and provided the resulting imines in low yields (Scheme 44).

Scheme 44: Acid promoted hydroamination of alkynes by Tanaka et. al.

$$
\begin{aligned}
& \mathrm{R}^{1}=\mathrm{R}^{2}+\mathrm{R}^{3}-\mathrm{NH}_{2} \quad \frac{\stackrel{\left(\mathrm{PPh}_{3}\right) \mathrm{AuCH}_{3}(0.2 \mathrm{~mol} \%)}{\mathrm{H}_{3} \mathrm{PW}_{12} \mathrm{O}_{40}(1.0 \mathrm{~mol} \%)}}{\text { solvent free, } 70 \mathrm{C}} \rightarrow \mathrm{R}^{1} \stackrel{\mathrm{NR}}{3}_{\mathrm{R}^{2}}^{\mathrm{N}^{3}}+\mathrm{R}^{1} \prod_{\mathrm{NR}^{3}}^{\mathrm{R}^{2}} \\
& \left(\mathrm{R}^{1}=\mathrm{C}_{6} \mathrm{H}_{5}, \mathrm{R}^{2}=\mathrm{H}, \mathrm{R}^{3}=\mathrm{C}_{6} \mathrm{H}_{5}\right) \\
& \left(R^{1}=R^{2}=n-C_{3} H_{7}, R^{3}=C_{6} H_{5}\right) \\
& \left(\mathrm{R}^{1}=\mathrm{n}-\mathrm{C}_{3} \mathrm{H}_{7}, \mathrm{R}^{2}=\mathrm{CH}_{3}, \mathrm{R}^{3}=4-\mathrm{BrC}_{6} \mathrm{H}_{4}\right)
\end{aligned}
$$


As indicated by the reaction profiles (Figure 19), in order to achieve effective internal alkyne hydroamination, higher temperature is needed (Figure 19, a and b). All of the tested non-triazole Au catalysts examined, clearly suffered from thermal decomposition/degradation over time, including the superior and highly popular, [IPrAuNTf $\left.{ }_{2}\right]$ 4.1e (Figure 19, d). However, with the application of neutral triazole-bound Au complex 4.5a, significant improvement was obtained, giving the desired products in good yields (Figure 19, f). This ligand effect was further supported by the addition of excess triazole ligand (Figure 18, e), where a lower reaction rate was observed, suggesting the coordination of the triazole ligand with the Au cation (competition with the alkyne substrate).

Figure 19: Reaction process profile: (a) $5 \%$ 4.1b, rt; (b) $5 \% 4.1 \mathrm{~b}, 80^{\circ} \mathrm{C}$; (c) $5 \% 4.1 \mathrm{~d}, 80$ ${ }^{\circ} \mathrm{C}$; (d) $5 \% 4.1 \mathrm{e}, 80{ }^{\circ} \mathrm{C}$; (e) $5 \% 4.5 \mathrm{a}+5 \%$ benzotriazole, $80{ }^{\circ} \mathrm{C}$; (f) $5 \% 4.5 \mathrm{a}, 80{ }^{\circ} \mathrm{C}$; (g) $1 \%$

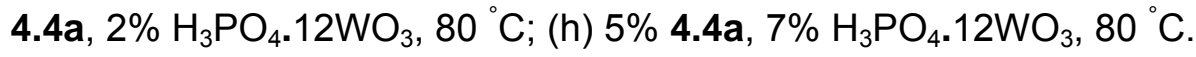
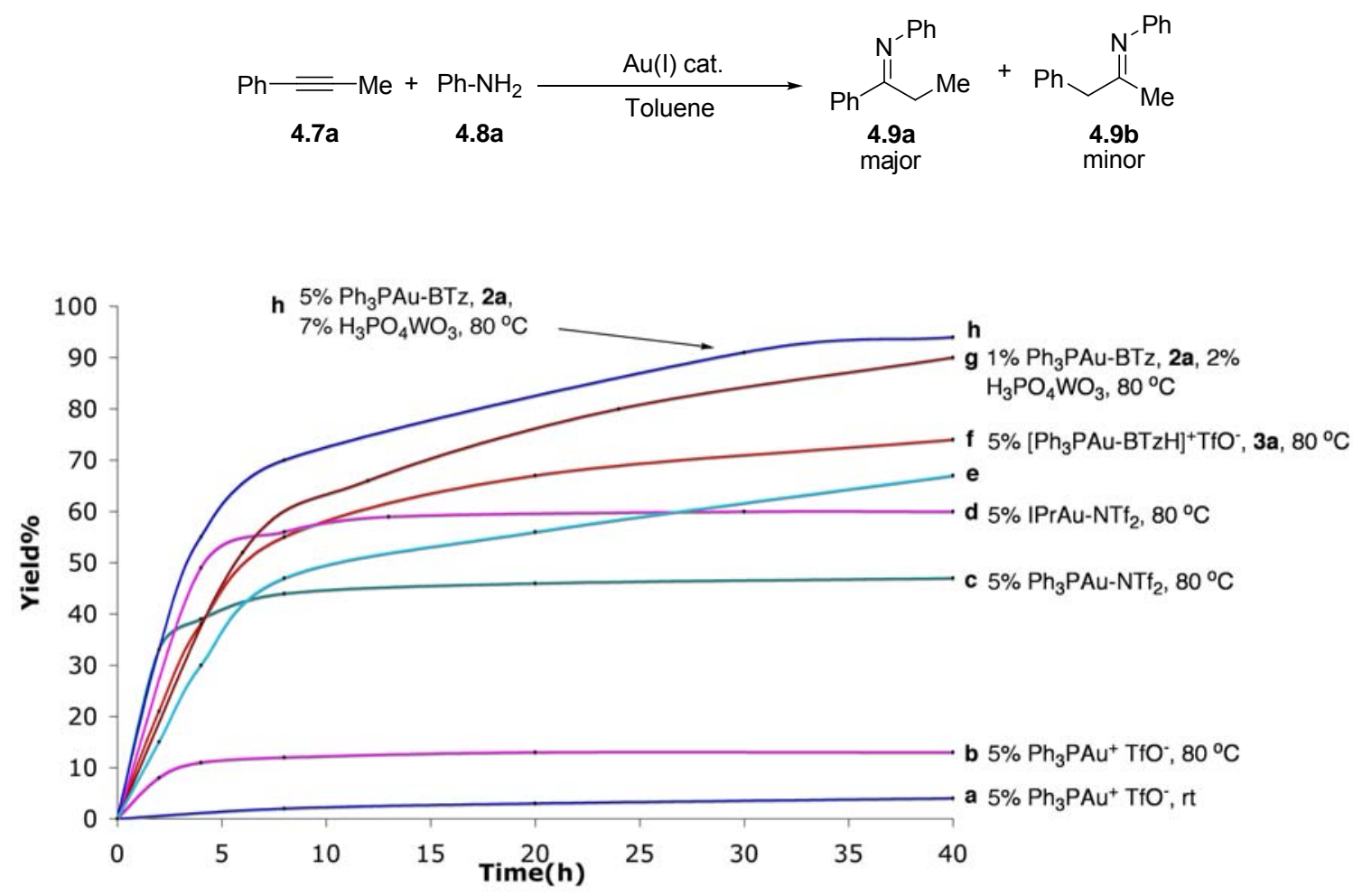
The reaction was further improved with the addition of acid promoters, such as $\mathrm{H}_{3} \mathrm{PO}_{4}$ $\cdot 12 \mathrm{WO}_{3}$, where an excellent yield $(91 \%)$ was achieved with only $1 \%$ of the catalyst loading. Notably, the addition of $\mathrm{H}_{3} \mathrm{PO}_{4} \cdot 12 \mathrm{WO}_{3}$ with $4.1 \mathrm{e}$ did not improve the reaction performance (Table 9, entry 12), eliminating the possibility of an acid effect in this improved thermal stability of the triazole-Au catalyst. Application of 4-phenyltriazole-Au(I) complexes (4.4b and $\mathbf{4 . 5 d}$ ) gave reactivity similar to that of the benzotriazole complexes (entries 5-6 and 10-11), suggesting that the dynamic coordination with the Au cation is a general property for the 1,2,3-triazoles. To the best of our knowledge, these triazole-Au complexes are by far the most efficient Au catalysts in promoting internal alkyne activation.

Table 9: Comparison of $\mathrm{Au}(\mathrm{I})$ catalysts in Internal Alkyne Hydroamination.

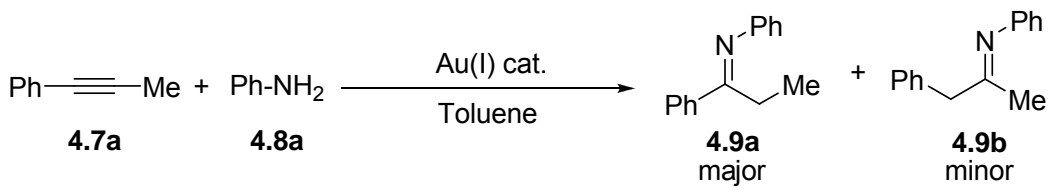

\begin{tabular}{ccccccc}
\hline entry & $\mathrm{Au}(\mathrm{I}) \mathrm{cat}$ & loading & cocatalyst & temp $\left({ }^{\circ} \mathrm{C}\right)$ & $\mathbf{9 a} / 9 \mathbf{b}^{\mathrm{b}}$ & yield $(\%)^{\mathrm{c}}$ \\
\hline 1 & $\mathbf{4 . 1 b}$ & $5 \%$ & - & $\mathrm{rt}$ & - & 4 \\
2 & $\mathbf{4 . 1 b}$ & $5 \%$ & - & 80 & $4: 1$ & 13 \\
3 & $\mathbf{4 . 1 d}$ & $5 \%$ & - & 80 & $4: 1$ & 47 \\
4 & $\mathbf{4 . 1 e}$ & $5 \%$ & - & 80 & $1.2: 1$ & 60 \\
5 & $\mathbf{4 . 5 a}$ & $5 \%$ & - & 80 & $6: 1$ & 74 \\
6 & $\mathbf{4 . 5 d}$ & $5 \%$ & - & 80 & $3: 1$ & 58 \\
7 & $\mathbf{4 . 5 a}$ & $5 \%$ & $\mathrm{BtzH}_{(5 \%)}$ & 80 & $6: 1$ & 67 \\
8 & $\mathbf{4 . 4 a}$ & $5 \%$ & $\mathrm{H}_{3} \mathrm{PO}_{4} \cdot 12 \mathrm{WO}_{3}(5 \%)$ & 80 & $6: 1$ & 94 \\
9 & $\mathbf{4 . 4 a}$ & $5 \%$ & $\mathrm{H}_{3} \mathrm{PO}_{4} \cdot 12 \mathrm{WO}_{3}(5 \%)$ & 100 & $1.5: 1$ & 92
\end{tabular}




$\begin{array}{ccccccc}10 & 4.4 a & 1 \% & \mathrm{H}_{3} \mathrm{PO}_{4} \cdot 12 \mathrm{WO}_{3}(2 \%) & 80 & 6: 1 & 91 \\ 11 & 4.4 \mathrm{~b} & 1 \% & \mathrm{H}_{3} \mathrm{PO}_{4} \cdot 12 \mathrm{WO}_{3}(25 \%) & 80 & 6: 1 & 86 \\ 12 & 4.1 \mathrm{e} & 5 \% & \mathrm{H}_{3} \mathrm{PO}_{4} \cdot 12 \mathrm{WO}_{3}(5 \%) & 80 & 1.2: 1 & 45 \\ 13 & - & - & \mathrm{H}_{3} \mathrm{PO}_{4} \cdot 12 \mathrm{WO}_{3}(5 \%) & 80 & - & \text { n.r } \\ 14 & - & - & \mathrm{TfOH}(10 \%) & 80 & - & \text { n.r }\end{array}$

${ }^{a}$ General reaction conditions: $4.7 a$ (1.0 equiv), $4.8 \mathrm{a}$ (1.2 equiv), and catalysts were mixed in dry toluene $([4.7 \mathrm{a}]=0.3 \mathrm{M})$. The reactions were monitored by TLC. ${ }^{b}$ Determined by NMR analysis of the crude reaction mixture. ${ }^{c}$ NMR yield using 1,3,5-trimethoxybenzene as an internal standard. ${ }^{d}$ Isolated yield of reduced amine after treating $4.9 \mathrm{a} / 4.9 \mathrm{~b}$ with $\mathrm{BH}_{3}$ in $\mathrm{THF}$.

Applications of the new catalyst $4.4 a$ with different alkynes and amines were then performed. The reaction substrate scope is shown in Tables 10 and 11. As expected, the triazole-Au catalyst gave a wide reaction substrate scope. For more reactive terminal alkynes, excellent yields (generally $>90 \%$ ) were achieved with only $0.1 \%$ catalyst loading. With less reactive internal alkynes (Table 11), a slightly higher catalytic loading (1\%) was needed to produce the desired hydroamination products in $>85 \%$ yield.

Moreover, with increased catalyst loading (10\%), the extremely challenging intermolecular, unprotected aliphatic amine hydroamination were achieved to afford $4.9 y$ and $4.9 \mathrm{z}$ (Table 11), though with modest yields. 
Table 10: Reaction substrate scope.

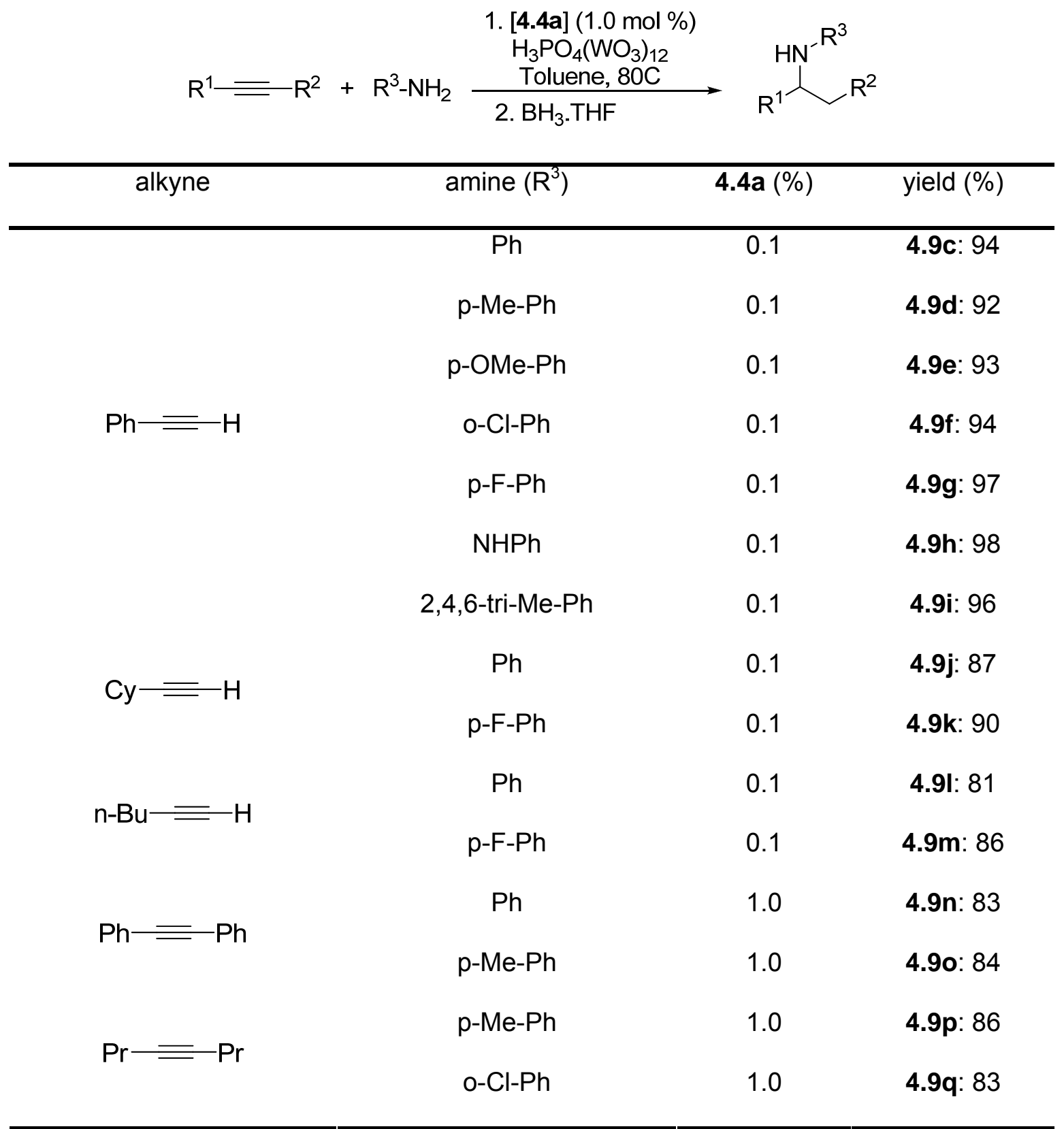

\footnotetext{
${ }^{a}$ General reaction conditions: 4.7 (1.0 equiv), 4.8 (1.2 equiv), and catalysts were mixed in dry toluene $([4.7]=0.3 \mathrm{M})$. The reactions were monitored by TLC. ${ }^{b}$ Isolated yields.
} 
Table 11: Reaction substrate scope (continued).

\begin{tabular}{|c|c|c|c|c|}
\hline \multirow[t]{2}{*}{$\mathrm{R}^{1}=$} & \multirow{2}{*}{ 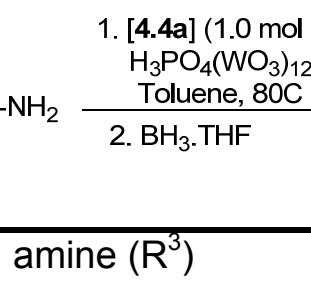 } & \multirow{2}{*}{ 4.4a (\%) } & \multicolumn{2}{|c|}{ 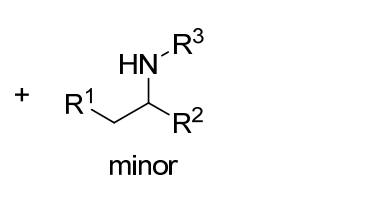 } \\
\hline & & & $\mathbf{a}: \mathbf{b}^{d}$ & yield $(\%)^{b}$ \\
\hline \multirow{4}{*}{$\mathrm{Ph}=\mathrm{Me}$} & $\mathrm{Ph}$ & 1.0 & $6: 1$ & $\begin{array}{c}4.9 a / 4.9 b \\
91\end{array}$ \\
\hline & p-Me-Ph & 1.0 & $5: 1$ & 4.9r: 89 \\
\hline & $\mathrm{p}-\mathrm{OMe}-\mathrm{Ph}$ & 1.0 & $6: 1$ & 4.9s: 89 \\
\hline & p-F-Ph & 1.0 & $6: 1$ & 4.9t: 89 \\
\hline $\mathrm{Ph}=\mathrm{Et}$ & $\mathrm{Ph}$ & 1.0 & $3: 1$ & 4.9u: 91 \\
\hline $\mathrm{Ph}=\mathrm{Bu}$ & $\mathrm{p}-\mathrm{F}-\mathrm{Ph}$ & 1.0 & $3: 1$ & 4.9v: 90 \\
\hline \multirow[t]{3}{*}{$\mathrm{Pr}=\mathrm{Me}$} & p-Me-Ph & 1.0 & $2: 1$ & $4.9 w: 85$ \\
\hline & Ts & 3.0 & - & 4.9x: 85 \\
\hline & p-F-Bn & 10 & - & $4.9 y: 85$ \\
\hline \multirow[t]{3}{*}{$\mathrm{Ph}=\mathrm{H}$} & morpholine & 10 & - & 4.9z: 85 \\
\hline & $\mathrm{cbz}$ & 10 & - & 4.9aa: 85 \\
\hline & $\mathrm{PhCO}$ & 10 & - & 4.9ab: 85 \\
\hline
\end{tabular}

\footnotetext{
${ }^{a}$ General reaction conditions: $\mathbf{4 a}$ (1.0 equiv), $\mathbf{5 a}$ (1.2 equiv), and catalysts were mixed in dry toluene $([4 \mathrm{a}]=0.3 \mathrm{M})$. The reactions were monitored by TLC. ${ }^{b}$ Isolated yield of reduced amine after treating $\mathbf{6 a} / \mathbf{6 b}$ with $\mathrm{BH} 3$ in THF. ${ }^{c}$ Determined by NMR analysis.
}

In addition, to further determine the superior reactivity of these triazole gold $(I)$ catalysts towards the hydroamination of internal/terminal alkynes, they were tested in comparison to the commonly employed active gold(I) catalysts. A few of the comparative data are shown below (for full details see supporting information). As indicated from Tables 13 and 14, the triazole gold(I) complex was a much more efficient catalyst for the 
hydroamination of internal alkynes, requiring much shorter reaction time ( $8 \mathrm{~h}$ in both the cases) and yet provided much higher yields (93\% and $91 \%$ respectively).

Table 12: Comparison of different gold(I) catalysts towards hydroamination of phenylacetylene and aniline.

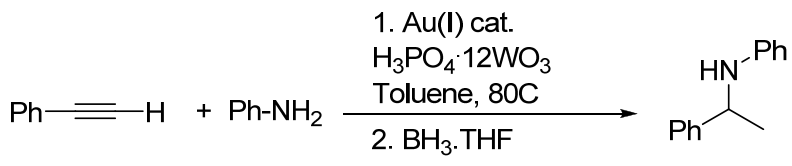

\begin{tabular}{ccccc}
\hline entry & cat & \% loading & co-cat & yield (\%) \\
\hline 1 & $\mathbf{4 . 4 a}$ & 0.1 & $\mathrm{H}_{3} \mathrm{PO}_{4} \cdot 12 \mathrm{WO}_{3} 0.2 \%$ & 94 \\
2 & $\mathbf{4 . 1 e}$ & 0.1 & - & 84 \\
3 & $\mathbf{4 . 1 e}$ & 0.1 & $\mathrm{H}_{3} \mathrm{PO}_{4} \cdot 12 \mathrm{WO}_{3} 0.2 \%$ & 80 \\
4 & $\mathbf{4 . 1 d}$ & 0.1 & $\mathrm{H}_{3} \mathrm{PO}_{4} \cdot 12 \mathrm{WO}_{3} 0.2 \%$ & 81 \\
\hline
\end{tabular}

All yields are NMR yields with 1,3,5-trimethoxybenzene as the internal standard

Table 13: Comparison of different gold(I) catalysts towards hydroamination of 1-phenyl1-propyne and p-fluoro-aniline.

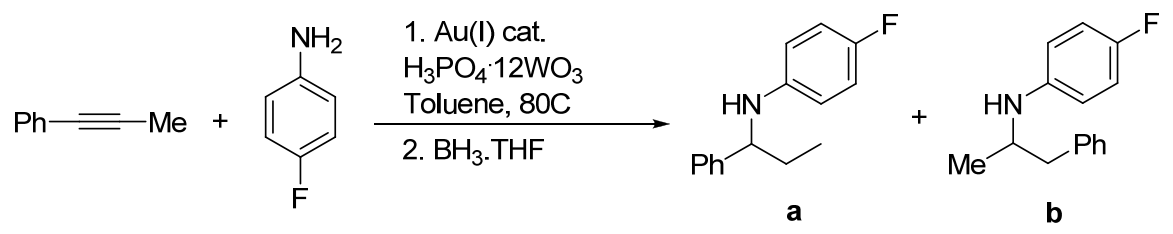

\begin{tabular}{ccccccc}
\hline entry & cat & $\begin{array}{c}\text { loading } \\
(\%)\end{array}$ & co-cat & time & d.r & $\begin{array}{c}\text { yield } \\
(\%)^{*}\end{array}$ \\
\hline 1 & $\mathbf{4 . 4 a}$ & 1.0 & $\mathrm{H}_{3} \mathrm{PO}_{4} \cdot 12 \mathrm{WO}_{3} 2.0 \%$ & $8 \mathrm{~h}$ & $6: 1$ & 93 \\
2 & $\mathbf{4 . 1 e}$ & 1.0 & - & $10 \mathrm{~h}$ & $4: 1$ & 60 \\
3 & $\mathbf{4 . 1 e}$ & 1.0 & $\mathrm{H}_{3} \mathrm{PO}_{4} \cdot 12 \mathrm{WO}_{3} 2.0 \%$ & $10 \mathrm{~h}$ & $4: 1$ & 58 \\
4 & $\mathbf{4 . 1 d}$ & 1.0 & $\mathrm{H}_{3} \mathrm{PO}_{4} \cdot 12 \mathrm{WO}_{3} 2.0 \%$ & $10 \mathrm{~h}$ & $4: 1$ & 58 \\
\hline
\end{tabular}

All yields are NMR yields with 1,3,5-trimethoxybenzene as the internal standard 
Table 14: Comparison of different gold(I) catalysts towards hydroamination of internal alkyne, 1-phenyl-1-butyne and aniline.

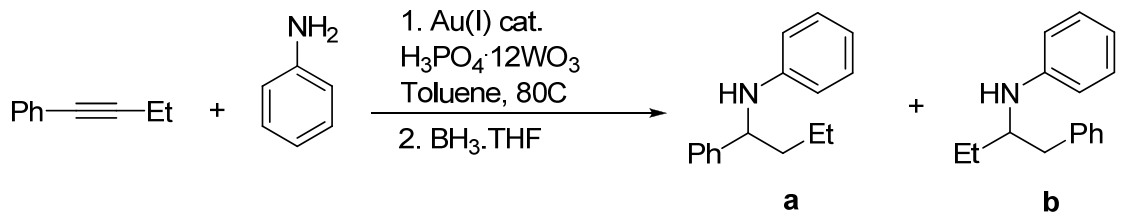

\begin{tabular}{ccccccc}
\hline entry & cat & $\begin{array}{c}\text { loading } \\
(\%)\end{array}$ & co-cat & time & d.r & $\begin{array}{c}\text { yield } \\
(\%)^{\mathrm{a}}\end{array}$ \\
\hline 1 & $\mathbf{4 . 4 a}$ & 1.0 & $\mathrm{H}_{3} \mathrm{PO}_{4} \cdot 12 \mathrm{WO}_{3} 2.0 \%$ & $8 \mathrm{~h}$ & $6: 1$ & 91 \\
2 & $\mathbf{4 . 1 e}$ & 1.0 & - & $12 \mathrm{~h}^{\mathrm{b}}$ & $3: 1$ & 48 \\
3 & $\mathbf{4 . 1 e}$ & 1.0 & $\mathrm{H}_{3} \mathrm{PO}_{4} \cdot 12 \mathrm{WO}_{3} 2.0 \%$ & $12 \mathrm{~h}^{\mathrm{b}}$ & $3: 1$ & 50 \\
4 & $\mathbf{4 . 1 d}$ & 1.0 & $\mathrm{H}_{3} \mathrm{PO}_{4} \cdot 12 \mathrm{WO}_{3} 2.0 \%$ & $13 \mathrm{~h}$ & $3: 1$ & 51 \\
\hline
\end{tabular}

${ }^{a}$ All yields are NMR yields with 1,3,5-trimethoxybenzene as the internal standard; ${ }^{b}$ after which gold mirror was formed

Furthermore, for the highly challenging intermolecular hydroamination employing aliphatic amine, benzylamine (Table 15), the triazole gold(I) complex 4.4a proves to be a much superior catalyst.

Table 15: Comparison of different gold(I) catalysts towards hydroamination of phenylacetylene and aliphatic amine, benzylamine.

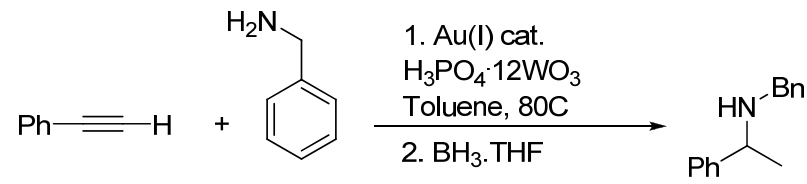

\begin{tabular}{cccccc}
\hline entry & cat & \% loading & co-cat & time & yield (\%) \\
\hline 1 & $\mathbf{4 . 4 a}$ & 10 & $\mathrm{H}_{3} \mathrm{PO}_{4} \cdot 12 \mathrm{WO}_{3} 10 \%$ & $8 \mathrm{~h}$ & 44 \\
2 & $\mathbf{4 . 1 e}$ & 10 & - & $15 \mathrm{~h}^{\mathrm{b}}$ & 15 \\
3 & $\mathbf{4 . 1 e}$ & 10 & $\mathrm{H}_{3} \mathrm{PO}_{4} \cdot 12 \mathrm{WO}_{3} 10 \%$ & $12 \mathrm{~h}^{\mathrm{b}}$ & 12 \\
4 & $\mathbf{4 . 1 d}$ & 10 & $\mathrm{H}_{3} \mathrm{PO}_{4} \cdot 12 \mathrm{WO}_{3} 10 \%$ & $15 \mathrm{~h}^{\mathrm{b}}$ & 10 \\
\hline
\end{tabular}

\footnotetext{
${ }^{a}$ All yields are NMR yields with 1,3,5-trimethoxybenzene as the internal standard; ${ }^{b}$ after which gold mirror was formed
} 
Since the key side reaction for aliphatic amine hydroamination is the decomposition of the imine, the diyne 4.10 was applied to trap the active imine intermediate through a second intramolecular hydroamination.12 The substituted pyrroles 4.11a-c were prepared in excellent yields, as shown in Scheme 45.

Scheme 45: Triazole-Au(I) complex catalyzed synthesis of substituted pyrroles.

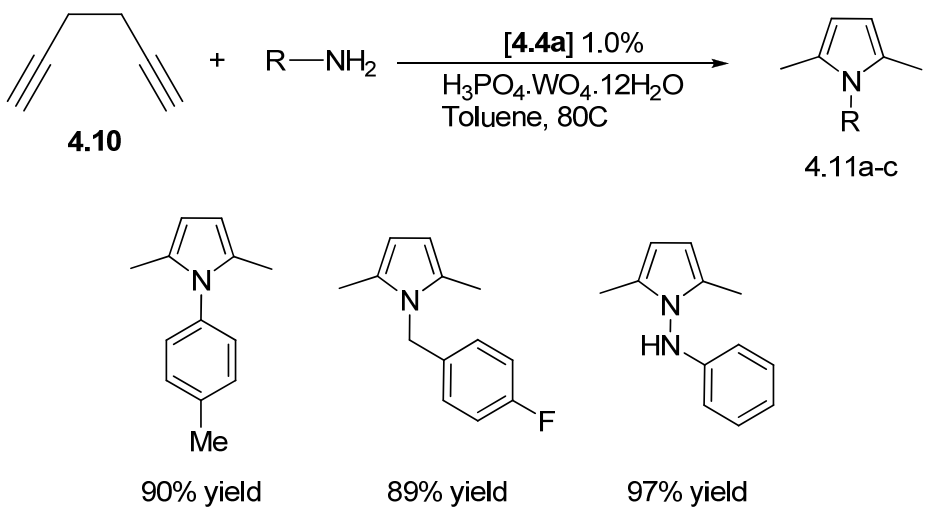

\subsection{Contributions}

Both Dr. Haifeng Duan and Sujata Sengupta were responsible for the synthesis of the triazole-Au(I) complexes. Dr. Duan was particularly responsible for the successful growth of the crystal structures of complexes $4.4 \mathrm{a}-\mathrm{b}$ and $\mathbf{4 . 5 a}$ and for the studies related to its dynamic coordination. Sujata Sengupta was particularly involved for the efforts towards the synthesis of chiral triazole complexes and for the comparative studies of the different Au-complexes towards hydroamination of both internal/terminal alkynes. Sujata Sengupta was also responsible for the growth of the crystal structure for $\mathbf{4 . 6 f}$. The detailed X-ray crystallography studies on all the triazole-Au(I) complexes were performed by Dr. Jeffrey Petersen. The detailed ${ }^{31} \mathrm{P}-\mathrm{NMR}$ studies were performed by Dr. 
Novruz G. Akhmedov, Instrument Specialist, C. Eugene Bennett Dept. of Chemistry, West Virginia University.

\subsection{Conclusion}

In conclusion, we have successfully developed a new class of stable and highly active triazole-Au(I) catalysts for the intermolecular hydroamination of internal/terminal alkynes. The exceptional activity of these catalysts maybe attributed to the dynamic coordination between the triazole and the $\mathrm{Au}(\mathrm{I})$ cation, as revealed through detailed VT NMT studies. The superior stability and cationic Au reactivity of these catalysts were evidenced in challenging transformation, such as intermolecular internal alkyne hydroamination and reaction with unprotected aliphatic amines. It is our belief that this catalytic system may open a new temperature range for homogenous $\mathrm{Au}(\mathrm{I})$ catalysis, and therefore, the discovery of new reactivities is expected in the near future. 


\section{References}

[1] (a) Corey, E. J. Angew. Chem., Int. Ed. 1991, 30, 455-465. (b) Chemler, S. R.;

Trauner, D.; Danishefsky, S. J. Angew. Chem., Int. Ed. 2001, 40, 4544-4568. (c) Trost, B. M.; Toste, F. D.; Pinkerton, A. B. Chem. ReV. 2001, 101, 2067-2096. (d) Nicolaou, K.

C.; Bulger, P. G.; Sarlah, D. Angew. Chem., Int. Ed. 2005, 44, 4442-4489.

[2] (a) Dalko, P. I.; Moisan, L. Angew. Chem., Int. Ed. 2004, 43, 5138-5175; (b) Dalko, P. I.; Moisan, L. Angew. Chem., Int. Ed. 2001, 40, 3726-3748.

[3] (a) Nicolaou, K. C.; Montagnon, T.; Snyder, S. A. Chem. Commun. 2003, 551-564.

(b) Nicolaou, K. C.; Edmonds, D. J.; Bulger, P. G. Angew. Chem., Int. Ed. 2006, 45, 7134-7186.

[4] (a) Zu, L. S.; Wang, J.; Li, H.; Xie, H. X.; Jiang, W.; Wang, W. J. Am. Chem. Soc. 2007, 129, 1036-1037. (b) Nicolaou, K. C.; Lim, Y. H.; Piper, J. L.; Papageorgiou, C. D. J. Am. Chem. Soc. 2007, 129, 4001-4013. (c) Baran, P. S.; Maimone, T. J.; Richter, J. M. Nature 2007, 446,404-408.

[5] (a) Hijicek, I. Chem. Listy 2005, 99, 298-317. (b) Hajicka, J. Chem. Listy 2005, 99, $317-317$.

[6] (a) Methot, J. L.; Roush, W. R. Adv. Synth. Catal. 2004, 346, 1035-1050. (b)

Basavaiah, D.; Rao, A. J.; Satyanarayana, T. Chem. Rev. 2003, 103, 811-891.

[7] Jansen, B. J. M.; Hendrikx, C. C. J.; Masalov, N.; Stork, G. A.; Meulemans, T. M.; Macaev, F. Z.; de Groot, A. Tetrahedron 2000, 56, 2075-2094. 
[8] For selected reviews, please see: (a) Almas, i, D.; Alonso, D. A.; Na’jera, C.

Tetrahedron: Asymmetry 2007, 18, 299-365; (b) Vicario, J. L.; Badı'a, D.; Carrillo, L.

Synthesis 2007, 14, 2065-2092; (c) Krause, N.; Hoffmann-Ro"der, A. Synthesis 2001, 2, 171-196; (d) Sibi, M. P.; Manyem, S. Tetrahedron 2000, 56, 8033-8061.

[9] Rauhut, M. M.; Currier, H. (American Cyanamid Co.), U.S. Patent 307,499,919,630,122, 1963; Chem. Abstr. 1963, 58, 11224a.

[10] Although the term 'vinylogous Morita-Baylis-Hillman' reaction has been used interchangeably with Rauhut-Currier in various literatures, it is referred specifically to the coupling of two activated olefins through 1,4-addition as the Rauhut-Currier reaction, whereas the $\mathrm{MBH}$ reaction involves 1,2-addition. This distinction is usually made to emphasize the multidimensional differences between the two reactions.

[11] For selected reviews, please see: (a) Drewes, S. E.; Roos, G. H. P. Tetrahedron 1988, 44, 4653-4670; (b) Basavaiah, D.; Rao, P. D.; Hyma, R. S. Tetrahedron 1996, 52, 8001-8062; (c) Basavaiah, D.; Rao, A. J.; Satyanarayana, T. Chem. Rev. 2003, 103, 811-891.

[12] The $\mathrm{RC}$ reaction can also be run using trialkylamines and thiols as nucleophilic catalysts.

[13] (a) Lee, K. Y.; Gowrisankar, S.; Kim, J. N. Bull. Korean Chem. Soc. 2005, 26, 14811490; (b) Masson, G.; Housseman, C.; Zhu, J. Angew. Chem., Int. Ed. 2007, 46, 46144628.

[14] Morita, K.; Kobayashi, T. Bull. Chem. Soc. Jpn. 1969, 42, 2732.

[15] McClure, J. D. J. Org. Chem. 1970, 35, 3045-3048.

[16] (a) Amri, H.; Villieras, J. Tetrahedron Lett. 1986, 27, 4307-4308.; (b) Basavaiah, D.; Gowriswari, V. V. L.; Bharathi, T. K. Tetrahedron Lett. 1987, 28, 
4591-4592.; (c) Drewes, S. E.; Emslie, N. D.; Karodia, N. Synth. Commun. 1990, 20, 1915-1921.; (d) Amri, H.; Rambaud, M.; Villieras, J. Tetrahedron Lett. 1989, 30, 73817382. (e) Hwu, J. R.; Hakimelahi, G. H.; Chou, C.-T. Tetrahedron Lett. 1992, 33, 64696472.

[17] Frank, S. A.; Mergott, D. J.; Roush, W. R. J. Am. Chem. Soc. 2002, 124, 24042405. Wang, L.-C.; Luis, A. L.; Agapiou, K.; Jang, H.-Y.; Krische, M. J. J. Am. Chem. Soc. 2002, 124, 2402-2403.

[18] Luis, A. L.; Agapiou, K.; Jang, H.-Y.; Krische, M. J. J. Am. Chem. Soc. 2002, 124, 2402-2403.

[19] Aroyan, C. E.; Miller, S. J. J. Am. Chem. Soc. 2007, 129, 256-257.

[20] (a) Zu, L.; Li, H.; Xie, H.; Wang, J.; Jiang, W.; Tang, Y.; Wang, W. Angew. Chem., Int. Ed. 2007, 46, 3732-3734. (b) Li, H.; Zu, L.; Xie, H.; Wang, J.; Jiang, W.; Wang, W. Org. Lett. 2007, 9, 1833-1835.

[21] (a) Zhu, X. F.; Schaffner, A. P.; Li, R. C.; Kwon, O. Org. Lett. 2005, 7, 2977-2980.

(b) Zhu, X. F.; Henry, C. E.; Wang, J.; Dudding, T.; Kwon, O. Org. Lett. 2005, 7, 13871390. (c) Zhu, X. F.; Lan, J.; Kwon, O. J. Am. Chem. Soc. 2003, 125, 4716-4717.

[22] Enders, D.; Huttl, M. R. M.; Grondal, C.; Raabe, G. Nature 2006, 441, 861-863.

[23] (a) Huisgen R. in 1,3-Dipolar Cycloaddition Chemistry (Ed.: Padwa, A.), Wiley, New York, 1984, pp. 1-176; (b) Padwa, A. in Comprehensive Organic Synthesis, Vol. 4 (Ed.:

Trost, B. M.), Pergamon, Oxford, 1991, pp. 1069-1109; (c) for a review of asymmetric 1,3-dipolar cycloaddition reactions, see Gothelf, K. V.; Jorgensen, K. A. Chem. Rev. 1998, 98, 863-909; d) for a review of synthetic applications, see Mulzer, J. Org. Synth. Highlights 1991, 77-95.

[24] (a) Fan, W. Q.; Katritzky, A. R. in Comprehensive Heterocyclic Chemistry II, Vol. 4 (Eds.: Katritzky, A. R., Rees, C. W., Scriven, E. F. V.), Pergamon, Oxford, 1996, pp. 
101-126; (b) Butler, R. N. in Comprehensive Heterocyclic Chemistry II, Vol. 4 (Eds.:

Katritzky, A. R., Rees, C. W., Scriven, E. F. V.), Pergamon, Oxford, 1996, pp. 621-678;

c) Banert, K. Chem. Ber. 1989, 122, 911-918.

[25] (a) Huisgen, R. Pure Appl. Chem. 1989, 61, 613-628; (b) Huisgen, R.; Szeimies, G.;

Moebius, L. Chem. Ber. 1967, 100, $2494 \pm 2507$; (c) Lwowski, W. in 1,3-Dipolar

Cycloaddition Chemistry, Vol. 1 (Ed.: Padwa, A.), Wiley, New York, 1984, chap. 5; (d)

Huisgen, R. Angew. Chem. Int. Ed. 1963, 2, 565-598; (e) Huisgen, R. Angew. Chem.

Int. Ed. 1963, 2, 633-645;

[26] Unless the acetylene component is attached to an electron-withdrawing group such as a carbonyl or perfluoroalkyl group: (a) Bastide, J.; Henri-Rousseau, V. Bull. Chim. Soc. Fr. 1973, 2294-2296; (b) Stepanova, N. P.; Orlova, N. A.; Galishev, V. A.; Turbanova, E. S.; Petrov, A. A. Zh. Org. Khim. 1985, 21, 979-983; (c) Clarke, D.; Mares, D. W.; McNab, H. J. Chem. Soc. Perkin Trans. 1 1997, 1799-1804.

[27] (a) Rostovtsev, V. V.; Green, L. G.; Fokin, V. V.; Sharpless, K. B. Angew. Chem., Int. Ed. 2002, 41, 2596-2599. (b) Torne, C. W.; Christensen, C.; Meldal, M. J. Org. Chem. 2002, 67, 3057.

[28] (a) Kolb, H. C.; Finn, M. G.; Sharpless, K. B. Angew. Chem., Int. Ed. 2001, 40, 2004-2021. (b) Bock, V. D.; Hiemstra, H.; Van Maarseveen, J. H. Eur. J. Org. Chem. 2006, 51-68. (c) Moses, J. E.; Moorhouse, A. D. Chem. Soc. Rev. 2007, 36, 1249-1262. [29] (a) Wu, P.; Feldman, A. K.; Nugent, A. K.; Hawker, C. J.; Scheel, A.; Voit, B.; Pyun, J.; Fre'chet, J. M. J.; Sharpless, K. B.; Fokin, V. V. Angew. Chem., Int. Ed. 2004, 43, 3928-3932. (b) Aucagne, V.; Ha"nni, K. D.; Leigh, D. A.; Lusby, P. J.; Walker, D. B. J. Am. Chem. Soc. 2006, 128, 2186-2187. (c) Ye, C. F.; Gard, G. L.; Winter, R. W.; Syvret, R. G.; Twamley, B.; Shreeve, J. M. Org. Lett. 2007, 9, 3841-3844. (d) Liu, Q. C.; Zhao, P.; Chen, Y. M. J. Polym. Sci., Part A: Polym. Chem. 2007, 45, 3330-3341. 
[30] (a) Agard, N. J.; Prescher, J. A.; Bertozzi, C. R. J. Am. Chem. Soc. 2004, 126, 15046-15047. (b) Moorhouse, A. D.; Santos, A. M.; Gunaratnam, M.; Moore, M.; Neidle, S.; Moses, J. E. J. Am. Chem. Soc. 2006, 128, 15972-15973. (c) Kumar, R.; El-Sagheer, A.; Tumpane, J.; Lincoln, P.; Wilhelmsson, L. M.; Brown, T. J. Am. Chem. Soc. 2007, 129, 6859- 6864 .

[31] (a) Manetsch, R.; Krasiski, A.; Radi, Z.; Raushel, J.; Taylor, P.; Sharpless, K. B.; Kolb, H. C. J. Am. Chem. Soc. 2004, 126, 12809-12818. (b) Wang, J.; Sui, G.; Mocharla, V. P.; Lin, R. J.; Phelps, M. E.; Kolb, H. C.; Tseng, H.-R. Angew. Chem., Int. Ed. 2006, 45, 5276-5281. (c) Sugawara, A.; Sunazuka, T.; Hirose, T.; Nagai, K.; Yamaguchi, Y.; Hanaki, H.; Sharpless, K. B.; Omura, S. Bioorg. Med. Chem. Lett. 2007, 17, 6340-6344. (d) Chen, H.; Taylor, J. L.; Abrams, S. R. Bioorg. Med. Chem. Lett. 2007, 17, 1979-1983. [32] Romero, A.; Liang, C. H.; Chiu, Y. H.; Yao, S.; Duffield, J.; Sucheck, S. J.; Marby, K.; Rabuka, D.; Leung, P. Y.; Shue, Y. K.; Ichikawa, Y.; Hwang, C. K. Tetrahedron Lett. 2005, 46, 1483-1487.

[33] (a) Loren, J. C.; Krasinski, A.; Fokin, V. V.; Sharpless, K. B. Synlett. 2005, 18, 28472850. (b) Yap, A. H.; Weinreb, S. M. Tetrahedron Lett. 2006, 47, 3035- 3038. (c)

Shchetnikov, G. T.; Peregudov, A. S.; Osipov, S. N. Synlett 2007, 136-140. (d) Skarpos, H.; Osipov, S. N.; Vorob'eva, D. V.; Odinets, I. L.; Lork, E.; Roschenthaler, G. V. Org. Bio. Chem. 2007, 5, 2361-2367.

[34] Zefirov, N. S.; Chapovskaya, N. K.; Kolesnikov, V. V. J. Chem. Soc., Dalton Trans. 1971, 17, 1001-1002.

[35] Quiclet-Sire, B.; Zard, S. Z. Synthesis 2005, 19, 3319-3326.

[36] Sun, X.; Sengupta, S.; Petersen, J. L.; Wang, H.; Lewis, J. P.; Shi, X. Org. Lett. 2007, 9, 4495-4498.

[37] Duan, H.; Sun, X.; Liao, W.; Petersen, J. L.; Shi, X Org. Lett. 2008, 10, 4113-4116. 
[38] Selected examples of nitro compound [3+2] reactions: (a) Voituriez, A.; Moulinas, J.; Kouklovsky, C.; Langlois, Y. Synthesis 2003, 9, 1419-1426. (b) Roger, P. Y.; Durand, A. C.; Rodriguez, J.; Dulcere, J. P. Org. Lett. 2004, 6, 2027-2029. (c) Kunetsky, R. A.; Dilman, A. D.; Struchkova, M. I.; Belyakov, P. A.; Tartakovsky, V. A.; loffe, S. L. Synthesis 2006, 13, 2265-2270. (d) Arrieta, A.; Otaegui, D.; Zubia, A.; Cossio, F. P.; Diaz-Ortiz, A.; de la Hoz, A.; Herrero, M. A.; Prieto, P.; Foces-Foces, C.; Pizarro, J. L.; Arriortua, M. I. J. Org. Chem. 2007, 72, 4313-4322.

[39] (a) Majumdar, S.; Spaeth, M. M.; Sivendran, S.; Juntunen, J.; Thomas, J. D.; Sloan, K. B. Tetrahedron Lett. 2007, 48, 4609-4611. (b) Csampai, A.; Kover, P.; Hajos, G.; Riedl, Z. J. Mol. Struct. 2002, 616, 73-78.

[40] Rheingold, A. L.; Liable-Sands, L. M.; Trofimenko, S. Inorg. Chim. Acta 2002, 330, 38-43.

[41] (a) Gandelman, M.; Jacobsen, E. N. Angew. Chem., Int. Ed. 2005, 44, 2393-2397.

(b) Diner, P.; Nielsen, M.; Marigo, M.; Jorgensen, K. A. Angew. Chem., Int. Ed. 2007, 46, 1983-1987. (c) Wang, J.; Li, H.; Zu, L.; Wang, W. Org. Lett. 2006, 8, 1319-1394.

[42] (a) Nicolaou, K. C.; Bulger, P. C.; Sarlah, D. Angew. Chem., Int. Ed. 2005 44, 4442.

(b) Clarke., P. A.; Cridland, A. P. Annu. Rep. Prog. Chem., Sect. B 2004 100, 91.

[43] (a) Crabtree, R. H. The Organometallic Chemistry of the Transition Metals, 4th ed.;

Wiley-Interscience: New York, 2005; (b) Hegedus, L. S. Transition Metals in the Synthesis of Complex Organic Molecules, 2nd ed.; University Science Books: Mill Valley, CA, 1999.

[44] Fu, G. C. Acc. Chem. Res. 2006, 39, 853-860.

[45] (a) Chaloner, P. A.; Esteruelas, M. A.; Joo', F.; Oro, L. A. Homogeneous Hydrogenation; Kluwer: Dordrecht, 1994. (b) Brown, J. M. In ComprehensiVe Asymmetric Catalysis; Jacobsen, E. N., Pfaltz, A., Yamamoto, H., Eds.; Springer: Berlin, 
1999; Vol. 1. (c) Parshall, G. W.; Ittel, S. D. Homogeneous Catalysis, Wiley: New York, 1992; (d) van Leeuwen, P. W. N. M.; Kamer, P. C. J.; Reek, J. N. H.; Dierkes, P. Chem. Rev. 2000, 100, 2741.

[46] Shimizu, H.; Nagasaki, I.; Saito, T. Tetrahedron 2005, 61, 5405-5432.

47 For recent reviews: (a) Shimizu, H.; Nagasaki, I.; Matsumura, K.; Sayo, N.; Saito, T. Acc. Chem. Res. 2007, 40, 1385-1393. (b) Berthod, M.; Mignani, G.; Woodward, G.;

Lemaire, M. Chem. ReV. 2005, 105, 1801-1836.

[48] (a) Jacobsen, E. N. Acc. Chem. Res. 2000, 33, 421-431. (b) Katsuki, T. Synlett 2003, 3, 281-297.

[49] (a) Busetto, L.; Marchetti, F.; Zucchini, S.; Zanotti, V. Inorg. Chim. Acta 2005, 358.

(b) Bronisz, R. Inorg. Chem. 2005, 44, 4463. (c) Armstrong, D. R.; Davies, R. P.; Haigh, R.; Hendy, H. M.; Raithby, P. R.; Snaith, R.; Wheatley, A. E. H. Eur. J. Inorg. Chem. 2003, 3363-3366.

[50] (a) Olson, J. R.; Yamauchi, M.; Butler, W. M. Inorg. Chim. Acta 1985, 99, 121-125. (b) Purnell, L. G.; Shepard, J. C.; Hodgson, D. J. J. Am. Chem. Soc. 1975, 97, 23762377.

[51] Chan, T. R.; Hilgraf, R.; Sharpless, K. B.; Fokin, V. V. Org. Lett., 2004, 6, 28532855.

[52] Similar mode of binding has been previously suggested for trisoxazolinebased ligands. See: Kohmura, Y.; Katsuki, T. Tetrahedron Lett. 2000, 41, 3941.

[53] Detz, R. J.; Arevalo Heras, S.; de Gelder, R.; van Leeuwen, P. W. N. M.; Hiemstra, H.; Reek, J. N. H.; van Maarseveen, J. H. Org. Lett. 2006, 8, 3227-3231.

[54] Suijkerbuijk, B. M. J. M.; Aerts, B. N. H.; Dijkstra, H. P.; Lutz, M.; Spek, A. L.; van Koten, G.; Klein Gebbink, R. J. M. Dalton Trans. 2007, 1273-1276. 
[55] According to ref 54, the Ka value for $\mathrm{NH}$-triazole to NCN-pincer Pd complex is 4.16, while the value for pyridine is 19.5 and for aniline is 0.30 .

[56] Poznanski, J.; Najda, A.; Bretner, M.; Shugar, D. J. Phys. Chem. A 2007, 111, 6501-6509. According to the paper, the pKa of benzotriazole is 8.3.

[57] Some recent examples: (a) Katritzky, A. R.; Lan, X.; Yang, J. Z.; Denisko, O. V. Chem. ReV. 1998, 98, 409. (b) Verma, A. K.; Singh, J.; Sankar, V. K.; Chaudhary, R.; Chandra, R. Tetrahedron Lett. 2007, 48, 4207-4210.

[58] Oro, L. A.; Pinillos, T.; Tejel, C. J. Organomet. Chem. 1985, 280, 261-267.

[59] Pinillos, M. T.; Elduque, A.; Oro, L. A. J. Organomet. Chem. 1988, 338, 411-419.

[60] (a) Rasmussen, P. G.; Hough, R. L.; Anderson, J. E.; Bailey, O. H.; Bayon, J. C. J. Am. Chem. Soc. 1984, 104, 1455-1456. (b) Rasmussen, P. G.; Bailey, O. H.; Bayon, J. C. Inorg. Chem. 1984, 23, 338.

[61] Sengupta, S.; Duan, H.; Lu, W.; Petersen, J. L.; Shi, X. Org. Lett. 2008, 10, 14931496.

[62] Chen, Y.; Liu, Y.; Petersen, J. L.; Shi, X. Chem. Commun. 2008, 3254-3256.

[63] The complex is stable enough to be dissolved in methylene chloride and purified by flash column chromatography $\left(R_{f}\right) 0.5$, hexane-ethyl acetate, $\left.6 / 1 \mathrm{v} / \mathrm{v}\right)$.

[64] Khand, I. U.; Knox, G. R.; Pauson, P. L.; Watts, W. E. J. Chem. Soc., Perkin Trans. 1 1973, 977-981.

65 For preliminary work see (a) Khand, I. U.; Knox, G. R.; Pauson, P. L.; Watts, W. E. J. Chem. Soc. D 1971, 36. (b) Khand, I. U.; Knox, G. R.; Pauson, P. L.; Watts, W. E. J. Chem. Soc., Perkin Trans. 1 1973, 975-977.

[66] (a) Buchwald, S. L.; Hicks, F. A. In Comprehensive Asymmetric Catalysis I-III; Jacobsen, E. N., Pfaltz, A., Yamamoto, H., Eds.; Springer-Verlag: Berlin, 1999; Vol. 2, pp 491-510. (b) Shibata, T. Adv. Synth. Catal. 2006, 348, 2328-2336. 
[67] Jeong, N.; Hwang, S. H.; Lee, Y. J. Am. Chem. Soc. 1994, 116, 3159-3160.

[68] Hicks, F. A.; Kablaoui, N. M.; Buchwald, S. L. J. Am. Chem. Soc. 1996, 118, 94509451.

[69] Kondo, T.; Suzuki, N.; Okada, T.; Mitsudo, T. J. Am. Chem. Soc. 1997, 119, 61876188.

[70] Jeong, N. Organometallics 1998, 17, 3642-3644.

[71] For recent reviews see: a) Gorin, D. J.; Sherry, B. D.; Toste, F. D. Chem. Rev. 2008, 108, 3351. (b) Li, Z. G.; Brouwer, C.; He, C. Chem. Rev. 2008, 108, 3239. (c) Jime'nezNu'ñez, E.; Echavarren, A. M. Chem. Rev. 2008, 108, 333-346. (d) Hashmi, A. S. K. Chem. Rev. 2007, 107, 3180-3211 (e) Marion, N.; Nolan, S. P. Angew. Chem., Int. Ed. 2007, 46, 2750. (f) Gorin, D. J.; Toste, F. D. Nature 2007, 446, 395-403. (g) Hashmi, A. S. K.; Hutchings, G. J. Angew. Chem, Int. Ed. 2006, 45, 7896-7936. (h) Zhang, L.; Sun, J.; Kozmin, S. A. Adv. Synth. Catal. 2006, 348, 2271.

[72] Some recent examples: (a) Liu, Z.; Wasmuth, A. S.; Nelson, S. G. J. Am. Chem. Soc. 2006, 128, 10352-10353. (b) Volz, F.; Krause, N. Org. Biomol. Chem. 2007, 5, 1519-1521. (c) Sato, K.; Asao, N.; Yamamoto, Y. J. Org. Chem. 2005, 70, 8977-8980. (d) Jung, H.; Floreancig, P. E. J. Org. Chem. 2007, 72, 7359-10. (e) Li, Y.; Zhou, F.; Forsyth, C. J. Angew. Chem. 2007, 46, 279-281.

[73] See [71] and references therein.

[74] For reviews, see refs $71 \mathrm{a}$ and $71 \mathrm{c}$ and references therein. For some related methodologies, see: (a) Hashmi, A. S. K.; Loos, A.; Littmann, A.; Braun, I.; Knight, J.; Doherty, S.; Rominger, F. Adv. Synth. Catal. 2009, 351, 576. (b) Lee, J. H.; Toste, F. D. Angew. Chem., Int. Ed. 2007, 46, 912. (c) Zhang, L.; Wang, S. J. Am. Chem. Soc. 2006, 128, 1442. (d) Zhang, Z.; Liu, C.; Kinder, R. E.; Han, X.; Qian, H.; Widenhoefer, R. A. J. Am. Chem. Soc. 2006, 128, 9066. (e) Buzas, A. K.; Istrate, F. M.; Gagosz, F. Angew. 
Chem., Int. Ed. 2007, 46, 1141. (f) Nieto-Oberhuber, C.; Muñoz, M. P.; Buñuel, E.; Nevado, C.; Cárdenas, D. J.; Echavarren, A. M. Angew. Chem., Int. Ed. 2004, 43, 2402. (g) Luzung, M. R.; Markham, J. P.; Toste, F. D. J. Am. Chem. Soc. 2004, 126, 10858. (h) Mamane, V.; Gress, T.; Krause, H.; Fürstner, A. J. Am. Chem. Soc. 2004, 126, 8654. [75] Protonation of an alkyl gold(I) complex with a strong acid may also be used to generate the cationic species; however, these conditions are not always compatible with most substrates.

[76] Zhang, G.; Huang, X.; Li, G.; Zhang, L. J. Am. Chem. Soc. 2008, 130, 1814.

[77] For a review, see: Widenhoefer, R. A.; Han, X. Eur. J. Org. Chem. 2006, 4555, and references therein.

[78] For a review on NHCs in catalysis, see: N-Heterocyclic Carbenes in Transition Metal Catalysis: Top. Organomet. Chem., ed. F. Glorius, Springer-Verlag, Berlin/Heidelberg, 2007, vol. 28.

[79] For a review on the stereoelectronic parameters of NHCs, see: S. Dĩez-González and S. P. Nolan, Coord. Chem. Rev., 2007, 251, 874-883.

[80] G. Minghetti and F. Bonati, J. Organomet. Chem., 1973, 54, C62-C63.

[81] For a review on NHC-gold complexes, see: (a) I. J. B. Lin and C. S. Vasam, Can. J. Chem., 2005, 83, 812-825; see also: (b) H. G. Raubenheimer and S. Cronje, Chem. Soc. Rev., 2008, 37, DOI: 10.1039/b708636a, in this special issue on gold. [82] Usually, the use of a glovebox is required to properly weigh the silver salt. [83] Weakly coordinating anions such as $\mathrm{BF}_{4}^{-}, \mathrm{PF}_{6}^{-}$, and $\mathrm{SbF}_{6}^{-}$are Lewis acid/base conjugates of a superior nucleophile (e.g., $\left.\mathrm{MF} n+1^{-} \rightarrow \mathrm{MF} n+\mathrm{F}^{-}\right)$. Their ability to act as inert counter ions is always limited by a competition reaction for that nucleophile (e.g., $\mathrm{F}^{-}$ ), and the free Lewis acid MFn can act as an oxidizing agent and thus cause unwanted 
side reactions. See: (a) Raabe, I.; Krossing, I. Angew. Chem., Int. Ed. 2004, 43, 2066-

2090. (b) Raabe, I.; Krossing, I. Chem. Eur. J. 2004, 10, 5017-5030.

[84] Echavarren and co-workers have reported the isolation of the two air-stable cationic complexes $\left(\mathrm{Ph}_{3} \mathrm{P}\right) \mathrm{Au}(\mathrm{NCMe}) \mathrm{SbF}_{6}$ and (2-(di-tert-butylphosphino) biphenyl)Au(NCMe)SbF 6 as active catalysts for cycloisomerization. See: (a) NietoOberhuber, C.; Lõpez, S.; Munoz, M. P.; Cardenas, D. J.; Bunuel, E.; Nevado, C.; Echavarren, A. M. Angew. Chem., Int. Ed. 2005, 44, 6146-6148. (b) Ferrer, C.; Echavarren, A. M. Angew. Chem., Int. Ed. 2006, 45, 1105-1109. (c) Nieto-Oberhuber, C.; Munoz, M. P.; Lõpez, S.; Jimenez-Nunez, E.; Nevado, C.; Herrero-Gomez, E.; Raducan, M.; Echavarren, A. M. Chem. Eur. J. 2006, 12, 1677-1693.

[85] Mezailles, N.; Ricard, L.; Gagosz, F. Org. Lett. 2005, 7, 4133.

[86] Ricard, L.; Gagosz, F. Organometallics 2007, 26, 4704.

[87] Duan, H.; Sengupta, S.; Petersen, J. L.; Shi, X. Organometallics 2009, 28, 2352. [88] For literature examples of N-heterocycle-bound Au complexes, see: (a) Kieft, R. L.; Peterson, W. M.; Blundell, G. L.; Horton, S.; Henry, R. A.; Jonassen, H. B. Inorg. Chem. 1976, 15, 1721. (b) Nomiya, K.; Noguchi, R.; Oda, M. Inorg. Chim. Acta 2000, 298, 24. (c) Partyka, D. V.; Updegraff, J. B.; Zeller, M.; Hunter, A. D.; Gray, T. G. Organometallics 2007, 26, 183. (d) Partyka, D. V.; Robilotto, T. J.; Zeller, M.; Hunter, A. D.; Gray, T. G. Proc. Natl. Acad. Sci. U.S.A. 2008, 105, 14293.

[89] Angermaier, K.; Schmidbaur, H. J. Chem. Soc., Dalton Trans, 1995, 559-564.

[90] Felici, M.; Pietroni, B. R.; Burini, A. Gazz. Chim. Ital. 1982, 112, 5-12.

[91] Minghetti, G.; Banditelli, G.; Bonati, F. Inorg. Chem. 1979, 18, 658-661.

[92] Munakata, M.; Yan, S. G.; Maekawa, M.; Akiyama, M.; Kitagawa, S. J. Chem. Soc., Dalton Trans. 1997, 4257. 
[93] Nomiya, K.; Noguchi, K.; Ohsawa, K.; Tsuda, J. J. Chem. Soc. Dalton Trans., 1998, 4101-4108.

[94] Duan, H.; Yan, W.; Sengupta, S.; Shi, X. Bioorg. Med. Chem. Lett. 2009, 38993902.

[95] Anderson, L. L.; Arnold, J.; Bergman, R. G. J. Am. Chem. Soc. 2005, 127, 1454214543. (b) Rosenfield, D. C.; Shekhar, S.; Takemiya, A.; Utsunomiya, M.; Hartwig, J. F. Org. Lett. 2006, 8, 4179-4182.

[96]

[97] See references and . Also: Kovac Gabor, G.; Ujaque, G.; Lledos, A. J. Am. Chem. Soc. 2008, $130,853-864$.

[98] (a) Müller, T. E.; Beller, M. Chem. Rev. 1998, 98, 675. (b) Beller, M.; Seayad, J.; Tillack, A.; Jiao, H. Angew. Chem. Int. Ed. 2004, 43, 3368. (c) Brunet, J. J.; Neibecker, D. in: Catalytic Heterofunctionalization (Eds.: Togni, A.; Grützmacher, H.), Wiley-VCH, Weinheim, 2001, pp. 91-142. (d) Hong, S.; Marks, T. J. Acc. Chem. Res. 2004, 37, 673. [99] For a recent review see: Widenhoefer, R. A.; Han, X. Eur. J. Org. Chem. 2006, $4555-4563$.

[100] (a) Mizushima, E.; Hayashi, T.; Tanaka, M. Org. Lett. 2003, 108, 3149-3173. (b) Muller, T. E.; Beller, M. Chem. Rev. 1998, 98, 675-708.

[101] See reference 100(a). 


\section{Supporting Information}

\section{Chapter 2: Intermolecular Cross Double Michael Addition between nitro and carbonyl activated olefins}

\section{General methods and materials:}

Unless otherwise noted, all commercial reagents and solvents were obtained from the commercial provider and used without further purification. Air and/or moisture-sensitive reactions were carried out under an atmosphere of nitrogen using oven/flame-dried

glassware and standard syringe/septa techniques. ${ }^{1} \mathrm{H}-\mathrm{NMR}$ and ${ }^{13} \mathrm{C}-\mathrm{NMR}$ spectra were recorded on Joel 270 and Varian $600 \mathrm{MHz}$ spectrometers. Chemical shifts were reported relative to internal tetramethylsilane $(\delta 0.00 \mathrm{ppm})$ or $\mathrm{CDCl}_{3}(\delta 7.26 \mathrm{ppm})$ or DMSO $(\delta$ $2.49 \mathrm{ppm})$ for ${ }^{1} \mathrm{H}$ and $\mathrm{CDCl}_{3}(\delta 77.0 \mathrm{ppm})$ or DMSO (ס $\left.39.5 \mathrm{ppm}\right)$ for ${ }^{13} \mathrm{C}$. Infrared (IR) spectra were obtained on a Prospect MIDAC FT-IR spectrometer. Flash column chromatography was performed on 230-430 mesh silica gel. Analytical thin layer chromatography was performed with precoated glass baked plates $(250 \mu)$ and visualized by fluorescence and by charring after treatment with potassium permanganate stain. $\mathrm{R}_{f}$ values were obtained by elution in the stated solvent ratios.

The nitroalkene starting materials were prepared according to the following reported procedures:

1) Ohta, H.; Kobayashi, N.; Ozaki, K. J. Org. Chem. 1989, 54, 1802-1804.

2) Lucet, D.; Sabelle, S.; Kostelitz, O.; Gall, T. L.; Mioskowski, C. Eur. J. Org. Chem. 1999, 2583-2591.

3) Jang, Y. J.; Lin, W. W.; Shih, Y. K.; Liu, J. T.; Hwang, M. H.; Yao, C. F. Tetrahedron, 2003, 59, 4979-4992. 


\section{General Procedure for Intermolecular double Michael addition reaction:}

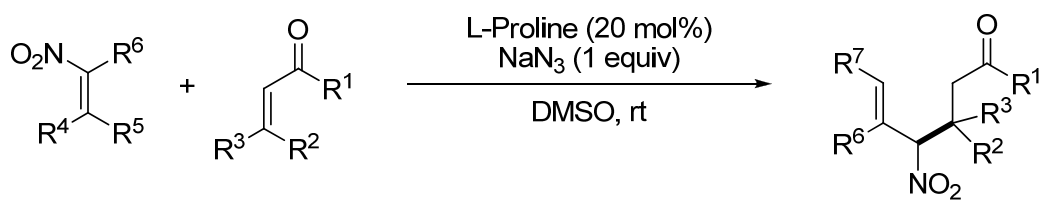

allylic nitro compound

The nitroalkene (1.0 equiv) was added to a solution of $\alpha, \beta$-unsaturated ketone/ester (2.0 equiv), L-Proline (20 mol\%) and $\mathrm{NaN}_{3}$ (1.0 equiv) in DMSO. The resulting reaction mixture was then stirred at room temperature for $5 \mathrm{~h}$. The reaction mixture was then diluted with dichloromethane and the organic layer was washed with water and saturated brine solution. The combined organic layer was dried over anhydrous sodium sulfate. The solvent was removed under reduced pressure. Flash silica gel chromatography gave the pure product.

\section{General procedure for functional group derivatization.}

\section{Synthesis of compound 1.6a:}

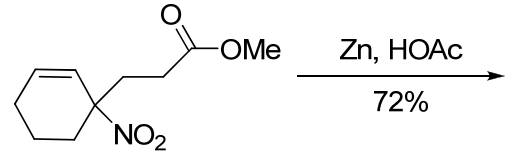

$1.5 f$

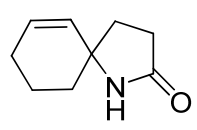

$1.6 a$

Zinc powder (440 mg, 6.76 mmols) was added over 10 minutes to a cooled solution of compound $1.5 \mathrm{f}(720 \mathrm{mg}, 3.38 \mathrm{mmols})$ in acetic acid $(2.5 \mathrm{ml})$. The resultant mixture was 
then stirred at room temperature for $1.5 \mathrm{~h}$, filtered through Celite, and then washed with ether $(20 \mathrm{ml})$. The filtrate was then diluted with water and cooled to $0^{\circ} \mathrm{C} .10 \mathrm{M}$ sodium hydroxide solution was added until the aqueous layer $\mathrm{pH}$ was 12. After separation, the aqueous phase was extracted with ether $(2 \times 50 \mathrm{ml})$. The combined organic layer was washed with water $(50 \mathrm{ml})$, dried over sodium sulfate and removed by vacuum. Purification by column chromatography gave the desired amine $1.6 \mathrm{a}$ (444mg, $72 \%$ yield). IR ( $\left.\mathrm{cm}^{-1} 1\right): 3175,2901,1975,1703,1547,1425{ }^{1} \mathrm{H} \mathrm{NMR}\left(270 \mathrm{MHz}, \mathrm{CDCl}_{3}\right) \delta$ 1.53-1.69 (m, 2H), 1.85-2.17 (m, 6H), $2.38(\mathrm{dd}, J=8.4,6.9 \mathrm{~Hz}, 2 \mathrm{H}), 5.56(\mathrm{~d}, J=10.2 \mathrm{~Hz}$, 1H), 5.93-5.99 (m, 1H); ${ }^{13} \mathrm{C}$ NMR (67.5 MHz, $\left.\mathrm{CDCl}_{3}\right) \delta$ 19.6, 24.2, 26.3, 30.0, 30.8, 63.3, 129.8, 132.0, 169.5; HRMS Calculated for $\left[\mathrm{C}_{9} \mathrm{H}_{13} \mathrm{NONa}\right]^{+}:$174.0895, Found: 174.0890.

\section{Synthesis of allylic alcohol $6 \mathrm{~b}$ :}

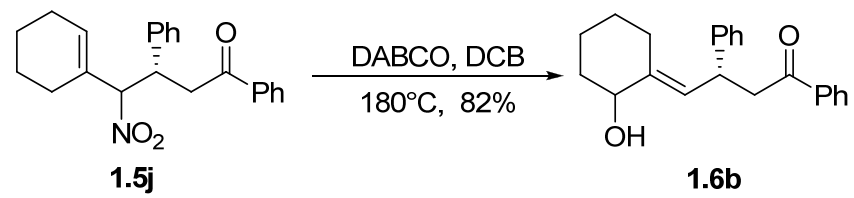

Compound 1.5j (175 mg, 1.0 equiv) was dissolved in 1,2-dichlorobenzene to which was added DABCO (56 mg, 1.0 equiv). The resulting reaction mixture was then refluxed at $180^{\circ} \mathrm{C}$ for $3 \mathrm{~h}$. The crude product was purified by flash chromatography (He/EA 8:2) to give $131 \mathrm{mg}$ of $\mathbf{1 . 6 b}$ as a pale red oil an exclusively as a single diastereomer. ${ }^{1} \mathrm{H}$ NMR (270 MHz, $\left.\mathrm{CDCl}_{3}\right) \delta 1.27-1.48(\mathrm{~m}, 4 \mathrm{H}), 1.60-2.00(\mathrm{~m}, 3 \mathrm{H}), 2.47-2.60(\mathrm{~m}, 1 \mathrm{H}), 3.30(\mathrm{dd}, J$ $=15.8,7.9 \mathrm{~Hz}, 1 \mathrm{H}), 3.39(\mathrm{dd}, J=15.8,6.2 \mathrm{~Hz}, 1 \mathrm{H}), 3.98(\mathrm{dd}, J=6.4,4.1 \mathrm{~Hz}, 1 \mathrm{H}), 4.36$ (ddd, J = 14.4, 6.2, 3.5 Hz, 1H), $5.56(\mathrm{~d}, J=9.9 \mathrm{~Hz}, 1 \mathrm{H}), 7.13-7.21(\mathrm{~m}, 1 \mathrm{H}), 7.24-7.29$ (m, 3H), 7.36-7.45 (m, 2H), 7.51-7.60 (m,1H), 7.89-7.93 (m, 2H); ${ }^{13} \mathrm{C}$ NMR $(67.5 \mathrm{MHz}$, $\left.\mathrm{CDCl}_{3}\right) \delta 23.3,26.9,27.1,36.3,39.0,45.9,73.4,123.0,126.4,127.3,128.3,128.6$, 
128.7, 133.1, 137.2, 142.0, 144.8, 198.9; HRMS Calculated for $\left[\mathrm{C}_{22} \mathrm{H}_{24} \mathrm{NO}_{2} \mathrm{Na}\right]^{+}$:

343.1674, Found: 343.1669 .

\section{General procedure for Nef reaction for synthesis of compound 6c:}

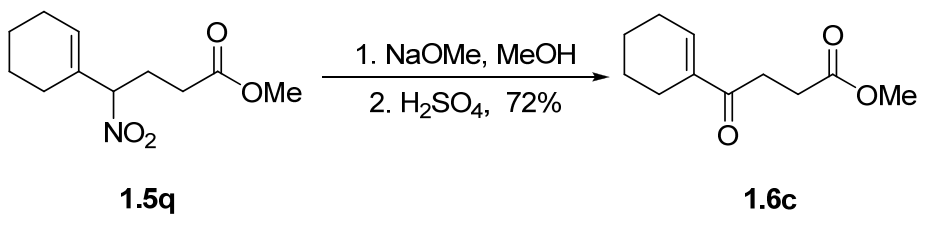

To a solution of compound $\mathbf{1 . 5 q}(227 \mathrm{mg}, 1.0 \mathrm{mmols})$ in methanol was added sodium methoxide $(25 \mathrm{mg})$ in methanol at $0^{\circ} \mathrm{C}$ and the mixture was stirred for $0.5 \mathrm{~h}$. To the nitronate solution was added a mixture of conc. sulfuric acid $(0.2 \mathrm{ml})$ and methanol (10 $\mathrm{ml}$ ). During the addition, the mixture was kept at $0^{\circ} \mathrm{C}$ and after additional stirring at $0^{\circ} \mathrm{C}$ for an hour, it was poured into dichloromethane $(20 \mathrm{ml})$.The organic layer was washed with cold water and the water layer was extracted with dichloromethane. The combined organic layer was dried over sodium sulfate and the solvent was removed under vacuum pressure. Dichloromethane and $2 \mathrm{~N}$ hydrochloric acid was added and the mixture was stirred at room temperature for $2 \mathrm{~h}$. The water layer was then washed with dichloromethane and the organic layer was dried over sodium sulfate and removed under vacuum and the crude product was then purified by column chromatography to give 1.6c in $72 \%$ yield. IR (cm-1) : 3394, 2934, 1735, 1666, $1436{ }^{1} \mathrm{H}$ NMR $(270 \mathrm{MHz}$, $\left.\mathrm{CDCl}_{3}\right) \delta 1.56-1.67(\mathrm{~m}, 4 \mathrm{H}), 2.21-2.25(\mathrm{~m}, 4 \mathrm{H}), 2.61(\mathrm{t}, J=6.6 \mathrm{~Hz}, 2 \mathrm{H}), 2.97(\mathrm{t}, J=6.6$ $\mathrm{Hz}, 2 \mathrm{H}), 3.67$ (s, 3H), 6.94-6.97 (br, 1H); ${ }^{13} \mathrm{C} \mathrm{NMR}\left(67.5 \mathrm{MHz}, \mathrm{CDCl}_{3}\right) \delta$ 21.5, 21.9, 23.0, 26.0, 28.1, 31.7, 51.7, 138.8, 140.2, 173.7, 198.9; HRMS Calculated for $\left[\mathrm{C}_{11} \mathrm{H}_{16} \mathrm{NO}_{3} \mathrm{H}\right]^{+}$: 197.1178, Found: 197.1173. 


\section{NMR spectra of the reaction between $1 \mathrm{a}$ and $2 \mathrm{a}$ forming 3.}

Figure S-1. The NMR spectra of the reaction between 1.1a and 1.2a: a) 1.2a; b) 1.1a; c) 1.3, a mixture of two double bond isomers with a ration of $2: 1$; d) reaction between $1.1 \mathrm{a}$ and 1.2a when time is 2 min.; e) 30 min.; f) 90 min.; g) 2 h.; h) 8 h.; i) 2 h.

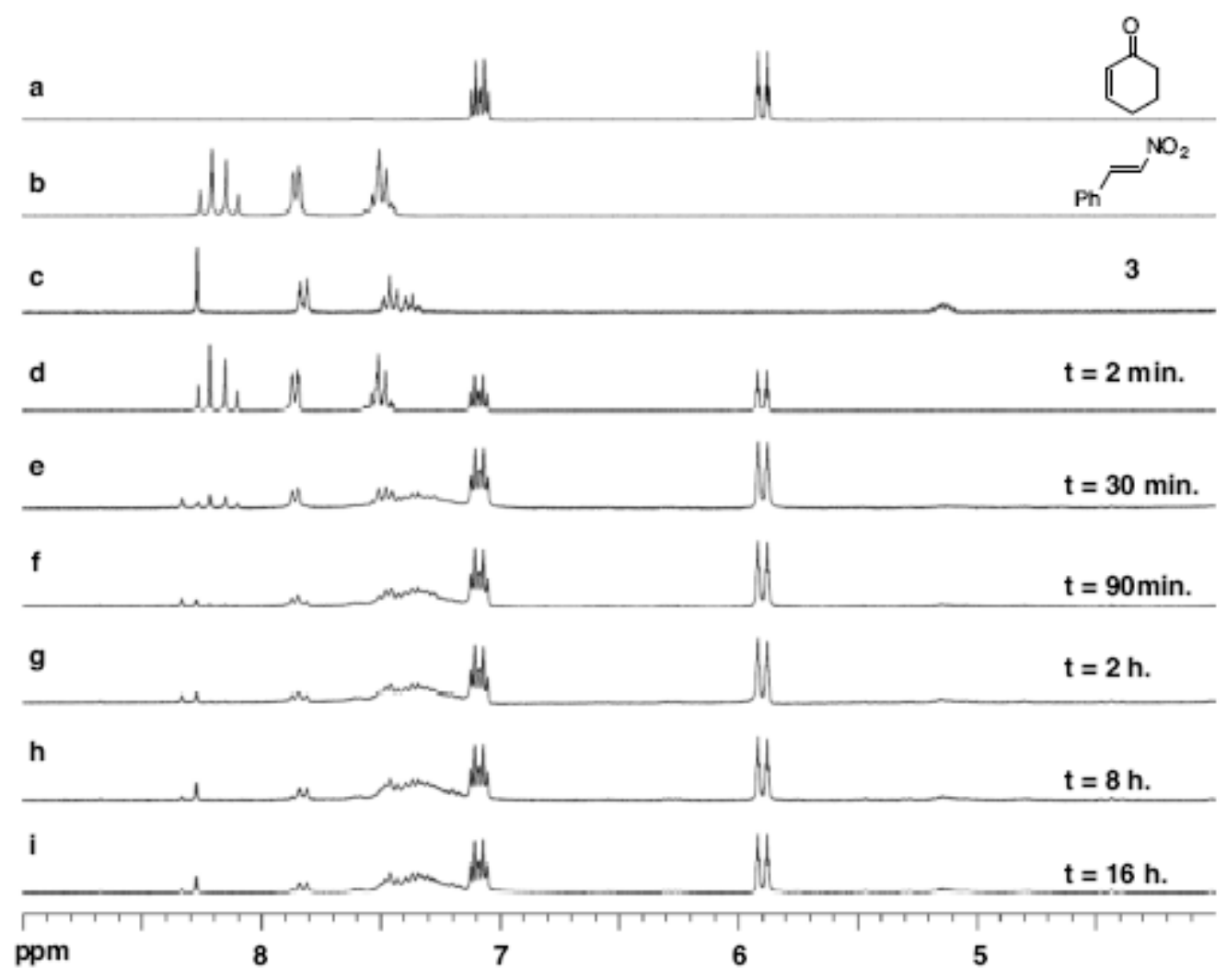

Based on the spectra, the nitroalkene was consumed rapidly. At 30 minutes, more than $90 \% 1.1 \mathrm{a}$ was consumed without the formation of product 1.3. The amount of $1.3 \mathrm{kept}$ increasing even after almost all 1.1a was consumed. These spectra clearly revealed two important mechanistic facts: 1) nitroalkene is more reactive Michael receptor than enone; and 2) the oligomerization of 1.1a is equilibrium and can come back to simple nitroalkene before polymerization. This result set up our key hypothesis that installation 
of a $\beta$-alkyl group will help the reaction to reach the desired cross double Michael addition.

\section{Compound Characterization:}<smiles>C=C(c1ccccc1)[C@H](C1CCCC(=O)C1)[N+](=O)[O-]</smiles>

(S)-3-((R)-1-nitro-2-phenylallyl) cyclohexanone $(\mathrm{d}: \mathrm{r}=1: 1)(\mathbf{1 . 5 a})$ : 1.5a was purified by flash chromatography (Hexane-EtOAc, v/v 5/1) as yellow oil with overall isolated yield: 87\%. Isomer 1: ${ }^{1} \mathrm{H}-\mathrm{NMR}\left(270 \mathrm{MHz}, \mathrm{CDCl}_{3}\right) \delta 1.37-1.82(\mathrm{~m}, 2 \mathrm{H}), 1.82-1.98(\mathrm{~m}, 2 \mathrm{H}), 2.00-$ $2.26(\mathrm{~m}, 2 \mathrm{H}), 2.32-2.52(\mathrm{~m}, 2 \mathrm{H}), 2.60-2.82(\mathrm{~m}, 1 \mathrm{H}), 5.24(\mathrm{~d}, J=10.4 \mathrm{~Hz}, 1 \mathrm{H}), 5.65(\mathrm{~s}$, 1H), $5.71(\mathrm{~s}, 1 \mathrm{H}), 7.30-7.40(\mathrm{~m}, 5 \mathrm{H}),{ }^{13} \mathrm{C}-N M R\left(67.5 \mathrm{MHz}, \mathrm{CDCl}_{3}\right)$ ठ 24.1, 28.5, 41.0, $42.3,43.2,94.1,119.3,126.6,128.7,129.0,139.5,141.7,208.5 ; \mathrm{IR}\left(\mathrm{cm}^{-1}\right): 2940,2346$, 1708, 1547, 1446; HRMS Calculated for $\left[\mathrm{C}_{15} \mathrm{H}_{17} \mathrm{NO}_{3} \mathrm{Na}\right]^{+}:$282.1106, Found: 282.1101. Isomer 2: ${ }^{1} \mathrm{H}-\mathrm{NMR}\left(270 \mathrm{MHz}, \mathrm{CDCl}_{3}\right) \delta$ 1.52-2.53 (m, 8H), 2.81-3.02 (m, 1H), $5.27(\mathrm{~d}, \mathrm{~J}$ $=7.4 \mathrm{~Hz}, 1 \mathrm{H}), 5.62(\mathrm{~s}, 1 \mathrm{H}), 5.67(\mathrm{~s}, 1 \mathrm{H}), 7.20-7.45(\mathrm{~m}, 5 \mathrm{H}) ;{ }^{13} \mathrm{C}-\mathrm{NMR}\left(67.5 \mathrm{MHz}, \mathrm{CDCl}_{3}\right)$ ठ24.3, 27.1, 40.9, 42.0, 44.4, 94.1, 118.9, 126.6, 128.7, 129.0, 139.5, 139.5, 208.2.<smiles>C=C(c1ccccc1)C(C1CCCCC(=O)C1)[N+](=O)[O-]</smiles>

3-(1-nitro-2-phenylallyl)cycloheptanone $(\mathrm{d}: \mathrm{r}=1.2: 1)(\mathbf{1 . 5 b}): \mathbf{1 . 5 b}$ was purified by flash chromatography (Hexane-EtOAc, v/v 5/1) as yellow oil with overall isolated yield: $72 \%$. ${ }^{1} \mathrm{H}-\mathrm{NMR}\left(270 \mathrm{MHz}, \mathrm{CDCl}_{3}\right) \delta 1.35-1.64(\mathrm{~m}, 3 \mathrm{H}), 1.85-1.92(\mathrm{~m}, 2 \mathrm{H}), 2.1-2.2(\mathrm{~m}, 2 \mathrm{H}), 2.48-$ 
2.58(m, 4H), 5.23(dd, J=9.7Hz, 1H), 5.69(dd, J=15hz, 1H), 7.33-7.40(m, 5H); ${ }^{13} \mathrm{C}-\mathrm{NMR}$ (67.5 MHz, $\left.\mathrm{CDCl}_{3}\right) \delta$ 24.3, 28.2, 32.0, 33.4, 39.2, 39.7, 43.5, 45.0, 46.0, 94.2, 119.2, 126.6, 128.8, 139.4, 142.4, 211.2; IR $\left(\mathrm{cm}^{-1}\right)$ : 2944, 2355, 1698 1542, 1438; HRMS Calculated for $\left[\mathrm{C}_{16} \mathrm{H}_{19} \mathrm{NO}_{3} \mathrm{Na}\right]^{+}:$296.12626, Found: 296.12576.<smiles>C=C(c1ccccc1)C(C1CCC(=O)C1)[N+](=O)[O-]</smiles>

3-(1-nitro-2-phenylallyl) cyclopentanone $(\mathrm{d}: \mathrm{r}=\mathbf{1 . 1}$ :1) $(\mathbf{1 . 5 c})$ : $\mathbf{1 . 5 c}$ was purified by flash chromatography (Hexane-EtOAc, v/v 3/1) as yellow oil, isolated yield $45 \%$ ${ }^{1} \mathrm{H}-\mathrm{NMR}\left(270 \mathrm{MHz}, \mathrm{CDCl}_{3}\right) \delta$ 1.20-1.82 (m, 2H), 2.03-2.62 (m, 5H), 3.05-3.22 (m, 1H), $5.27(\mathrm{~d}, \mathrm{~J}=10.3 \mathrm{~Hz}, 1 \mathrm{H}), 7.34-7.65(\mathrm{~m}, 5 \mathrm{H}) ;{ }^{13} \mathrm{C}-\mathrm{NMR}\left(67.5 \mathrm{MHz}, \mathrm{CDCl}_{3}\right) \delta 25.8,27.3$, $38.0,40.1,41.3,42.8,94.2,119.6,126.7,128.8,139.0,142.6,215.5 ; \operatorname{IR}\left(\mathrm{cm}^{-1}\right): 2195$, $1690,1546,1497,1436 ;$ HRMS calculated for $\left[\mathrm{C}_{14} \mathrm{H}_{15} \mathrm{NO}_{3} \mathrm{Na}\right]^{+}: 268.0949$, found 286.09486<smiles>C=C(c1ccccc1)C(CC(=O)c1ccccc1)c1ccccc1</smiles>

(3S, 4R)-4-nitro-1,3,5-triphenylhex-5-en-one(d:r = 1.6:1) (1.5d): $\mathbf{1 . 5 d}$ was purified by flash chromatography (Hexane-EtOAc, v/v 3/1) as White solid, isolated yield: $70 \% .{ }^{1} \mathrm{H}-$ $\operatorname{NMR}\left(270 \mathrm{MHz}, \mathrm{CDCl}_{3}\right) \delta 3.19(\mathrm{dd}, J=16.8,3.5 \mathrm{~Hz}, 1 \mathrm{H}), 3.34(\mathrm{dd}, J=17.1,9.6 \mathrm{~Hz}$, 1H), 4.40-4.49 (m, 1H), $5.75(\mathrm{~s}, 1 \mathrm{H}), 5.89(\mathrm{~d}, J=11.6 \mathrm{~Hz} 1 \mathrm{H}), 6.01(\mathrm{~s}, 1 \mathrm{H}), 7.12-7.57(\mathrm{~m}$, 13H), 7.66-7.69 (m, 2H); ${ }^{13} \mathrm{C}-\mathrm{NMR}\left(67.5 \mathrm{MHz}, \mathrm{CDCl}_{3}\right)$ ठ 41.1, 45.2, 93.9, 120.2, 127.9, 128.0, 128.2, 128.7, 128.9, 129.1, 133.4, 138.9, 196.6; IR $\left(\mathrm{cm}^{-1}\right): 2175,1674,1534$, 1497, 1446; HRMS Calculated for $\left[\mathrm{C}_{24} \mathrm{H}_{21} \mathrm{NO}_{3} \mathrm{Na}\right]^{+}: 394.1419$, Found: 394.1415. 
<smiles>CC(=O)CCC1([N+](=O)[O-])C=CCCC1</smiles>

4-((S)-1-nitrocyclohex-2-enyl)-butan-2-one (1.5e): 1.5e was purified by flash chromatography (Hexane-EtOAc, v/v 3/1) as yellow oil, isolated yield: 93\%. ${ }^{1} \mathrm{H}-\mathrm{NMR}\left(270 \mathrm{MHz}, \mathrm{CDCl}_{3}\right) \delta$ 1.40-1.56 (m, 1H), 1.59-1.73 (m, 2H), 1.86-2.16 (m, 7H), 2.36-2.52 (m, 3H), 5.81 (ddd, $J=10.1,3.6,2.1 \mathrm{~Hz} 1 \mathrm{H}), 6.02(\mathrm{ddd}, J=10.1,4.1,3.5 \mathrm{~Hz}$, $1 \mathrm{H}) ;{ }^{13} \mathrm{C}-\mathrm{NMR}\left(67.5 \mathrm{MHz}, \mathrm{CDCl}_{3}\right) \delta 18.8,24.8,30.0,31.9,34.0,37.6,88.4,125.1,134.2$, 206.4; IR $\left(\mathrm{cm}^{-1}\right): 2294,2331,1708,1534,1444 ; \mathrm{HRMS}$ Calculated for $\left[\mathrm{C}_{10} \mathrm{H}_{15} \mathrm{NO}_{3} \mathrm{Na}\right]^{+}$: 220.0950, Found: 220.0945.<smiles>COC(=O)CCC1([N+](=O)[O-])C=CCCC1</smiles>

Methyl-3-((s)-1-nitrocyclohex-2-enyl) propionate (1.5f): 1.5f was purified by flash chromatography (Hexane-EtOAc, v/v 3/1) as yellow oil, isolated yield: $85 \%$. ${ }^{1} \mathrm{H}-\mathrm{NMR}\left(270 \mathrm{MHz}, \mathrm{CDCl}_{3}\right) \delta$ 1.40-1.75 (m, 3H), 1.85-2.33 (m, 6H), 2.38-2.54 (m, 1H), 3.60 (s, 3H), 5.81 (ddd, $J=9.9,3.7,2.2 \mathrm{~Hz}, 1 \mathrm{H}), 6.02$ (ddd, $J=10.2,4.2,3.2 \mathrm{~Hz}, 1 \mathrm{H}$ ); ${ }^{13} \mathrm{C}-\mathrm{NMR}\left(67.5 \mathrm{MHz}, \mathrm{CDCl}_{3}\right) \delta$ 18.8, 24.7, 28.5, 31.6, 35.3, 51.9, 88.3, 124.9, 134.4, 172.5; IR $\left(\mathrm{cm}^{-1}\right): 2956,2331,1742,1538,1448$; HRMS Calculated for $\left[\mathrm{C}_{10} \mathrm{H}_{15} \mathrm{NO}_{4} \mathrm{Na}\right]^{+}$: 236.0899, Found: 236.0896.

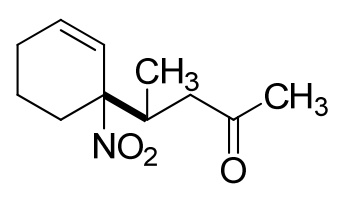


4-Methyl-5-((S)-1-nitrocyclohex-2-enyl) pentan-2-one (d/r=1.6/1) (1.5g): $1.5 g$ was purified by flash chromatography (Hexane-EtOAc, v/v 3/1) as yellow oil, isolated yield: 81\%. ${ }^{1} \mathrm{H}$ NMR (270 MHz, $\left.\mathrm{CDCl}_{3}\right) \delta 0.77(\mathrm{~d}, \mathrm{~J}=6.8 \mathrm{~Hz}, 1.8 \mathrm{H}), 0.81(\mathrm{~d}, \mathrm{~J}=6.7 \mathrm{~Hz}, 1.2 \mathrm{H})$, 1.28-2.53 (m, 11H), 2.65-2.74 (m, 1H), 5.71-5.79 (m, 1H), 5.99-6.08 (m, 1H); Isomer 1: ${ }^{13} \mathrm{C}$ NMR $\left(67.5 \mathrm{MHz}, \mathrm{CDCl}_{3}\right) \delta 14.6,18.6,24.9,27.3,30.5,30.5,37.2,45.6,125.4$, 135.6, 206.1; Isomer 2: ${ }^{13} \mathrm{C}$ NMR (67.5 MHz, $\left.\mathrm{CDCl}_{3}\right) \delta 15.1,18.7,24.8,27.6,30.5,37.1$, 45.1, 124.9, 135.0, 206.2; HRMS Calculated for $\left[\mathrm{C}_{11} \mathrm{H}_{17} \mathrm{NO}_{3} \mathrm{Na}\right]^{+}:$234.1106, Found: 214.1101.<smiles>O=C1CCC(C2([N+](=O)[O-])C=CCCC2)CC1</smiles>

(S)-3-((S)-1-nitrocyclohex-2-enyl) cyclohexanone (d:r = 1.3:1) (1.5h) : Both isomers of 1.5h were purified by flash chromatography (Hexane-EtOAc, v/v 3/1) as yellow oils, with overall isolated yield: $76 \% .{ }^{1} \mathrm{H}-\mathrm{NMR}\left(270 \mathrm{MHz}^{\mathrm{C}} \mathrm{CDCl}_{3}\right) \delta 1.31-1.81(\mathrm{~m}, 6 \mathrm{H}), 1.87-2.62$ $(\mathrm{m}, 9 \mathrm{H}), 5.81-5.92(\mathrm{~m}, 1 \mathrm{H}), 6.08-6.19(\mathrm{~m}, 1 \mathrm{H})$; Isomer $1:{ }^{13} \mathrm{C}-\mathrm{NMR}\left(67.5 \mathrm{MHz}, \mathrm{CDCl}_{3}\right) \delta$ $18.8,24.5,25.0,25.9,28.5,41.0,42.5,46.5,91.8,123.7,135.8,209.2$; Isomer $2:{ }^{13} \mathrm{C}$ $\operatorname{NMR}\left(67.5 \mathrm{MHz}, \mathrm{CDCl}_{3}\right) \delta 18.7,24.5,24.8,25.6,27.4,41.0,42.7,46.7,124.7,135.4$, 209.2; HRMS Calculated for $\left[\mathrm{C}_{12} \mathrm{H}_{17} \mathrm{NO}_{3} \mathrm{Na}\right]^{+}:$246.1106, Found: 246.1101.<smiles>O=C1CCCC(C(C2=CCCCC2)[N+](=O)[O-])C1</smiles>

(S)-3-((R)-cyclohexenylnitromethyl) cyclohexanone $(\mathrm{d}: \mathrm{r}=1.2: 1)(\mathbf{1 . 5 i}): \mathbf{1 . 5 i}$ was purified by flash chromatography (Hexane-EtOAc, v/v 3/1) as yellow oil, isolated yield: 90\%. ${ }^{1} \mathrm{H}-\mathrm{NMR}\left(270 \mathrm{MHz}, \mathrm{CDCl}_{3}\right) \delta$ 1.11-1.79 (m, 7H), 1.79-2.07 (m, 6H), 2.10-2.35 (m, 
3H), 2.49-2.68 (m, 1H), $4.59(\mathrm{~d}, J=10.6 \mathrm{~Hz}, 0.62 \mathrm{H}), 4.60(\mathrm{~d}, J=10.8 \mathrm{~Hz}, 0.38 \mathrm{H}), 5.87-$ 5.90 (br, 1H); Isomer 1: ${ }^{13} \mathrm{C}-\mathrm{NMR}\left(67.5 \mathrm{MHz}, \mathrm{CDCl}_{3}\right) \delta$ 21.7, 22.3, 23.7, 24.3, 25.5, 26.9, 38.4, 41.0, 44.4, 98.9, 130.7, 133.3, 208.5; Isomer 2: ${ }^{13} \mathrm{C}-\mathrm{NMR}\left(67.5 \mathrm{MHz}, \mathrm{CDCl}_{3}\right) \delta$ $21.6,22.2,23.6,24.2,25.5,28.2,38.3,41.0,43.1,98.8,130.2,133.7,209.1 ; \operatorname{IR}\left(\mathrm{cm}^{-1}\right)$ : 2294, 2331, 1713, 1534, 1439; HRMS Calculated for $\left[\mathrm{C}_{13} \mathrm{H}_{19} \mathrm{NO}_{3} \mathrm{Na}\right]^{+}: 260.1263$, Found: 260.1258.<smiles>O=C(CC(c1ccccc1)c1ccccc1)C1=CCCCC1</smiles>

4-cyclohexenyl-4-nitro-1,3-diphenylbutan-1-one (1.5j); 1.5j was purified by flash chromatography (Hexane-EtOAc, v/v 3/1) as white solid, isolated yield: $70 \%(\mathrm{~d}: \mathrm{r}=4: 1$ ) Isomer 1:' ${ }^{1} \mathrm{H}-\mathrm{NMR}\left(270 \mathrm{MHz}, \mathrm{CDCl}_{3}\right) \delta$ 1.24-1.43(m, 4H), 1.71-2.04(m, 4H), 3.19(dd, $J=16.6 \mathrm{~Hz}, 1 \mathrm{H}), 3.49(\mathrm{dd}, \mathrm{J}=16.8 \mathrm{~Hz}, 1 \mathrm{H}), 4.2-4.32(\mathrm{~m}, 1 \mathrm{H}), 5.21(\mathrm{~d}, \mathrm{~J}=11.1 \mathrm{~Hz}, 1 \mathrm{H}), 5.77(\mathrm{~s}$, $1 \mathrm{H}), 7.12-7.24(\mathrm{~m}, 1 \mathrm{H}), 7.36-7.41(\mathrm{~m}, 2 \mathrm{H}), 7.47-7.53(\mathrm{~m}, 1 \mathrm{H}), 7.79-7.82(\mathrm{~m}, 2 \mathrm{H}) ;{ }^{13} \mathrm{C}-\mathrm{NMR}$ $\left(67.5 \mathrm{MHz}, \mathrm{CDCl}_{3}\right) \delta 21.53,22.2,24.5,42.1,97.8,127.4,128.0,132.9,133.3,196.7 ; \mathrm{IR}$ $\left(\mathrm{cm}^{-1}\right): 2274,2355,1709,1534,1469$; HRMS Calculated for $\left[\mathrm{C}_{22} \mathrm{H}_{23} \mathrm{NO}_{3} \mathrm{Na}\right]^{+}: 372.1575$, Found: 372.15732; Isomer 2: ${ }^{1} \mathrm{H}-\mathrm{NMR}\left(270 \mathrm{MHz}, \mathrm{CDCl}_{3}\right) \delta$ 1.50-1.63(m, 4H), 1.992.18(m, 4H), 3.13(dd, J=4.2Hz, 1H), 3.23(dd, J=8.9Hz, 1H), 4.34-4.38(m 1H), 5.30(d, $\mathrm{J}=11.8 \mathrm{~Hz}, 1 \mathrm{H}), 6.13(\mathrm{~s}, 1 \mathrm{H}), 7.21-7.42(\mathrm{~m}, 7 \mathrm{H}) ;{ }^{13} \mathrm{C}-\mathrm{NMR}\left(67.5 \mathrm{MHz}, \mathrm{CDCl}_{3}\right) \delta 21.7,22.3$, 23.7, 25.6, 41.2, 98.8, 127.6, 128.0, 133.3, 134.4, 196.7.<smiles>CC(=O)CC(C)C(C1=CCCCC1)[N+](=O)[O-]</smiles> 
$(4 R, 5 R)-5-m e t h y l-5-n i t r o p e n t a n-2-o n e(1.5 k)$ : both isomers of $1.5 k$ was purified by flash chromatography (Hexane-EtOAc, v/v 3/1) as yellow oils, isolated yield: $81 \%(d / r=$ 1.6/1). Isomer-1: ${ }^{1} \mathrm{H}-\mathrm{NMR}\left(270 \mathrm{MHz}, \mathrm{CDCl}_{3}\right) \delta 0.89(\mathrm{~d}, J=6.9 \mathrm{~Hz}, 3 \mathrm{H}), 1.52-1.69(\mathrm{~m}$, $5 \mathrm{H}), 2.01-2.19(\mathrm{~m}, 6 \mathrm{H}), 2.33(\mathrm{dd}, J=17.1,8.9 \mathrm{~Hz}, 1 \mathrm{H}), 2.45(\mathrm{dd}, J=17.1,3.2 \mathrm{~Hz}, 1 \mathrm{H})$, 2.80-2.90 (m, 1H), $4.69(\mathrm{~d}, J=10.9 \mathrm{~Hz}, 1 \mathrm{H}), 5.90-6.00(\mathrm{br}, 1 \mathrm{H}) ;{ }^{13} \mathrm{C}-\mathrm{NMR}(67.5 \mathrm{MHz}$, $\left.\mathrm{CDCl}_{3}\right) \delta 15.90,21.8,22.3,23.7,25.5,29.8,30.5,46.6,98.6,130.1,132.7,206.3 ;$ HRMS Calculated for $\left[\mathrm{C}_{12} \mathrm{H}_{19} \mathrm{NO}_{3} \mathrm{Na}\right]^{+}:$248.1263, Found: 248.1258 . Isomer-2: ${ }^{1} \mathrm{H}-\mathrm{NMR}$ (270 MHz, $\left.\mathrm{CDCl}_{3}\right) \delta 0.98(\mathrm{~d}, J=6.2 \mathrm{~Hz}, 3 \mathrm{H}), 1.45-1.74(\mathrm{~m}, 4 \mathrm{H}), 1.89-2.20(\mathrm{~m}, 7 \mathrm{H}), 2.26$ (dd, $J=17.6,8.9 \mathrm{~Hz}, 1 \mathrm{H}), 2.41(\mathrm{dd}, J=17.3,3.5 \mathrm{~Hz}, 1 \mathrm{H}), 2.83-3.06(\mathrm{~m}, 1 \mathrm{H}), 4.72(\mathrm{~d}, J=$ 11.1 Hz, 1H), 5.90-6.10 (br, 1H); ${ }^{13} \mathrm{C}-\mathrm{NMR}\left(67.5 \mathrm{MHz}, \mathrm{CDCl}_{3}\right) \delta$ 16.9, 21.7, 22.3, 23.8, $25.5,29.8,30.7,45.6,99.2,131.3,133.2,206.1$.<smiles>O=C1CCCCC(C(C2=CCCCC2)[N+](=O)[O-])C1</smiles>

(S)-3-((R)-cyclohexenylnitromethyl-cyclopentanone $(\mathrm{d}: \mathrm{r}=1: 1)(\mathbf{1 . 5}): \mathbf{1 . 5}$ I was purified by flash chromatography (Hexane-EtOAc, v/v 3/1) as yellow oil, isolated yield: 76\%. ${ }^{1} \mathrm{H}-\mathrm{NMR}\left(270 \mathrm{MHz}, \mathrm{CDCl}_{3}\right) \delta$ 1.08-2.64 (m, 19H), $4.63(\mathrm{~d}, \mathrm{~J}=11.1 \mathrm{~Hz}, 1 \mathrm{H}), 5.92-$ $6.08(\mathrm{br}, 1 \mathrm{H})$; Isomer 1: ${ }^{13} \mathrm{C}-\mathrm{NMR}\left(67.5 \mathrm{MHz}, \mathrm{CDCl}_{3}\right) \delta$ 21.7, 22.2, 23.5, 24.4, 25.5, 28.2, 33.5, 36.0, 43.6, 44.9, 99.2, 130.8, 134.1, 211.8; Isomer 2: ${ }^{13} \mathrm{C}-\mathrm{NMR}\left(67.5 \mathrm{MHz}, \mathrm{CDCl}_{3}\right)$ ठ 21.7, 22.3, 23.8, 24.6, 25.5, 28.5, 31.5, 35.7, 43.6, 46.4, 98.8, 131.0, 133.7, 211.3; HRMS Calculated for $\left[\mathrm{C}_{14} \mathrm{H}_{21} \mathrm{NO}_{3} \mathrm{Na}\right]^{+}:$274.1419, Found: 274.1414 .<smiles>CCCCCC(C)C(C)CC(C)=O</smiles> 
(E)-methyl 3,4-dimethyl-4-nitrodec-5-enoate $(1.5 \mathrm{~m})$ : $1.5 \mathrm{~m}$ was purified by flash chromatography (Hexane-EtOAc, v/v 5/1) as yellow oil, isolated yield: $82 \%$ ${ }^{1} \mathrm{H}-\mathrm{NMR}\left(270 \mathrm{MHz}, \mathrm{CDCl}_{3}\right) \delta$ 0.84-0.91(m, 6H), 1.23-1.40( m, 4H), 1.57(d, J=4.2Hz, 3H), 2.07-2.47(m,7H), 2.84-3.01(m, 1H), 5.76-7.83(m, 2H), ${ }^{13} \mathrm{C}-\mathrm{NMR}\left(67.5 \mathrm{MHz}, \mathrm{CDCl}_{3}\right) \delta$ $13.8,14.8,15.3,16.9,17.5,22.2,30.2,30.9,32.1,37.0,45.6,94.4,128.7,135.1,135.8$, 206.0; IR $\left(\mathrm{cm}^{-1}\right): 2930,2346,1718,1537,1456$; HRMS Calculated for $\left[\mathrm{C}_{13} \mathrm{H}_{23} \mathrm{NO}_{3} \mathrm{Na}\right]^{+}$: 264.15756, Found: 264.15695.<smiles>[10BH2]/C=C/C(C)(CCC(=O)OC)[N+](=O)[O-]</smiles>

$(R, E)$-methyl 4-methyl-4-nitrodec-5-enoate (1.5n): 1.5n was purified by flash chromatography (Hexane-ETOAc, v/v 5/1) as yellow oil, isolated yield: $70 \%$. ${ }^{1} \mathrm{H}$ NMR $\left(270 \mathrm{MHz}, \mathrm{CDCl}_{3}\right) \delta 0.83(\mathrm{t}, \mathrm{J}=6.9 \mathrm{~Hz}, 3 \mathrm{H}), 1.97-2.06(\mathrm{~m}, 2 \mathrm{H}), 1.59(\mathrm{~s}, 3 \mathrm{H})$, 1.98-2.06 (m, 2H), 2.17-2.39 (m, 4H), $3.61(\mathrm{~s}, 3 \mathrm{H}), 5.65-5.80(\mathrm{~m}, 2 \mathrm{H}) ;{ }^{13} \mathrm{C}$ NMR $(67.5$ $\left.\mathrm{MHz}_{\mathrm{CDCl}}\right) \delta 13.9,22.2,29.1,30.9,32.0,34.5,51.9,90.2,128.7,134.8,172.6 ; \mathrm{IR}\left(\mathrm{cm}^{-}\right.$ $\left.{ }^{-1}\right):$ 2956, 2346, 1738, 1538, 1437; HRMS Calculated for $\left[\mathrm{C}_{12} \mathrm{H}_{21} \mathrm{NO}_{4} \mathrm{Na}\right]^{+}: 266.1368$, Found: 266.1365 .<smiles>C=C(C)C(C1CCCC(=O)C1)[N+](=O)[O-]</smiles>

(S)-3-((R)-2-methyl-1-nitroallyl) cyclohexanone $(\mathrm{d} / \mathrm{r}=1.1 / 1)(\mathbf{1 . 5 0}): \mathbf{1 . 5 0}$ was purified by flash chromatography (Hexane-EtOAc, v/v 5/1) as yellow oil, isolated yield: $67 \% .{ }^{1} \mathrm{H}-$ $\operatorname{NMR}\left(270 \mathrm{MHz}, \mathrm{CDCl}_{3}\right) \delta$ 1.21-2.47 (m, 11H), 2.55-2.71 (m, 1H), $4.74(\mathrm{~d}, J=10.4 \mathrm{~Hz}$ $0.67 \mathrm{H}), 4.75(\mathrm{~d}, J=10.8 \mathrm{~Hz}, 0.33 \mathrm{H}), 5.19(\mathrm{~s}, 0.67 \mathrm{H}), 5.20(\mathrm{~s}, 0.33 \mathrm{H}), 5.20(\mathrm{~s}, 0.33 \mathrm{H})$, 
5.21 (s, 0.67H); Isomer 1: ${ }^{13} \mathrm{C}-\mathrm{NMR}\left(67.5 \mathrm{MHz}, \mathrm{CDCl}_{3}\right) \delta$ 17.9, 24.3, 26.9, 38.7, 41.0, 44.3, 97.9, 121.0, 137.2, 208.2; Isomer 2: ${ }^{13} \mathrm{C}-\mathrm{NMR}\left(67.5 \mathrm{MHz}, \mathrm{CDCl}_{3}\right) \delta 17.7,24.2$, 28.2, 38.7, 41.0, 43.0, 97.8, 121.4, 136.7, 208.7; HRMS Calculated for $\left[\mathrm{C}_{10} \mathrm{H}_{15} \mathrm{NO}_{3} \mathrm{Na}\right]^{+}$: 220.0949, Found: 220.0946.<smiles>C=C(c1ccccc1)C([N+](=O)[O-])C(C)(C)CC(C)=O</smiles>

(R)-4,4-dimethyl-5-nitro-6-phenylhept-6-en-2-one (1.5p) : 1.5p was purified by flash chromatography (Hexane-EtOAc, v/v 5/1) as yellow oil, isolated yield: $35 \%$.

${ }^{1} \mathrm{H}$ NMR (270 MHz, CDCl $\left.)_{3}\right) \delta 1.06$ (s, 3H), 1.19 (s, 3H), 1.78 (s, 3H), 2.39(q, J=18.03Hz, 2H), 5.55(s, 1H), 5.70(s, 1H), 7.31-7.37(m,5H); ${ }^{13} \mathrm{C}-\mathrm{NMR}\left(67.5 \mathrm{MHz}, \mathrm{CDCl}_{3}\right) \delta$ 23.9, 24.2, 31.1, 37.9, 51.1, 93.8, 126.9, 128.3, 128.9, 141.2, 206.7; HRMS Calculated for $\left[\mathrm{C}_{15} \mathrm{H}_{19} \mathrm{NO}_{3} \mathrm{Na}\right]^{+}:$284.12626, Found: 284.12587.<smiles>COC(=O)CCC(C1=CCCCC1)[N+](=O)[O-]</smiles>

(R)-Methyl-4-cyclohexenyl-4-nitrobutanoate (1.5q): $1.5 q$ was purified by flash chromatography (Hexane-EtOAc, v/v 5/1) as yellow oil, isolated yield: 85\%. ${ }^{1} \mathrm{H}$ NMR (270 MHz, $\left.\mathrm{CDCl}_{3}\right) \delta$ 1.38-1.65 (m, 4H), 1.80-2.18 (m, 5H), $2.26(\mathrm{t}, J=6.9 \mathrm{~Hz}, 2 \mathrm{H}), 2.32-$ $2.45(\mathrm{~m}, 1 \mathrm{H}), 3.61(\mathrm{~s}, 3 \mathrm{H}), 4.84(\mathrm{t}, J=7.4 \mathrm{~Hz}, 1 \mathrm{H}), 5.86-5.89(\mathrm{br}, 1 \mathrm{H}) .{ }^{13} \mathrm{C}$ NMR $(67.5$ $\left.\mathrm{MHz}_{\mathrm{CDCl}}\right) \delta 21.7,22.2,23.4,25.3,25.7,30.1,51.9,92.4,131.5,131.6,172.4 ; \mathrm{IR}\left(\mathrm{cm}^{-}\right.$ $\left.{ }^{-1}\right): 2916,2346,1706,1478,1433$; HRMS Calculated for $\left[\mathrm{C}_{11} \mathrm{H}_{17} \mathrm{NO}_{4} \mathrm{Na}\right]^{+}:$: 250.1055, Found: 250.1051. 


\section{ORTEP Drawing of the Crystal Structures ${ }^{1}$}

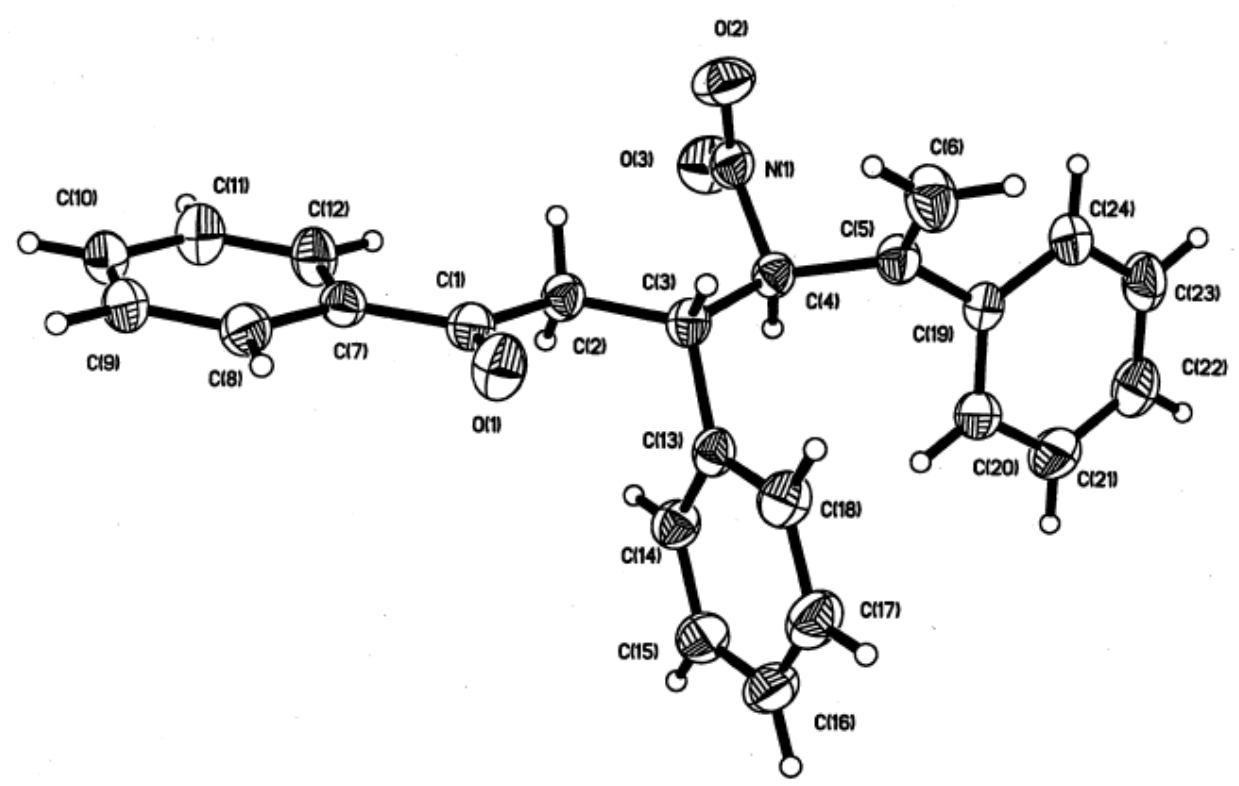

Figure S1. ORTEP drawing of the crystal structure of compound $\mathbf{1 . 5 d}$

CCDC deposition number 656161

${ }^{1}$ For details regarding the crystal structure, refer to supporting information for paper: Sun, $X$.; Sengupta, S.; Petersen, J. L.; Wang, H.; Lewis, J. P.; Shi, X Org. Lett. 2007, 9, 4495-4498. 


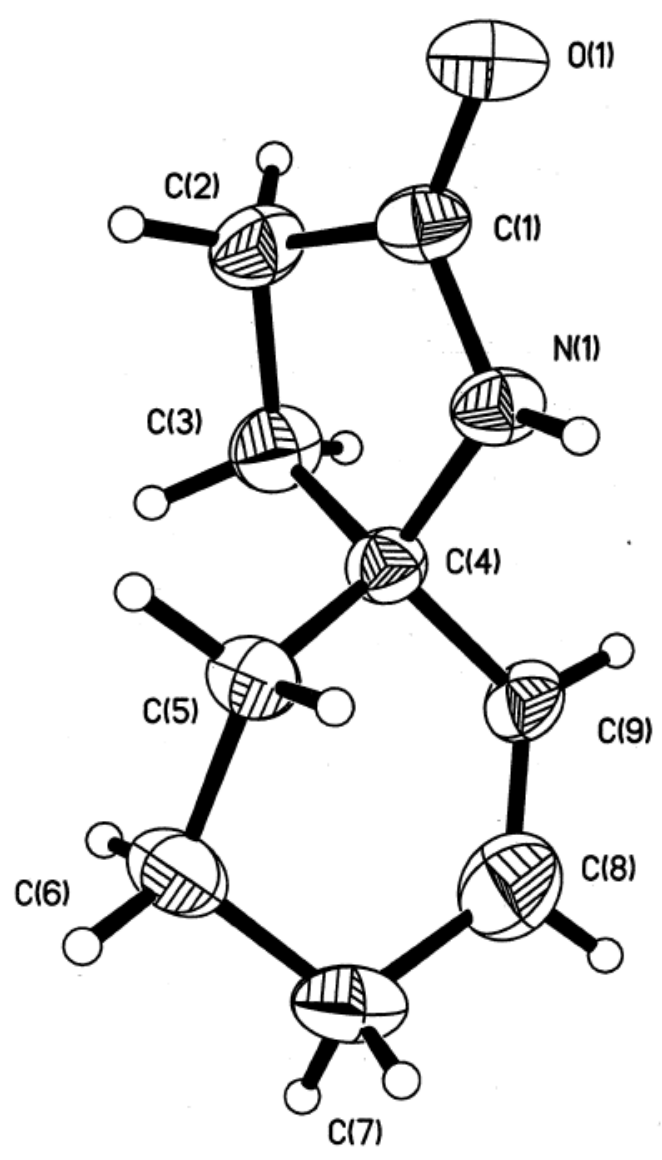

Figure S2. ORTEP drawing of the crystal structure of compound $\mathbf{1 . 6 a}$ CCDC deposition number 656162 


\section{Chapter 2: One Step Cascade Synthesis of 4,5-Disubstituted- 1,2,3- (NH)-Triazoles}

\section{General Methods and Materials:}

Unless otherwise noted, all commercial reagents and solvents were obtained from the commercial provider and used without further purification. Air and/or moisture-sensitive reactions were carried out under an atmosphere of nitrogen using oven/flame-dried glassware and standard syringe/septa techniques. ${ }^{1} \mathrm{H}-\mathrm{NMR}$ and ${ }^{13} \mathrm{C}-\mathrm{NMR}$ spectra were recorded on Joel 270 and Varian $600 \mathrm{MHz}$ spectrometers. Chemical shifts were reported relative to internal tetramethysilane $(\delta 0.00 \mathrm{ppm})$ or $\mathrm{CDCl}_{3}(\delta 7.26 \mathrm{ppm})$ or DMSO $(\delta$ $2.49 \mathrm{ppm})$ for ${ }^{1} \mathrm{H}$ and $\mathrm{CDCl}_{3}(\delta 77.0 \mathrm{ppm})$ or DMSO ( $\left.\delta 39.5 \mathrm{ppm}\right)$ for ${ }^{13} \mathrm{C}$. Infrared (IR) spectra were obtained on a Prospect MIDAC FT-IR spectrometer. Flash column chromatography was performed on $230-430$ mesh silica gel. Analytical thin layer chromatography was performed with precoated

glass baked plates $(250 \mu)$ and visualized by fluorescence and by charring after treatment with potassium permanganate stain. $\mathrm{R} f$ values were obtained by elution in the stated solvent ratios.

The nitroalkene starting materials were prepared according to the following reported procedures:

1) Ohta, H.; Kobayashi, N.; Ozaki, K. J. Org. Chem. 1989, 54, 1802-1804.

2) Lucet, D.; Sabelle, S.; Kostelitz, O.; Gall, T. L.; Mioskowski, C. Eur. J. Org. Chem. 1999, 2583-2591.

3) Jang, Y. J.; Lin, W. W.; Shih, Y. K.; Liu, J. T.; Hwang, M. H.; Yao, C. F. Tetrahedron, 2003, 59, 4979-4992.

General Procedure for synthesis of $\mathrm{NH}$-triazole $6 \mathrm{a}$ 


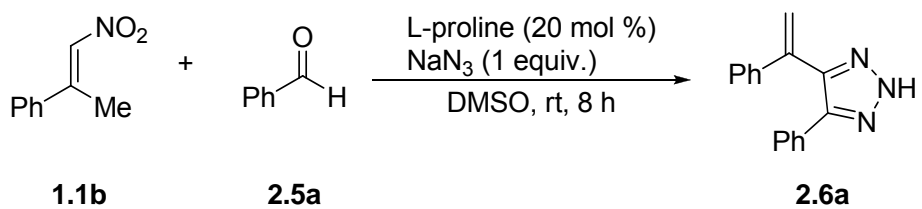

The nitroalkene $1.1 \mathrm{~b}(200 \mathrm{mg}, 1.98 \mathrm{mmol})$ was added to a solution of benzaldehyde 2.5a (420 mg, $3.96 \mathrm{mmol}$ ), L-Proline (46 mg, $20 \mathrm{~mol} \%$ ) and $\mathrm{NaN}_{3}$ (129 mg, $1.98 \mathrm{mmol}$ ) in DMSO $(0.2 \mathrm{M}$ of $\mathbf{1 . 1 b})$. The resulting reaction mixture was then stirred at room temperature for $8 \mathrm{~h}$. The reaction mixture was then diluted with ethyl acetate and the organic layer was washed with water and saturated brine solution. The combined organic layer was dried over anhydrous sodium sulfate. The solvent was removed under reduced pressure and flash silica gel chromatography gave the pure 4,5-disubstituted1,2,3-triazole $2.6 \mathrm{a}$ ( $432 \mathrm{mg}, 89 \%$ yield).

\section{General Procedure for synthesis of 2.7a}

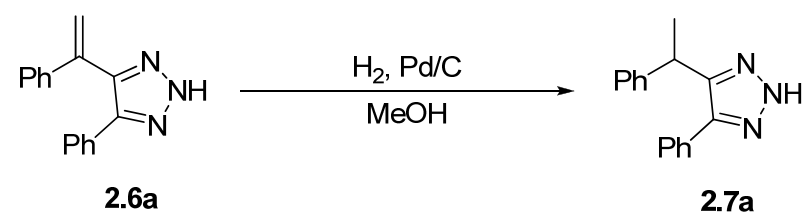

To a suspension of $\mathrm{Pd} / \mathrm{C}(1 \mathrm{~g}, 0.95 \mathrm{mmol})$ in $70 \mathrm{~mL}$ of $\mathrm{EtOH}$ was added triazole $2.6 \mathrm{a}$ $(9.5 \mathrm{mmol})$ in one portion under $\mathrm{N}_{2}$. The resulting mixture was then stirred at room temperature for $2 \mathrm{~h}$. The solution was then passed through a short silica pad to filter off the $\mathrm{Pd} / \mathrm{C}$ after which the solvent was removed under reduced pressure to give $\mathbf{2 . 7 a}$ in quantitative yield. 


\section{Procedure for synthesis of $2.7 \mathrm{~b}$}

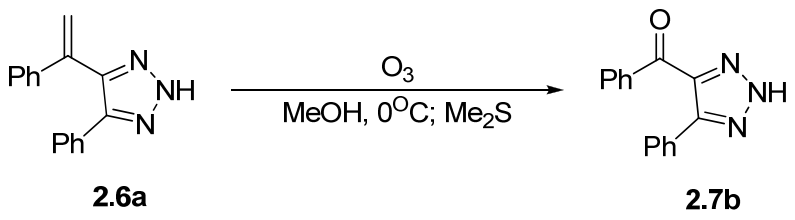

The triazole $2.6 \mathrm{a}(2.5 \mathrm{~g}, 8.4 \mathrm{mmol})$ was dissolved in $20 \mathrm{ml}$ of methanol in a $50 \mathrm{ml}$ twoneck flask equipped with a gas dispersing tube. A stream of ozone was bubbled through the solution at $0{ }^{\circ} \mathrm{C}$. Ozone treatment was terminated when the mixture assumed a light yellow color. To the solution was then added $\mathrm{Me}_{2} \mathrm{~S}$ after which the solvent was removed under reduced pressure and flash silica gel chromatography by elution with hexane: ethyl acetate (4:1) gave $\mathbf{2 . 7 b}$ in $85 \%$ yield as colorless oil.

\section{Procedure for synthesis of $2.7 \mathrm{c}$}

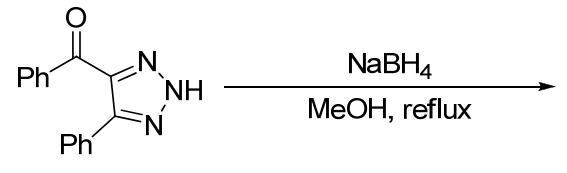

2.7b

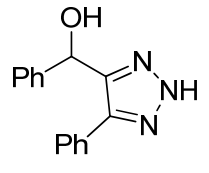

2.7c

To a solution of ketone $2.7 \mathrm{~b}(2.1 \mathrm{~g}, 8.4 \mathrm{mmol})$ in methanol $(40 \mathrm{ml})$ was added $\mathrm{NaBH}_{4}$ (1.3g, $33 \mathrm{mmol})$. The reaction mixture was then refluxed under $\mathrm{N}_{2}$ for $24 \mathrm{~h}$. After being cooled to room temperature, the solution was diluted with ethyl acetate $(50 \mathrm{ml})$ and washed with water. The water phase was extracted with ethyl acetate ( $3 \times 50 \mathrm{ml})$. The combined organic phases were then washed with brine and dried over anhydrous 
sodium sulfate. The solvent was removed under reduced pressure and flash silica gel chromatography (hexane:ethyl acetate $=3: 1$ ) gave $2.7 \mathrm{c}$ in $95 \%$ yield as white solid.

\section{Il. Compounds Characterization:}<smiles>C=C(c1ccccc1)c1n[nH]nc1-c1ccccc1</smiles>

4-phenyl-5-(1-phenylvinyl)-2H-1,2,3-triazole (2.6a): 2.6a was purified by flash chromatography (hexane-EtOAc, v/v 2/1) as pale red solid (yield 89\%), m.p. $96-98{ }^{\circ} \mathrm{C}$; IR(cm $\left.{ }^{-1}\right): 3028,2739,1971,1740,1606,1211 ;{ }^{1} \mathrm{H}$ NMR $\left(270 \mathrm{MHz}, \mathrm{CDCl}_{3}\right): \delta$ 7.59-7.63 (m, 2H), 7.23-7.35 (m, 9H), $5.86(\mathrm{~s}, 1 \mathrm{H}), 5.58(\mathrm{~s}, 1 \mathrm{H}) ;{ }^{13} \mathrm{C} \mathrm{NMR}\left(67.5 \mathrm{MHz}, \mathrm{CDCl}_{3}\right): \delta$ 138.5, 129.9, 128.6, 128.5, 128.4, 127.7, 126.9, 119.2; HRMS Calculated for $\mathrm{C}_{16} \mathrm{H}_{14} \mathrm{~N}_{3}$ $[\mathrm{M}+\mathrm{H}]^{+}:$247.2945, Found: 247.29164 .<smiles>C=C(c1ccccc1)c1n[nH]nc1-c1ccc([N+](=O)[O-])cc1</smiles>

4-(4-nitrophenyl)-5-(1-phenylvinyl)-2H-1,2,3-triazole (2.6b): 2.6b was purified by flash chromatography (hexane-EtOAc, v/v 2/1) as pale yellow solid (yield 88 \%), m.p. 116-118 ${ }^{\circ} \mathrm{C} ; \mathrm{IR}\left(\mathrm{cm}^{-1}\right): 3722,3030,2862,1601,1517,1339,1219 ;{ }^{1} \mathrm{H}$ NMR $\left(270 \mathrm{MHz}, \mathrm{CDCl}_{3}\right): \delta$ $8.10(\mathrm{~d}, J=8.9 \mathrm{~Hz}, 2 \mathrm{H}), 7.81(\mathrm{~d}, J=8.8 \mathrm{~Hz}, 2 \mathrm{H}), 7.28-7.39(\mathrm{~m}, 5 \mathrm{H}), 5.97(\mathrm{~s}, 1 \mathrm{H}), 5.64(\mathrm{~s}$, $1 \mathrm{H}) ;{ }^{13} \mathrm{C} \mathrm{NMR}\left(67.5 \mathrm{MHz}, \mathrm{CDCl}_{3}\right): \delta 137.6,136.5,128.7,128.0,126.6,123.7,119.7$; HRMS Calculated for C16H13N4O2 [M+H]+ : 293.10385, Found: 293.10329. 
<smiles>C=C(c1ccccc1)c1n[nH]nc1-c1cccc([N+](=O)[O-])c1</smiles>

4-(3-nitrophenyl)-5-(1-phenylvinyl)-2H-1,2,3-triazole (2.6c): 2.6c was purified by flash chromatography (hexane-EtOAc, v/v 2/1) as pale brown solid (yield 85 \%), m.p. > 112 ${ }^{\circ} \mathrm{C}$ (decomposition); IR( $\left.\mathrm{cm}^{-1}\right): 3722,3030,2862,1601,1517,1339,1219 ;{ }^{1} \mathrm{H}$ NMR $(270$ $\left.\mathrm{MHz}, \mathrm{CDCl}_{3}\right): \delta 8.43(\mathrm{t}, J=1.8 \mathrm{~Hz}, 1 \mathrm{H}), 7.95(\mathrm{~m}, 2 \mathrm{H}), 7.42(\mathrm{t}, J=8.0 \mathrm{~Hz}, 1 \mathrm{H}), 7.23-7.33$ $(\mathrm{m}, 5 \mathrm{H}), 5.95(\mathrm{~s}, 1 \mathrm{H}), 5.67(\mathrm{~s}, 1 \mathrm{H}) ;{ }^{13} \mathrm{C} \mathrm{NMR}\left(67.5 \mathrm{MHz}, \mathrm{CDCl}_{3}\right): \delta$ 148.2, 133.2, 129.3, 128.6, 126.8, 122.8,122.5, 119.6. HRMS Calculated for $\mathrm{C}_{16} \mathrm{H}_{13} \mathrm{~N}_{4} \mathrm{O}_{2}[\mathrm{M}+\mathrm{H}]^{+}:$293.10385, Found: 293.10327.<smiles>C=C(c1ccccc1)c1n[nH]nc1-c1ccccc1[N+](=O)[O-]</smiles>

4-(2-nitrophenyl)-5-(1-phenylvinyl)-2H-1,2,3-triazole (2.6d): 2.6d was purified by flash chromatography (hexane-EtOAc, v/v 2/1) as pale brown solid (yield 81 \%), m.p. 142-143 ${ }^{\circ} \mathrm{C} ; \mathrm{IR}\left(\mathrm{cm}^{-1}\right): 3210,2181,1736,1615,1521,1428,1217 ;{ }^{1} \mathrm{H}$ NMR $\left(270 \mathrm{MHz}, \mathrm{CDCl}_{3}\right): \delta$ $7.88(\mathrm{~d}, J=7.91 \mathrm{~Hz}, 1 \mathrm{H}), 7.41-7.55(\mathrm{~m}, 3 \mathrm{H}), 7.19-7.31(\mathrm{~m}, 6 \mathrm{H}), 5.59(\mathrm{~s}, 1 \mathrm{H}), 5.49(\mathrm{~s}, 1 \mathrm{H})$; ${ }^{13} \mathrm{C} \mathrm{NMR}\left(67.5 \mathrm{MHz}_{\mathrm{CDCl}}\right): \delta 132.9,132.6,129.7,128.4,127.7,124.7,118.7 . \mathrm{HRMS}$ Calculated for $\mathrm{C}_{16} \mathrm{H}_{13} \mathrm{~N}_{4} \mathrm{O}_{2}[\mathrm{M}+\mathrm{H}]^{+}:$293.10385, Found: 293.10324 .<smiles>C=C(c1ccccc1)c1n[nH]nc1-c1ccc(C#N)cc1</smiles> 
4-(5-(1-phenylvinyl)-2H-1,2,3-triazol-4-yl)benzonitrile (2.6e): 2.6e was purified by flash chromatography (hexane-EtOAc, v/v 2/1) as pale yellow solid (yield $78 \%$ ), m.p. $118-120^{\circ} \mathrm{C} ; \mathrm{IR}\left(\mathrm{cm}^{-1}\right): 3210,2181,1778,1615,1521,1456,1217 ;{ }^{1} \mathrm{H}$ NMR $(270 \mathrm{MHz}$, $\left.\mathrm{CDCl}_{3}\right): \delta 7.42(\mathrm{~d}, J=8.4 \mathrm{~Hz}, 2 \mathrm{H}), 7.52(\mathrm{~d}, J=8.4 \mathrm{~Hz}, 2 \mathrm{H}), 7.24-7.29(\mathrm{~m}, 5 \mathrm{H}), 5.95(\mathrm{~s}$, 1H), $5.62(\mathrm{~s}, 1 \mathrm{H}) ;{ }^{13} \mathrm{C} \mathrm{NMR}\left(67.5 \mathrm{MHz}, \mathrm{CDCl}_{3}\right): \delta 142.5,137.5,134.7,132.3,128.8$, 128.6, 127.9, 126.7, 119.7, 118.7, 111.5; HRMS Calculated for $\mathrm{C}_{17} \mathrm{H}_{13} \mathrm{~N}_{4}[\mathrm{M}+\mathrm{H}]^{+}$: 273.11402, Found: 273.11349.<smiles>C=C(c1ccccc1)c1n[nH]nc1-c1ccc(Cl)cc1</smiles>

4-(4-chlorophenyl)-5-(1-phenylvinyl)-2H-1,2,3-triazole (2.6f): $2.6 f$ was purified by flash chromatography (hexane-EtOAc, v/v 2/1) as cream solid (yield 74 \%), m.p. 133$135^{\circ} \mathrm{C} ; \mathrm{IR}\left(\mathrm{cm}^{-1}\right): 3224,2334,2179,1740,1556,1427,1370,1218 ;{ }^{1} \mathrm{H}$ NMR $(270 \mathrm{MHz}$, $\left.\mathrm{CDCl}_{3}\right): \delta 7.56(\mathrm{~d}, J=8.4 \mathrm{~Hz}, 2 \mathrm{H}), 7.22-7.31(\mathrm{~m}, 7 \mathrm{H}), 5.88(\mathrm{~d}, J=5.9 \mathrm{~Hz}, 1 \mathrm{H}), 5.57(\mathrm{~d}, J=$ $5.4 \mathrm{~Hz}, 1 \mathrm{H}) ;{ }^{13} \mathrm{C} \operatorname{NMR}\left(67.5 \mathrm{MHz}, \mathrm{CDCl}_{3}\right): \delta 138.0,134.2,128.8,128.6,128.5,128.4$, 126.7,119.2. HRMS Calculated for $\mathrm{C}_{16} \mathrm{H}_{13} \mathrm{CIN}_{3}[\mathrm{M}+\mathrm{H}]^{+}:$282.07980, Found: 282.07927 .<smiles>C=C(c1ccccc1)c1n[nH]nc1-c1ccc(OC)cc1</smiles>

4-(4-methoxyphenyl)-5-(1-phenylvinyl)-2H-1,2,3-triazole (2.6g): $2.6 \mathrm{~g}$ was purified by flash chromatography (hexane-EtOAc, v/v 4/1) as cream sticky-solid (yield 40 \%), m.p. > $110^{\circ} \mathrm{C}$ (decomposition); IR( $\left.\mathrm{cm}^{-1}\right): 3323,3049,2917,2854,1678,1603,1555,1458$, 1445; ${ }^{1} \mathrm{H}$ NMR $\left(270 \mathrm{MHz}, \mathrm{CDCl}_{3}\right): 7.52(\mathrm{~d}, J=8.6 \mathrm{~Hz}, 2 \mathrm{H}), 7.24-7.33(\mathrm{~m}, 5 \mathrm{H}), 6.78(\mathrm{~d}, J$ 
$=8.8 \mathrm{~Hz}, 2 \mathrm{H}), 5.86(\mathrm{~s}, 1 \mathrm{H}), 5.57(\mathrm{~s}, 1 \mathrm{H}), 3.70(\mathrm{~s}, 3 \mathrm{H}) ;{ }^{13} \mathrm{C} \mathrm{NMR}\left(67.5 \mathrm{MHz}, \mathrm{CDCl}_{3}\right)$ :

ס159.6, 138.5, 128.9, 128.4, 128.2, 127.8, 126.8, 118.8, 98.1, 55.2. HRMS Calculated for $\mathrm{C}_{17} \mathrm{H}_{16} \mathrm{~N}_{3} \mathrm{O}[\mathrm{M}+\mathrm{H}]^{+}:$:278.3205, Found: 278.32112.<smiles>O=C(c1ccccc1)c1n[nH]nc1-c1c(Cl)cccc1Cl</smiles>

4-(2,6-dichlorophenyl)-5-(1-phenylvinyl)-2H-1,2,3-triazole (2.6h): $2.6 \mathrm{~h}$ was purified by flash chromatography (hexane-EtOAc, v/v 2/1) as cream colored solid (yield 76\%), m.p. $100-101^{\circ} \mathrm{C} ; \operatorname{IR}\left(\mathrm{cm}^{-1}\right): 3224,2334,2179,1740,1556,1427,1370,1218 ;{ }^{1} \mathrm{H}$ NMR $(270$ $\left.\mathrm{MHz}, \mathrm{CDCl}_{3}\right): \delta 7.16-7.35(\mathrm{~m}, 8 \mathrm{H}), 5.49(\mathrm{~s}, 1 \mathrm{H}), 5.46(\mathrm{~s}, 1 \mathrm{H}) ;{ }^{13} \mathrm{C} \mathrm{NMR}(67.5 \mathrm{MHz}$, $\left.\mathrm{CDCl}_{3}\right): \delta 138.9,136.3,130.5,128.1,128.0,127.8,127.5,117.8$. HRMS Calculated for $\mathrm{C}_{16} \mathrm{H}_{12} \mathrm{Cl}_{2} \mathrm{~N}_{3}[\mathrm{M}+\mathrm{H}]^{+}:$316.04083, Found: 316.04030 .<smiles>C=C(c1ccccn1)c1n[nH]nc1-c1ccccc1</smiles>

3-(5-(1-phenylvinyl)-2H-1,2,3-triazol-4-yl)pyridine (2.6i): 2.6i was purified by flash chromatography (hexane-EtOAc, v/v 1/1) as pale yellow solid (yield 76\%), m.p. 144-146 ${ }^{\circ} \mathrm{C} ; \mathrm{IR}\left(\mathrm{cm}^{-1}\right)$ m.p. 108-110 oC: 3028, 2640, 2112, 1737, 1604, 1574, 1493, 1411, 1175; ${ }^{1} \mathrm{H}$ NMR $\left(270 \mathrm{MHz}, \mathrm{CDCl}_{3}\right): \delta 8.89(\mathrm{~d}, J=1.5 \mathrm{~Hz}, J=9.2 \mathrm{~Hz}, 1 \mathrm{H}), 8.47(\mathrm{dd}, J=1.5 \mathrm{~Hz}, J=$ 4.8Hz, 1H), 7.89- $7.94(\mathrm{~m}, 1 \mathrm{H}), 7.18-7.32(\mathrm{~m}, 6 \mathrm{H}), 5.89(\mathrm{~s}, 1 \mathrm{H}), 5.62(\mathrm{~s}, 1 \mathrm{H}) ;{ }^{13} \mathrm{C}$ $\operatorname{NMR}\left(67.5 \mathrm{MHz}, \mathrm{CDCl}_{3}\right): \delta$ 148.1, 147.9, 140.9, 138.6, 138.3, 135.6, 128.7, 128.6, 127.6, 127.1, 123.7, 119.3; HRMS Calculated for C15H12N4: HRMS Calculated for $\mathrm{C}_{15} \mathrm{H}_{13} \mathrm{~N}_{4}$ $[\mathrm{M}+\mathrm{H}]^{+}:$249.11402, Found: 
249.11345.<smiles>C=C(c1ccccc1)c1n[nH]nc1-c1ccncc1</smiles>

4-(5-(1-phenylvinyl)-2H-1,2,3-triazol-4-yl)pyridine (2.6j): 2.6j was purified by flash chromatography (hexane-EtOAc, v/v 2/1) as cream solid (yield $75 \%$ ), m.p. $153-155{ }^{\circ} \mathrm{C}$; $\mathrm{IR}\left(\mathrm{cm}^{-1}\right): 3575,2971,2489,1915,1739,1608,1425,1365,1228 ;{ }^{1} \mathrm{H}$ NMR $(270 \mathrm{MHz}$, $\left.\mathrm{CDCl}_{3}\right): \delta 8.50(\mathrm{dd}, J=1.5 \mathrm{~Hz}, J=4.7 \mathrm{~Hz}, 2 \mathrm{H}), 7.60(\mathrm{dd}, J=1.5 \mathrm{~Hz}, J=4.7 \mathrm{~Hz}, 2 \mathrm{H}), 7.28-$ $7.32(\mathrm{~m}, 5 \mathrm{H}), 5.97(\mathrm{~s}, 1 \mathrm{H}), 5.62(\mathrm{~s}, 1 \mathrm{H}) ;{ }^{13} \mathrm{C} \mathrm{NMR}\left(67.5 \mathrm{MHz}, \mathrm{CDCl}_{3}\right): \delta 149.2,141.6$, 138.8, 137.9, 137.8, 128.8, 128.7, 126.6, 121.8, 119.4. HRMS Calculated for $\mathrm{C}_{15} \mathrm{H}_{13} \mathrm{~N}_{4}$ $[\mathrm{M}+\mathrm{H}]^{+}:$249.11402, Found: 249.11343.<smiles>C=C(c1ccccc1)c1n[nH]nc1-c1cccc2ccccc12</smiles>

4-(naphthalen-1-yl)-5-(1-phenylvinyl)-2H-1,2,3-triazole (2.6k): 2.6k was purified by flash chromatography (hexane-EtOAc, v/v 3/1) as pale yellow solid (yield 81\%), m.p. $122-124{ }^{\circ} \mathrm{C} ; \mathrm{IR}\left(\mathrm{cm}^{-1}\right): 3035,2164,1951,1555,1444,1213 ;{ }^{1} \mathrm{H}$ NMR $\left(270 \mathrm{MHz}, \mathrm{CDCl}_{3}\right):$ ס 7.80-7.85 (m, 3H), 7.37-7.50 (m, 5H), 7.14-7.16 (m, 4H), $5.47(\mathrm{~s}, 1 \mathrm{H}), 5.37(\mathrm{~s}, 1 \mathrm{H}) ;{ }^{13} \mathrm{C}$ $\operatorname{NMR}\left(67.5 \mathrm{MHz}, \mathrm{CDCl}_{3}\right): \delta 138.9,133.5,131.6,129.2,128.3,128.2,128.0,127.9,127.2$, $126.5,125.9,125.4,125.0,118.5$

HRMS Calculated for $\mathrm{C}_{20} \mathrm{H}_{16} \mathrm{~N}_{3}[\mathrm{M}+\mathrm{H}]^{+}:$298.3532, Found: 298.35462. 
<smiles>C=C(c1ccccc1)c1n[nH]nc1-c1ccc2ccccc2c1</smiles>

4-(naphthalen-2-yl)-5-(1-phenylvinyl)-2H-1,2,3-triazole (2.6I): 2.6I was purified by flash chromatography (hexane-EtOAc, v/v 3/1) as pale yellow sticky-solid (yield 83\%), m.p. $>134{ }^{\circ} \mathrm{C}$ (decomposition); IR( $\left(\mathrm{cm}^{-1}\right)$ : 3035, 2168, 1951, 1558, 1454, 1213; ${ }^{1} \mathrm{H}$ NMR $\left(270 \mathrm{MHz}, \mathrm{CDCl}_{3}\right): \delta 8.08(\mathrm{t}, J=11.4 \mathrm{~Hz}, 1 \mathrm{H}), 7.36-7.79(\mathrm{~m}, 11 \mathrm{H}), 5.91(\mathrm{~s}, 1 \mathrm{H}), 5.61(\mathrm{~s}$, $1 \mathrm{H}) ;{ }^{13} \mathrm{C} \operatorname{NMR}\left(67.5 \mathrm{MHz}, \mathrm{CDCl}_{3}\right): \delta 138.9,133.5,131.6,129.2,128.3,128.2,128.0$, $127.9,127.2,126.5,125.9,125.4,125.0,118.5$. HRMS Calculated for $\mathrm{C}_{20} \mathrm{H}_{16} \mathrm{~N}_{3}[\mathrm{M}+\mathrm{H}]^{+}$: 298.3532, Found: 298.35119.<smiles>O=C(c1ccccc1)c1n[nH]nc1-c1c(O)ccc2ccccc12</smiles>

1-(5-(1-phenylvinyl)-2H-1,2,3-triazol-4-yl)naphthalen-2-ol (2.6m): 2.6m was purified by flash chromatography (hexane-EtOAc, v/v 3/1) as pale brown solid (yield 56\%), m.p. . $119^{\circ} \mathrm{C}$ (decomposition); ${ }^{1} \mathrm{H}$ NMR (270 MHz, $\mathrm{CDCl}_{3}$ ): $\delta$ 7.16-7.24 (m, 2H), 6.70-7.85 (m, $5 \mathrm{H}), 6.62-6.69(\mathrm{~m}, 4 \mathrm{H}), 4.80(\mathrm{~s}, 2 \mathrm{H}) ;{ }^{13} \mathrm{C} \mathrm{NMR}\left(67.5 \mathrm{MHz}, \mathrm{CDCl}_{3} / \mathrm{DMSO}: 10 / 1\right): \delta$ 153.6, 139.3, 138.8, 133.6, 130.1, 127.7, 127.4, 127.3, 127.2, 126.3, 125.9, 123.6, 122.5, 117.9, 116.1. HRMS Calculated for $\left[\mathrm{C}_{20} \mathrm{H}_{15} \mathrm{~N}_{3} \mathrm{OH}\right]^{+}: 314.35260$, Found: 314.35112.<smiles>C1=C(c2n[nH]nc2-c2ccccc2)CCCC1</smiles> 
4-cyclohexenyl-5-phenyl-2H-1,2,3-triazole (2.6n): 2.6n was purified by flash

chromatography (hexane-EtOAc, v/v 3/1) as pale yellow solid (yield 72\%), m.p. $>125{ }^{\circ} \mathrm{C}$ (decomposition); ${ }^{1} \mathrm{H}$ NMR (270 MHz, $\left.\mathrm{CDCl}_{3}\right): \delta$ 7.63-7.66 (m, 2H), 7.33-7.42 (m, 3H), $6.05(\mathrm{~m}, 1 \mathrm{H}), 2.05-2.29(\mathrm{~m}, 4 \mathrm{H}), 1.67(\mathrm{~m}, 4 \mathrm{H}) ;{ }^{13} \mathrm{C} \mathrm{NMR}\left(67.5 \mathrm{MHz}, \mathrm{CDCl}_{3}\right): \delta$ 131.0, 130.1, 128.4, 128.1, 127.9, 27.4, 25.4, 22.5, 22.1. HRMS Calculated for $\left[\mathrm{C}_{14} \mathrm{H}_{14} \mathrm{~N}_{4} \mathrm{O}_{2} \mathrm{H}\right]^{+}$: 271.11950, Found: 271.11898.<smiles>O=[N+]([O-])c1ccc(-c2n[nH]nc2C2=CCCCC2)cc1</smiles>

4-cyclohexenyl-5-(4-nitrophenyl)-2H-1,2,3-triazole (2.60): 2.60 was purified by flash chromatography (hexane-EtOAc, v/v 2/1) as pale yellow solid (yield 78\%), m.p. 95-96 ${ }^{\circ} \mathrm{C} ;{ }^{1} \mathrm{H}$ NMR $\left(270 \mathrm{MHz}, \mathrm{CDCl}_{3}\right): \delta 8.29(\mathrm{~d}, J=8.4 \mathrm{HZ}, 2 \mathrm{H}), 7.91(\mathrm{~d}, J=8.6 \mathrm{~Hz}, 2 \mathrm{H}), 6.08$ (s,1H), $2.18(\mathrm{~m}, 4 \mathrm{H}), 1.73-1.74(\mathrm{~m}, 4 \mathrm{H}) ;{ }^{13} \mathrm{C} \mathrm{NMR}\left(67.5 \mathrm{MHz}, \mathrm{CDCl}_{3}\right): \delta 134.2,130.6$, 129.7, 129.3, 128.8, 127.2, 124.1, 27.9, 25.7, 22.7, 21.8; HRMS Calculated for $\mathrm{C}_{14} \mathrm{H}_{15} \mathrm{~N}_{4} \mathrm{O}^{2}[\mathrm{M}+\mathrm{H}]^{+}:$: 271.11950, Found: 271.11898.<smiles>Clc1ccc(-c2n[nH]nc2C2=CCCCC2)cc1</smiles>

4-(4-chlorophenyl)-5-cyclohexenyl-2H-1,2,3-triazole (2.6p): 2.6p was purified by flash chromatography (hexane-EtOAc, v/v 2/1) as pale yellow solid (yield 74\%), m.p. 128-130 ${ }^{\circ} \mathrm{C} ; \mathrm{IR}\left(\mathrm{cm}^{-1}\right): 3665,2163,1740,1365,1228,1217 ;{ }^{1} \mathrm{H}$ NMR $\left(270 \mathrm{MHz}, \mathrm{CDCl}_{3}\right): \delta 7.61$ (d, 
$J=8.4 \mathrm{~Hz}, 2 \mathrm{H}), 7.39(\mathrm{~d}, J=8.4 \mathrm{~Hz}, 2 \mathrm{H}), 6.05(\mathrm{~m}, 1 \mathrm{H}), 2.29(\mathrm{~m}, 2 \mathrm{H}), 2.14-2.17(\mathrm{~m}, 2 \mathrm{H})$, 1.67-1.76 (m, 4H); ${ }^{13} \mathrm{C} \mathrm{NMR}\left(67.5 \mathrm{MHz}, \mathrm{CDCl}_{3}\right): 134.2,130.6,129.7,129.3,128.8$, 127.1, 27.5, 25.4, 22.5, 21.7. HRMS Calculated for $\mathrm{C}_{14} \mathrm{H}_{15} \mathrm{CIN}_{4}[\mathrm{M}+\mathrm{H}]^{+}: 260.09545$, Found: 260.09490 .<smiles>C1=C(c2n[nH]nc2-c2ccncc2)CCCC1</smiles>

4-(5-cyclohexenyl-2H-1,2,3-triazol-4-yl)pyridine (2.6q): $2.6 q$ was purified by flash chromatography (hexane-EtOAc, v/v 1/1) as pale white solid (yield 71\%), m.p. 184-186 ${ }^{\circ} \mathrm{C} ;{ }^{1} \mathrm{H} \mathrm{NMR}\left(270 \mathrm{MHz}, \mathrm{CDCl}_{3}\right): \delta 8.68(\mathrm{~d}, J=6.2 \mathrm{~Hz}, 2 \mathrm{H}), 7.68(\mathrm{dd}, J=1.5 \mathrm{~Hz}, J=6.4 \mathrm{~Hz}$, $2 \mathrm{H}), 6.07(\mathrm{~m}, 1 \mathrm{H}), 2.18-2.32(\mathrm{~m}, 4 \mathrm{H}), 1.72-1.80(\mathrm{~m}, 4 \mathrm{H}) ;{ }^{13} \mathrm{C} \mathrm{NMR}\left(67.5 \mathrm{MHz}, \mathrm{CDCl}_{3}\right): \delta$ 149.4, 140.2, 139.9, 131.3, 127.1, 122.2, 27.8, 25.5, 22.5, 21.7. HRMS Calculated for $\mathrm{C}_{13} \mathrm{H}_{15} \mathrm{~N}_{4}[\mathrm{M}+\mathrm{H}]^{+}:$:227.12967, Found: 227.12916.<smiles>C1=C(c2n[nH]nc2-c2cccc3ccccc23)CCCC1</smiles>

4-cyclohexenyl-5-(naphthalen-2-yl)-2H-1,2,3-triazole (2.6r): 2.6r was purified by flash chromatography (hexane-EtOAc, v/v 2/1) as pale yellow solid (yield $73 \%$ ), m. p. $>85^{\circ} \mathrm{C}$ (decomposition); ${ }^{1} \mathrm{H}$ NMR $\left(270 \mathrm{MHz}, \mathrm{CDCl}_{3}\right): \delta 7.88-7.94(\mathrm{~m}, 2 \mathrm{H}), 7.66(\mathrm{~d}, J=8.6 \mathrm{~Hz}$, 1H), $7.54(\mathrm{~s}, 1 \mathrm{H}), 7.52(\mathrm{dd}, J=1.2 \mathrm{~Hz}, J=3.7 \mathrm{~Hz}, 1 \mathrm{H}), 7.48(\mathrm{t}, J=1.9 \mathrm{~Hz}, 1 \mathrm{H}), 7.43(\mathrm{dd}, J$ $=1.2 \mathrm{~Hz}, J=3.8 \mathrm{~Hz}, 1 \mathrm{H}), 5.83(\mathrm{~s}, 1 \mathrm{H}), 2.25(\mathrm{~s}, 2 \mathrm{H}), 1.91(\mathrm{t}, J=2.7 \mathrm{~Hz}, 2 \mathrm{H}), 1.52-1.62(\mathrm{~m}$, 
$4 \mathrm{H}) ;{ }^{13} \mathrm{C} \mathrm{NMR}\left(67.5 \mathrm{MHz}, \mathrm{CDCl}_{3}\right): \delta$ 133.6, 131.9, 129.2, 128.7, 128.6, 126.4, 126.1, 125.6, 125.2, 26.6, 25.4, 22.4, 21.7. HRMS Calculated for $\mathrm{C}_{18} \mathrm{H}_{18} \mathrm{~N}_{3}[\mathrm{M}+\mathrm{H}]^{+}:$: 276.15007, Found: 276.14948 .<smiles>Oc1ccccc1-c1n[nH]nc1C1=CCCCC1</smiles>

2-(5-cyclohexenyl-2H-1,2,3-triazol-4-yl)phenol (2.6s): 2.6s was purified by flash chromatography (hexane-EtOAc, v/v 3/1) as bright yellow solid (yield 65\%), m. p. 114$116{ }^{\circ} \mathrm{C} ;{ }^{1} \mathrm{H}$ NMR $\left(270 \mathrm{MHz}, \mathrm{CDCl}_{3}\right): \delta 8.22(\mathrm{~s}, 1 \mathrm{H}), 7.56(\mathrm{dd}, J=1.2 \mathrm{~Hz}, J=7.9 \mathrm{~Hz}, 1 \mathrm{H})$, 7.22-7.28 (m, 3H), 6.80-6.91 (m, 2H), $5.92(\mathrm{~s}, 1 \mathrm{H}), 5.28(\mathrm{bs}, 1 \mathrm{H}), 2.13(\mathrm{~m}, 4 \mathrm{H}), 1.69(\mathrm{~m}$, $4 \mathrm{H}) .{ }^{13} \mathrm{C} \mathrm{NMR}\left(67.5 \mathrm{MHz}, \mathrm{CDCl}_{3}\right): \delta$ 155.5, 152.1, 134.9, 132.1, 130.1, 129.3, 127.7 , $120.9,119.4,116.3,27.3,25.7,22.5,21.5$. HRMS Calculated for $\mathrm{C}_{14} \mathrm{H}_{16} \mathrm{~N}_{3} \mathrm{O}[\mathrm{M}+\mathrm{H}]^{+}$: 242.12934, Found: 242.12884 .<smiles>C=C(C)c1n[nH]nc1-c1ccc([N+](=O)[O-])cc1</smiles>

4-(4-nitrophenyl)-5-(prop-1-en-2-yl)-2H-1,2,3-triazole (2.6t): $2.6 t$ was purified by flash chromatography (hexane-EtOAc, v/v 3/1) as pale white solid (yield $58 \%$ ), m.p. $93-95{ }^{\circ} \mathrm{C}$; IR( $\left.\mathrm{cm}^{-1}\right): 2970,1738,1645,1365,1228,1217 ;{ }^{1} \mathrm{H} \mathrm{NMR}\left(270 \mathrm{MHz}, \mathrm{CDCl}_{3}\right): \delta 8.29$ (d, J = $8.7 \mathrm{~Hz}, 2 \mathrm{H}), 7.90(\mathrm{~d}, J=8.7 \mathrm{~Hz}, 2 \mathrm{H}), 5.36(\mathrm{~s}, 1 \mathrm{H}), 5.28(\mathrm{~s}, 1 \mathrm{H}), 2.16(\mathrm{~s}, 3 \mathrm{H}) ;{ }^{13} \mathrm{C}$ $\operatorname{NMR}\left(67.5 \mathrm{MHz}, \mathrm{CDCl}_{3}\right): \delta 147.6,137.5,128.8,123.9,118.9,22.0$. HRMS Calculated for $\mathrm{C}_{11} \mathrm{H}_{11} \mathrm{~N}_{4} \mathrm{O}_{2}[\mathrm{M}+\mathrm{H}]^{+}: 231.08820$, Found: 231.08770 . 
<smiles>C=C(C)c1n[nH]nc1-c1ccncc1</smiles>

4-(5-(prop-1-en-2-yl)-2H-1,2,3-triazol-4-yl)pyridine (2.6u): 2.6u was purified by flash chromatography (hexane-EtOAc, v/v 2/1) as pale white solid (yield 55\%), m.p. 162-163 ${ }^{\circ} \mathrm{C} ; \mathrm{IR}\left(\mathrm{cm}^{-1}\right): 2970,1738,1610,1365,1228,1217 ;{ }^{1} \mathrm{H}$ NMR $\left(270 \mathrm{MHz}, \mathrm{CDCl}_{3}\right): \delta 8.69$ (d, $5.5 \mathrm{~Hz}, 2 \mathrm{H}), 7.57(\mathrm{dd}, J=1.8 \mathrm{~Hz}, J=5.6 \mathrm{~Hz}, 2 \mathrm{H}), 5.36(\mathrm{~s}, 1 \mathrm{H}), 5.31(\mathrm{~s}, 1 \mathrm{H}), 2.16(\mathrm{~s}, 3 \mathrm{H})$; ${ }^{13} \mathrm{C} \mathrm{NMR}\left(67.5 \mathrm{MHz}, \mathrm{CDCl}_{3}\right): \delta 149.7,140.9,139.8,133.9,122.6,118.7,22.2 . \mathrm{HRMS}$ Calculated for $\mathrm{C}_{10} \mathrm{H}_{11} \mathrm{~N}_{4}[\mathrm{M}+\mathrm{H}]^{+}:$187.09837, Found: 187.09788 .<smiles>CC(C)=Cc1n[nH]nc1-c1ccncc1</smiles>

4-(5-(2-methylprop-1-enyl)-2H-1,2,3-triazol-4-yl)pyridine (2.6v): 2.6v was purified by flash chromatography (hexane-EtOAc, v/v 3/1) as pale white solid (yield 56\%), m.p. $>145^{\circ} \mathrm{C}$ (decomposition); IR( $\left(\mathrm{cm}^{-1}\right): 3689,2970,1739,1440,1365,1228,1217 ;{ }^{1} \mathrm{H}$ NMR $\left(270 \mathrm{MHz}, \mathrm{CDCl}_{3}\right): \delta 8.69(\mathrm{~d}, J=6.18 \mathrm{~Hz}, 2 \mathrm{H}), 7.72(\mathrm{dd}, J=1.6 \mathrm{~Hz}, J=6.2 \mathrm{~Hz}, 2 \mathrm{H}), 6.22-$ $6.23(\mathrm{~m}, 1 \mathrm{H}), 2.01(\mathrm{~s}, 3 \mathrm{H}), 1.88(\mathrm{~s}, 3 \mathrm{H}) ;{ }^{13} \mathrm{C} \mathrm{NMR}\left(67.5 \mathrm{MHz}, \mathrm{CDCl}_{3}\right): \delta$ 149.7, 143.6, 141.2, 139.6, 121.6, 111.4, 26.4, 20.2. HRMS Calculated for $\mathrm{C}_{11} \mathrm{H}_{13} \mathrm{~N}_{4}[\mathrm{M}+\mathrm{H}]^{+}$: 201.1198, Found: 201.11312. 
<smiles>C=C(c1ccc(Cl)cc1)c1n[nH]nc1-c1ccncc1</smiles>

4-(5-(1-(4-chlorophenyl)vinyl)-2H-1,2,3-triazol-4-yl)pyridine (2.6w): 2.6w was purified by flash chromatography (hexane-EtOAc, v/v 3/1) as pale white solid (yield 81\%), m.p. $>125{ }^{\circ} \mathrm{C}$ (decomposition); ${ }^{1} \mathrm{H}$ NMR $\left(270 \mathrm{MHz}, \mathrm{CDCl}_{3}\right): \delta 8.44$ (d, J = 5.9Hz, 2H), 7.49 (d, $J=6.0 \mathrm{~Hz}, 2 \mathrm{H}), 7.20-7.59(\mathrm{~m}, 4 \mathrm{H}), 5.89(\mathrm{~s}, 1 \mathrm{H}), 5.56(\mathrm{~s}, 1 \mathrm{H}) ;{ }^{13} \mathrm{C} \mathrm{NMR}(67.5 \mathrm{MHz}$, $\left.\mathrm{CDCl}_{3}\right): \delta 149.3,137.8,136.7,136.2,133.6,128.2,127.5,120.1,119.0 ; \mathrm{HRMS}$ Calculated for $\mathrm{C}_{15} \mathrm{H}_{12} \mathrm{CIN}_{4}[\mathrm{M}+\mathrm{H}]^{+}:$282.7276, Found:282.71182<smiles>CC(c1ccccc1)c1n[nH]nc1-c1ccccc1</smiles>

4-phenyl-5-(1-phenylethyl)-2H-1,2,3-triazole (2.7a): 2.7a was purified by flash chromatography (hexane-EtOAc, v/v 3/1) as oil (yield 100\%); ${ }^{1} \mathrm{H}$ NMR (270 MHz, $\left.\mathrm{CDCl}_{3}\right): \delta 7.48-7.52(\mathrm{~m}, 2 \mathrm{H}), 7.34-7.38(\mathrm{~m}, 2 \mathrm{H}), 7.16-7.29(\mathrm{~m}, 5 \mathrm{H}), 4.42(\mathrm{dd}, J=7.2 \mathrm{~Hz}$, $J=14.3 \mathrm{~Hz}, 1 \mathrm{H}), 1.73(\mathrm{~d}, J=7.2 \mathrm{~Hz}, 1 \mathrm{H}) ;{ }^{13} \mathrm{C} \operatorname{NMR}\left(67.5 \mathrm{MHz}, \mathrm{CDCl}_{3}\right): \delta$ 144.6, 130.3, 128.7, 128.4, 128.2, 127.5, 126.6, 36.3, 22.7; HRMS Calculated for $\mathrm{C}_{16} \mathrm{H}_{16} \mathrm{~N}_{3}[\mathrm{M}+\mathrm{H}]^{+}$: 250.4104 , Found: 250.41524.<smiles>O=C(c1ccccc1)c1n[nH]nc1-c1ccccc1</smiles>

phenyl(5-phenyl-2H-1,2,3-triazol-4-yl)methanone (2.7b): 2.7b was purified by flash chromatography (hexane-EtOAc, v/v 4/1) as colorless oil (yield 85\%); ${ }^{1} \mathrm{H}$ NMR (270 $\left.\mathrm{MHz}, \mathrm{CDCl}_{3}\right): \delta 7.99(\mathrm{~d}, J=7.18 \mathrm{~Hz}, 2 \mathrm{H}), 7.61-7.64(\mathrm{~m}, 2 \mathrm{H}), 7.48-7.51(\mathrm{~m}, 1 \mathrm{H}), 7.25-$ 
$7.39(\mathrm{~m}, 5 \mathrm{H}) ;{ }^{13} \mathrm{C} \mathrm{NMR}\left(67.5 \mathrm{MHz}, \mathrm{CDCl}_{3}\right): \delta 188.5,145.6,140.8,136.9,133.7,130.6$, 129.7, 128.9, 128.7, 128.5, 127.3; HRMS Calculated for $\mathrm{C}_{15} \mathrm{H}_{12} \mathrm{~N}_{3} \mathrm{O}[\mathrm{M}+\mathrm{H}]^{+}: 250.2673$, Found: 250.26824 .<smiles>Nc1ccc(-c2n[nH]nc2C2CCCCC2)cc1</smiles>

phenyl(5-phenyl-2H-1,2,3-triazol-4-yl)methanol (2.7c): $2.7 \mathrm{c}$ was purified by flash chromatography (hexane-EtOAc, v/v 3/1) as white solid (yield 85\%), m.p. $145147^{\circ} \mathrm{C}$; 1H NMR (270 MHz, CDCl3/DMSO: 10/1): $\delta 7.55$ (dd, $J=1.8 \mathrm{~Hz}, J=8.1 \mathrm{~Hz}, 2 \mathrm{H}), 7.13-$ $7.28(\mathrm{~m}, 8 \mathrm{H}), 6.01(\mathrm{~s}, 1 \mathrm{H}) ;{ }^{13} \mathrm{C} \mathrm{NMR}\left(67.5 \mathrm{MHz}, \mathrm{CDCl}_{3}\right): \delta 141.69,129.62,127.6,127.2$, 127.1, 127.0, 126.4, 125.8, 66.3; HRMS Calculated for $\mathrm{C}_{15} \mathrm{H}_{14} \mathrm{~N}_{3} \mathrm{O}[\mathrm{M}+\mathrm{H}]^{+}:$:252.2832,

Found: 252.28332 .

\section{ORTEP Drawing of the Crystal Structure ${ }^{2}$}

\footnotetext{
${ }^{2}$ For details regarding the crystal structure, refer to supporting information for paper: Sengupta, S., Duan, H.-F., Lu, W.-B., Petersen, J. L., Shi, X.-D. Org. Lett. 2008, 10, 1493-1496.
} 

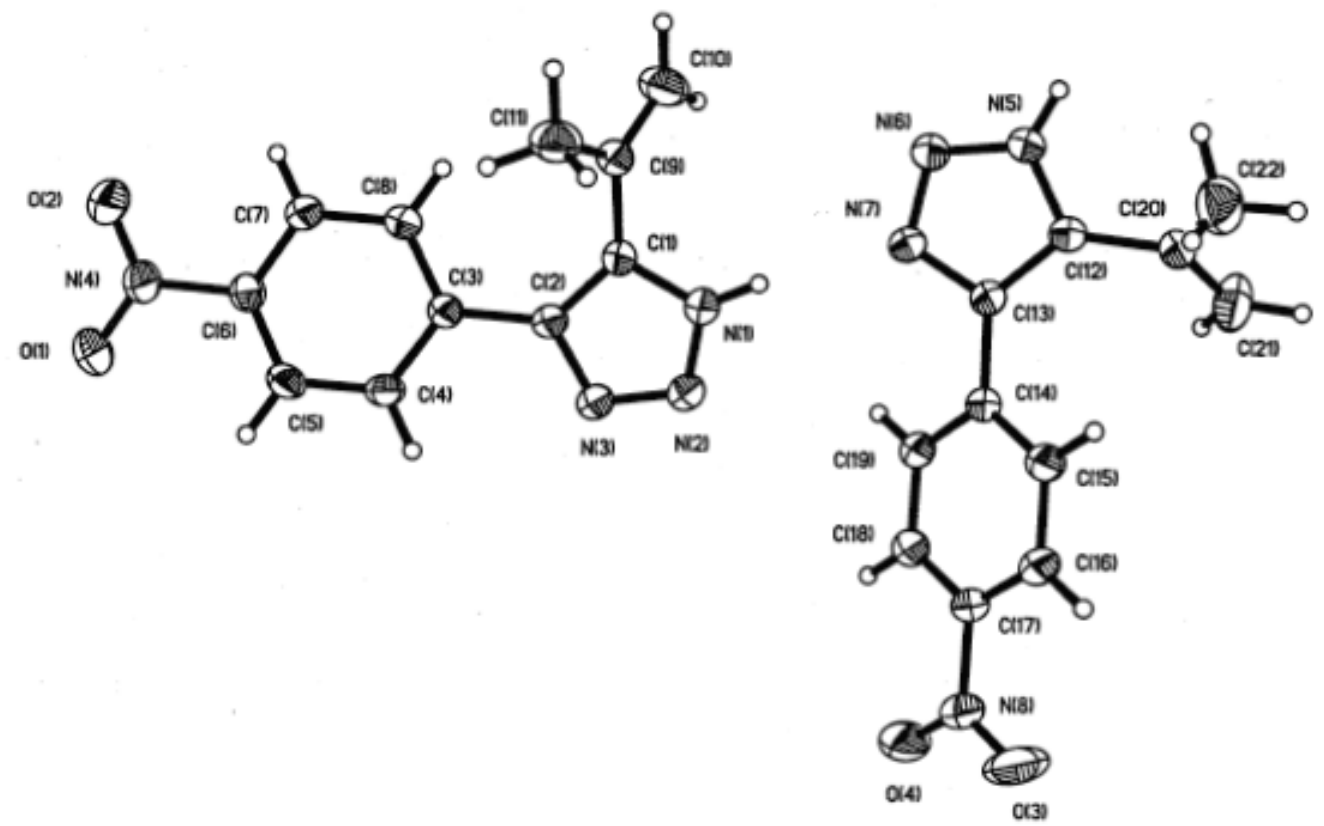

Figure S3: ORTEP drawing of the crystal structure of compound 2.6t

CCDC deposition number 662424 


\section{Chapter 3: Synthesis and Characterization of (NH)-triazole bound Rh(I) complexes- Substituted group controlled regioselective coordination}

\section{General Methods and Materials:}

Unless otherwise noted, all commercial reagents and solvents were obtained from the commercial provider and used without further purification. $[\mathrm{RhCl}(\mathrm{COD})]_{2}$ (crystalline solid) and DPPP were purchased and stored under nitrogen. ${ }^{1} \mathrm{H}-\mathrm{NMR}$ and ${ }^{13} \mathrm{C}-\mathrm{NMR}$ spectra were recorded on $270 \mathrm{MHz}$ and $600 \mathrm{MHz}$ spectrometers. Chemical shifts were reported relative to internal tetramethysilane $(\delta 0.00 \mathrm{ppm})$ or $\mathrm{CDCl}_{3}(\delta 7.26 \mathrm{ppm})$ for ${ }^{1} \mathrm{H}$ and $\mathrm{CDCl}_{3}(\delta 77.0 \mathrm{ppm})$ for ${ }^{13} \mathrm{C}$. Flash column chromatography was performed on 230 430 mesh silica gel. Analytical thin layer chromatography was performed with precoated glass baked plates $(250 \mu)$ and visualized by fluorescence or by charring after treatment with potassium permanganate stain. Melting points were determined on a MelTemp and are uncorrected. Elemental analyses were performed in the Department of Chemical Engineering, College of Engineering and Mineral Resources, West Virginia University.

4,5-Disubstituted-1,2,3-Triazoles were synthesized according to our reported procedure ${ }^{3}$<smiles>CC(c1ccccc1)c1n[nH]nc1-c1ccncc1</smiles>

4-(4-pyridinyl)-(5-(1-phenylethyl)-2H-1,2,3-triazole was purified by flash chromatography (hexane-EtOAc, v/v 2/1) as white solid, m.p. 190-192 ${ }^{\circ} \mathrm{C} ;{ }^{1} \mathrm{H}$ NMR (600

${ }^{3}$ Sengupta, S., Duan, H.-F., Lu, W.-B., Petersen, J. L., Shi, X.-D. Org. Lett. 2008, 10, 1493-1496. 
$\left.\mathrm{MHz}, \mathrm{CDCl}_{3} / \mathrm{DMSO}=10 / 1\right)$ : $\delta 8.48$ (br s, 2H), 7.41 (br s, 2H), 7.21-7.10 (m, 5H), 4.38 (s, 1H), $1.65(\mathrm{~d}, J=6.6 \mathrm{~Hz}, 3 \mathrm{H}) ;{ }^{13} \mathrm{C} \operatorname{NMR}\left(150 \mathrm{MHz} \mathrm{CDCl}_{3}\right): 150.0,144.6,140.8,139.3$, 128.9, 127.4, 126.8, 122.0, 36.6, 22.9; HRMS Calculated for $\mathrm{C}_{15} \mathrm{H}_{14} \mathrm{~N}_{4}[\mathrm{M}+\mathrm{H}]^{+}$: 251.12967, Found: 251.12951.

\section{Synthesis and Characterization of Rh-trizole Complex}

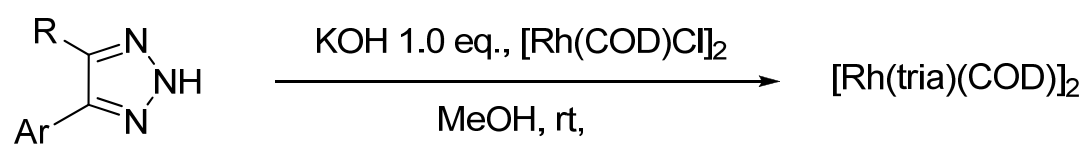

To a suspension of $[\mathrm{RhCl}(\mathrm{COD})]_{2}(100 \mathrm{mg}, 0.2 \mathrm{mmol})$ in $30 \mathrm{ml}$ methanol was added triazole $(0.4 \mathrm{mmol})$. Then under stirring the $10 \mathrm{ml} 0.04 \mathrm{M} \mathrm{KOH}(22.4 \mathrm{mg}, 0.4 \mathrm{mmol})$ solution in methanol was added dropwise at room temperature. After $8 \mathrm{~h}$ stirring at room temperature, yellow powder of Rh-triazole was produced and it was filtered off using a folded filter paper (Whatman No. 2). The yellow powder was washed with methanol and dried by vacuum pump, yield $\sim 95 \%$. (For further purification, the yellow solid was stable enough to be dissolved into dichloromethane and purified by flash column chromatography $\left(R_{f}=0.5\right.$, hexane-EtOAc, $\left.v / v=6 / 1\right)$ ).

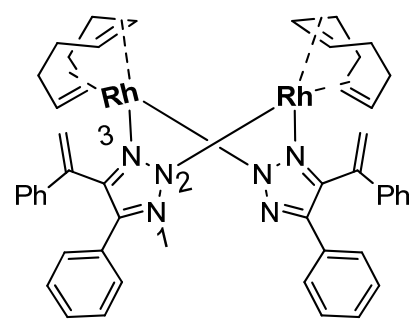

$3.1 a$ 
Yellow solid, m.p. $>263^{\circ} \mathrm{C}$ (decompose) $;{ }^{1} \mathrm{H}$ NMR $\left(600 \mathrm{MHz}, \mathrm{C}_{6} \mathrm{D}_{6}\right): \delta 7.74(\mathrm{~d}, \mathrm{~J}=12.0$, $1 \mathrm{H}, \mathrm{Ar}-\mathrm{H}), 7.26-7.14(\mathrm{~m}, 3 \mathrm{H}, \mathrm{Ar}-\mathrm{H}), 7.12-7.02(\mathrm{~m}, 3 \mathrm{H}, \mathrm{Ar}-\mathrm{H}), 7.00-6.84(\mathrm{~m}, 3 \mathrm{H}, \mathrm{Ar}-\mathrm{H})$, $5.68(\mathrm{~s}, 1 \mathrm{H}, \mathrm{CH}), 5.56(\mathrm{~s}, 1 \mathrm{H}, \mathrm{CH}), 4.28-4.12(\mathrm{~m}, 4 \mathrm{H}, \mathrm{CH}), 2.96-2.82\left(\mathrm{~m}, 1 \mathrm{H}, \mathrm{CH}_{2}\right), 2.36-$ $2.18\left(\mathrm{~m}, 2 \mathrm{H}, \mathrm{CH}_{2}\right), 2.04-1.70\left(\mathrm{~m}, 3 \mathrm{H}, \mathrm{CH}_{2}\right), 1.58-1.50\left(\mathrm{~m}, 1 \mathrm{H}, \mathrm{CH}_{2}\right), 1.32-1.22(\mathrm{~m}, 1 \mathrm{H}$, $\left.\mathrm{CH}_{2}\right) ;{ }^{13} \mathrm{C}$ NMR $\left(150 \mathrm{MHz}, \mathrm{C}_{6} \mathrm{D}_{6}\right): \delta 146.1,142.9,139.7,132.9,129.3,128.9,128.2$, 128.0, 127.7, 127.4, 126.9, 118.1, 86.1, 83.6, 79.8, 77.8, 33.5, 31.7, 29.8, 28.8. 3.1.1. Anal. Calcd for $\mathrm{C}_{52} \mathrm{H}_{60} \mathrm{~N}_{6} \mathrm{Rh}_{2}$ : C, 64.06; H, 6.20; N, 8.62. Found: C, 63.99; $\mathrm{H}, 5.79 ; \mathrm{N}$, 9.18.

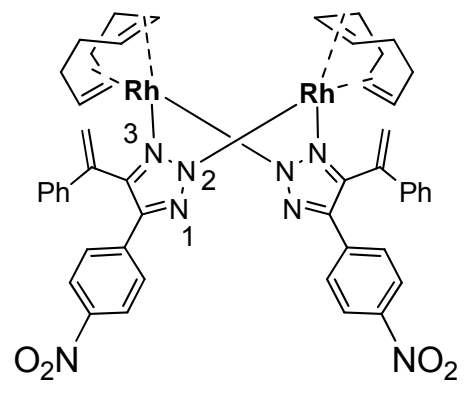

\section{1b}

Yellow solid, m.p. $>280{ }^{\circ} \mathrm{C}$ (decompose) $;{ }^{1} \mathrm{H}$ NMR $\left(600 \mathrm{MHz}, \mathrm{CDCl}_{3}\right): \delta 8.01$ (d, $J=8.4$, $2 \mathrm{H}, \mathrm{Ar}-\mathrm{H}), 7.65(\mathrm{~d}, \mathrm{~J}=8.4,2 \mathrm{H}, \mathrm{Ar}-\mathrm{H}), 7.32-7.22(\mathrm{~m}, 3 \mathrm{H}, \mathrm{Ar}-\mathrm{H}), 7.22-7.16(\mathrm{~m}, 1 \mathrm{H}, \mathrm{Ar}-\mathrm{H})$, 7.14-7.06 (m, 1H, Ar-H), $6.05(\mathrm{~s}, 1 \mathrm{H}, \mathrm{CH}), 5.70(\mathrm{~s}, 1 \mathrm{H}, \mathrm{CH}), 4.38-4.08(\mathrm{~m}, 4 \mathrm{H}, \mathrm{CH}), 3.10-$ $3.02\left(\mathrm{~m}, 1 \mathrm{H}, \mathrm{CH}_{2}\right), 2.62-2.52\left(\mathrm{~m}, 1 \mathrm{H}, \mathrm{CH}_{2}\right), 2.42-2.32\left(\mathrm{~m}, 1 \mathrm{H}, \mathrm{CH}_{2}\right), 2.30-2.22(\mathrm{~m}, 1 \mathrm{H}$, $\left.\mathrm{CH}_{2}\right), 2.08-1.98\left(\mathrm{~m}, 2 \mathrm{H}, \mathrm{CH}_{2}\right), 1.92-1.84\left(\mathrm{~m}, 1 \mathrm{H}, \mathrm{CH}_{2}\right), 1.64-1.54\left(\mathrm{~m}, 1 \mathrm{H}, \mathrm{CH}_{2}\right) ;{ }^{13} \mathrm{C} \mathrm{NMR}$ $\left(150 \mathrm{MHz}, \mathrm{CDCl}_{3}\right): \delta 146.5,144.1,143.3,139.2,138.9,138.5,129.5,129.1,128.9$, $128.8,128.4,128.1,127.9,127.6,127.0,126.6,123.5,123.5,123.3,119.2,117.8,86.3$, 86.2, 84.3, 84.2, 81.2, 81.1, 78.8, 78.7, 33.2, 31.6, 31.1, 30.5, 30.3, 29.2. Anal. Calcd for $\mathrm{C}_{52} \mathrm{H}_{58} \mathrm{~N}_{8} \mathrm{O}_{4} \mathrm{Rh}_{2}$ : C, 58.65; H, 5.49; N, 10.52. Found: C, 58.11; H, 4.96; N, 10.91. 


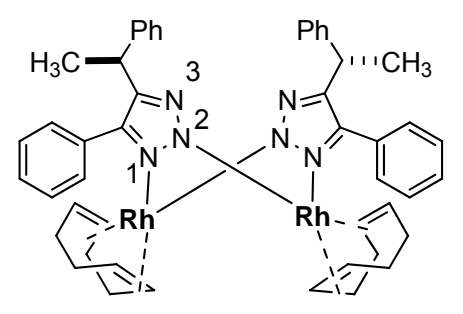

\section{$3.1 c$}

Yellow solid, m.p. > $165^{\circ} \mathrm{C}$ (decompose) ; ${ }^{1} \mathrm{H}$ NMR $\left(600 \mathrm{MHz}, \mathrm{CDCl}_{3}\right): \delta 7.80-7.56(\mathrm{~m}$, $2 \mathrm{H}, \mathrm{Ar}-\mathrm{H}), 7.52-7.34(\mathrm{~m}, 3 \mathrm{H}, \mathrm{Ar}-\mathrm{H})$, 7.32-7.22 (m, 3H, Ar-H), 7.22-7.14 (m, 1H, Ar-H), 7.12-7.06 (m, 1H, Ar-H), 4.36-3.92 (m, 4H, CH), 3.78-3.64 (m, 1H, $\left.\mathrm{CH}_{2}\right), 3.34-3.12(\mathrm{~m}$, $\left.1 \mathrm{H}, \mathrm{CH}_{2}\right), 2.98-2.60\left(\mathrm{~m}, 3 \mathrm{H}, \mathrm{CH}_{2}\right), 2.20-1.72\left(\mathrm{~m}, 3 \mathrm{H}, \mathrm{CH}_{2}\right), 1.59\left(\mathrm{~d}, \mathrm{~J}=7.2 \mathrm{~Hz}, 3 \mathrm{H}, \mathrm{CH}_{3}\right)$, 1.32-1.22(m, $\left.1 \mathrm{H}, \mathrm{CH}_{2}\right) ; ;{ }^{13} \mathrm{C}$ NMR (150 MHz, $\left.\mathrm{CDCl}_{3}\right): \delta 147.7,147.2,143.2,132.5$, $132.3,129.6,129.4,129.2,128.6,128.4,128.3,128.2,128.1,127.9,125.9,86.7,86.6$, $85.9,85.3,85.2,82.9,82.0,81.5,80.5,79.0,53.6,37.1,37.0,36.7,35.0,32.2,32.0$, $31.8,31.2,31.1,30.8,30.1,29.3,25.5,24.4,22.9,21.8,20.9,14.3$. Anal. Calcd for $\mathrm{C}_{52} \mathrm{H}_{64} \mathrm{~N}_{6} \mathrm{Rh}_{2}$ : C, 63.80; H, 6.59; N, 8.59. Found: C, 63.40; H, 6.39; N, 8.72.

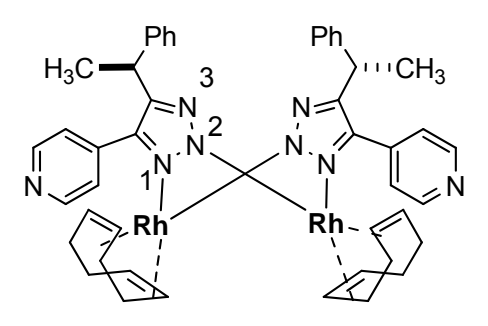

\section{1d}

Yellow solid, m.p. $>188^{\circ} \mathrm{C}$ (decompose); ${ }^{1} \mathrm{H}$ NMR $\left(600 \mathrm{MHz}, \mathrm{CDCl}_{3}\right): \delta 7.71$ (s, 2H, Ar$\mathrm{H}), 7.75(\mathrm{~s}, 2 \mathrm{H}, \mathrm{Ar}-\mathrm{H}), 7.30-7.05(\mathrm{~m}, 5 \mathrm{H}, \mathrm{Ar}-\mathrm{H}), 4.40-3.98(\mathrm{~m}, 4 \mathrm{H}, \mathrm{CH}), 3.20-3.02(\mathrm{~m}, 1 \mathrm{H}$, $\mathrm{CH}), 3.00-2.42\left(\mathrm{~m}, 3 \mathrm{H}, \mathrm{CH}_{2}\right), 2.26-1.80\left(\mathrm{~m}, 5 \mathrm{H}, \mathrm{CH}_{2}\right), 1.64-1.42\left(\mathrm{~m}, 3 \mathrm{H}, \mathrm{CH}_{3}\right) ;{ }^{13} \mathrm{C} \mathrm{NMR}$ $\left(150 \mathrm{MHz}, \mathrm{CDCl}_{3}\right): \delta$ 150.0, 149.7, 148.7, 146.9, 140.8, 139.8, 128.9, 128.3, 127.6, 
127.2, 126.3, 123.3, 86.4, 83.9, 82.4, 79.5, 37.2, 32.3, 31.4, 31.1, 30.9, 29.8, 24.2. Anal. Calcd for $\mathrm{C}_{50} \mathrm{H}_{62} \mathrm{~N}_{8} \mathrm{Rh}_{2}$ : C, 61.22; $\mathrm{H}, 6.37 ; \mathrm{N}, 11.42$. Found: C, 60.48; $\mathrm{H}, 5.99 ; \mathrm{N}, 11.30$.

\section{Rh-trizole complex catalyzed Pauson-Khand Reaction (Procedure and data)}

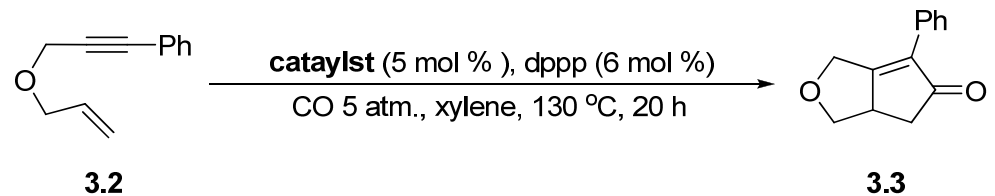

To a $20 \mathrm{ml}$ dry sealable flask was added rhodium-triazole complex 3.1 (0.025 mmol Rh), dppp (12.4 mg, $0.03 \mathrm{mmol}$ ), xylene ( $3 \mathrm{ml})$. Then mixture was then stirred for 10 minutes after which the enyne $3.2(0.5 \mathrm{mmol})$ was added. The flask was then charged with $5 \mathrm{~atm}$ of $\mathrm{CO}$ and heated to $130^{\circ} \mathrm{C}$ for $20 \mathrm{~h}$, after which the flask was cooled and the $\mathrm{CO}$ was cautiously released in the hood. The crude product was purified using flash column chromatography (Hexane- EtOAc, v/v 3:1) to afford 3.3 as colorless oil. ${ }^{1} \mathrm{H}$ NMR (600 $\left.\mathrm{MHz}, \mathrm{CDCl}_{3}\right): \delta 7.52(\mathrm{~d}, J=7.2 \mathrm{~Hz}, 2 \mathrm{H}), 7.41-7.38(\mathrm{~m}, 2 \mathrm{H}), 7.35-7.32(\mathrm{~m}, 1 \mathrm{H}), 4.92(\mathrm{~d}, J$ $=16.2 \mathrm{~Hz}, 1 \mathrm{H}), 4.57(\mathrm{~d}, J=16.2 \mathrm{~Hz}, 1 \mathrm{H}), 4.36(\mathrm{t}, J=8.4 \mathrm{~Hz}, 1 \mathrm{H}), 3.31-3.30(\mathrm{~m}, 1 \mathrm{H}), 3.22$ $(\mathrm{dd}, J=10.8 \mathrm{~Hz}, J=7.8 \mathrm{~Hz} 1 \mathrm{H}), 2.83(\mathrm{dd}, J=18.0 \mathrm{~Hz}, J=6.6 \mathrm{~Hz} 1 \mathrm{H}), 2.32(\mathrm{dd}, J=$ 18.0Hz, $J=3.6 \mathrm{~Hz} 1 \mathrm{H}) ;{ }^{13} \mathrm{C} \mathrm{NMR}\left(150 \mathrm{MHz}, \mathrm{CDCl}_{3}\right): \delta 206.7,177.3,134.6,130.5,128.6$, $128.5,127.9,71.3,66.2,43.2,40.2$ 


\section{Catalytic reactivity of the triazole bound $\mathrm{Rh}(\mathrm{I})$ complexes.}

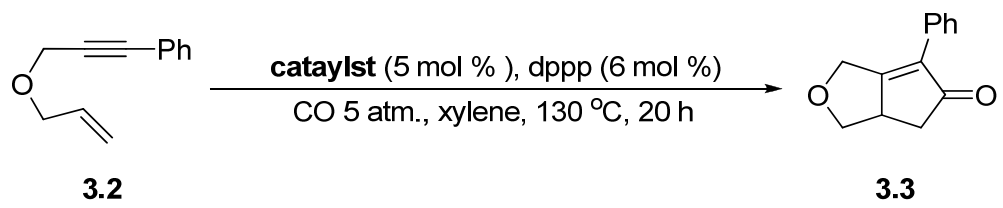

\begin{tabular}{cccc}
\hline catalyst & loading $(\%)$ & time $(\mathrm{h})$ & yield (\%) \\
\hline$\left[\mathrm{Rh}(\mathrm{COD}) \mathrm{Cl}_{2}\right.$ & 5 & 20 & 82 \\
$3.1 \mathrm{a}$ & 5 & 20 & 80 \\
3.1b & 5 & 20 & 88 \\
3.1c & 5 & 20 & 82 \\
$3.1 \mathrm{~d}$ & 5 & 20 & 60 \\
{$\left[\mathrm{Rh}(\mathrm{COD}) \mathrm{Cl}_{2}\right.$} & 1 & 36 & 42 \\
$3.1 \mathrm{a}$ & 1 & 36 & 55 \\
\hline
\end{tabular}




\section{ORTEP Drawing of the Crystal Structures of triazole-Rh(I) complexes. ${ }^{4}$}

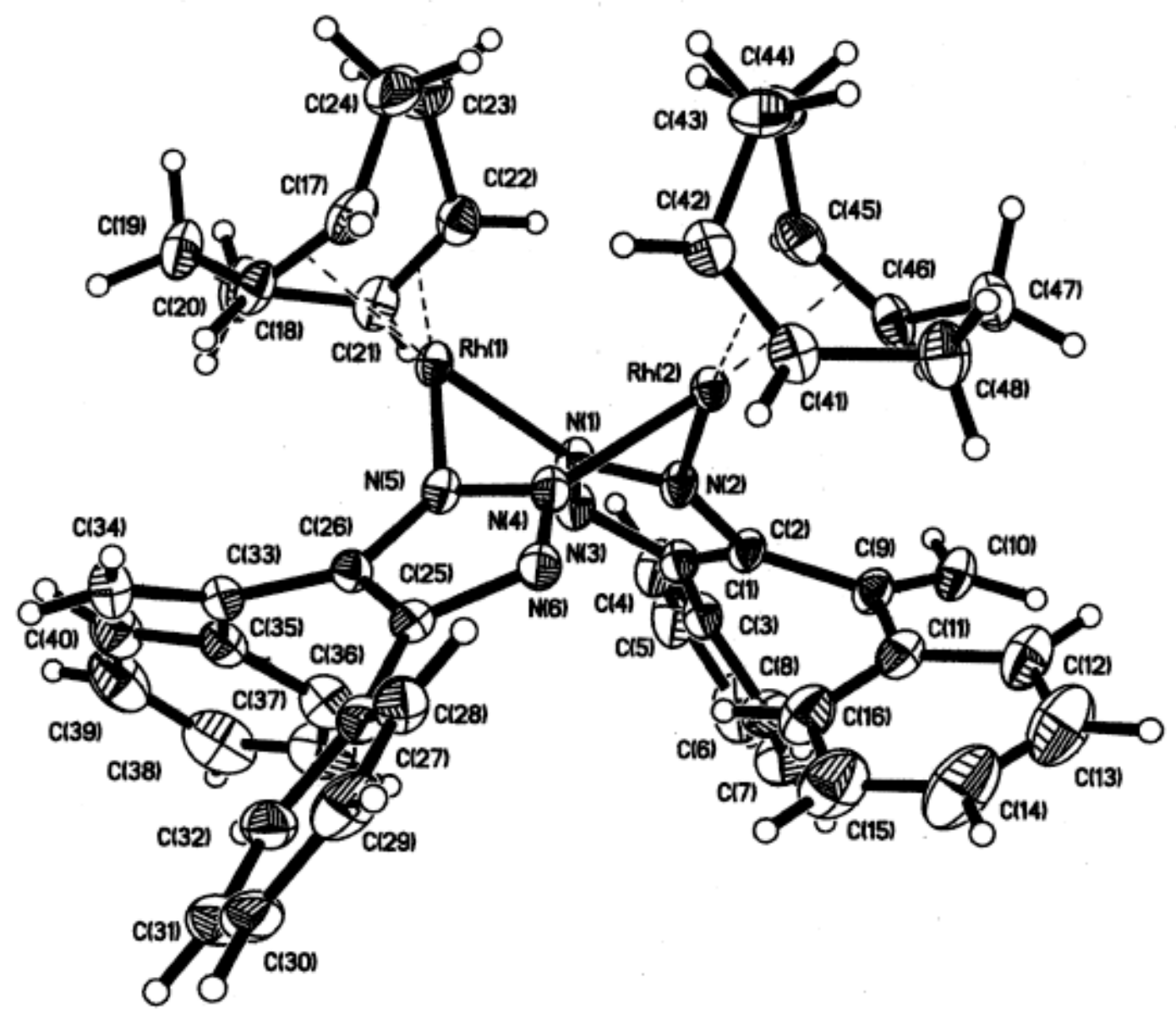

Figure S4: Perspective view of the molecular structure of complex $\mathrm{C}_{52} \mathrm{H}_{60} \mathrm{~N}_{6} \mathrm{Rh}_{2}$ 3.1a with the atom labeling scheme. The thermal ellipsoids are scaled to enclose $20 \%$ probability. CCDC deposition number 662421.

\footnotetext{
${ }^{4}$ For details regarding the crystal structure, refer to supporting information for paper: Duan, $\mathrm{H}$.; Sengupta, S.; Petersen, J. L.; Shi, X. Organometallics 2009, 28, 2352.
} 


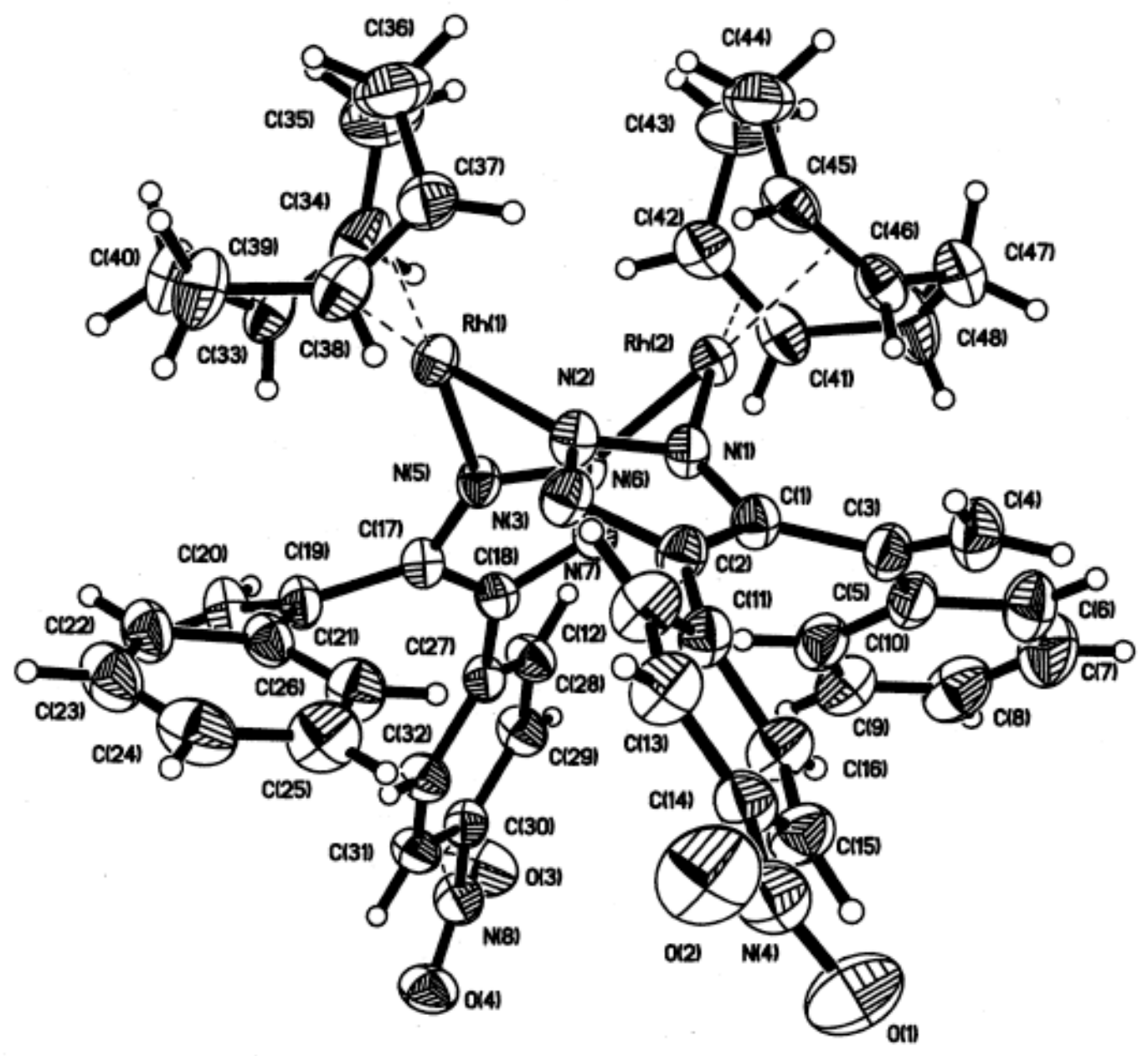

Figure S5: Perspective view of the molecular structure of complex $\mathrm{C}_{52} \mathrm{H}_{58} \mathrm{~N}_{8} \mathrm{O}_{4} \mathrm{Rh}_{2} 3.1$ with the atom labeling scheme. The thermal ellipsoids are scaled to enclose $30 \%$ probability. CCDC deposition number 662422. 


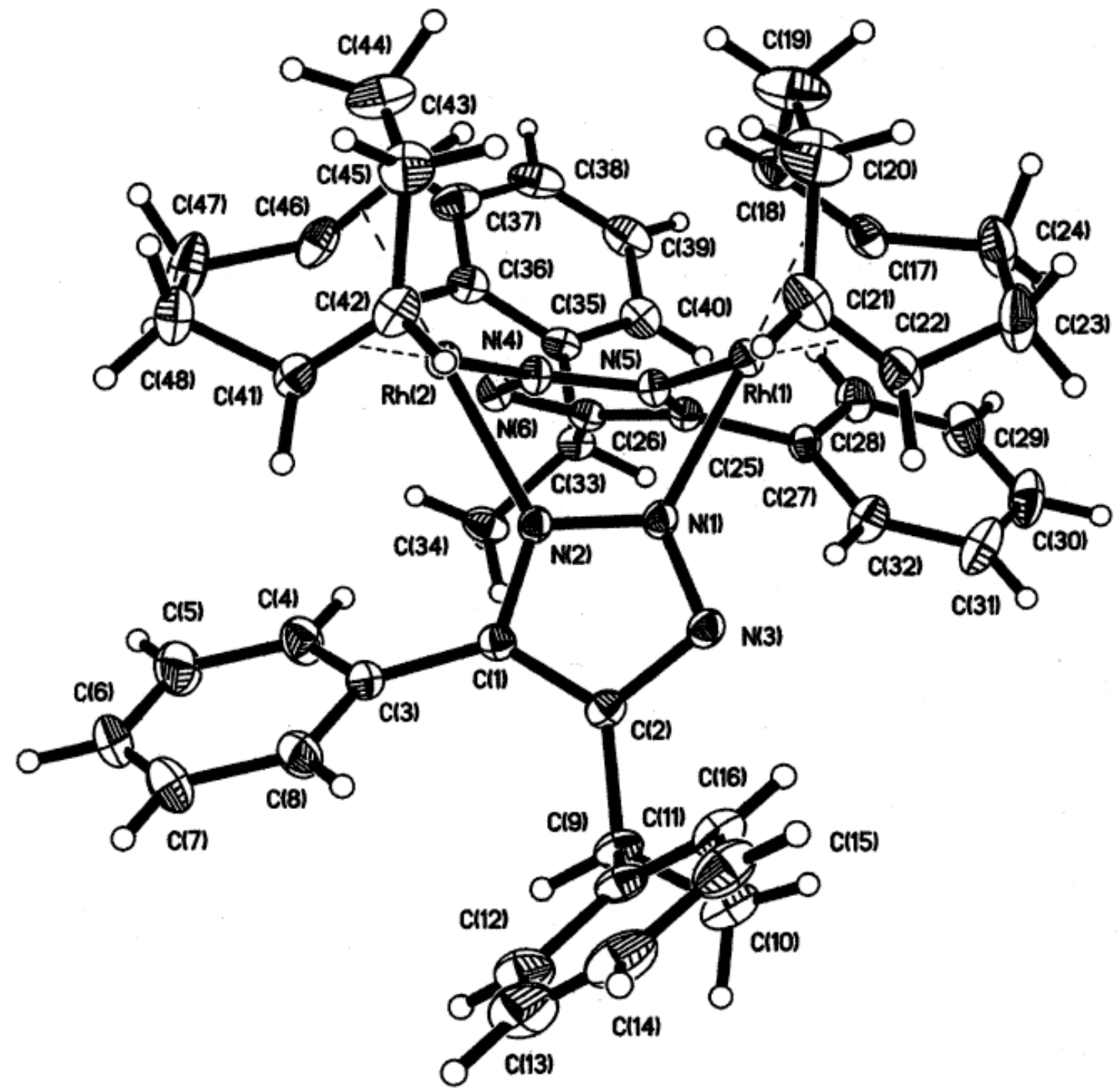

Figure S6: Perspective view of the molecular structure of complex $\mathrm{C}_{52} \mathrm{H}_{64} \mathrm{~N}_{6} \mathrm{Rh}_{2}$ 3.1c with the atom labeling scheme. The thermal ellipsoids are scaled to enclose $30 \%$ probability. CCDC deposition number 662423. 


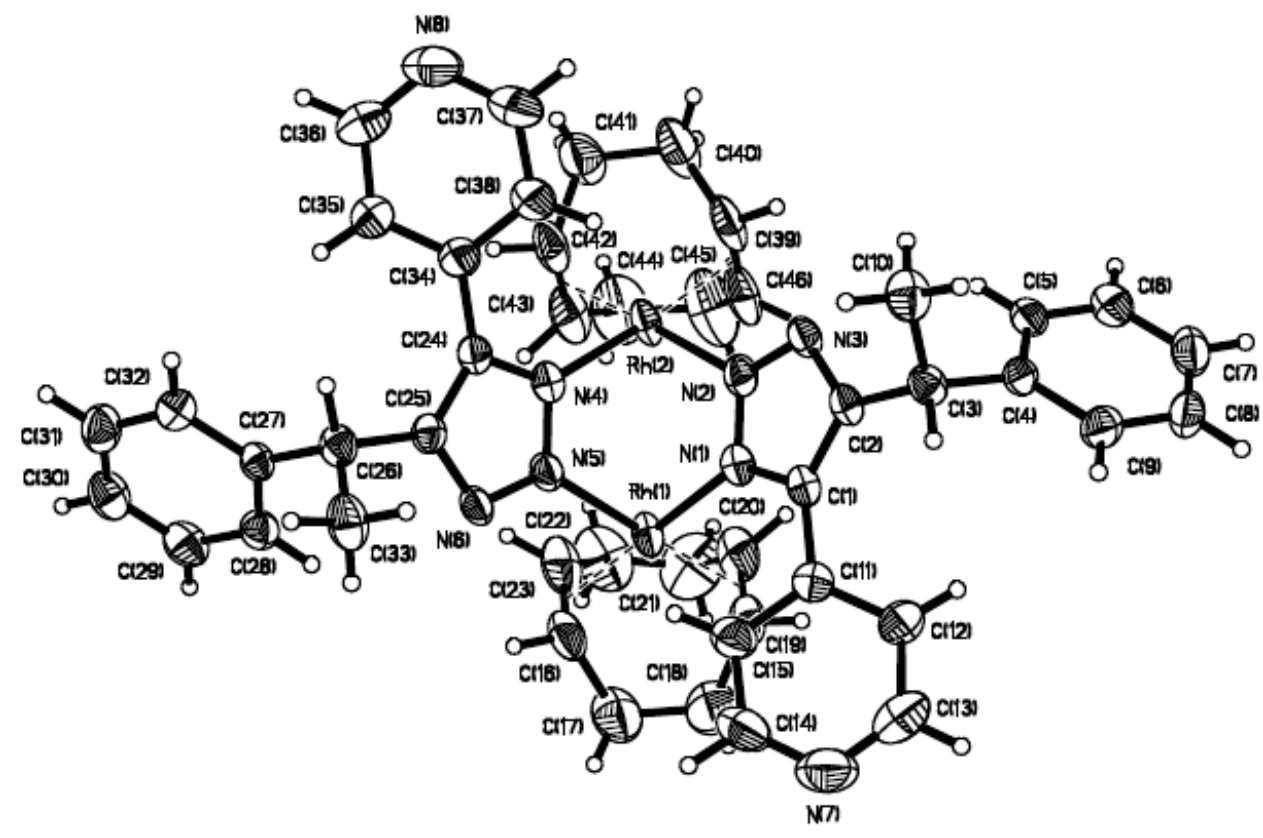

Figure S7: Perspective view of the molecular structure of complex $\mathrm{C}_{50} \mathrm{H}_{62} \mathrm{~N}_{8} \mathrm{Rh}_{2}$ 3.1d with the atom labeling scheme. The thermal ellipsoids are scaled to enclose $30 \%$ probability. CCDC deposition number 662424. 


\section{Chapter 4: Triazole-Au(I) Complexes: A new class of catalysts with improved thermo-stability and reactivity towards intermolecular alkyne hydroamination}

\section{General Methods and materials:}

Unless otherwise noted, all commercial reagents and solvents were obtained from the commercial provider and used without further purification. Anhydrous toluene was distilled from sodium benzophenone ketyl. ${ }^{1} \mathrm{H}-\mathrm{NMR}$ and ${ }^{13} \mathrm{C}-\mathrm{NMR}$ spectra were recorded on Joel 270 and Varian $600 \mathrm{MHz}$ spectrometers. Chemical shifts were reported relative to internal tetramethysilane $(\delta 0.00 \mathrm{ppm})$ or $\mathrm{CDCl}_{3}(\delta 7.26 \mathrm{ppm})$ for ${ }^{1} \mathrm{H}$ and $\mathrm{CDCl}_{3}(\delta 77.0$ ppm) for ${ }^{13}$ C. ${ }^{31} \mathrm{P}-\mathrm{NMR}$ was recorded on Varian $600 \mathrm{MHz}$ spectrometer operating at 242.88 $\mathrm{MHz}$ for ${ }^{31} \mathrm{P}$. Chemical shifts were reported in ppm down field from internal $\mathrm{Me}_{4} \mathrm{Si}$ and external $85 \% \mathrm{H}_{3} \mathrm{PO}_{4}$, respectively. Flash column chromatography was performed on 230-430 mesh silica gel. Melting points were measured on a Mel-Temp 1001D apparatus and uncorrected. HRMS were recorded on LTQ-FTUHRA spectrometer.

$\mathrm{PPh}_{3} \mathrm{AuCl}, \mathrm{PPh}_{3} \mathrm{AuNTf}_{2}$ and IPrAuNTf ${ }_{2}$ were prepared according to the following reported procedure:

1. Al-Sa'Ady, A. K.; McAuliffe, C. A.; Parish, R. V.; Sandeank, J. A. Inorg. Synth, 1985, 191.

2. Li, Y.; Tang, P.; Chen, Y.; Yu. B. J. Org. Chem. 2008, 73, 4323. 


\section{Procedure for synthesis of Triazole-Gold complex 4.4a, 4.4b}

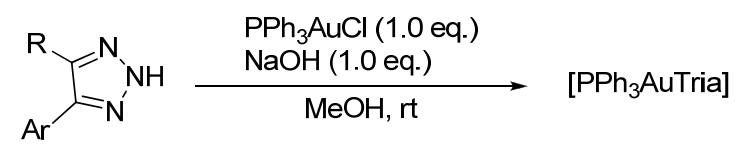

To a suspension of $\mathrm{PPh}_{3} \mathrm{AuCl}(990 \mathrm{mg}, 2.0 \mathrm{mmol})$ in $40 \mathrm{ml}$ methanol was added triazole (2.1 mmol), after which $10 \mathrm{ml}$ of $0.21 \mathrm{M} \mathrm{NaOH}(84 \mathrm{mg}, 2.1 \mathrm{mmol})$ solution in methanol was added dropwise at room temperature. After stirring at room temperature for $8 \mathrm{~h}$., the cloudy solution was filtered through a short pad of celite. The clear solution was concentrated and diluted again using $\mathrm{CHCl}_{3}$. The resultant cloudy solution was again filtered through a short pad of celite. Most of the $\mathrm{CHCl}_{3}$ was then removed till about $5 \mathrm{ml}$ remains and then added dropwise to a flask containing $50 \mathrm{ml}$ hexane. The resultant white solid was collected and washed with hexane and dried by vacuum pump, the triazole-gold complexes were synthesized in quantitative yields.

To get the crystal structures, the triazole-gold complex was dissolved in minimum amount of $\mathrm{CH}_{2} \mathrm{Cl}_{2}$ to which was added hexane very slowly on the top of the $\mathrm{CH}_{2} \mathrm{Cl}_{2}$ layer. After 2 days colorless flaky crystals were obtained.

\section{Procedure for synthesis of Triazole-Gold complex 4.6a, 4.6b, 4.6c}

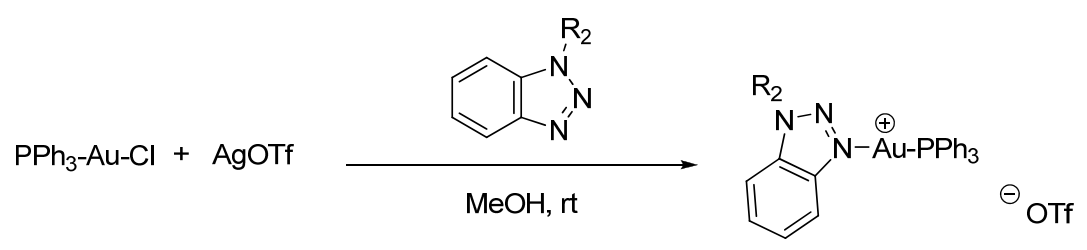


To a suspension of $\mathrm{PPh}_{3} \mathrm{AuCl}(990 \mathrm{mg}, 2.0 \mathrm{mmol})$ in $40 \mathrm{ml}$ methanol was added AgOTf (539 mg, $2.1 \mathrm{mmol})$. After stirring for 5 minutes, triazole $(2.0 \mathrm{mmol})$ in $10 \mathrm{ml}$ methanol was added. After stirring at room temperature for $4 \mathrm{~h}$, the cloudy solution was filtered through a short pad of celite. The filtrate was concentrated to $3 \mathrm{ml}$, and then Hexane was added very slowly on the top of the $\mathrm{CH}_{2} \mathrm{Cl}_{2}$ layer. The colorless crystals were obtained after 2 days in near quantitative yields.

\section{General Procedure for Au(I)-catalyzed hydroamination:}

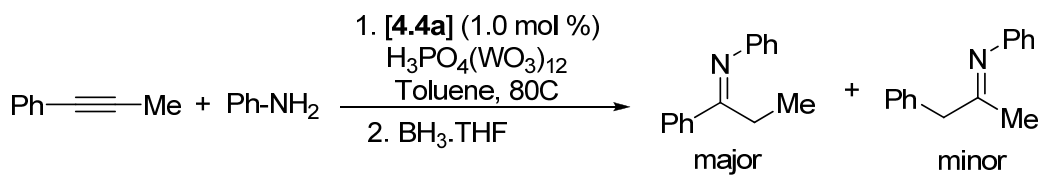

To a $10 \mathrm{ml}$ dry sealable flask was added triazole-Au complex $4.4 \mathrm{a}(6.5 \mathrm{mg}, 0.011 \mathrm{mmol})$, $\mathrm{H}_{3} \mathrm{PO}_{4}\left(\mathrm{WO}_{3}\right)_{12}(63 \mathrm{mg}, 0.022 \mathrm{mmol})$ in toluene $(3.5 \mathrm{ml})$ and stirred for 5 minutes. To the flask was then added 1-phenyl-1-propyne 4.7a (128 mg, $1.1 \mathrm{mmol}$ ), aniline 4.8a (153 $\mathrm{mg}, 1.65 \mathrm{mmol}$ ) and then heated to $80^{\circ} \mathrm{C}$ and monitored by TLC. When all the starting material was consumed, the flask was cooled to $-20{ }^{\circ} \mathrm{C}$. To the flask was added $\mathrm{BH}_{3}$.THF (1M solution in THF, $2.2 \mathrm{mmol})$ and o-phthalic $(2.2 \mathrm{mmol})$. After $2 \mathrm{~h}$ from $-20^{\circ} \mathrm{C}$ to $\mathrm{rt}$, the reaction was quenched by adding $\mathrm{H}_{2} \mathrm{O}$. Extracted by EtOAc, the organic phase was washed with brine and dried by $\mathrm{NaSO}_{4}$, then concentrated. The crude product was then purified by column chromatography (Hexane: $\mathrm{EtOAc}=8: 1)$ to give $4.9 \mathrm{a}$ and $4.9 \mathrm{~b}(91 \%$ yield, d.r: 6:1). 


\section{General Procedure for synthesis of substituted pyrroles:}

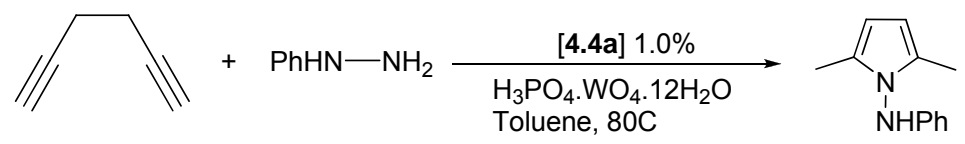

To a $10 \mathrm{ml}$ dry sealable flask was added triazole-Au complex $4.4 \mathrm{a}(6.5 \mathrm{mg}, 0.011 \mathrm{mmol})$, $\mathrm{H}_{3} \mathrm{PO}_{4}\left(\mathrm{WO}_{3}\right)_{12}(63 \mathrm{mg}, 0.022 \mathrm{mmol})$ in toluene $(3.5 \mathrm{ml})$ and stirred for 5 minutes. To the flask was then added 1,5-diyne 4.10 (70 mg, $1.1 \mathrm{mmol})$, phenylhydrazine (153 $\mathrm{mg}, 1.65$ mmol) and then heated to $80{ }^{\circ} \mathrm{C}$ and stirred for $16 \mathrm{~h}$. The reaction mixture was cooled and then filtered through a short silica plug and concentrated. The crude product was then purified by column chromatography (Hexane: EtOAc $=8: 1)$ to give $4.11 \mathrm{c}(97 \%$ yield). 
II ${ }^{31} \mathrm{P}$ NMR chemical shifts of Different $\mathrm{Au}(\mathrm{I})$ Complexes:
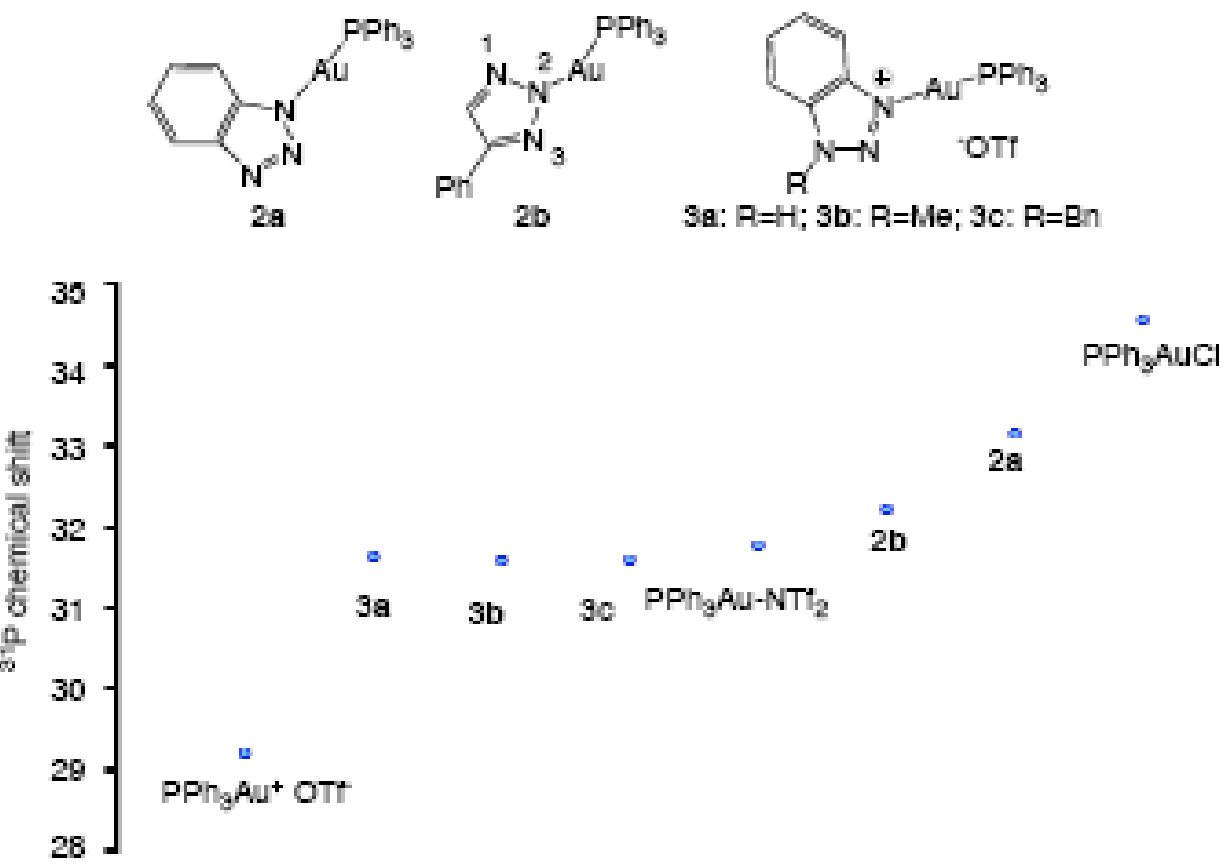

Figure S7: ${ }^{31} \mathrm{P}$ NMR chemical shifts of different $A u(I)$ complexes at $60{ }^{\circ} \mathrm{C}$. 

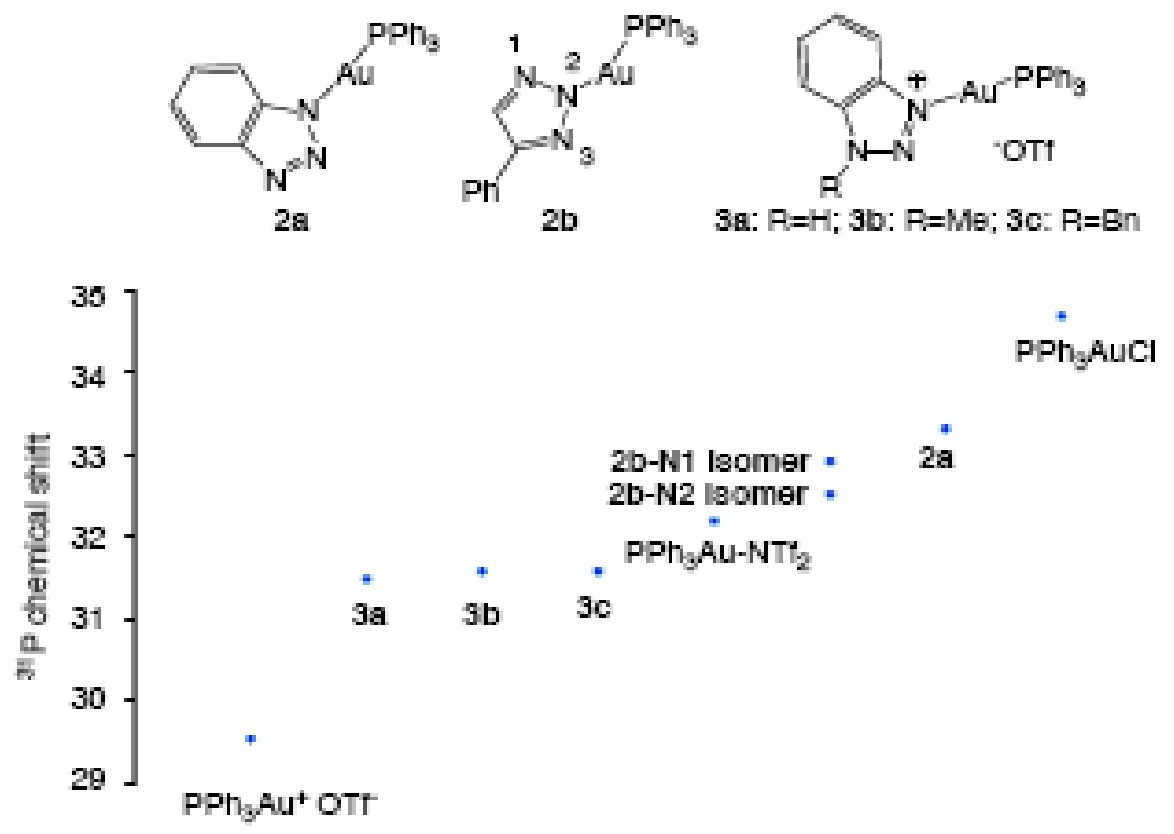

Figure S8: ${ }^{31} \mathrm{P}$ NMR chemical shifts of different $\mathrm{Au}(\mathrm{I})$ complexes at $-55^{\circ} \mathrm{C}$.

\section{Details of ${ }^{31} \mathrm{P}-\mathrm{NMR}$ study of complex $4.4 \mathrm{~b}$ and $4.6 \mathrm{~d}$ :}

Low-temperature ${ }^{31} \mathrm{P}$ NMR spectra of $4.4 \mathrm{~b}$ were recorded in the temperature range of $-68{ }^{\circ} \mathrm{C}$ to $+58{ }^{\circ} \mathrm{C}$ in this study. The spectral simulations for exchange of phosphorous sites were performed using a gNMR program. Rate constants were derived from the spectra by a single line-shape analysis. In order to build a simulated spectrum the resonance frequency for each peak $\left(v_{i}\right)$ and the exchange rate $(k)$ were used.

The ${ }^{31} \mathrm{P}$ NMR spectrum at $+28{ }^{\circ} \mathrm{C}$ in $\mathrm{CDCl}_{3}$ solution consists of two broad peaks centered at $32.15 \mathrm{ppm}$ for the $\mathrm{AuPPh}_{3}$ groups respectively (Fig S-2). The phosphorous peak of minor isomer gradually appears downfield from the major resonance. At low temperatures from 0 to $-60{ }^{\circ} \mathrm{C}$ the phosphorous resonance broaden and splits into two peaks of unequal intensity centered at ppm and separated by $200 \mathrm{~Hz}$ at $-50{ }^{\circ} \mathrm{C}$. At this 
temperature, the ratio of areas is $\sim 1: 2$, with the upfield isomer predominating. The coalescence temperature was observed at $+58{ }^{\circ} \mathrm{C}$. The determined exchange rate constants for 4.4b gave a nonlinear (or nearly linear) Arrhenius and Eyring plots (Fig S1) in the temperature range from $-60{ }^{\circ} \mathrm{C}$ to $+58{ }^{\circ} \mathrm{C}$, affording $\mathrm{E}_{\mathrm{a}}=5.94 \pm 0.38 \mathrm{kcal} \mathrm{mol}^{-1}$, $\Delta \mathrm{H}^{\ddagger}=5.40 \pm 0.37 \mathrm{kcal} \mathrm{mol}^{-1}$, and $\Delta \mathrm{S}^{\ddagger}=-30.91 \pm 1.39 \mathrm{cal} \mathrm{mol}^{-1} \mathrm{~K}^{-1}$. The high entropy for this exchange process where the Au binds with either the $N(1)$ or $N(2)$ of the triazole to position 2 provides as a conclusive evidence for an intramolecular process for interconversion of the ${ }^{+} \mathrm{AuPPh}_{3}$ group. The rate constants at each temperature (a first- order process is assumed), was determined using complete line shape analysis, corresponds to a free energy of activation of $5.94 \mathrm{kcal} \mathrm{mol}^{-1}$ for conversion of the major isomer to the minor isomer.

The Arrhenius activation energy Ea for the interconversion I = II was obtained by the method of least squares, by fitting the rate constants (Ink) at a series of temperatures to the Arrhenius equation, $\ln k=\ln A-E a / R T ;$ Eyring's equation: $k=$ $\left(\mathrm{k}_{\mathrm{B}} T / \mathrm{h}\right) \exp \left(\Delta \mathrm{S}^{\ddagger} / \mathrm{R}\right) \exp \left(-\Delta \mathrm{H}^{\ddagger} / \mathrm{RT}\right)$ was used to determine the activation parameters $\Delta \mathrm{S}^{\ddagger}$, $\Delta H^{\ddagger}$ and $\Delta G^{\ddagger}$ through a plot of $\ln (k / T)$ versus $1 / T$. In the above equation, $k_{B}$ is the Boltzman constant, $\mathrm{h}$ is Planck's constant, $\mathrm{R}$ is the gas constant and $\mathrm{T}$ is the absolute temperature. 
Figure S9: Single Line-shape ${ }^{31} \mathrm{P}-\mathrm{NMR}$ for complex $4.4 \mathrm{~b}$ (based on VT NMR from -68 ${ }^{\circ} \mathrm{C}$ to $\left.58^{\circ} \mathrm{C}\right)$ :

Arrhenius plot of $4.4 \mathrm{~b}$ :

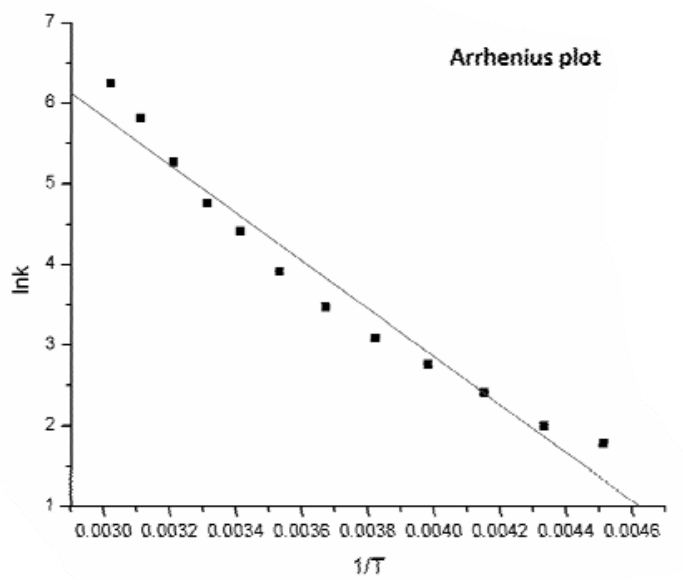

Eyring plot of $4.4 \mathrm{~b}$ :

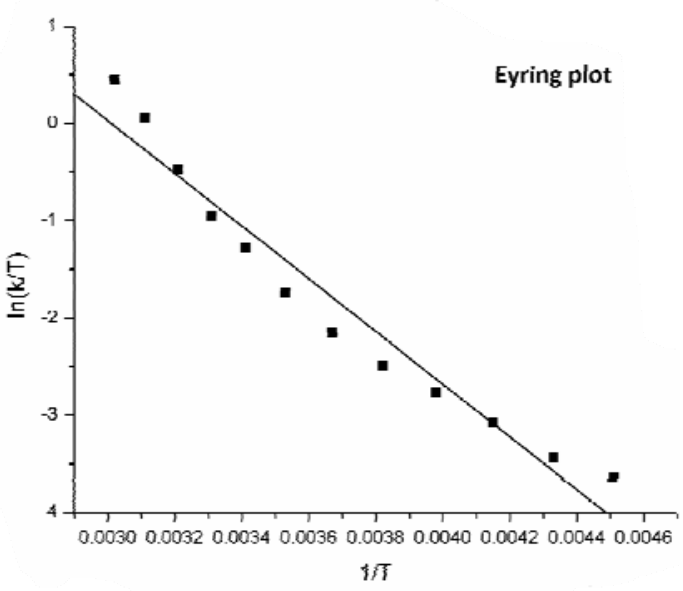


Figure 200: Single Line-shape ${ }^{31} \mathrm{P}-\mathrm{NMR}$ for complex 4.4b (based on VT NMR from -68 ${ }^{\circ} \mathrm{C}$ to $58{ }^{\circ} \mathrm{C}$ )

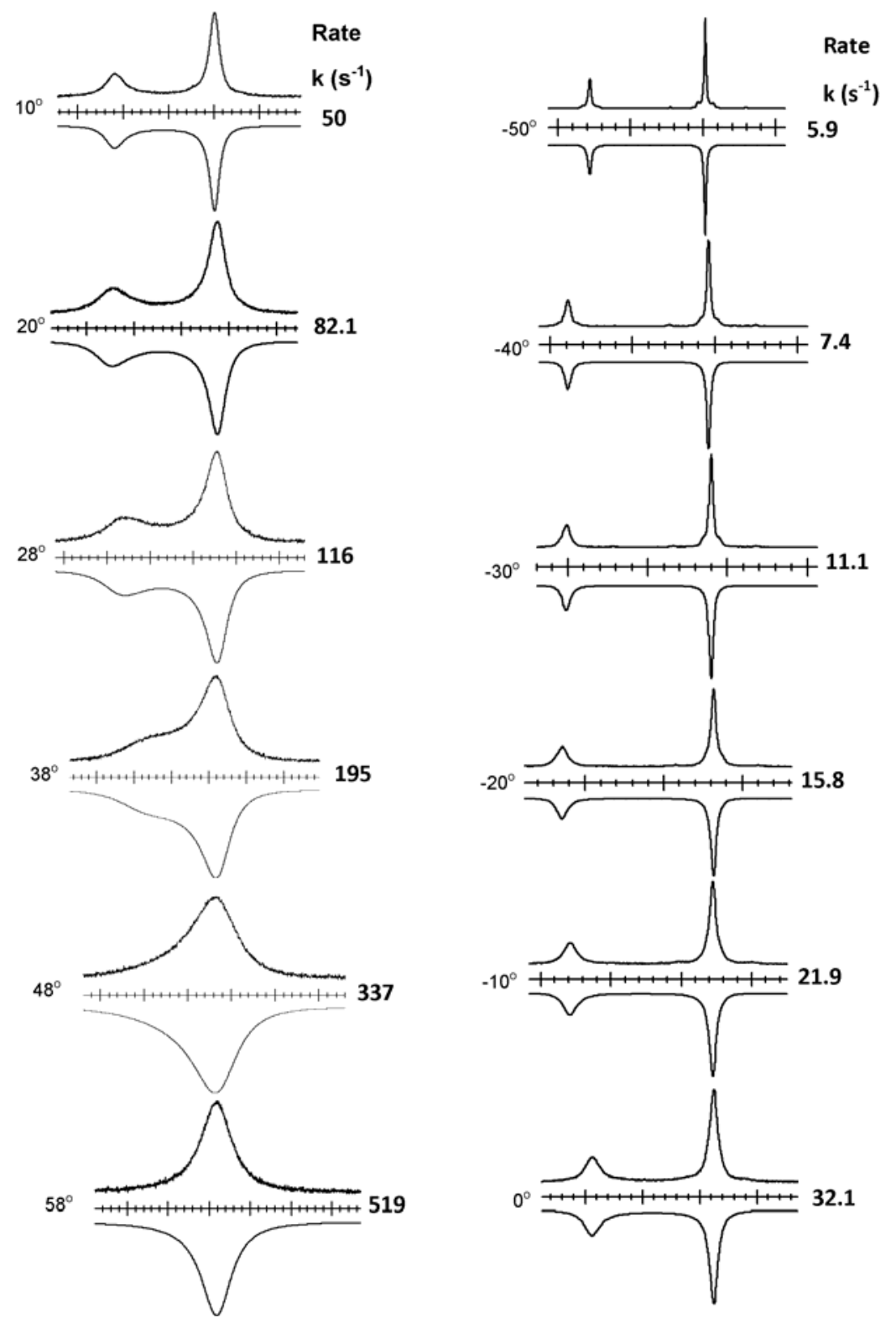


Figure 11: Temperature Dependent ${ }^{31} \mathrm{P}$-NMR spectra's for complex $4.6 \mathrm{~d}$ based on VT NMR from $-60{ }^{\circ} \mathrm{C}$ to $58^{\circ} \mathrm{C}$.
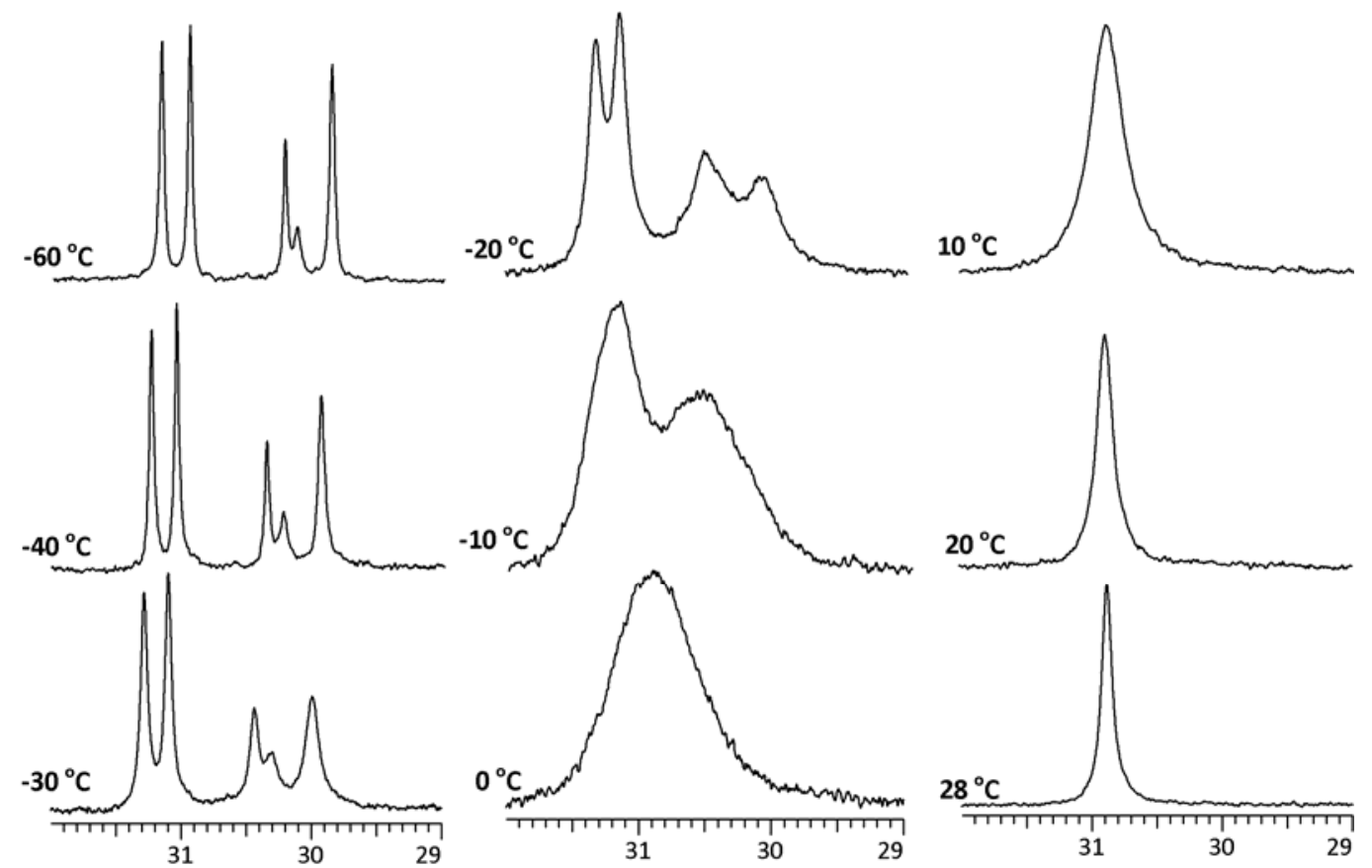


\section{Comparison of different catalysts:}

For all the studies below, the following general reaction condition was followed: Alkyne (1.0 equiv), amine (1.2 equiv) and catalysts were mixed in dry toluene ( $c=0.3 \mathrm{M}$ of alkyne). The reactions were monitored by TLC.

1.

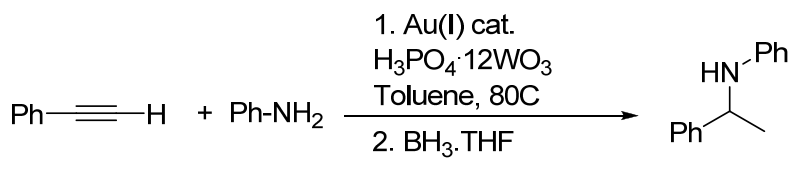

\begin{tabular}{lllll}
\hline entry & cat & \% loading & co-cat & yield (\%) \\
\hline 1 & $4.4 a$ & 0.1 & $\mathrm{H}_{3} \mathrm{PO}_{4} \cdot 12 \mathrm{WO}_{3} 0.2 \%$ & 94 \\
2 & $\mathbf{4 . 1 e}$ & 0.1 & - & 84 \\
3 & $\mathbf{4 . 1 e}$ & 0.1 & $\mathrm{H}_{3} \mathrm{PO}_{4} \cdot 12 \mathrm{WO}_{3} 0.2 \%$ & 80 \\
4 & $4.1 d$ & 0.1 & $\mathrm{H}_{3} \mathrm{PO}_{4} \cdot 12 \mathrm{WO}_{3} 0.2 \%$ & 81
\end{tabular}

${ }^{*}$ All yields are NMR yields with 1,3,5-trimethoxybenzene as the internal standard

2.<smiles>CC(Nc1ccc(F)cc1)c1ccccc1</smiles>

\begin{tabular}{lllll}
\hline entry & cat & \% loading & co-cat & yield (\%) \\
\hline 1 & $\mathbf{4 . 4 a}$ & 0.1 & $\mathrm{H}_{3} \mathrm{PO}_{4} \cdot 12 \mathrm{WO}_{3} 0.2 \%$ & 97 \\
2 & $\mathbf{4 . 1 e}$ & 0.1 & - & 81 \\
3 & $\mathbf{4 . 1 e}$ & 0.1 & $\mathrm{H}_{3} \mathrm{PO}_{4} \cdot 12 \mathrm{WO}_{3} 0.2 \%$ & 80 \\
4 & $\mathbf{4 . 1 d}$ & 0.1 & $\mathrm{H}_{3} \mathrm{PO}_{4} \cdot 12 \mathrm{WO}_{3} 0.2 \%$ & 82
\end{tabular}

*All yields are NMR yields with 1,3,5-trimethoxybenzene as the internal standard

3.

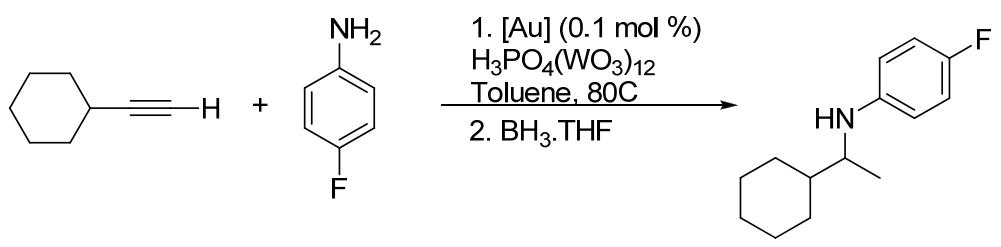

\begin{tabular}{lllll}
\hline entry & cat & \% loading & co-cat & yield $(\%)$ \\
\hline 1 & $\mathbf{4 . 4 a}$ & 0.1 & $\mathrm{H}_{3} \mathrm{PO}_{4} \cdot 12 \mathrm{WO}_{3} 0.2 \%$ & 93 \\
\hline
\end{tabular}




\begin{tabular}{lllll}
\hline 2 & $4.1 e$ & 0.1 & - & 60 \\
3 & $4.1 e$ & 0.1 & $\mathrm{H}_{3} \mathrm{PO}_{4} \cdot 12 \mathrm{WO}_{3} 0.2 \%$ & 58 \\
4 & $4.1 d$ & 0.1 & $\mathrm{H}_{3} \mathrm{PO}_{4} \cdot 12 \mathrm{WO}_{3} 0.2 \%$ & 58
\end{tabular}

${ }^{*}$ All yields are NMR yields with 1,3,5-trimethoxybenzene as the internal standard

4.

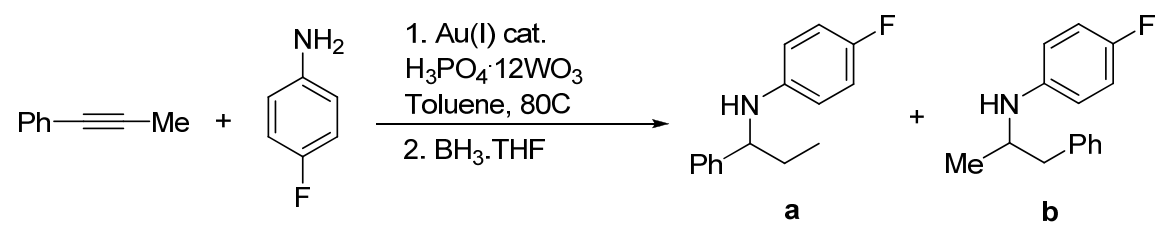

\begin{tabular}{lllllll}
\hline entry & cat & $\begin{array}{l}(\%) \\
\text { loading }\end{array}$ & co-cat & time & d.r & $\begin{array}{c}\text { yield } \\
(\%)^{*}\end{array}$ \\
\hline 1 & $\mathbf{4 . 4 a}$ & 1.0 & $\mathrm{H}_{3} \mathrm{PO}_{4} \cdot 12 \mathrm{WO}_{3} 2.0 \%$ & $8 \mathrm{~h}$ & $6: 1$ & 93 \\
2 & $\mathbf{4 . 1 e}$ & 1.0 & - & $10 \mathrm{~h}$ & $4: 1$ & 28 \\
3 & $\mathbf{4 . 1 e}$ & 1.0 & $\mathrm{H}_{3} \mathrm{PO}_{4} \cdot 12 \mathrm{WO}_{3} 2.0 \%$ & $10 \mathrm{~h}$ & $4: 1$ & 25 \\
4 & $4.1 \mathrm{~d}$ & 1.0 & $\mathrm{H}_{3} \mathrm{PO}_{4} \cdot 12 \mathrm{WO}_{3} 2.0 \%$ & $10 \mathrm{~h}$ & $4: 1$ & 32 \\
& All yields are NMR yields with 1,3,5-trimethoxybenzene as the internal standard
\end{tabular}

5.

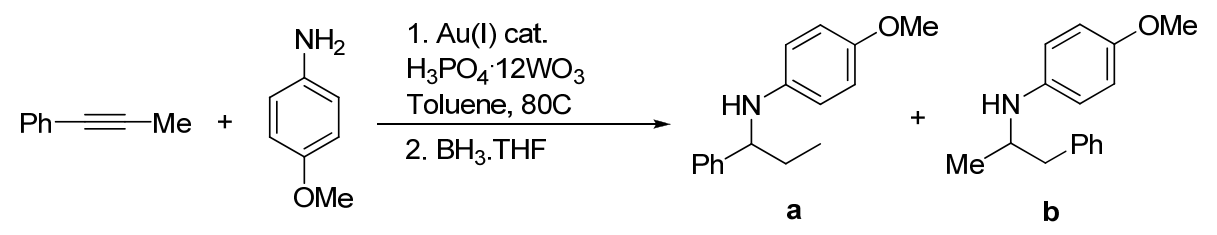

\begin{tabular}{lllllll}
\hline entry & cat & $\begin{array}{l}(\%) \\
\text { loading }\end{array}$ & co-cat & time & d.r & $\begin{array}{l}\text { yield } \\
(\%)^{\mathrm{a}}\end{array}$ \\
\hline 1 & $\mathbf{4 . 4 a}$ & 1.0 & $\mathrm{H}_{3} \mathrm{PO}_{4} \cdot 12 \mathrm{WO}_{3} 2.0 \%$ & $8 \mathrm{~h}$ & $6: 1$ & 87 \\
2 & $\mathbf{4 . 1 e}$ & 1.0 & - & $12 \mathrm{~h}^{\mathrm{b}}$ & $4: 1$ & 10 \\
3 & $\mathbf{4 . 1 e}$ & 1.0 & $\mathrm{H}_{3} \mathrm{PO}_{4} \cdot 12 \mathrm{WO}_{3} 2.0 \%$ & $12 \mathrm{~h}^{\mathrm{b}}$ & $4: 1$ & $<5$ \\
4 & $\mathbf{4 . 1 d}$ & 1.0 & $\mathrm{H}_{3} \mathrm{PO}_{4} \cdot 12 \mathrm{WO}_{3} 2.0 \%$ & $13 \mathrm{~h}^{\mathrm{b}}$ & $4: 1$ & 15
\end{tabular}

${ }^{a}$ All yields are NMR yields with 1,3,5-trimethoxybenzene as the internal standard; ${ }^{b}$ after which gold mirror was formed

6. 


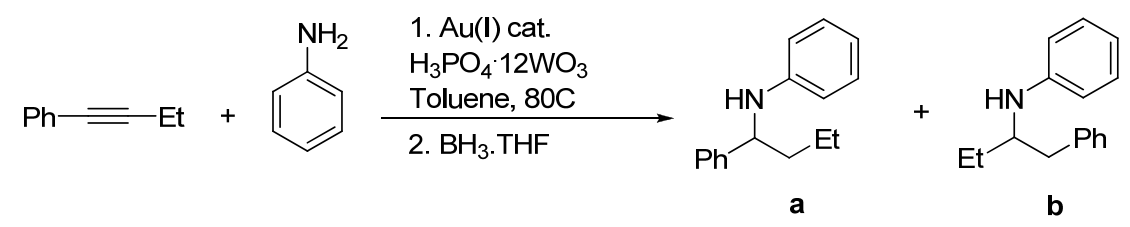

\begin{tabular}{lllllll}
\hline entry & cat & $\begin{array}{l}(\%) \\
\text { loading }\end{array}$ & co-cat & time & d.r & $\begin{array}{l}\text { yield } \\
(\%)^{a}\end{array}$ \\
\hline 1 & $\mathbf{4 . 4 a}$ & 1.0 & $\mathrm{H}_{3} \mathrm{PO}_{4} \cdot 12 \mathrm{WO}_{3} 2.0 \%$ & $8 \mathrm{~h}$ & $6: 1$ & 91 \\
2 & $\mathbf{4 . 1 e}$ & 1.0 & - & $12 \mathrm{~h}^{\mathrm{b}}$ & $3: 1$ & 18 \\
3 & $\mathbf{4 . 1 e}$ & 1.0 & $\mathrm{H}_{3} \mathrm{PO}_{4} \cdot 12 \mathrm{WO}_{3} 2.0 \%$ & $12 \mathrm{~h}^{\mathrm{b}}$ & $3: 1$ & 12 \\
4 & $\mathbf{4 . 1 d}$ & 1.0 & $\mathrm{H}_{3} \mathrm{PO}_{4} \cdot 12 \mathrm{WO}_{3} 2.0 \%$ & $13 \mathrm{~h}$ & $3: 1$ & 20
\end{tabular}

${ }^{a}$ All yields are NMR yields with 1,3,5-trimethoxybenzene as the internal standard; ${ }^{b}$ after which gold mirror was formed

7.

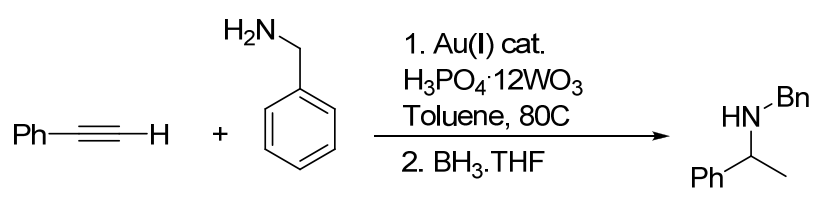

\begin{tabular}{llllll}
\hline entry & cat & \% loading & co-cat & time & yield $(\%)^{\mathrm{a}}$ \\
\hline 1 & $\mathbf{4 . 4 a}$ & 10 & $\mathrm{H}_{3} \mathrm{PO}_{4} \cdot 12 \mathrm{WO}_{3} 10 \%$ & $8 \mathrm{~h}$ & 44 \\
2 & $\mathbf{4 . 1 e c}$ & 10 & - & $15 \mathrm{~h}^{\mathrm{b}}$ & 15 \\
3 & $\mathbf{4 . 1 e}$ & 10 & $\mathrm{H}_{3} \mathrm{PO}_{4} \cdot 12 \mathrm{WO}_{3} 10 \%$ & $12 \mathrm{~h}^{\mathrm{b}}$ & 12 \\
4 & $\mathbf{4 . 1 d}$ & 10 & $\mathrm{H}_{3} \mathrm{PO}_{4} \cdot 12 \mathrm{WO}_{3} 10 \%$ & $15 \mathrm{~h}^{\mathrm{b}}$ & 10
\end{tabular}

${ }^{a}$ All yields are NMR yields with 1,3,5-trimethoxybenzene as the internal standard; ${ }^{b}$ after which gold mirror was formed

8.

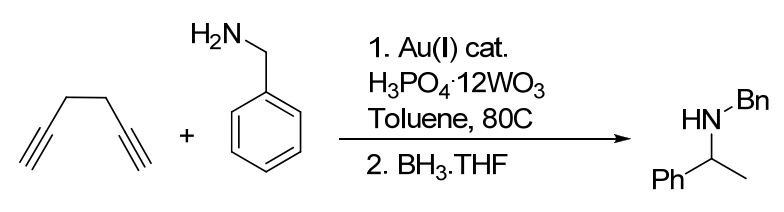

\begin{tabular}{llllll}
\hline entry & cat & \% loading & co-cat & time $^{\mathrm{a}}$ & yield (\%) $)^{\mathrm{a}}$ \\
\hline 1 & $4.4 \mathrm{a}$ & 5 & $\mathrm{H}_{3} \mathrm{PO}_{4} \cdot 12 \mathrm{WO}_{3} 7 \%$ & $16 \mathrm{~h}$ & 89 \\
2 & $4.1 \mathrm{e}$ & 5 & - & $12 \mathrm{~h}^{\mathrm{b}}$ & 68 \\
3 & $4.1 \mathrm{e}$ & 5 & $\mathrm{H}_{3} \mathrm{PO}_{4} \cdot 12 \mathrm{WO}_{3} 7 \%$ & $13 \mathrm{~h}^{\mathrm{b}}$ & 60 \\
4 & $4.1 \mathrm{~d}$ & 5 & $\mathrm{H}_{3} \mathrm{PO}_{4} \cdot 12 \mathrm{WO}_{3} 7 \%$ & $13 \mathrm{~h}^{\mathrm{b}}$ & 62
\end{tabular}

${ }^{a}$ All yields are NMR yields with 1,3,5-trimethoxybenzene as the internal standard; ${ }^{b}$ after which gold mirror was formed 


\section{Compound Characterization:}<smiles>OCC(c1ccccc1)c1nn(Cc2ccccc2)nc1-c1ccccc1</smiles>

\section{6b}

2-(2-benzyl-5-phenyl-2H-1,2,3-triazol-4-yl)-2-phenylethanol (4.6b): 4.6b was purified by flash chromatography (Hexane-EtOAc, v/v 5/1) as white solid with overall isolated yield: 88\%. ${ }^{1} \mathrm{H}-\mathrm{NMR}\left(600 \mathrm{MHz}, \mathrm{CDCl}_{3}\right) \delta$ 7.43-7.45 (m, 2H), 7.20-7.37 (m, 13H), 5.65 (s, , 2H), 4.39-4.42 (m, 2H), 4.04-4.18 (m, 1H), 4.05 (d, J = 6.6 Hz 2H); ${ }^{13} \mathrm{C}-\mathrm{NMR}(150 \mathrm{MHZ}$, $\left.\mathrm{CDCl}_{3}\right) \delta 146.4,145.1,139.8,135.2,130.4,128.8,128.7,128.5,128.4,128.3,128.1$, 127.8, 127.7, 127.0, 67.1, 58.7, 45.4; HRMS Calculated for $\mathrm{C}_{23} \mathrm{H}_{22} \mathrm{~N}_{3} \mathrm{O}[\mathrm{M}+\mathrm{H}]^{+}$: 356.4323, Found356.4311.<smiles>[O+]CC(c1ccccc1)c1nn(Cc2ccccc2)nc1-c1ccccc1</smiles>

\section{2-(2-benzyl-5-phenyl-2H-1,2,3-triazol-4-yl)-2-phenylethyl 4-methylbenzenesulfonate}

(4.6c): 4.6c was purified by flash chromatography (Hexane-EtOAc, v/v 5/1) as sticky yellow oil with near quantitative yield ${ }^{1} \mathrm{H}-\mathrm{NMR}\left(600 \mathrm{MHz}, \mathrm{CDCl}_{3}\right) \delta 7.34-7.55(\mathrm{~m}, 2 \mathrm{H})$, 7.24-7.38 (m, 6H), 7.14-7.23 (m, 10H), $5.57(\mathrm{~d}, J=7.2$, 2H), 4.62-4.65 (m, 1H), 4.434.48 (m, 2H), 2.38 (s, 3H); ${ }^{13} \mathrm{C}-\mathrm{NMR}\left(150 \mathrm{MHZ}, \mathrm{CDCl}_{3}\right) \delta 146.1,144.4,142.2,138.1$, $135.5,133.0,130.2,129.6,128.8,128.7,128.5,128.4,128.3,128.2,127.8,127.7,127.6$, 127.5, 72.6, 58.6, 42.1, 21.6; HRMS Calculated for $\mathrm{C}_{30} \mathrm{H}_{28} \mathrm{~N}_{3} \mathrm{O}_{3} \mathrm{~S}[\mathrm{M}+\mathrm{H}]^{+}:$510.6107, Found 510.6126. 
<smiles>O=P(CC(c1ccccc1)c1nn(Cc2ccccc2)nc1-c1ccccc1)(c1ccccc1)c1ccccc1</smiles>

\section{2-benzyl-4-(2-(diphenylphosphoryl)-1-phenylethyl)-5-phenyl-2H-1,2,3-triazole}

(4.6d): 4.6d was purified by flash chromatography (Hexane-EtOAc, v/v 6/1) as sticky pale brown oil with $56 \%$ yield; ${ }^{1} \mathrm{H}-\mathrm{NMR}\left(270 \mathrm{MHz}, \mathrm{CDCl}_{3}\right) \delta 7.24-7.65(\mathrm{~m}, 25 \mathrm{H}), 5.34$ (q, $J=6.8,2 \mathrm{H}), 4.94-4.96(\mathrm{~m}, 1 \mathrm{H}), 3.43-3.52(\mathrm{~m}, 1 \mathrm{H}), 2.94-2.99(\mathrm{~m}, 1 \mathrm{H}) ;{ }^{13} \mathrm{C}-\mathrm{NMR}(150$ $\left.\mathrm{MHZ}, \mathrm{CDCl}_{3}\right) \delta 146.1,144.4,142.2,138.1,135.5,133.0,130.2,129.6,128.8,128.7$ $128.5,128.4,128.3,128.2,127.8,127.7,127.6,127.5,72.6,58.6,42.1$, 21.6; HRMS Calculated for $\mathrm{C}_{35} \mathrm{H}_{31} \mathrm{~N}_{3} \mathrm{OP}[\mathrm{M}+\mathrm{H}]^{+}:$540.21993, Found 540.21921.<smiles>CCC(Nc1ccccc1)c1ccccc1</smiles>

N-(1-phenylpropyl)aniline (4.9a): 4.9a was purified by flash chromatography (HexaneEtOAc, v/v 5/1) as yellow oil with overall isolated yield: $78 \% .{ }^{1} \mathrm{H}-\mathrm{NMR}\left(600 \mathrm{MHz}, \mathrm{CDCl}_{3}\right)$ ठ 7.30-7.34 (m, 4H), 7.20-7.22 (m, 1H), 7.06-7.08 (m, 2H), $6.61(\mathrm{t}, J=7.8 \mathrm{~Hz}, 1 \mathrm{H}), 6.50$ $(\mathrm{d}, J=8.0 \mathrm{~Hz}, 2 \mathrm{H}), 4.22(\mathrm{t}, J=6.6 \mathrm{~Hz}, 1 \mathrm{H}), 4.04(\mathrm{bs}, \mathrm{NH}), 1.78-1.86(\mathrm{~m}, 2 \mathrm{H}), 0.95(\mathrm{t}, J=$ 7.8 Hz, 3H); ${ }^{13} \mathrm{C}-\mathrm{NMR}\left(150 \mathrm{MHZ}, \mathrm{CDCl}_{3}\right) \delta 147.7,144.1,129.2,128.7,127.0,126.7$, 117.3, 113.5, 59.9, 31.9, 11.0; HRMS Calculated for $\mathrm{C}_{15} \mathrm{H}_{18} \mathrm{~N}[\mathrm{M}+\mathrm{H}]^{+}:$212.14338, Found: 212.14418.<smiles>CC(Cc1ccccc1)Nc1ccccc1</smiles>

$\mathrm{N}$-(1-phenylpropan-2-yl)aniline (4.9b): 4.9b was purified by flash chromatography (Hexane-EtOAc, v/v 5/1) as oil with overall isolated yield: $13 \% .{ }^{1} \mathrm{H}-\mathrm{NMR}(600 \mathrm{MHz}$, 
$\left.\mathrm{CDCl}_{3}\right) \delta 7.30(\mathrm{t}, J=7.2 \mathrm{~Hz}, 2 \mathrm{H}), 7.18-7.23(\mathrm{~m}, 5 \mathrm{H}), 6.70(\mathrm{t}, J=7.2 \mathrm{~Hz}, 1 \mathrm{H}), 6.64(\mathrm{~d}, J=$ $8.0 \mathrm{~Hz}, 2 \mathrm{H}), 3.76-3.80$ (s, 1H), $3.58(\mathrm{bs}, \mathrm{NH}), 2.95(\mathrm{dd}, J=4.8 \mathrm{~Hz}, 13.2 \mathrm{~Hz}, 1 \mathrm{H}), 2.71$ (dd, $J=7.2 \mathrm{~Hz}, 13.2 \mathrm{~Hz}, 1 \mathrm{H}), 1.16(\mathrm{~d}, J=6.6 \mathrm{~Hz}, 3 \mathrm{H}) ;{ }^{13} \mathrm{C}-\mathrm{NMR}\left(67.5 \mathrm{M} \mathrm{Hz}, \mathrm{CDCl}_{3}\right) \delta$ 147.4, 138.9, 129.7, 129.6, 128.5, 126.5, 117.5, 113.6, 49.6, 42.6, 20.4; HRMS Calculated for $\mathrm{C}_{15} \mathrm{H}_{18} \mathrm{~N}[\mathrm{M}+\mathrm{H}]^{+}:$212.14338, Found: 212.14418.<smiles>CC([NH+]c1ccccc1)c1ccccc1</smiles>

N-(1-phenylethyl)aniline (4.9c): 4.9c was purified by flash chromatography (HexaneEtOAc, v/v 5/1) as colorless oil with overall isolated yield: $94 \%$. ${ }^{1} \mathrm{H}-\mathrm{NMR}(600 \mathrm{MHz}$, $\left.\mathrm{CDCl}_{3}\right)$ $\delta$ 7.40-7.42 (m, 2H), 7.34-7.37 (m, 2H), 7.25-7.28 (m, 1H), 7.12-7.15(m, 2H), $6.69(\mathrm{t}, J=14.4 \mathrm{~Hz}, 1 \mathrm{H}), 6.56(\mathrm{~d}, J=5.4 \mathrm{~Hz}, 2 \mathrm{H}), 4.53(\mathrm{q}, J=13.2,1 \mathrm{H}), 3.98(\mathrm{bs}, \mathrm{NH})$, 3.90 (s, 3H), 1.55 (d, $J=6.6 \mathrm{~Hz}, 3 \mathrm{H}) ;{ }^{13} \mathrm{C}-\mathrm{NMR}\left(150 \mathrm{MHz}, \mathrm{CDCl}_{3}\right) \delta$ 147.2, 145.2, 129.1, 128.6, 126.8, 125.8, 117.2, 113.3, 53.2, 24.9; HRMS Calculated for $\mathrm{C}_{14} \mathrm{H}_{16} \mathrm{~N}[\mathrm{M}+\mathrm{H}]^{+}$: 198.12773, Found: 198.12844.<smiles>Cc1ccc(NC(C)c2ccccc2)cc1</smiles>

4-methyl-N-(1-phenylethyl)aniline (4.9d): 6d was purified by flash chromatography (Hexane-EtOAc, v/v 5/1) as yellow oil with overall isolated yield: 92\%. ${ }^{1} \mathrm{H}-\mathrm{NMR}(600$ $\left.\mathrm{MHz}, \mathrm{CDCl}_{3}\right)$ ס 7.34-7.35 (m, 1H), 7.28-7.33 (m, 2H), 7.16-7.27 (m, 2H), $6.87(\mathrm{~d}, J=10.8$ Hz, 2H), $6.42(\mathrm{~d}, J=10.8 \mathrm{~Hz}, 1 \mathrm{H}), 4.42(\mathrm{~m}, 1 \mathrm{H}), 3.98(\mathrm{bs}, \mathrm{NH}), 2.17$ (s, 3H), 1.47 (d, J = 6.6 Hz, 3H); ${ }^{13} \mathrm{C}-\mathrm{NMR}\left(150 \mathrm{MHz}, \mathrm{CDCl}_{3}\right) \delta 145.4,144.9,129.5,128.5,126.7,126.3$, 125.8, 113.4, 53.6, 24.9, 20.8; HRMS Calculated for $\mathrm{C}_{15} \mathrm{H}_{18} \mathrm{~N}[\mathrm{M}+\mathrm{H}]^{+}:$212.14338, Found: 212.14414. 
<smiles>COc1ccc(NC(C)c2ccccc2)cc1</smiles>

4-methoxy-N-(1-phenylethyl)aniline (4.9e): 4.9e was purified by flash chromatography (Hexane-EtOAc, v/v 5/1) as yellow oil with overall isolated yield: 93\%. ${ }^{1} \mathrm{H}-\mathrm{NMR}(600$ $\left.\mathrm{MHz}_{\mathrm{CDCl}}\right)$ ठ 7.34-7.36 (d, J = 8.4 Hz, 2H), $7.31(\mathrm{t}, J=18 \mathrm{~Hz}, 1 \mathrm{H}), 7.20-7.21(\mathrm{~m}, 2 \mathrm{H})$, 6.67(d, J = 6.6 Hz, 2H), 6.46(d, $J=8.4 \mathrm{~Hz}, 2 \mathrm{H}), 4.39$ (q, $J=13.2,1 \mathrm{H}), 3.67(\mathrm{~s}, 3 \mathrm{H}), 1.48$ $(\mathrm{d}, J=6.6 \mathrm{~Hz}, 3 \mathrm{H}) ;{ }^{13} \mathrm{C}-\mathrm{NMR}\left(150 \mathrm{MHz}, \mathrm{CDCl}_{3}\right) \delta 151.9,144.4,141.5,128.6,126.8$, $125.9,114.7,114.5,55.7,54.2,25.0$; HRMS Calculated for $\mathrm{C}_{15} \mathrm{H}_{18} \mathrm{NO}[\mathrm{M}+\mathrm{H}]^{+}$: 228.13829, Found: 228.13813.<smiles>CC(Nc1ccccc1Cl)c1ccccc1</smiles>

2-chloro-N-(1-phenylethyl)aniline (4.9f): $4.9 f$ was purified by flash chromatography (Hexane-EtOAc, v/v 5/1) as yellow oil with overall isolated yield: 94\%. ${ }^{1} \mathrm{H}-\mathrm{NMR}(600$ $\left.\mathrm{MHz}, \mathrm{CDCl}_{3}\right) \delta$ 7.34-7.38 (m, 2H), 7.25-7.34 (m, 2H), $6.98(\mathrm{t}, J=18 \mathrm{~Hz}, 1 \mathrm{H}), 6.60$ (t, $J=$ $18 \mathrm{~Hz}, 1 \mathrm{H}), 6.45(\mathrm{~d}, J=7.8 \mathrm{~Hz}, 1 \mathrm{H}), 4.56(\mathrm{q}, J=6.6 \mathrm{~Hz}, 1 \mathrm{H}), 1.60(\mathrm{~d}, J=6.6 \mathrm{~Hz}, 3 \mathrm{H})$; ${ }^{13} \mathrm{C}-\mathrm{NMR}\left(150 \mathrm{MHz}, \mathrm{CDCl}_{3}\right) \delta 144.4,142.9,128.9,128.7,127.6,126.9,125 . .7,118.9$, 117.2, 112.5, 53.3, 25.1; HRMS Calculated for $\mathrm{C}_{14} \mathrm{H}_{15} \mathrm{CIN}[\mathrm{M}+\mathrm{H}]^{+}:$232.08875, Found: 232.08963.<smiles>CC(Nc1ccc(F)cc1)c1ccccc1</smiles> 
4-fluoro-N-(1-phenylethyl)aniline (4.9g): $4.9 \mathrm{~g}$ was purified by flash chromatography (Hexane-EtOAc, v/v 5/1) as yellow oil with overall isolated yield: 97\%. ${ }^{1} \mathrm{H}-\mathrm{NMR}(600$ $\left.\mathrm{MHz}, \mathrm{CDCl}_{3}\right)$ ठ 7.28-7.33 (m, 4H), 7.19-7.22 (m, 1H), 6.74-6.79 (m, 2H), 6.39-6.42(m, $2 \mathrm{H}), 4.39(\mathrm{q}, J=13.2,1 \mathrm{H}), 1.47(\mathrm{~d}, J=6.6 \mathrm{~Hz}, 3 \mathrm{H}) ;{ }^{13} \mathrm{C}-\mathrm{NMR}\left(150 \mathrm{MHz}, \mathrm{CDCl}_{3}\right) \delta 156.4$, $154.8,144.9,143.6,143.5,128.6,126.9,125.8,115.5,115.4,114.1,114.0,54.0,25.0$; HRMS Calculated for $\mathrm{C}_{14} \mathrm{H}_{15} \mathrm{FN}[\mathrm{M}+\mathrm{H}]^{+}:$216.11830, Found: 216.11913.<smiles>CC(NNc1ccccc1)c1ccccc1</smiles>

1-(1-phenylethyl)-2-o-tolylhydrazine (4.9h): $4.9 \mathrm{~h}$ was purified by flash chromatography (Hexane-EtOAc, v/v 5/1) as yellow oil with overall isolated yield: 98\%. ${ }^{1} \mathrm{H}-\mathrm{NMR}(600$ $\left.\mathrm{MHz}, \mathrm{CDCl}_{3}\right) \delta$ 7.70-7.72 (m, 2H), $7.50(\mathrm{~d}, J=7.8,2 \mathrm{H})$, 7.39-7.46 (m, 5H), 7.29-7.38(m, 1H), $4.91(q, J=13.8,1 \mathrm{H}), 1.71(\mathrm{~d}, J=7.2 \mathrm{~Hz}, 3 \mathrm{H}) ;{ }^{13} \mathrm{C}-\mathrm{NMR}\left(150 \mathrm{MHz}, \mathrm{CDCl}_{3}\right) \delta 152.3$, $141.8,130.7,129.5,129.2,128.8,128.5,127.4,125.5,122.6,113.5,21.0 ;$ HRMS Calculated for $\mathrm{C}_{14} \mathrm{H}_{16} \mathrm{~N}_{2}[\mathrm{M}+\mathrm{H}]^{+}:$213.13863, Found: 213.13863 .<smiles>Cc1cc(C)c(NC(C)c2ccccc2)c(C)c1</smiles>

2,4,6-trimethyl-N-(1-phenylethyl)aniline (4.9i): 4.9i was purified by flash chromatography (Hexane-EtOAc, v/v 5/1) as yellow oil with overall isolated yield: $96 \%$. ${ }^{1} \mathrm{H}-\mathrm{NMR}\left(600 \mathrm{MHz}, \mathrm{CDCl}_{3}\right)$ ठ 7.30-7.34 (m, 4H), 7.23-7.26 (m, 1H), $6.80(\mathrm{~s}, 2 \mathrm{H}), 4.26(\mathrm{q}$, $J=6.6 \mathrm{~Hz}, 1 \mathrm{H}), 2.22(\mathrm{~s}, 3 \mathrm{H}), 2.15(\mathrm{~s}, 3 \mathrm{H}), 1.51(\mathrm{~d}, J=6.6 \mathrm{~Hz}, 3 \mathrm{H}) ;{ }^{13} \mathrm{C}-\mathrm{NMR}(150 \mathrm{MHz}$, $\left.\mathrm{CDCl}_{3}\right) \delta 145.3,142.2,130.9,129.7,129.4,128.4,128.3,126.9,126.2,57.1,22.5,20.6$, 18.7; HRMS Calculated for $\mathrm{C}_{17} \mathrm{H}_{21} \mathrm{~N}[\mathrm{M}+\mathrm{H}]^{+}:$240.17469, Found: 240.17558. 
<smiles>CC(Nc1ccccc1)C1CCCCC1</smiles>

$\mathrm{N}$-(1-cyclohexylethyl)aniline (4.9j): $4.9 \mathrm{j}$ was purified by flash chromatography (Hexane-EtOAc, v/v 5/1) as colorless oil with overall isolated yield: $87 \%$. ${ }^{1} \mathrm{H}-\mathrm{NMR}(600$ $\left.\mathrm{MHz}, \mathrm{CDCl}_{3}\right) \delta 7.11-7.14(\mathrm{~m}, 2 \mathrm{H}), 6.26(\mathrm{t}, J=7.2 \mathrm{~Hz}, 1 \mathrm{H}), 6.55(\mathrm{~d}, J=7.2 \mathrm{~Hz}, 2 \mathrm{H}), 3.49$ (bs, NH), $3.30(q, J=6.0 \mathrm{~Hz}, 1 \mathrm{H}), 1.64-1.82(\mathrm{~m}, 5 \mathrm{H}), 1.44-1.45(\mathrm{~m}, 1 \mathrm{H}), 1.11-1.26(\mathrm{~m}$, 3H), $1.09(\mathrm{~d}, \mathrm{~J}=6.6 \mathrm{~Hz}, 3 \mathrm{H}), 1.01-1.07(\mathrm{~m}, 2 \mathrm{H}) ;{ }^{13} \mathrm{C}-\mathrm{NMR}\left(150 \mathrm{MHz}, \mathrm{CDCl}_{3}\right) \delta 148.2$, 129.5, 116.8, 113.3, 53.3, 43.2, 30.5, 28.7, 26.9, 26.8, 26.6, 17.7; HRMS Calculated for $\mathrm{C}_{14} \mathrm{H}_{22} \mathrm{~N}[\mathrm{M}+\mathrm{H}]^{+}:$204.17468, Found: 204.17538.<smiles>CC(Nc1ccc(F)cc1)C1CCCCC1</smiles>

$N$-(1-cyclohexylethyl)-4-fluorobenzenamine (4.9k): 4.9k was purified by flash chromatography (Hexane-EtOAc, v/v 5/1) as colorless oil with overall isolated yield: 90\%. ${ }^{1} \mathrm{H}-\mathrm{NMR}\left(600 \mathrm{MHz}, \mathrm{CDCl}_{3}\right)$ ठ 6.70-6.87 (m, 2H), 6.45-6.50 (m, 2H), 3.31 (bs, NH), $3.21(\mathrm{~m}, 1 \mathrm{H}), 1.66-1.85(\mathrm{~m}, 4 \mathrm{H}), 1.39-1.42(\mathrm{~m}, 1 \mathrm{H}), 1.14-1.7(\mathrm{~m}, 3 \mathrm{H}), 1.06(\mathrm{~d}, J=6.6 \mathrm{~Hz}$, 3H), 1.01-1.09 (m, 2H); ${ }^{13} \mathrm{C}-\mathrm{NMR}\left(150 \mathrm{MHz}, \mathrm{CDCl}_{3}\right) \delta 156,154.8,144.5,115.9,115.8$, 114.2, 114.1, 54.1, 43.2, 30.0, 28.6, 26.9, 26.7, 26.6, 17.5; HRMS Calculated for $\mathrm{C}_{14} \mathrm{H}_{21} \mathrm{FN}[\mathrm{M}+\mathrm{H}]^{+}:$222.16525, Found: 222.16616.<smiles>CCCCC(C)Nc1ccccc1</smiles> 
$\mathrm{N}$-(hexan-2-yl)aniline (4.9l): 4.9l was purified by flash chromatography (Hexane-EtOAc, v/v 5/1) as yellow oil with overall isolated yield: $81 \%$. ${ }^{1} \mathrm{H}-\mathrm{NMR}\left(600 \mathrm{MHz}, \mathrm{CDCl}_{3}\right) \delta 7.12-$ $7.15(\mathrm{~m}, 2 \mathrm{H}), 6.64(\mathrm{t}, J=7.2 \mathrm{~Hz}, 1 \mathrm{H}), 6.55(\mathrm{~d}, J=6.0 \mathrm{~Hz}, 2 \mathrm{H}), 3.40-3.46(\mathrm{~m}, 1 \mathrm{H}), 1.54-$ $1.57(\mathrm{~m}, 1 \mathrm{H}), 1.30-1.46(\mathrm{~m}, 5 \mathrm{H}), 1.16(\mathrm{~d}, J=6.6 \mathrm{~Hz}, 3 \mathrm{H}), 0.89(\mathrm{t}, J=7.2 \mathrm{~Hz}, 3 \mathrm{H}) ;{ }^{13} \mathrm{C}-$ NMR $\left(150 \mathrm{MHz}, \mathrm{CDCl}_{3}\right) \delta 147.9,129.5,117.0,113.4,48.7,37.2,28.6,23.0,21.0,14.3$ HRMS Calculated for $\mathrm{C}_{12} \mathrm{H}_{20} \mathrm{~N}[\mathrm{M}+\mathrm{H}]^{+}:$178.15903, Found: 178.15961

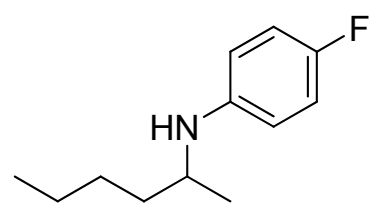

4-fluoro-N-(hexan-2-yl)aniline (4.9m): $4.9 \mathrm{~m}$ was purified by flash chromatography (Hexane-EtOAc, v/v 5/1) as yellow oil with overall isolated yield: 86\%. ${ }^{1} \mathrm{H}-\mathrm{NMR}(600$ $\left.\mathrm{MHz}, \mathrm{CDCl}_{3}\right)$ ס 6.83-6.87 (m, 2H), 6.46-6.51 (m, 2H), 3.32-3.37 (m, 1H), 3.25 (bs, NH), 1.52-1.56 (m, 2H), 1.29-1.42 (m, 6H), $1.13(\mathrm{~d}, J=6.6 \mathrm{~Hz}, 3 \mathrm{H}), 0.89(\mathrm{t}, J=7.2 \mathrm{~Hz}, 3 \mathrm{H})$; ${ }^{13} \mathrm{C}-\mathrm{NMR}\left(150 \mathrm{MHz}, \mathrm{CDCl}_{3}\right) \delta 156.5,154.9,144.3,115.9,115.8,114.3,114.2,49.5$, 37.1, 28.6, 22.9, 20.9, 14.3; HRMS Calculated for $\mathrm{C}_{12} \mathrm{H}_{19} \mathrm{FN}[\mathrm{M}+\mathrm{H}]^{+}:$196.14960, Found: 196.15027.<smiles>c1ccc(CC(Nc2ccccc2)c2ccccc2)cc1</smiles>

$\mathrm{N}$-(1,2-diphenylethyl)aniline (4.9n): 4.9n was purified by flash chromatography (Hexane-EtOAc, v/v 5/1) as yellow oil with overall isolated yield: 83\%. ${ }^{1} \mathrm{H}-\mathrm{NMR}(600$ $\left.\mathrm{MHz}, \mathrm{CDCl}_{3}\right) \delta$ 7.18-7.32 (m, 9H), $7.11(\mathrm{~d}, J=7.8 \mathrm{~Hz}, 2 \mathrm{H}), 7.02-7.05(\mathrm{~m}, 2 \mathrm{H}), 6.62(\mathrm{t}, J=$ $7.2 \mathrm{~Hz}, 1 \mathrm{H}), 6.46(\mathrm{~d}, J=7.8 \mathrm{~Hz}, 2 \mathrm{H}), 4.57-4.59(\mathrm{~m}, 1 \mathrm{H}), 3.11-3.15(\mathrm{~m}, 1 \mathrm{H}), 3.01-3.15(\mathrm{~m}$, 1H); ${ }^{13} \mathrm{C}-\mathrm{NMR}\left(150 \mathrm{MHz}, \mathrm{CDCl}_{3}\right) \delta 147.4,143.6,137.8,129.4,129.2,128.8,128.7$, 
127.3, 126.9, 126.7, 117.8, 113.9, 59.5, 45.3, 20.5; HRMS Calculated for $\mathrm{C}_{20} \mathrm{H}_{19} \mathrm{~N}$ $[\mathrm{M}+\mathrm{H}]^{+}:$274.15903, Found: 274.15911.<smiles>Cc1ccc(NC(Cc2ccccc2)c2ccccc2)cc1</smiles>

N-(1,2-diphenylethyl)-4-methylaniline (4.9o): 4.9o was purified by flash chromatography (Hexane-EtOAc, v/v 5/1) as yellow oil with overall isolated yield: $84 \%$. ${ }^{1} \mathrm{H}-\mathrm{NMR}\left(600 \mathrm{MHz}, \mathrm{CDCl}_{3}\right)$ ठ 7.22-7.34 (m, 8H), $7.14(\mathrm{~d}, J=7.2 \mathrm{~Hz}, 2 \mathrm{H}), 6.88(\mathrm{~d}, J=8.4$ $\mathrm{Hz}, 2 \mathrm{H}), 6.40$ (d, J = 8.4 Hz, 2H), 4.58 (q, $J=7.8 \mathrm{~Hz}, 1 \mathrm{H}), 4.58$ (bs, NH), 3.14 (dd, $J=$ $8.4 \mathrm{~Hz}, 13.8 \mathrm{~Hz}, 1 \mathrm{H}), 3.02$ (dd, J = 8.4 Hz, $13.8 \mathrm{~Hz}, 1 \mathrm{H}), 2.18(\mathrm{~s}, 3 \mathrm{H}) ;{ }^{13} \mathrm{C}-\mathrm{NMR}(150$ $\left.\mathrm{MHz}, \mathrm{CDCl}_{3}\right) \delta 145.2,143.9,138.5,129.9,129.8,129.4,128.8,128.7,128.6,127.8$, 127.2, 126.9, 126.7, 114.0, 59.7, 45.4, 20.5; HRMS Calculated for $\mathrm{C}_{21} \mathrm{H}_{22} \mathrm{~N}[\mathrm{M}+\mathrm{H}]^{+}$: 288.17468, Found: 288.17479.

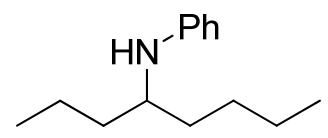

2-chloro-N-(octan-4-yl)aniline (4.9p): 4.9p was purified by flash chromatography (Hexane-EtOAc, v/v 5/1) as yellow oil with overall isolated yield: 86\%. ${ }^{1} \mathrm{H}-\mathrm{NMR}(600$ $\left.\mathrm{MHz}, \mathrm{CDCl}_{3}\right) \delta 6.94(\mathrm{~d}, J=8.4 \mathrm{~Hz}, 2 \mathrm{H}), 6.48(\mathrm{~d}, J=10.0 \mathrm{~Hz}, 2 \mathrm{H}), 3.27-3.29(\mathrm{~m}, 1 \mathrm{H})$, $2.21(\mathrm{~s}, 3 \mathrm{H}), 1.27-2.21(\mathrm{~m}, 10 \mathrm{H}), 0.87-0.90(\mathrm{~m}, 6 \mathrm{H}) ;{ }^{13} \mathrm{C}-\mathrm{NMR}\left(150 \mathrm{MHz}, \mathrm{CDCl}_{3}\right) \delta$ $146.3,130.0,125.9,113.3,53.2,37.5,37.6,34.9,28.4,23.2,20.7,19.4,14.5,14.7$; HRMS Calculated for $\mathrm{C}_{15} \mathrm{H}_{26} \mathrm{~N}[\mathrm{M}+\mathrm{H}]^{+}:$200.3657, Found: 200.36558 . 
<smiles>CCCCC(CCC)Nc1ccccc1Cl</smiles>

2-chloro-N-(octan-4-yl)aniline (4.9q): 4.9q was purified by flash chromatography (Hexane-EtOAc, v/v 5/1) as yellow oil with overall isolated yield: 83\%. ${ }^{1} \mathrm{H}-\mathrm{NMR}(600$

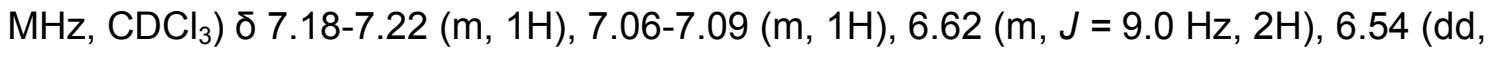
$J=6.0,7.2 \mathrm{~Hz}, 1 \mathrm{H}), 4.09(\mathrm{bs}, \mathrm{NH}), 3.37(\mathrm{q}, J=6.0 \mathrm{~Hz} 1 \mathrm{H}), 1.36-1.58(\mathrm{~m}, 10 \mathrm{H}), 0.88-$ 0.92 (m, 6H); ${ }^{13} \mathrm{C}-\mathrm{NMR}\left(150 \mathrm{MHz}, \mathrm{CDCl}_{3}\right) \delta 144.2,129.5,127.8,119.1,116.5,52.9,37.5$, $34.9,28.3,23.1,19.3,14.5,14.3$<smiles>CCC(Nc1ccc(C)cc1)c1ccccc1</smiles>

4-methyl-N-(1-phenylpropyl)aniline (4.9r-major): 4.9r major was purified by flash chromatography (Hexane-EtOAc, v/v 5/1) as colorless oil with overall isolated yield: 76\%. ${ }^{1} \mathrm{H}-\mathrm{NMR}\left(600 \mathrm{MHz}, \mathrm{CDCl}_{3}\right)$ ठ 7.35-7.38 (m, 4H), $7.25(\mathrm{~m}, 1 \mathrm{H}), 6.94(\mathrm{~d}, J=8.4 \mathrm{~Hz}$, 2H), $6.49(\mathrm{~d}, J=8.4 \mathrm{~Hz}, 2 \mathrm{H}), 4.24(\mathrm{t}, J=6.6 \mathrm{~Hz}, 1 \mathrm{H}), 2.22(\mathrm{~s}, 3 \mathrm{H}), 1.82-1.90(\mathrm{~m}, 2 \mathrm{H})$, 0.99 (t, $J=7.8 \mathrm{~Hz}, 3 \mathrm{H}) ;{ }^{13} \mathrm{C}-\mathrm{NMR}\left(150 \mathrm{MHz} \mathrm{CDCl}_{3}\right) \delta 145.5,144.4,129.8,128.7,127.1$, 126.8, 113.7, 60.2, 31.9, 20.6, 11.1; HRMS Calculated for $\mathrm{C}_{16} \mathrm{H}_{20} \mathrm{~N}[\mathrm{M}+\mathrm{H}]^{+}:$226.15903, Found: 226.15997.<smiles>Cc1ccc(NC(C)Cc2ccccc2)cc1</smiles>

4-methyl-N-(1-phenylpropyl)aniline (4.9r-minor): 4.9r minor was purified by flash chromatography (Hexane-EtOAc, v/v 5/1) as colorless oil with overall isolated yield: 
13\%. ${ }^{1} \mathrm{H}-\mathrm{NMR}\left(600 \mathrm{MHz}, \mathrm{CDCl}_{3}\right) \delta$ 7.30(t, $\left.J=7.2 \mathrm{~Hz}, 2 \mathrm{H}\right), 7.19-7.24(\mathrm{~m}, 4 \mathrm{H}), 7.01(\mathrm{~d}, J$ $=8.4 \mathrm{~Hz}, 2 \mathrm{H}), 6.57(\mathrm{~d}, J=6.6 \mathrm{~Hz}, 2 \mathrm{H}), 3.72-3.77(\mathrm{~m}, 1 \mathrm{H}), 2.95(\mathrm{dd}, J=4.8 \mathrm{~Hz}, 13.2 \mathrm{~Hz}$, 1H), $2.69(\mathrm{dd}, J=7.2 \mathrm{~Hz}, 13.2 \mathrm{~Hz}, 1 \mathrm{H}), 2.22(\mathrm{~s}, 3 \mathrm{H}), 1.15(\mathrm{~d}, J=6.6 \mathrm{~Hz}, 3 \mathrm{H}) ;{ }^{13} \mathrm{C}-\mathrm{NMR}$ $\left(150 \mathrm{MHz}, \mathrm{CDCl}_{3}\right) \delta 145.2,138.9,130.0,129.7,128.5,126.7,126.4,113.9,49.9,42.6$, 20.6, 20.4.

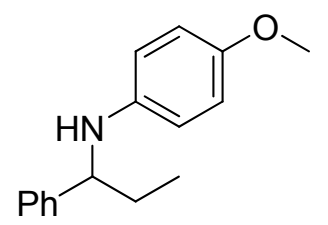

4-methoxy-N-(1-phenylpropyl)aniline (4.9s-major): 4.9s major was purified by flash chromatography (Hexane-EtOAc, v/v 5/1) as colorless oil with overall isolated yield: 72\%. ${ }^{1} \mathrm{H}-\mathrm{NMR}\left(600 \mathrm{MHz}, \mathrm{CDCl}_{3}\right)$ ठ 7.31-7.36 (m, 4H), 7.22-7.24 (m, 1H), $6.70(\mathrm{~d}, J=6.6$ $\mathrm{Hz}, 2 \mathrm{H}), 6.49(\mathrm{~d}, J=6.6 \mathrm{~Hz}, 2 \mathrm{H}), 4.17(\mathrm{t}, J=6.6 \mathrm{~Hz}, 1 \mathrm{H}), 3.69(\mathrm{~s}, 3 \mathrm{H}), 1.78-1.83(\mathrm{~m}$, 2H), $0.96(\mathrm{t}, J=7.8 \mathrm{~Hz}, 3 \mathrm{H}) ;{ }^{13} \mathrm{C}-\mathrm{NMR}\left(150 \mathrm{MHz}, \mathrm{CDCl}_{3}\right) \delta$ 152.1, 144.4, 142.1, 128.7, 128.6, 127.1, 126.8, 115.0, 114.7, 60.8, 55.9, 31.9, 11.1; HRMS Calculated for $\mathrm{C}_{16} \mathrm{H}_{19} \mathrm{NO}[\mathrm{M}+\mathrm{H}]^{+}: 242.15394$, Found: 242.15486.<smiles>COc1ccc(NC(C)Cc2ccccc2)cc1</smiles>

4-fluoro-N-(1-phenylpropan-2-yl)aniline (4.9s-minor): 4.9s minor was purified by flash chromatography (Hexane-EtOAc, v/v 5/1) as colorless oil with overall isolated yield: 14\%. ${ }^{1} \mathrm{H}-\mathrm{NMR}\left(600 \mathrm{MHz}, \mathrm{CDCl}_{3}\right) \delta 7.29(\mathrm{t}, J=7.8 \mathrm{~Hz}, 2 \mathrm{H}), 7.17-7.21(\mathrm{~m}, 3 \mathrm{H}), 6.78-6.80$ (m, 2H), 6.59-6.61 (m, 2H), 3.75(s, 3H), 3.66-3.69 (m, 1H), $2.93(\mathrm{dd}, J=4.8 \mathrm{~Hz}, 13.2 \mathrm{~Hz}$, 1H), $2.67(\mathrm{dd}, J=7.2 \mathrm{~Hz}, 13.2 \mathrm{~Hz}, 1 \mathrm{H}), 1.13(\mathrm{~d}, J=6.6 \mathrm{~Hz}, 3 \mathrm{H}) ;{ }^{13} \mathrm{C}-\mathrm{NMR}(150 \mathrm{MHz}$, 
$\left.\mathrm{CDCl}_{3}\right) \delta 152.3,141.6,138.9,129.7,128.6,128.5,126.4,115.3,115.2,56.0,50.6,42.6$ 20.5 .<smiles>CCC(Nc1ccc(F)cc1)c1ccccc1</smiles>

4-fluoro-N-(1-phenylpropyl)aniline (4.9t-major): 4.9t major was purified by flash chromatography (Hexane-EtOAc, v/v 5/1) as yellow oil with overall isolated yield: $80 \%$. ${ }^{1} \mathrm{H}-\mathrm{NMR}\left(600 \mathrm{MHz}, \mathrm{CDCl}_{3}\right) \delta 7.31(\mathrm{~d}, \mathrm{~J}=4.8 \mathrm{~Hz}, 4 \mathrm{H}), 7.21-7.24(\mathrm{~m}, 1 \mathrm{H}), 6.76-6.79(\mathrm{~m}$, 2H), 6.42-6.89 (m, 2H), $4.15(\mathrm{t}, J=7.2 \mathrm{~Hz}, 1 \mathrm{H}), 1.77-1.85(\mathrm{~m}, 2 \mathrm{H}), 0.94(\mathrm{t}, J=7.8 \mathrm{~Hz}$, $3 \mathrm{H}) ;{ }^{13} \mathrm{C}-\mathrm{NMR}\left(150 \mathrm{MHz}, \mathrm{CDCl}_{3}\right) \delta 156.5,155.1,144.0,143.8,128.7,127.2,126.7$, 117.6, 114.3, 114.3, 60.2, 31.9, 10.9; HRMS Calculated for $\mathrm{C}_{15} \mathrm{H}_{17} \mathrm{FN}[\mathrm{M}+\mathrm{H}]^{+}$: 230.13395, Found: 230.13492.<smiles>CCCC(Cc1ccccc1)Nc1ccccc1</smiles>

\section{$N$-(1-phenylbutyl)benzenamine and $N$-(1-phenylbutan-2-yl)benzenamine}

(inseperable mixture) (4.9u): 4.9u was purified by flash chromatography (HexaneEtOAc, v/v 5/1) as inseparable colorless oil with overall isolated yield: $91 \%$ (d.r.:2/1) . ${ }^{1} \mathrm{H}-$ NMR (600 MHz, $\left.\mathrm{CDCl}_{3}\right)$ 7.46-7.38 (m, 4.8H, Ar-H), 7.33-7.38 (m, 3.4H, Ar-H), 7.21-7.18 (m, 2H, Ar-H), $6.80(\mathrm{t}, \mathrm{J}=8.4 \mathrm{~Hz}, 0.5 \mathrm{H}(1 \mathrm{H}$, for minor), Ar- $\mathrm{H}), 6.76-6.72(\mathrm{~m}, 2 \mathrm{H}, \mathrm{Ar}-\mathrm{H})$, 6.64-6.62 (m, 2H, Ar-H), $4.42(\mathrm{t}, J=7.2 \mathrm{~Hz}, 1 \mathrm{H}$ (for major), $\mathrm{CH}), 3.72-3.64(\mathrm{~m}, 0.5 \mathrm{H}$ (1H, for minor), $\mathrm{CH}), 2.99-2.89\left(\mathrm{~m}, 2 \mathrm{H}\right.$, (for major), $\left.\mathrm{CH}_{2}\right), 1.92-1.83\left(\mathrm{~m}, 2 \mathrm{H}, \mathrm{CH}_{2}\right), 1.74-$ $1.70\left(\mathrm{~m}, 0.5 \mathrm{H}(1 \mathrm{H}\right.$, for minor $\left.), \mathrm{CH}_{2}\right), 1.58-1.43\left(2.5 \mathrm{H}, \mathrm{CH}_{2}\right), 1.08(\mathrm{t}, J=7.2 \mathrm{~Hz}, 1.5 \mathrm{H}(3 \mathrm{H}$ for minor), $\mathrm{CH}_{3}$ ), 1.05 (t, $J=7.2 \mathrm{~Hz}, 3 \mathrm{H}$ (for major), $\left.\mathrm{CH}_{3}\right) .{ }^{13} \mathrm{C}-\mathrm{NMR}\left(150 \mathrm{MHz}, \mathrm{CDCl}_{3}\right) \delta$ $148.1,147.9,144.7,139.0,129.9,129.7,123.4,128.9,128.6,127.2,126.7,126.5$ 
$117.5,117.3,113.7,113.6,58.3,53.9,41.5,40.2,26.9,19.8,14.3,10.8$; HRMS Calculated for $\mathrm{C}_{16} \mathrm{H}_{20} \mathrm{~N}[\mathrm{M}+\mathrm{H}]^{+}:$226.15903, Found: 226.15913 .<smiles>Fc1ccc(NC(CBr)c2ccccc2)cc1</smiles>

4-fluoro-N-(1-phenylhexyl)benzenamine (4.9v): 4.9v was purified by flash chromatography (Hexane-EtOAc, v/v 5/1) as inseparable colorless oil with overall isolated yield: 90\%. ${ }^{1} \mathrm{H}-\mathrm{NMR}\left(600 \mathrm{MHz}, \mathrm{CDCl}_{3}\right) \delta$ 7.24-7.30 (m, 3H), 7.18-7.20 (m, $\left.1 \mathrm{H}\right)$, 7.12-7.13 (m, 1H), $6.86(\mathrm{t}, J=9.0 \mathrm{~Hz}, 1 \mathrm{H}), 6.75(\mathrm{~m}, 1 \mathrm{H}), 3.65-3.69(\mathrm{~m}, 1 \mathrm{H}), 2.91$ (dd, $J=$ $4.8 \mathrm{~Hz}, 13.2 \mathrm{~Hz}, 1 \mathrm{H}), 2.69$ (dd, $J=7.2 \mathrm{~Hz}, 13.2 \mathrm{~Hz}, 1 \mathrm{H}), 1.15(\mathrm{~d}, J=6.6 \mathrm{~Hz}, 3 \mathrm{H}) ;{ }^{13} \mathrm{C}-$ NMR $\left(150 \mathrm{MHz}, \mathrm{CDCl}_{3}\right) \delta$ 156.7, 156.6, 155.1, 154.9, 144.4, 144.3, 144.3, 144.2, 138.8, $129.8,129.0,128.8,128.5,128.4,127.6,126.5,116.1,115.9,115.8,115.7,114.3$ $114.3,114.2,59.2,54.7,40.4,39.2,34.1,31.9,31.8,28.6,26.3,22.9,22.8,14.3,14.2$ HRMS Calculated for $\mathrm{C}_{18} \mathrm{H}_{23} \mathrm{FN}[\mathrm{M}+\mathrm{H}]^{+}:$272.18090, Found: 272.18100.<smiles>Fc1ccc(NC(Cc2ccccc2)Cc2ccccc2)cc1</smiles>

\section{$N$-(hexan-3-yl)-4-methylbenzenamine $(4.9 w)$ : $4.9 w$ was purified by flash} chromatography (Hexane-EtOAc, v/v 5/1) as yellow oil with overall isolated yield: $85 \%$. ${ }^{1} \mathrm{H}-\mathrm{NMR}\left(600 \mathrm{MHz}, \mathrm{CDCl}_{3}\right)$ ठ 6.94-6.95 (m, 3H), 6.47-6.49 (m, 3H), 3.37-3.41(m, $\left.1 \mathrm{H}\right)$, $3.24(\mathrm{~m}, 1 \mathrm{H}), 2.22(\mathrm{~s}, 3 \mathrm{H}), 2.21(\mathrm{~s}, 1 \mathrm{H}), 1.53-1.56(\mathrm{~m}, 2 \mathrm{H}), 1.14-1.41(\mathrm{~m}, 7 \mathrm{H}), 1.40(\mathrm{~d}, \mathrm{~J}$ $=6.6 \mathrm{~Hz}, 3 \mathrm{H}), 0.87-0.94(\mathrm{~m}, 5 \mathrm{H}) ;{ }^{13} \mathrm{C}-\mathrm{NMR}\left(150 \mathrm{MHz}, \mathrm{CDCl}_{3}\right) \delta$ 146.2, $145.7,129.9,126.2,125.8,113.6,113.3,54.4,49.0,37.2,37.0,28.6,27.5,23.0,21.0$ 
20.6, 20.5, 19.4, 14.7, 14.3, 10.2; HRMS Calculated for $\mathrm{C}_{13} \mathrm{H}_{22} \mathrm{~N}[\mathrm{M}+\mathrm{H}]^{+}:$192.17468, Found: 192.17474.

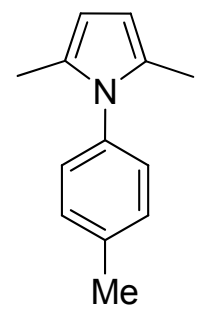

2,5-dimethyl-1-p-tolyl-1H-pyrrole (4.11a): 4.11a was purified by flash chromatography (Hexane-EtOAc, v/v 6/1) as yellow oil with overall isolated yield: 90\%. ${ }^{1} \mathrm{H}-\mathrm{NMR}(600$ $\left.\mathrm{MHz}, \mathrm{CDCl}_{3}\right) \delta 7.23$ (d, J = 7.2 Hz, 2H), 7.07 (d, J = 7.2 Hz, 2H), 5.87 (s, 2H), 2.41 (s, 3H), 2.04 (s, 6H); ${ }^{13} \mathrm{C}-\mathrm{NMR}\left(150 \mathrm{MHz}, \mathrm{CDCl}_{3}\right) \delta 137.6,136.6,129.9,129.1,128.2,105.6$, 29.9, 21.3, 13.2; HRMS Calculated for $\mathrm{C}_{13} \mathrm{H}_{16} \mathrm{~N}[\mathrm{M}+\mathrm{H}]^{+}:$186.12773, Found: 186.12844.

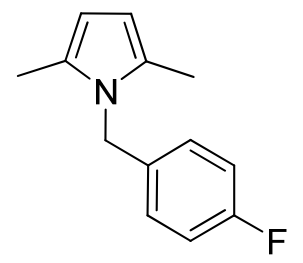

1-(4-fluorobenzyl)-2,5-dimethyl-1H-pyrrole (4.11b): 4.11b was purified by flash chromatography (Hexane-EtOAc, v/v 5/1) as yellow oil with overall isolated yield: $89 \%$. ${ }^{1} \mathrm{H}-\mathrm{NMR}\left(600 \mathrm{MHz}, \mathrm{CDCl}_{3}\right)$ ठ 6.96-6.99 (m, 2H), 6.83-6.85 (m, 2H), $5.86(\mathrm{~s}, 2 \mathrm{H}), 4.97$ (s, 2H), $2.14(\mathrm{~s}, 6 \mathrm{H}), 0.87-0.90(\mathrm{~m}, 6 \mathrm{H}) ;{ }^{13} \mathrm{C}-\mathrm{NMR}\left(150 \mathrm{MHz}, \mathrm{CDCl}_{3}\right) \delta$ 134.5, 128.1,127.5, 127.4, 115.9, 115.7, 105.8, 46.3, 12.6; HRMS Calculated for $\mathrm{C}_{13} \mathrm{H}_{15} \mathrm{FN}[\mathrm{M}+\mathrm{H}]^{+}$: 204.11830, Found: 204.11911. 


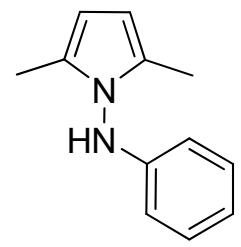

$N$-(2,5-dimethyl-1H-pyrrol-1-yl)benzenamine (4.11c): 4.11c was purified by flash chromatography (Hexane-EtOAc, v/v 5/1) as yellow oil with overall isolated yield: $97 \%$. ${ }^{1} \mathrm{H}-\mathrm{NMR}\left(600 \mathrm{MHz}, \mathrm{CDCl}_{3}\right) \delta 7.16-7.24(\mathrm{~m}, 2 \mathrm{H}), 6.87(\mathrm{t}, J=7.2 \mathrm{~Hz}, 1 \mathrm{H}), 6.45(\mathrm{~d}, J=8.0$ $\mathrm{Hz}, 2 \mathrm{H}), 6.25$ (bs, NH), $5.84(\mathrm{~s}, 2 \mathrm{H}), 2.17(\mathrm{~s}, 6 \mathrm{H}) ;{ }^{13} \mathrm{C}-\mathrm{NMR}\left(150 \mathrm{MHz}, \mathrm{CDCl}_{3}\right) \delta 147.9$, 129.6,128.5, 120.7, 112.7, 103.8, 11.5; HRMS Calculated for $\mathrm{C}_{12} \mathrm{H}_{15} \mathrm{~N}_{2}[\mathrm{M}+\mathrm{H}]^{+}$: 187.12298, Found: 187.12304. 


\section{ORTEP Drawing of the Crystal Structures of triazole-Au(I) complexes. ${ }^{5}$}

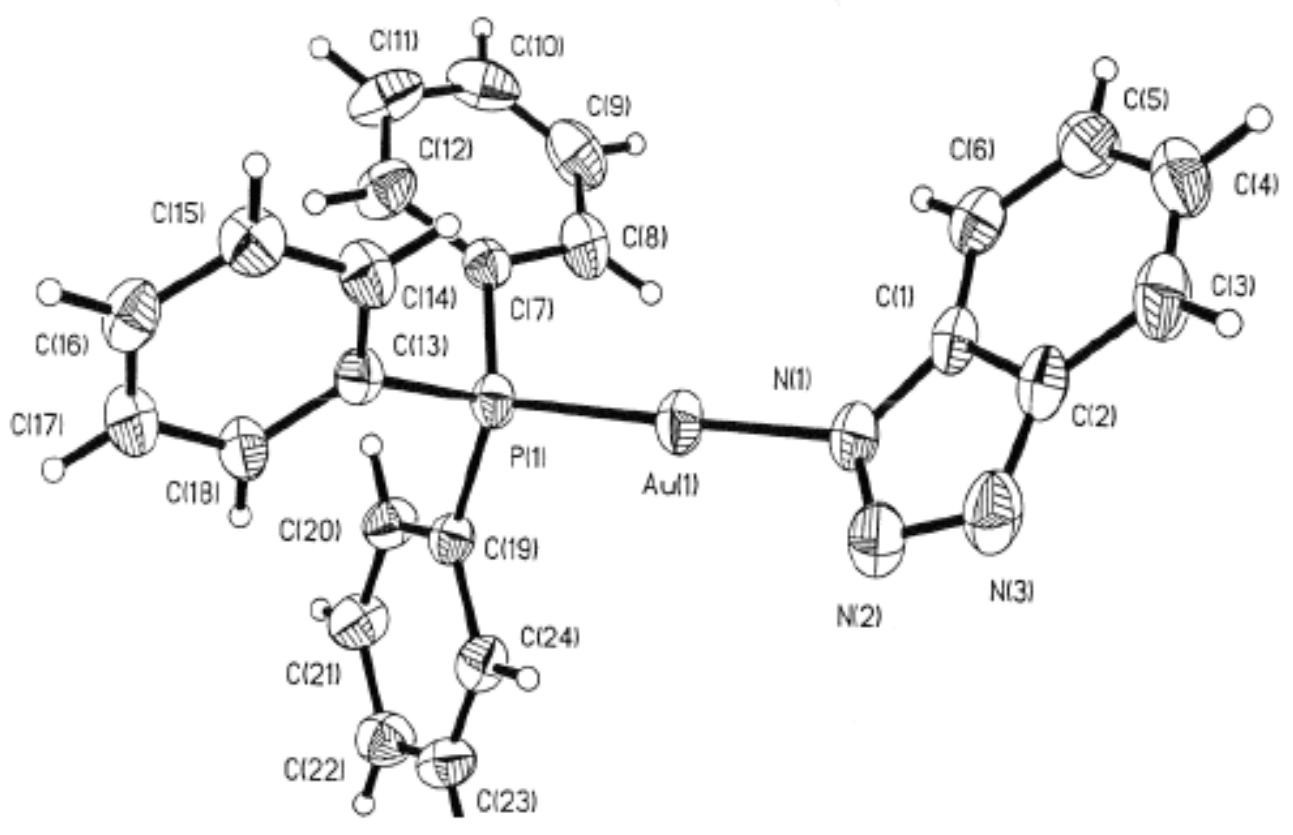

Figure S8: Perspective view of the molecular structure of $\mathrm{Au}\left(\mathrm{N}_{3} \mathrm{C}_{6} \mathrm{H}_{4}\right)\left(\mathrm{PPh}_{3}\right)$ 4.4a with the atom labeling scheme. The thermal ellipsoids are scaled to enclose $30 \%$ probability. CCDC deposition number 723080 .

${ }^{5}$ For details regarding the crystal structure, refer to supporting information for paper: Duan, $\mathrm{H}_{\text {.; }}$ Sengupta, S.; Petersen, J. L.; Akhmedov, N. G.; Shi, X. J. Am. Chem. Soc. 2009, 131, $12100-$ 12102. 


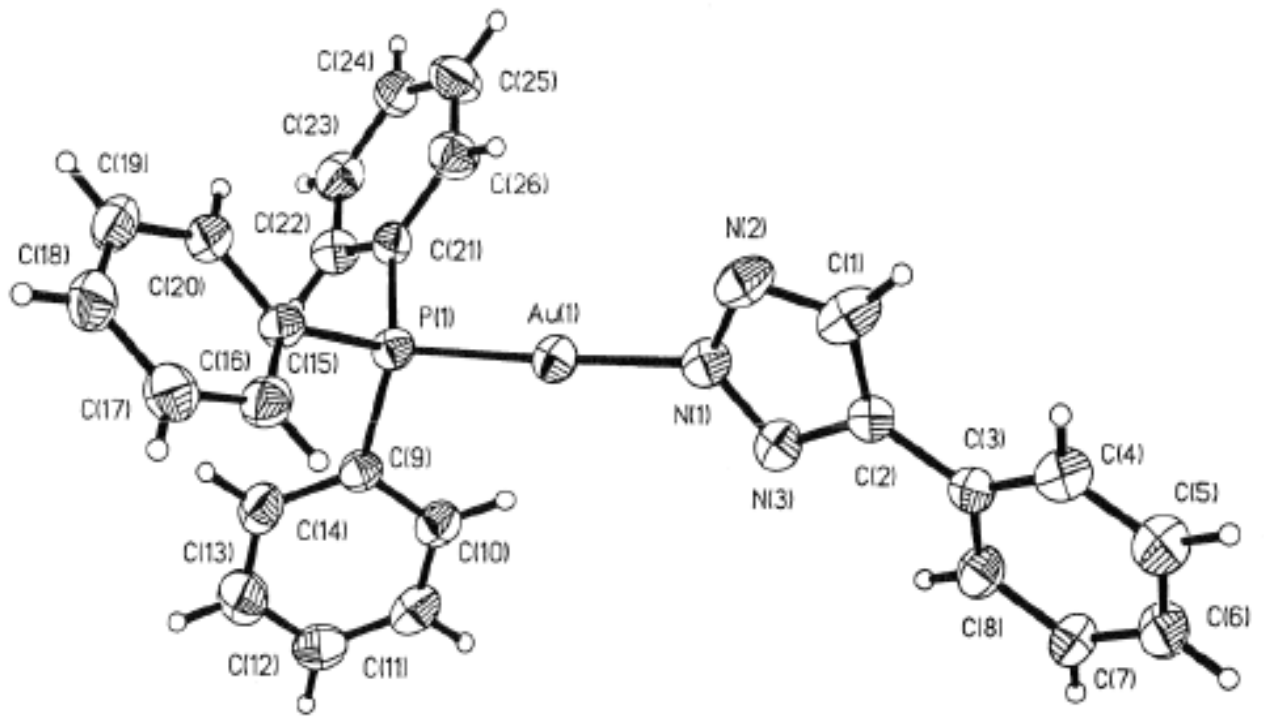

Figure S9: Perspective view of the molecular structure of $\mathrm{Au}(\mathrm{N} 3 \mathrm{C} 8 \mathrm{H} 6)(\mathrm{PPh} 3)$ 4.4b with the atom labeling scheme. The thermal ellipsoids are scaled to enclose $30 \%$ probability. CCDC deposition number 723081. 


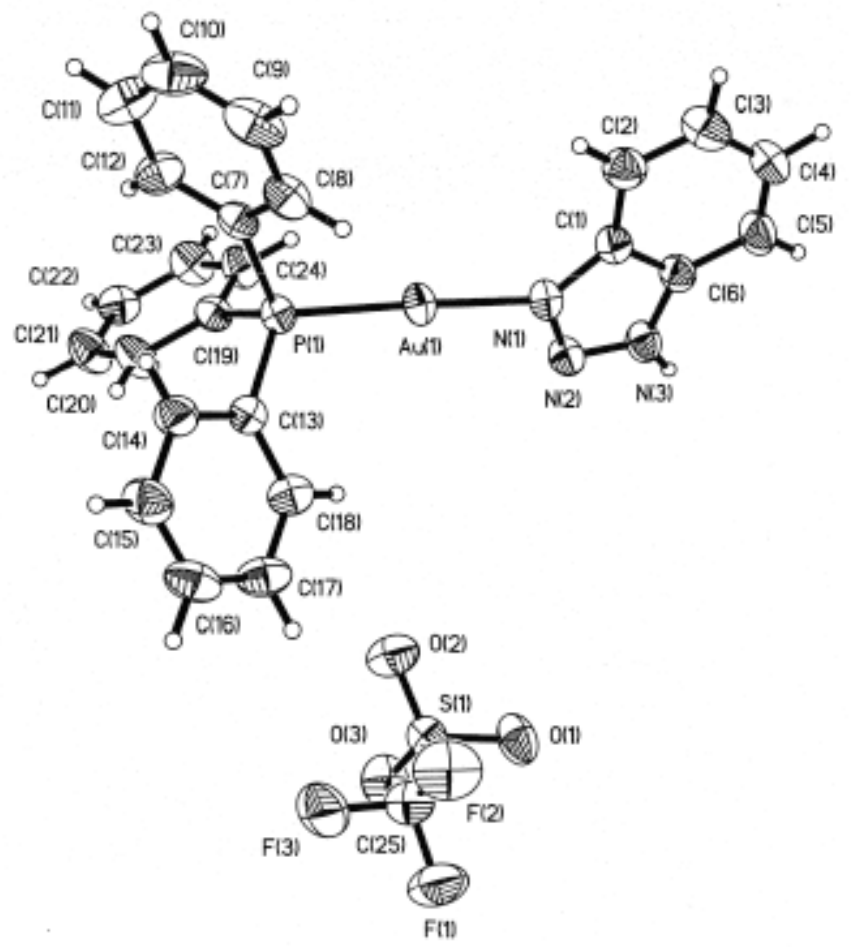

Figure S10: Perspective view of the molecular structure of $\left[\mathrm{Au}\left(\mathrm{PPh}_{3}\right)\left(\mathrm{N}_{3} \mathrm{C}_{6} \mathrm{H}_{5}\right)\right]\left[\mathrm{SO}_{3} \mathrm{CF}_{3}\right]$ 4.6a with the atom labeling scheme. The thermal ellipsoids are scaled to enclose $30 \%$ probability. CCDC deposition number 723082. 


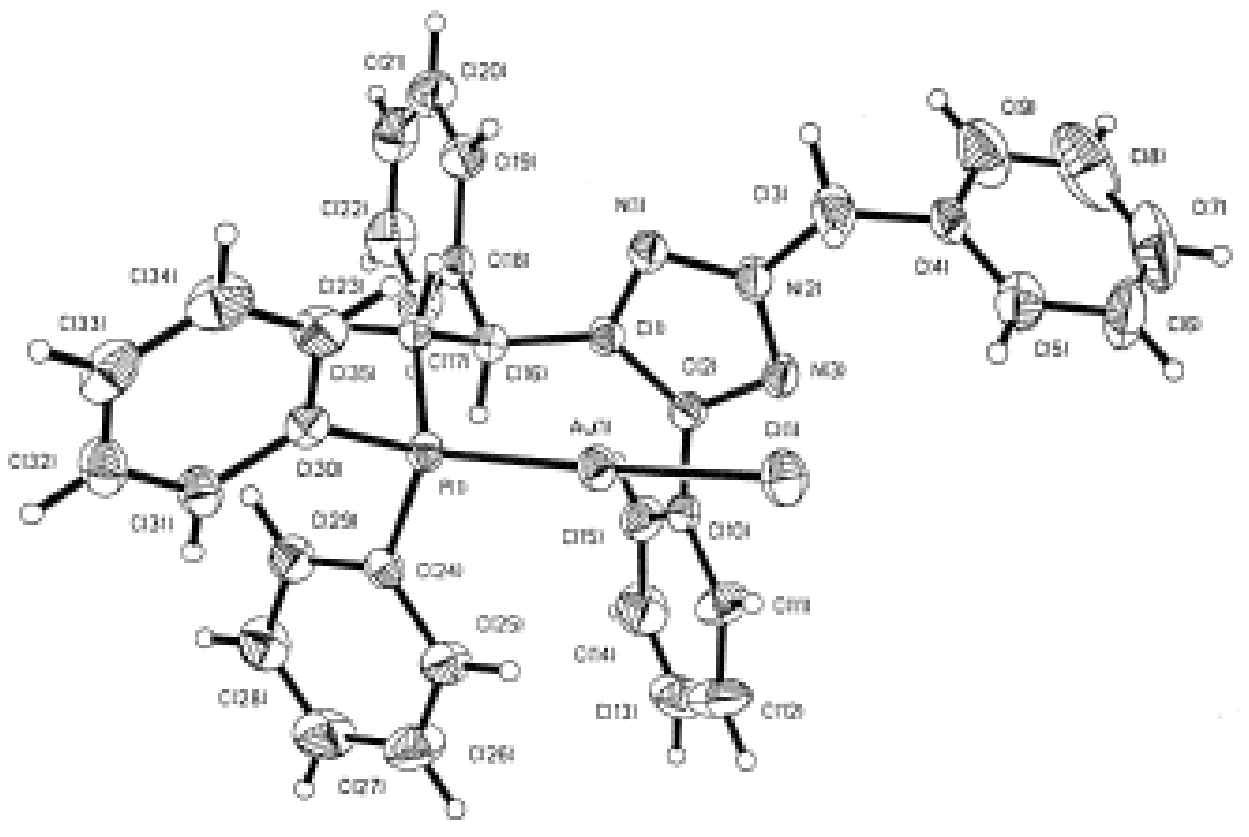

Figure S11: Perspective view of the molecular structure of $\mathrm{C}_{35} \mathrm{H}_{30} \mathrm{~N}_{3} \mathrm{CIPAu} 4.6 \mathrm{f}$ with the atom labeling scheme. The thermal ellipsoids are scaled to enclose $30 \%$ probability. CCDC deposition number 723083. 


\section{Appendix}

${ }^{1} \mathrm{H}-\mathrm{NMR}$ and ${ }^{13} \mathrm{C}-\mathrm{NMR}$ Spectral Data

Chapter 2: Intermolecular Cross Double Michael Addition 


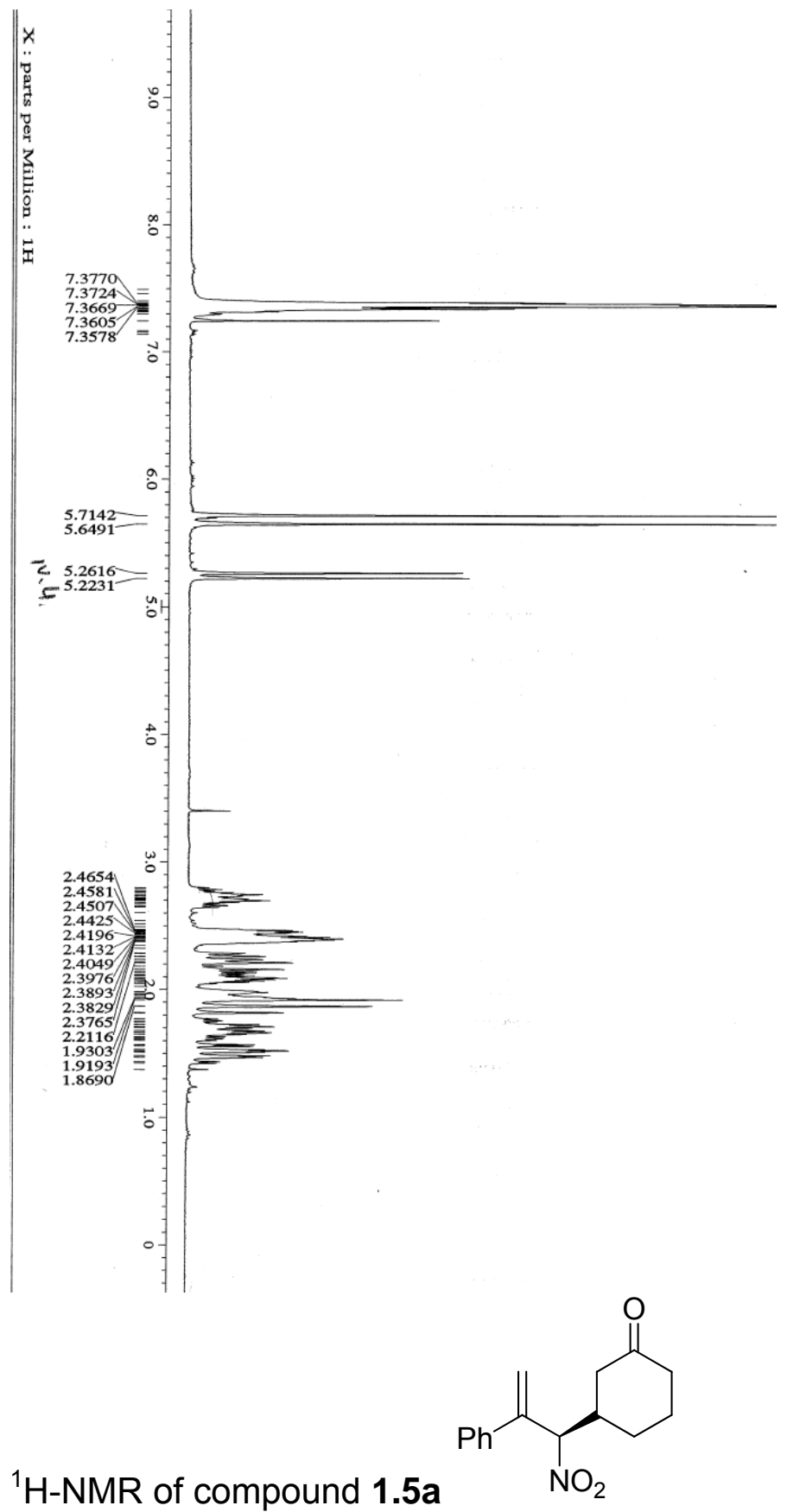



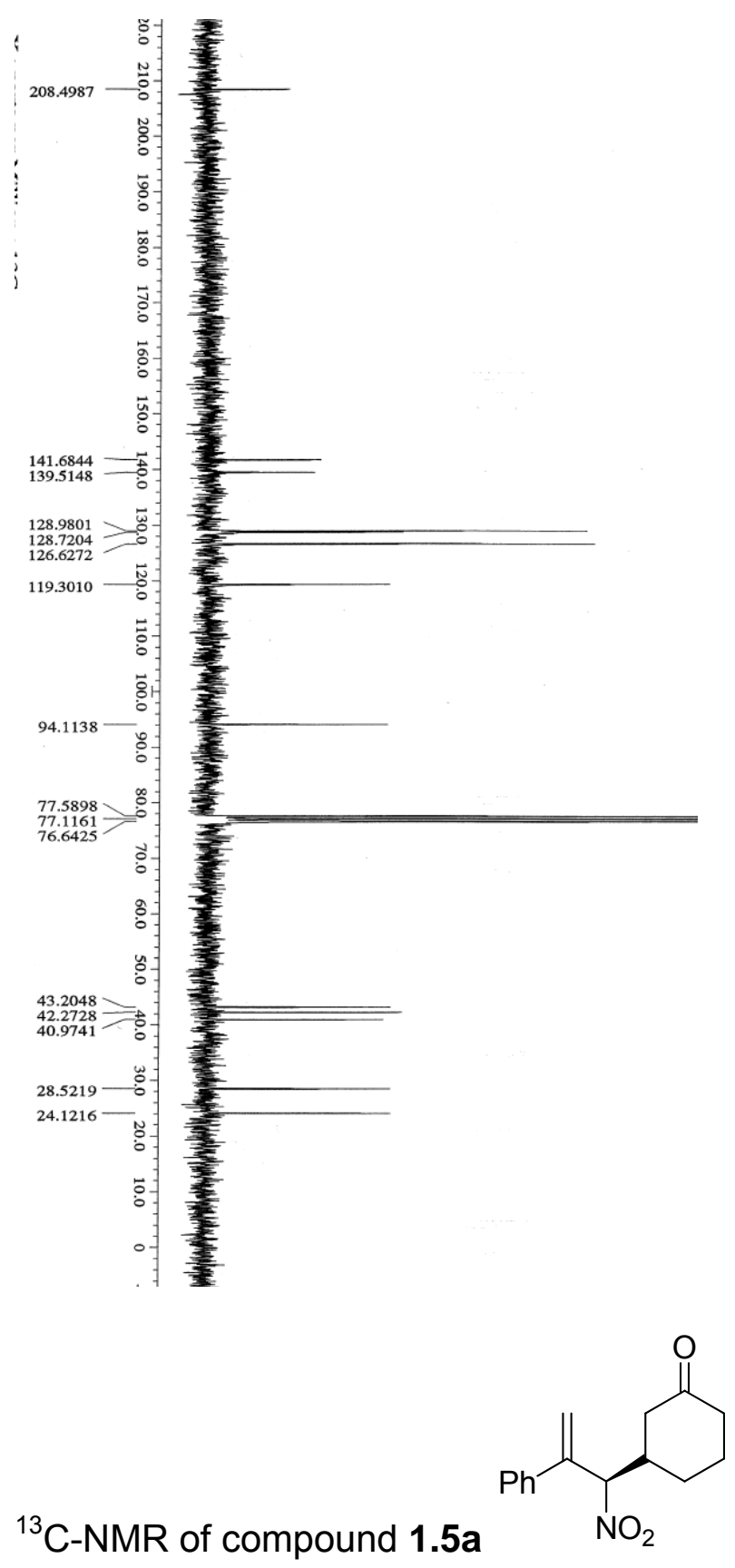


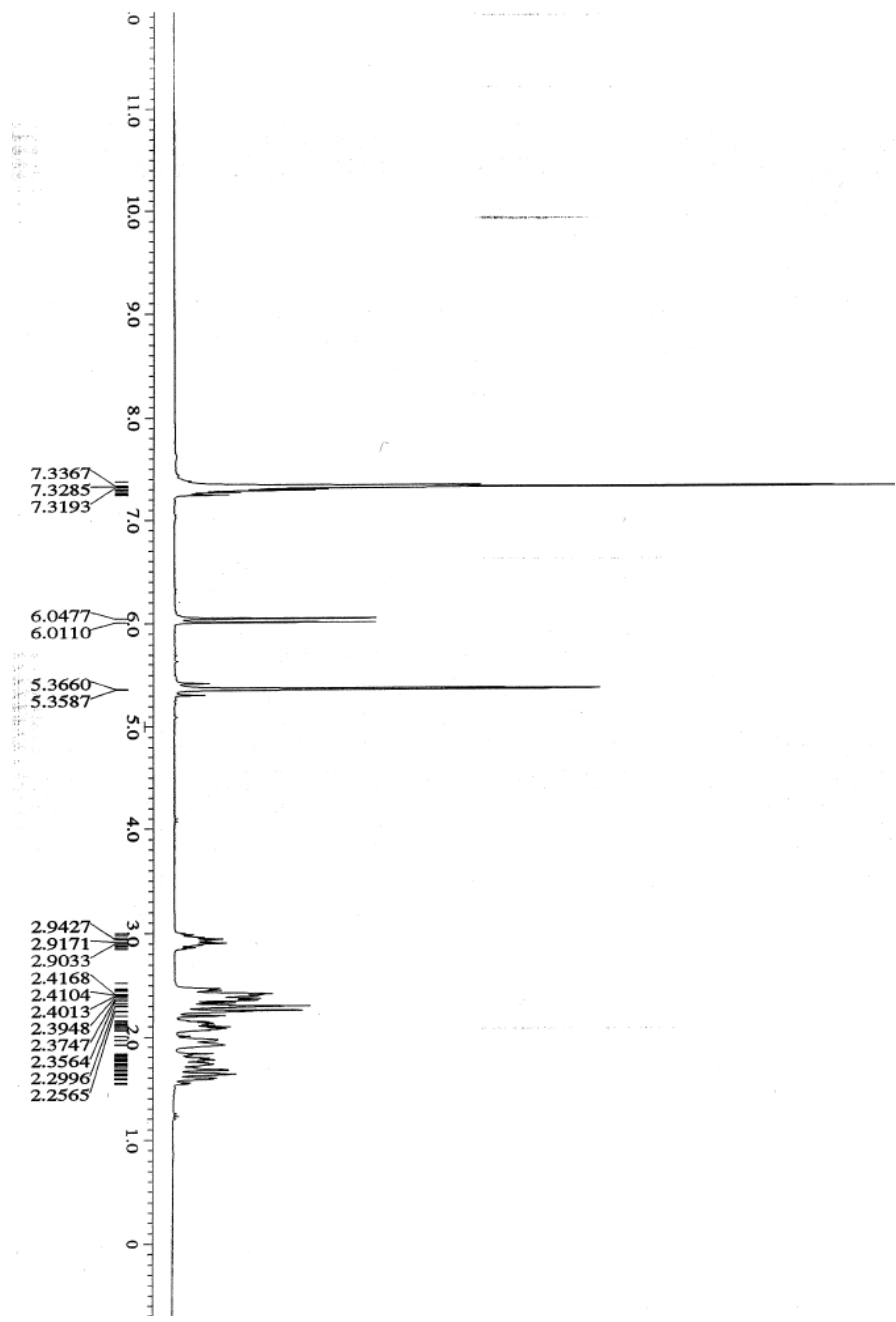

${ }^{1} \mathrm{H}-\mathrm{NMR}$ of Compound 1.5a (Isomer 2) 


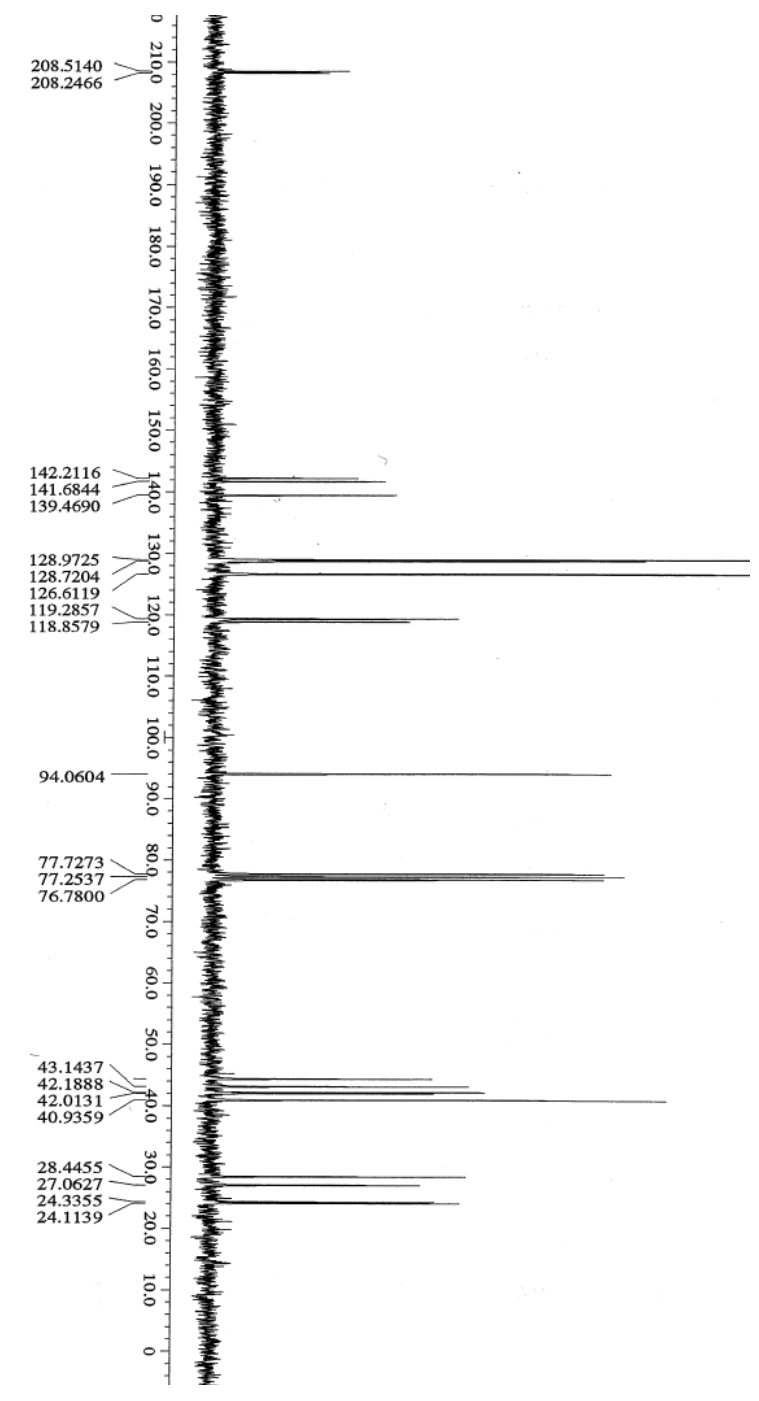

${ }^{13} \mathrm{C}-\mathrm{NMR}$ of compound 1.5a (Isomer 2) 

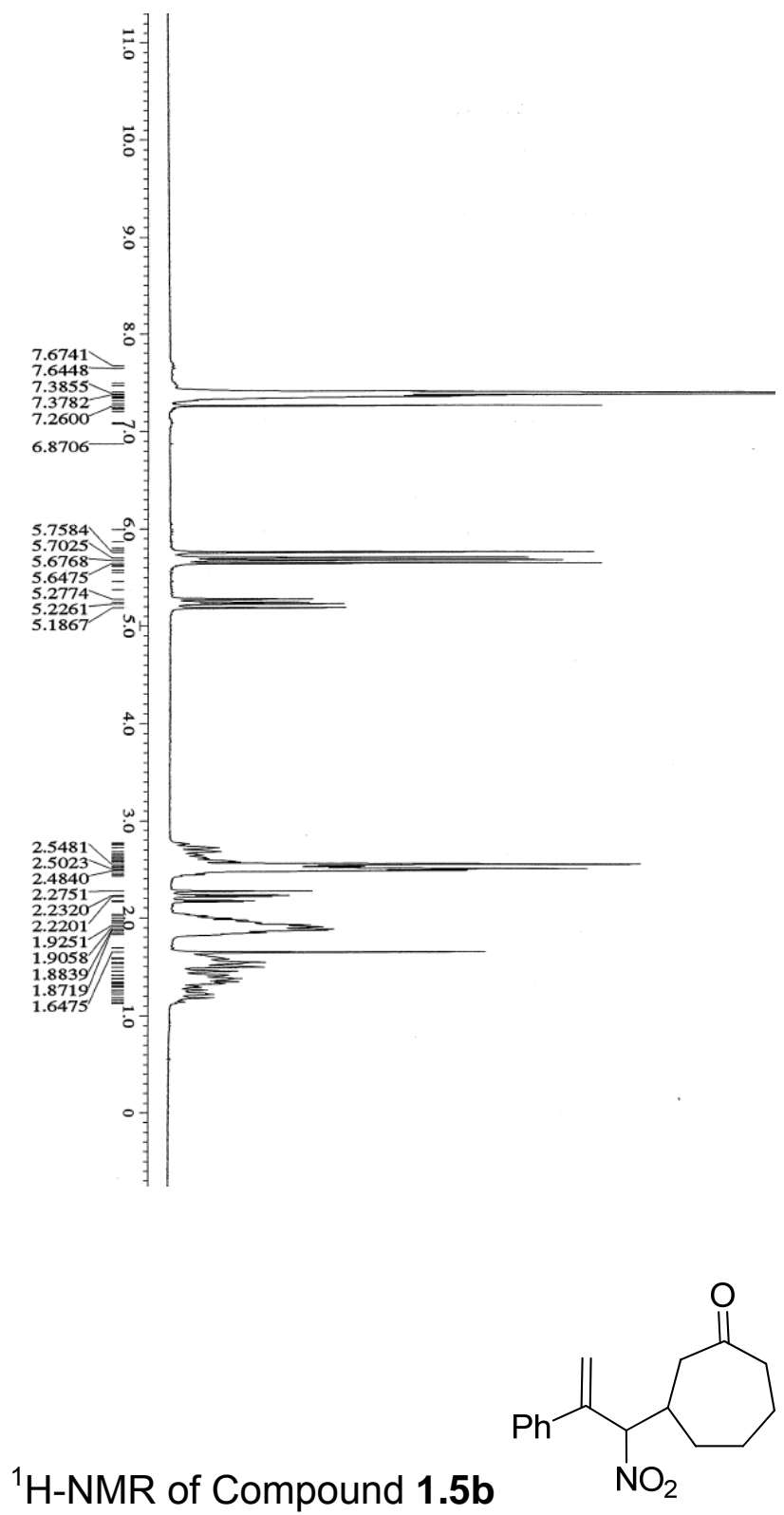

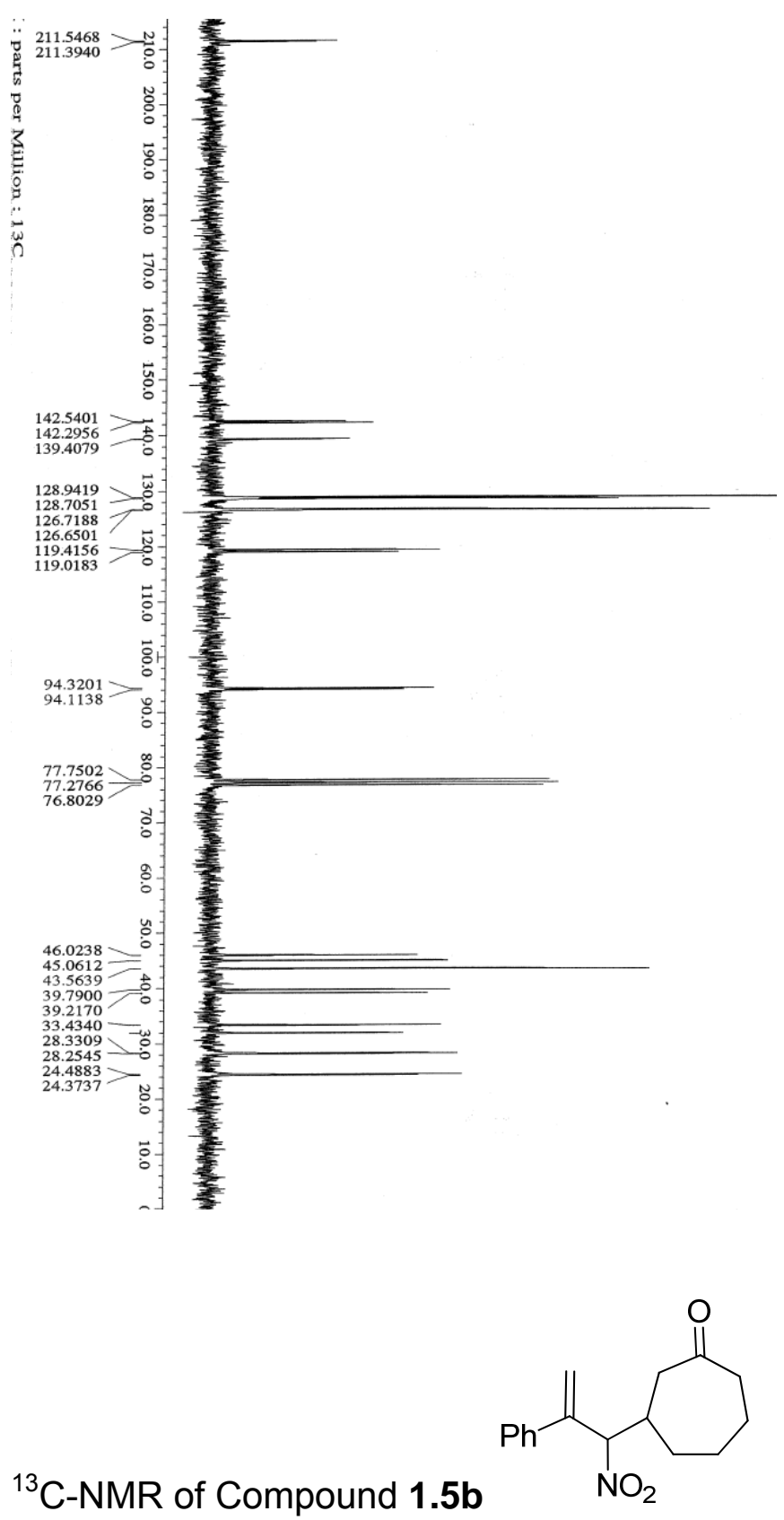

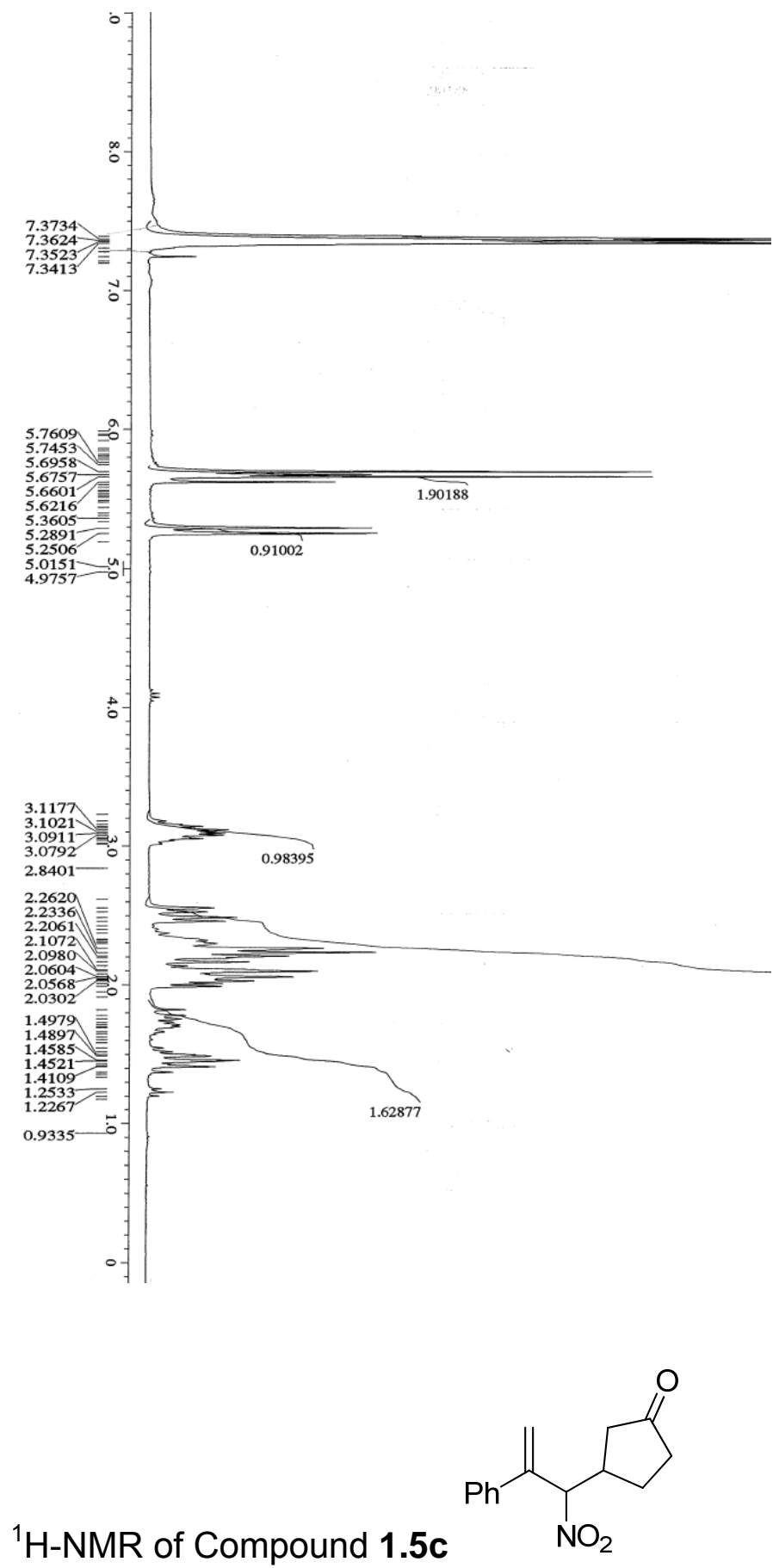

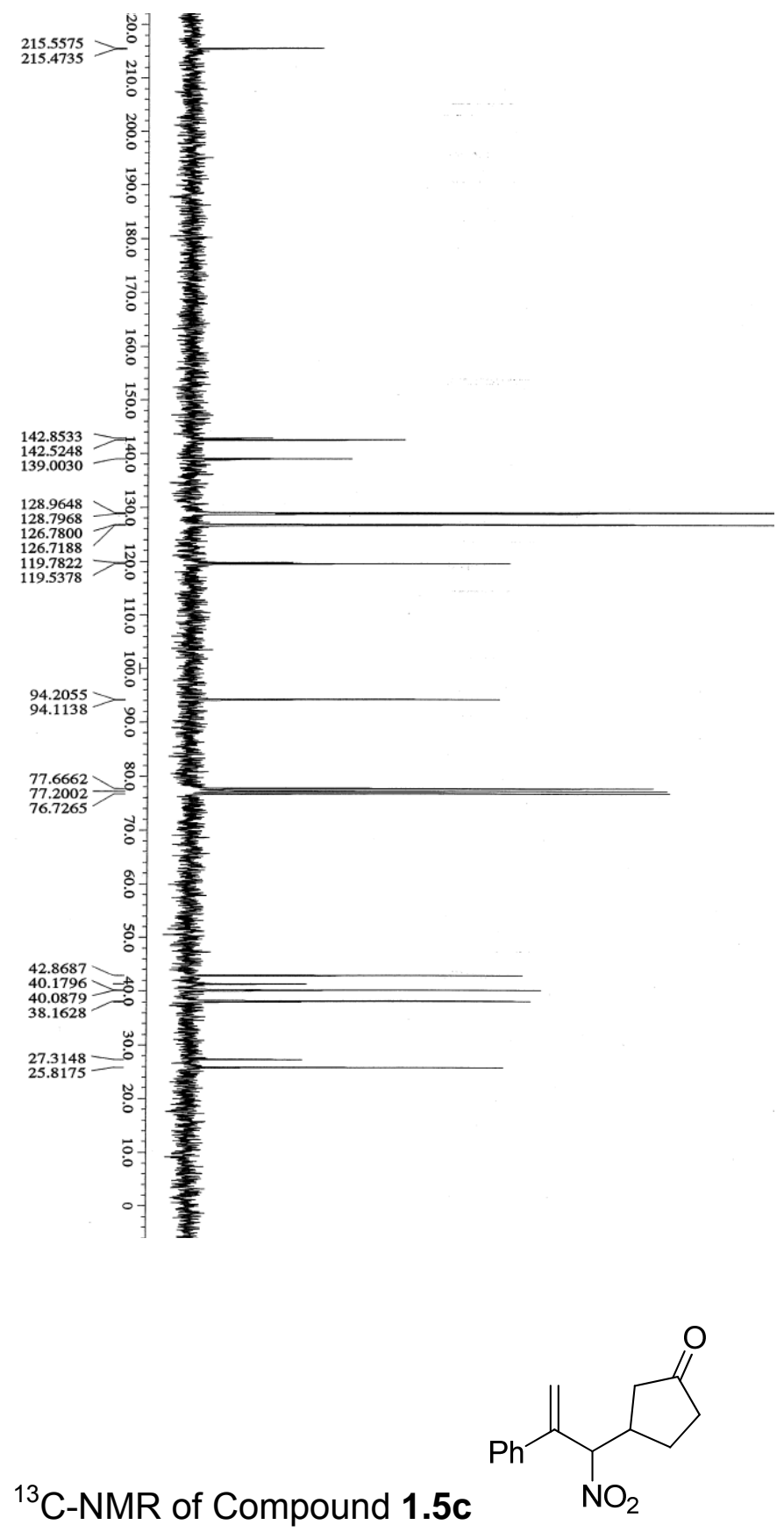


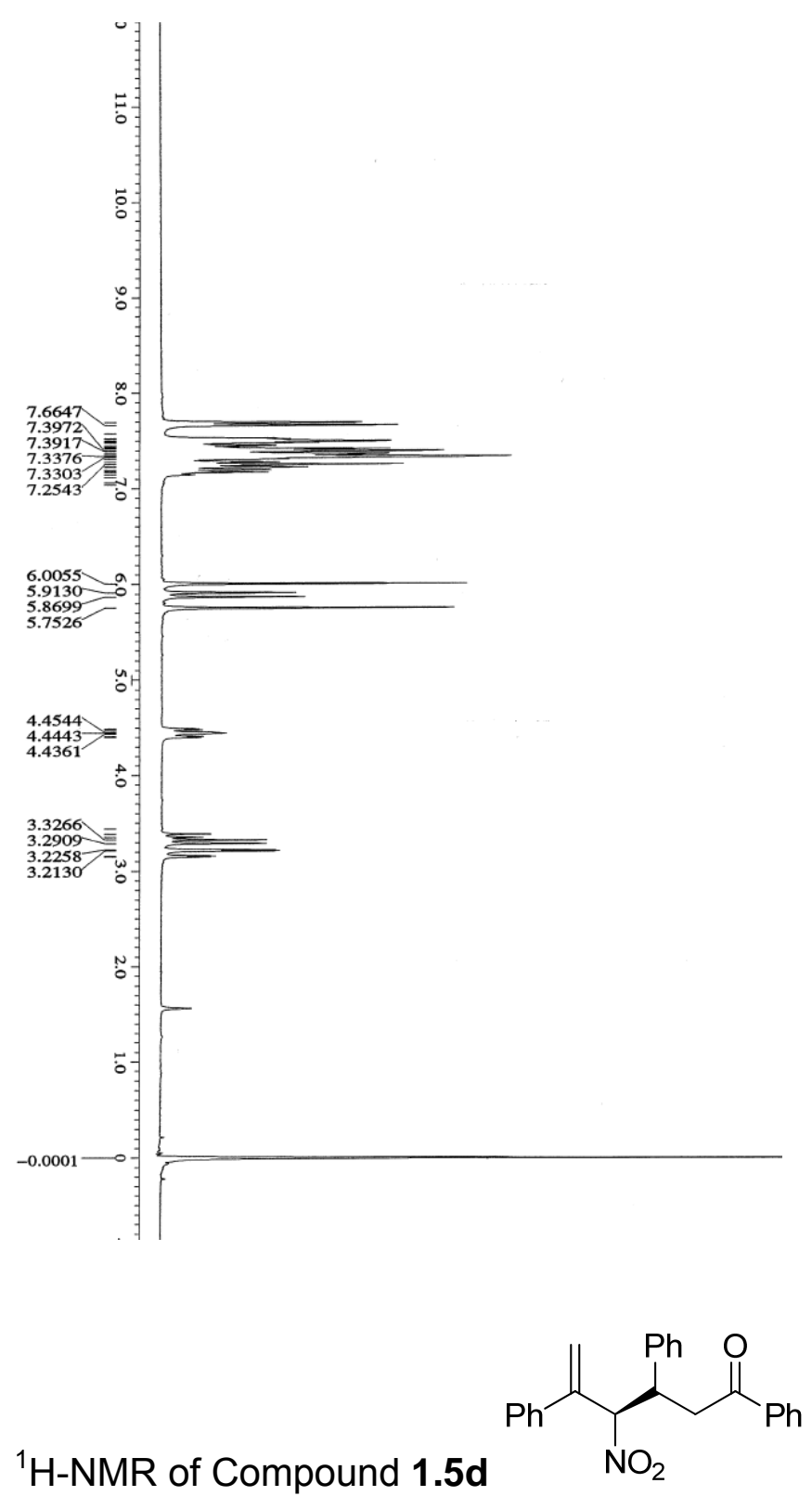




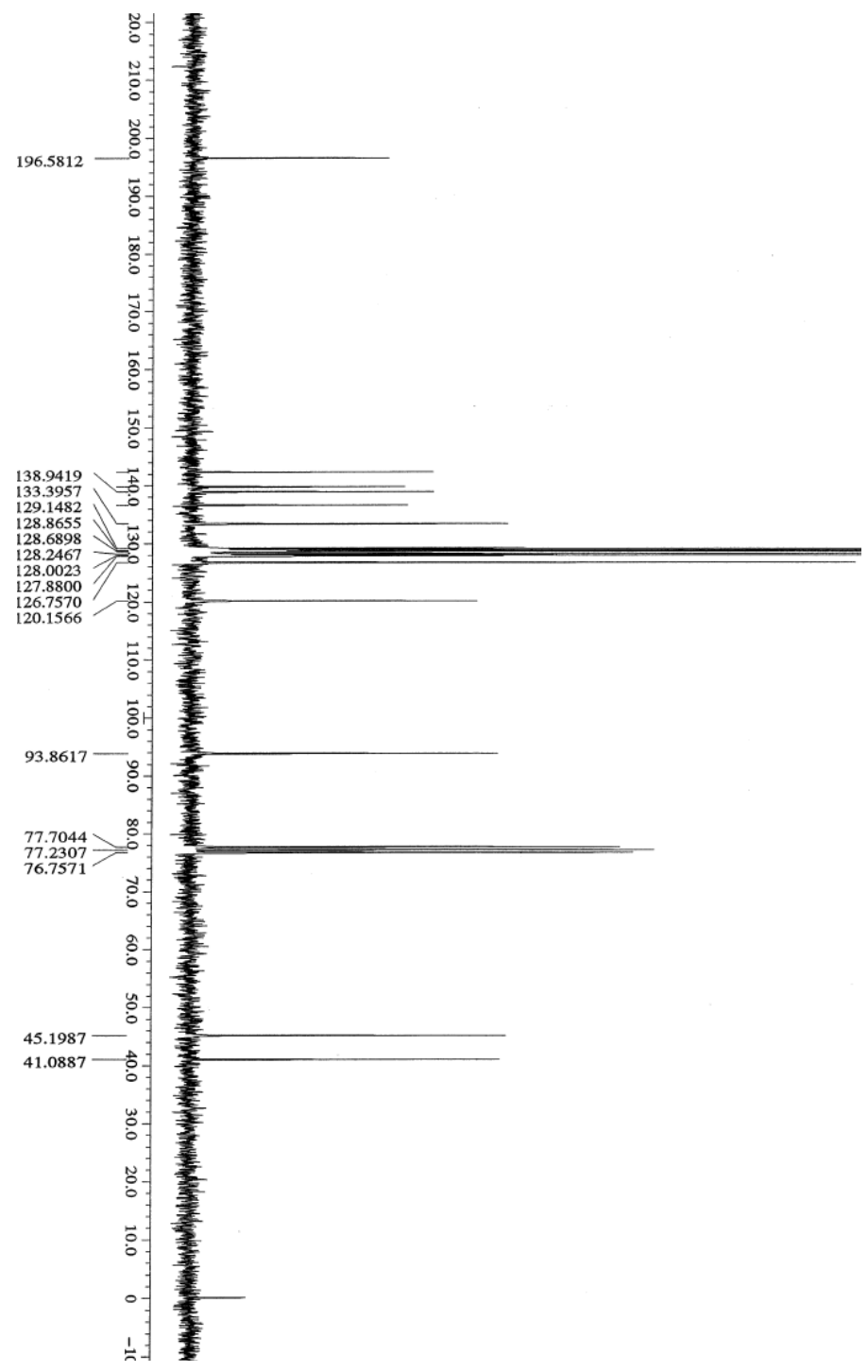

${ }^{13} \mathrm{C}-\mathrm{NMR}$ of Compound 1.5d 

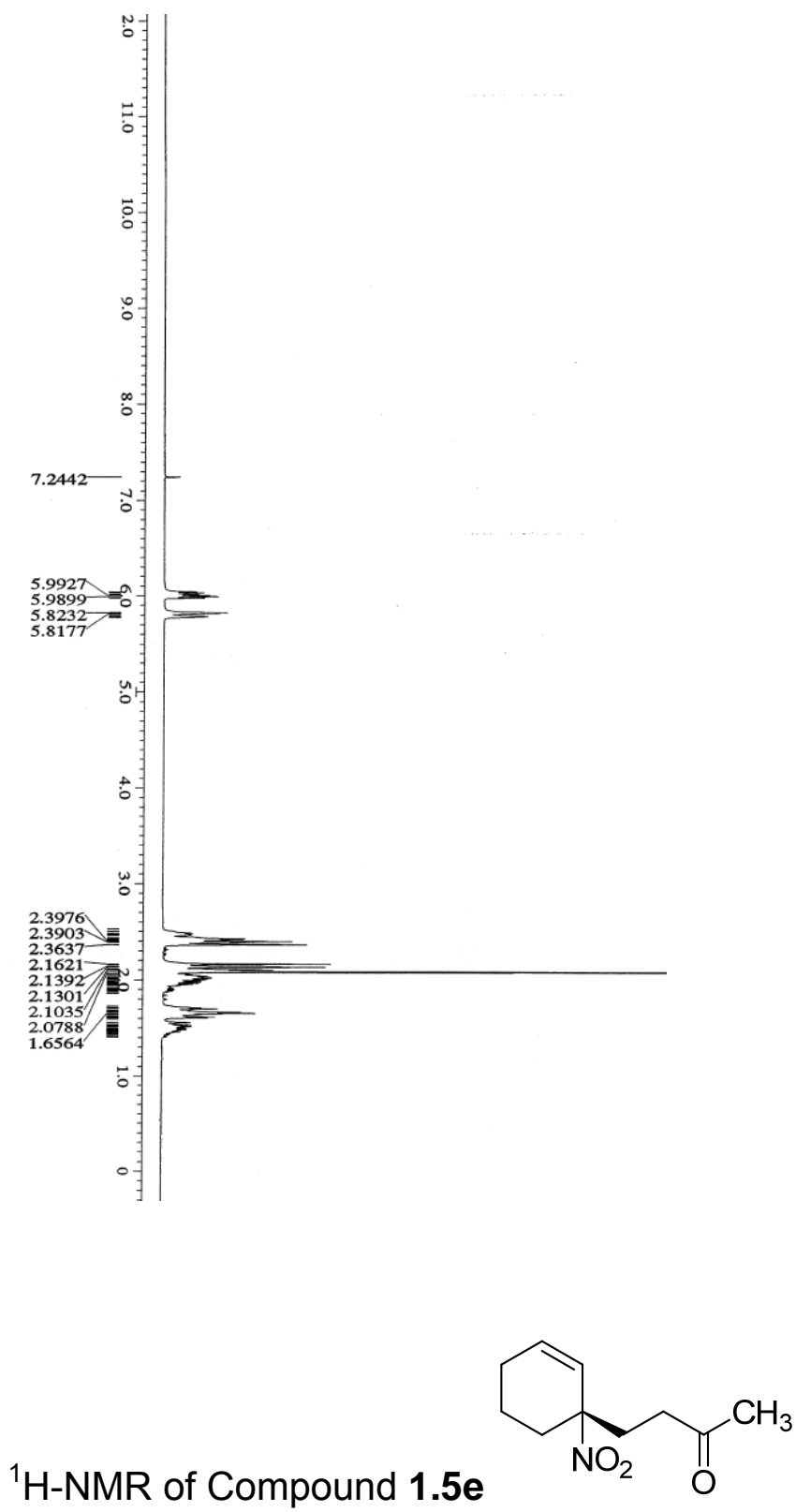

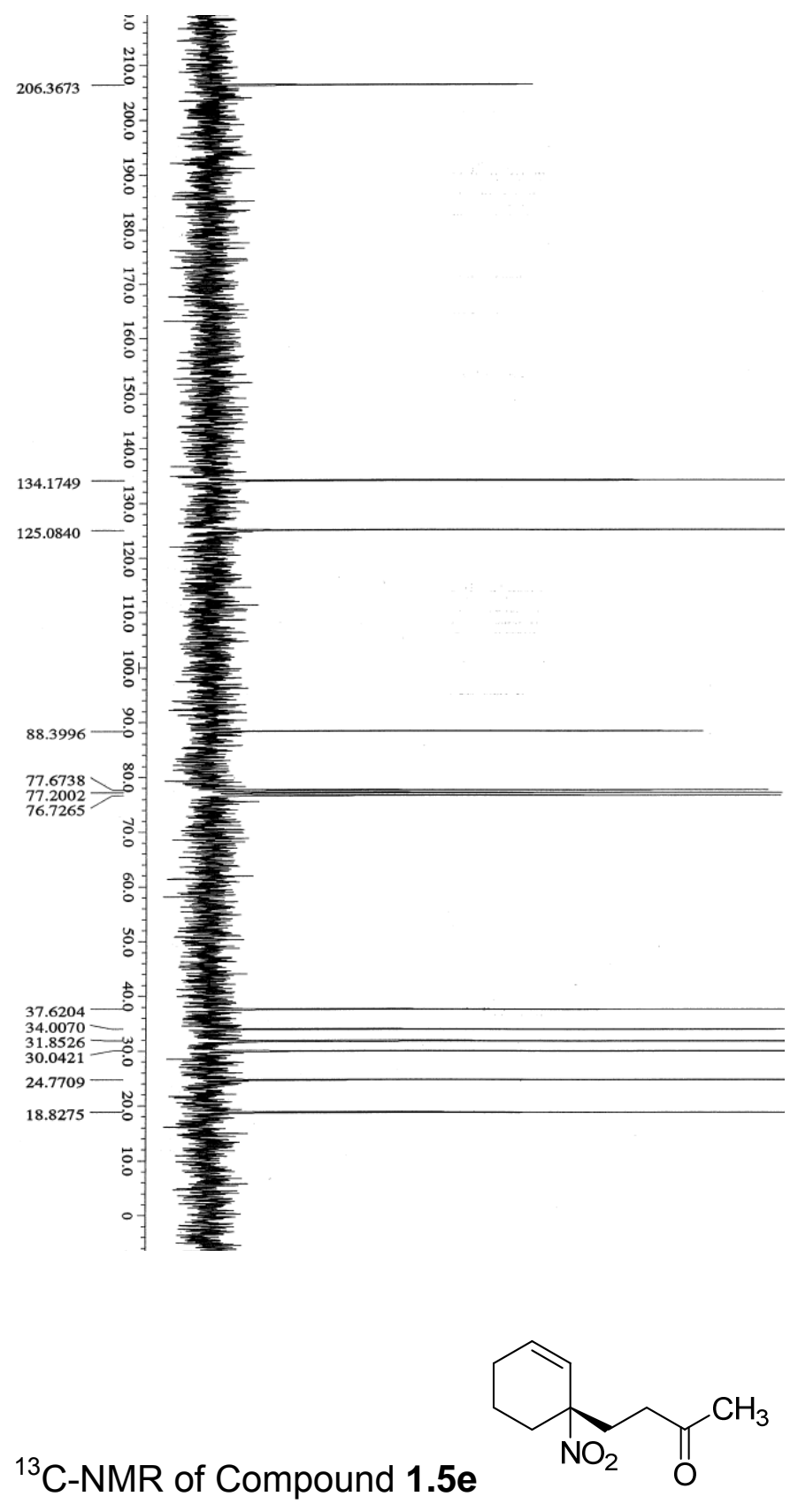

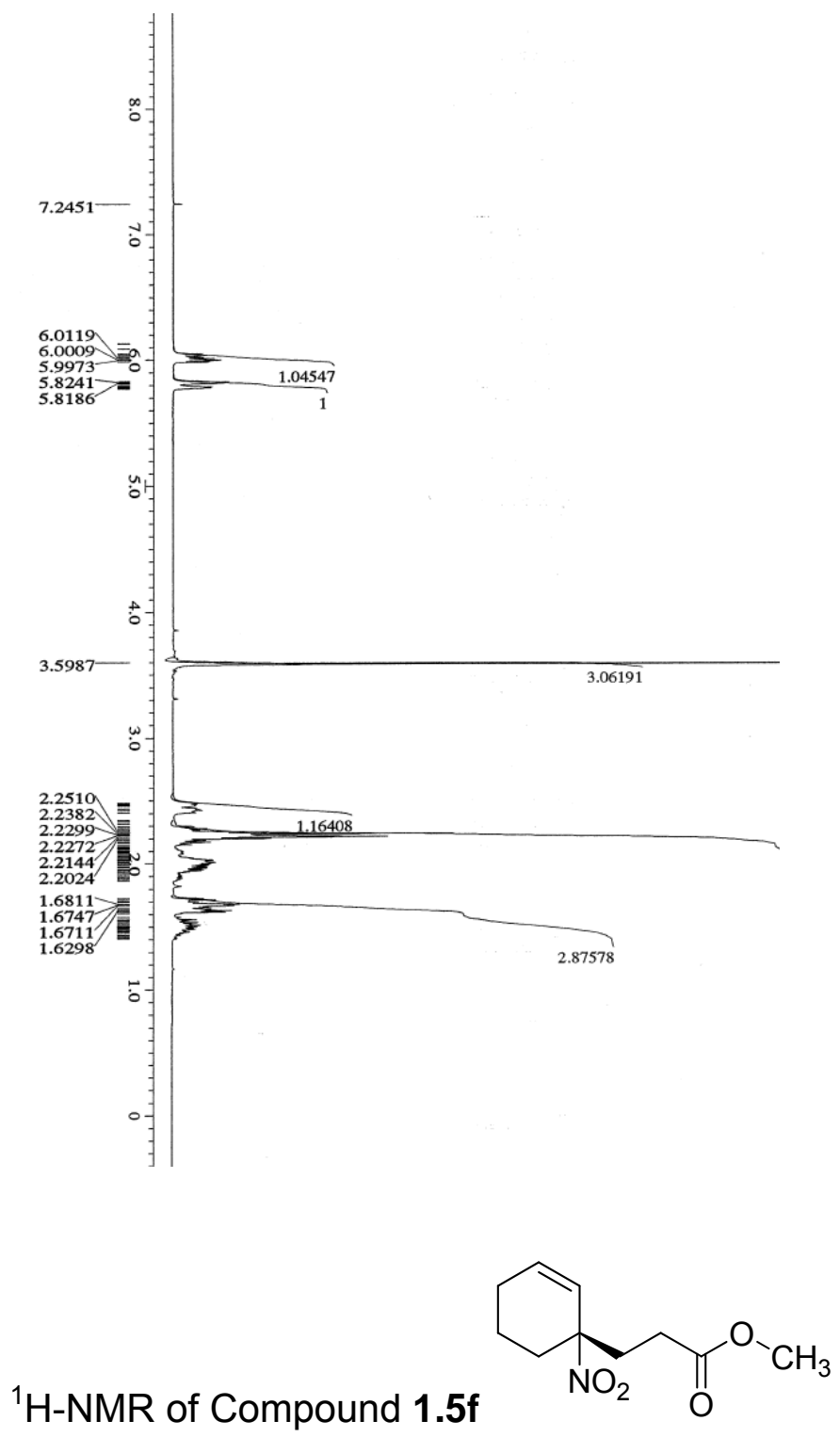


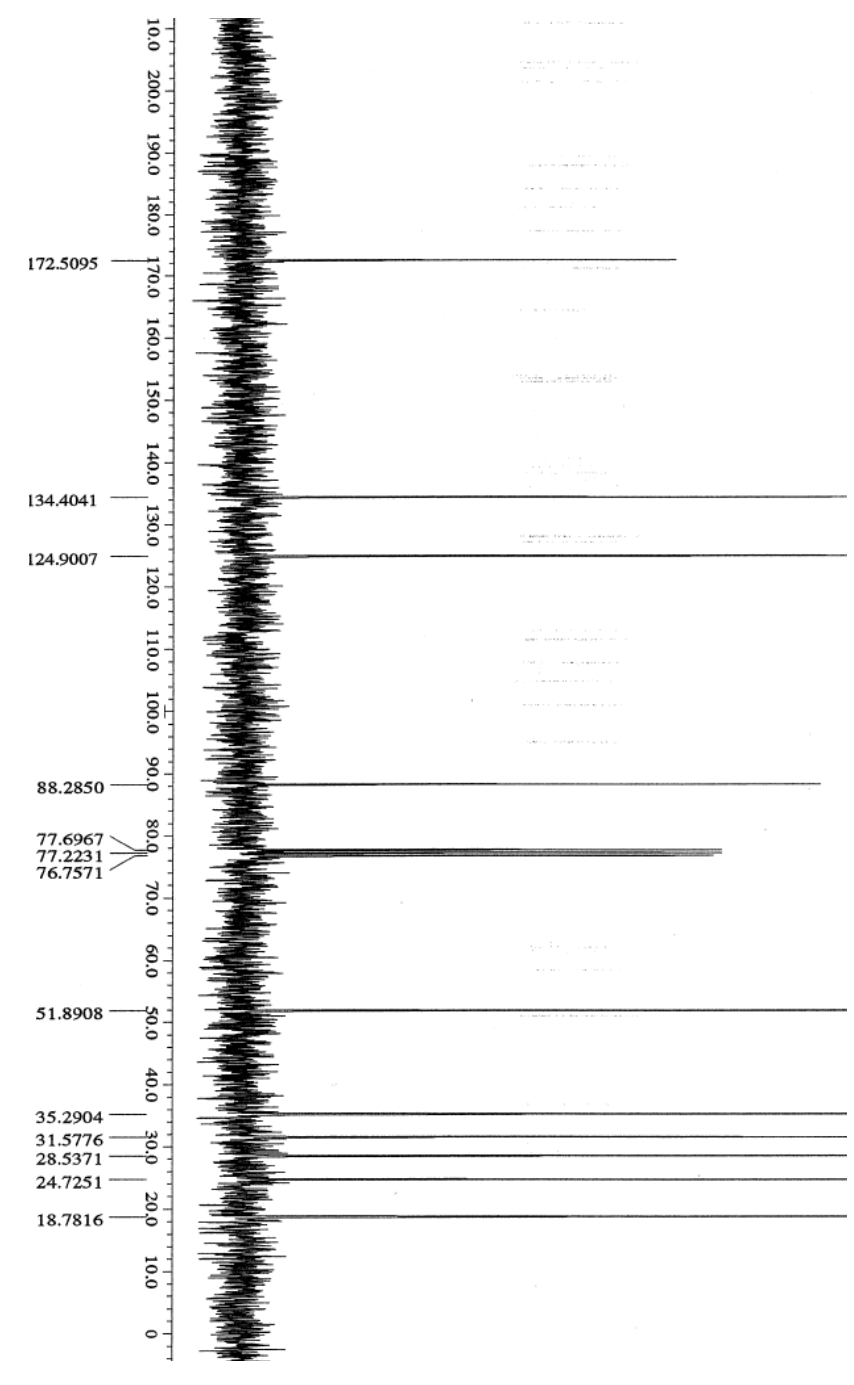

${ }^{13} \mathrm{C}$-NMR of Compound $\mathbf{1 . 5 f}$ 

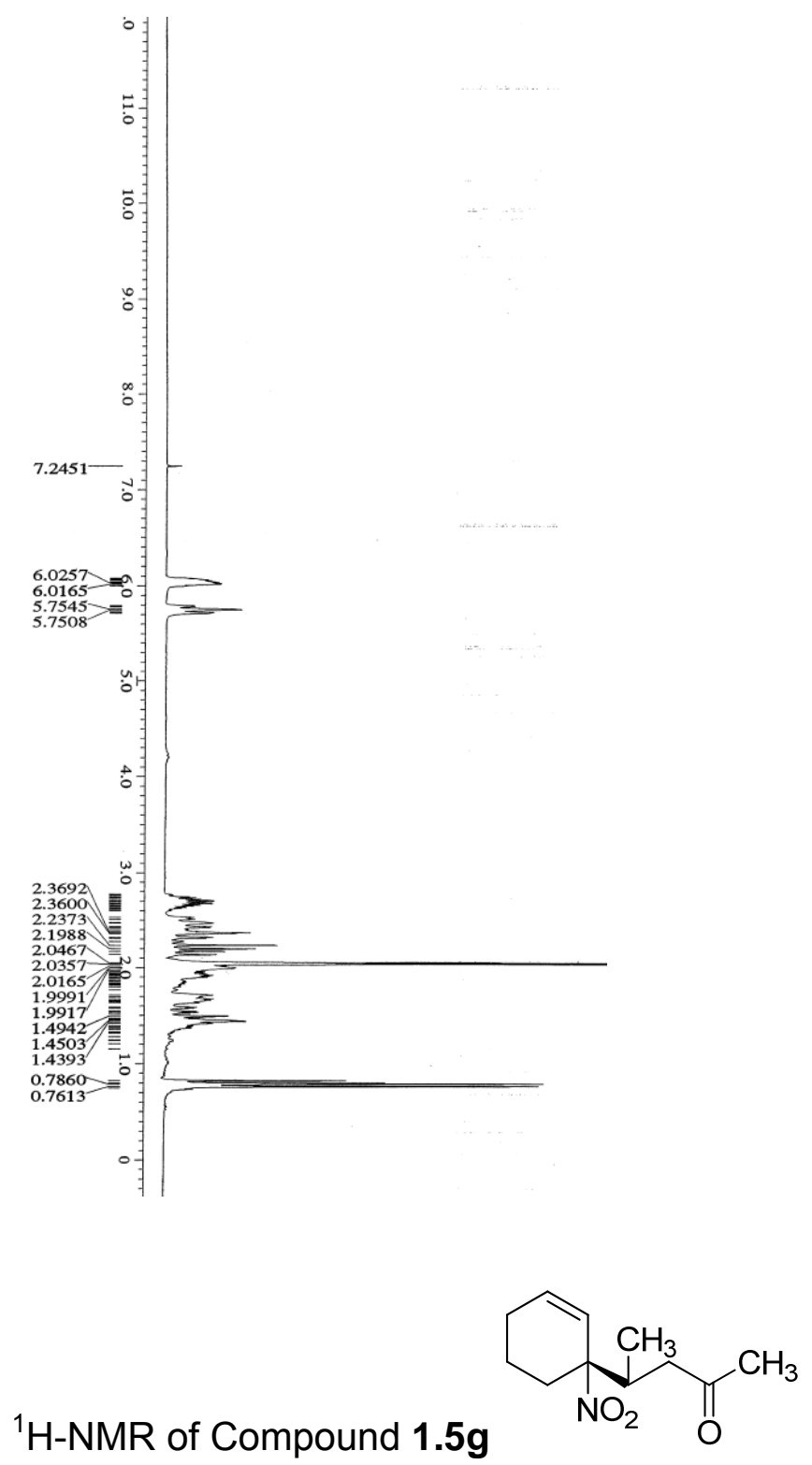


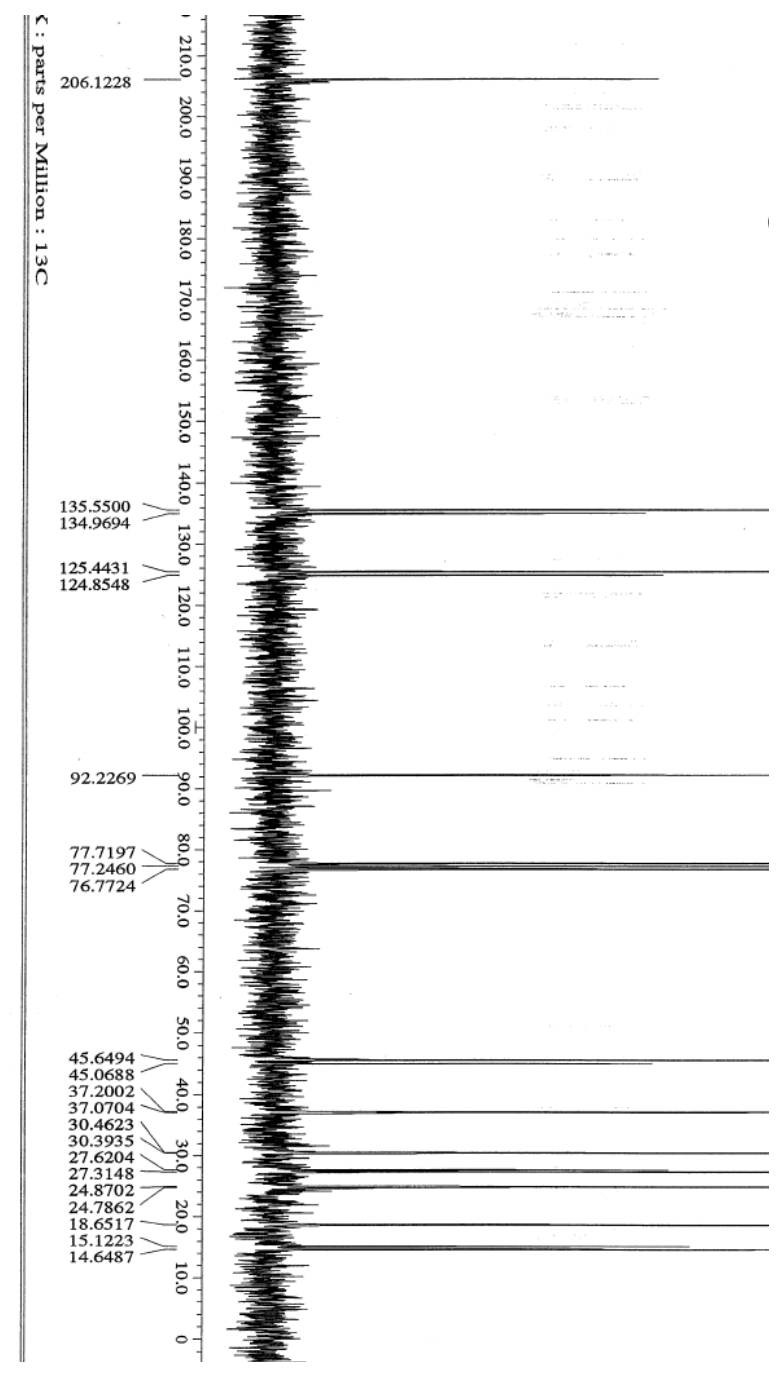

${ }^{13} \mathrm{C}-\mathrm{NMR}$ of Compound $\mathbf{1 . 5} \mathrm{g}$ 

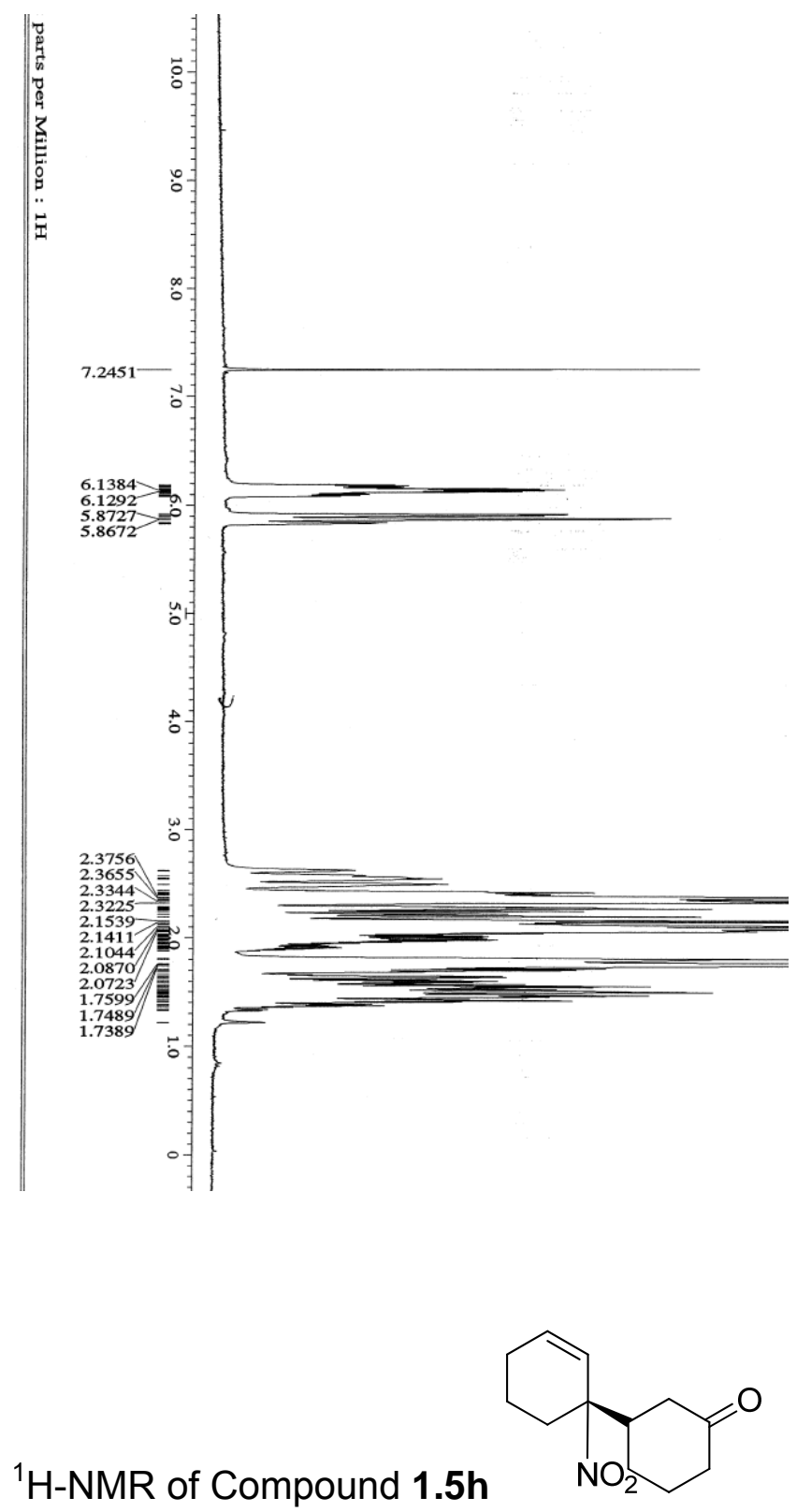


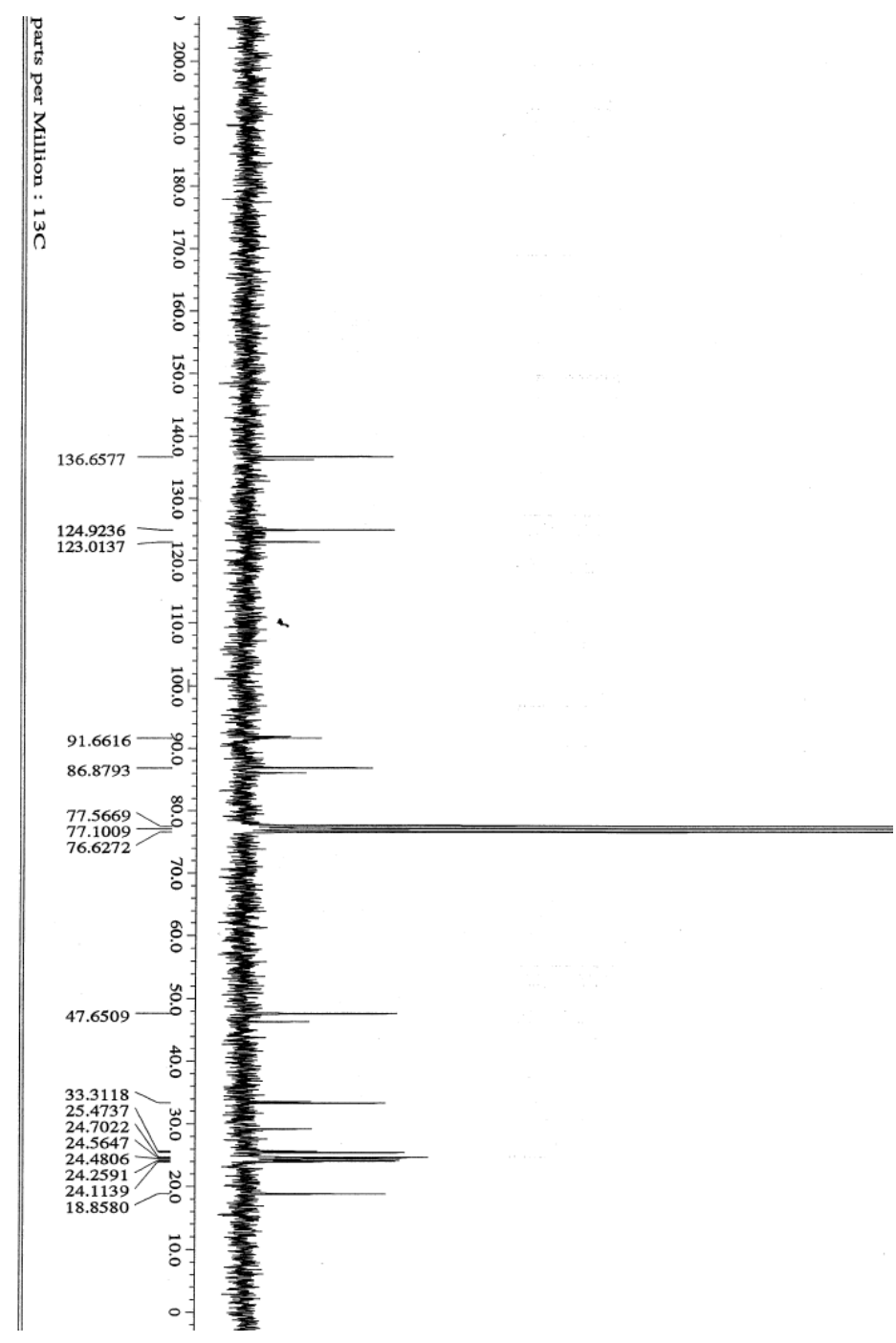

${ }^{13} \mathrm{C}-\mathrm{NMR}$ of Compound $\mathbf{1 . 5 h}$ (Isomer 1)

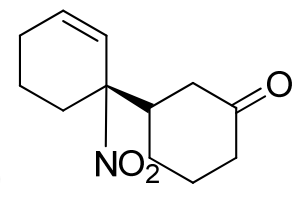




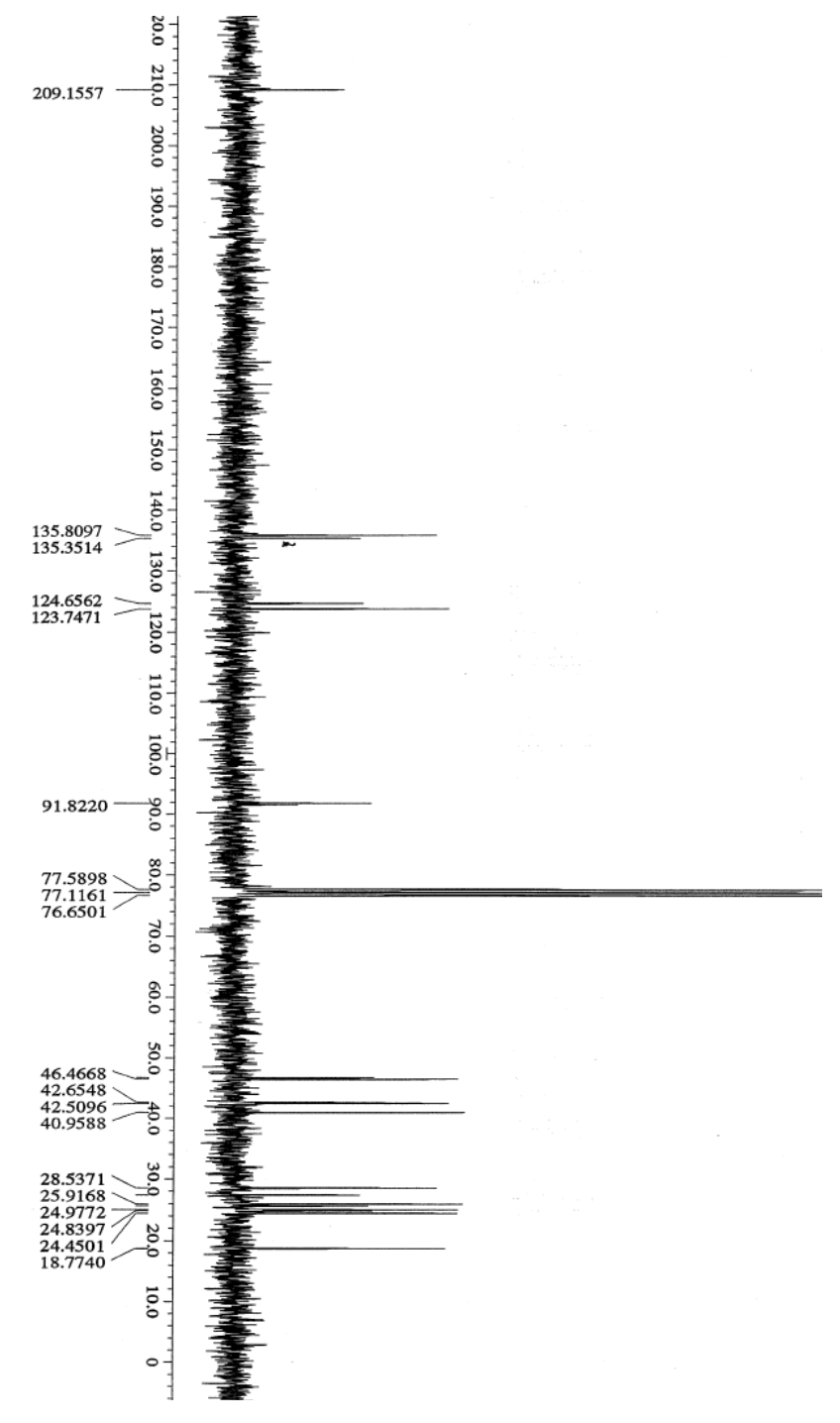

${ }^{13} \mathrm{C}$-NMR of Compound 1.5h (Isomer 2)

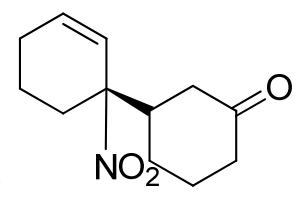



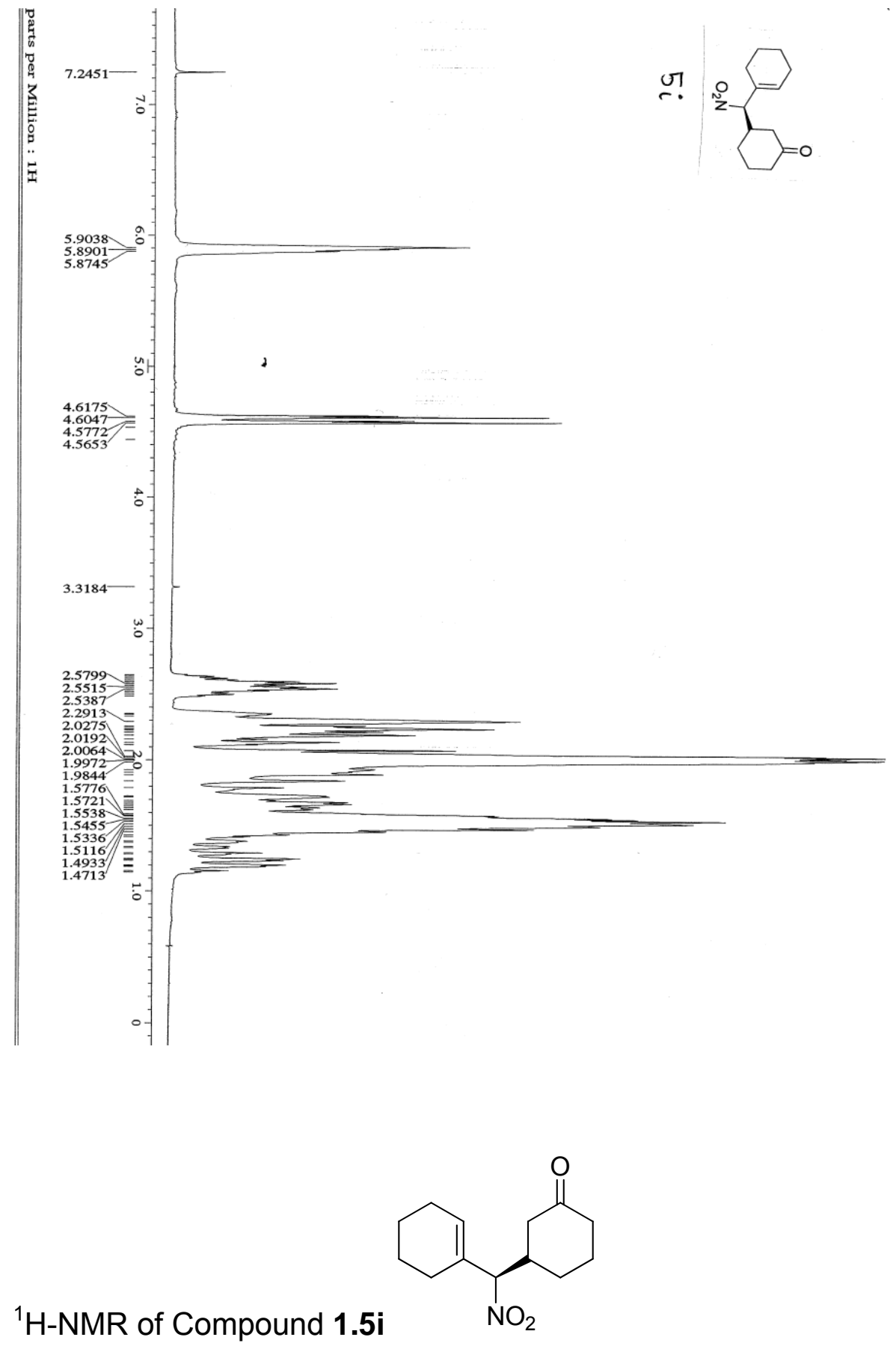

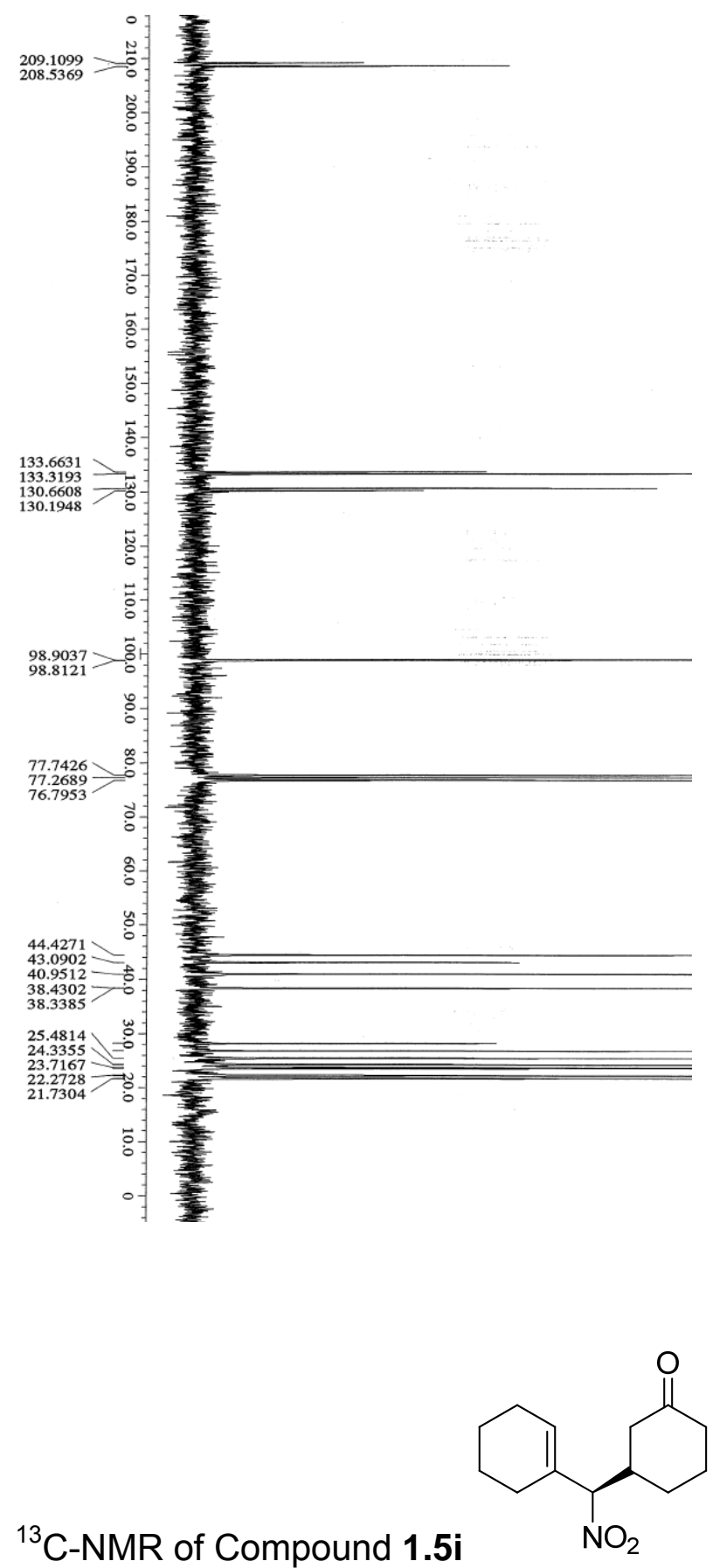

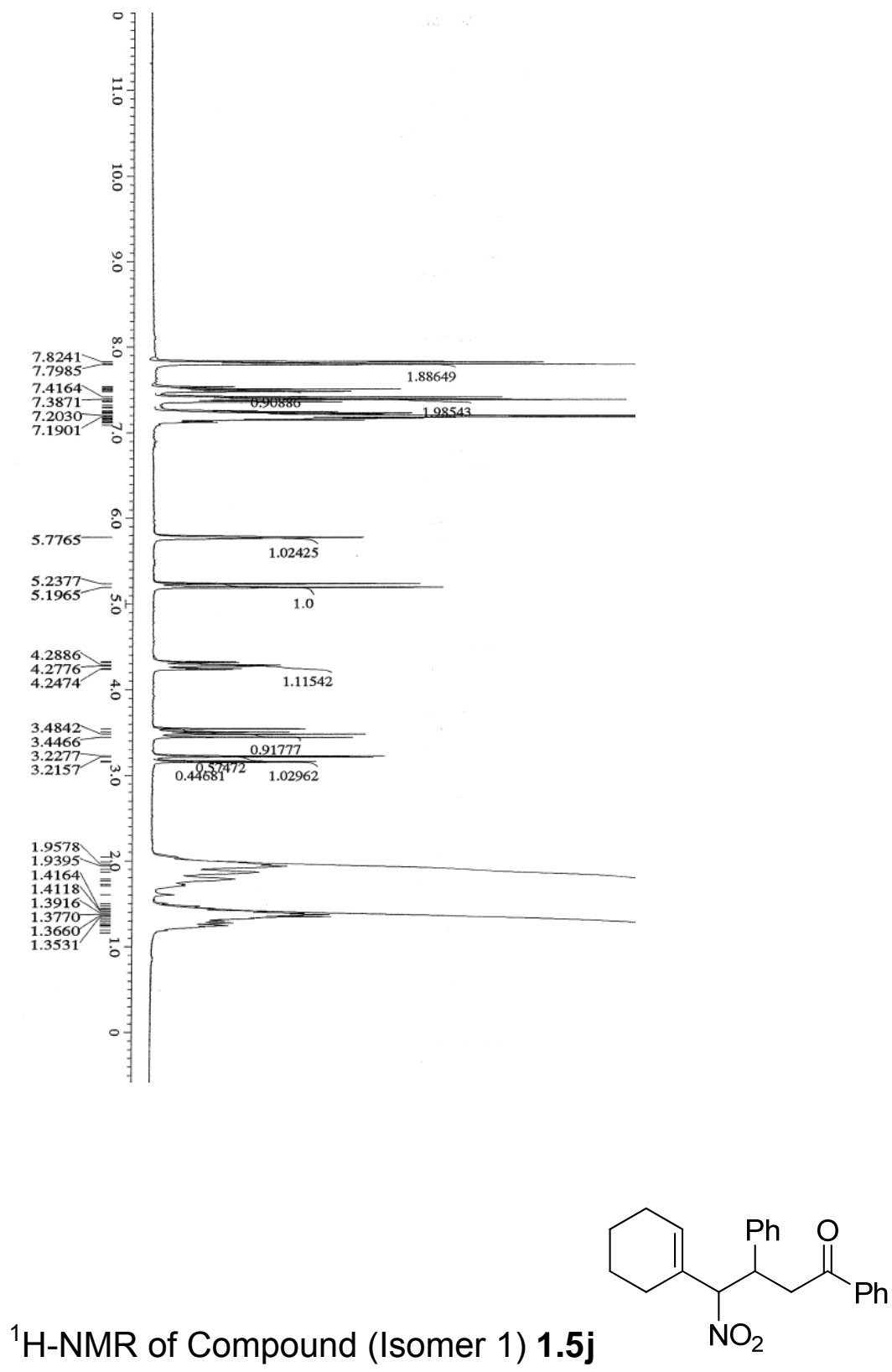

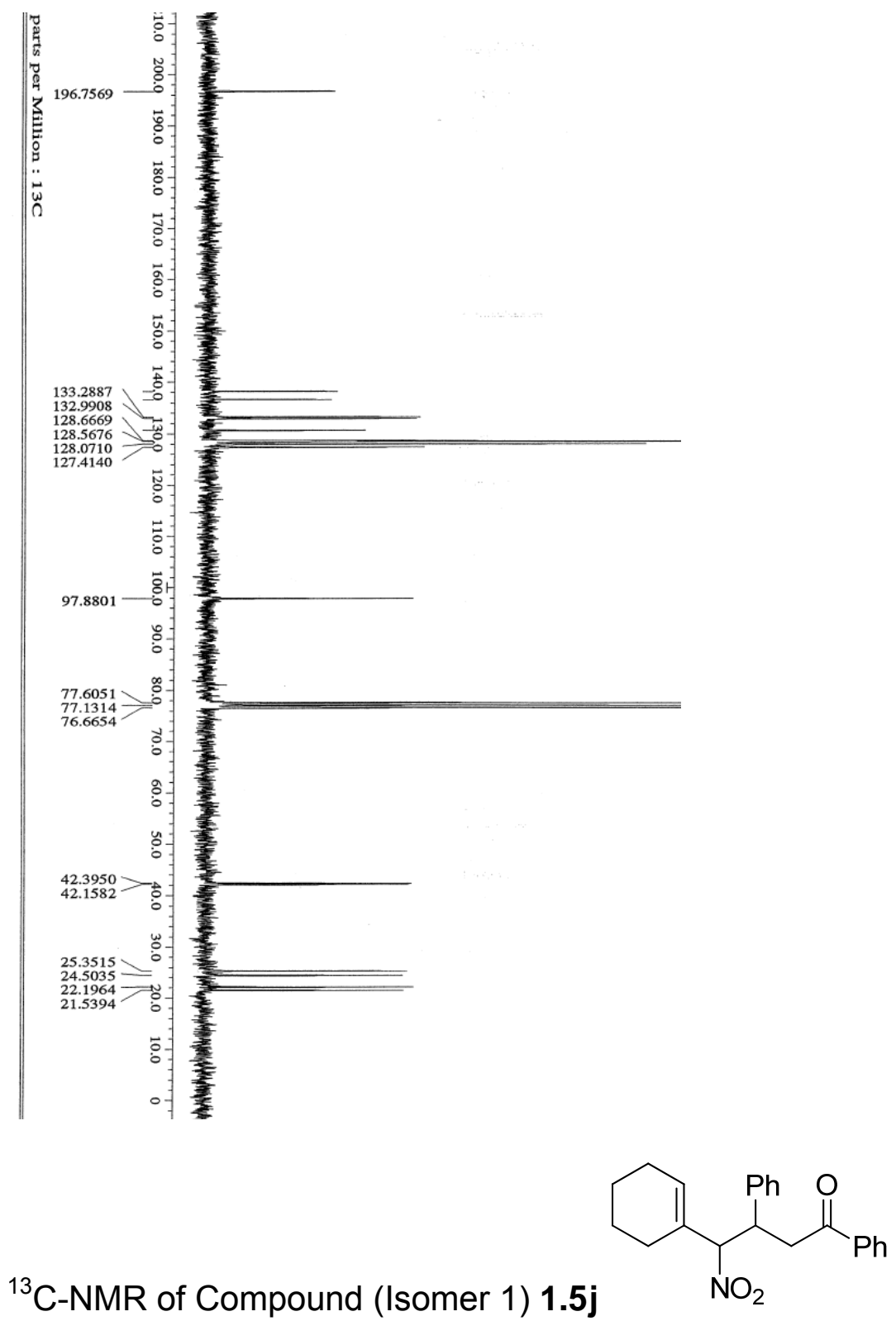


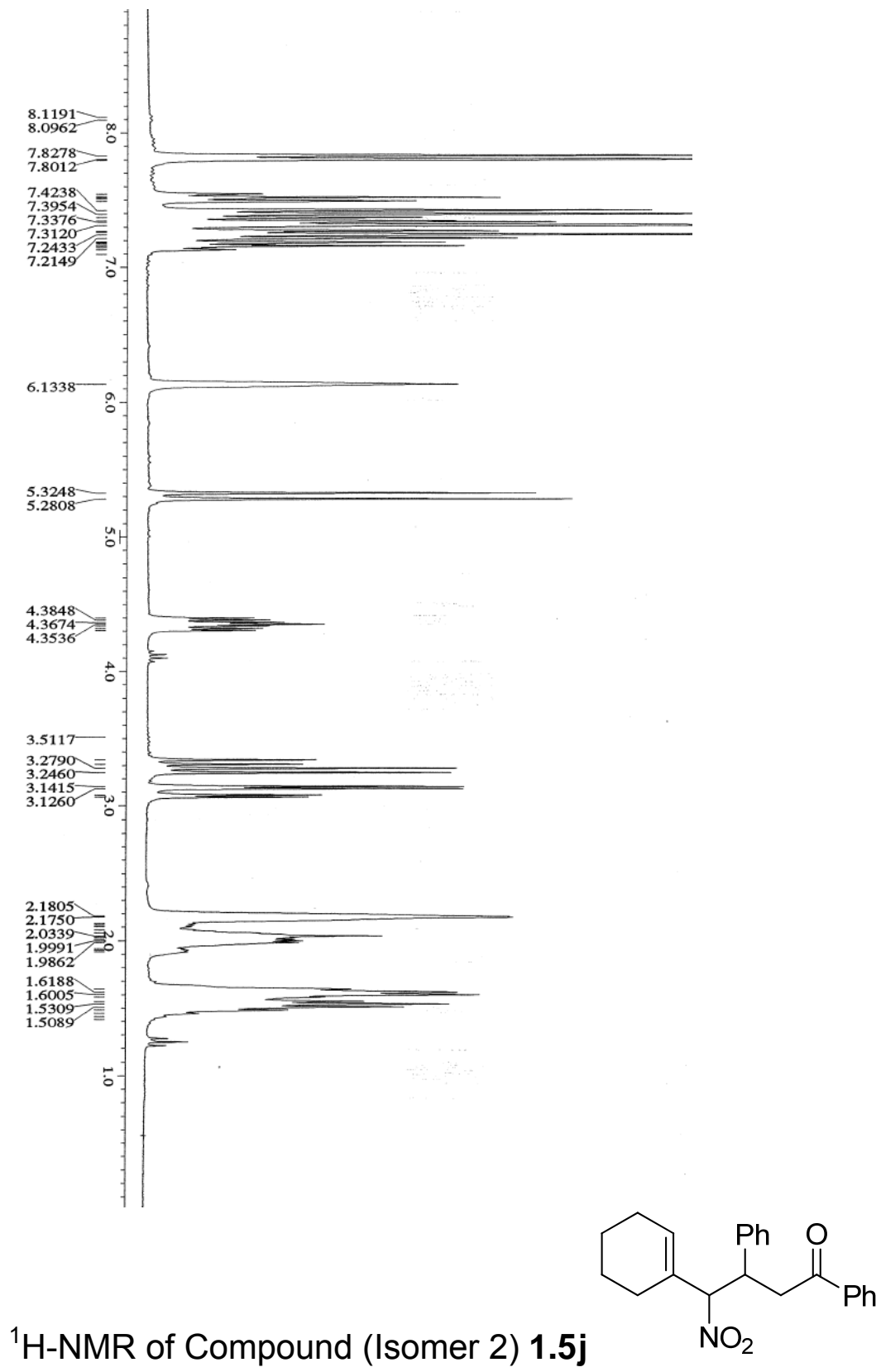




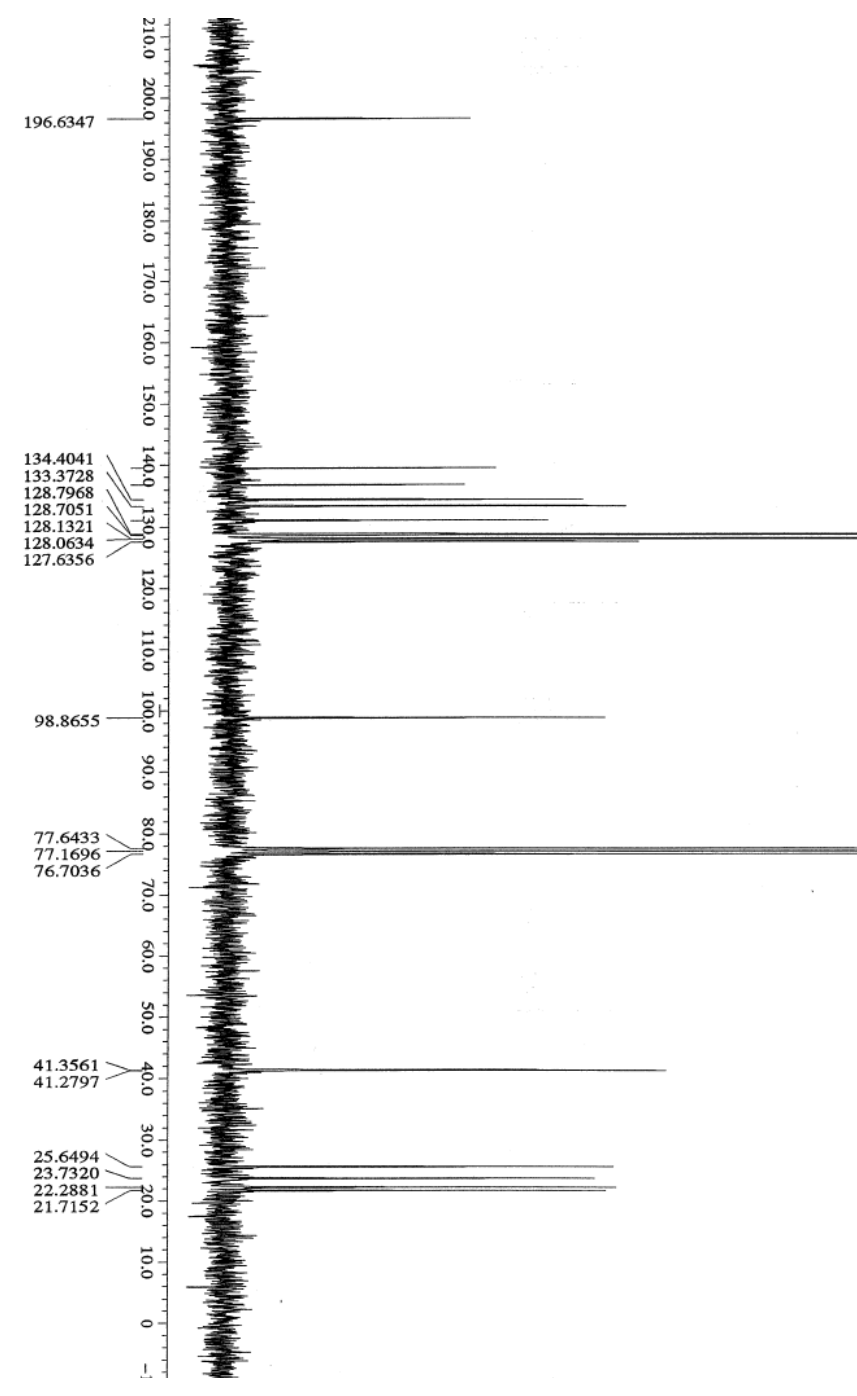

${ }^{13} \mathrm{C}-\mathrm{NMR}$ of Compound (Isomer 2) 1.5j<smiles>O=C(CC(c1ccccc1)C(C1=CCCCC1)[N+](=O)[O-])c1ccccc1</smiles> 


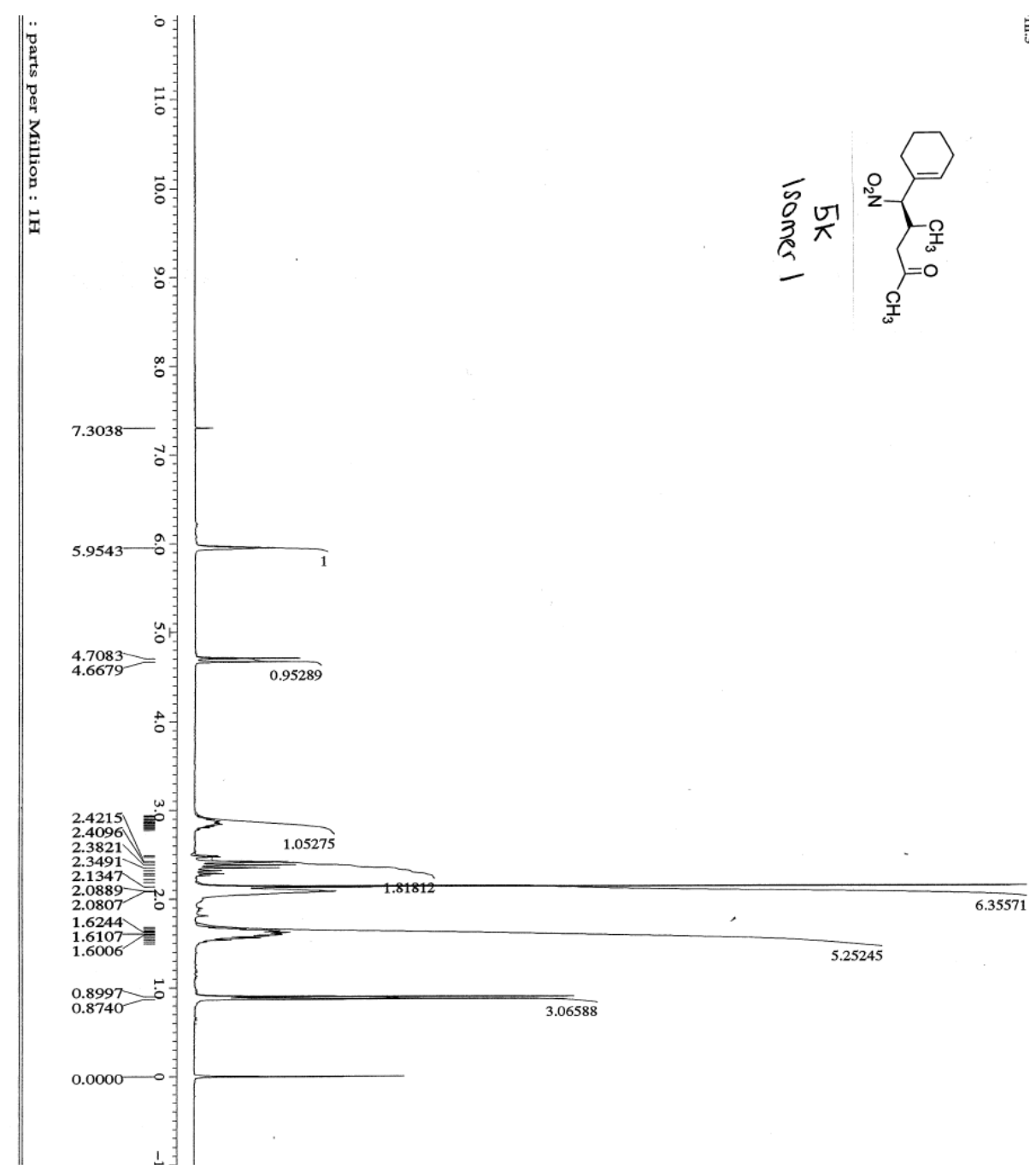

${ }^{1} \mathrm{H}-\mathrm{NMR}$ of Compound (Isomer 1) 1.5k

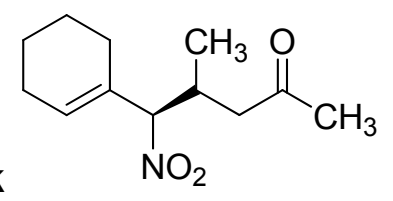




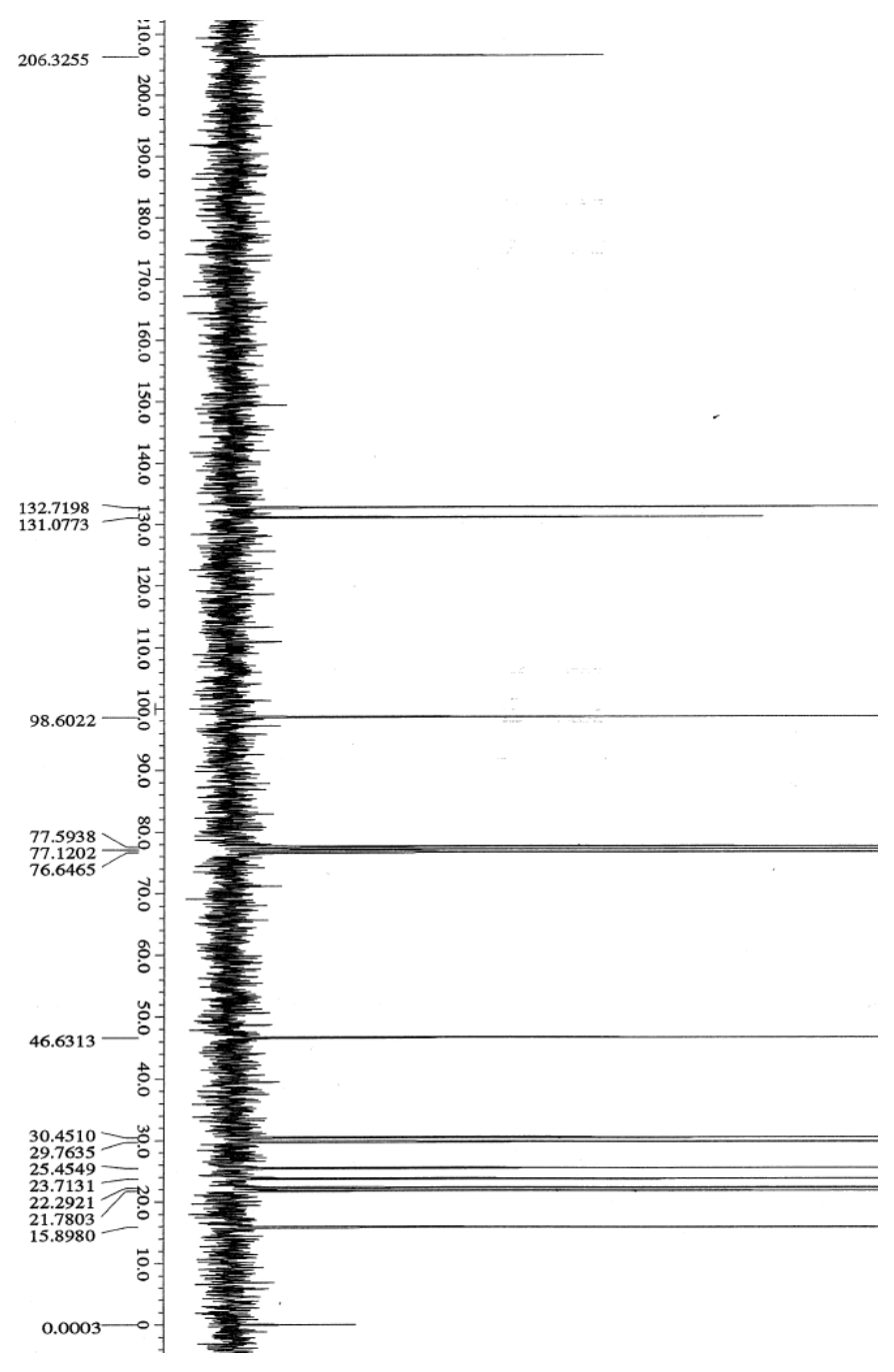

${ }^{13} \mathrm{C}-\mathrm{NMR}$ of Compound (Isomer 1) 1.5k $\quad \mathrm{NO}_{2}$ 


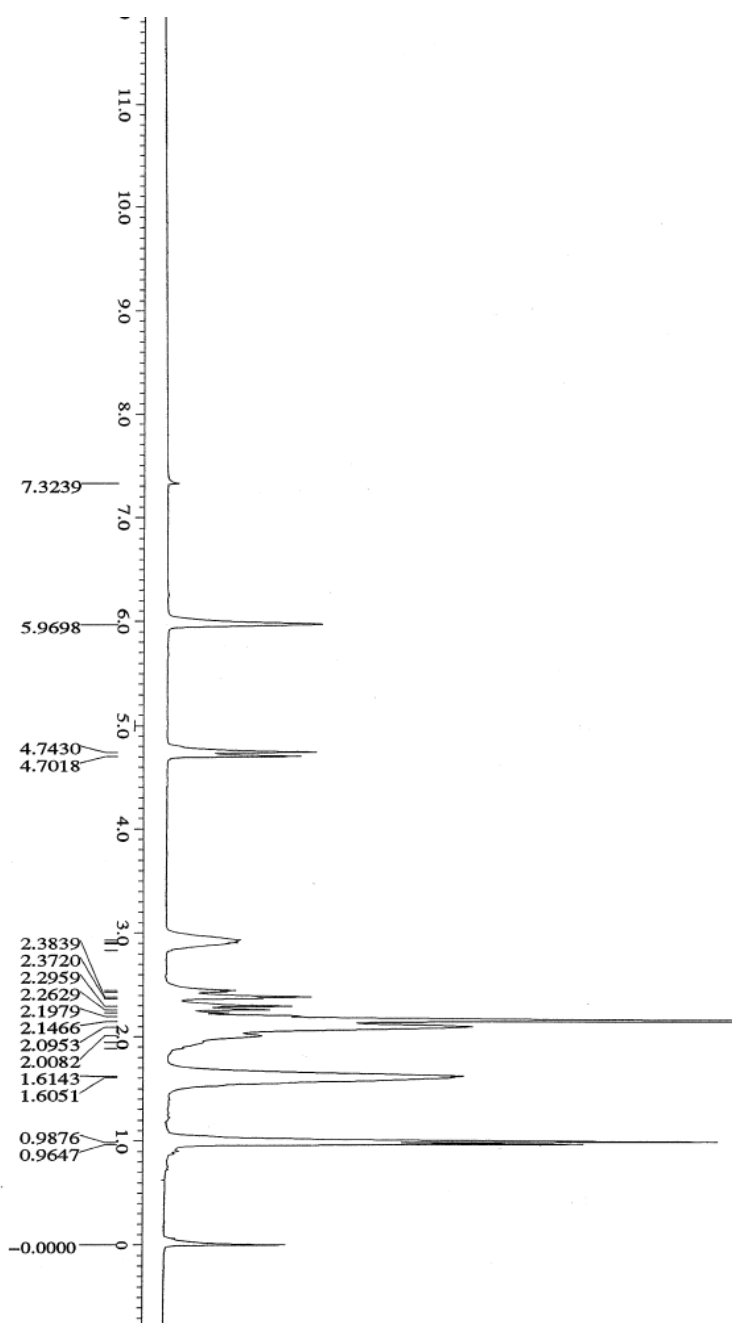

${ }^{1} \mathrm{H}-\mathrm{NMR}$ of Compound (Isomer 2) 1.5k $\quad \mathrm{NO}_{2}$ 


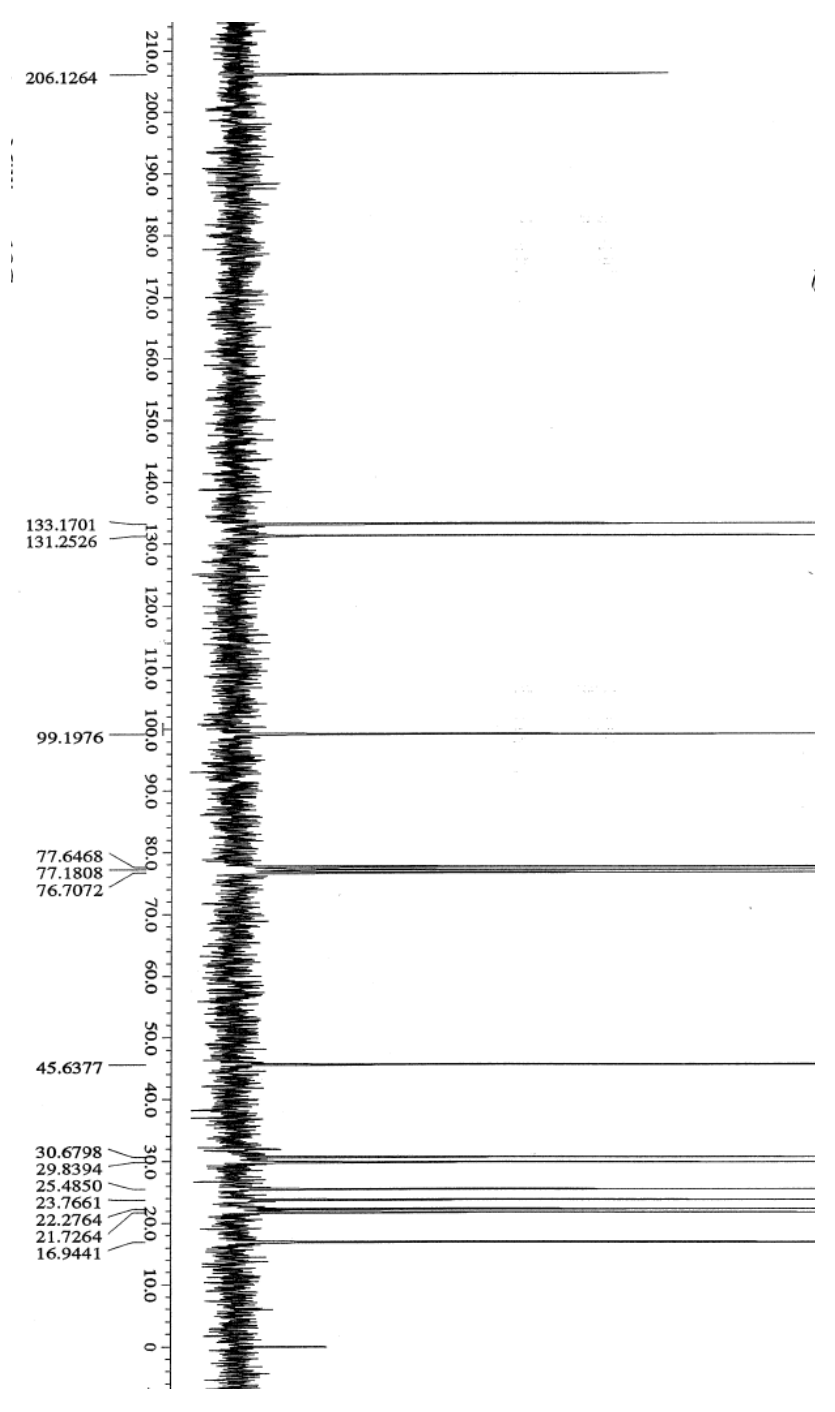

${ }^{13} \mathrm{C}-\mathrm{NMR}$ of Compound (Isomer 2) 1.5k<smiles>CC(=O)CC(C)[C@H](C1=CCCCC1)[N+](=O)[O-]</smiles> 

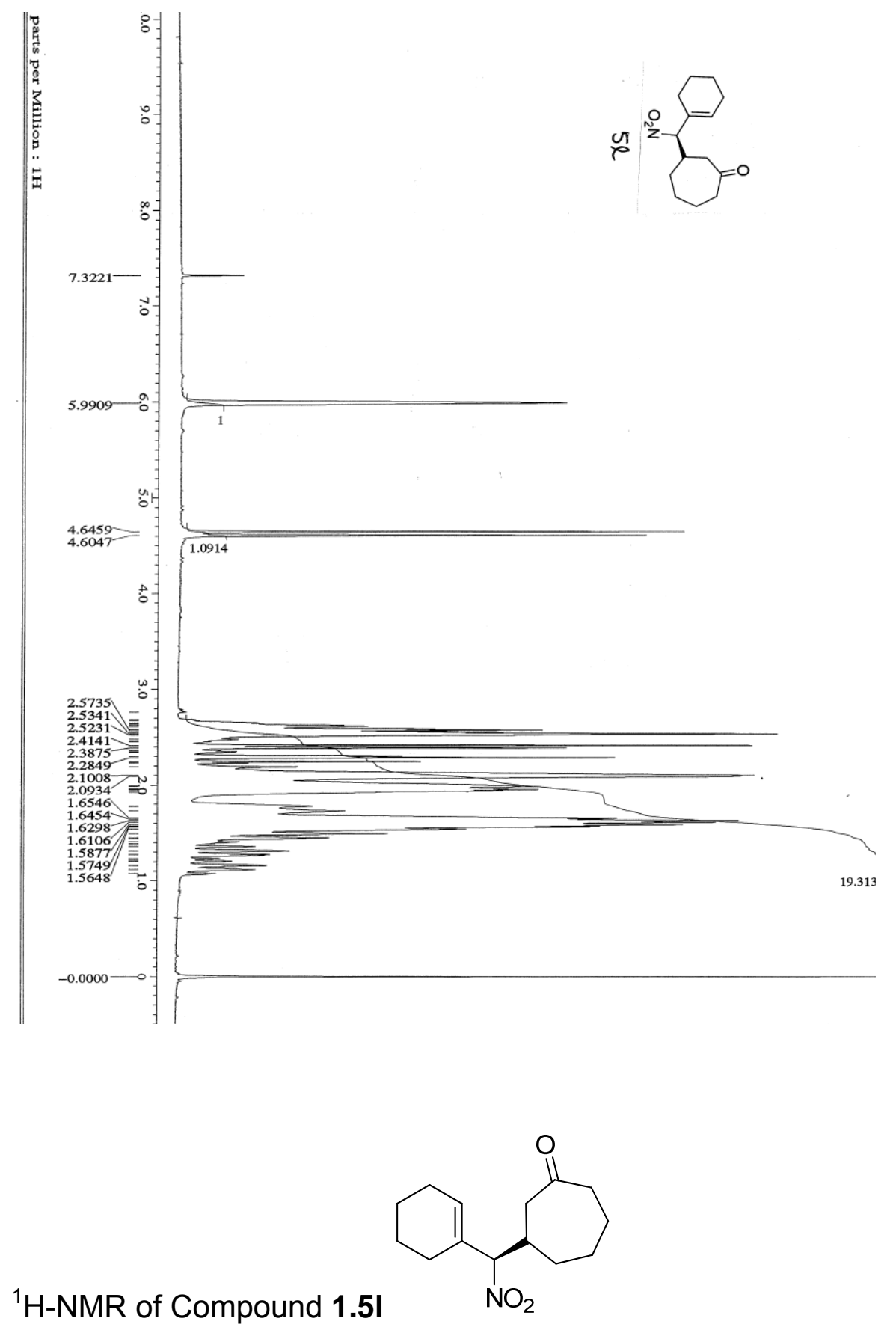


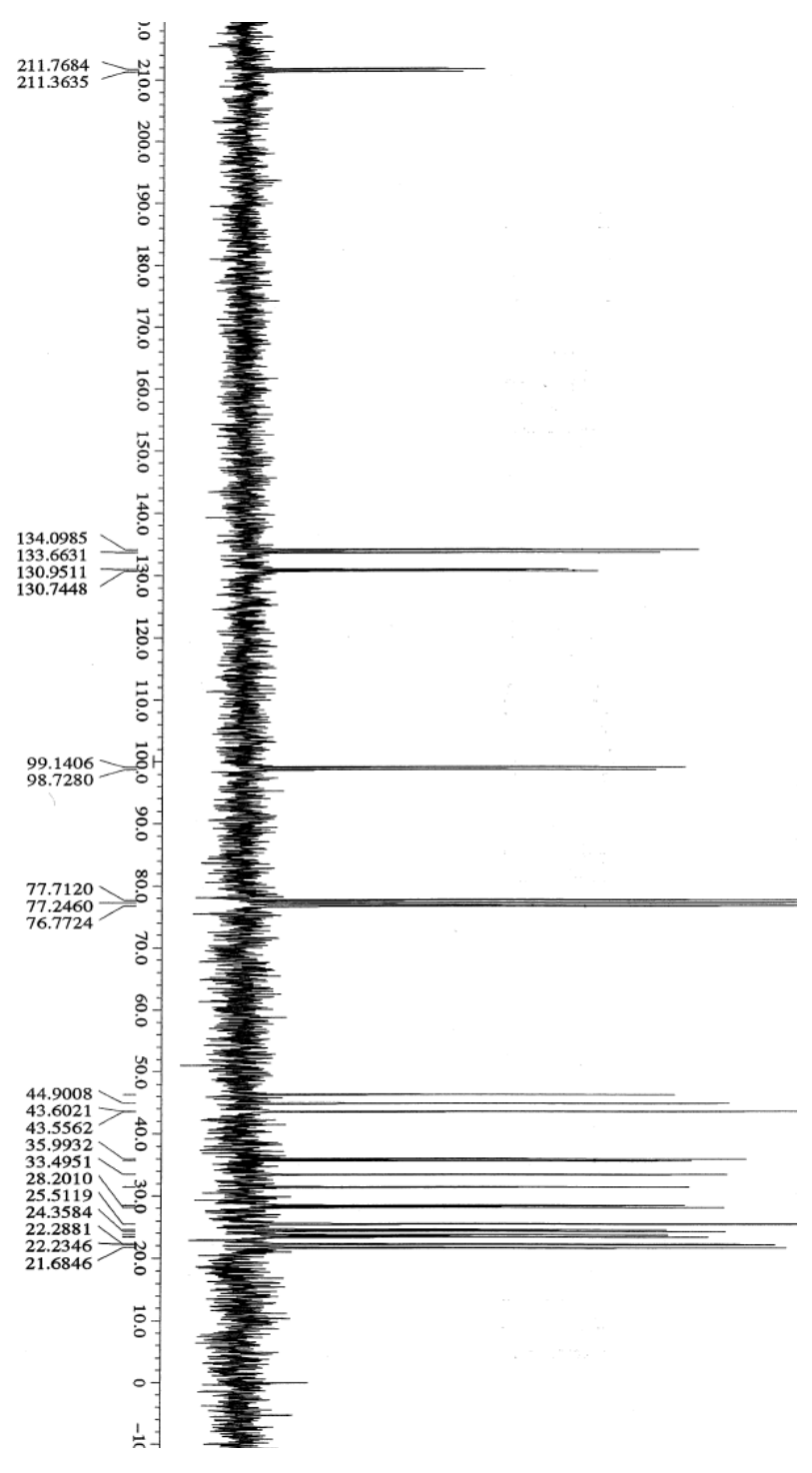

${ }^{13} \mathrm{C}$-NMR of Compound 1.5I (Isomer 1) 

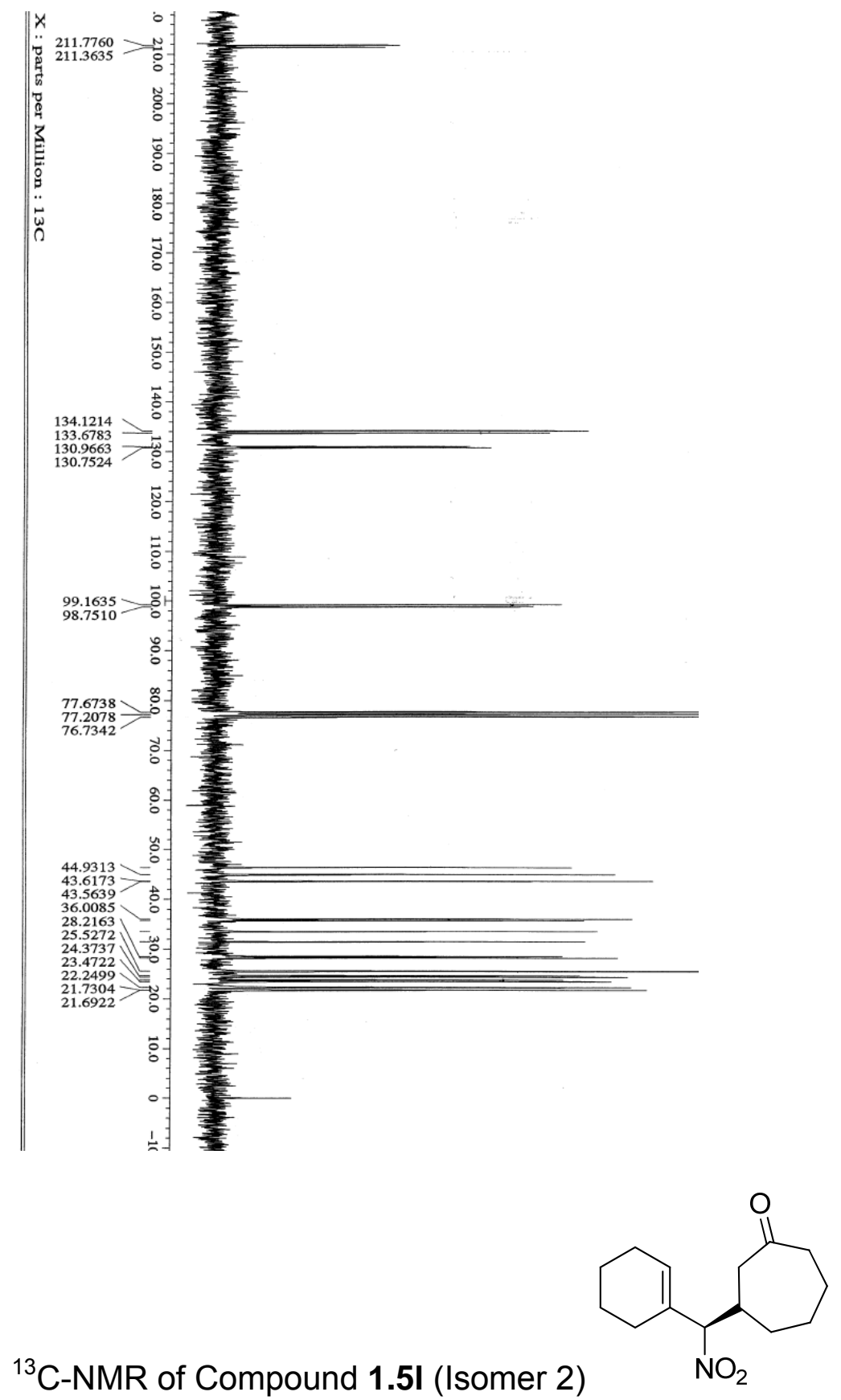


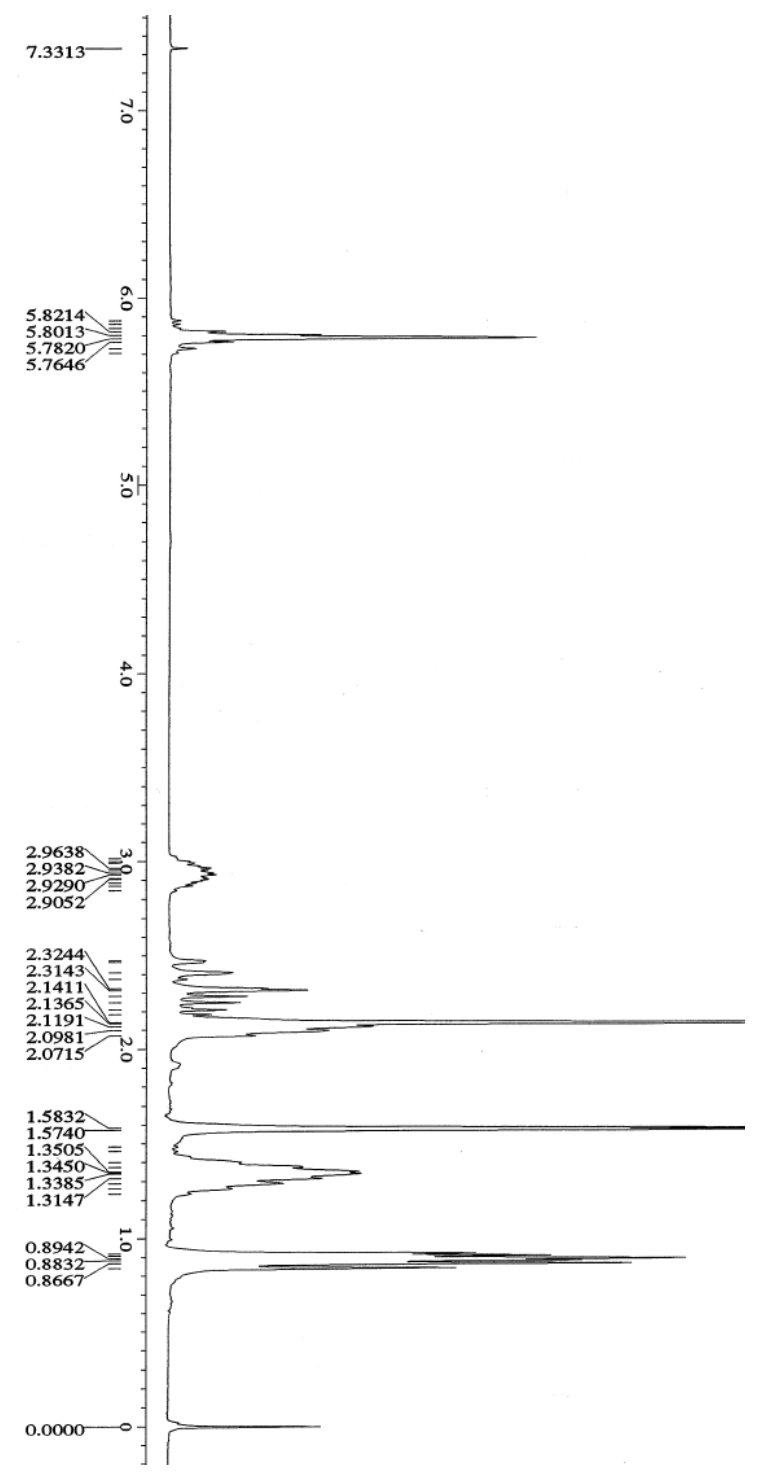

${ }^{1} \mathrm{H}$-NMR of Compound $1.5 \mathrm{~m}$ 


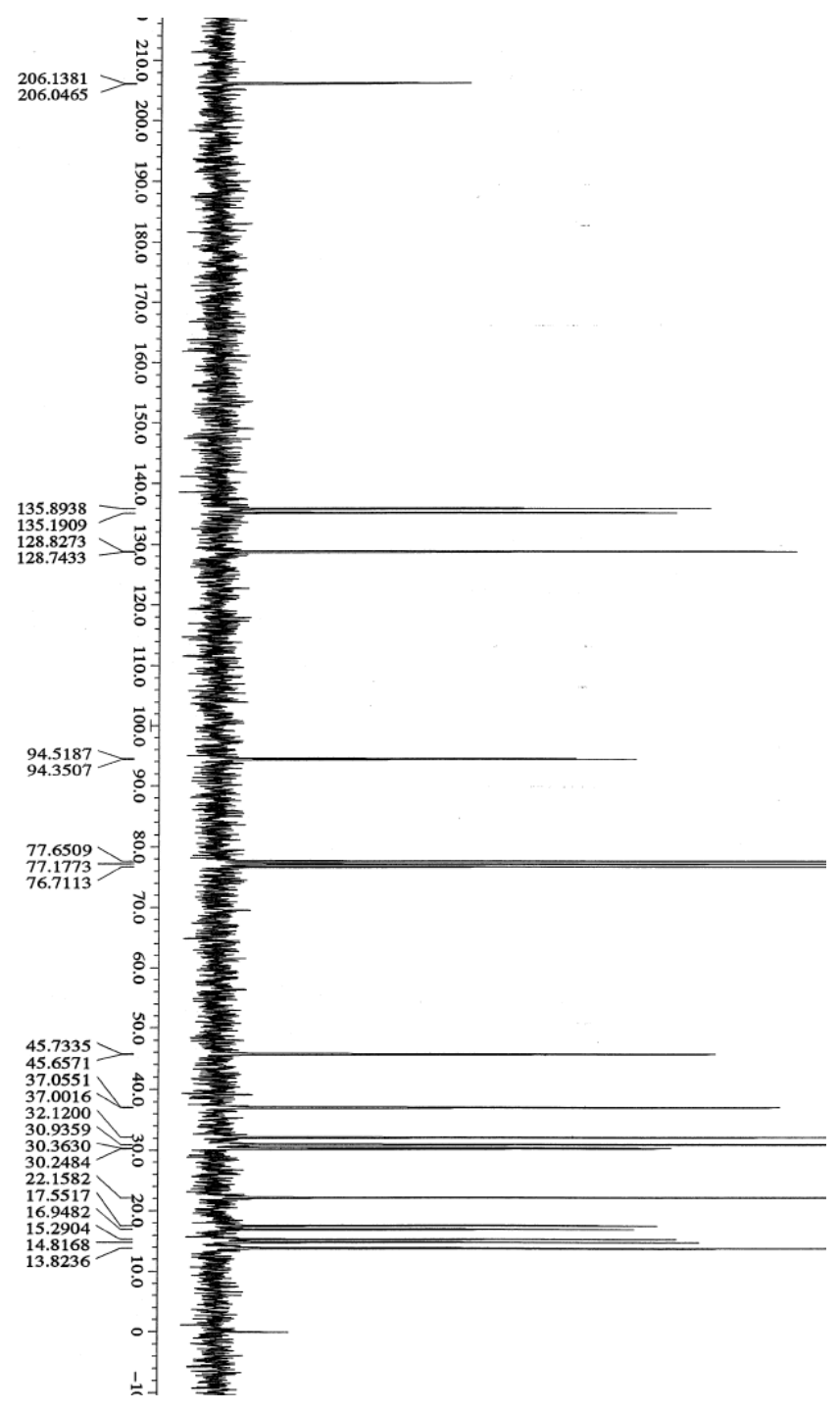

${ }^{13} \mathrm{C}$-NMR of Compound $1.5 \mathrm{~m}$ 


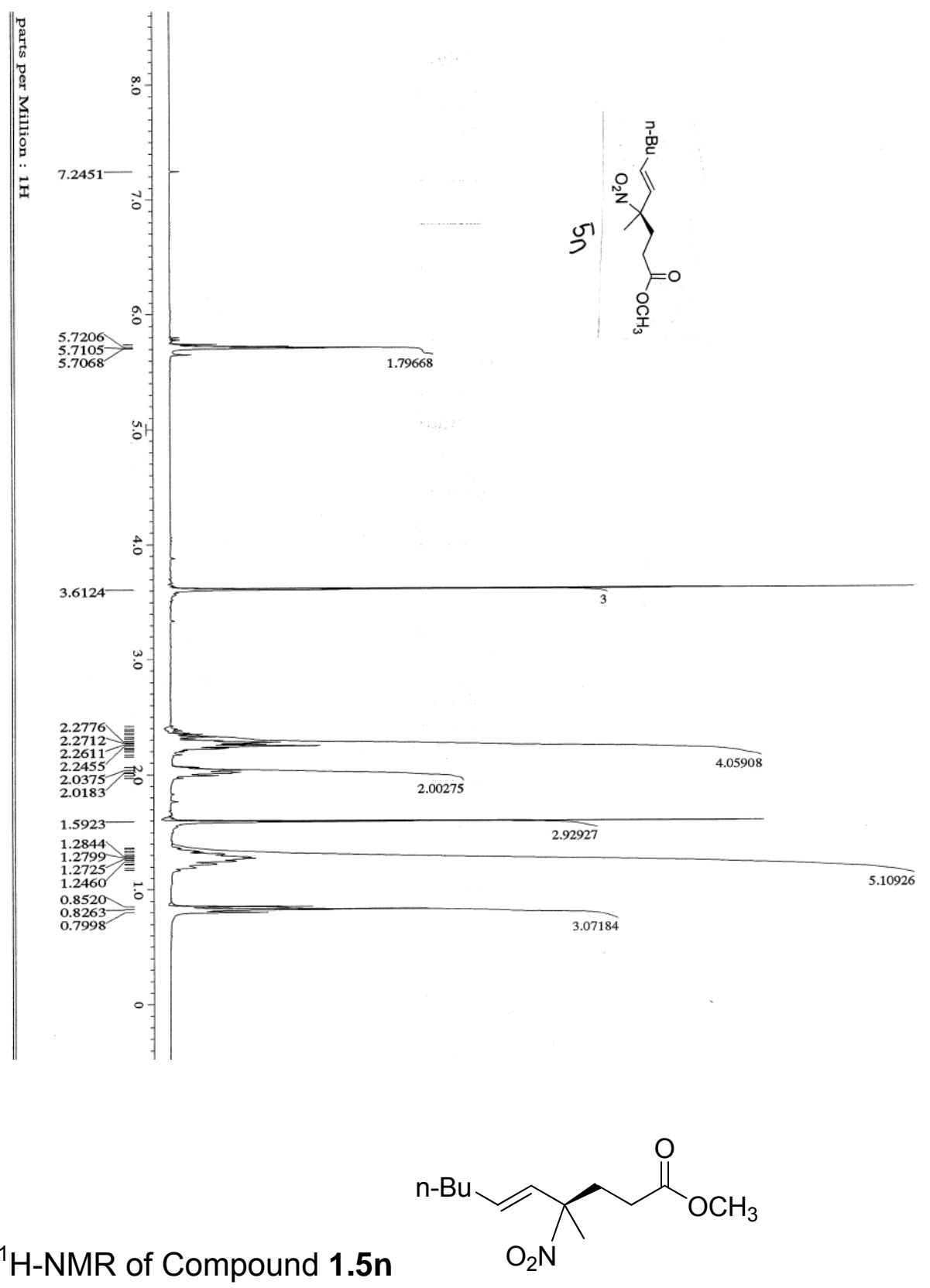




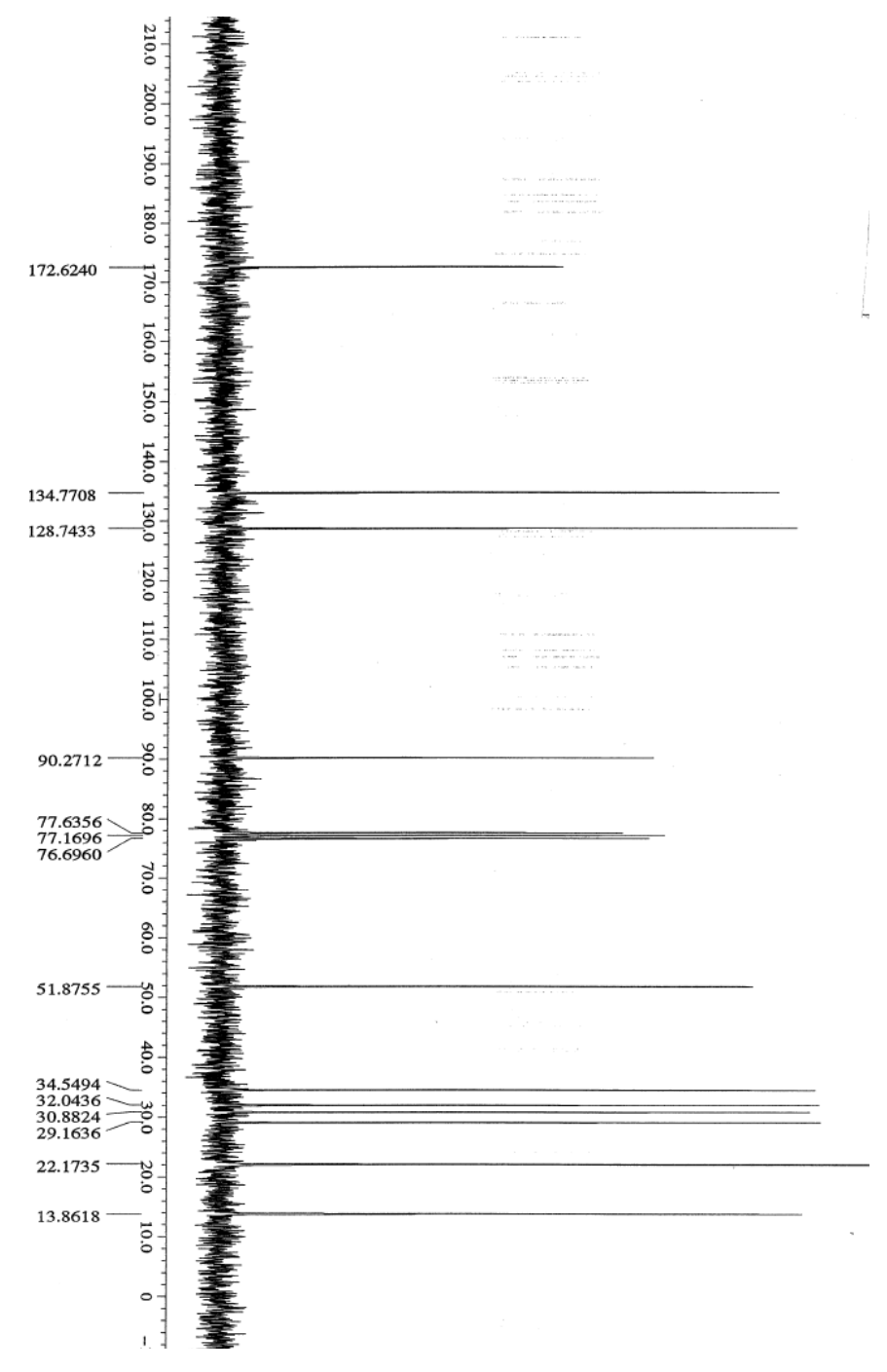

${ }^{13} \mathrm{C}$-NMR of Compound 1.5n 

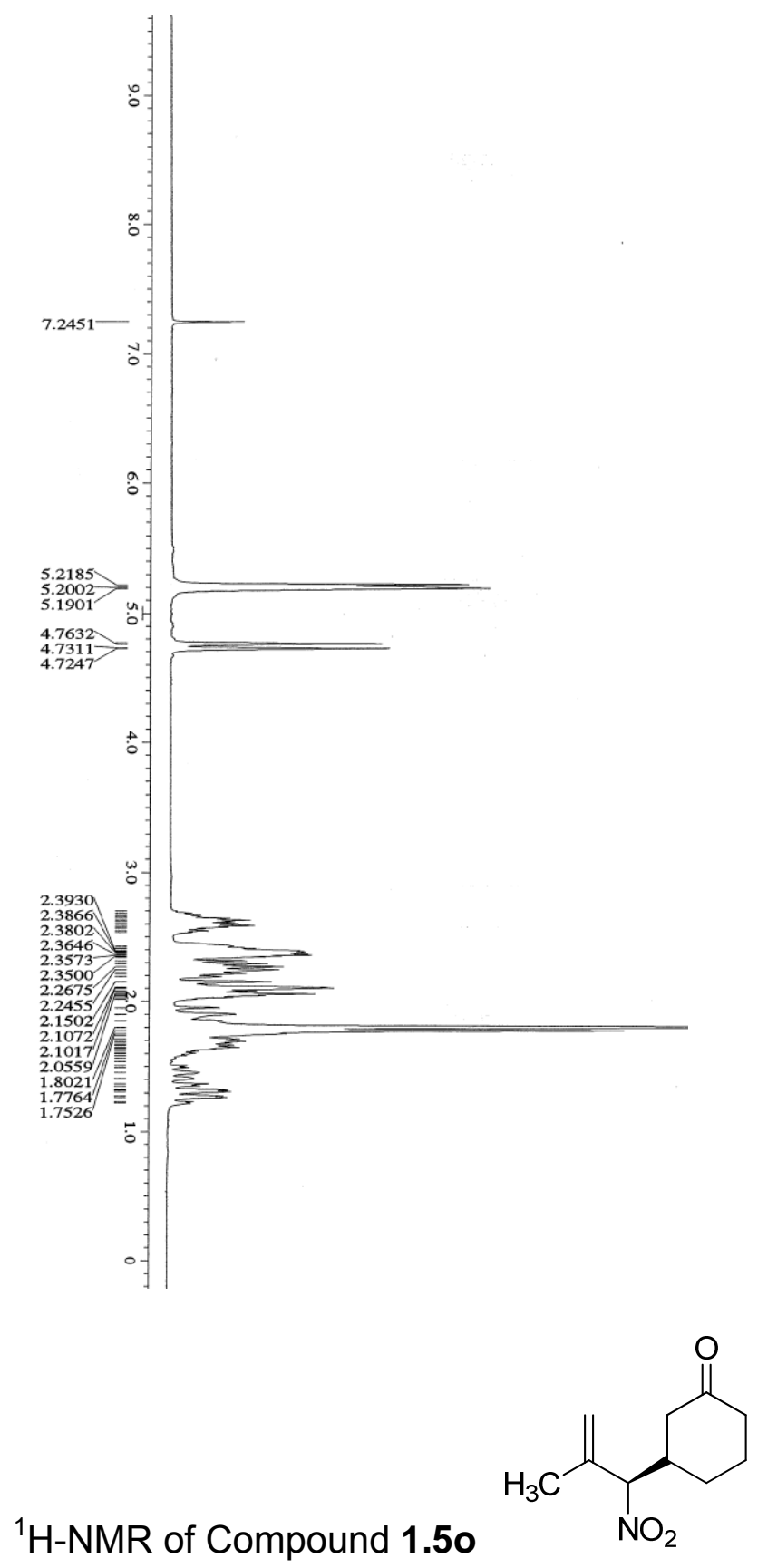

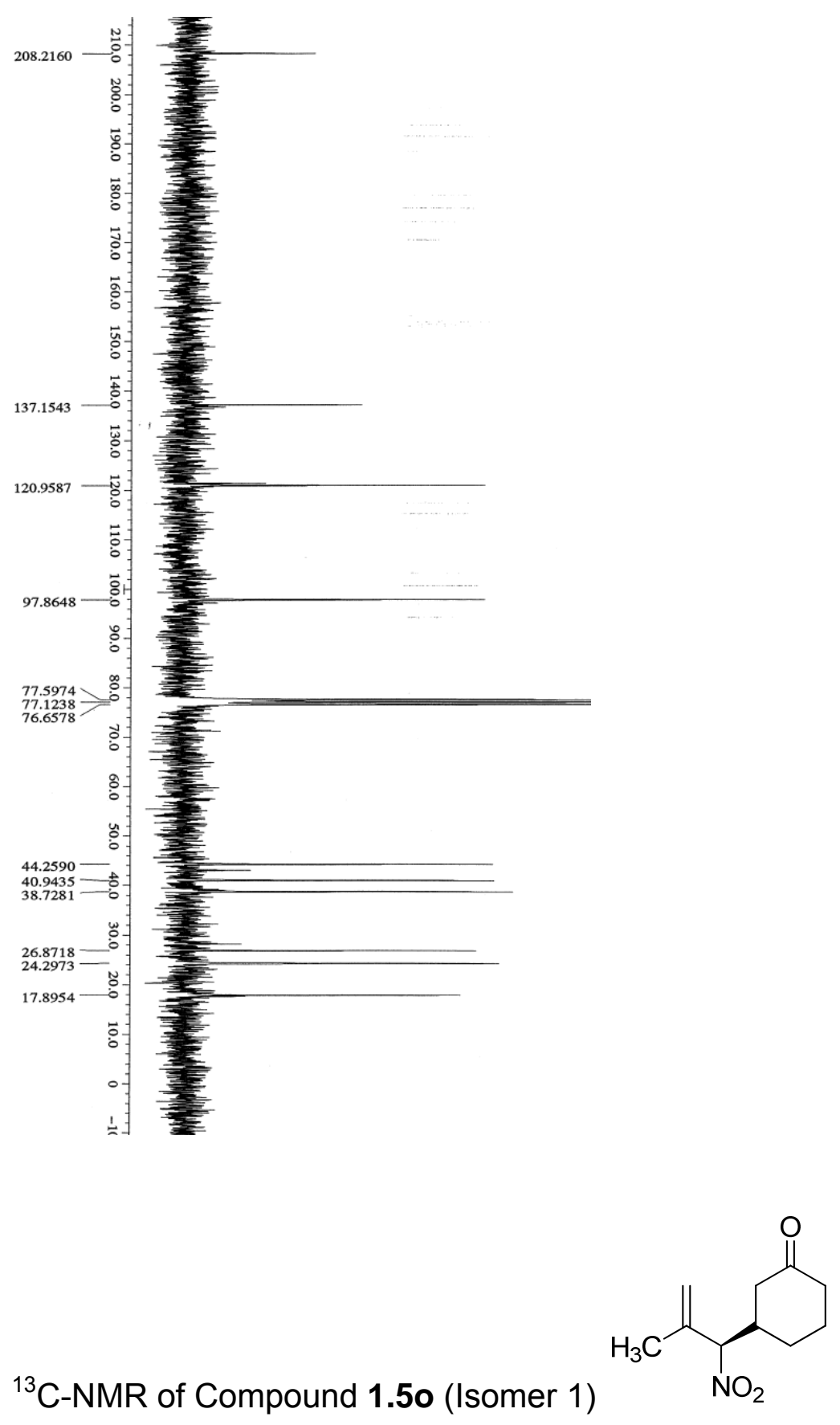


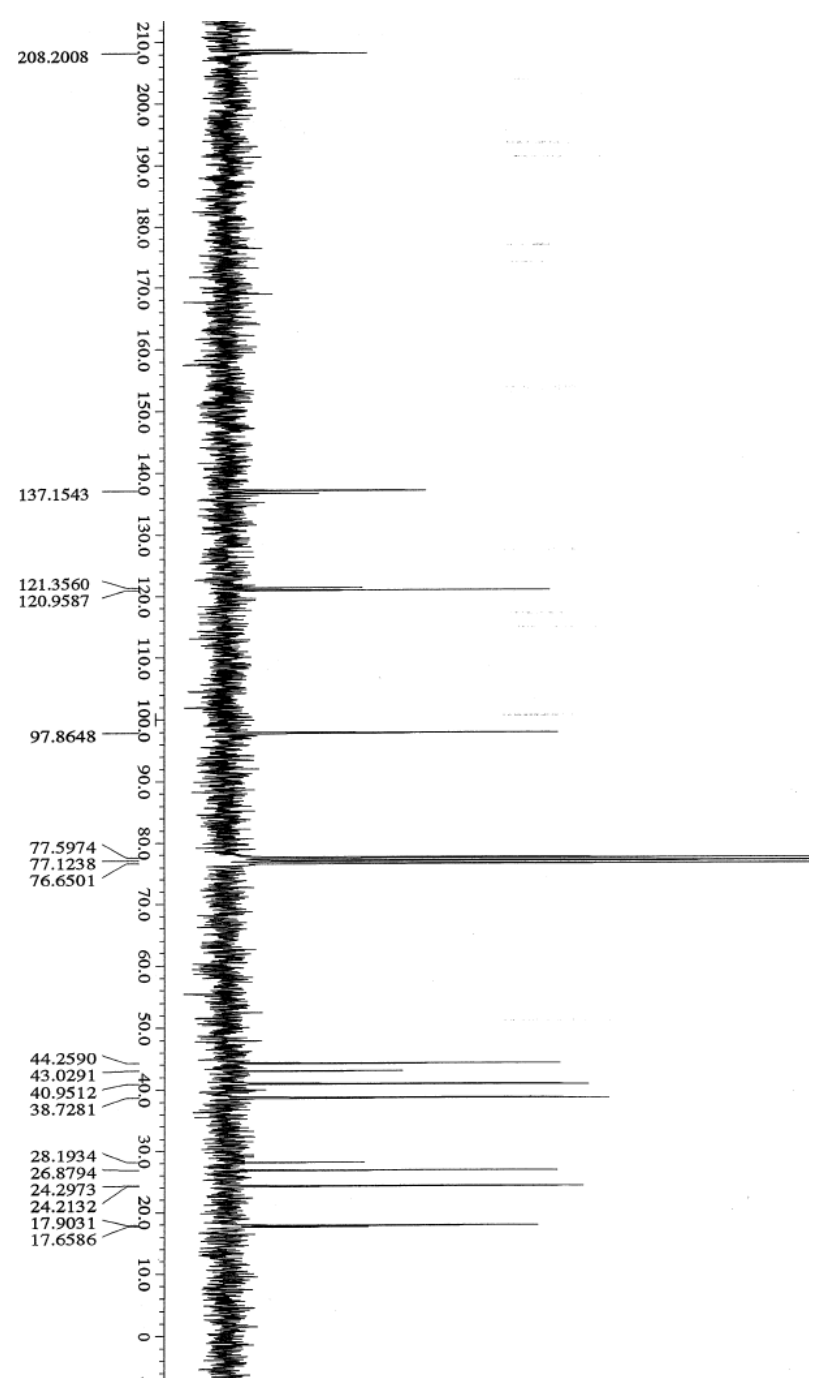

${ }^{13} \mathrm{C}$-NMR of Compound 1.5o (Isomer 2) 


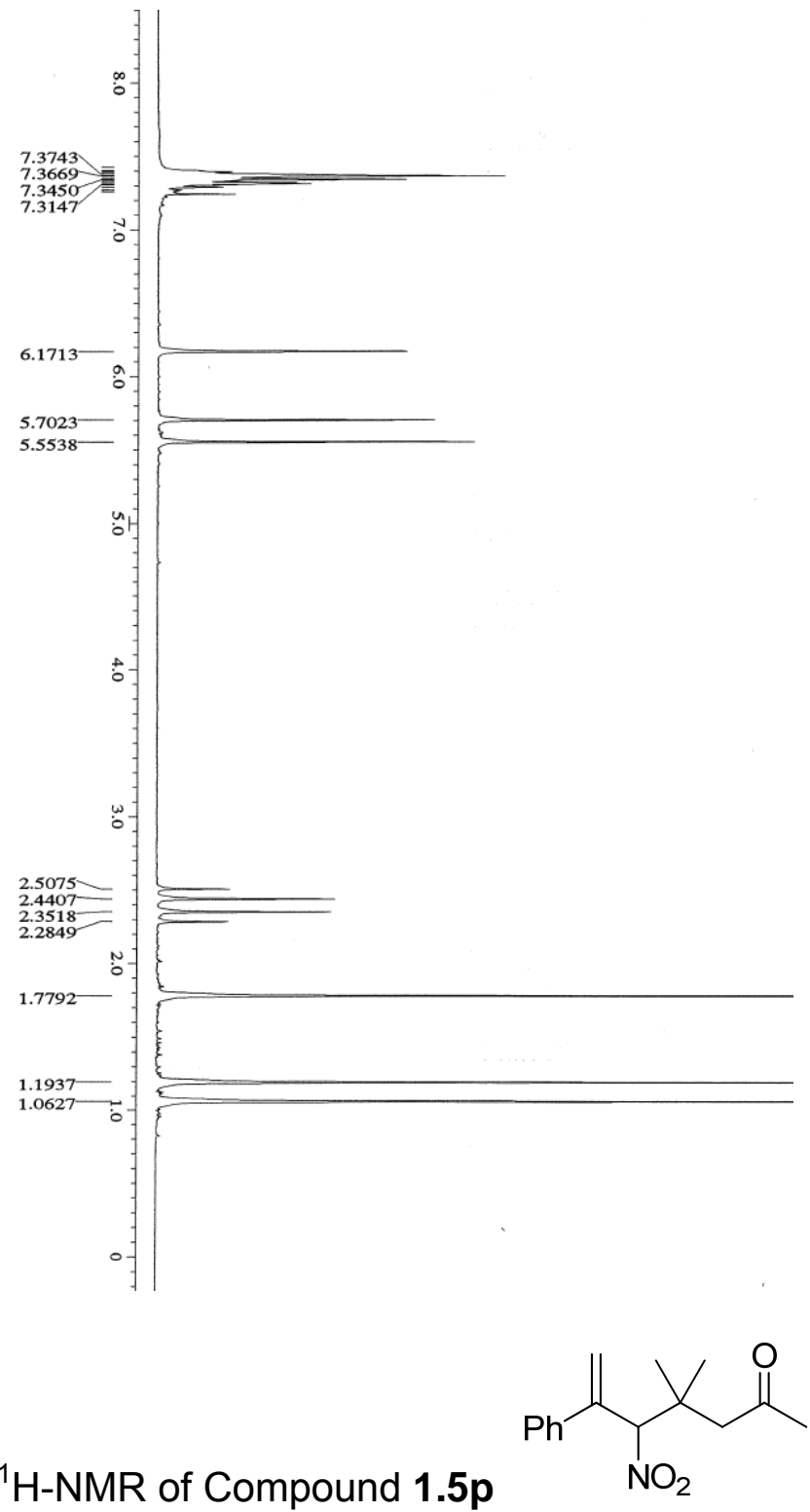




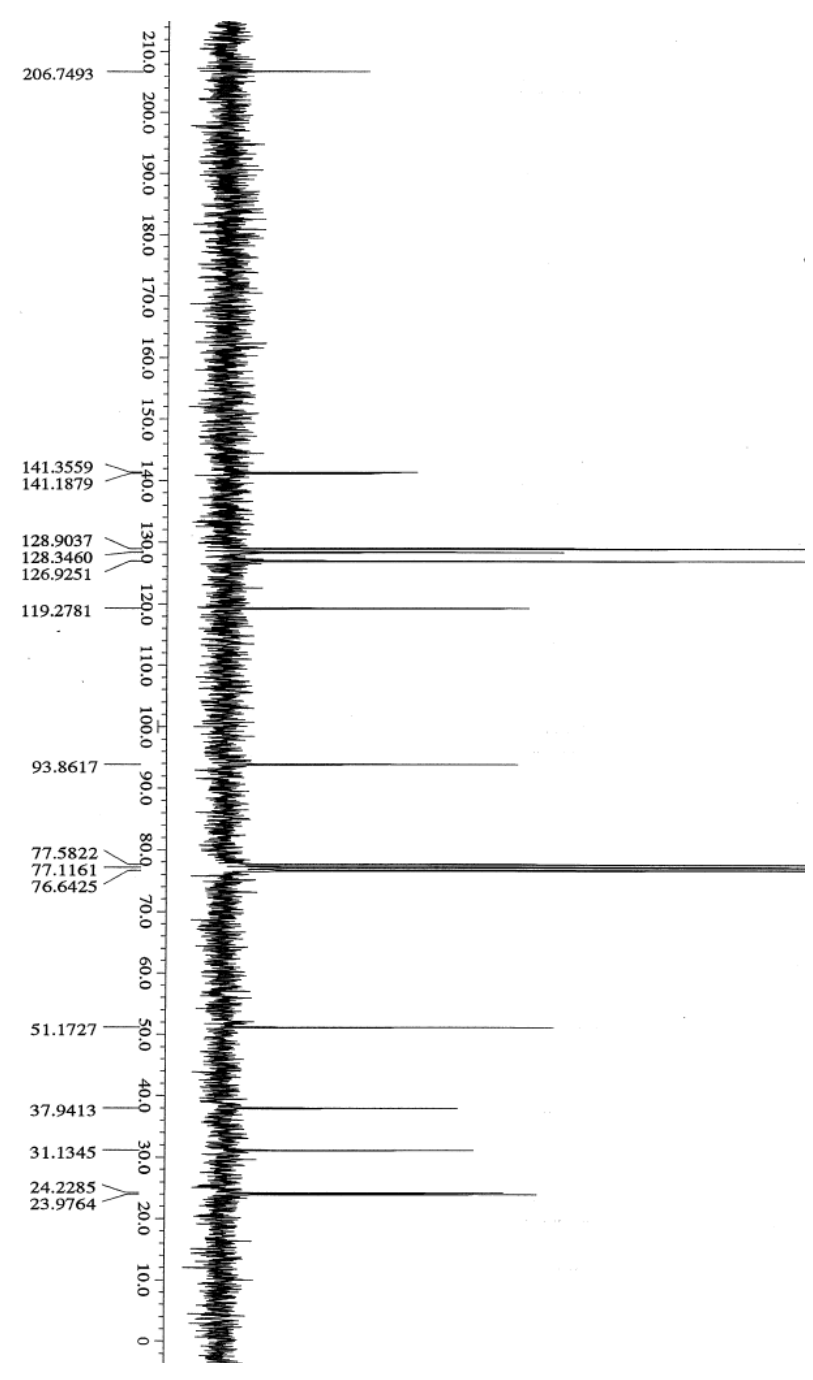

${ }^{13} \mathrm{C}-\mathrm{NMR}$ of Compound 1.5p 


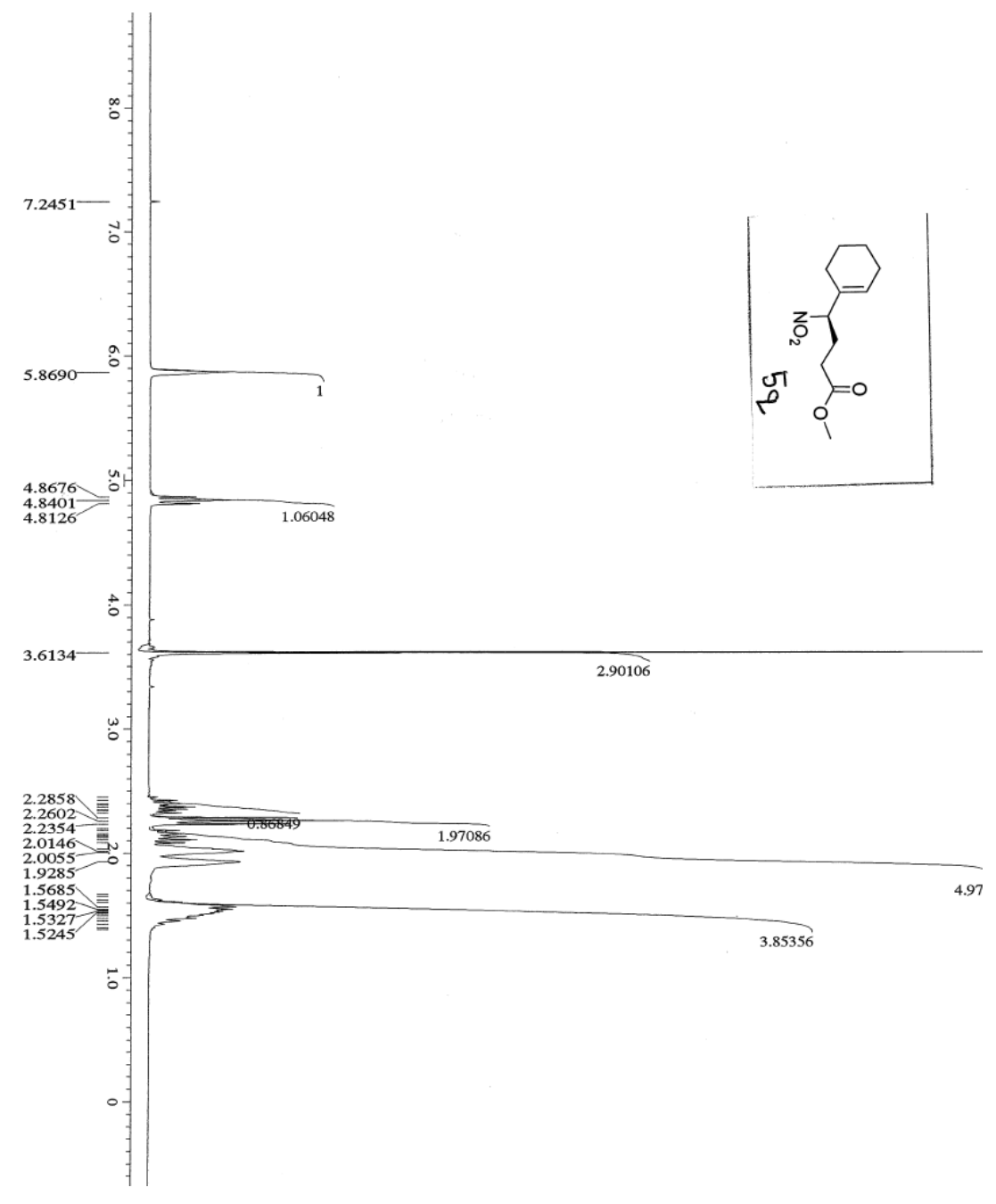

${ }^{1} \mathrm{H}-\mathrm{NMR}$ of Compound $\mathbf{1 . 5 q}$

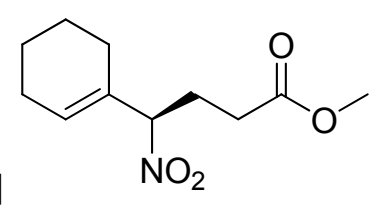



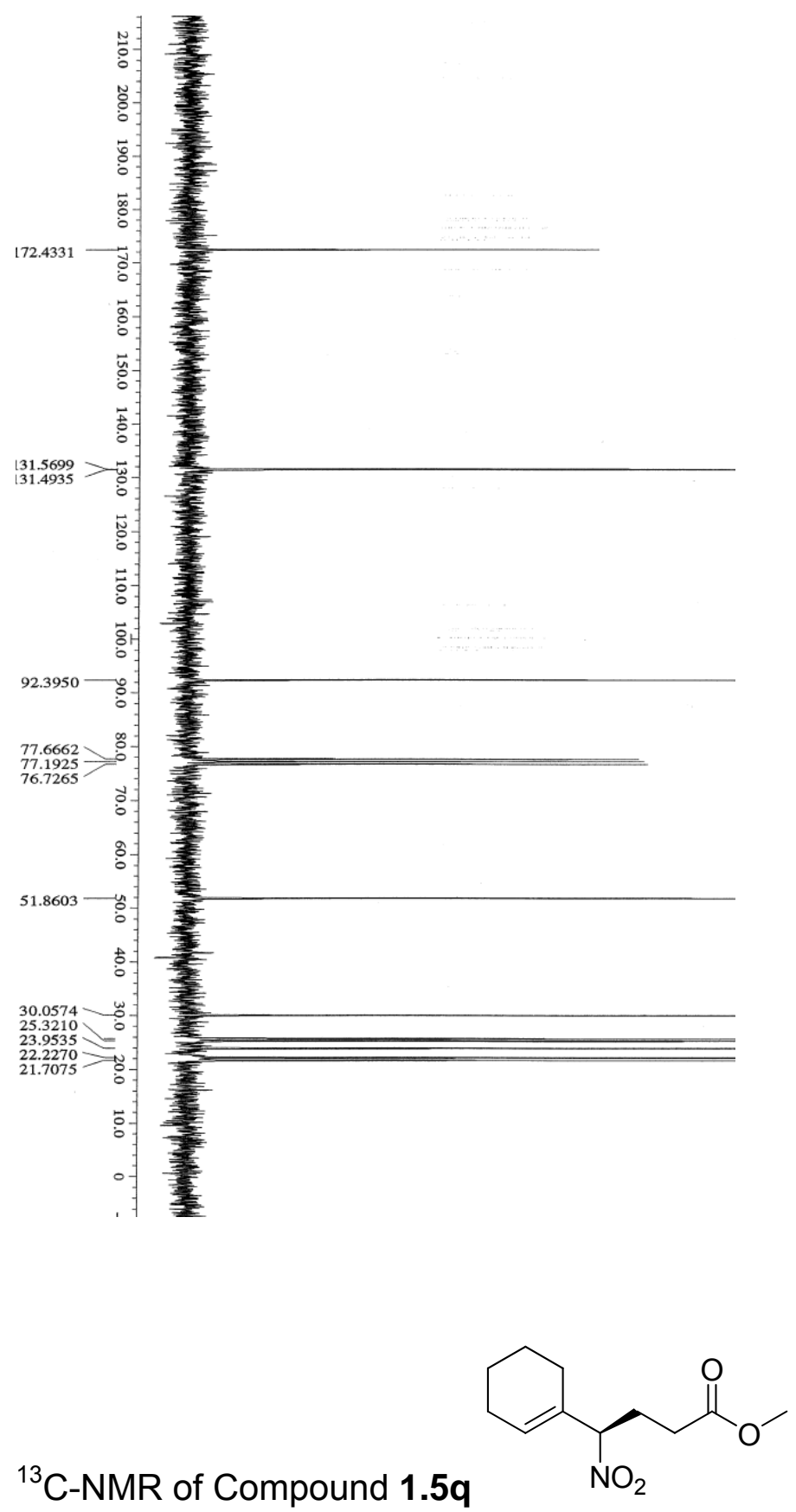


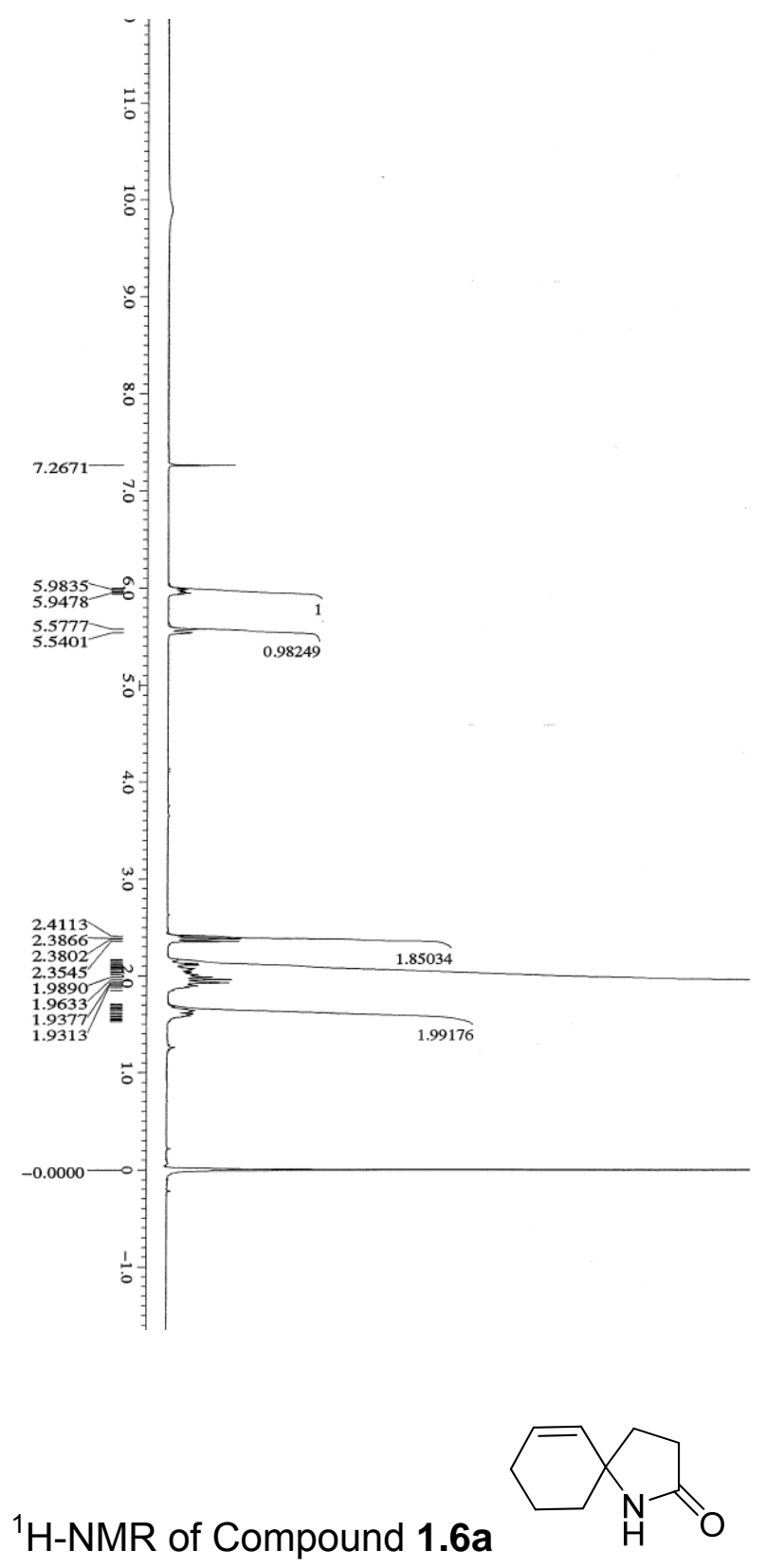



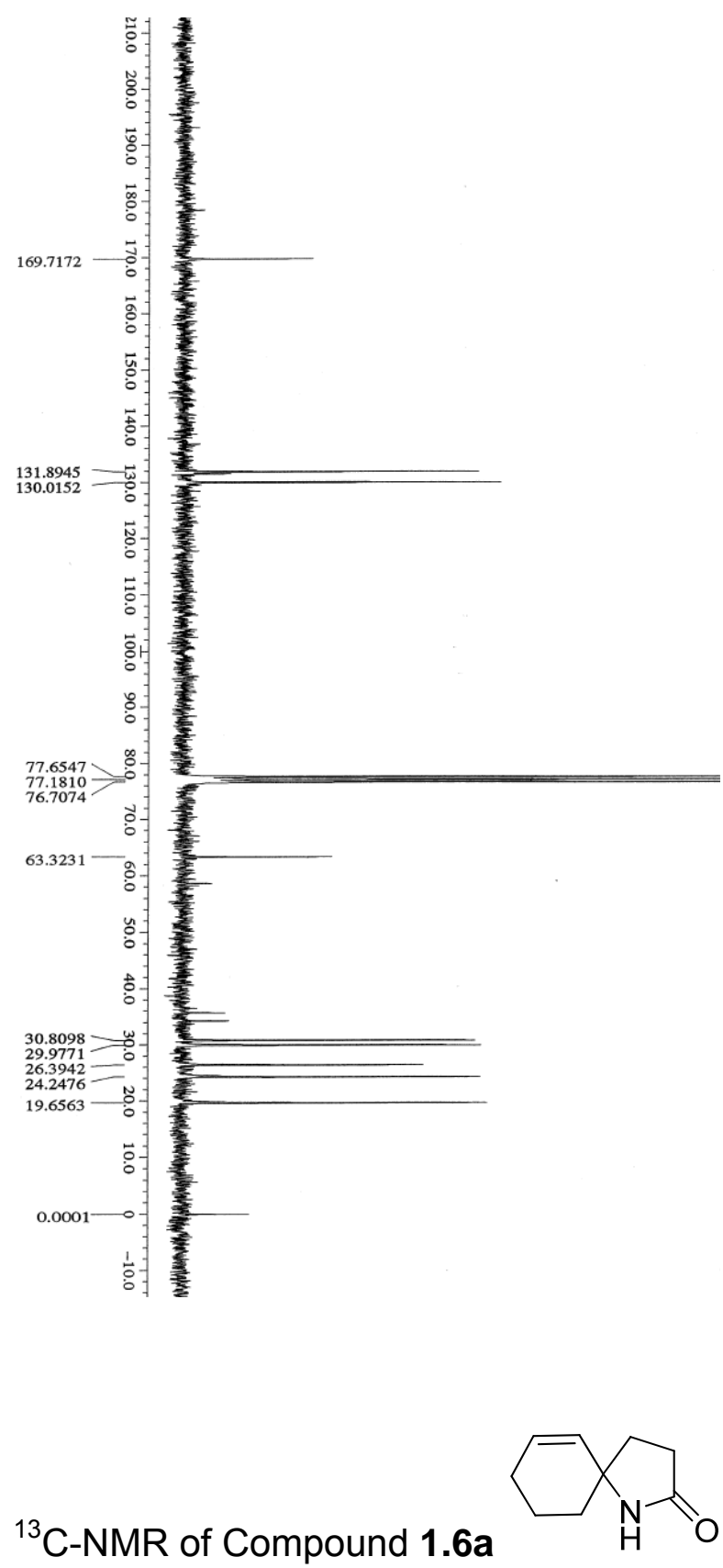

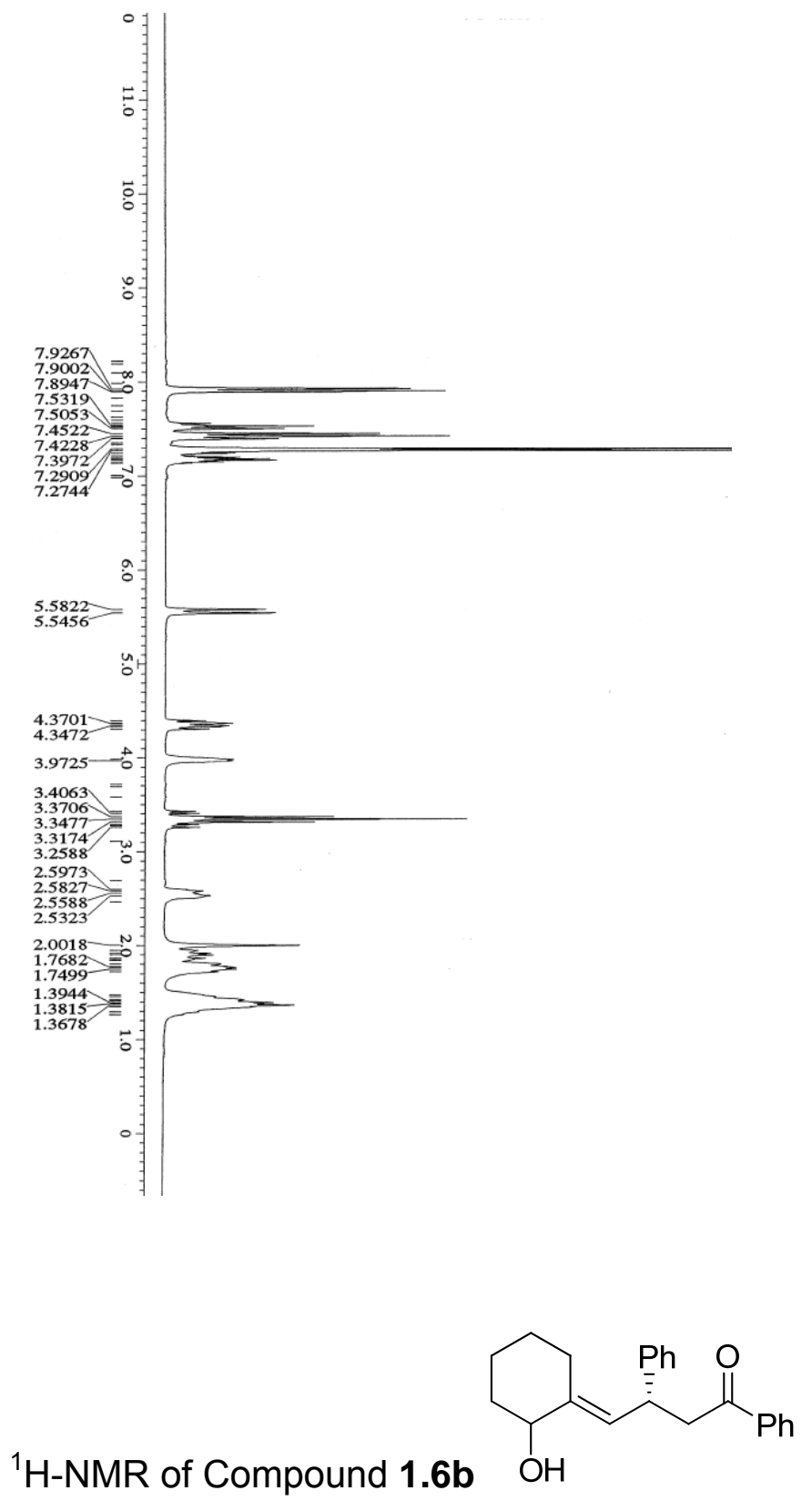


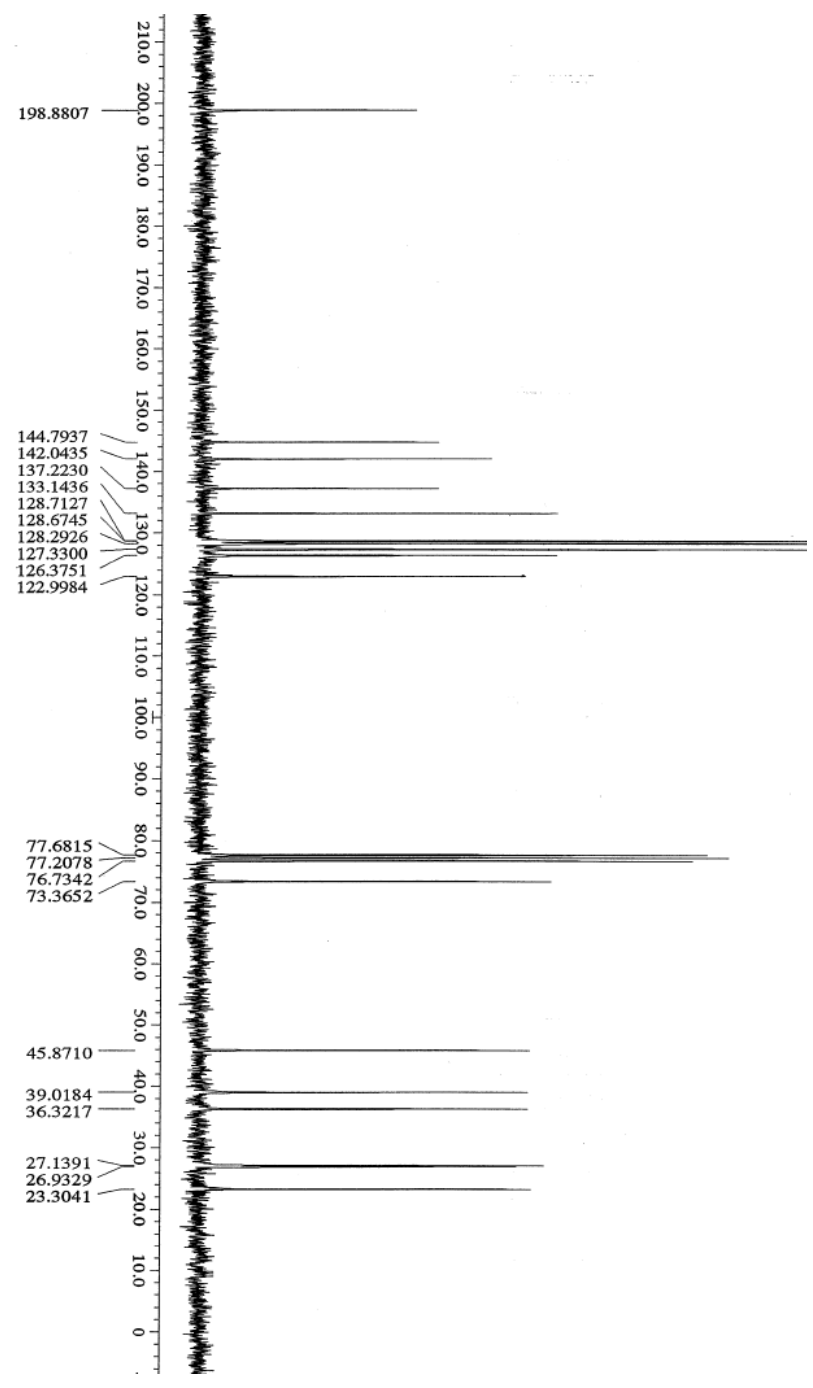

${ }^{13} \mathrm{C}-\mathrm{NMR}$ of Compound 1.6b 

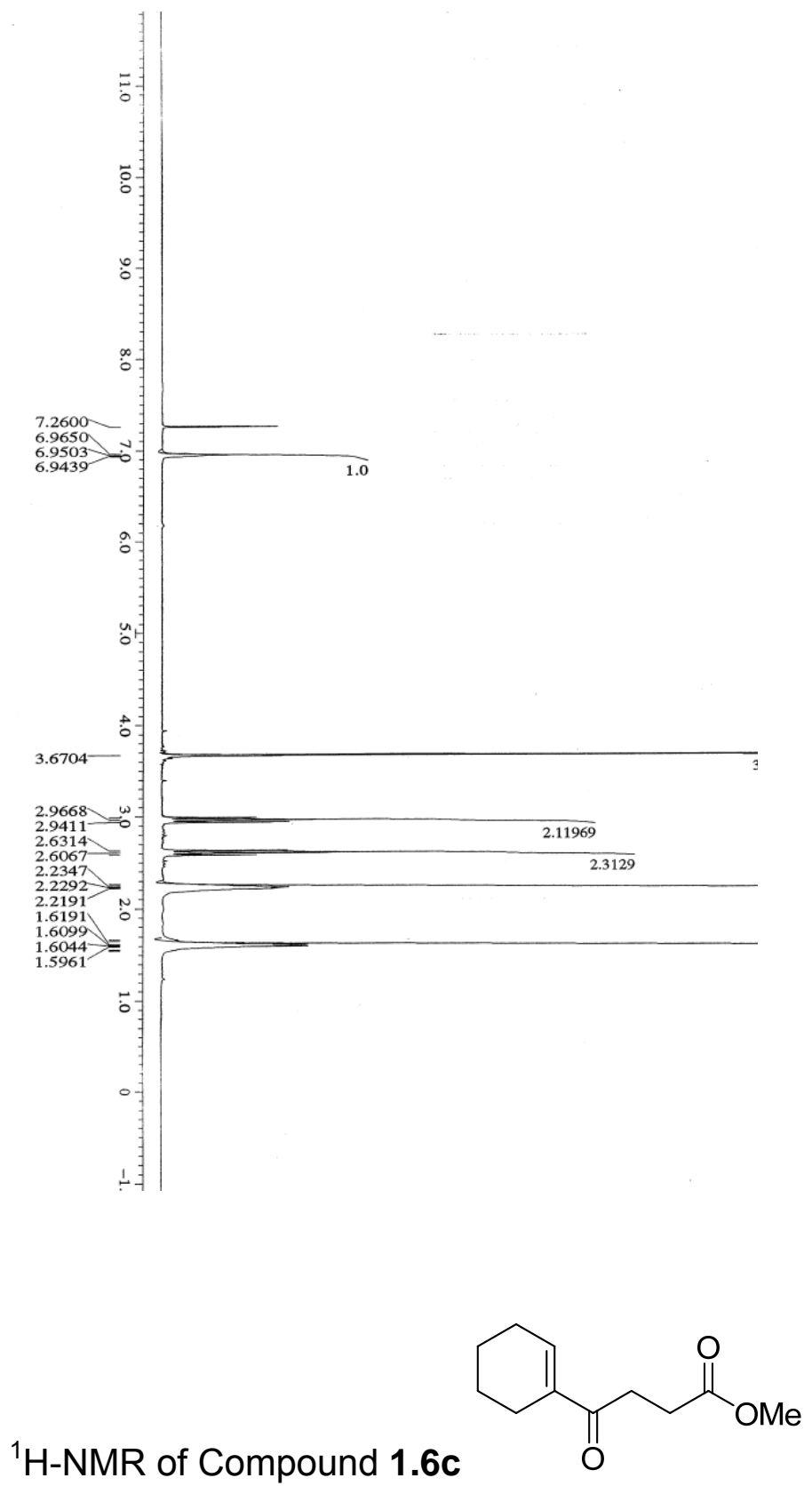


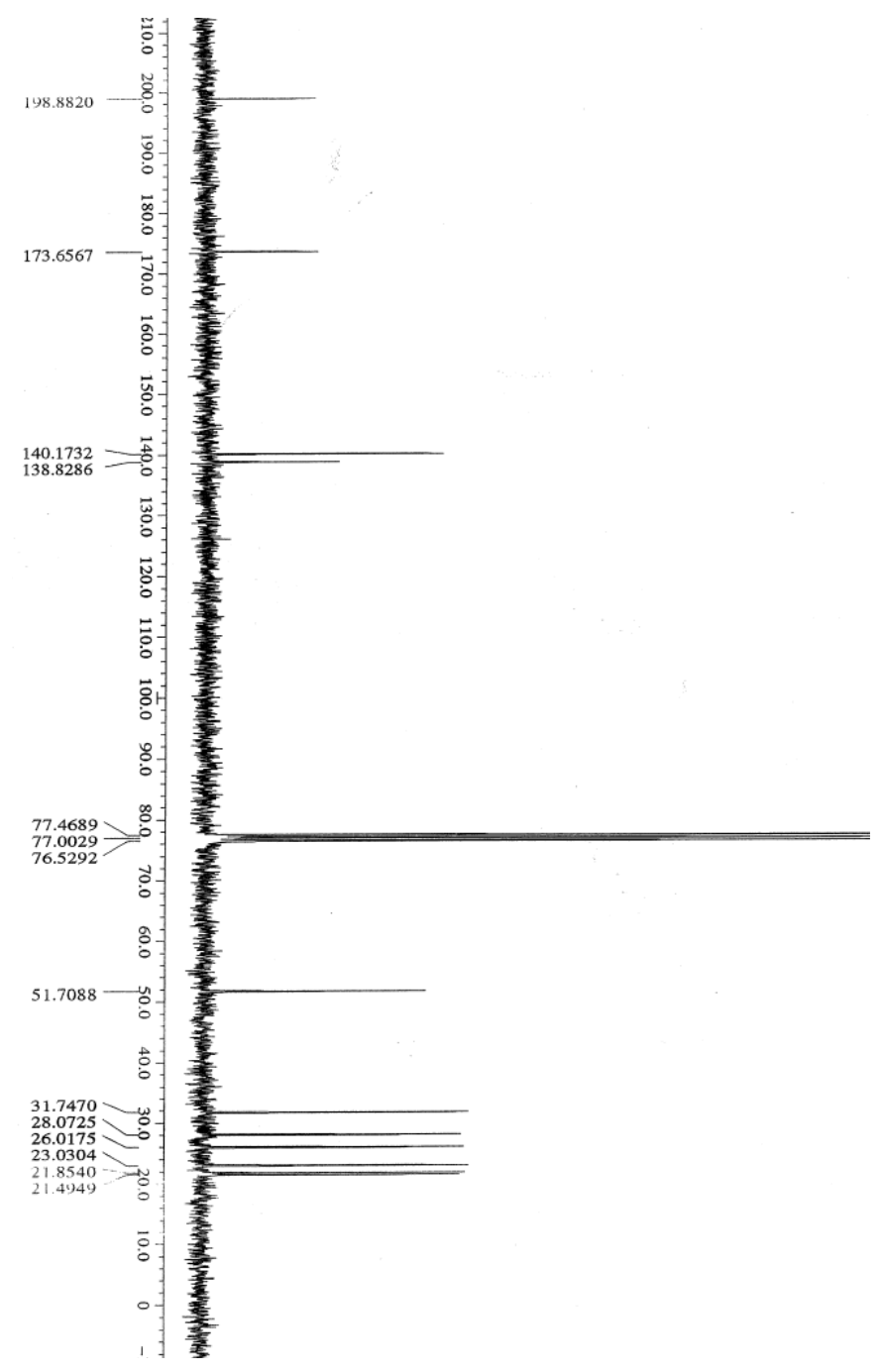

${ }^{13} \mathrm{C}-\mathrm{NMR}$ of Compound 1.6c<smiles>COC(=O)CCC(=O)C1=CCCCC1</smiles> 
Chapter 2: Triazole synthesis

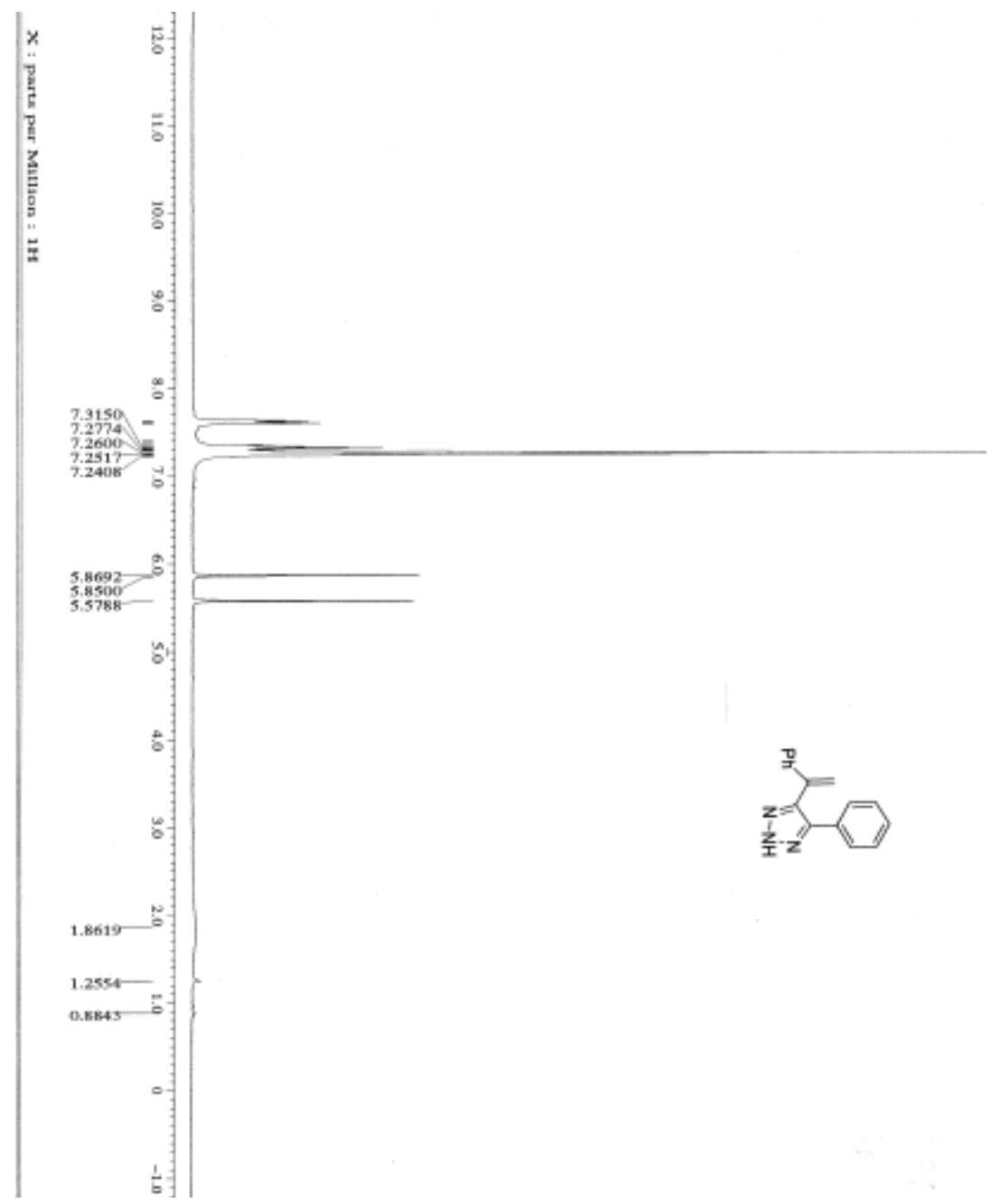

${ }^{1} \mathrm{H}-\mathrm{NMR}$ of Compound 2.6a 


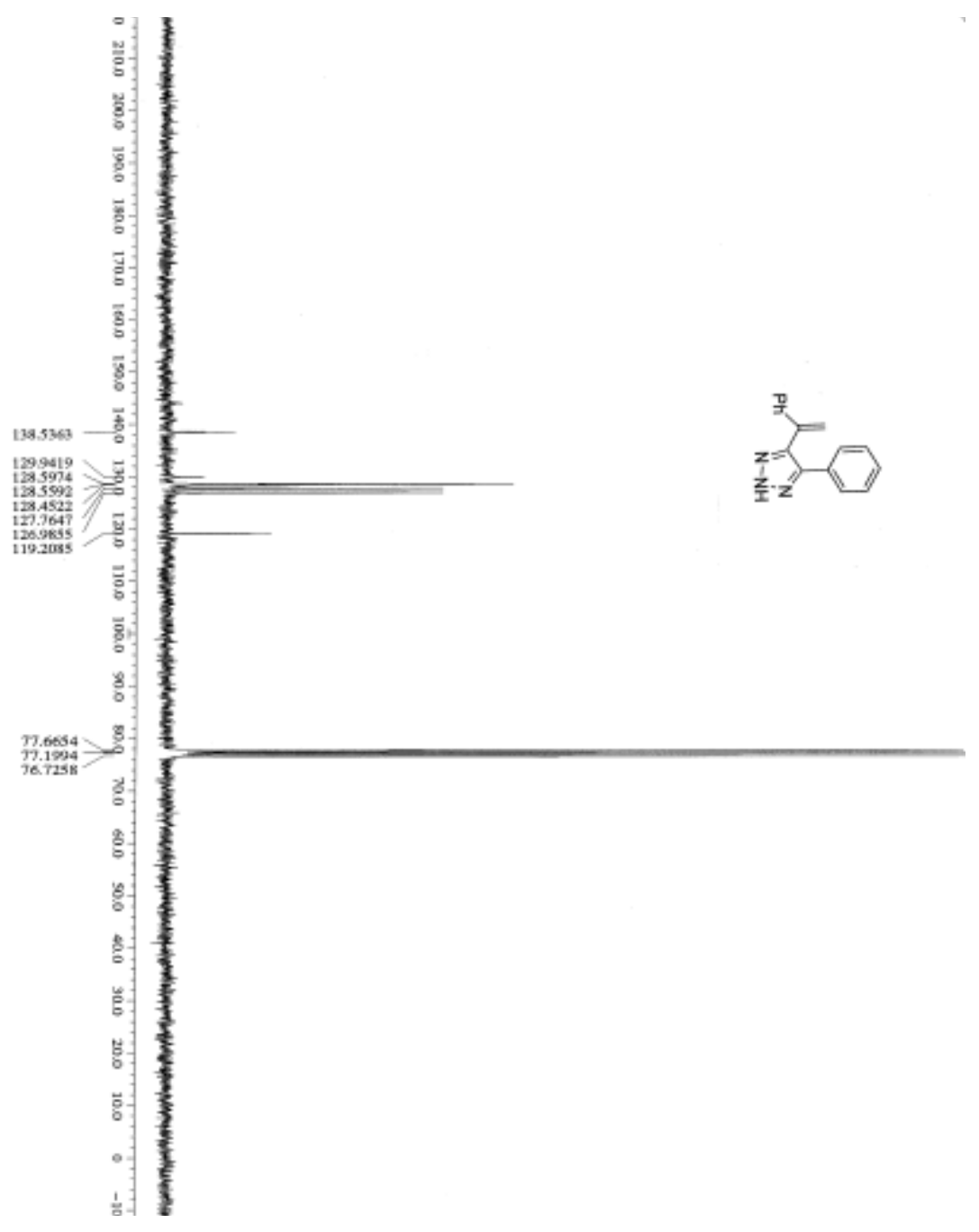

${ }^{13} \mathrm{C}-\mathrm{NMR}$ of Compound 2.6a

215 


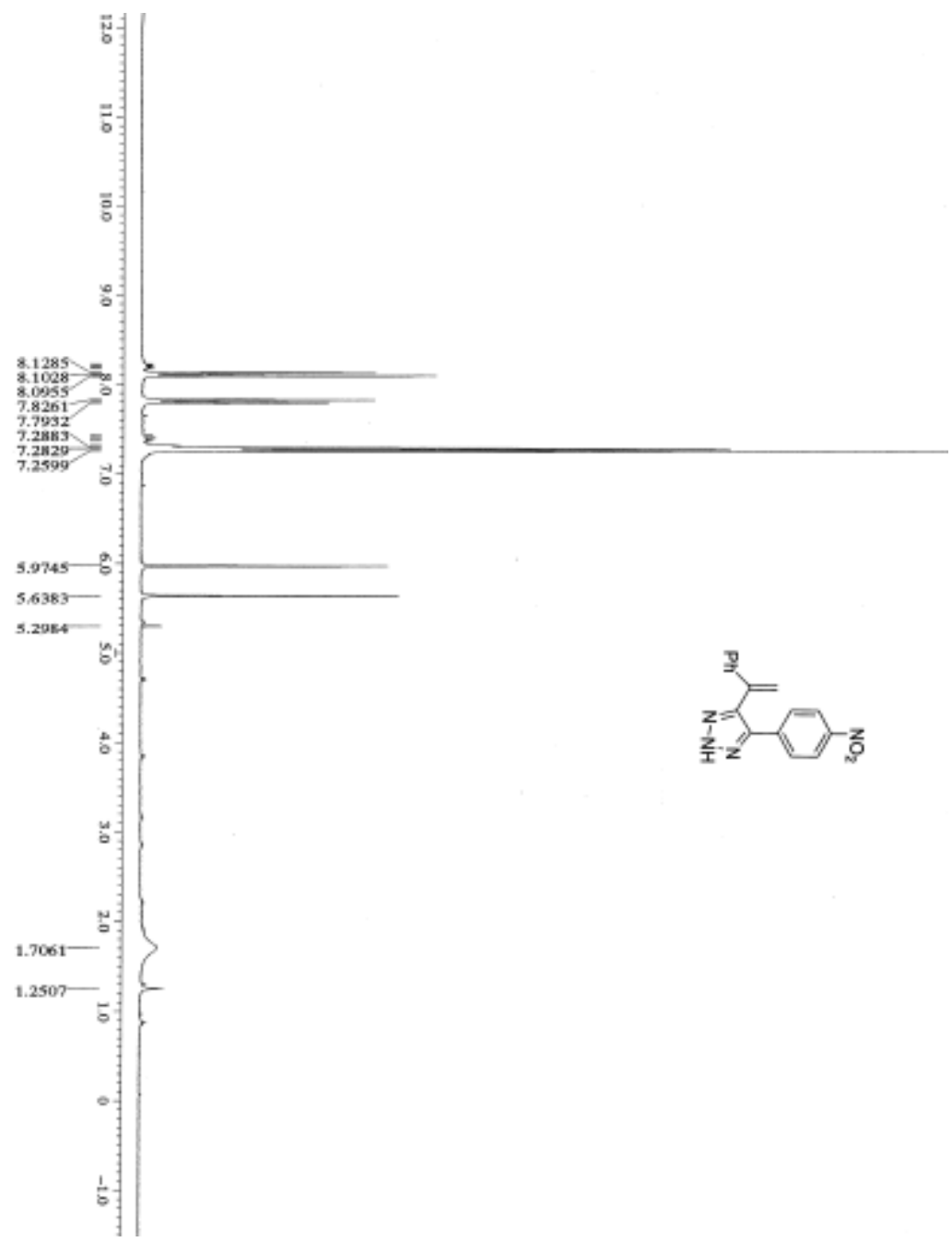

${ }^{1} \mathrm{H}-\mathrm{NMR}$ of Compound $\mathbf{2 . 6 b}$ 


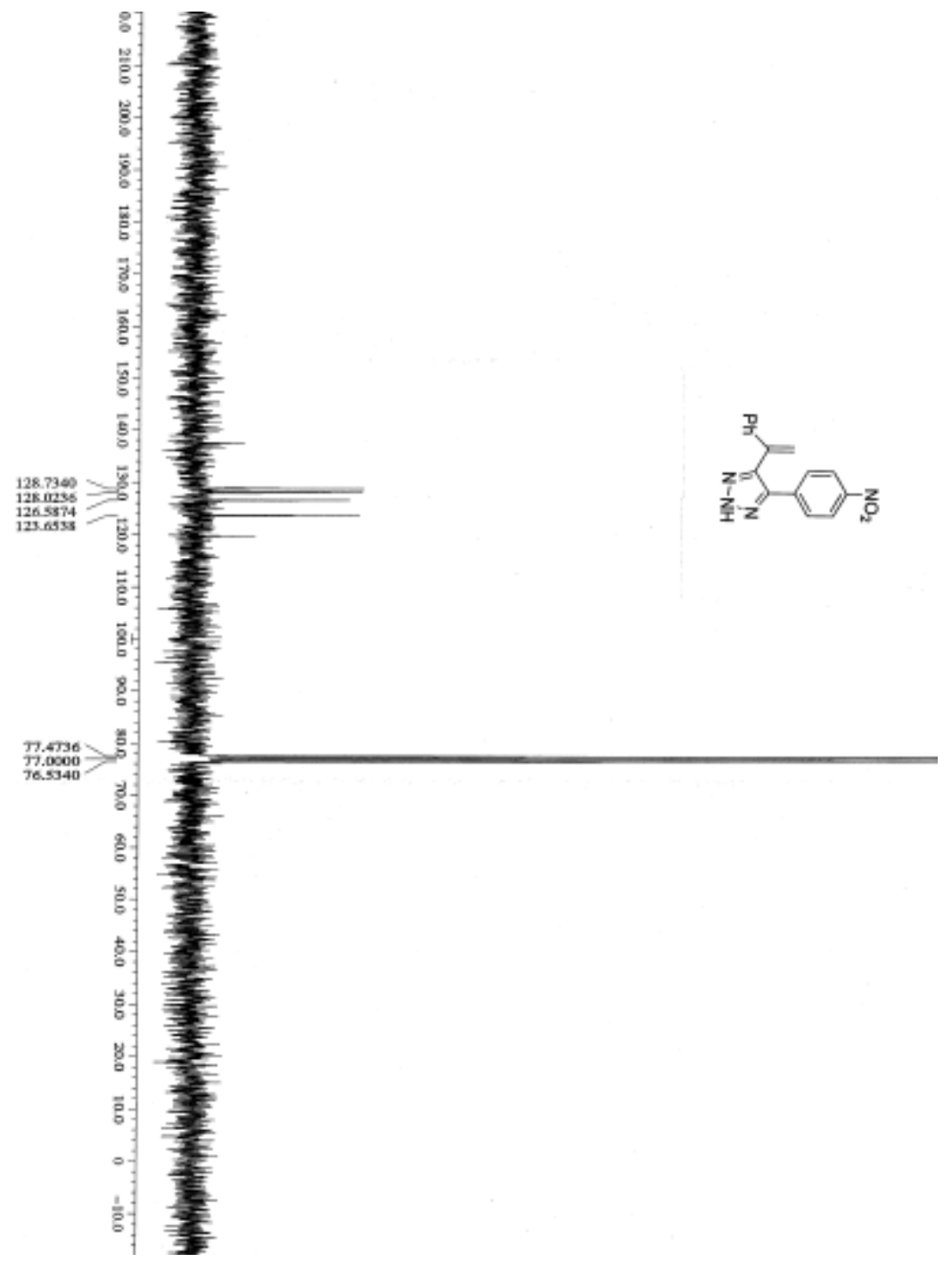

${ }^{13} \mathrm{C}-\mathrm{NMR}$ of Compound 2.6b 


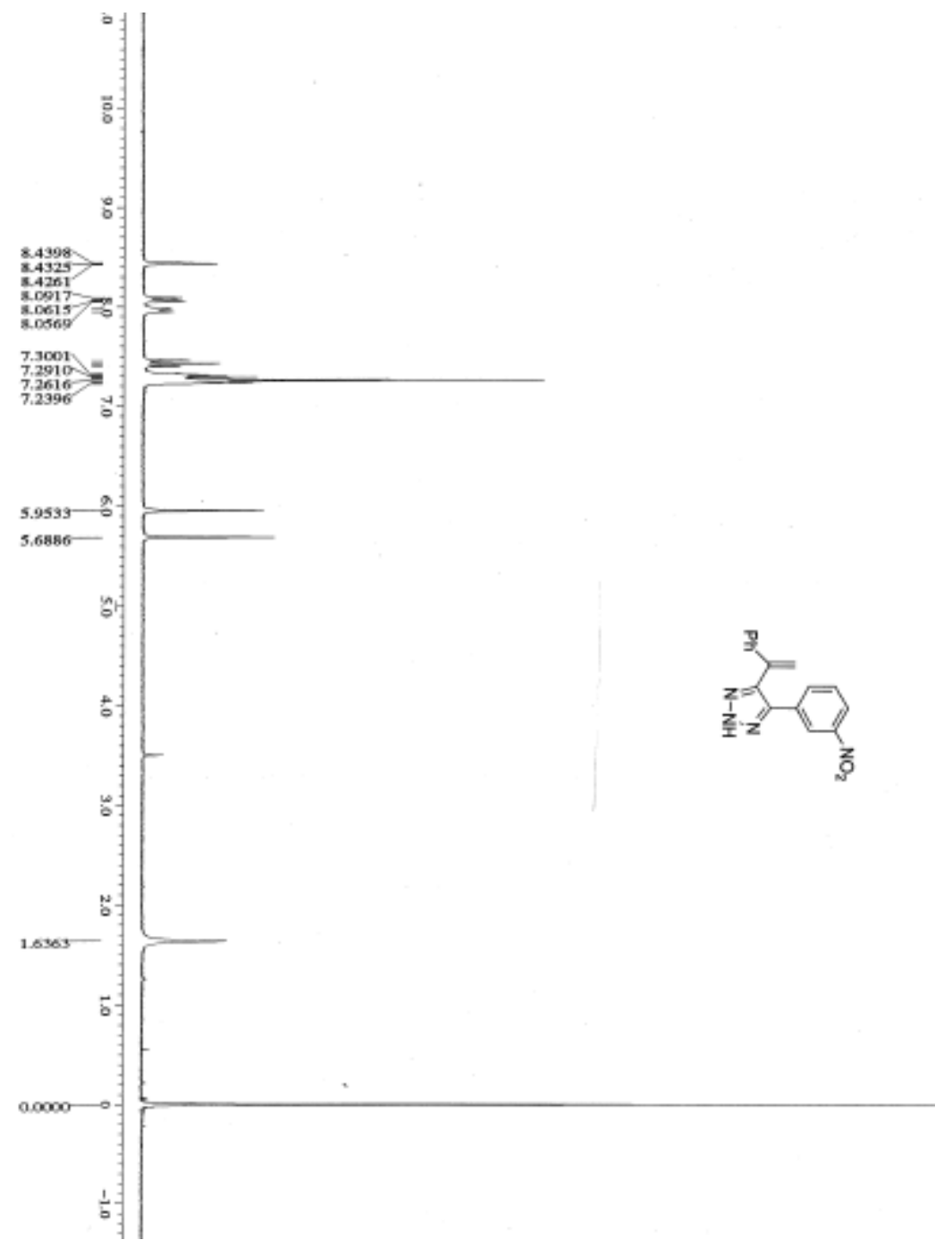

${ }^{1} \mathrm{H}-\mathrm{NMR}$ of Compound 2.6c 


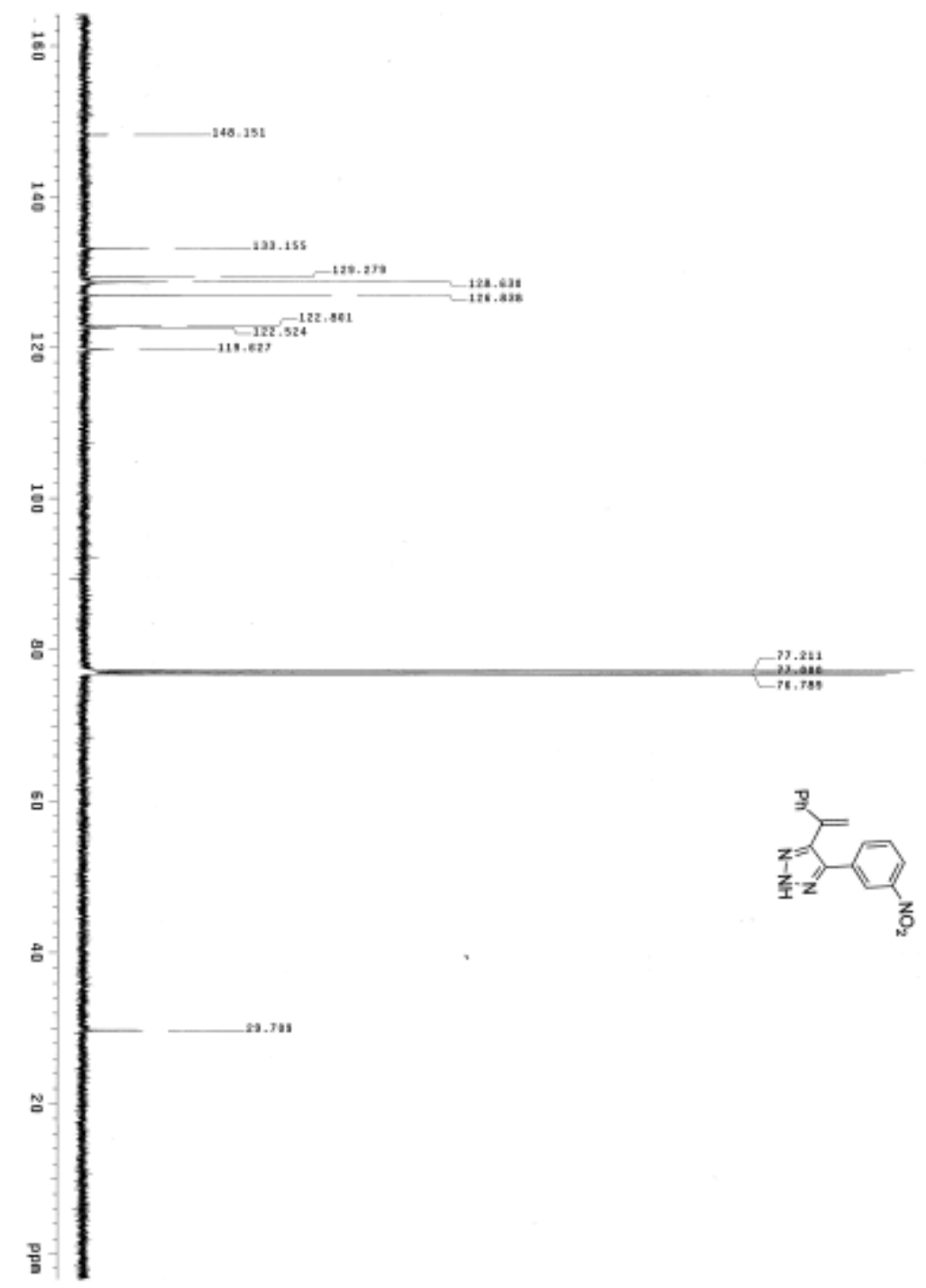

${ }^{13} \mathrm{C}-\mathrm{NMR}$ of Compound 2.6c 


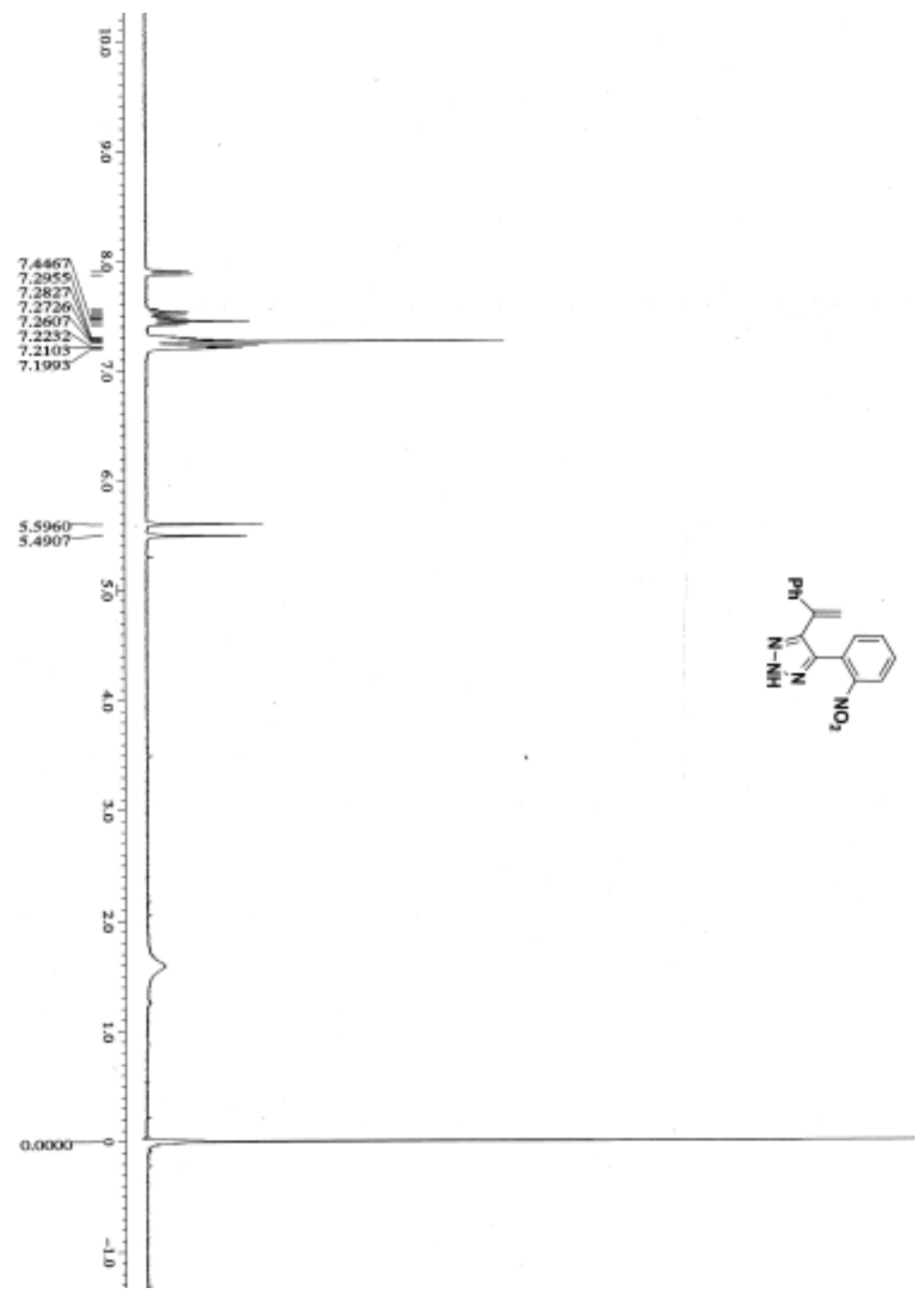

${ }^{1} \mathrm{H}-\mathrm{NMR}$ of Compound 2.6d 


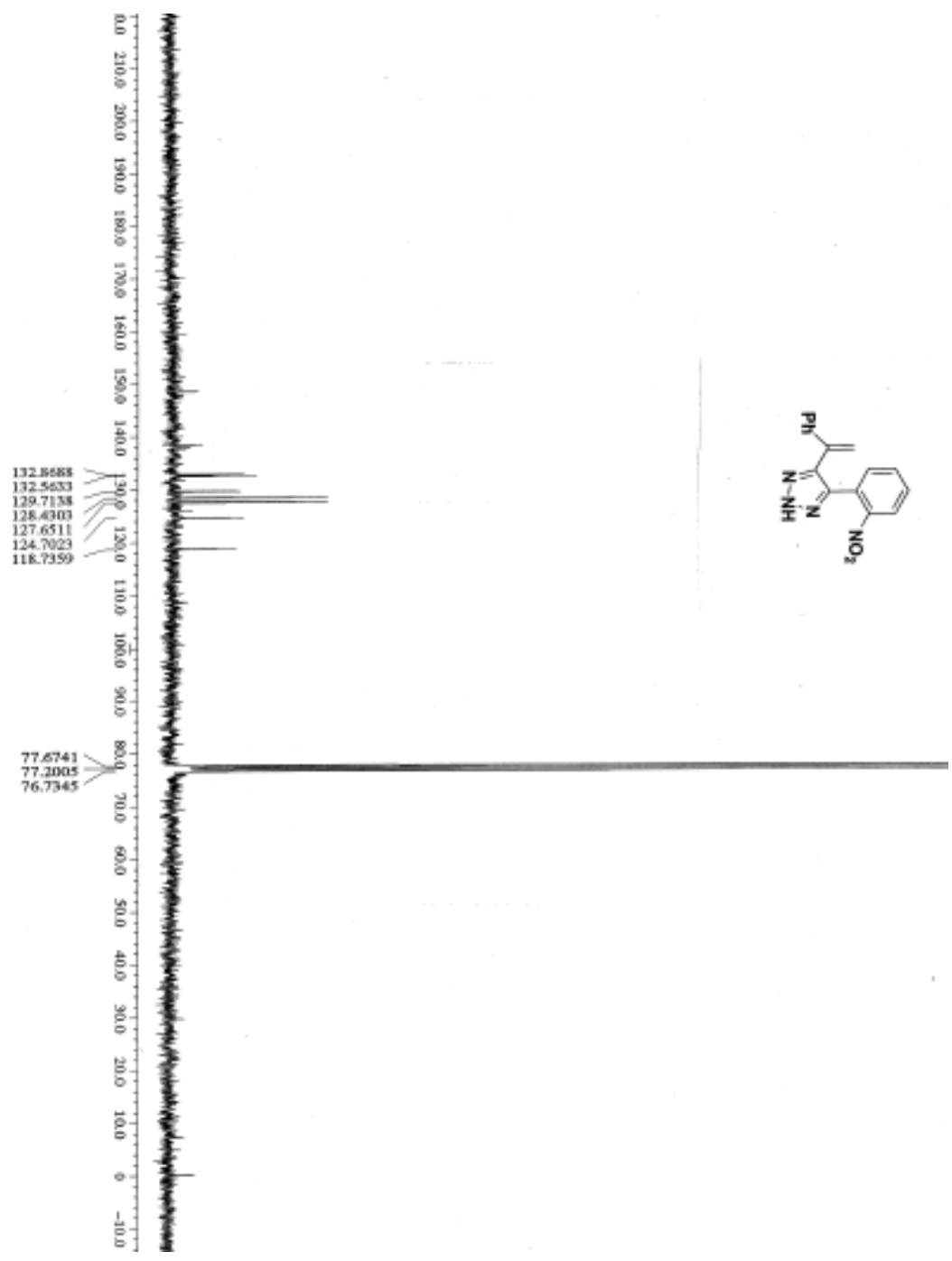

${ }^{13} \mathrm{C}-\mathrm{NMR}$ of Compound 2.6d 


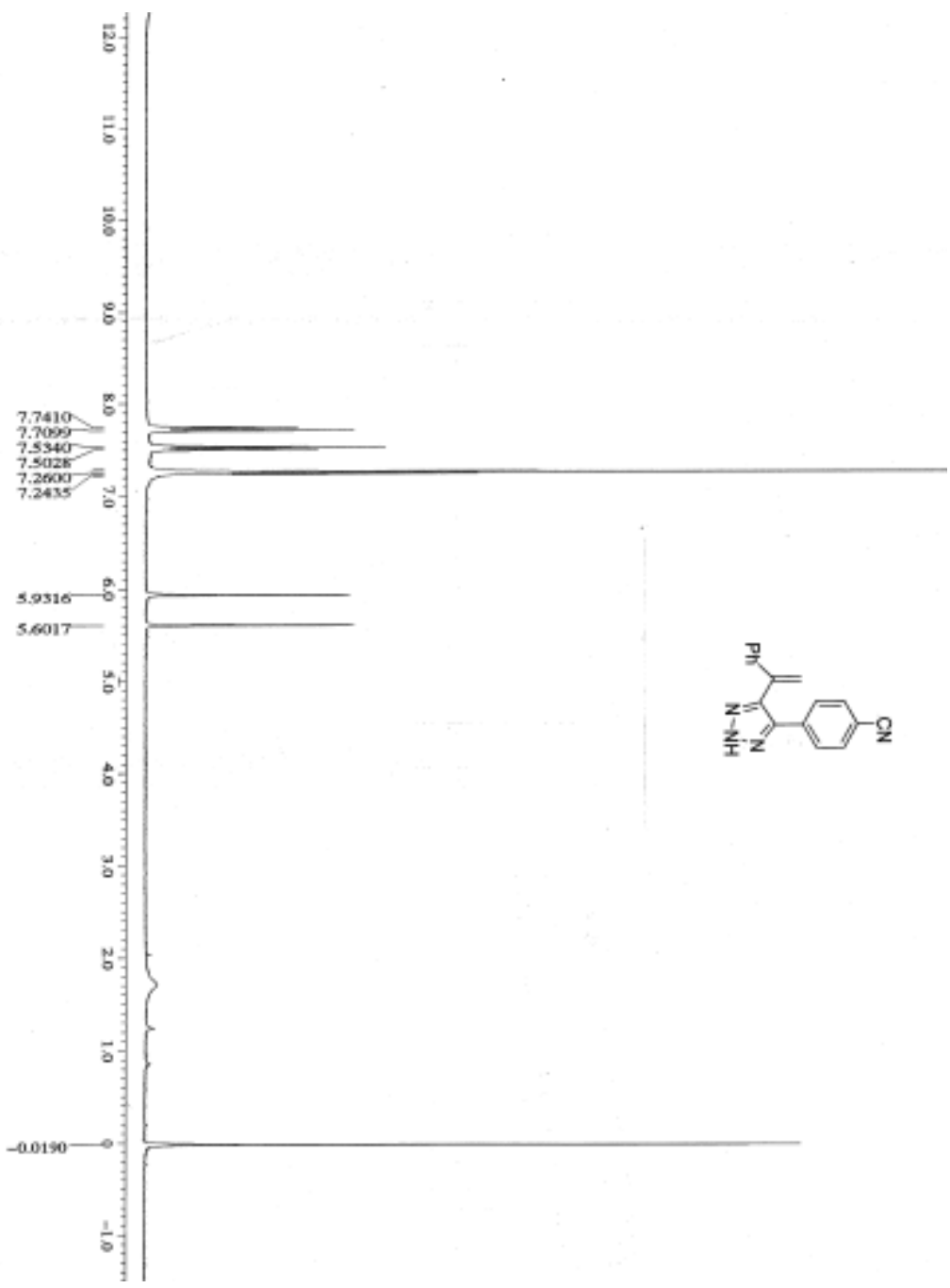

${ }^{1} \mathrm{H}-\mathrm{NMR}$ of Compound $\mathbf{2 . 6 e}$ 


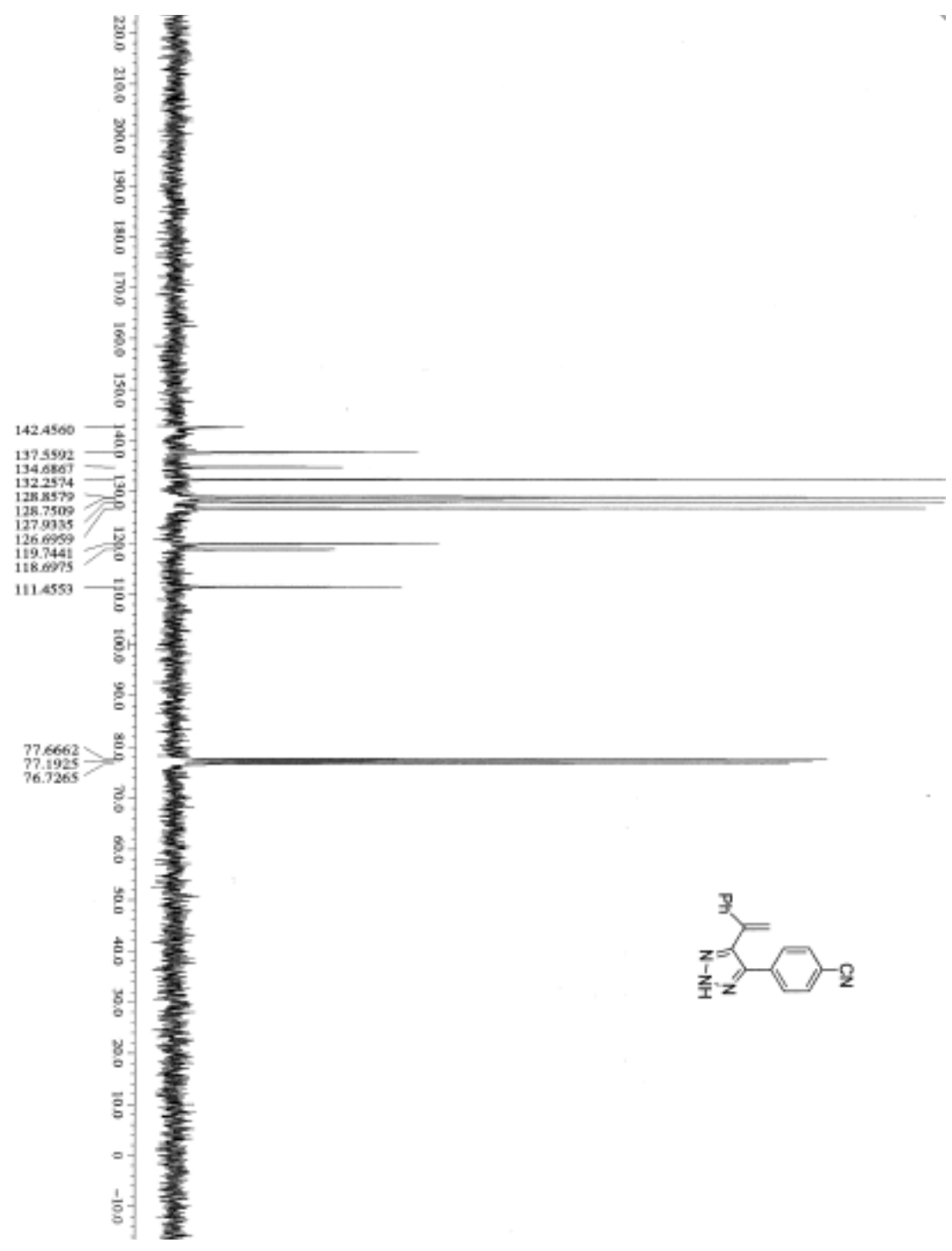

${ }^{13} \mathrm{C}-\mathrm{NMR}$ of Compound 2.6e 


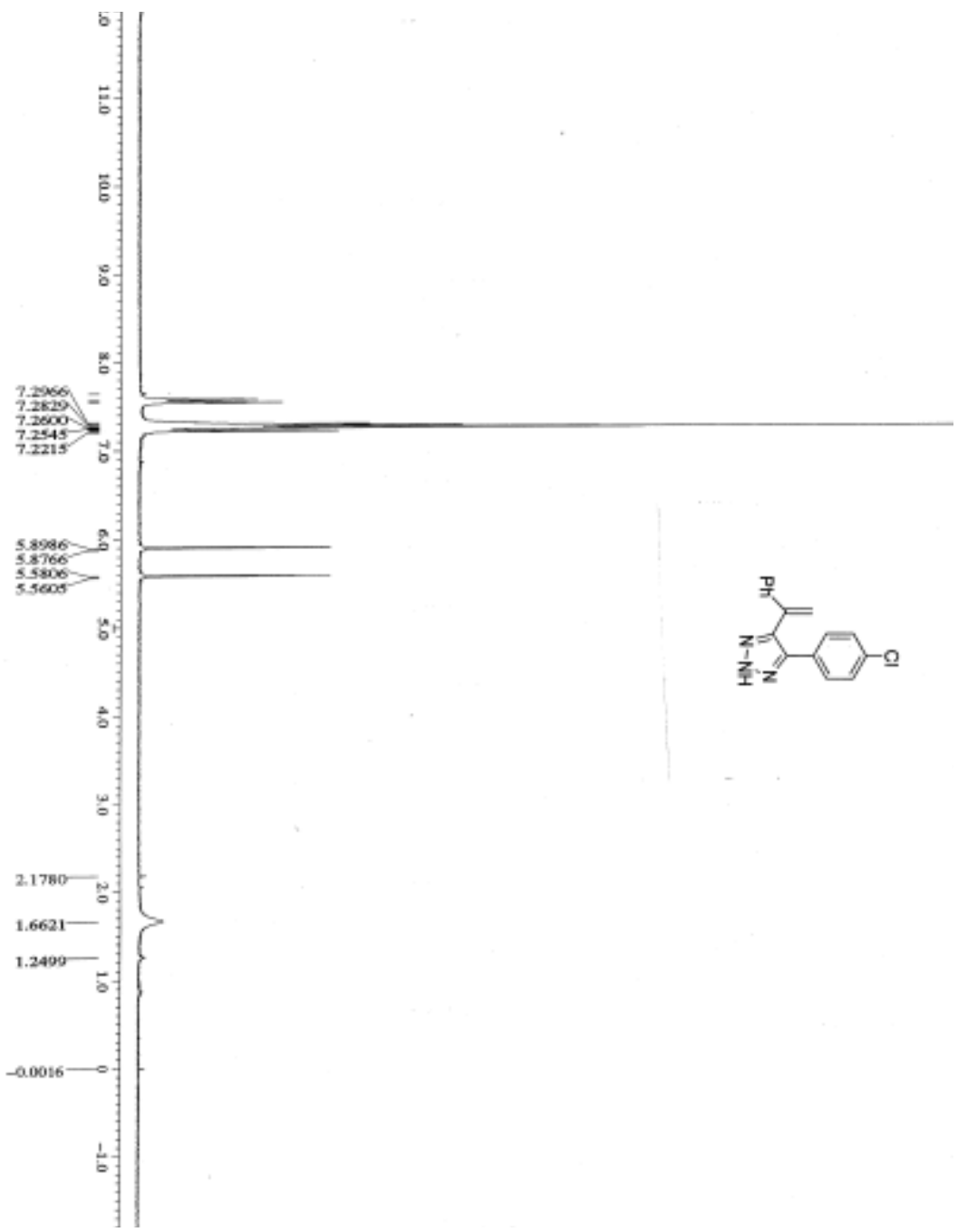

${ }^{1} \mathrm{H}-\mathrm{NMR}$ of Compound $\mathbf{2 . 6 f}$ 


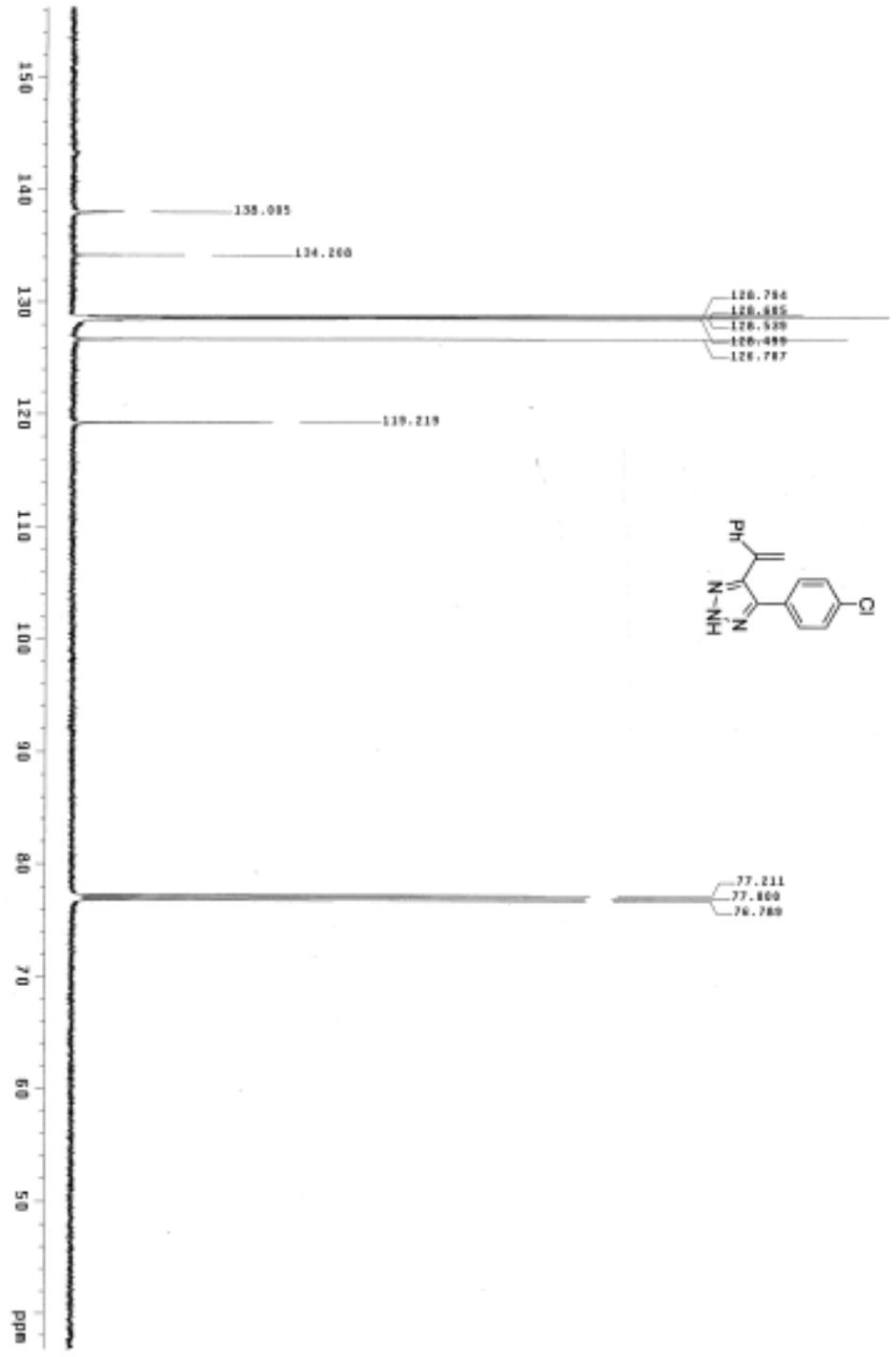

${ }^{13} \mathrm{C}-\mathrm{NMR}$ of Compound $2.6 \mathrm{f}$ 


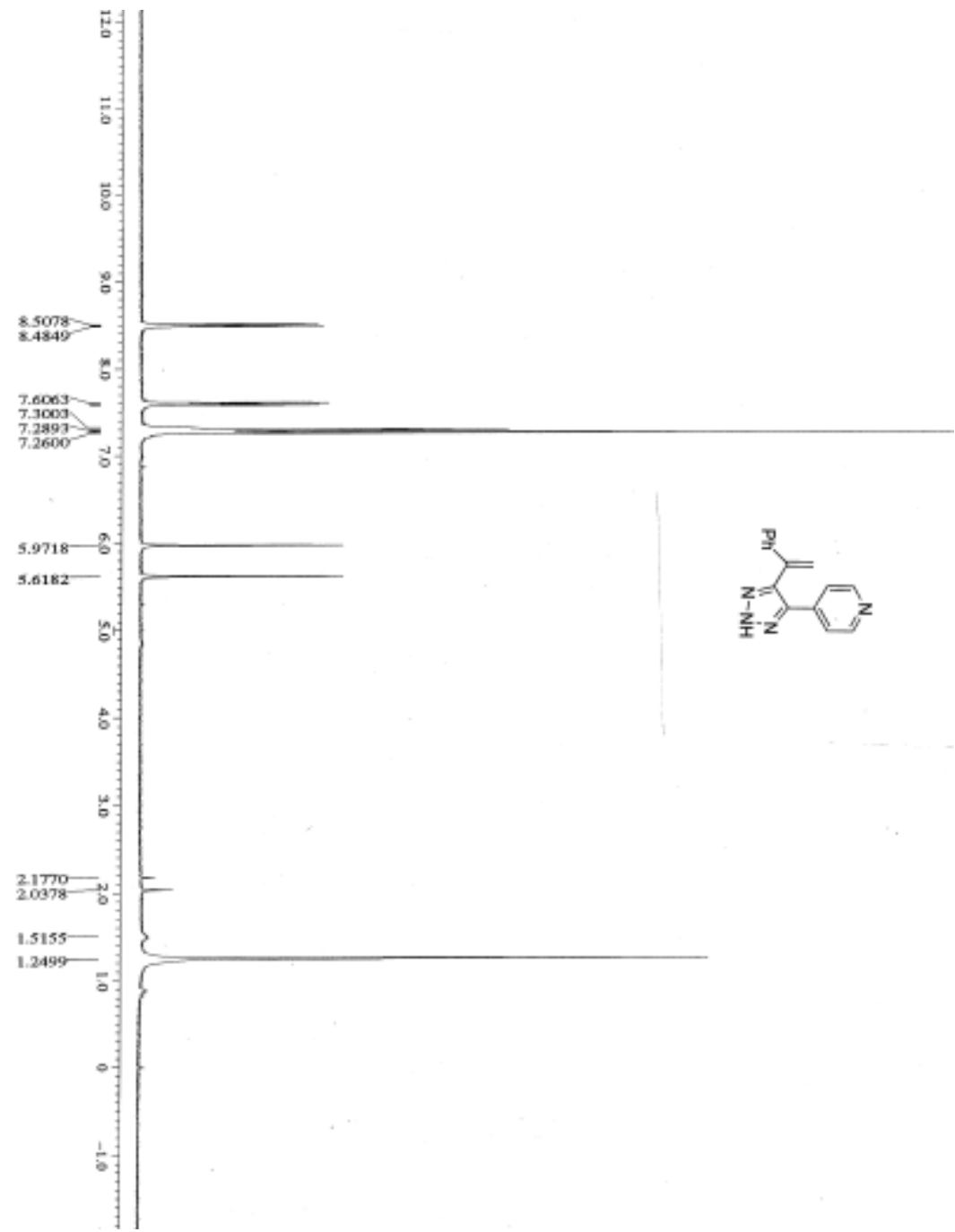

${ }^{1} \mathrm{H}-\mathrm{NMR}$ of Compound 2.6i 


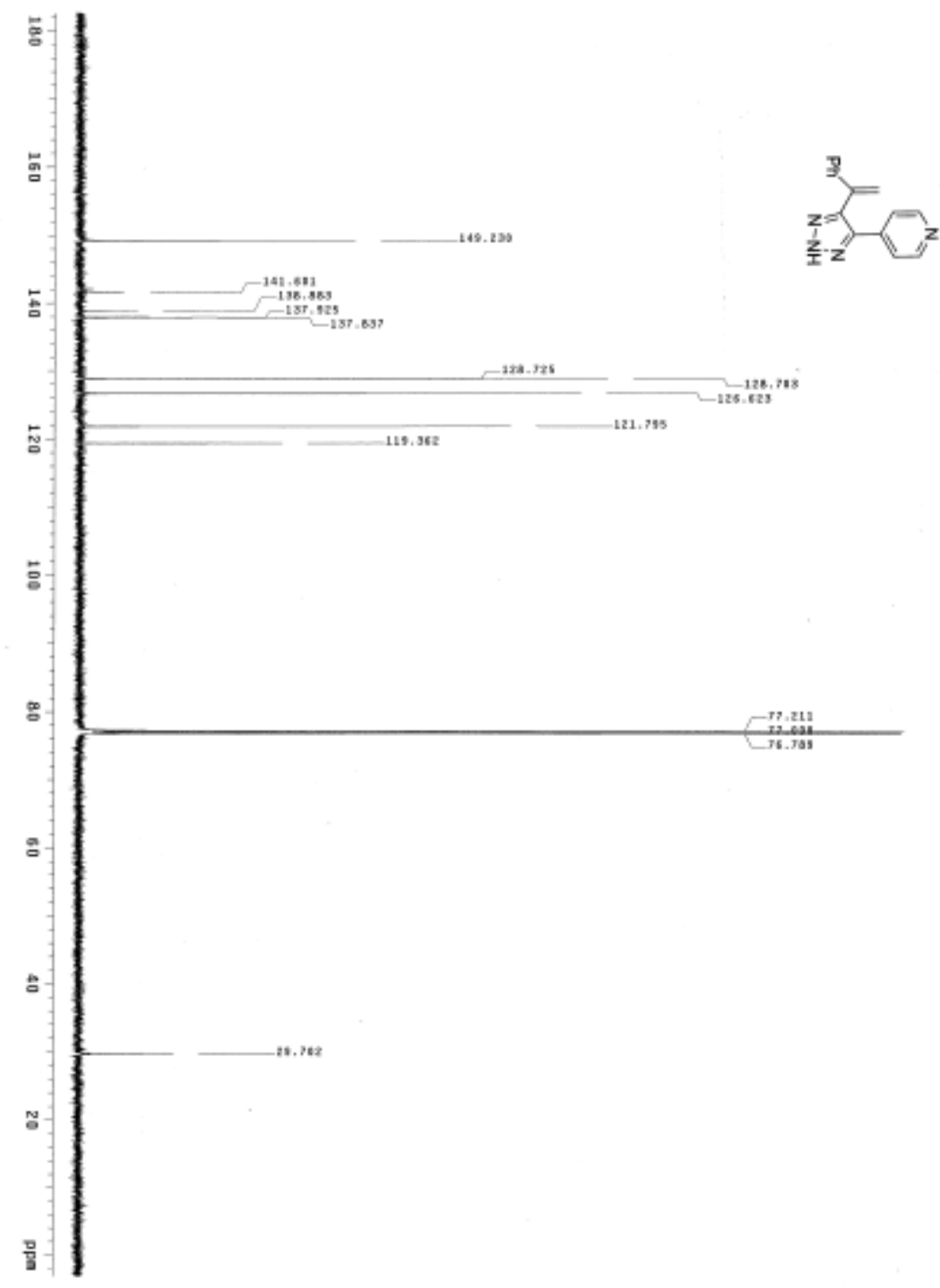

${ }^{13} \mathrm{C}-\mathrm{NMR}$ of Compound 2.6i 


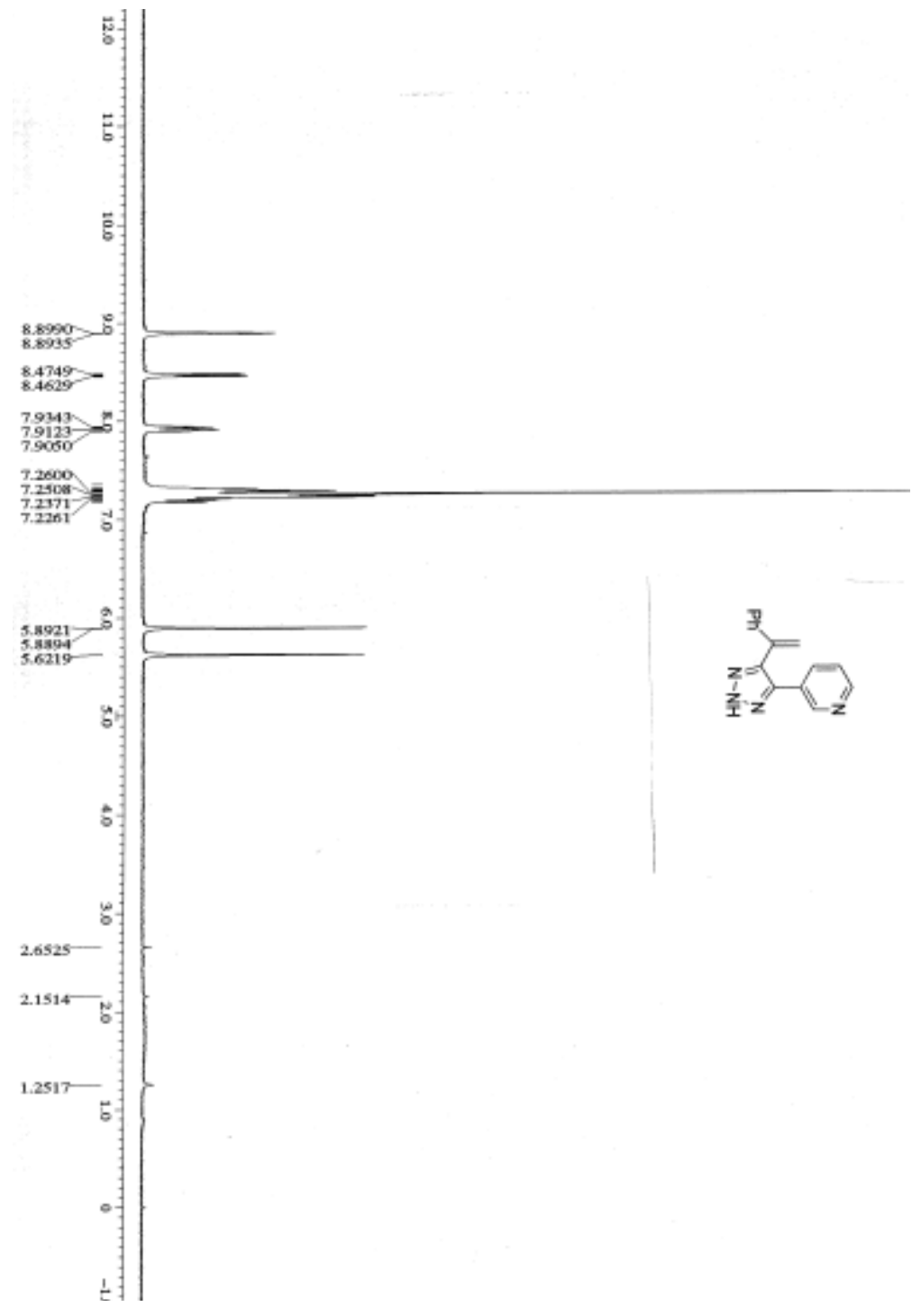

${ }^{1} \mathrm{H}-\mathrm{NMR}$ of Compound 2.6j 


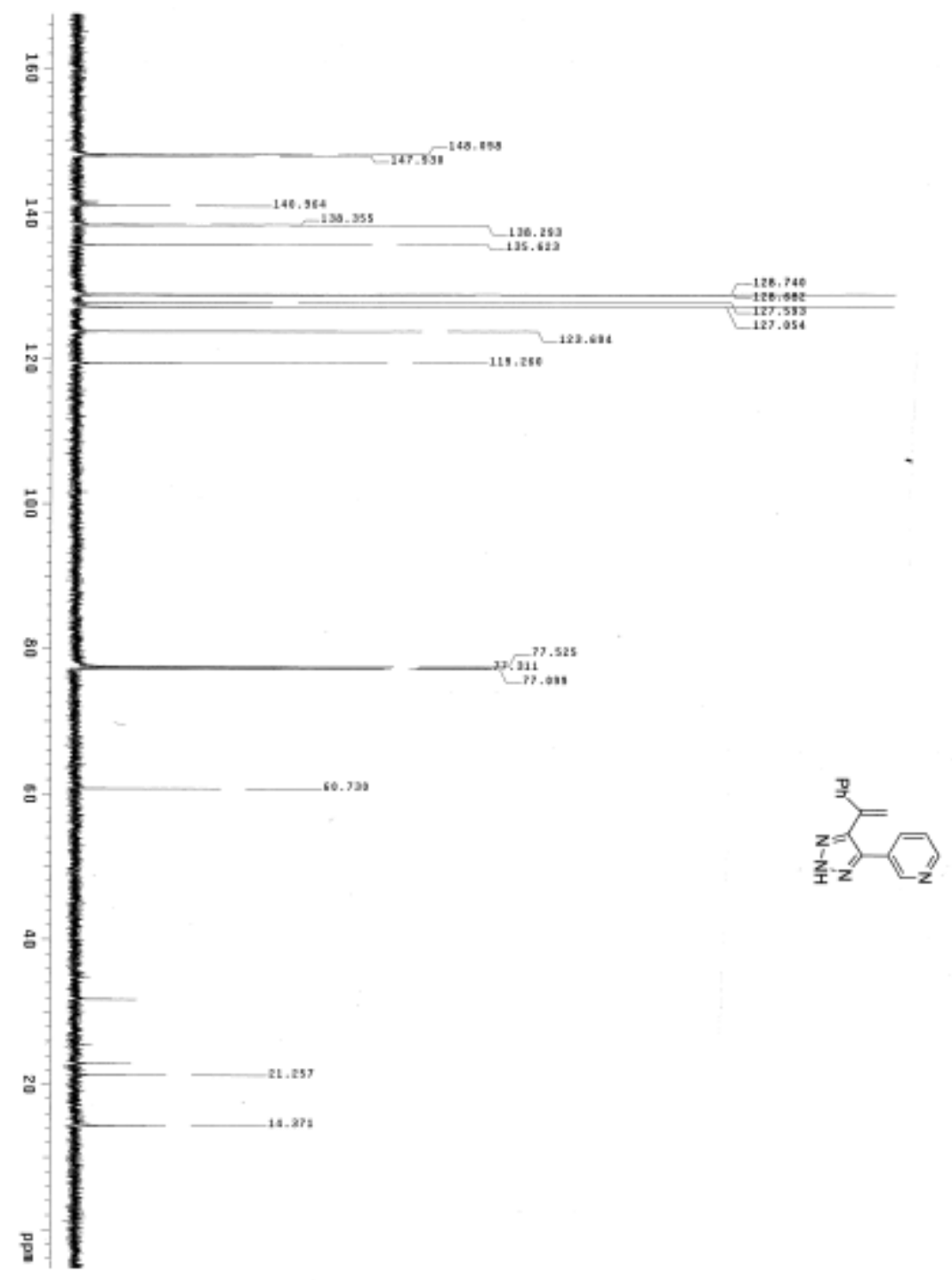

${ }^{13} \mathrm{C}-\mathrm{NMR}$ of Compound 2.6j 


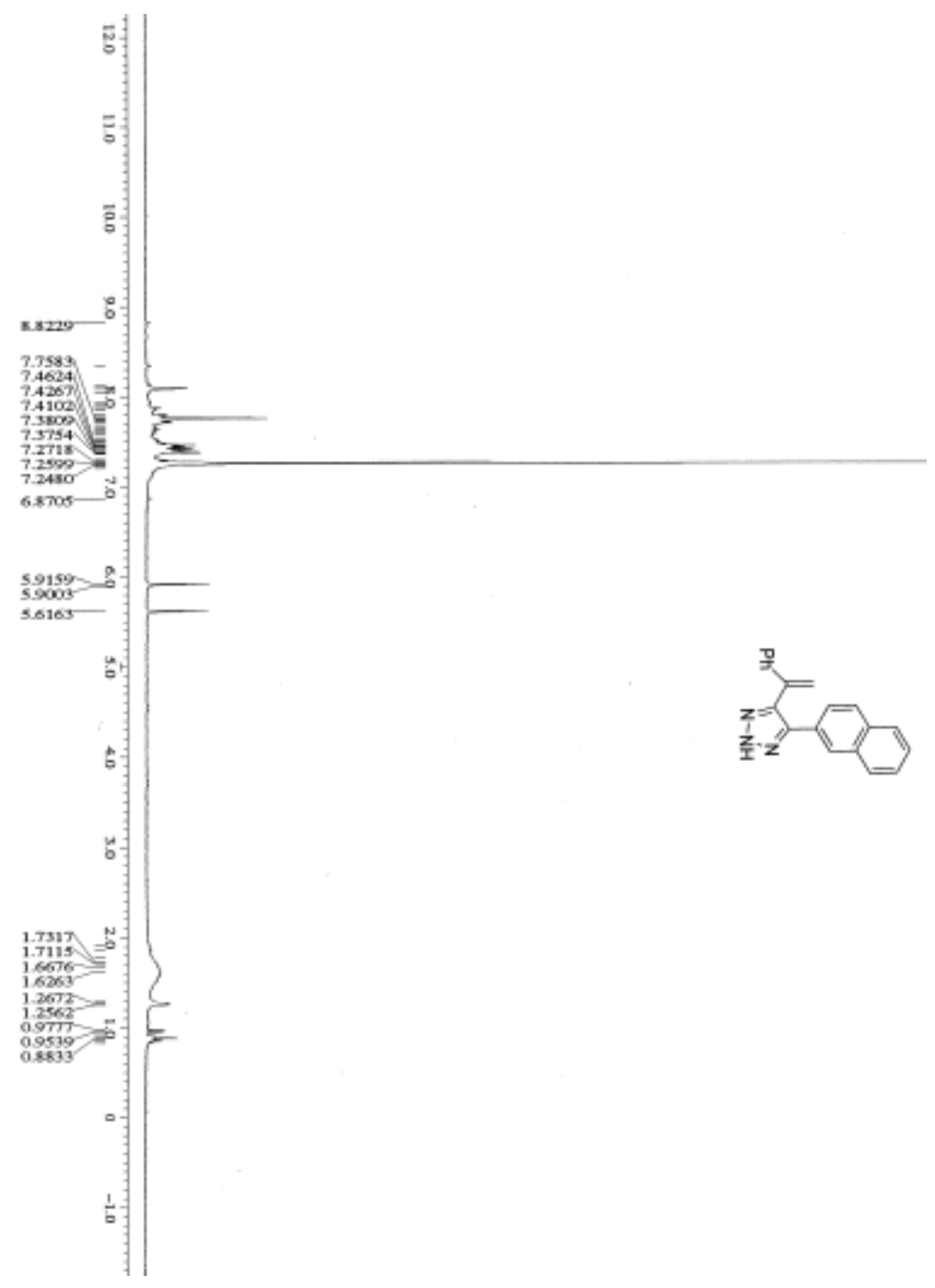

${ }^{1} \mathrm{H}-\mathrm{NMR}$ of Compound 2.6I 


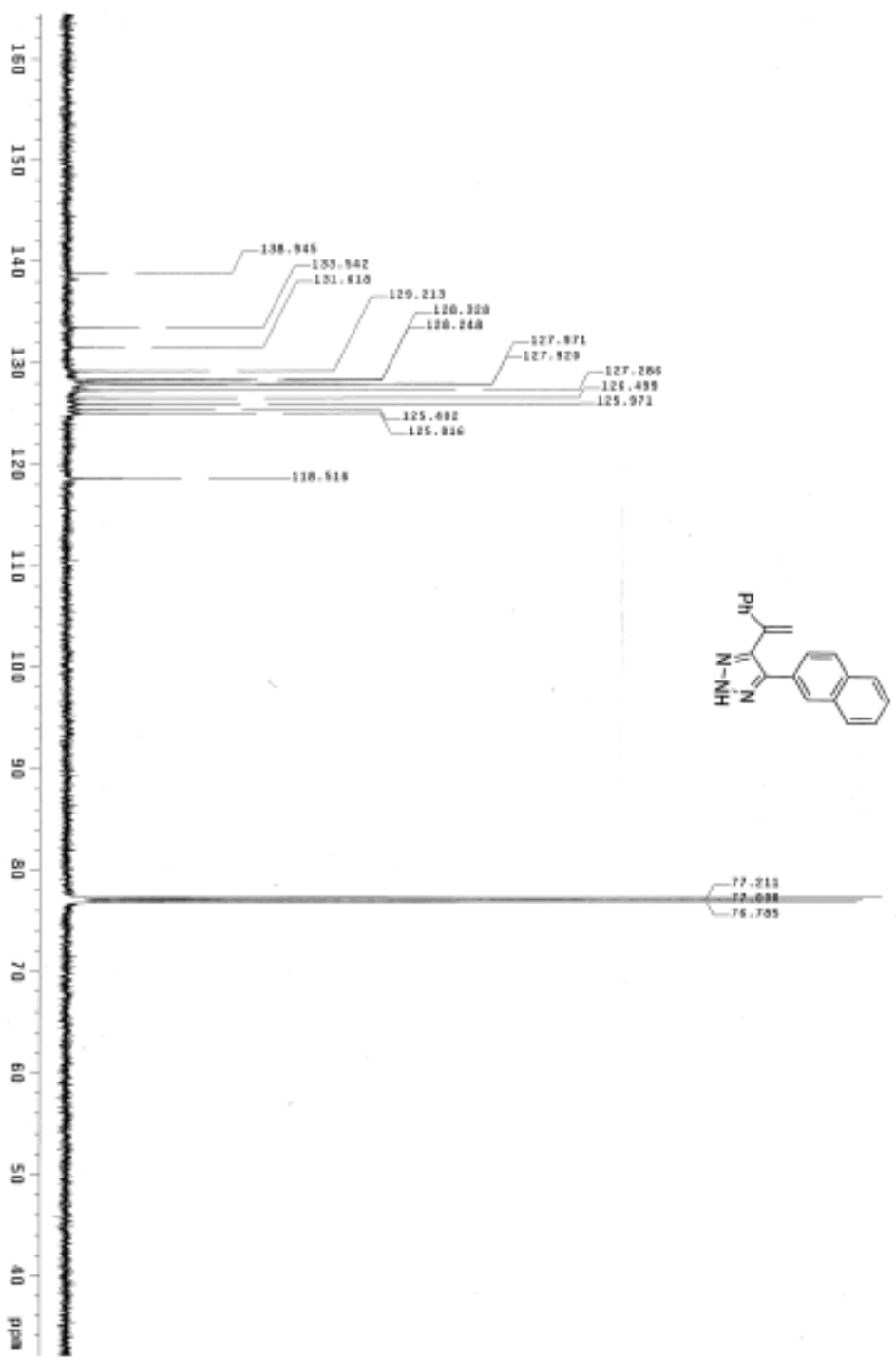

${ }^{13} \mathrm{C}-\mathrm{NMR}$ of Compound 2.6I 


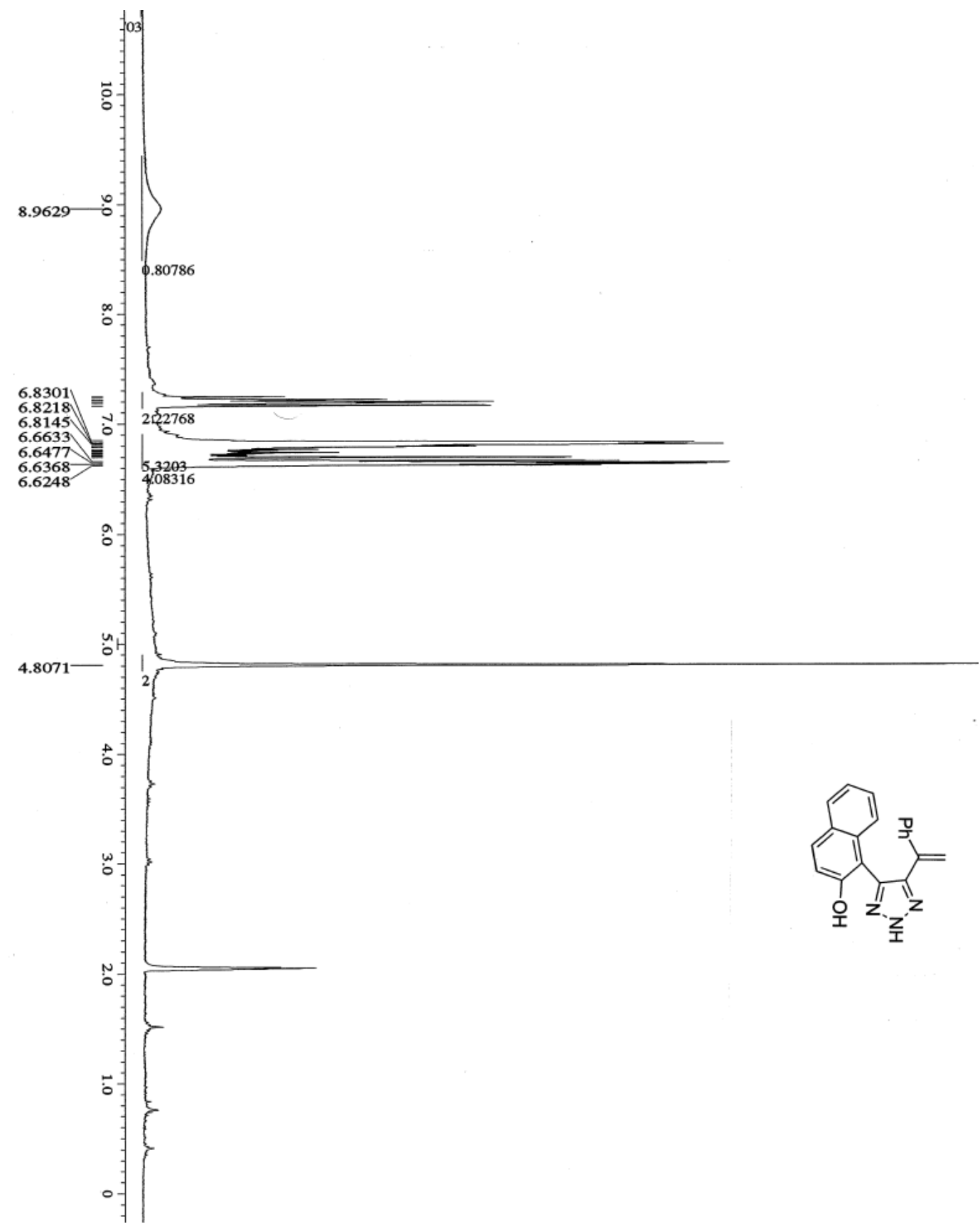

${ }^{1} \mathrm{H}-\mathrm{NMR}$ of Compound $2.6 \mathrm{~m}$ 


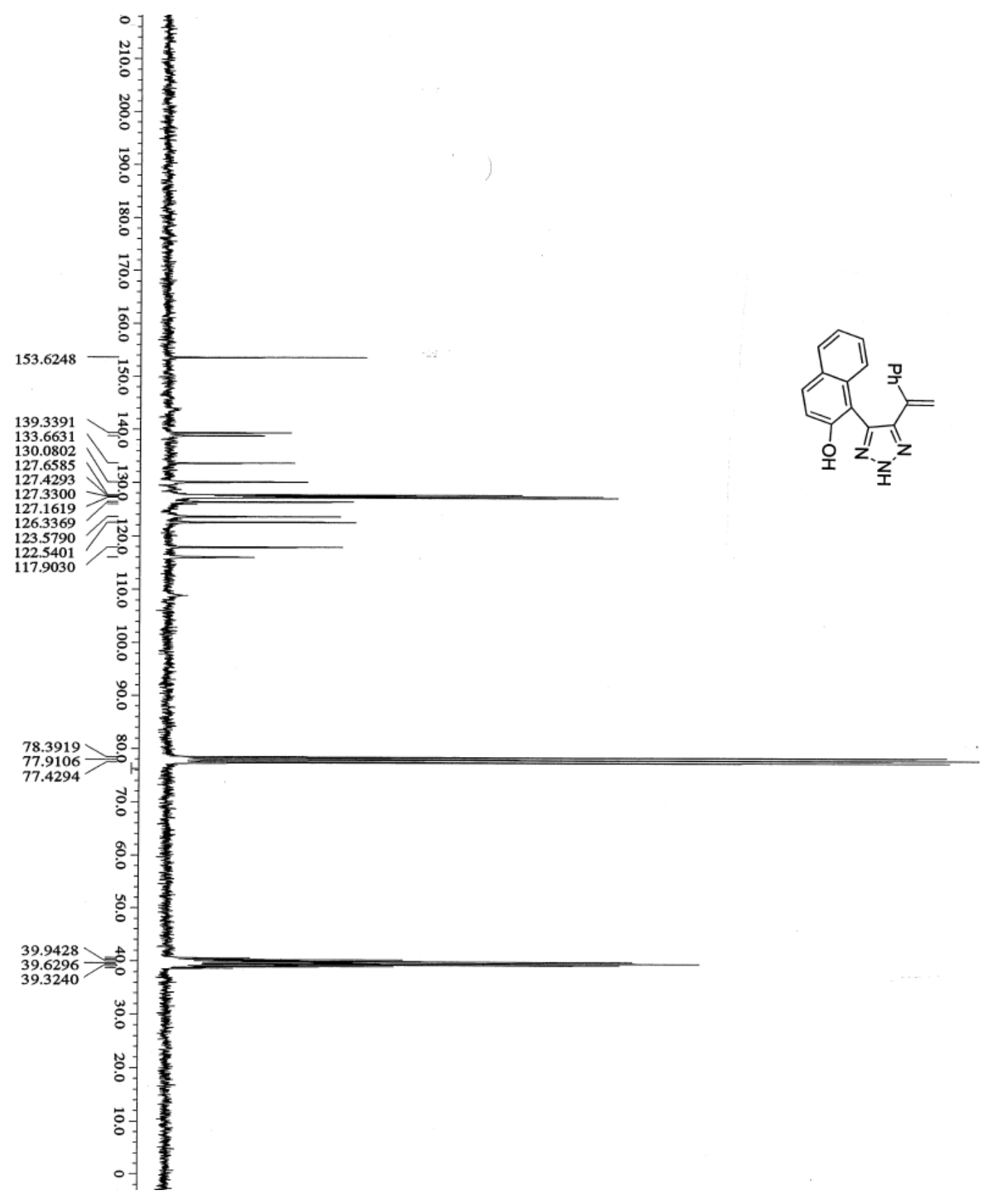

${ }^{13} \mathrm{C}$-NMR of Compound $\mathbf{2 . 6 m}$

233 


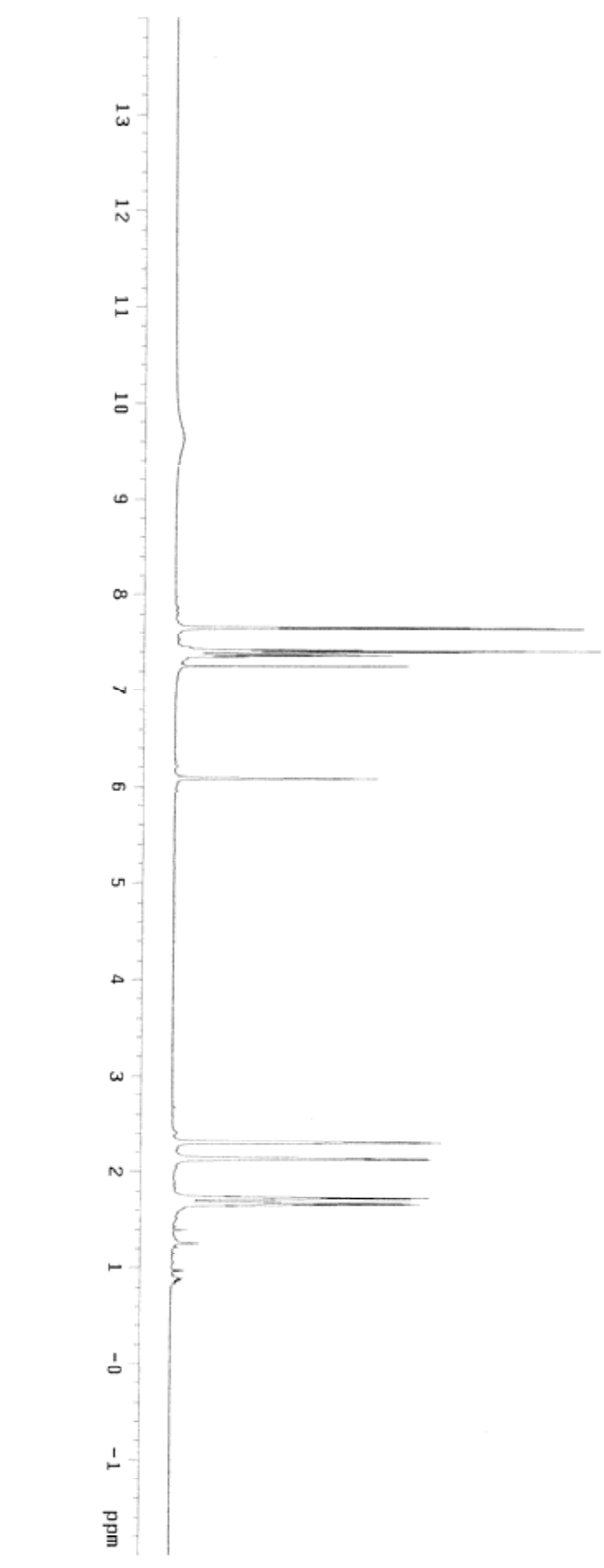

${ }^{1} \mathrm{H}-\mathrm{NMR}$ of Compound 2.6n 


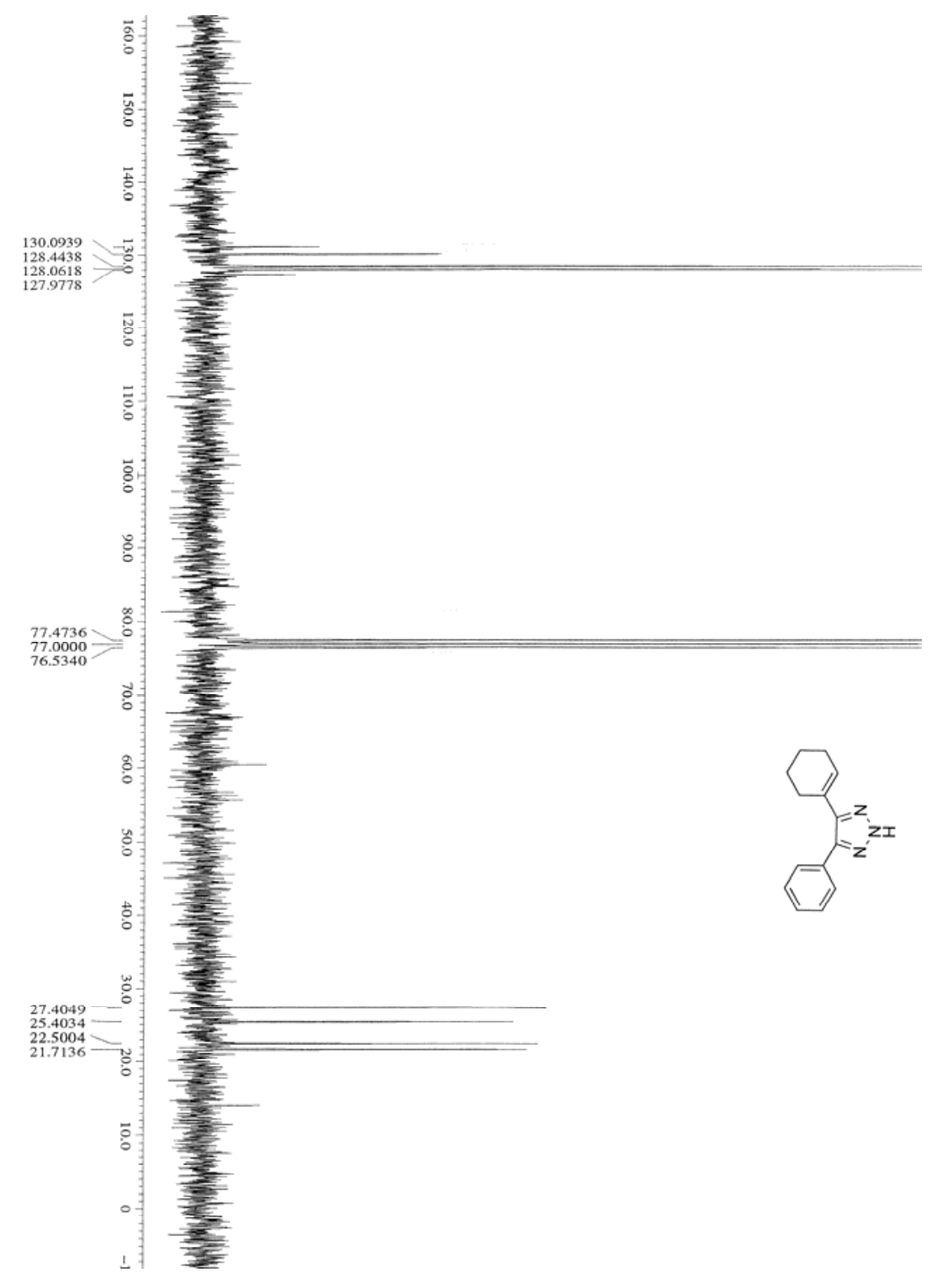

${ }^{13} \mathrm{C}-\mathrm{NMR}$ of Compound 2.6n 


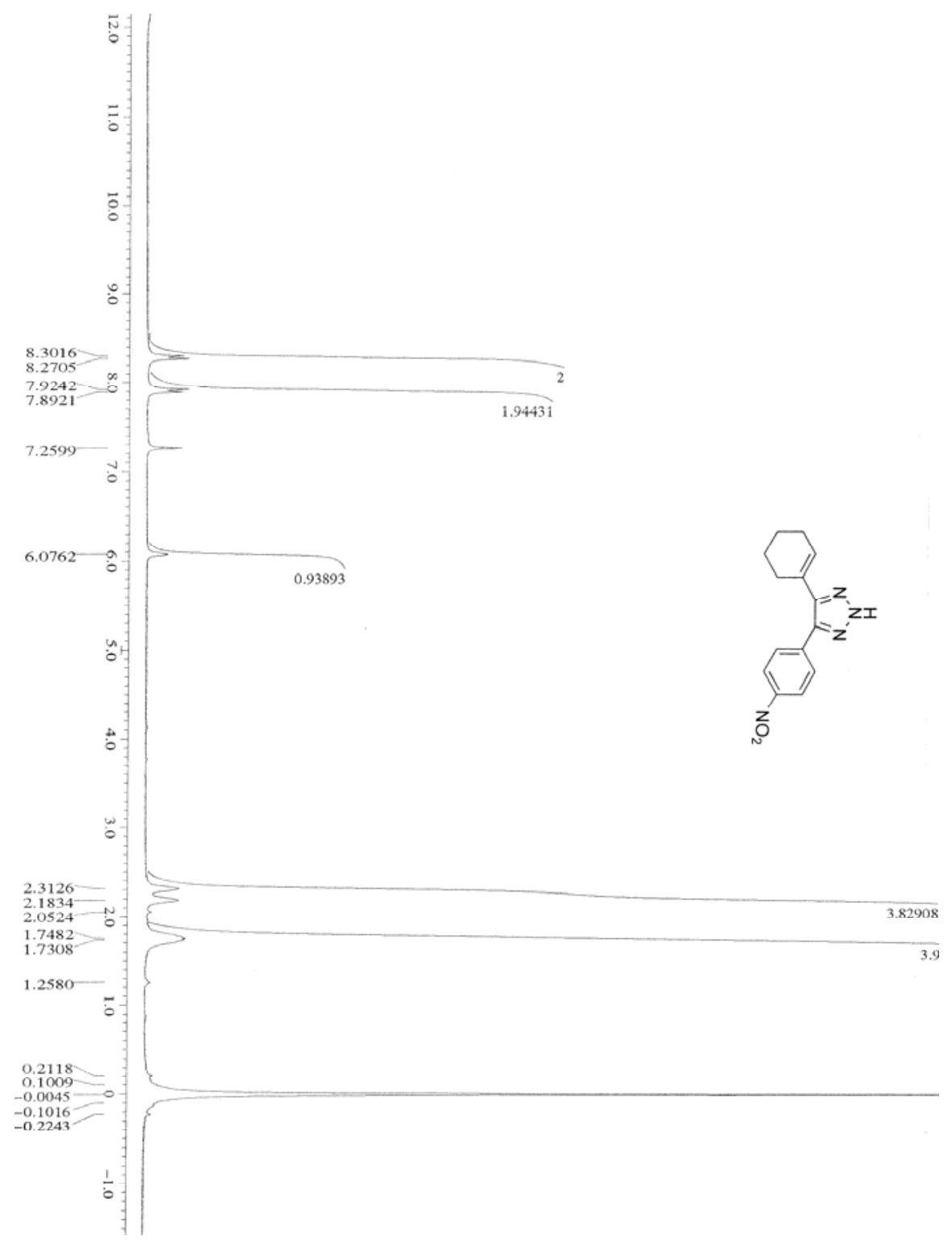

${ }^{1} \mathrm{H}-\mathrm{NMR}$ of Compound $\mathbf{2 . 6 0}$ 


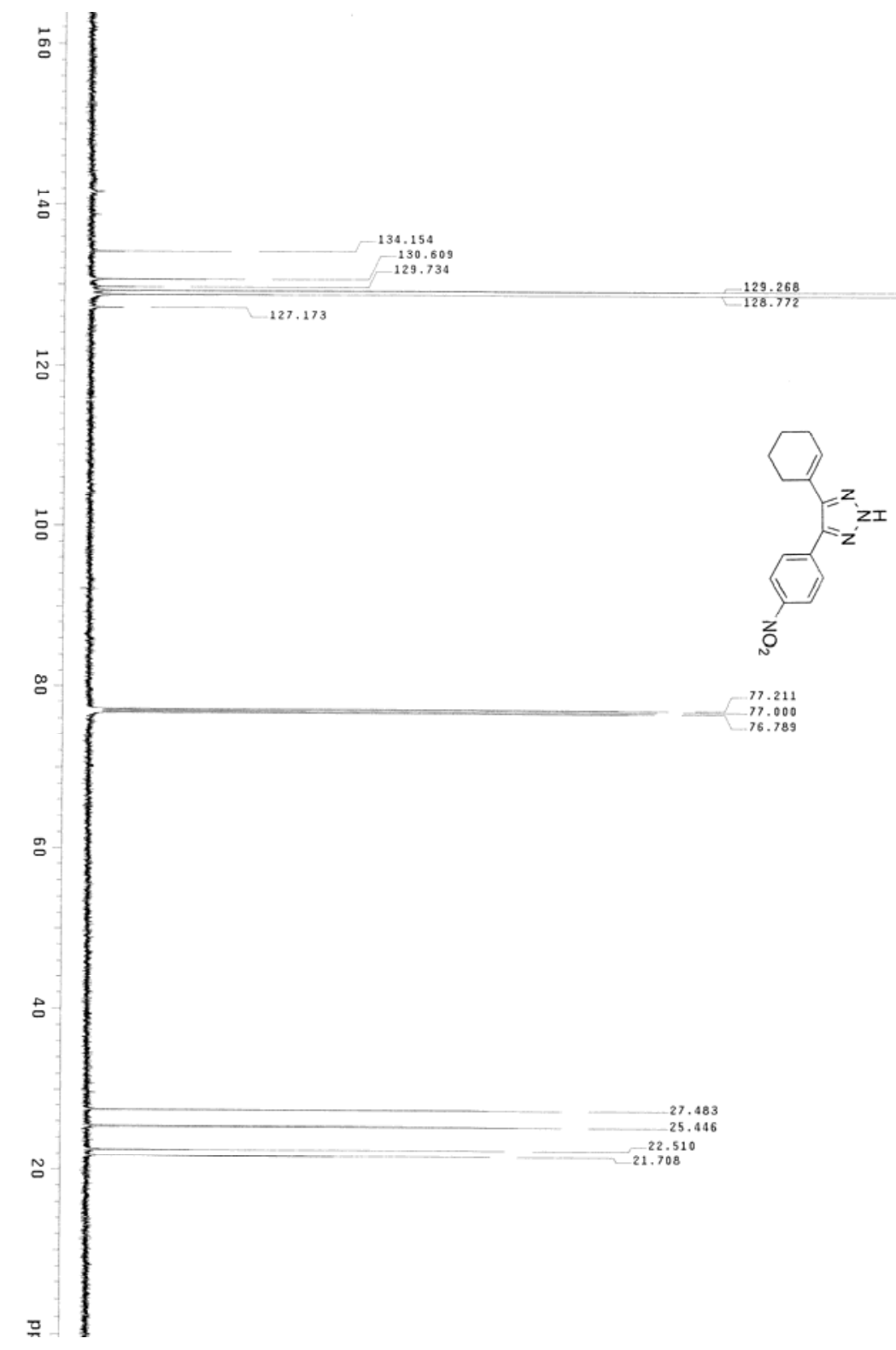

${ }^{13} \mathrm{C}-\mathrm{NMR}$ of Compound 2.60 


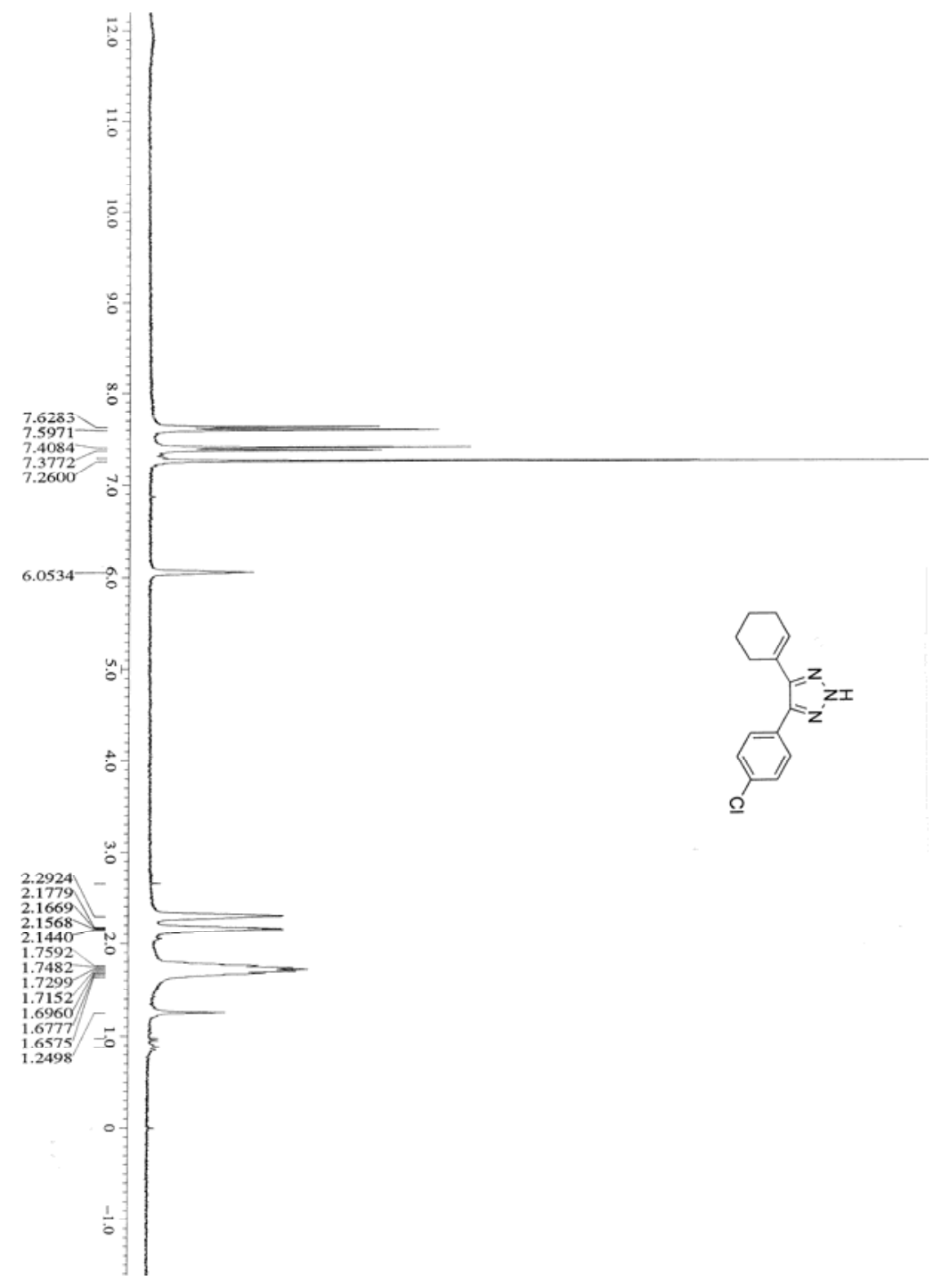

${ }^{1} \mathrm{H}-\mathrm{NMR}$ of Compound 2.6p 


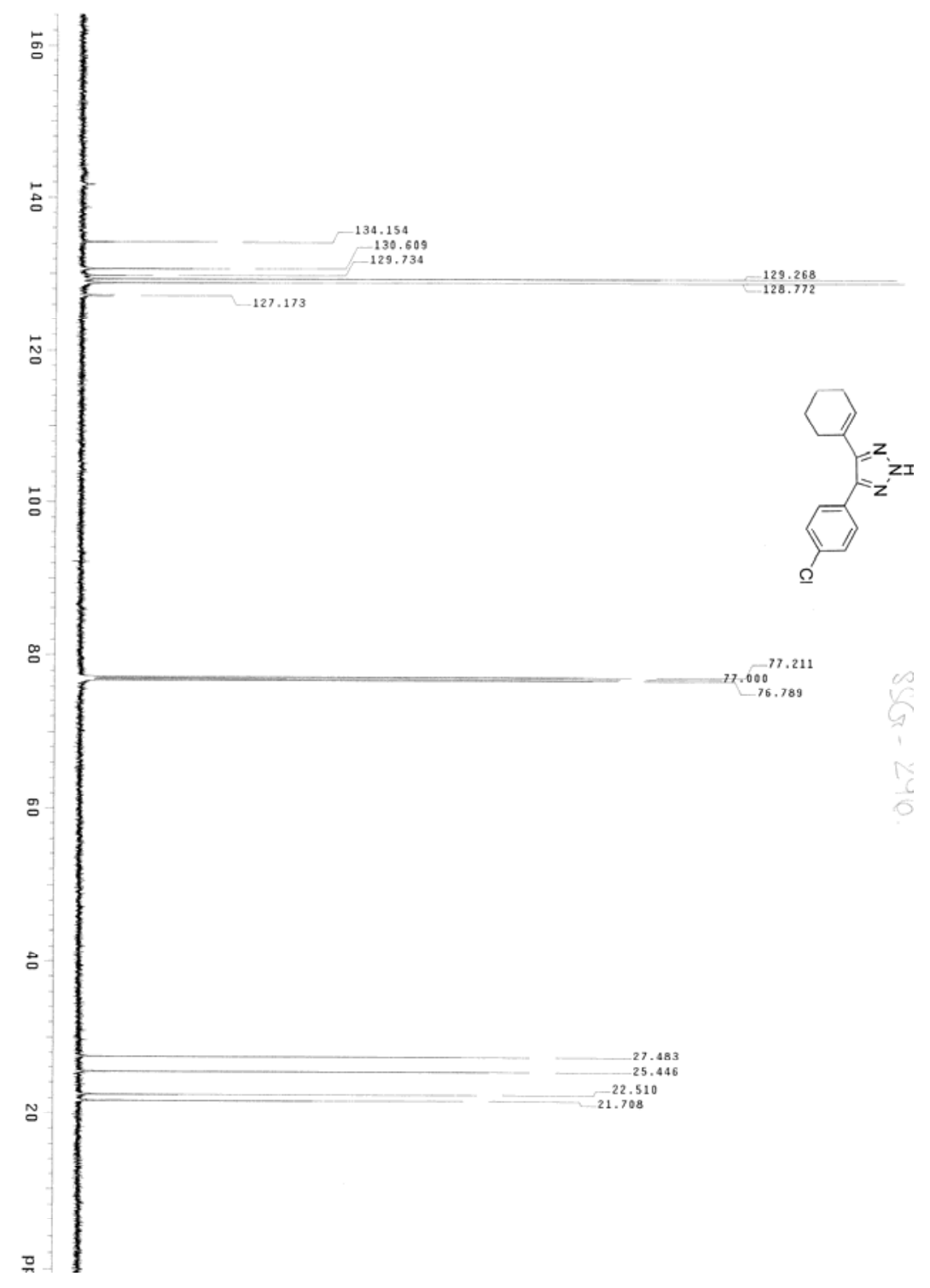

${ }^{13} \mathrm{C}-\mathrm{NMR}$ of Compound 2.6p 


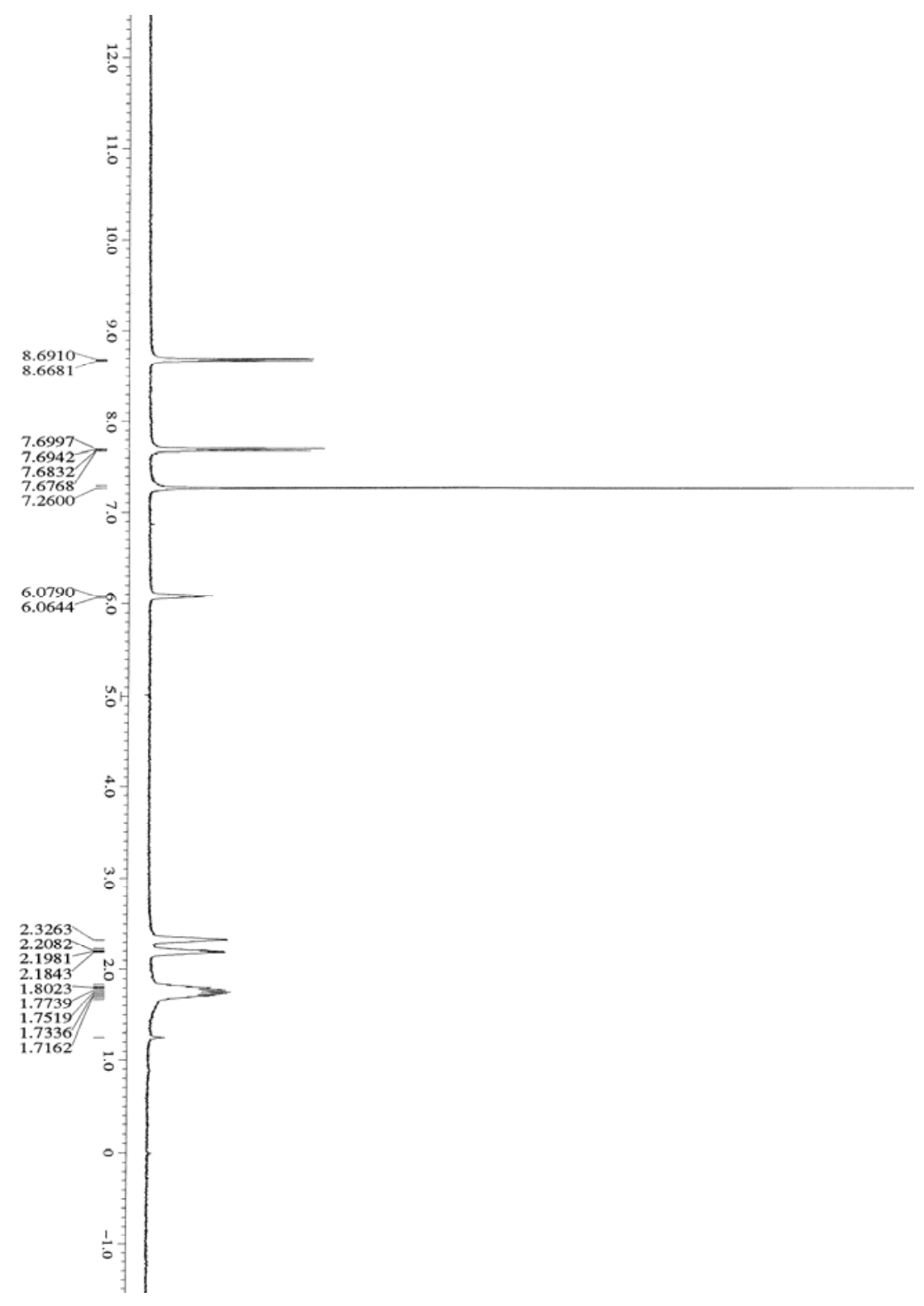

${ }^{1} \mathrm{H}-\mathrm{NMR}$ of Compound $\mathbf{2 . 6 q}$ 


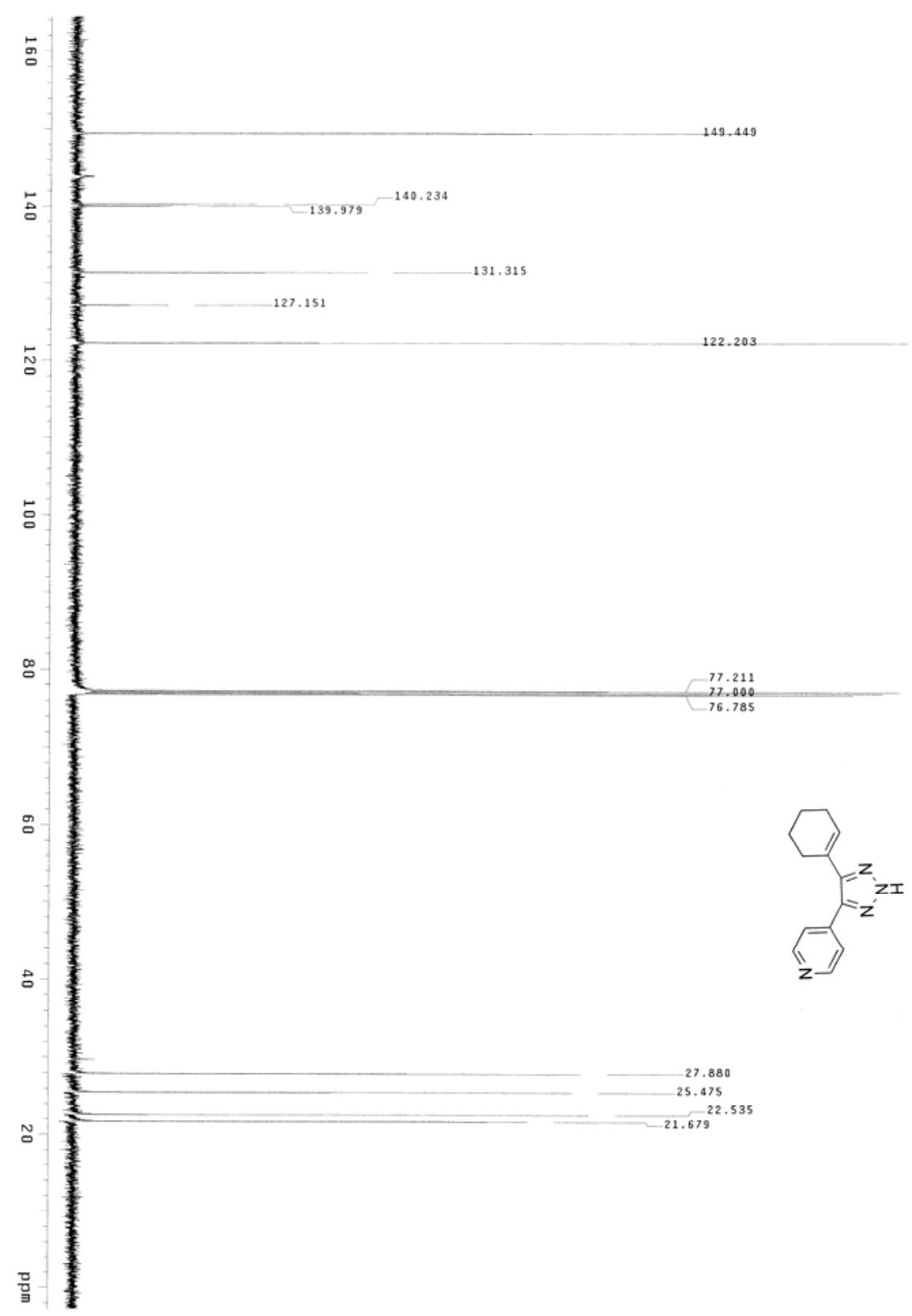

${ }^{13} \mathrm{C}-\mathrm{NMR}$ of Compound $\mathbf{2 . 6 q}$ 


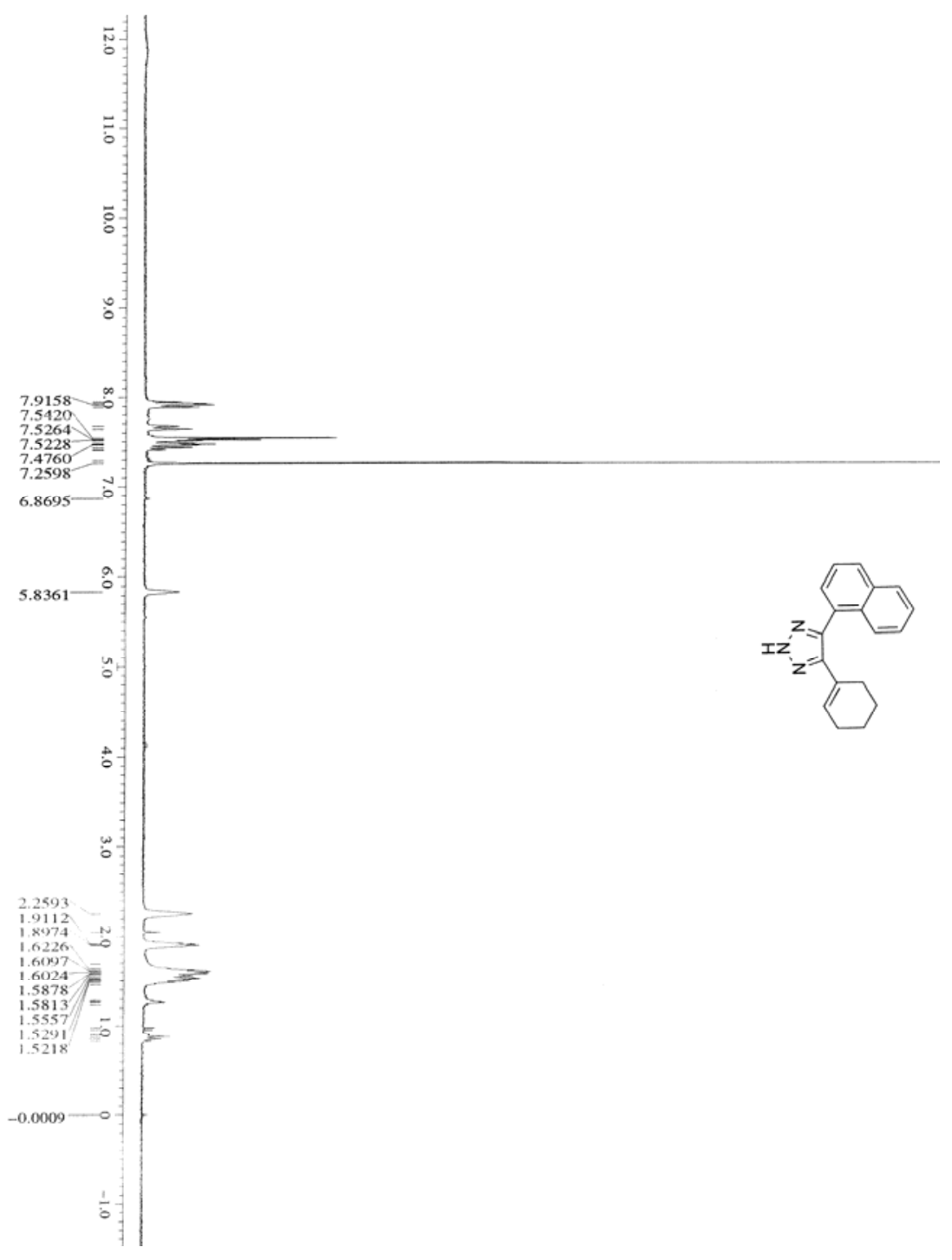

${ }^{1} \mathrm{H}-\mathrm{NMR}$ of Compound 2.6r 


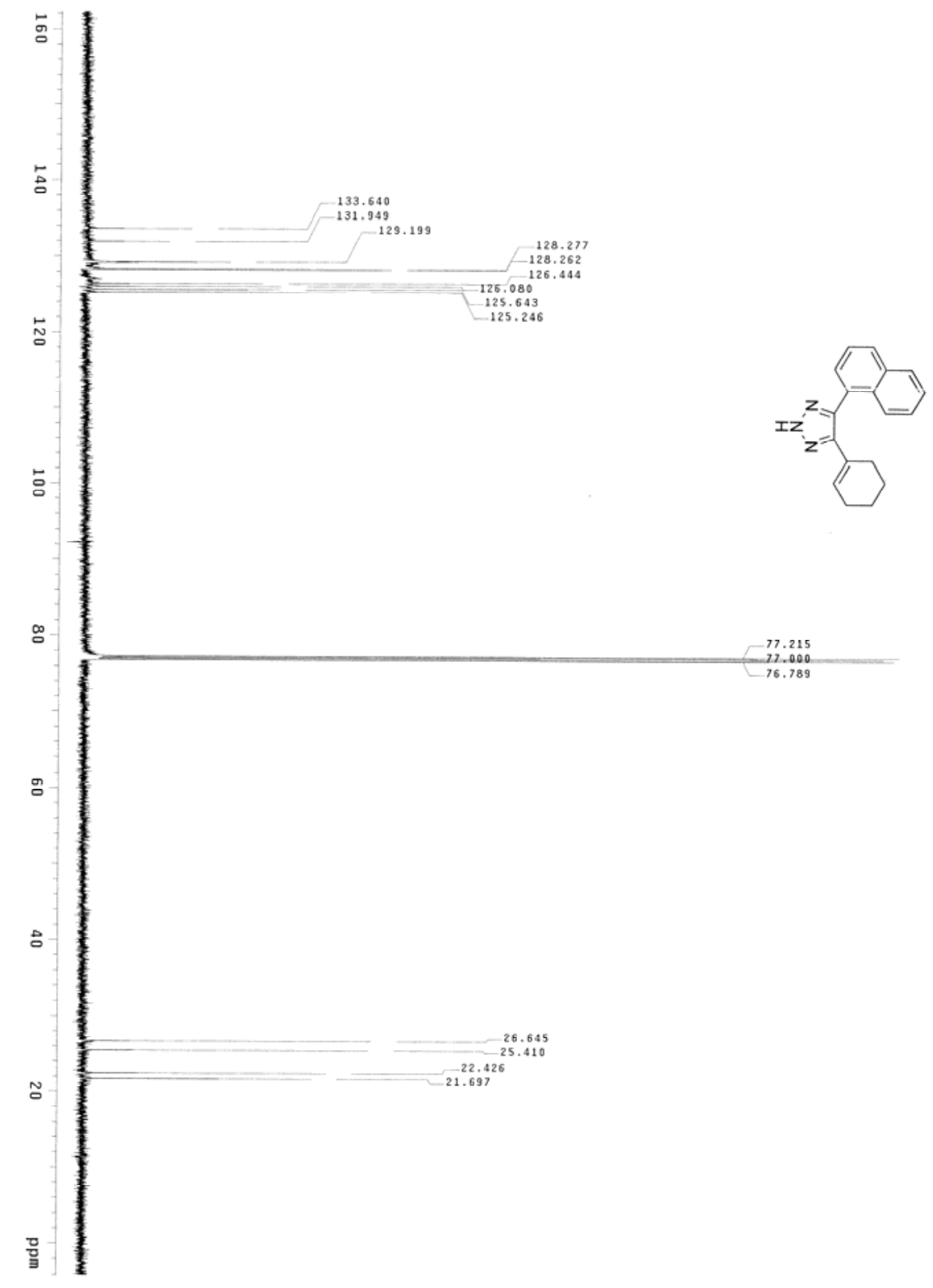

${ }^{13} \mathrm{C}-\mathrm{NMR}$ of Compound $\mathbf{2 . 6 r}$ 


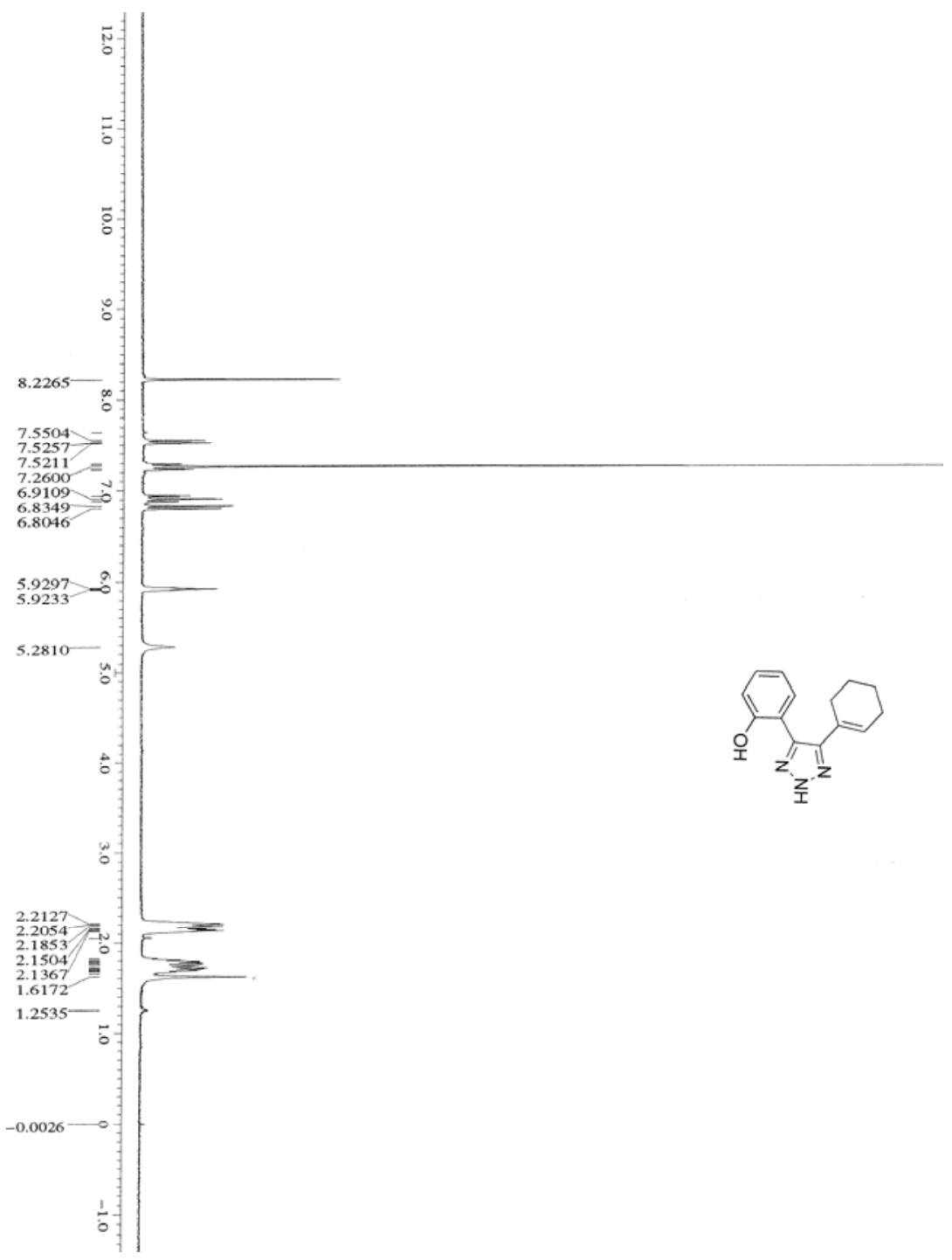

${ }^{1} \mathrm{H}-\mathrm{NMR}$ of Compound 2.6s 


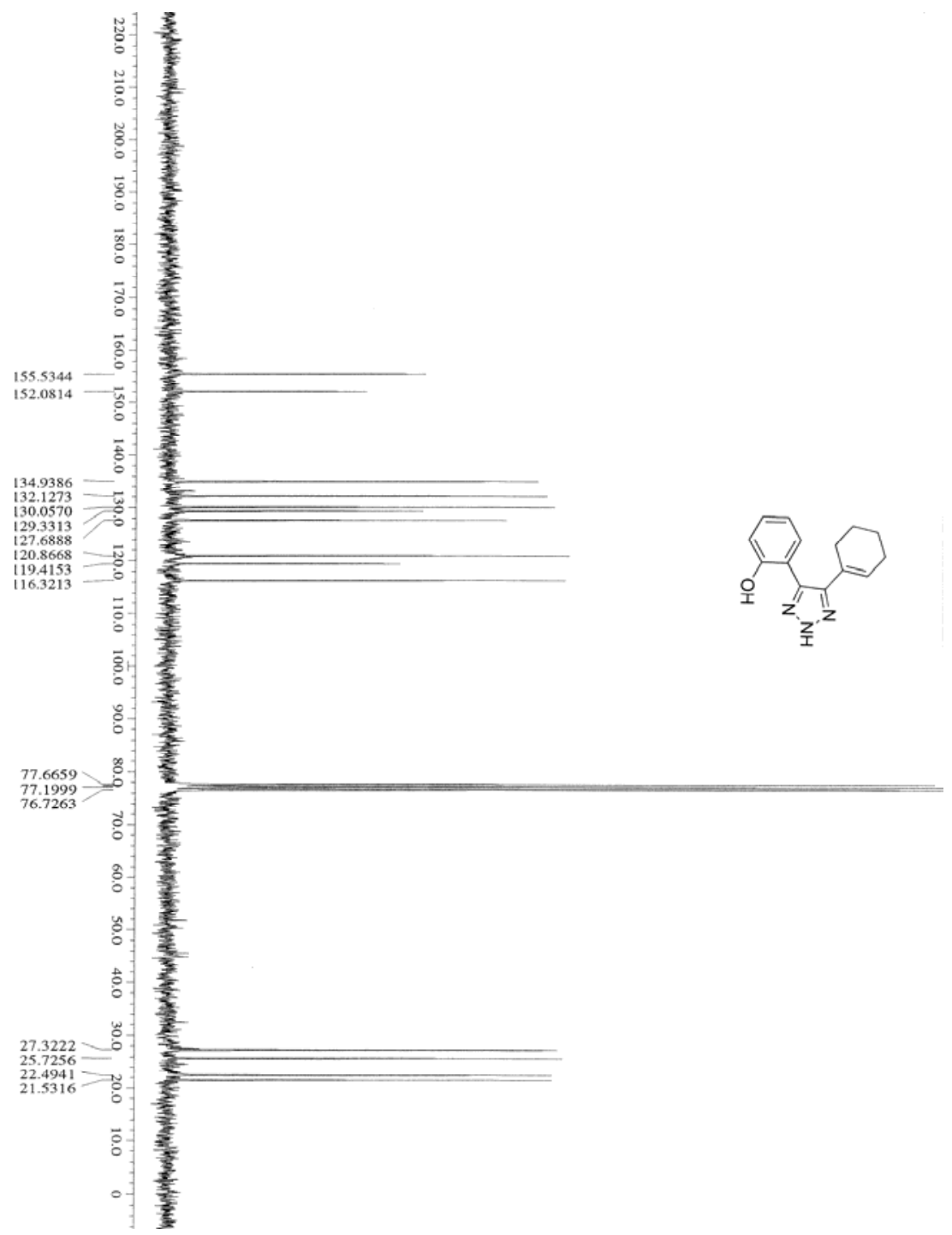

${ }^{13} \mathrm{C}-\mathrm{NMR}$ of Compound 2.6s 


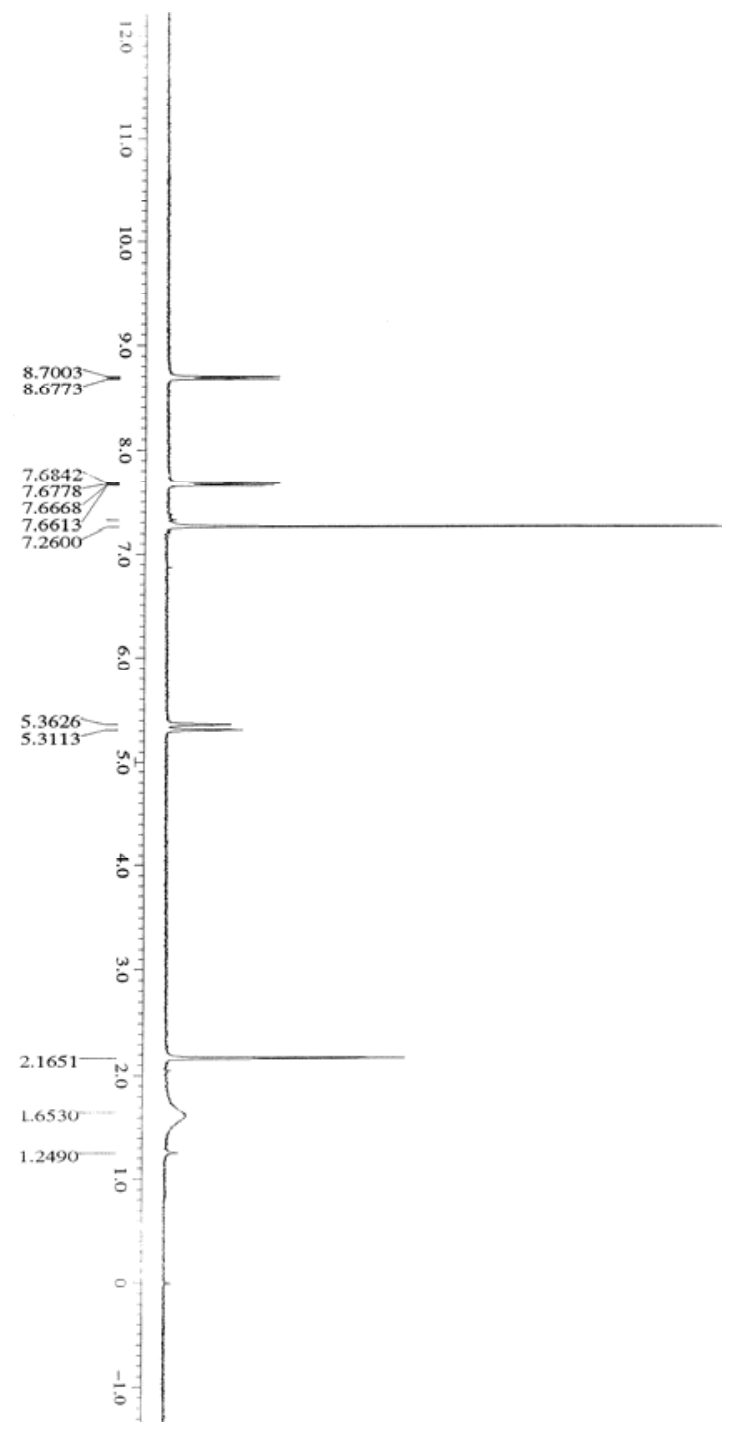

${ }^{1} \mathrm{H}-\mathrm{NMR}$ of Compound $\mathbf{2 . 6 u}$ 

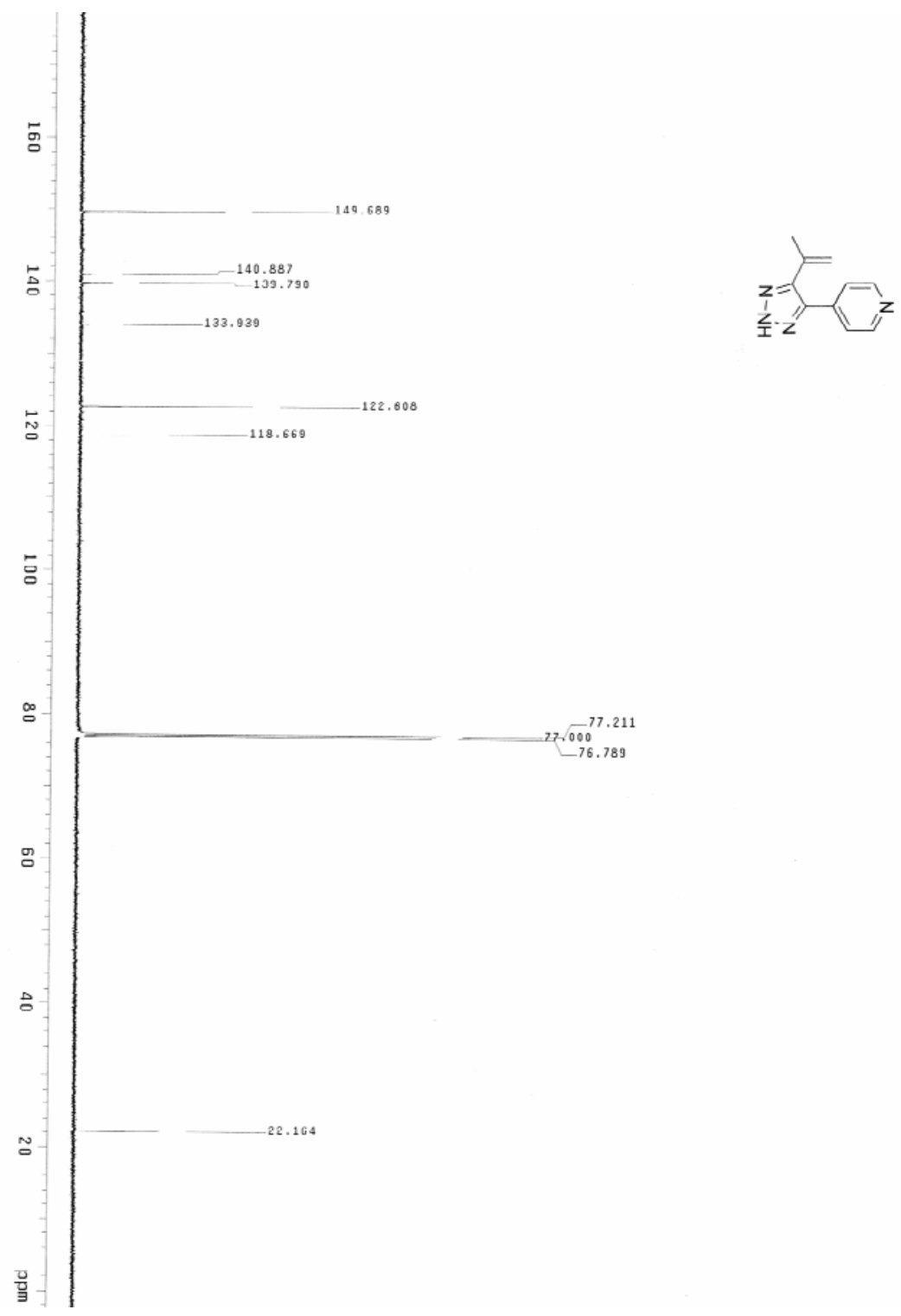

${ }^{13} \mathrm{C}-\mathrm{NMR}$ of Compound 2.6u 


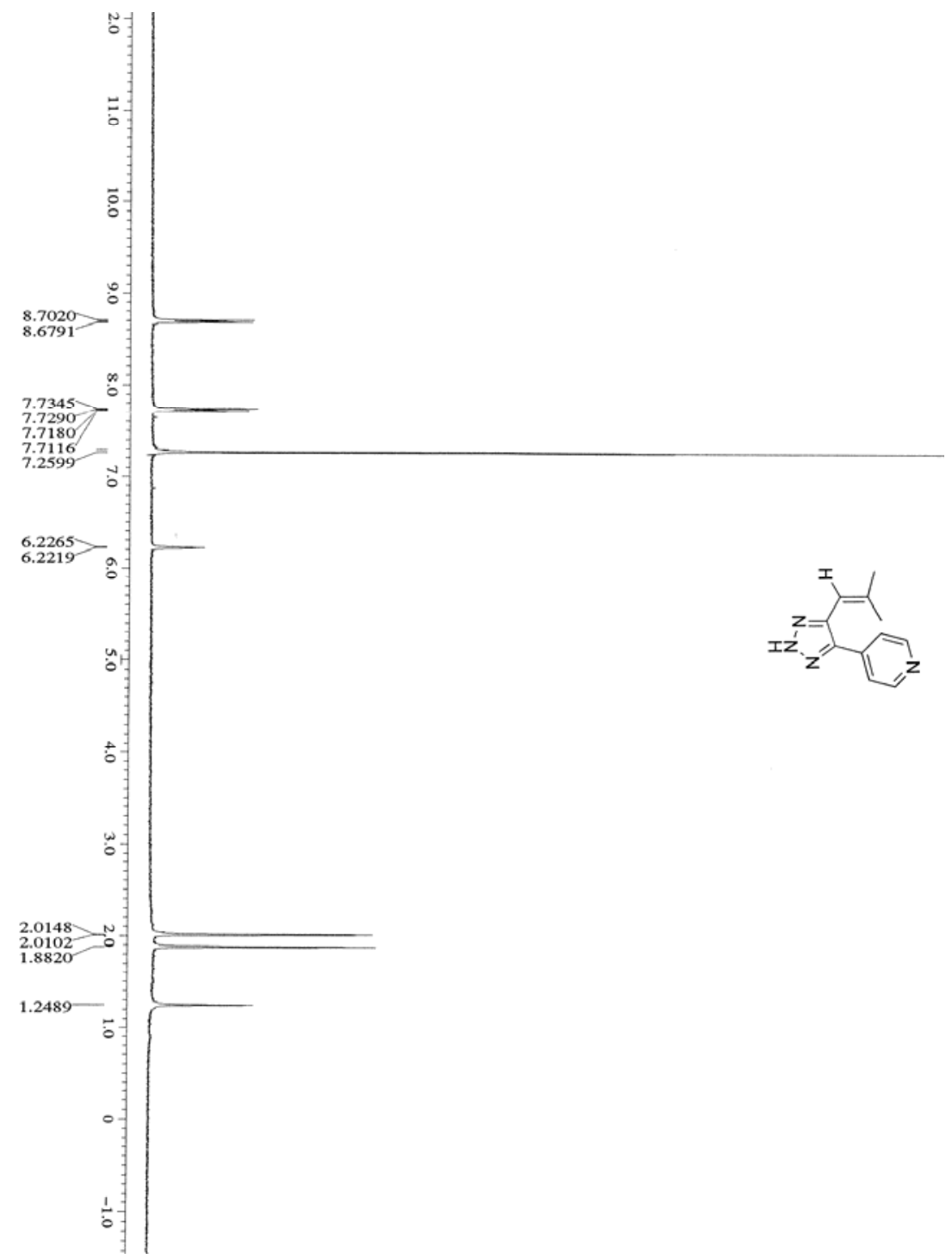

${ }^{1} \mathrm{H}-\mathrm{NMR}$ of Compound 2.6v 


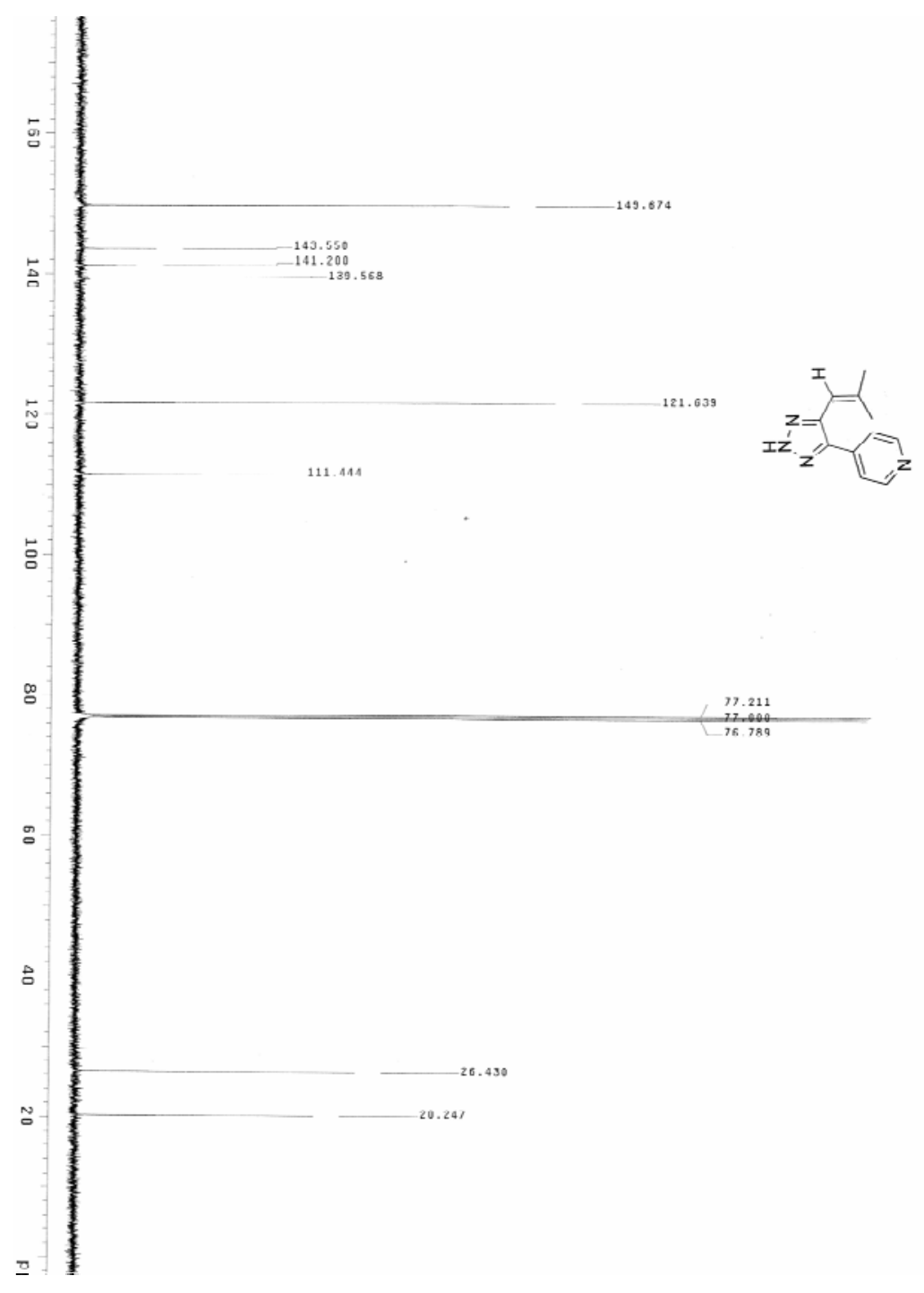

${ }^{13} \mathrm{C}-\mathrm{NMR}$ of Compound 2.6v 


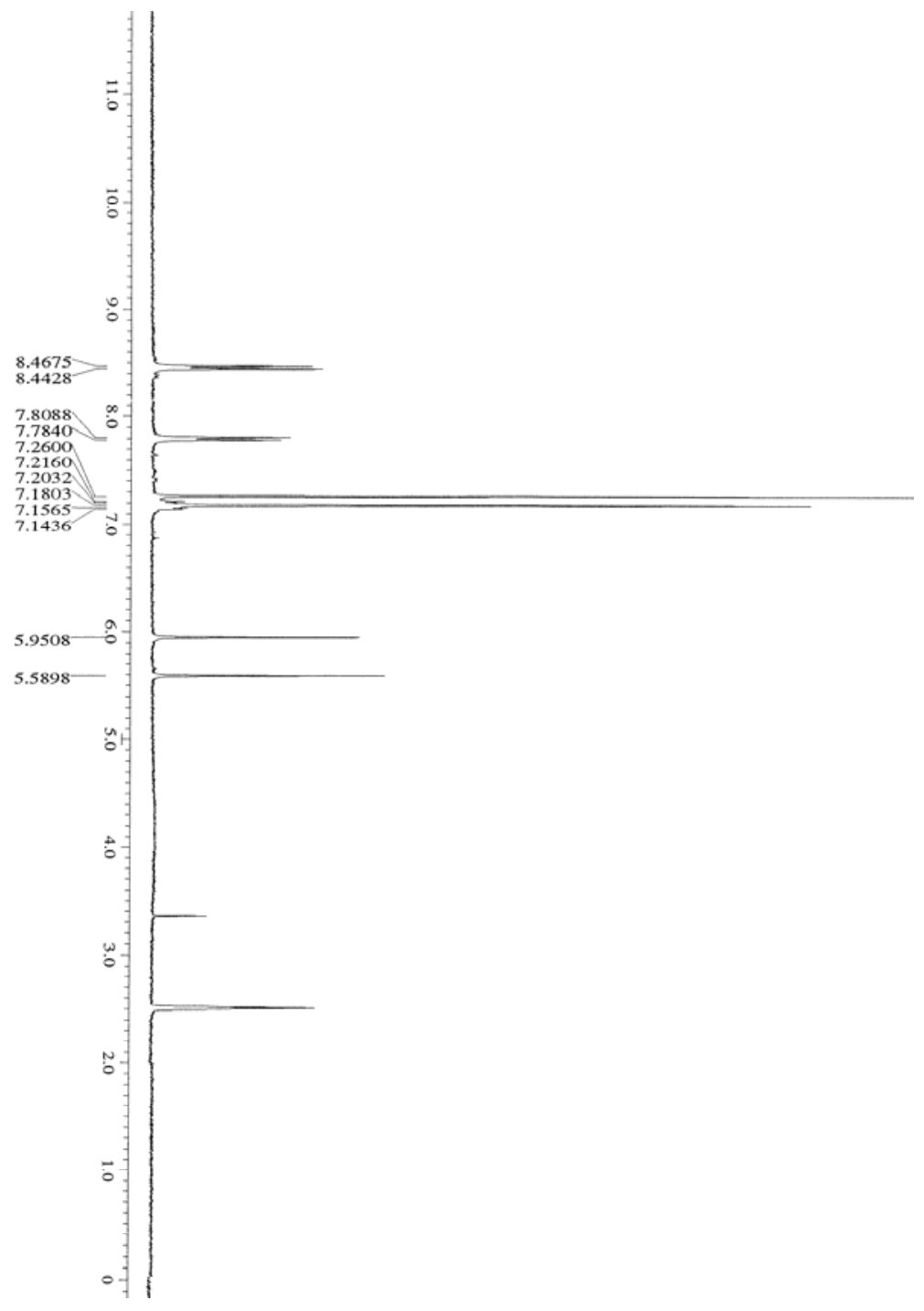

${ }^{1} \mathrm{H}-\mathrm{NMR}$ of Compound 2.6w 


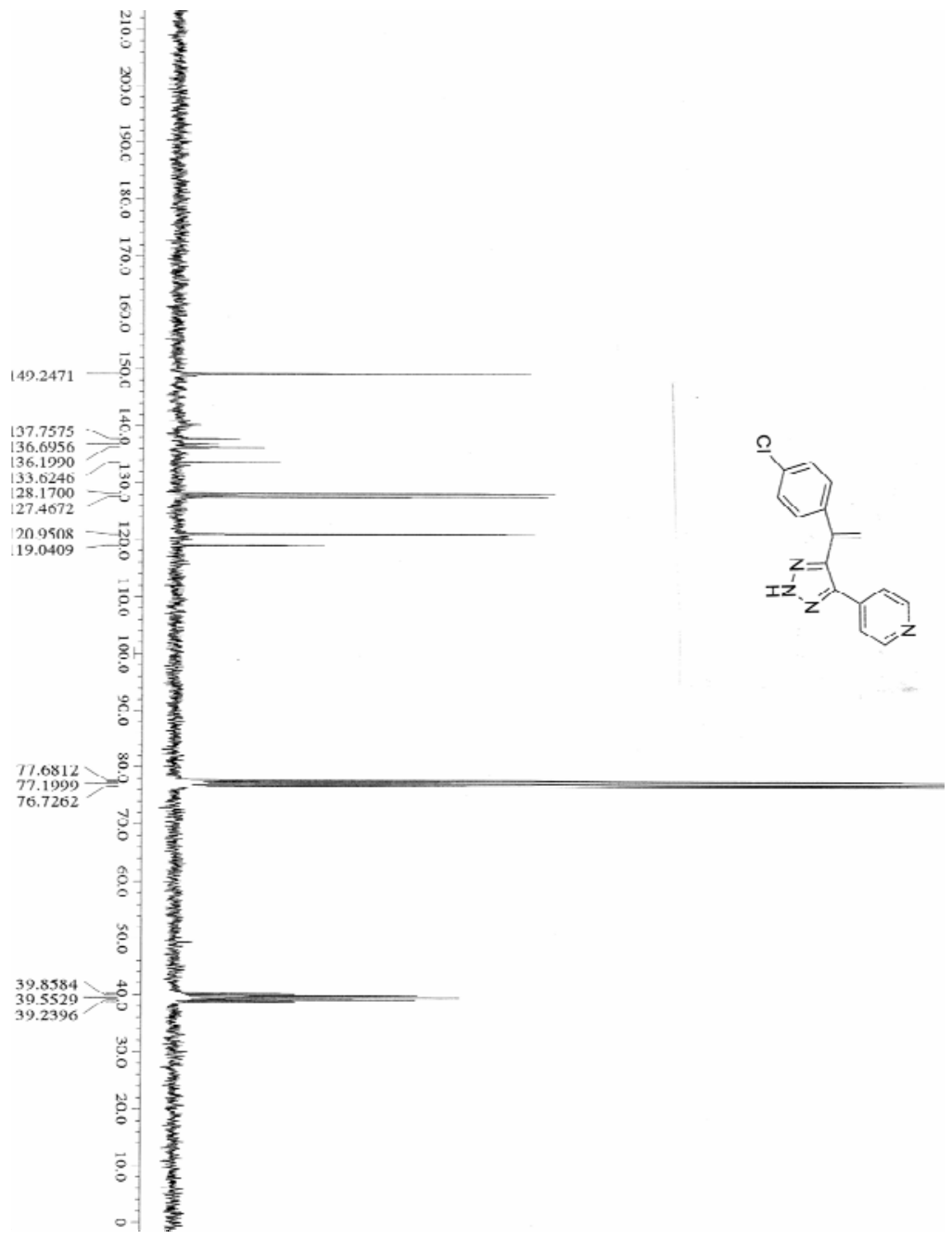

${ }^{13} \mathrm{C}-\mathrm{NMR}$ of Compound 2.6w 


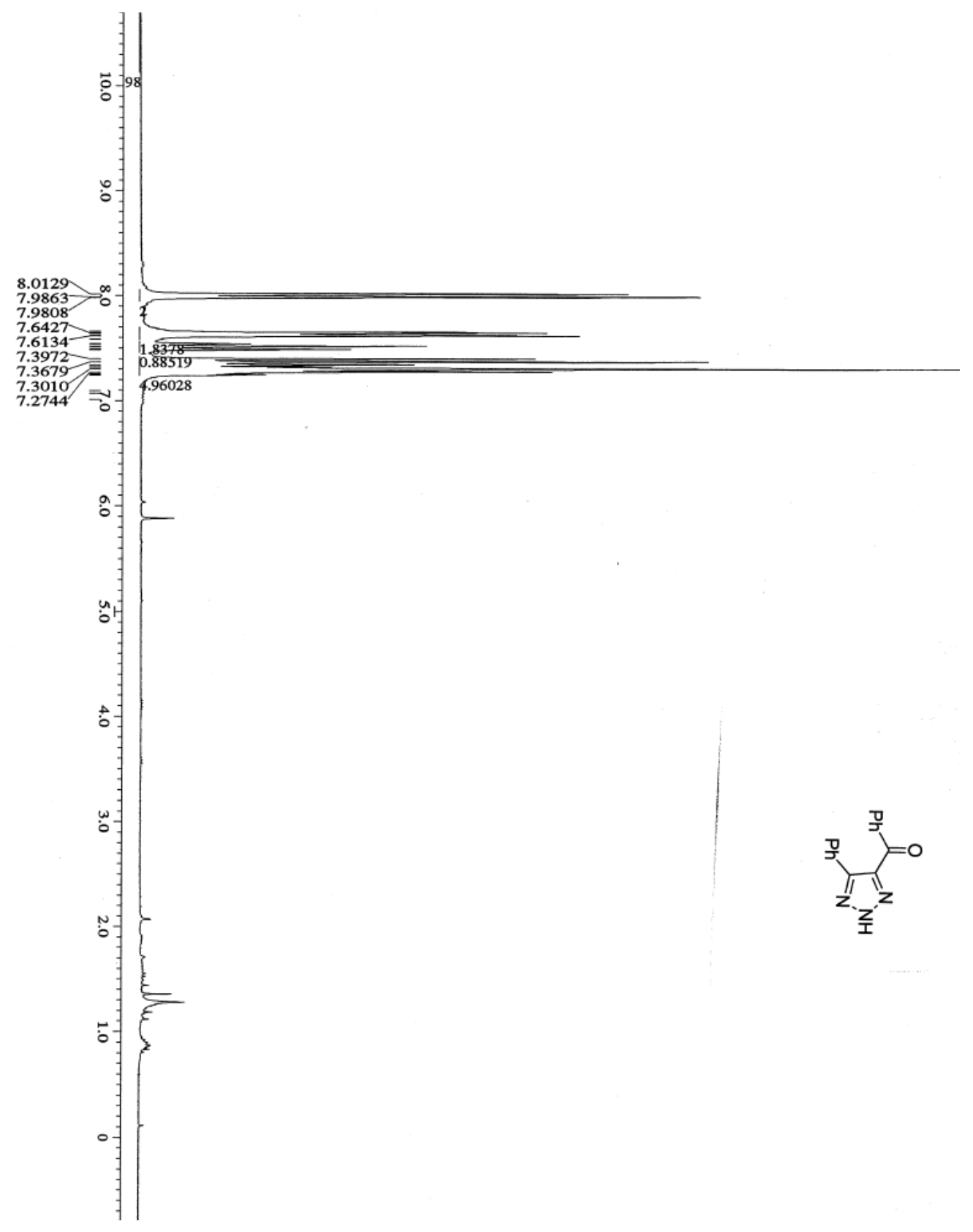

${ }^{1} \mathrm{H}-\mathrm{NMR}$ of Compound $2.7 \mathrm{~b}$ 


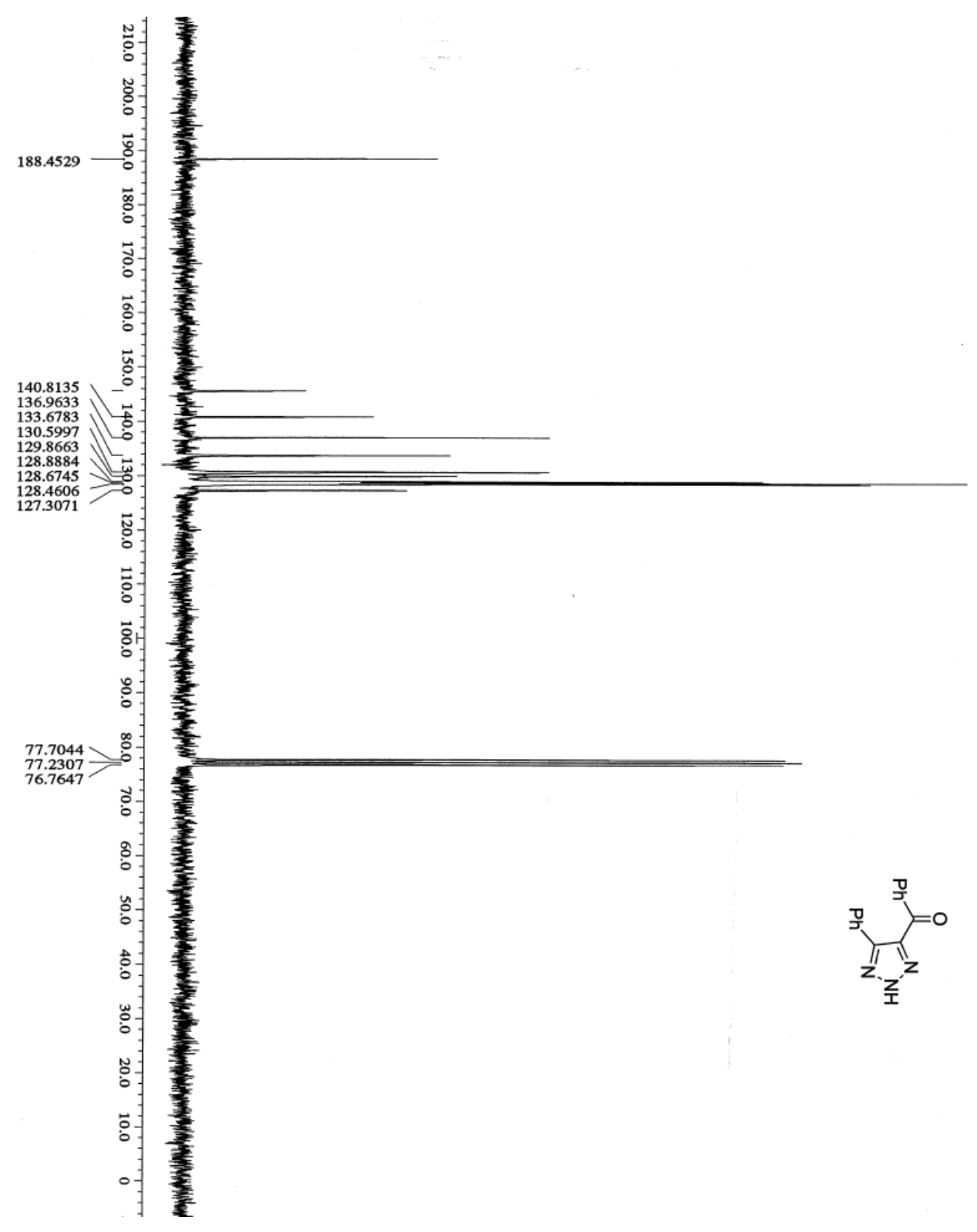

${ }^{13} \mathrm{C}-\mathrm{NMR}$ of Compound 2.7b 


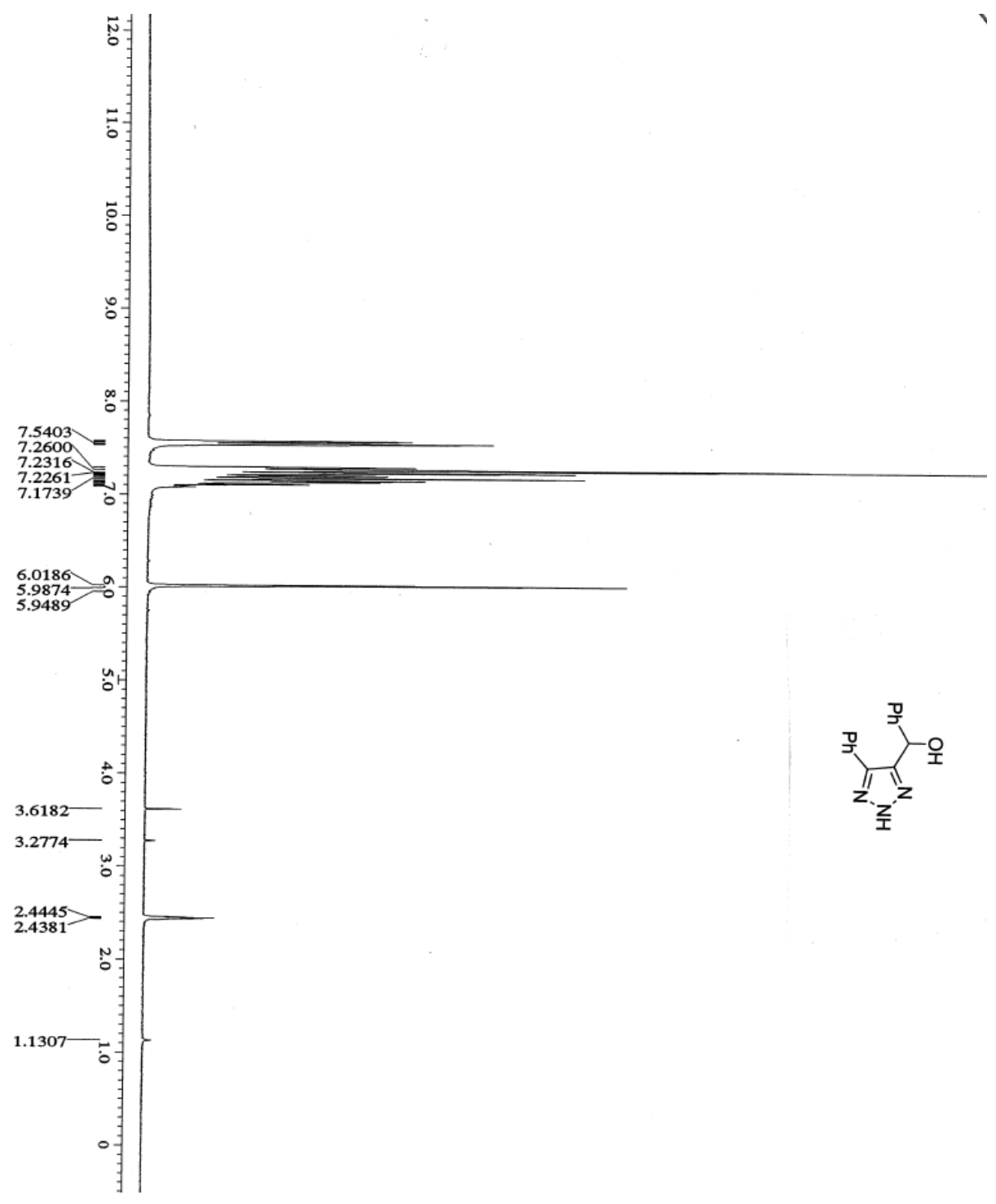

${ }^{1} \mathrm{H}-\mathrm{NMR}$ of Compound 2.7c 


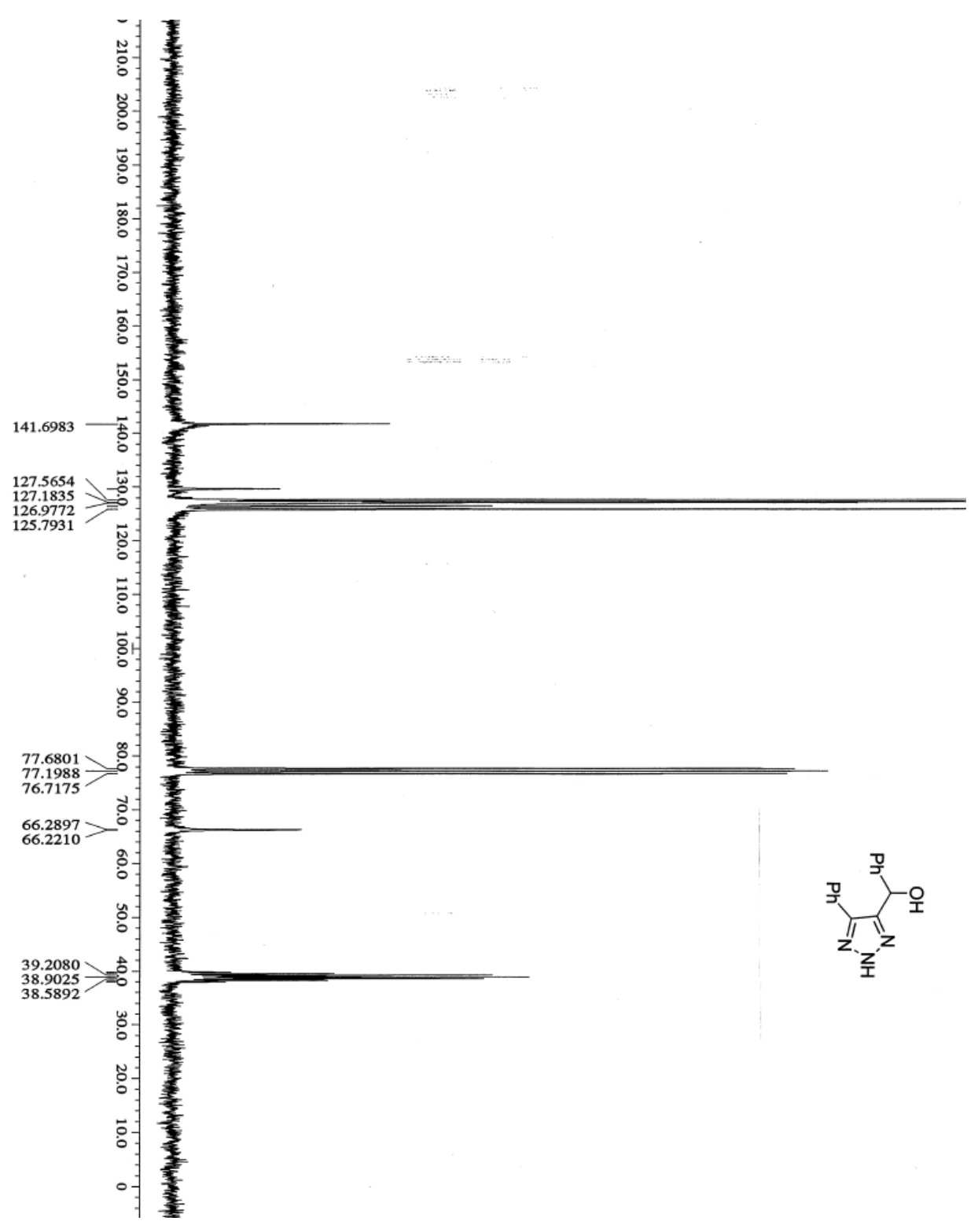

${ }^{13}$ C-NMR of Compound 2.7c 
Chapter Four: Triazole-Au complexes catalyzed Hydroamination

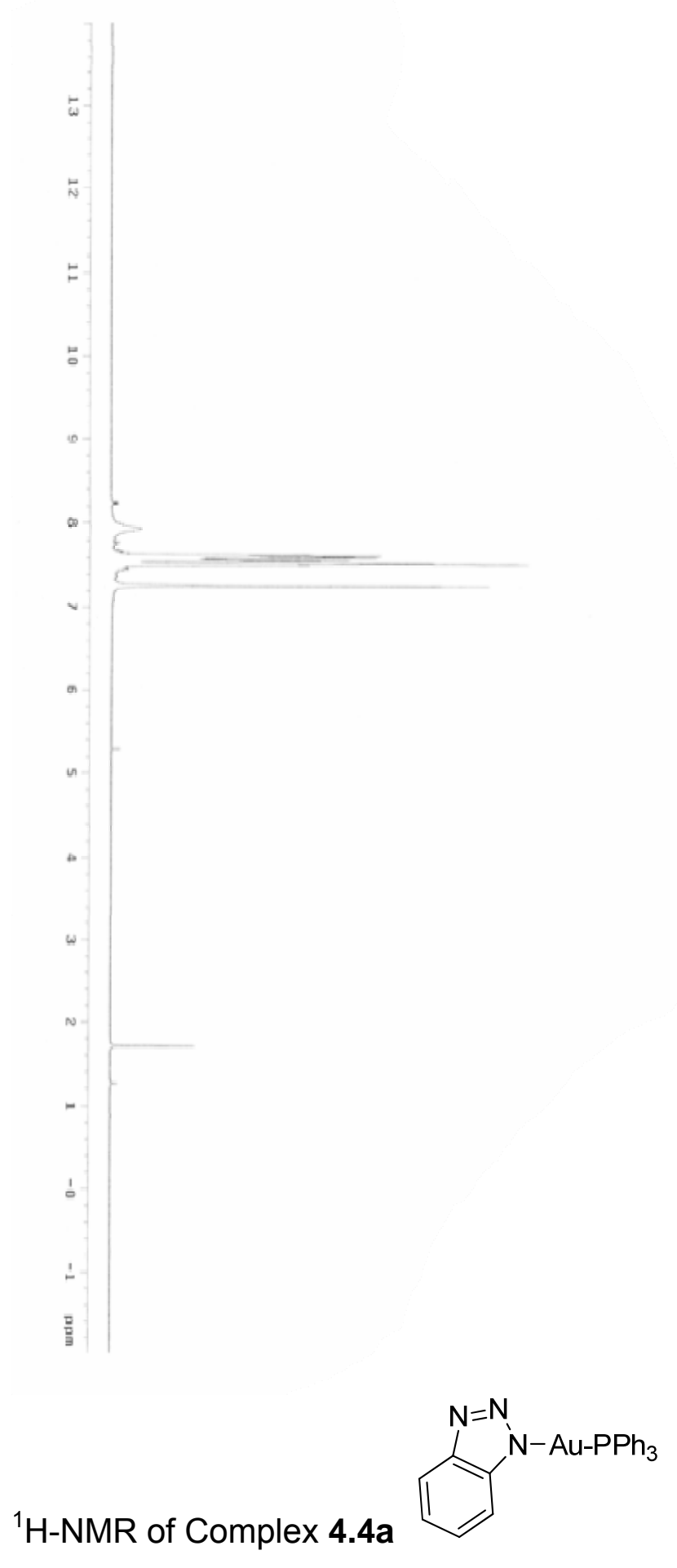




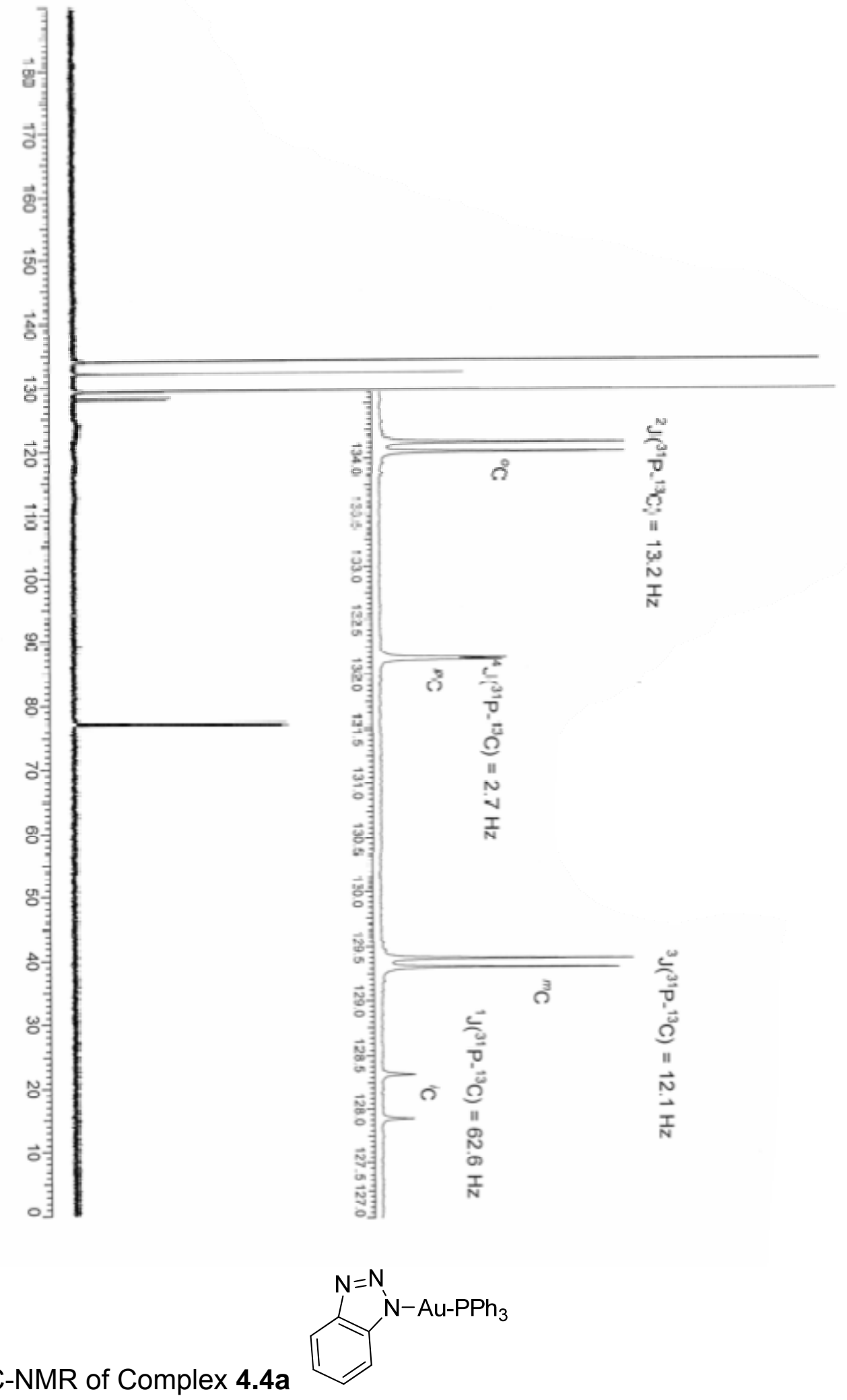


${ }^{31} \mathrm{P}-\mathrm{NMR}$ of Complex 4.4a
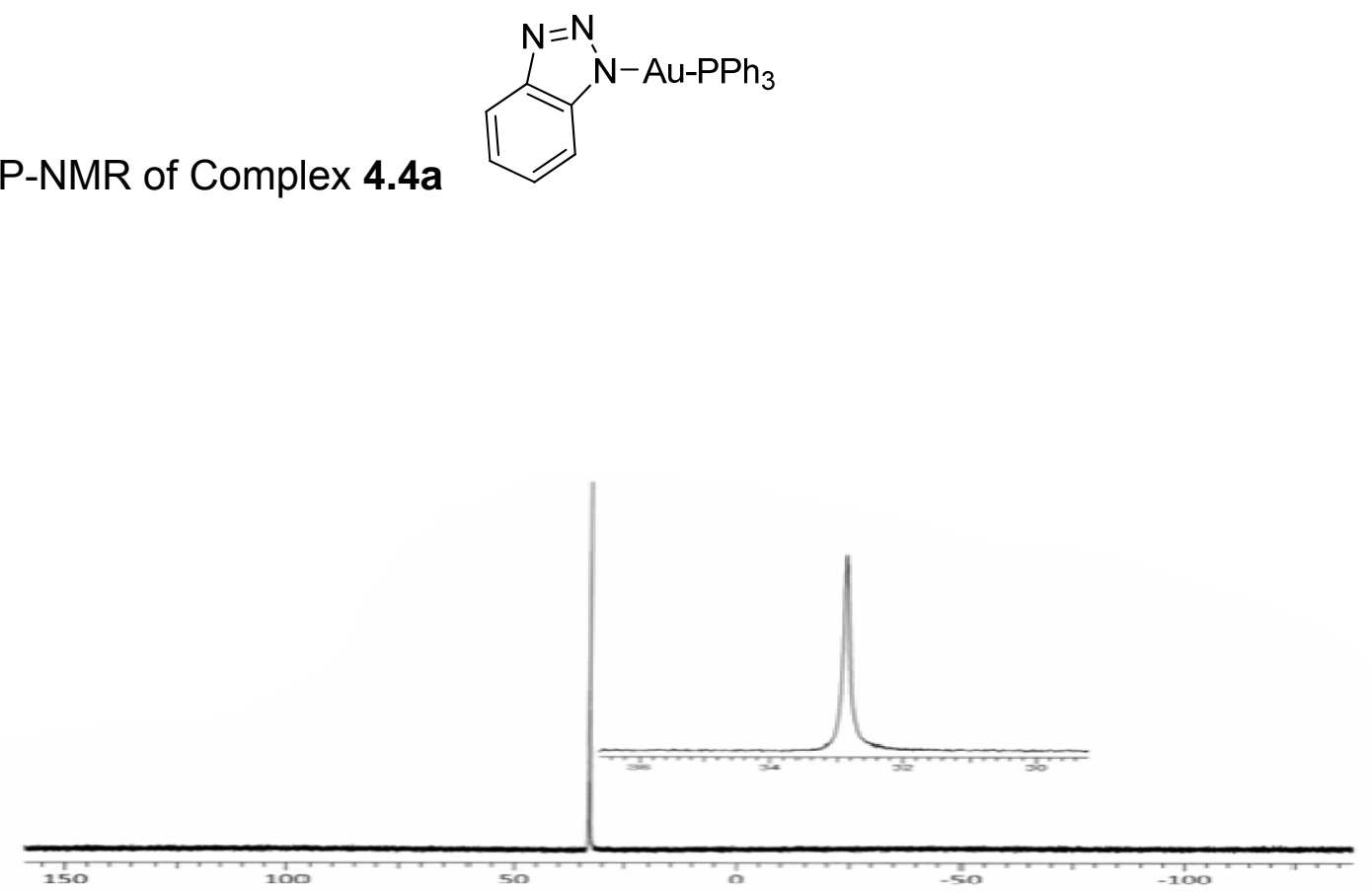


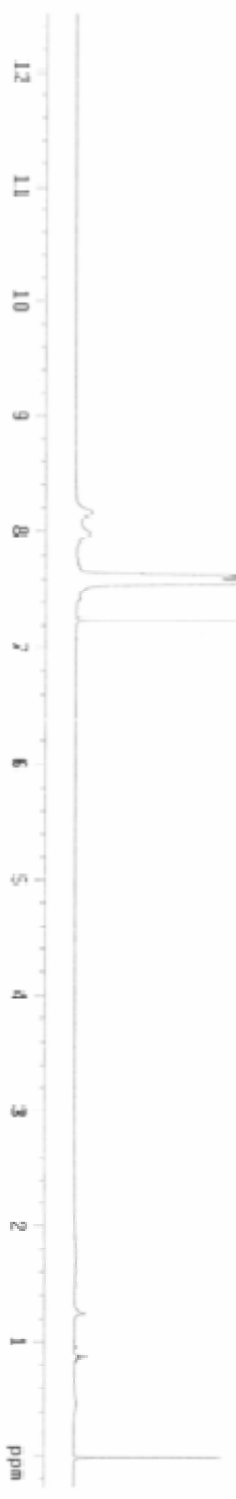

${ }^{1} \mathrm{H}-\mathrm{NMR}$ of Complex 4.5a 


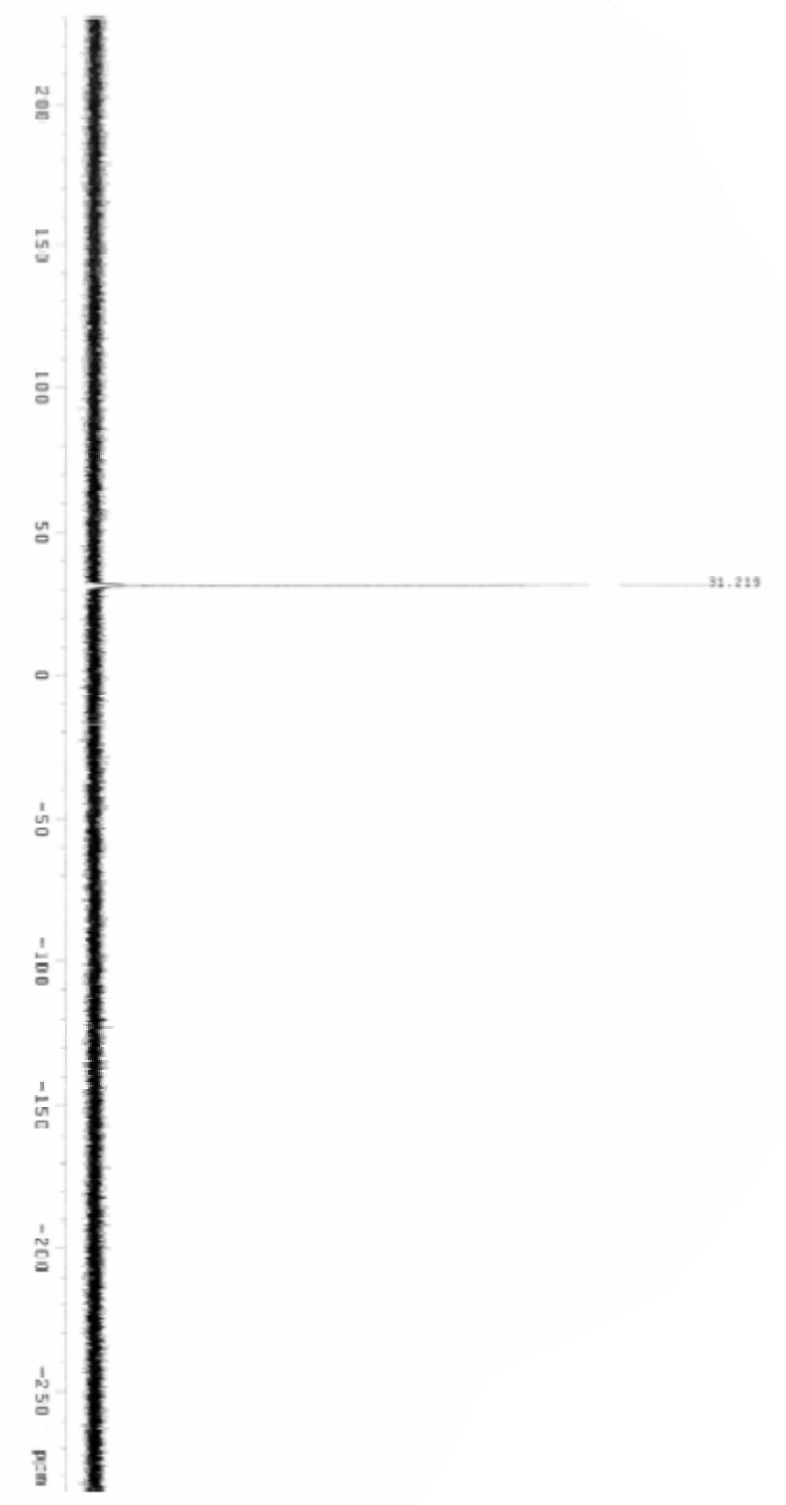

${ }^{31}$ P-NMR of Complex 4.5a 


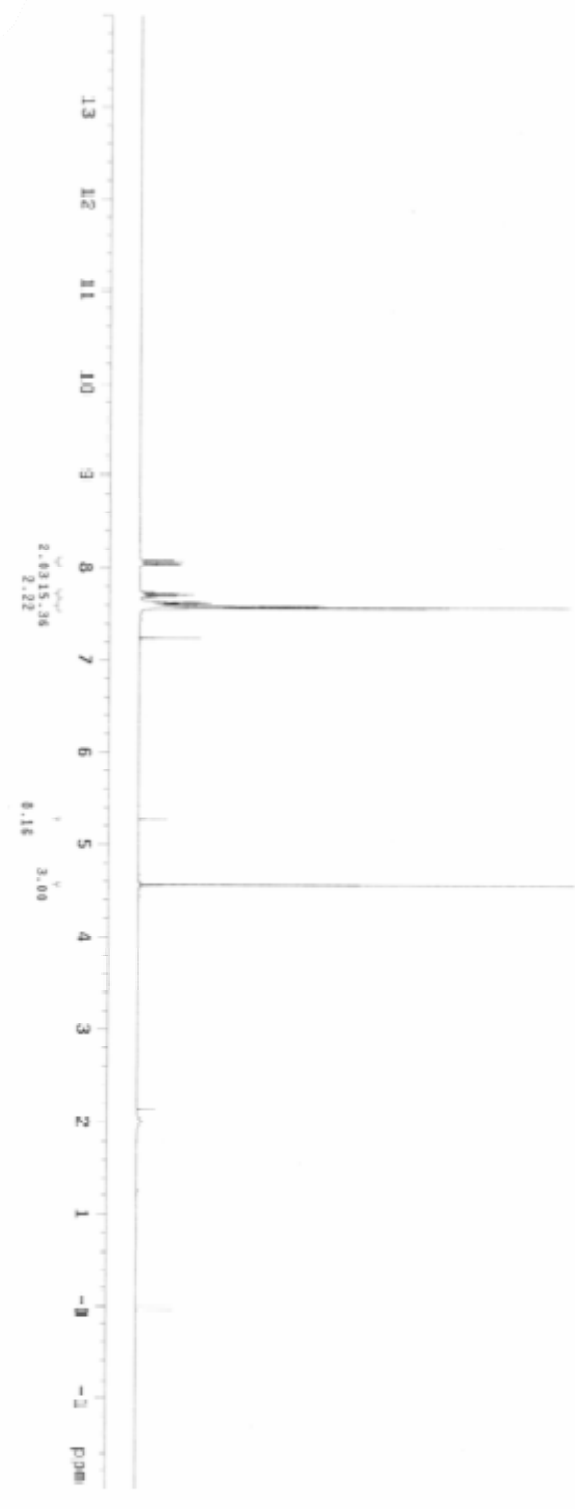

${ }^{1} \mathrm{H}-\mathrm{NMR}$ of Complex 4.5b 


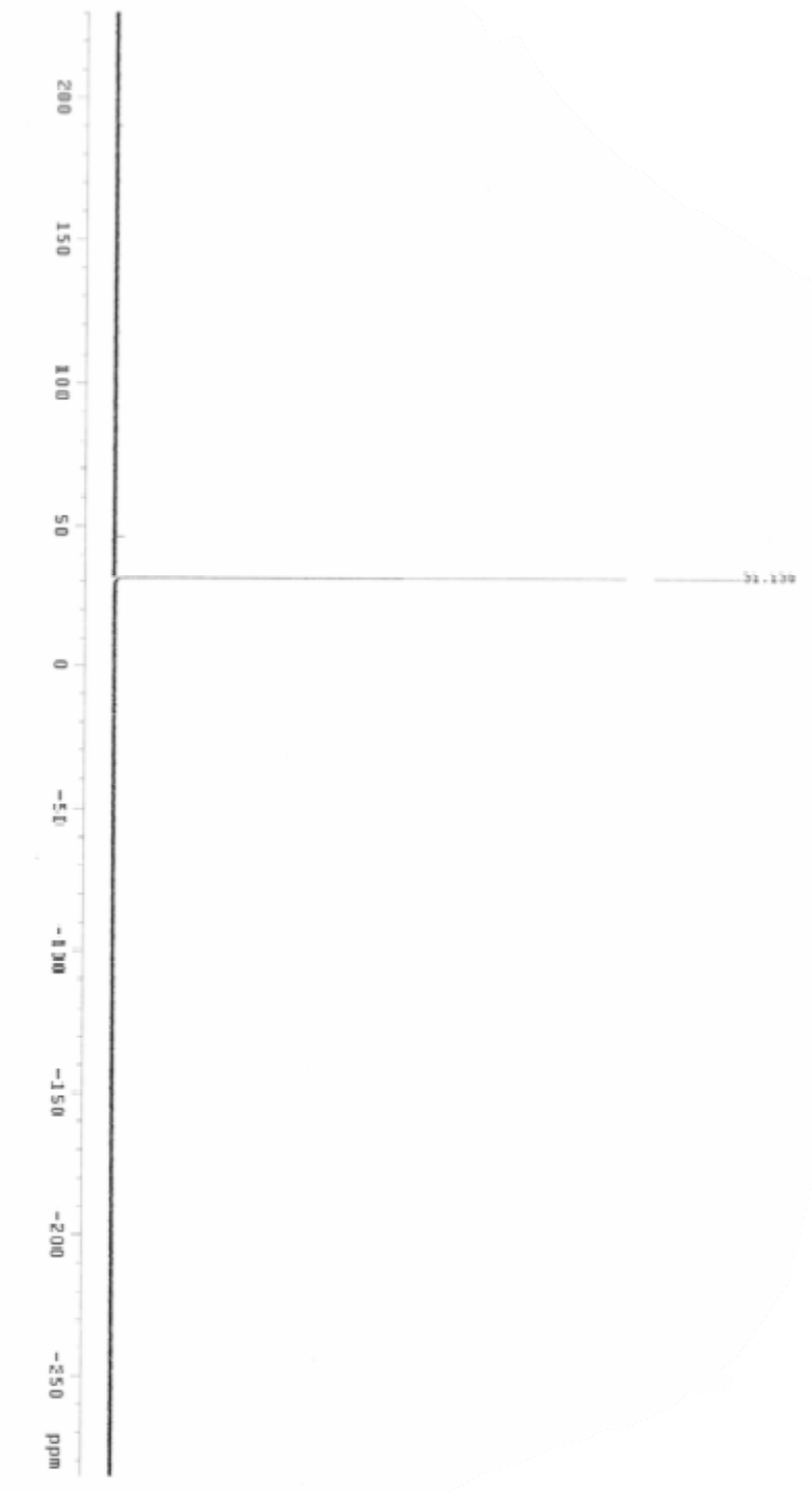

${ }^{31}$ P-NMR of Complex 4.5b 


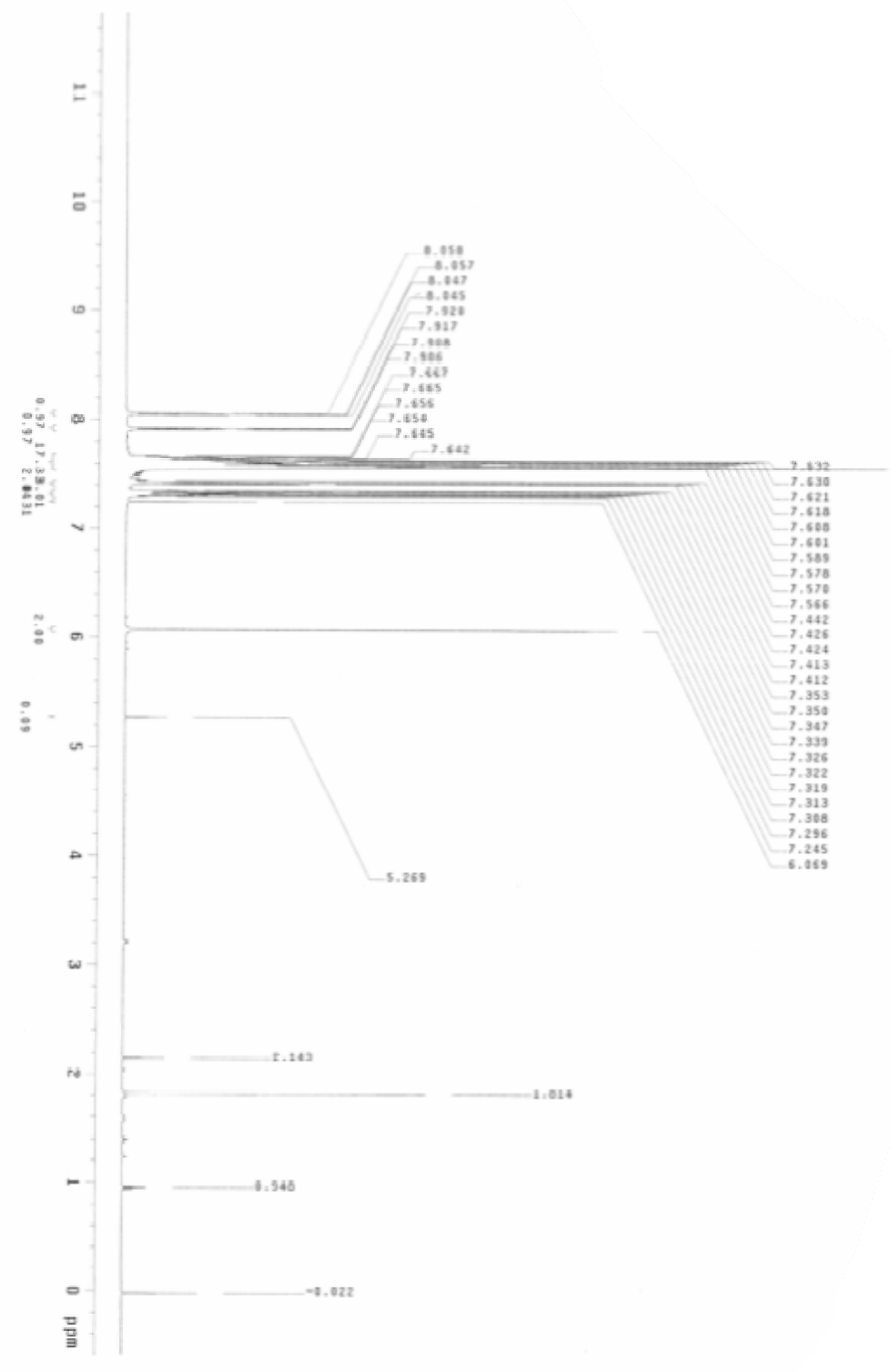

${ }^{1} \mathrm{H}-\mathrm{NMR}$ of Complex 4.5c

Bn

${ }^{1} \mathrm{H}-\mathrm{NMR}$ of Complex 4.5c 


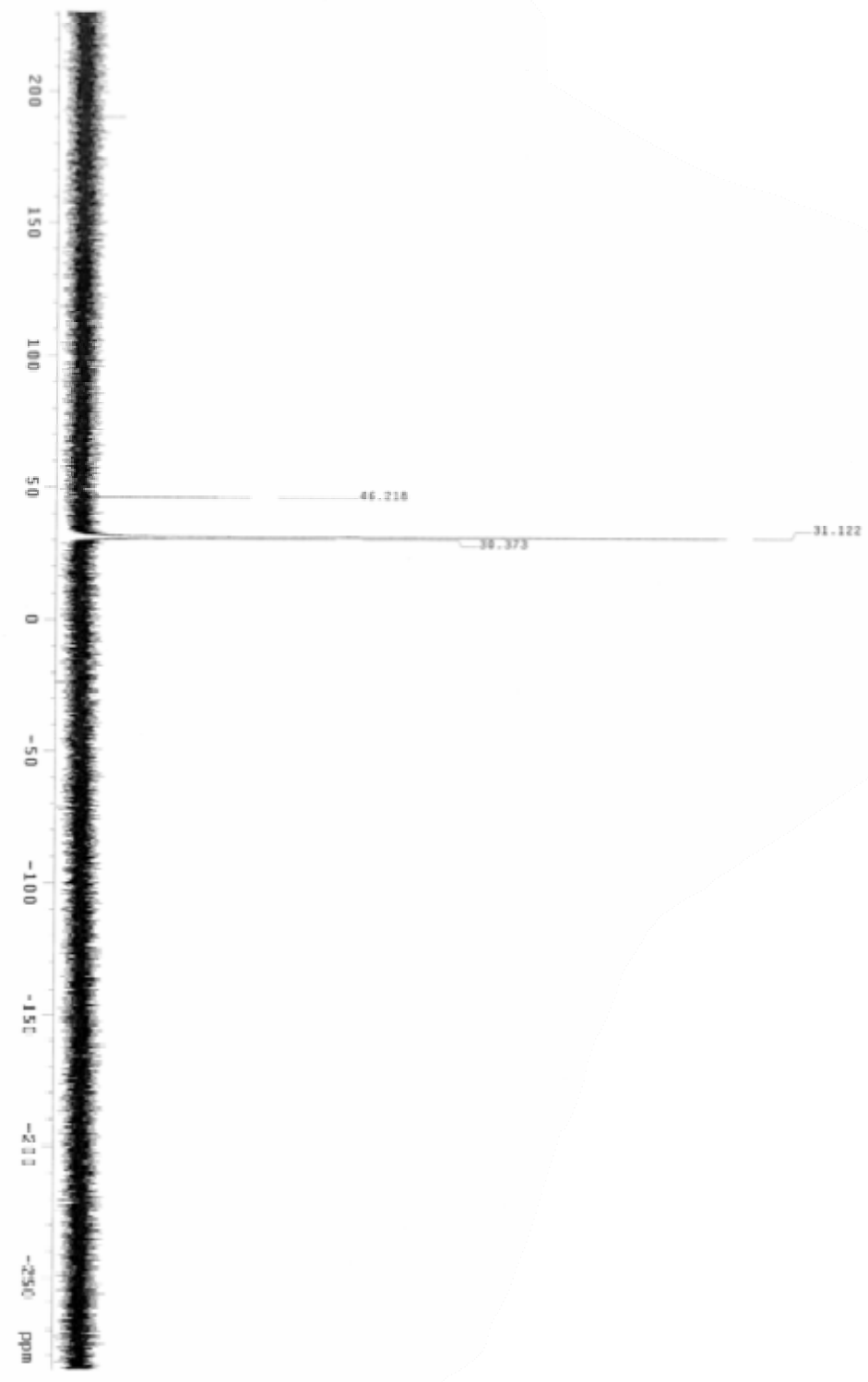

${ }^{31}$ P-NMR of Complex 4.5c 


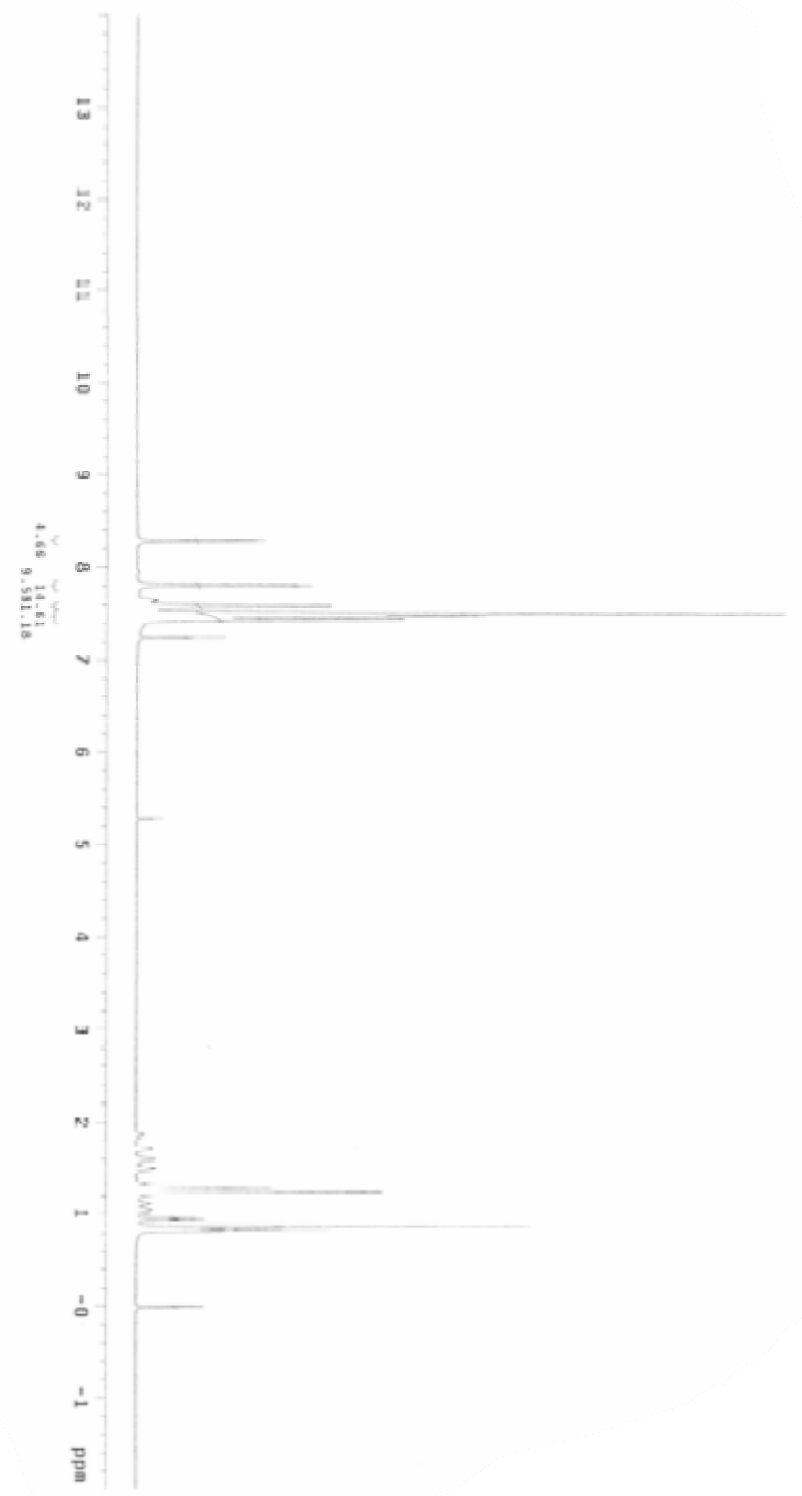

${ }^{1} \mathrm{H}-\mathrm{NMR}$ of Complex $4.5 \mathrm{~d}$ 


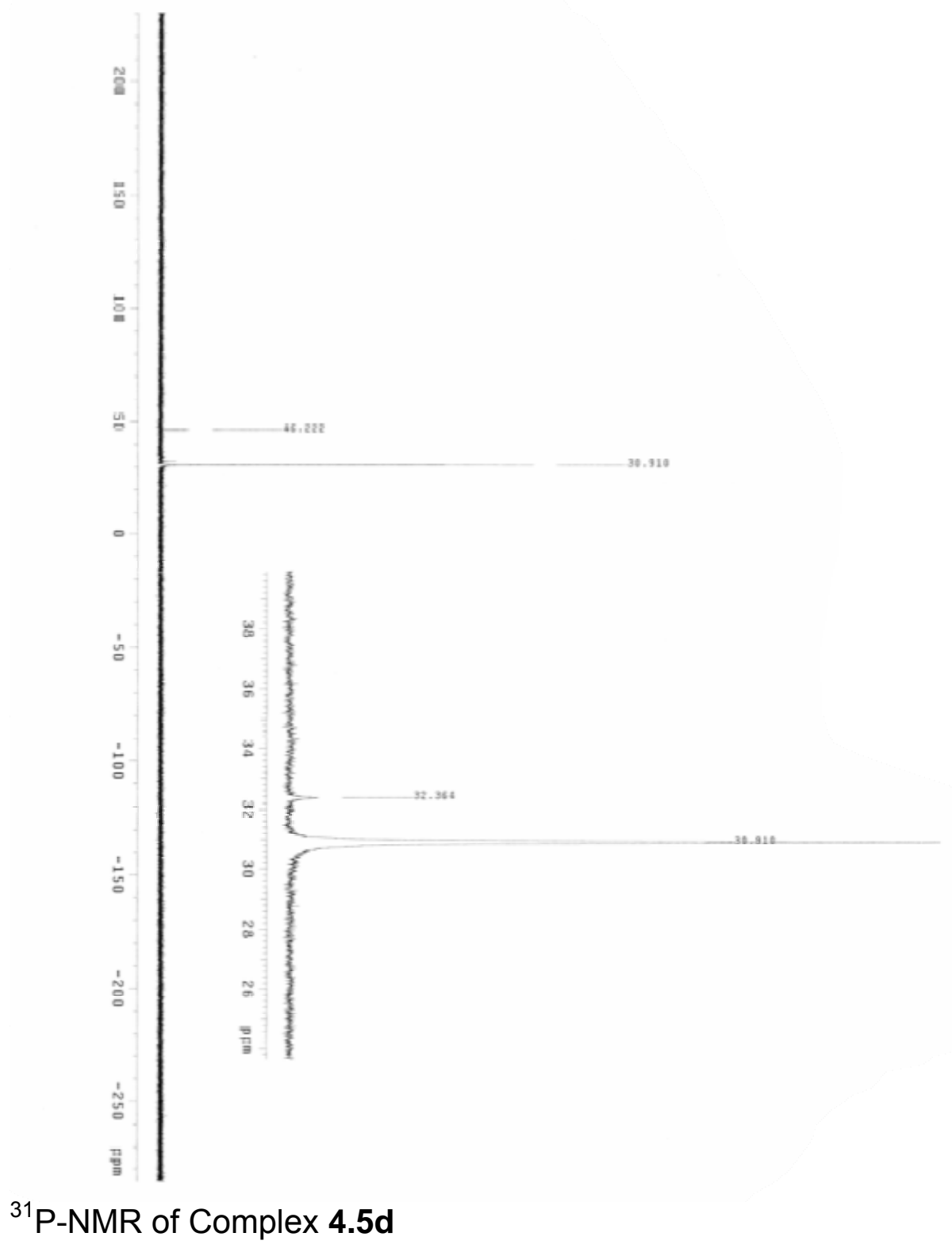



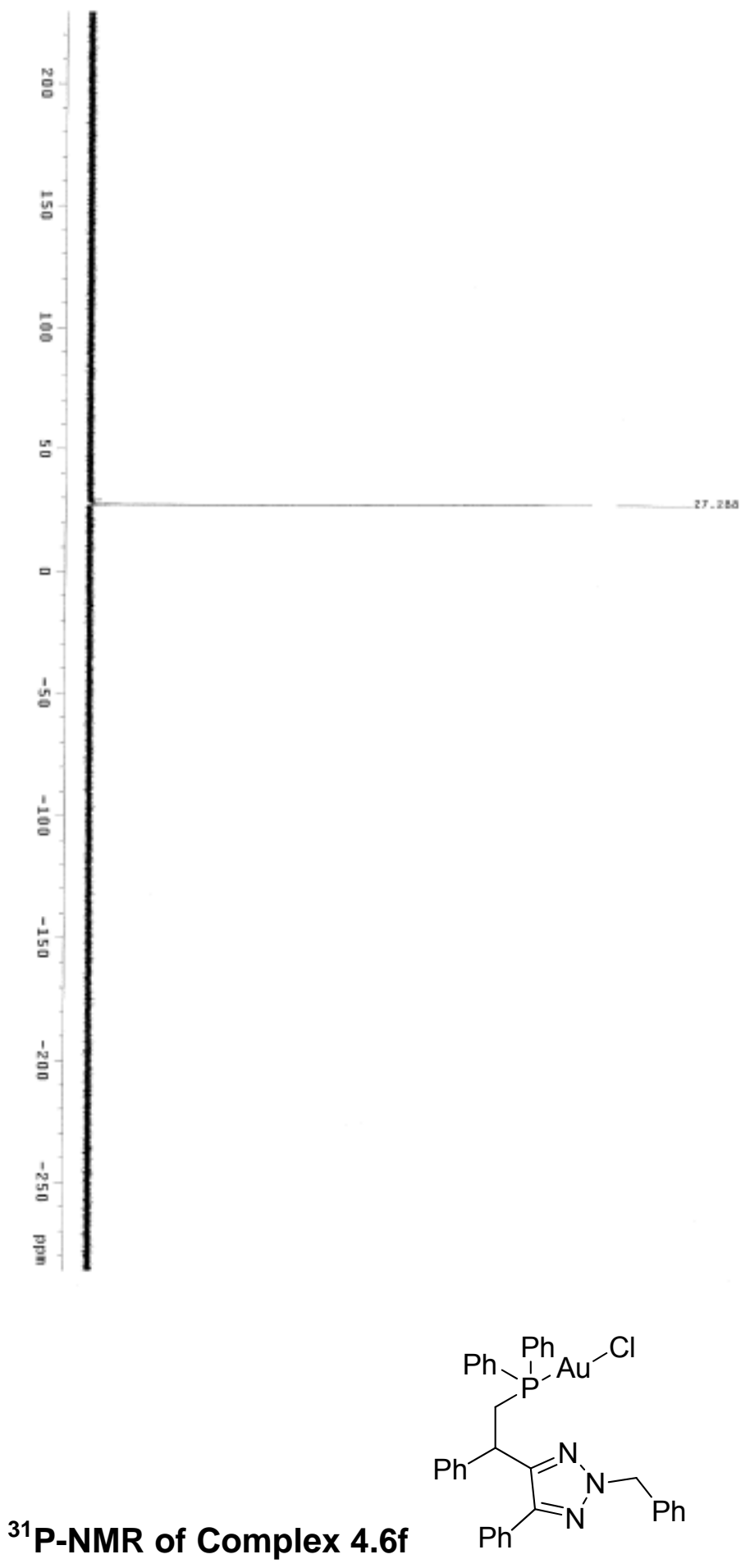

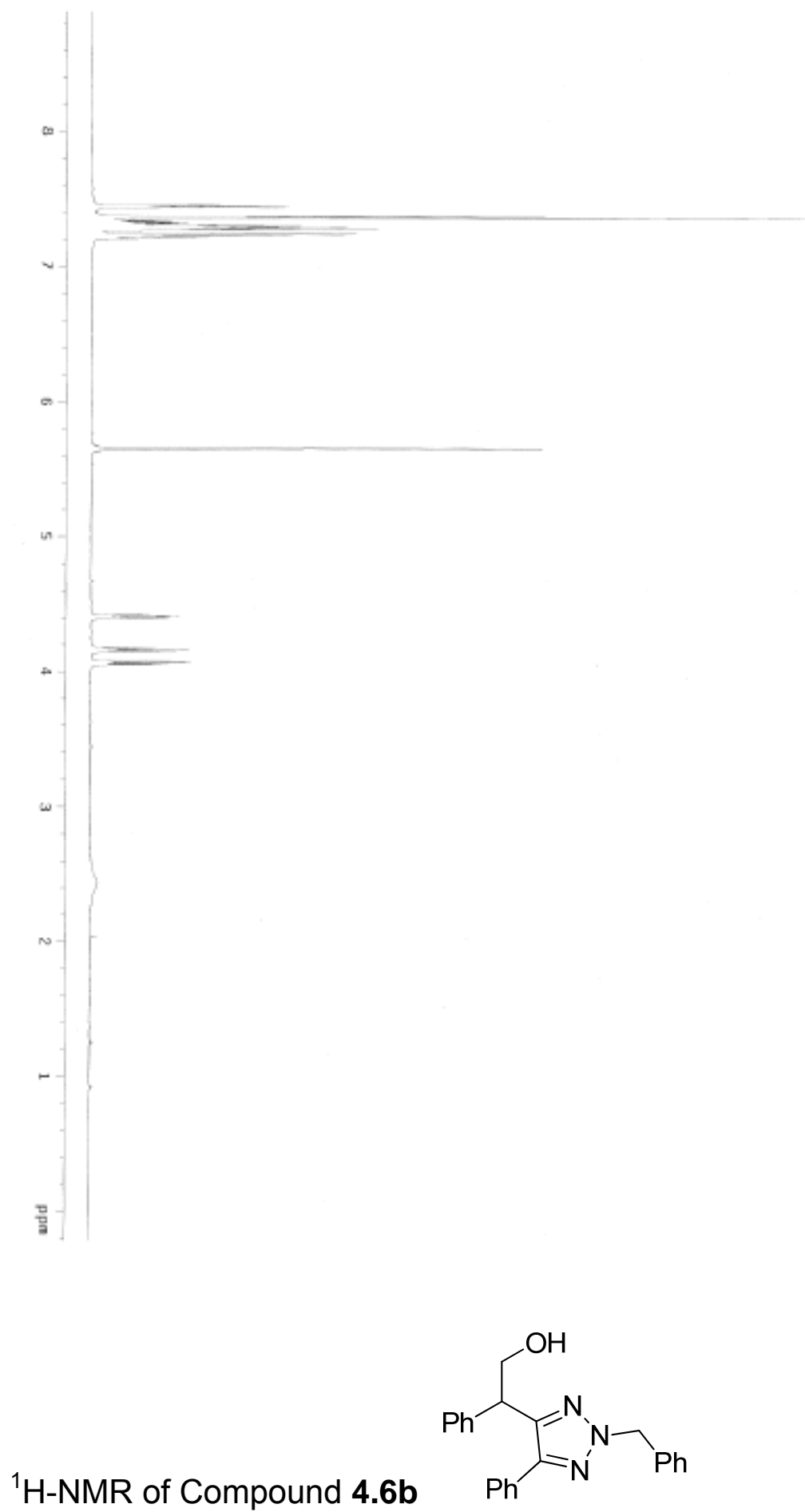

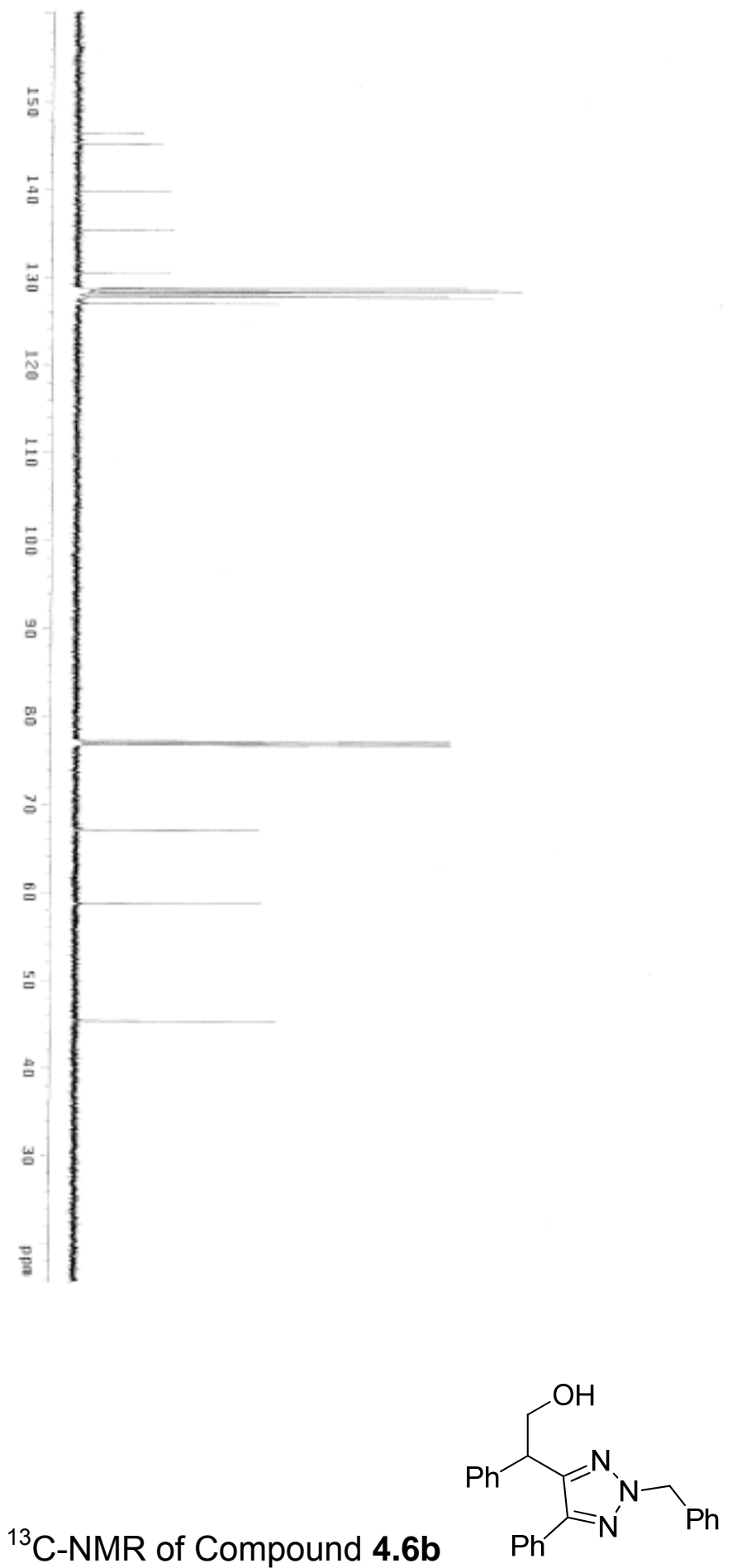

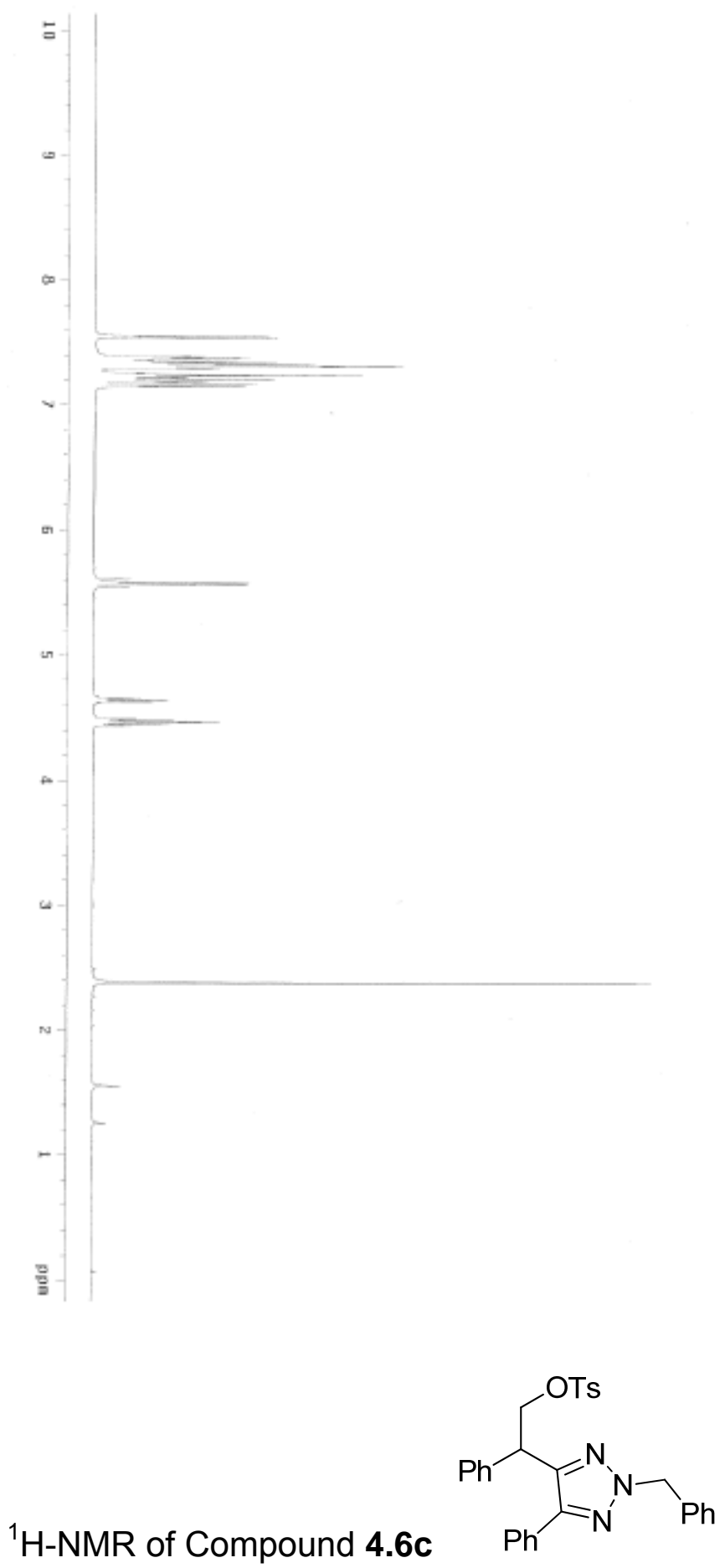

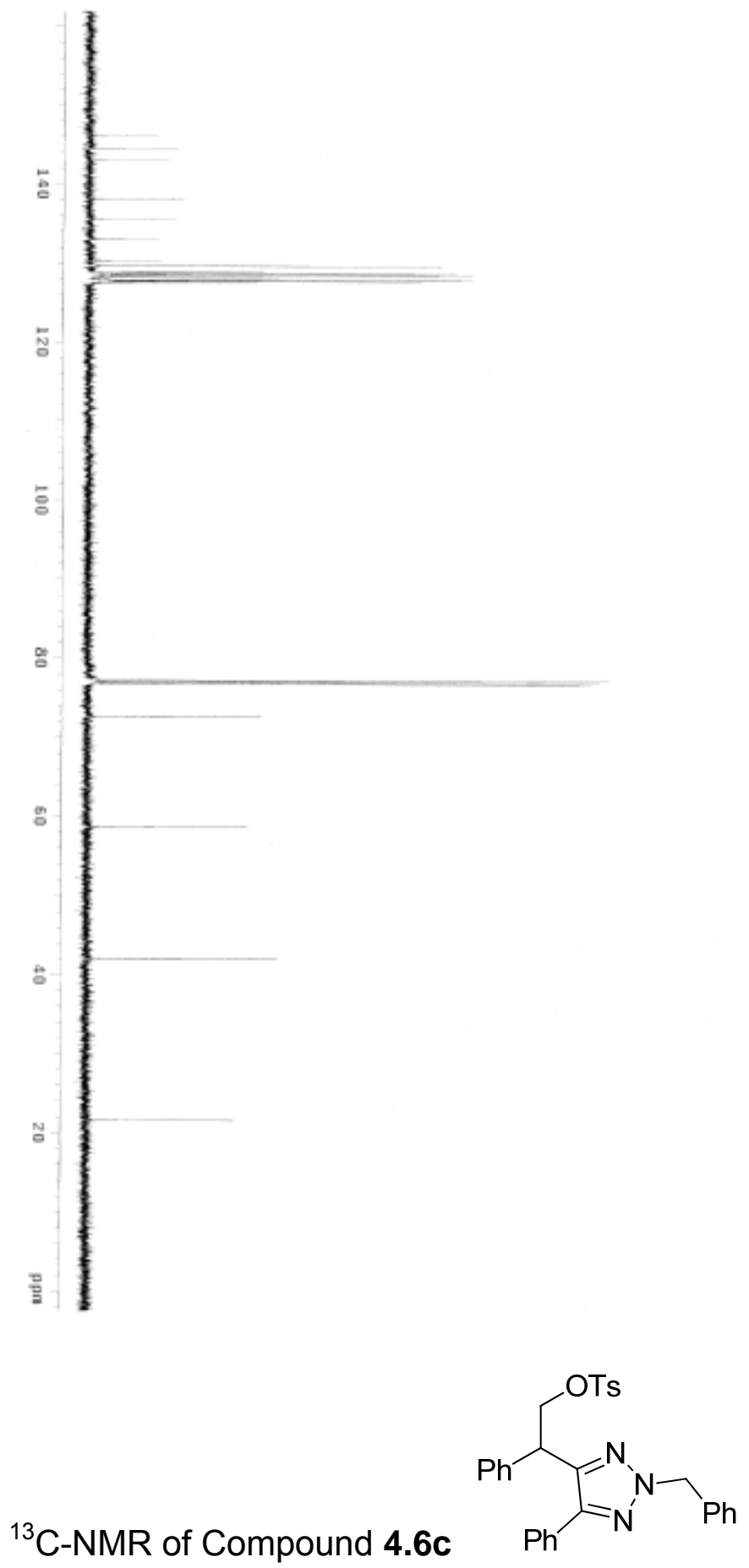

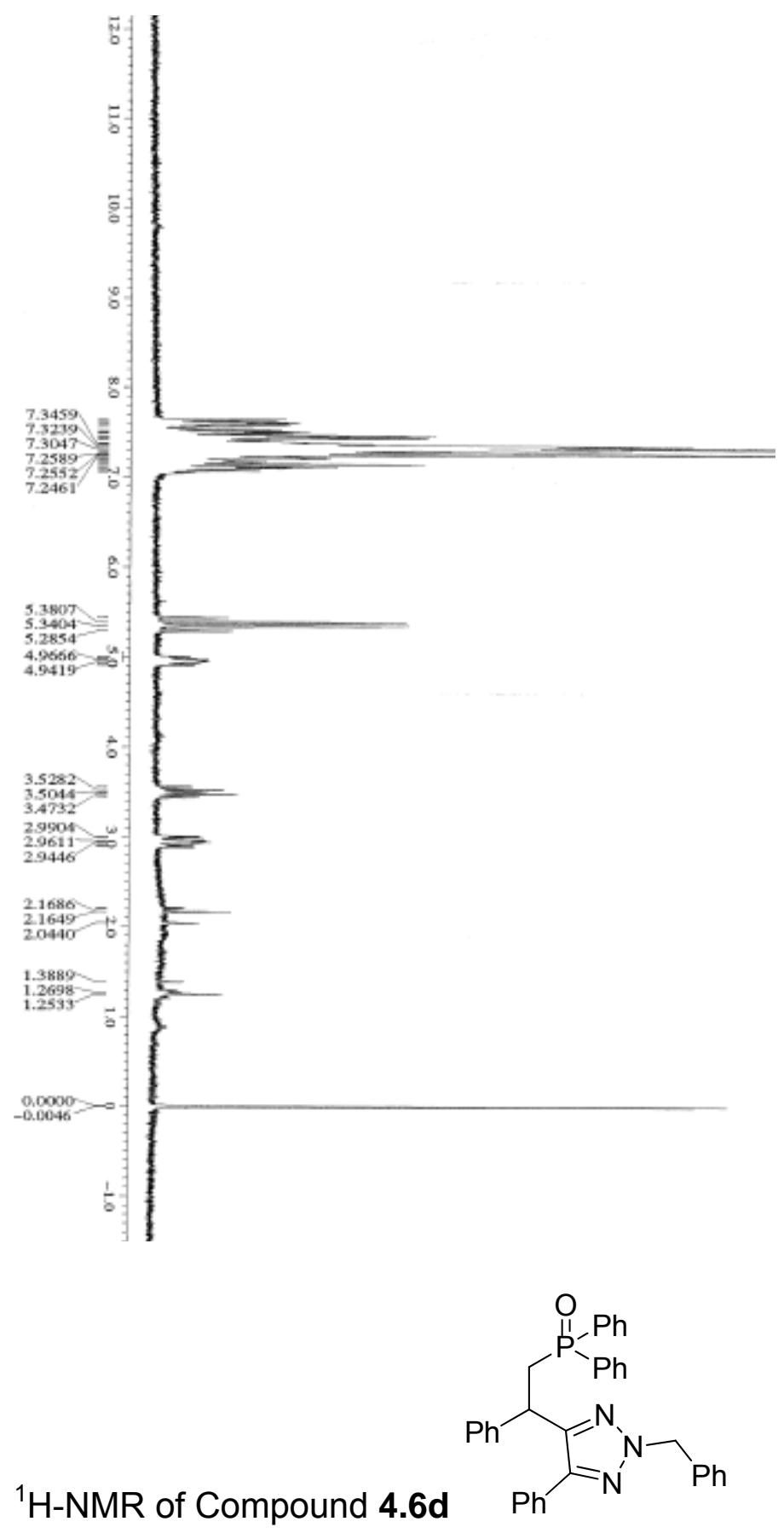


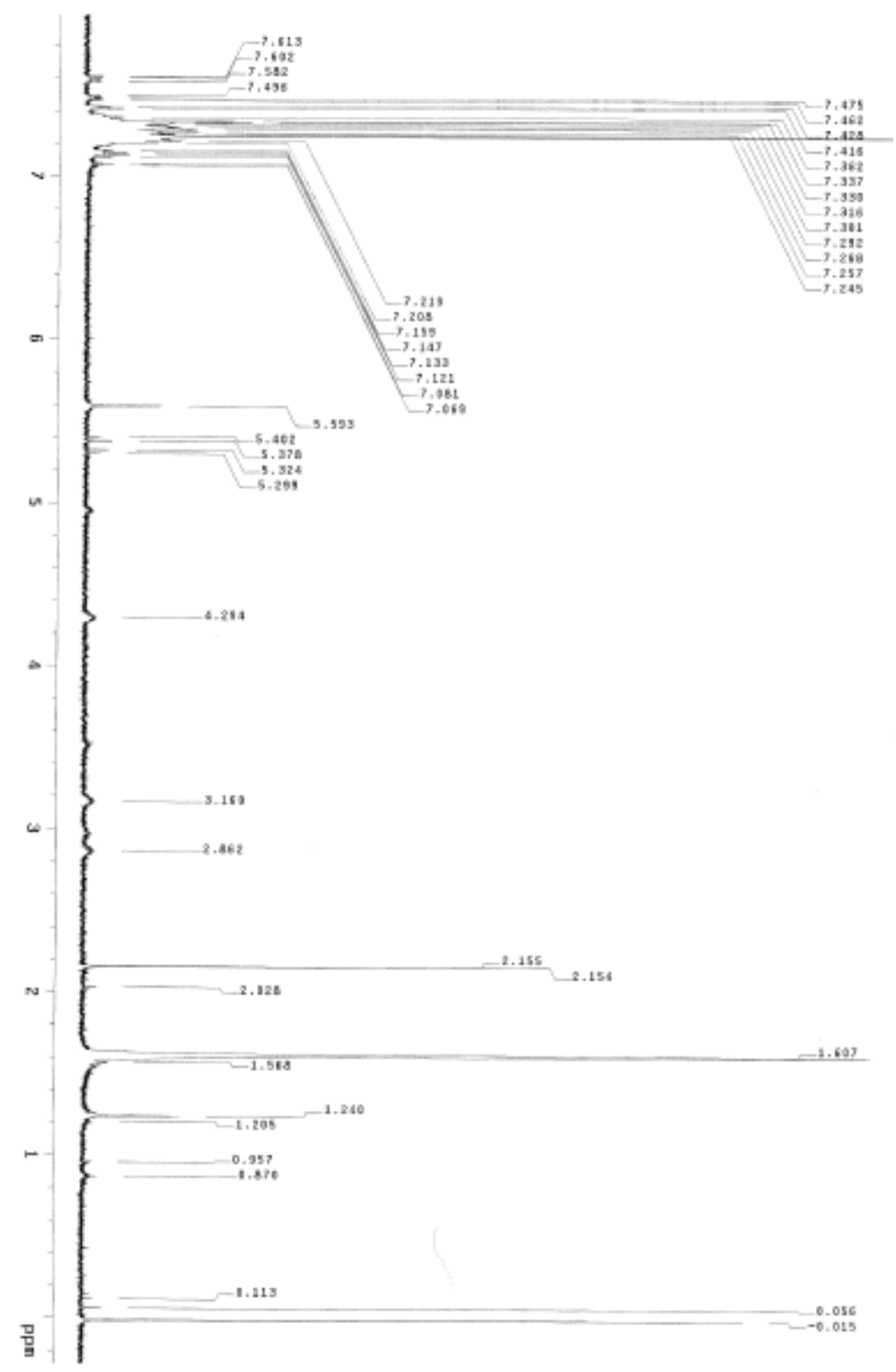

${ }^{1} \mathrm{H}-\mathrm{NMR}$ of Compound 4.6e (was too unstable for a good characterization) 


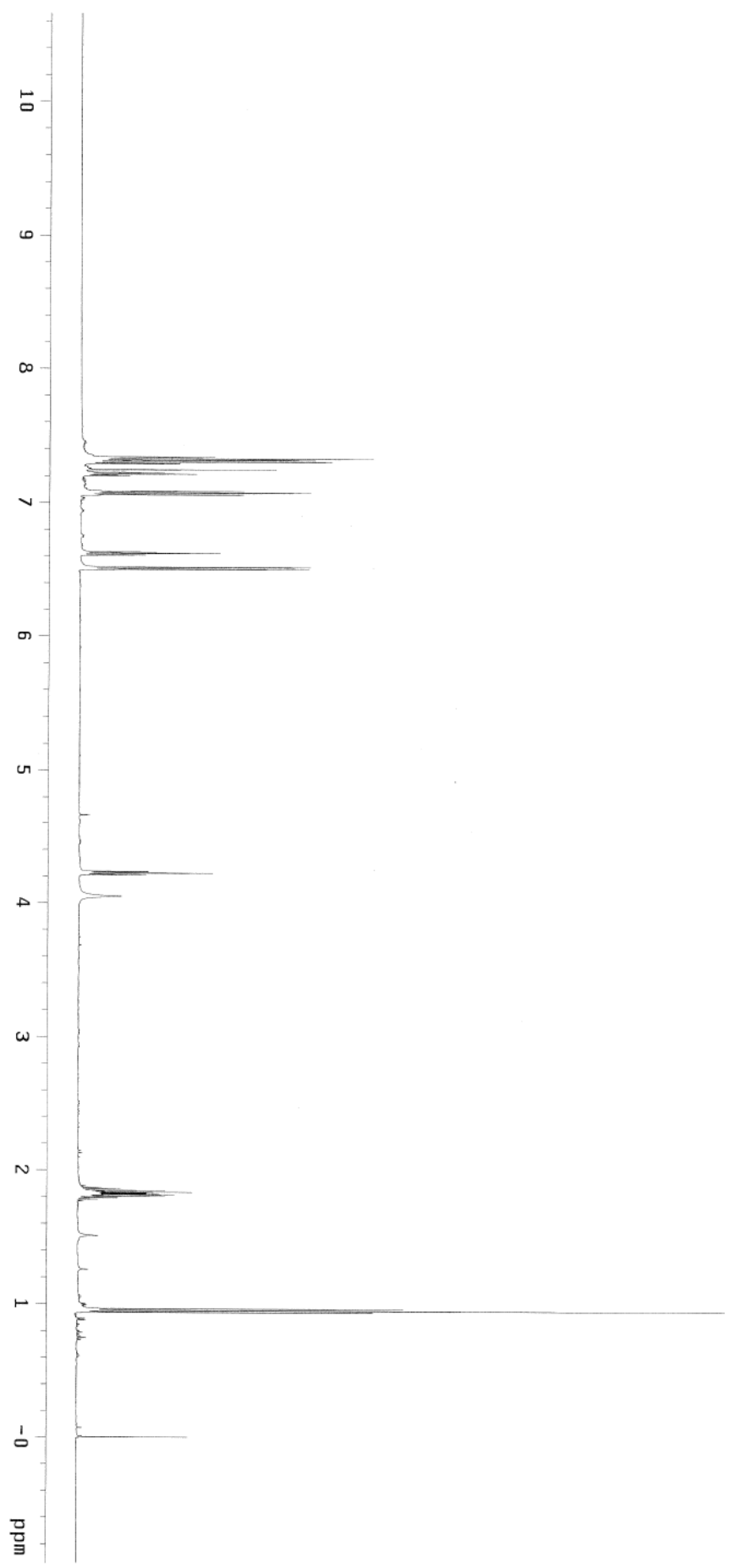

${ }^{1} \mathrm{H}-\mathrm{NMR}$ of Compound 4.9a 


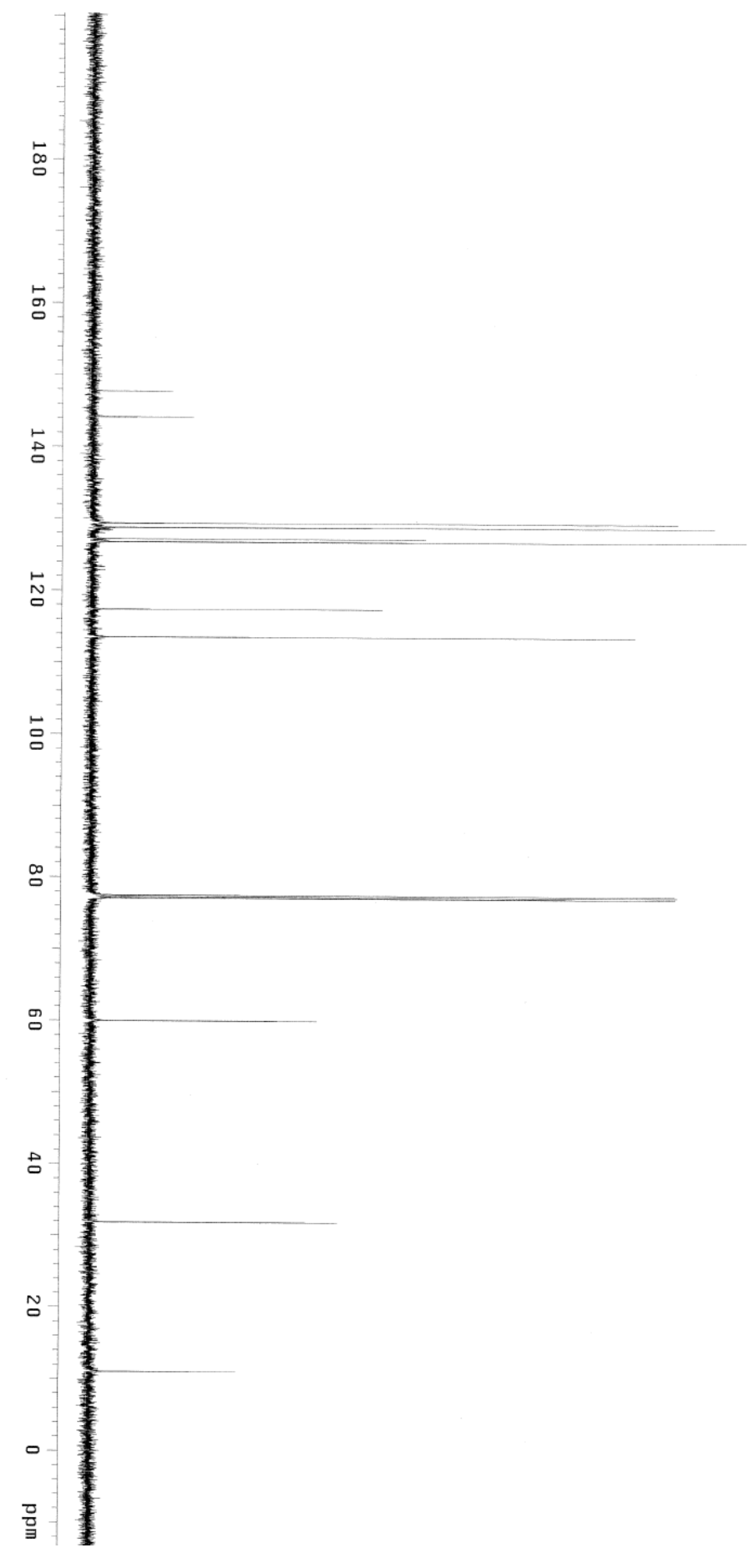

${ }^{13} \mathrm{C}-\mathrm{NMR}$ of Compound 4.9a 


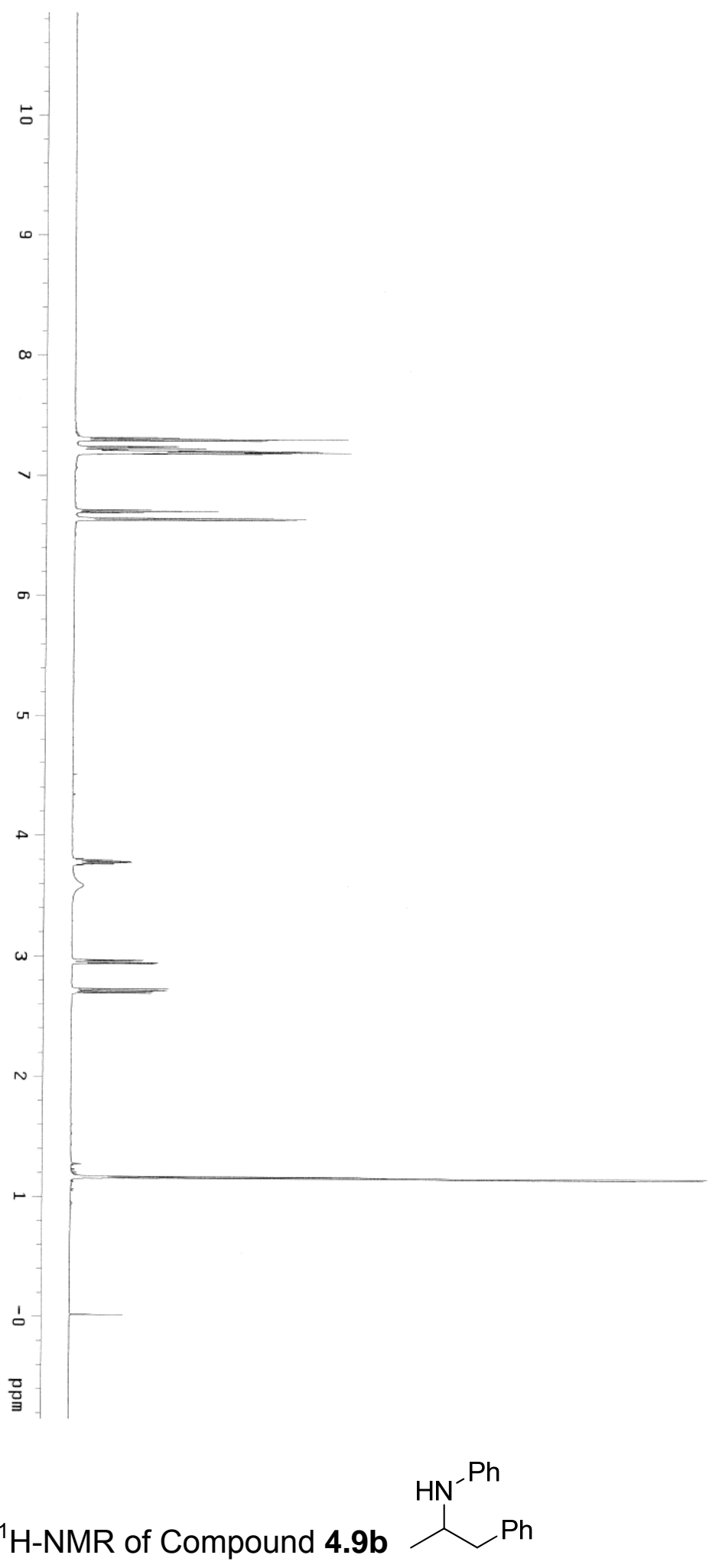



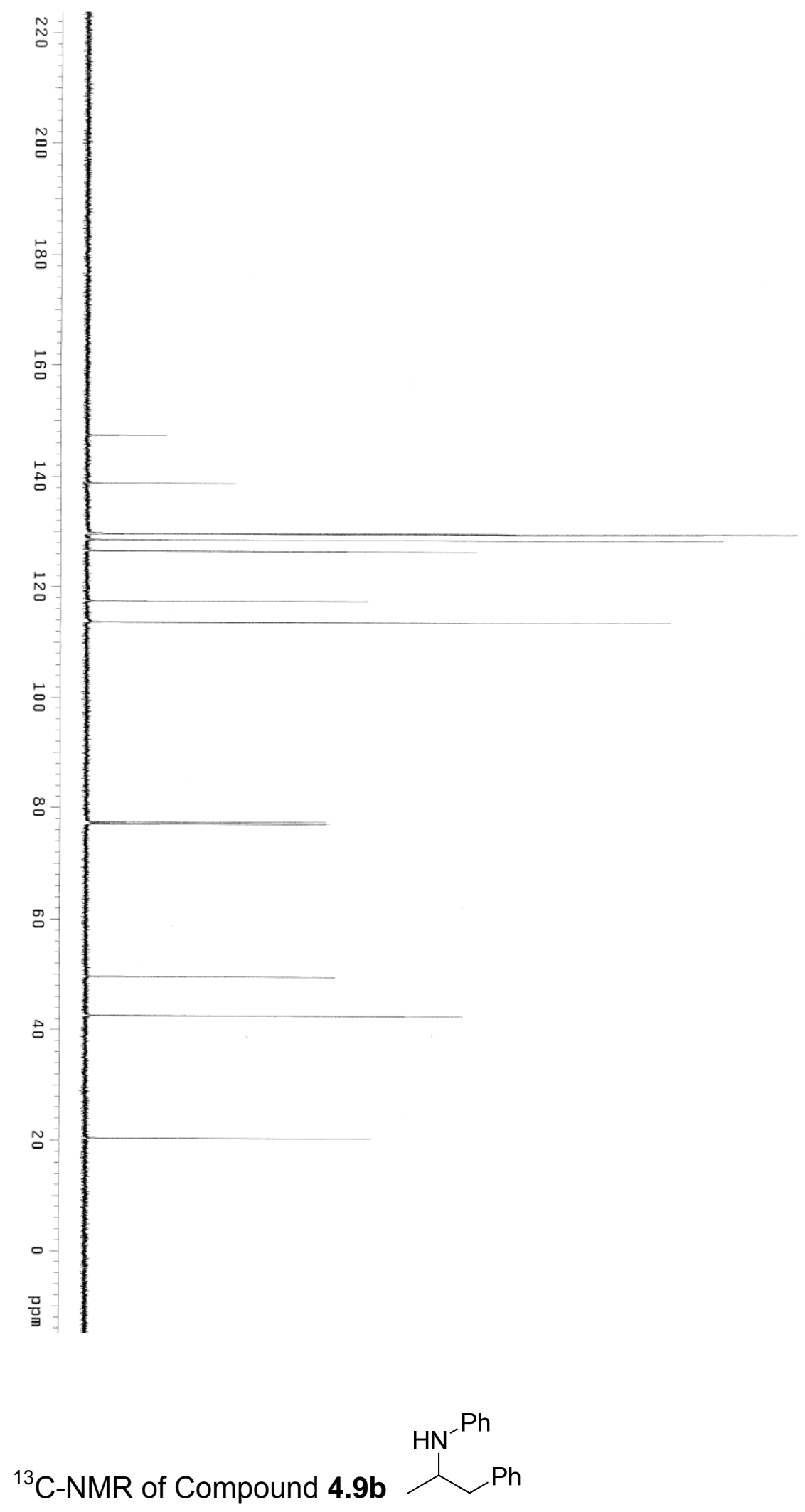

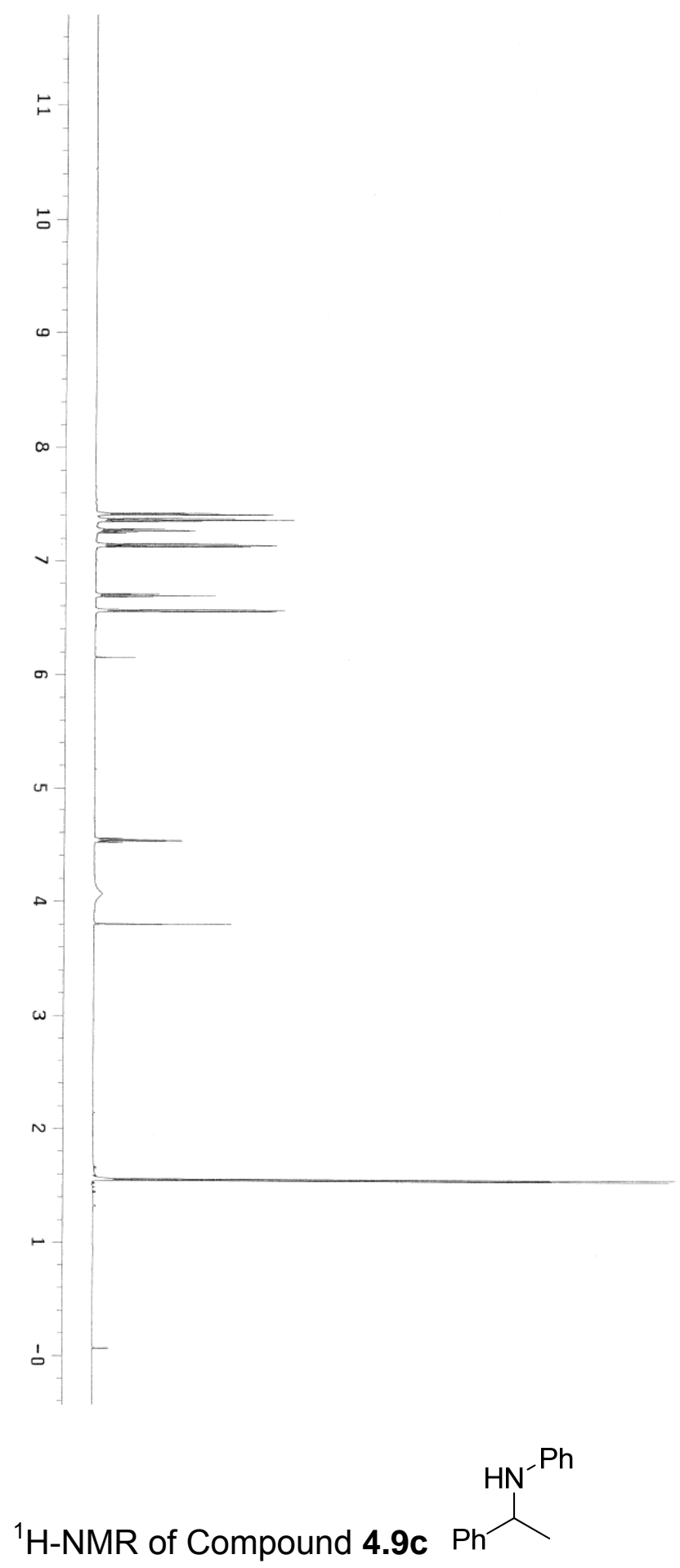


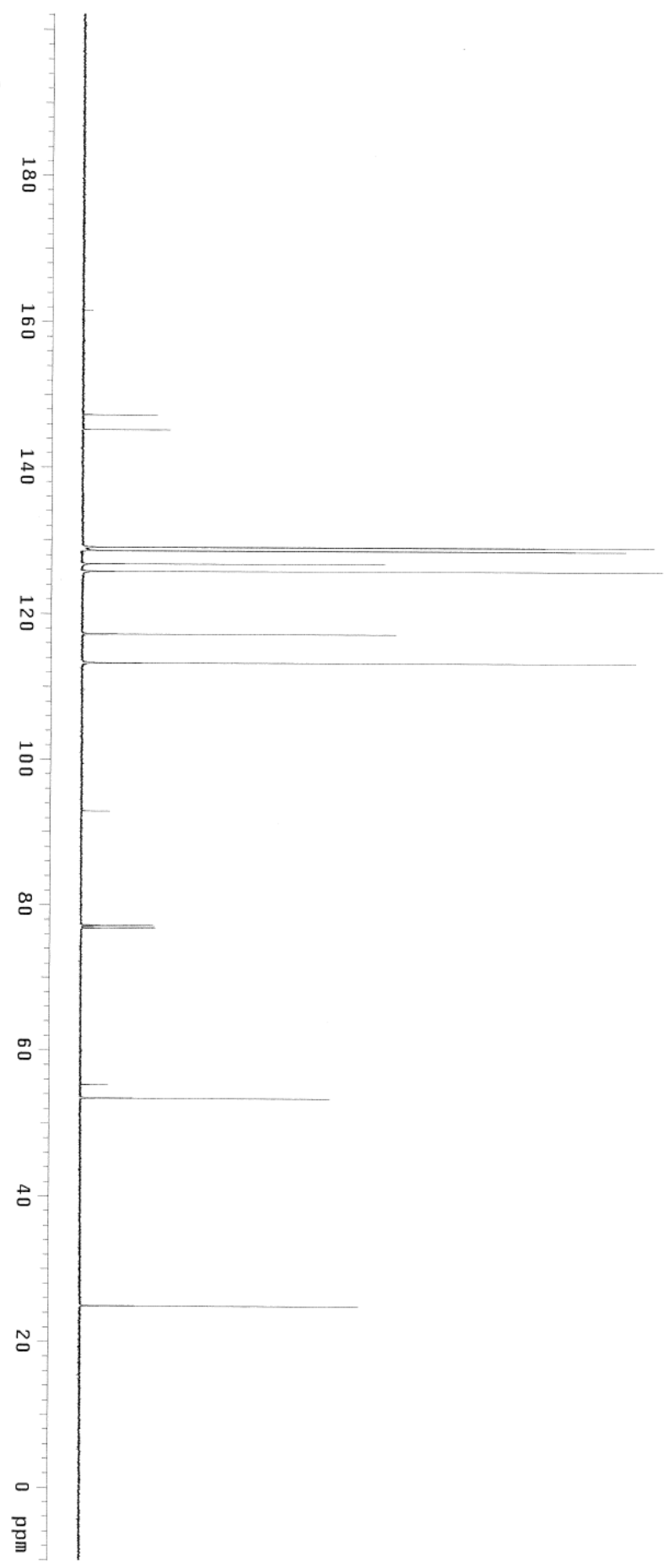

${ }^{13} \mathrm{C}-\mathrm{NMR}$ of Compound 4.9c 

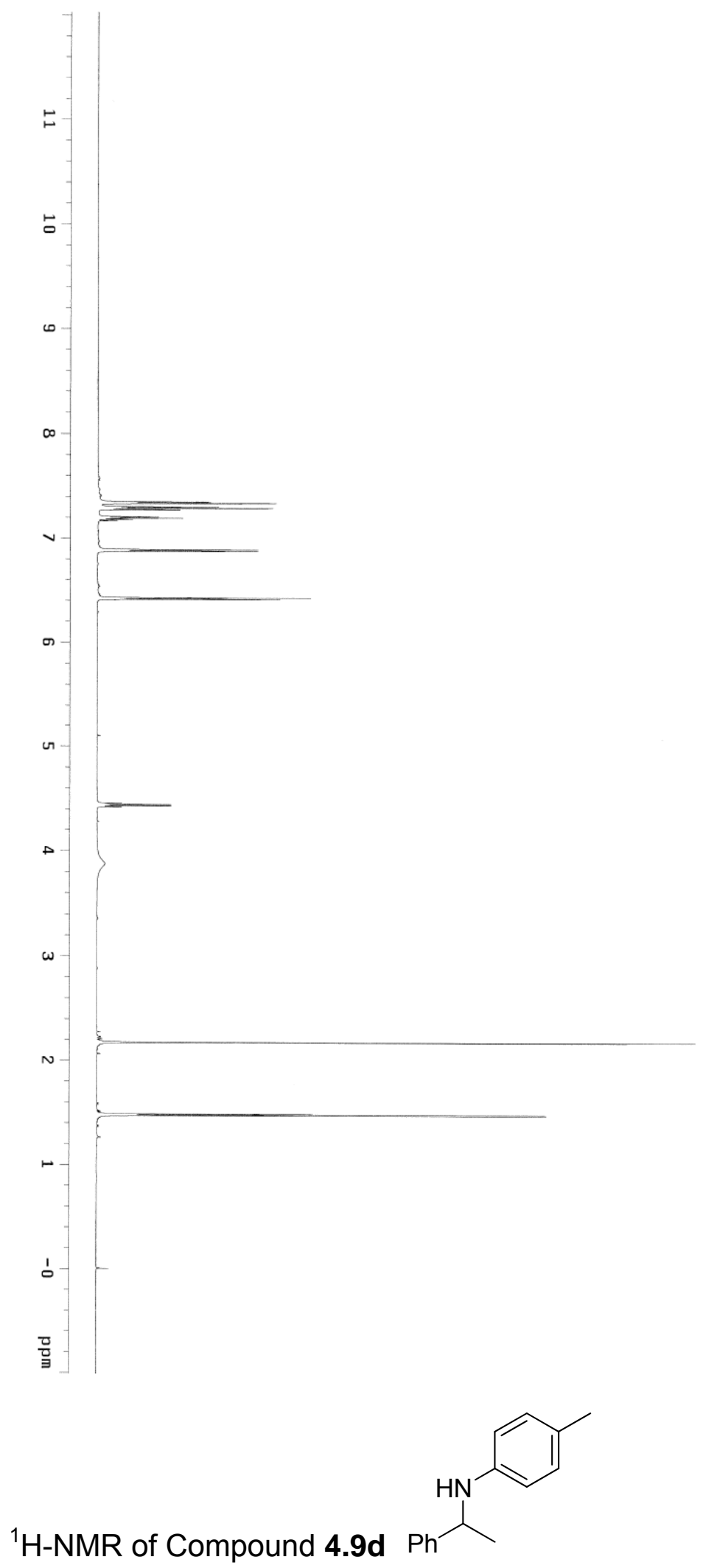

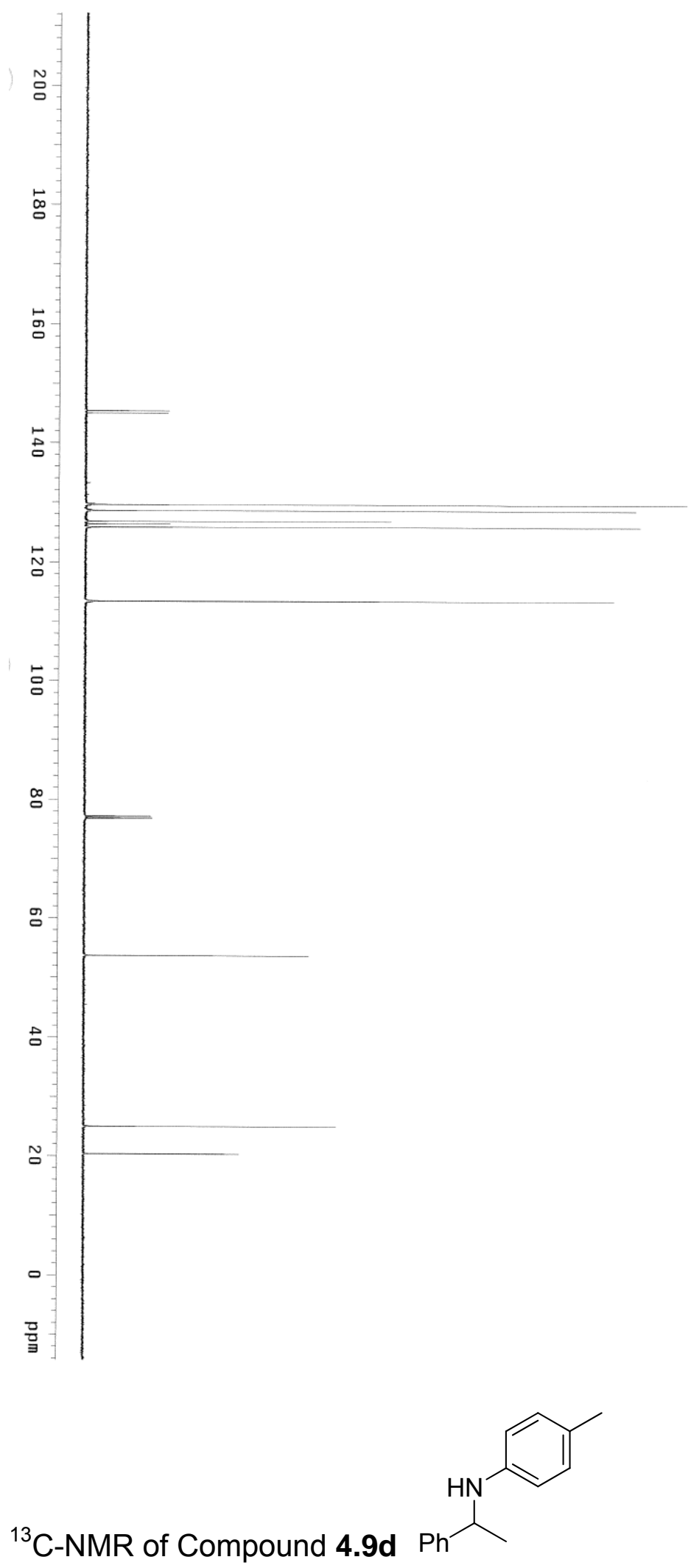

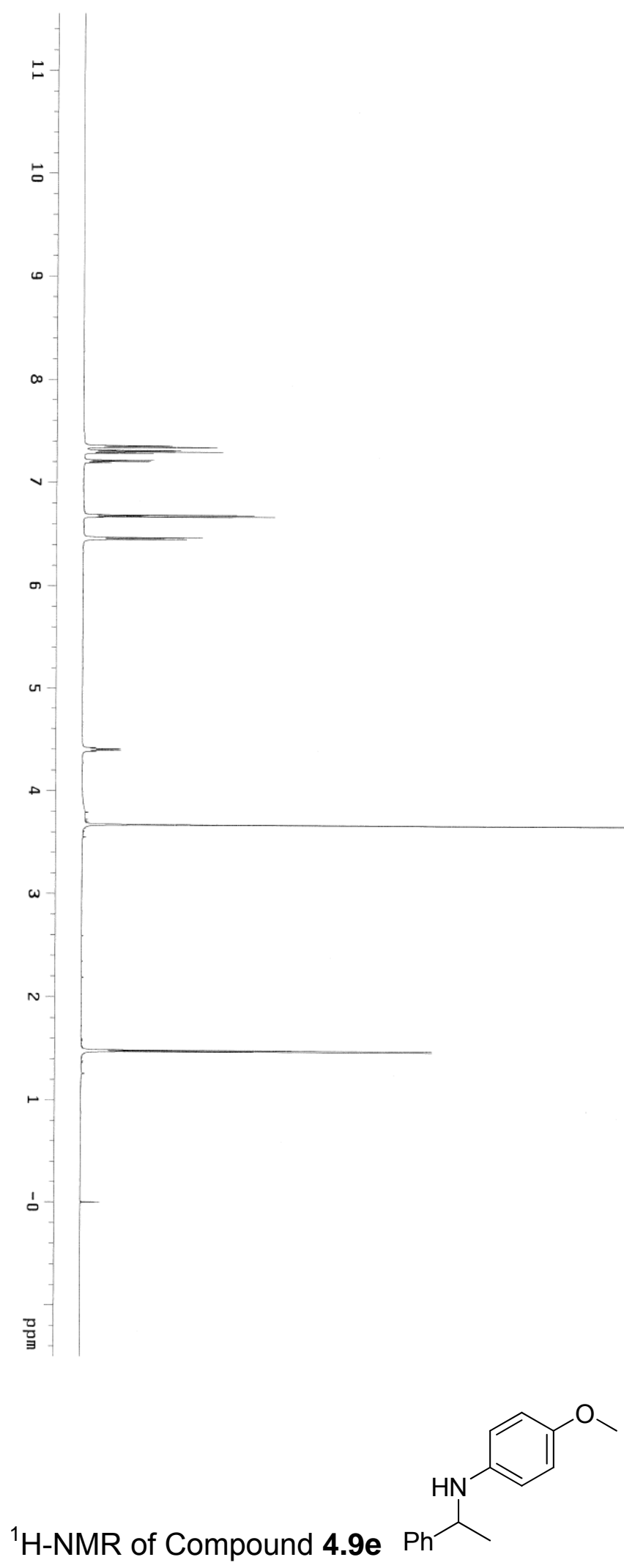

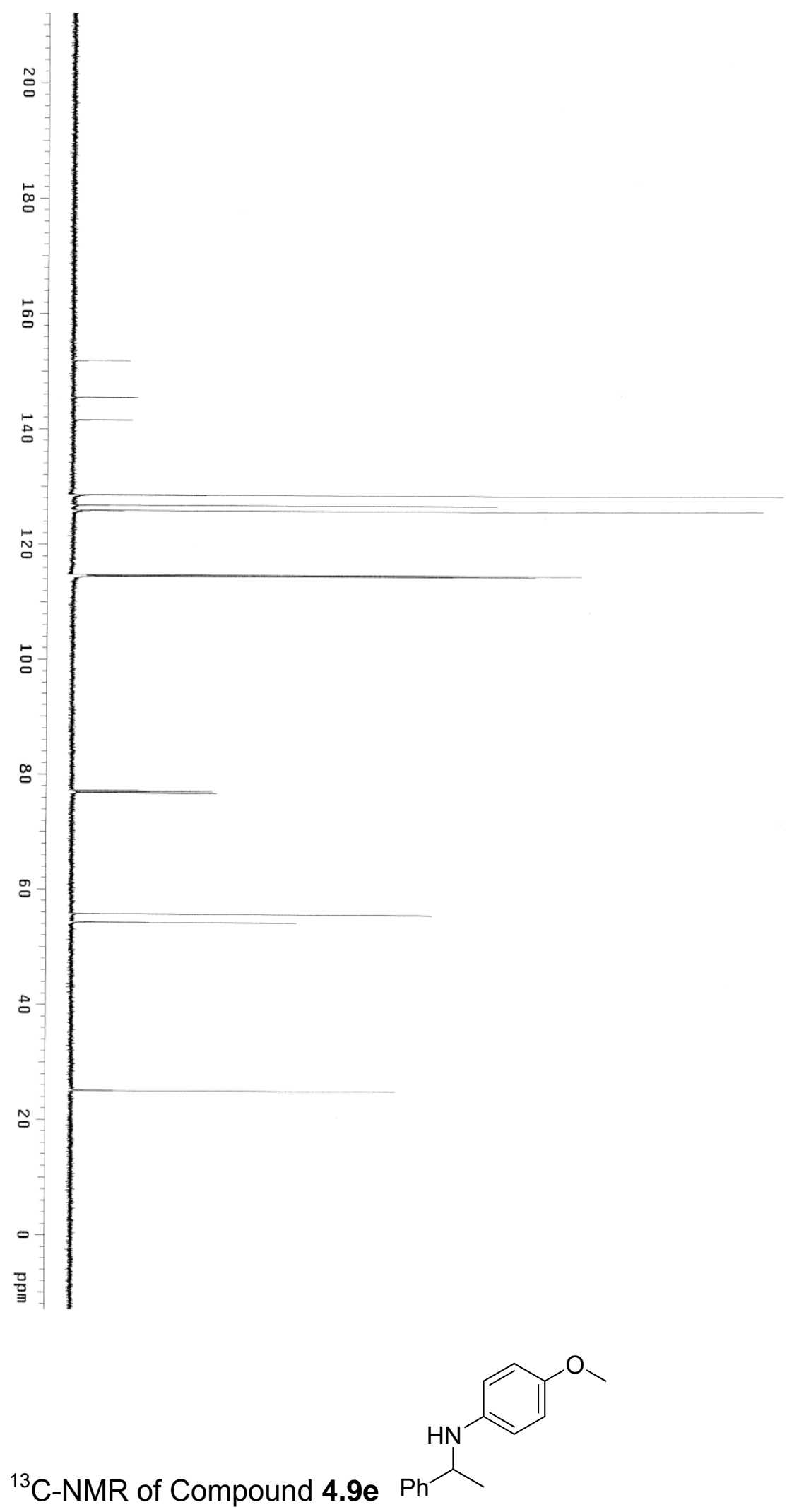

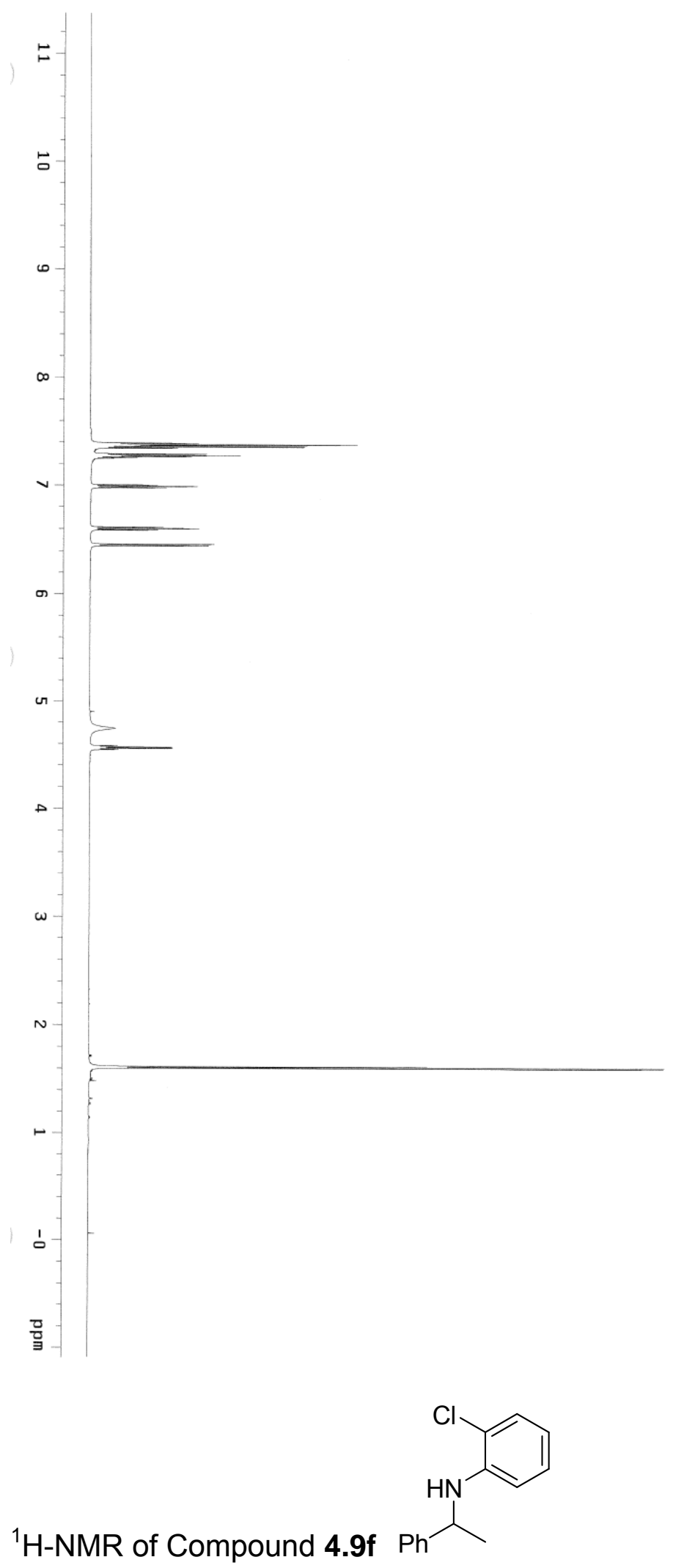

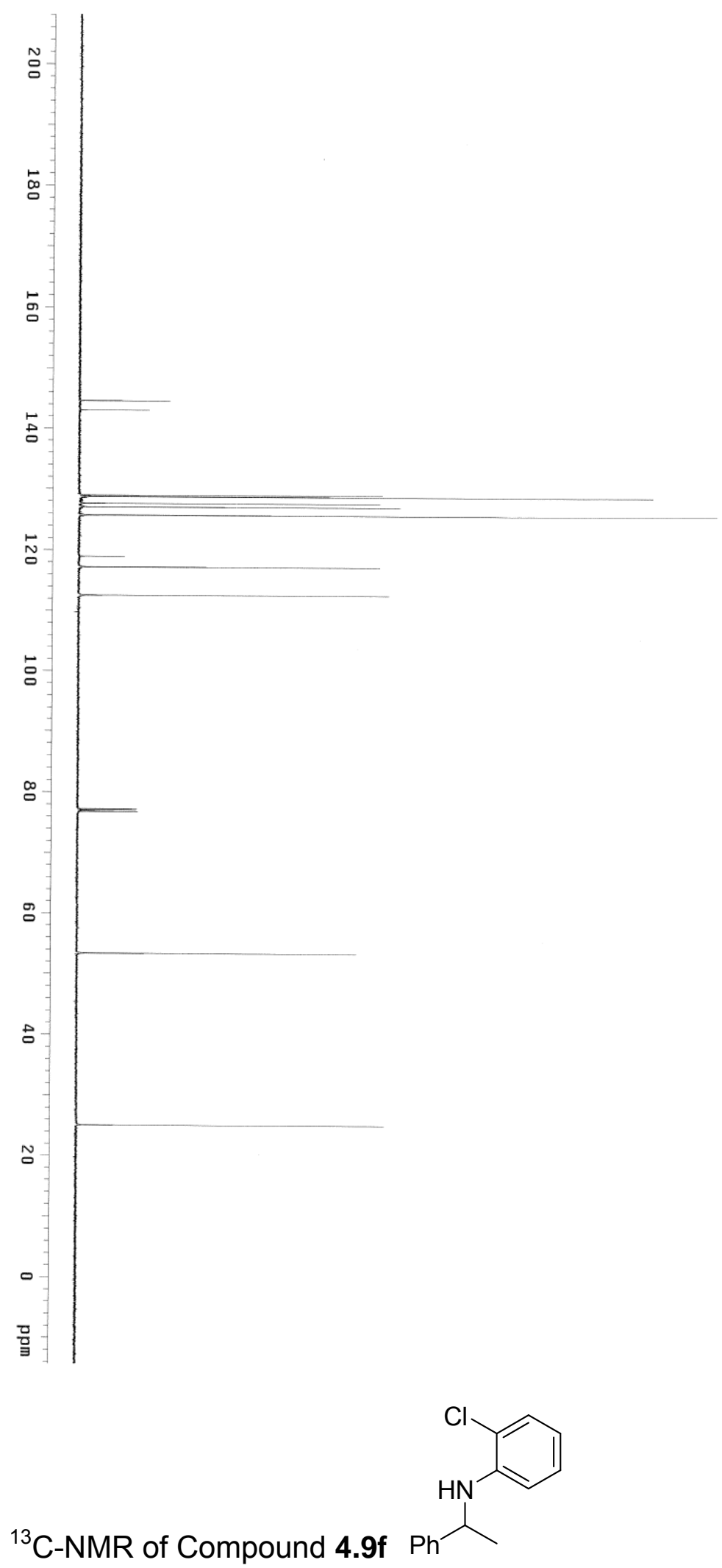


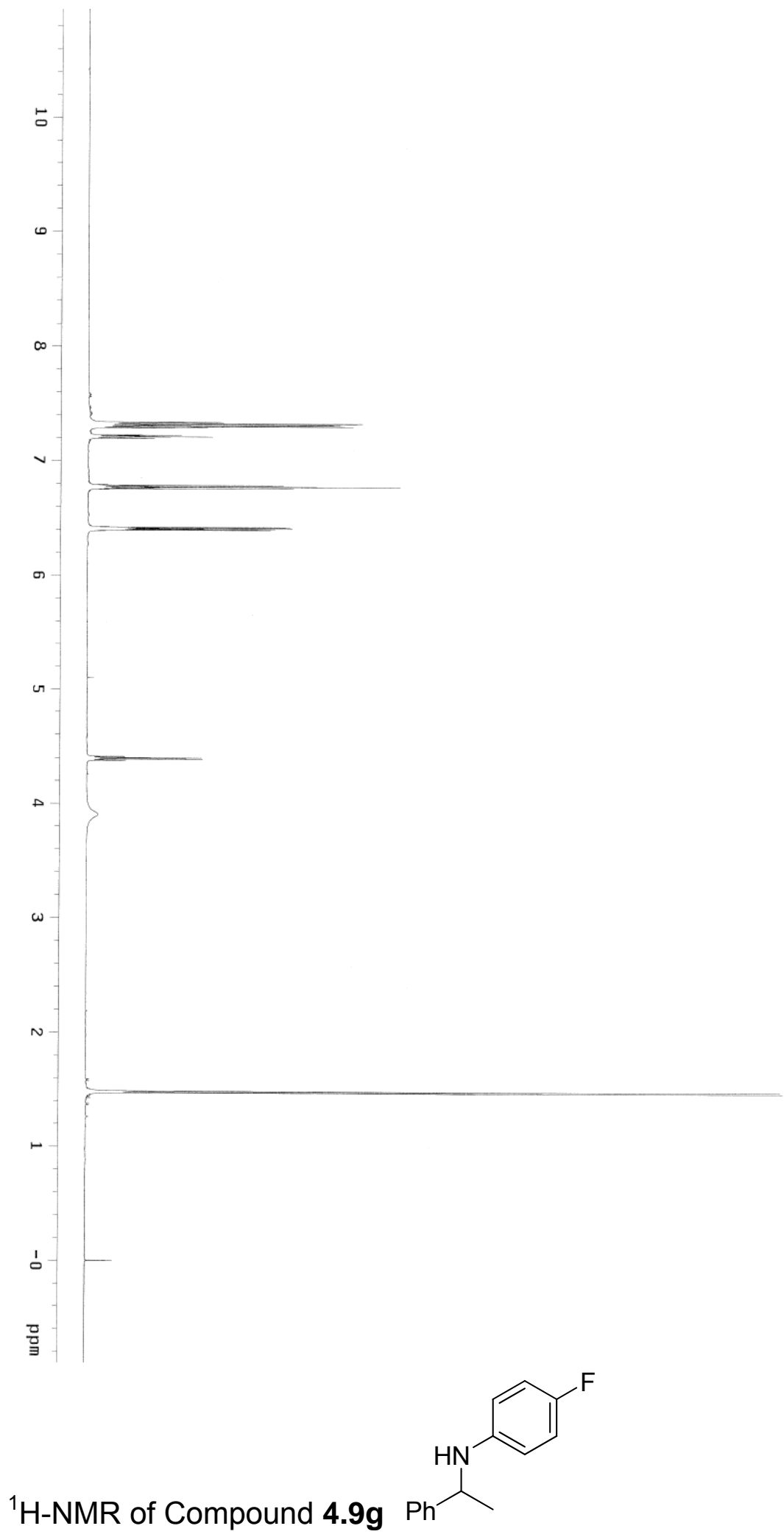




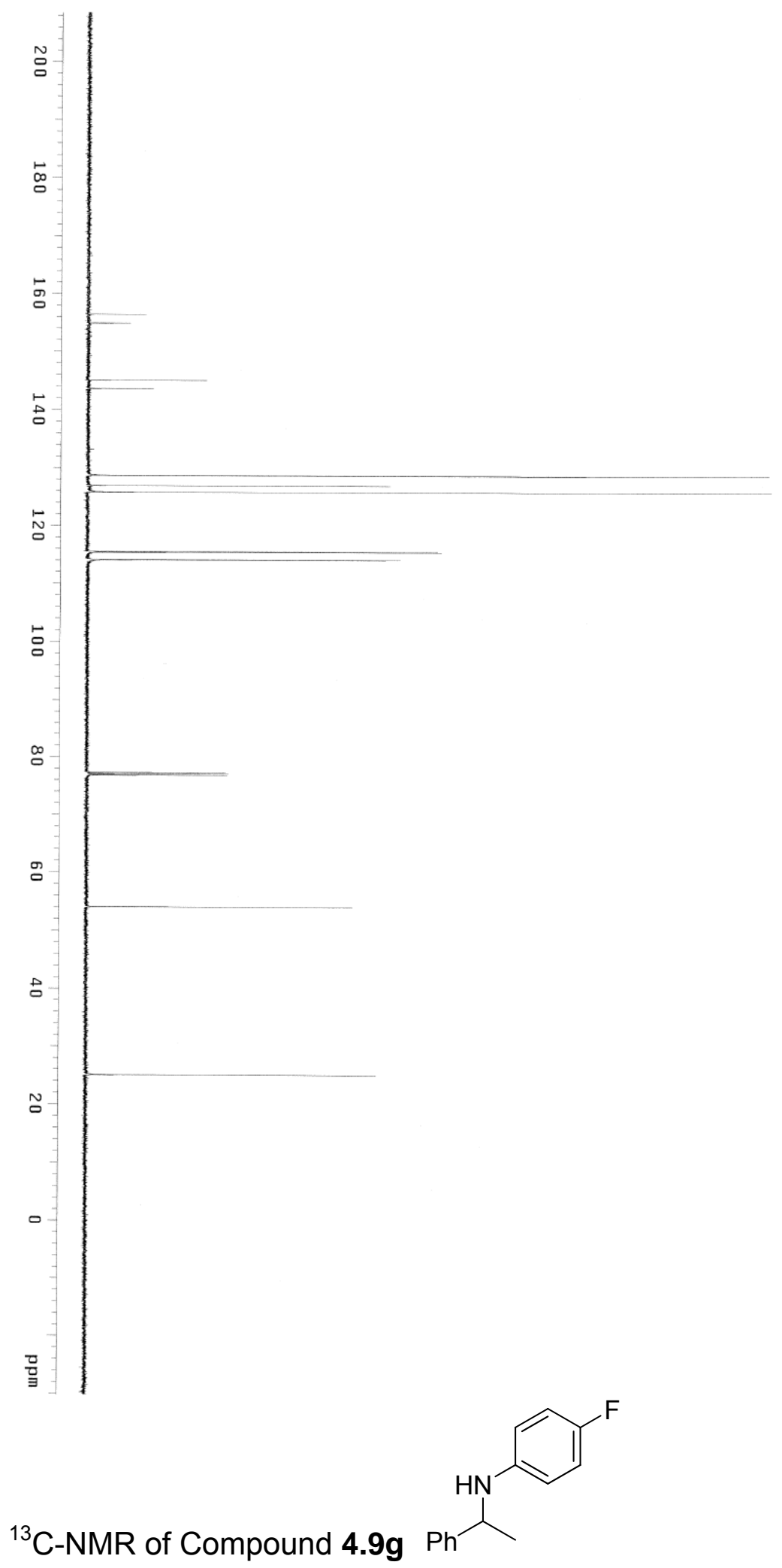



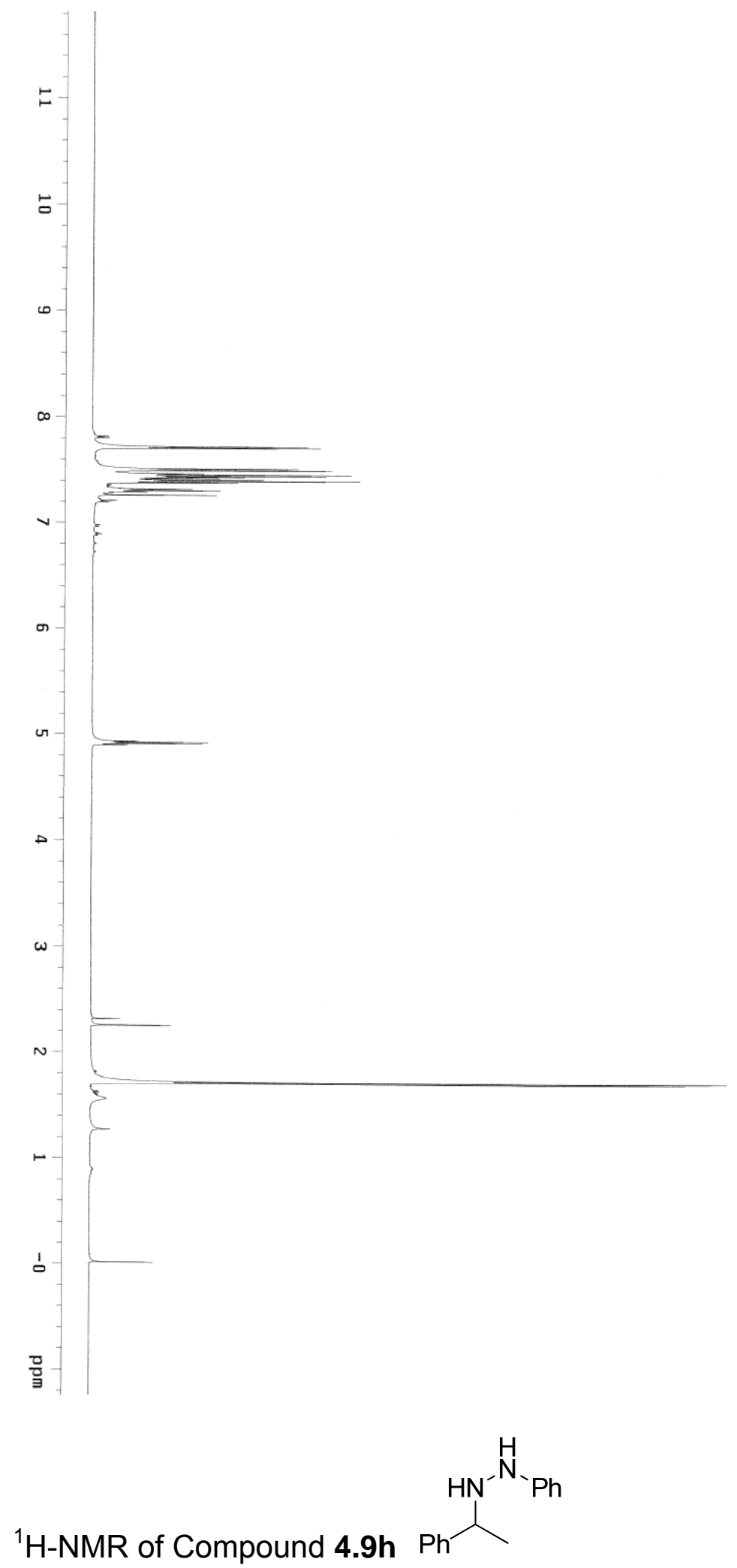


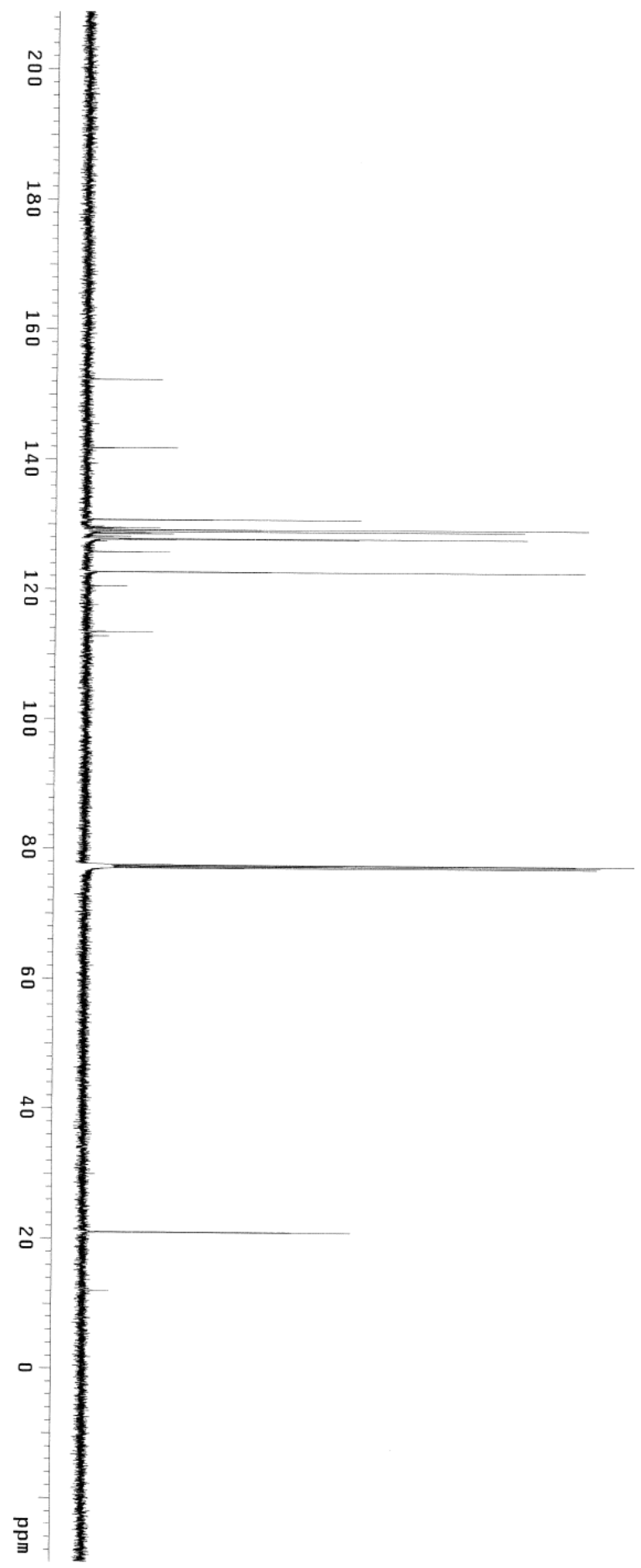

${ }^{13} \mathrm{C}-\mathrm{NMR}$ of Compound 4.9h 


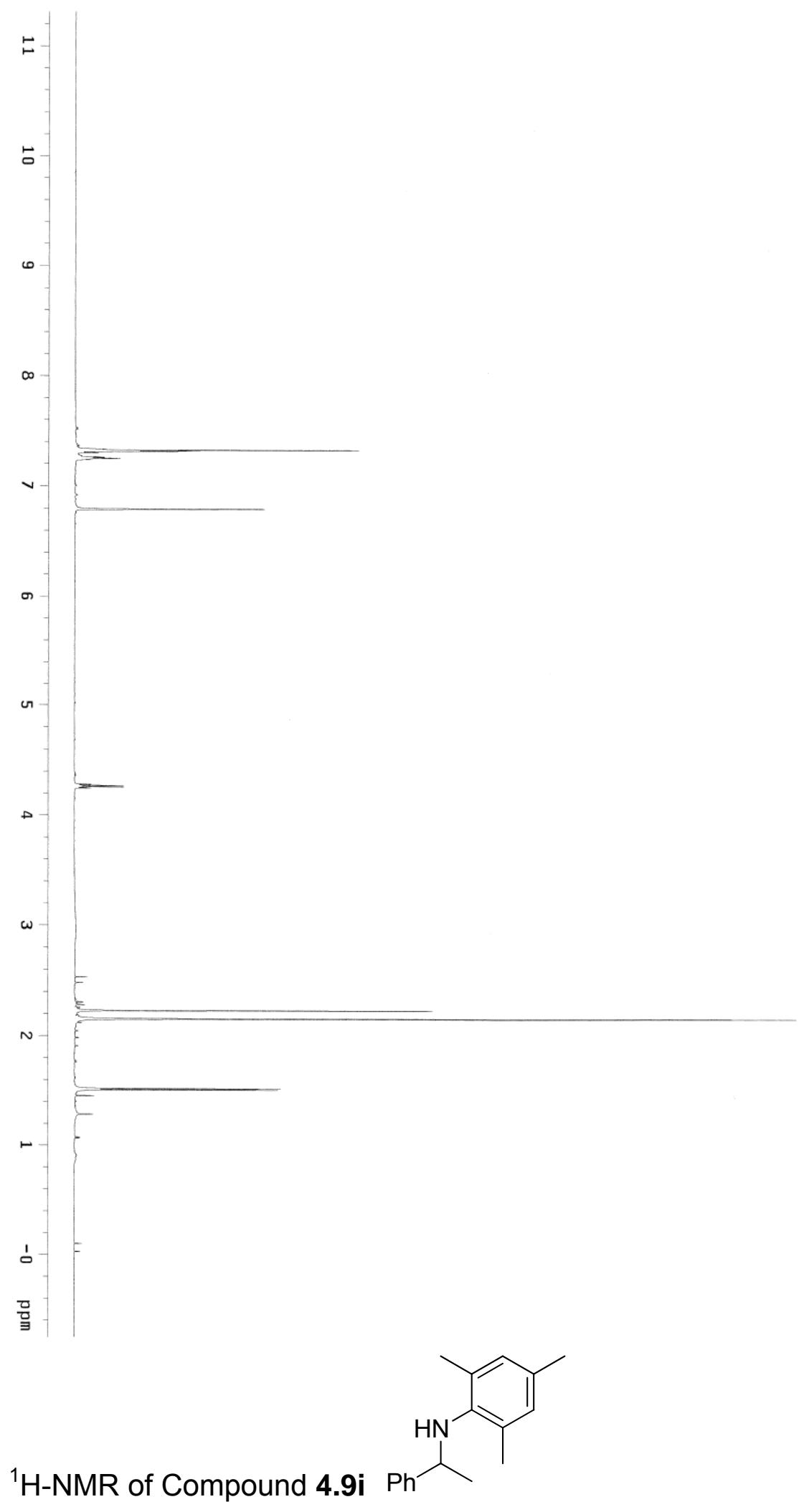



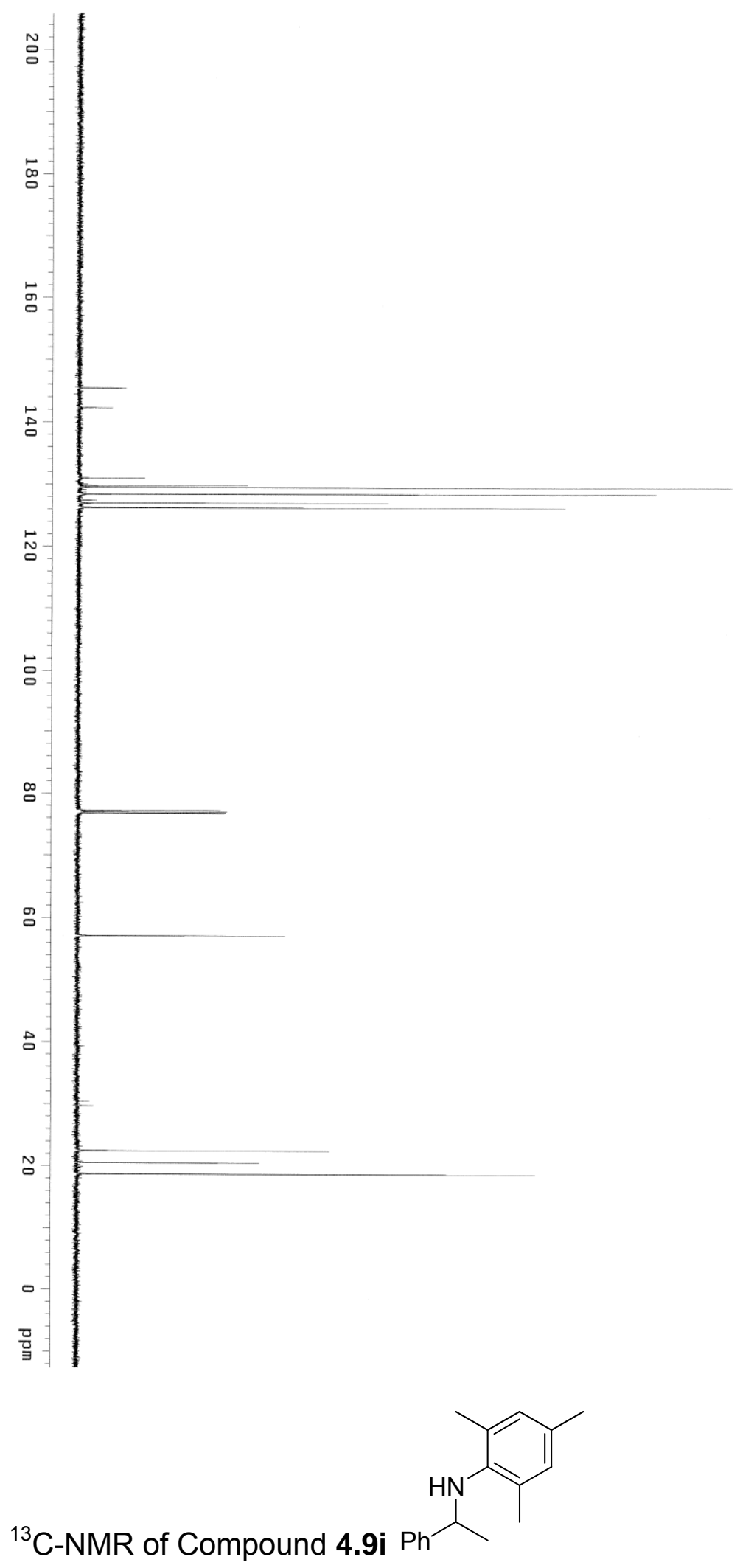


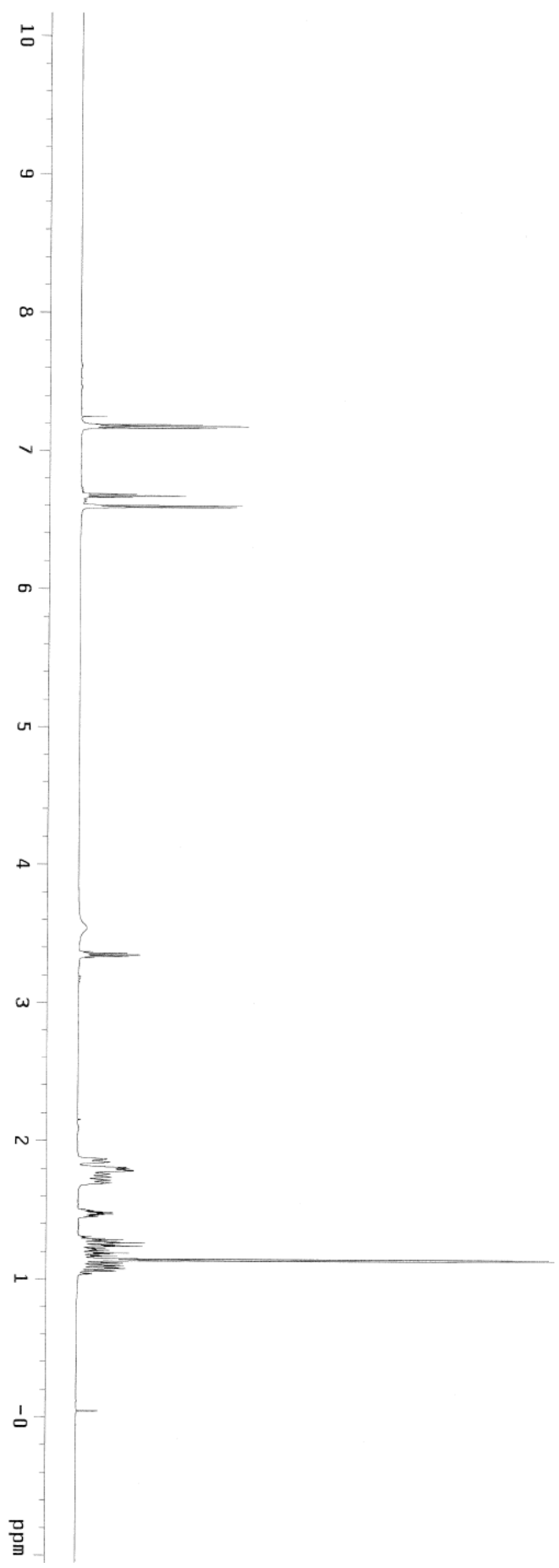

${ }^{1} \mathrm{H}-\mathrm{NMR}$ of Compound $4.9 \mathrm{j}$ 


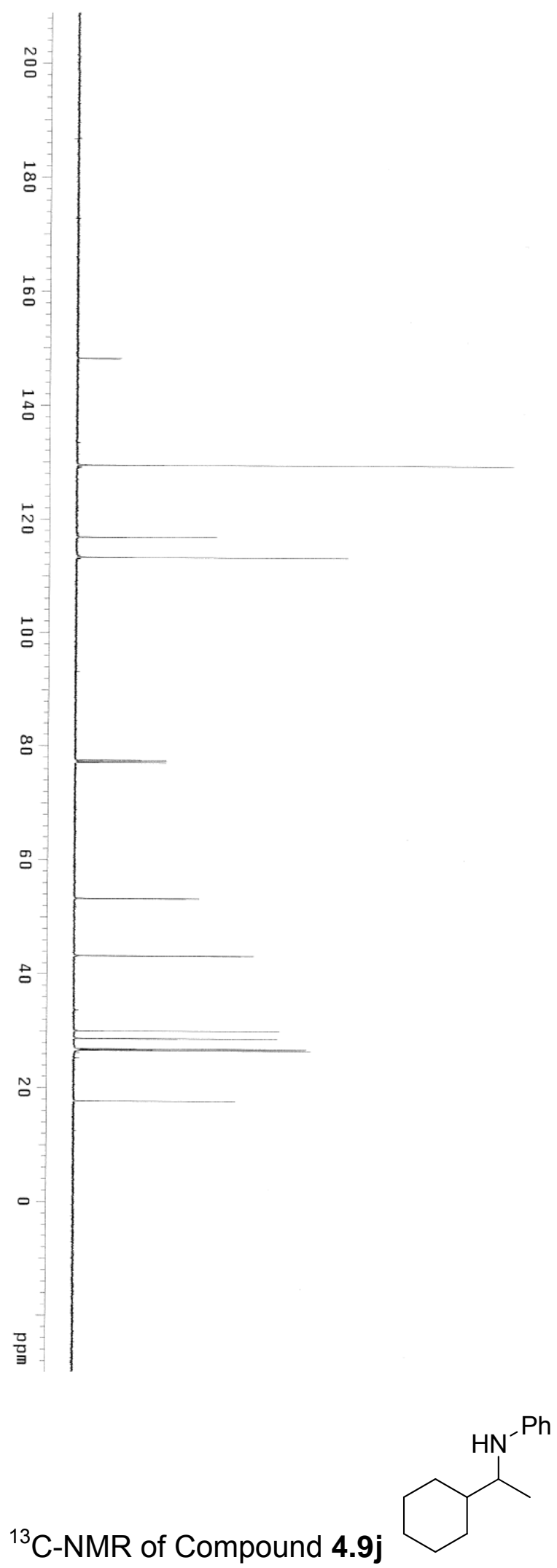



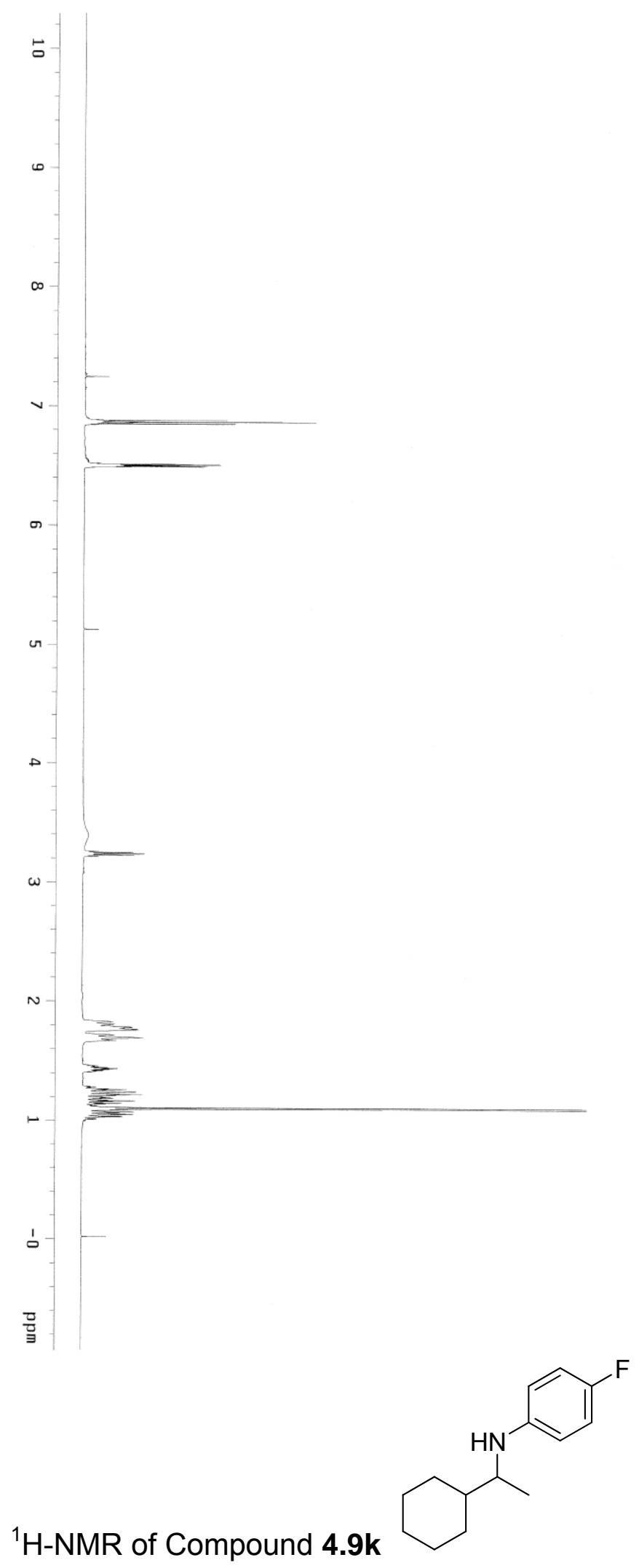

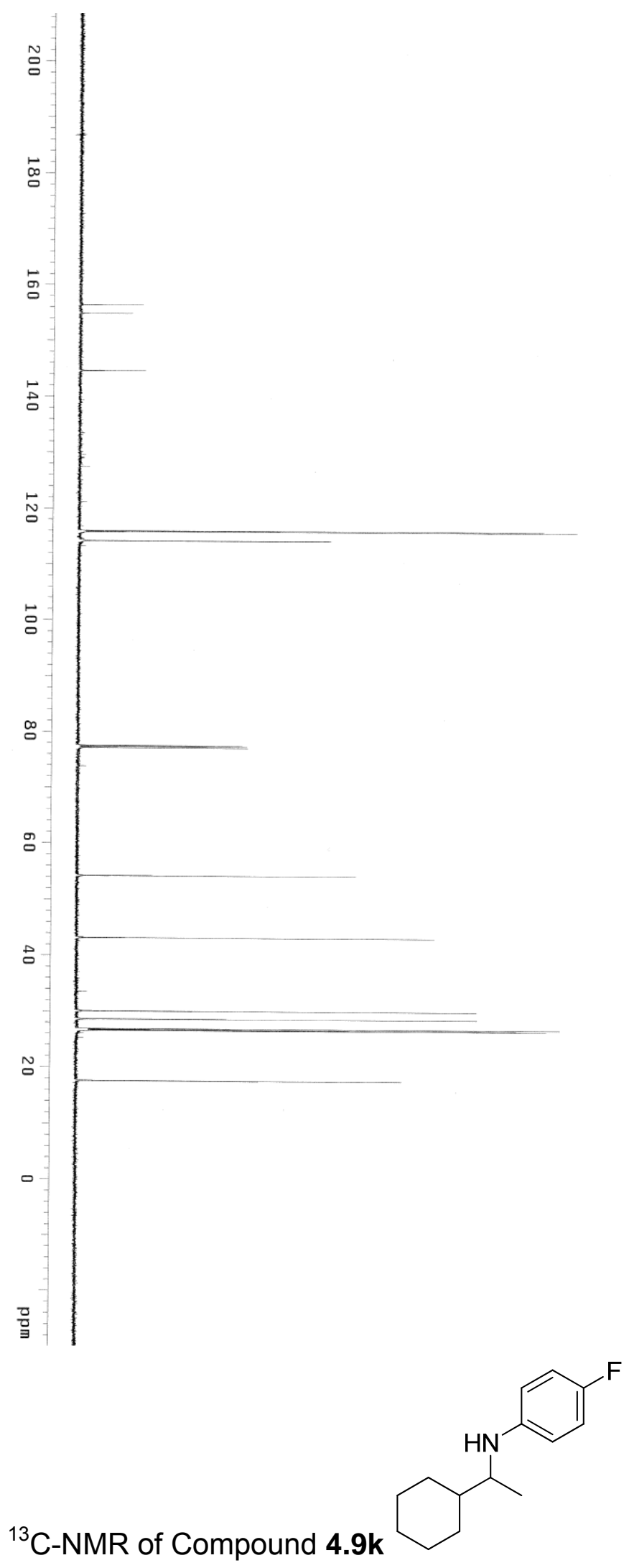


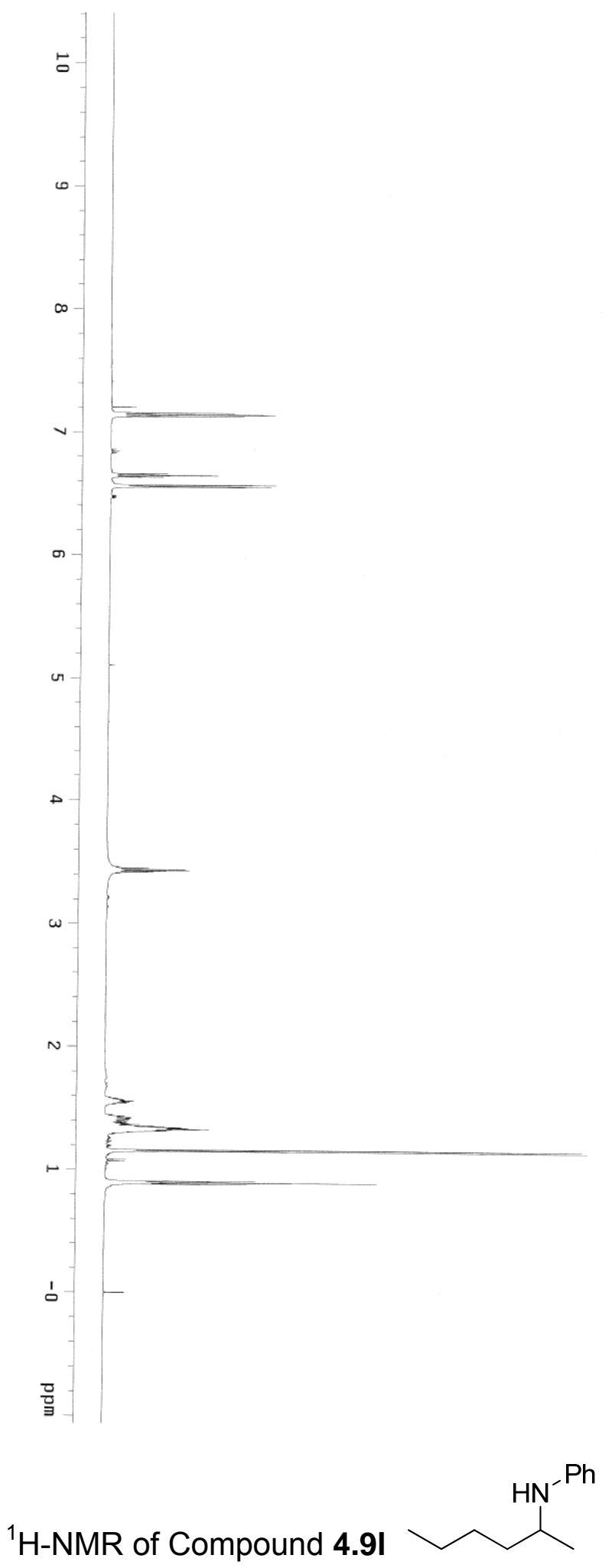




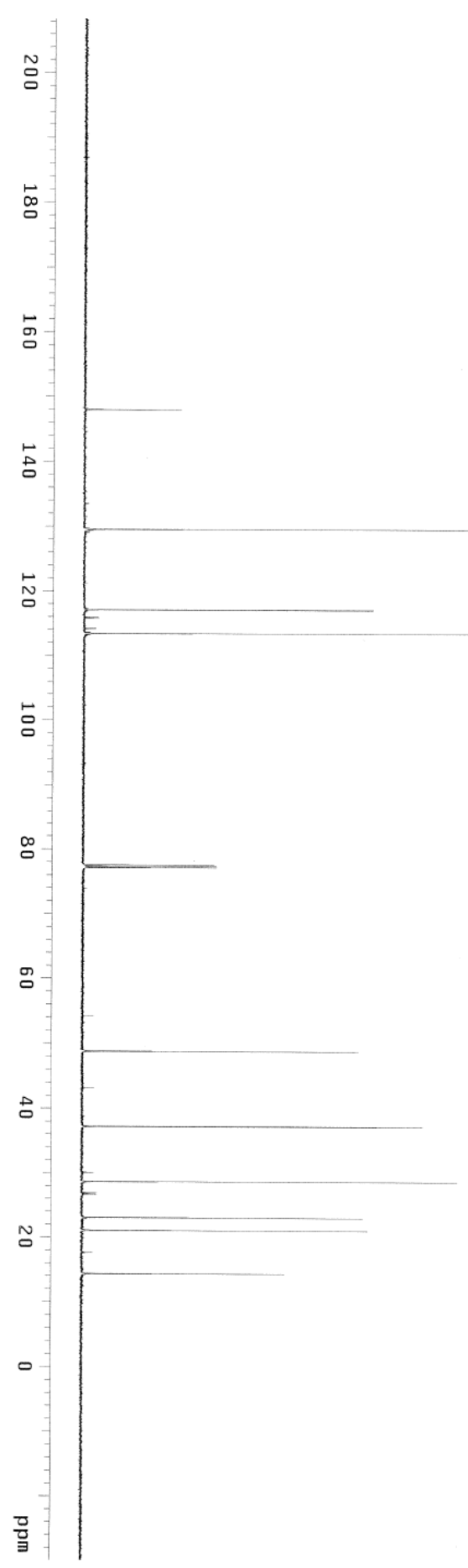

${ }^{13} \mathrm{C}-\mathrm{NMR}$ of Compound $4.9 \mathrm{I}$ 

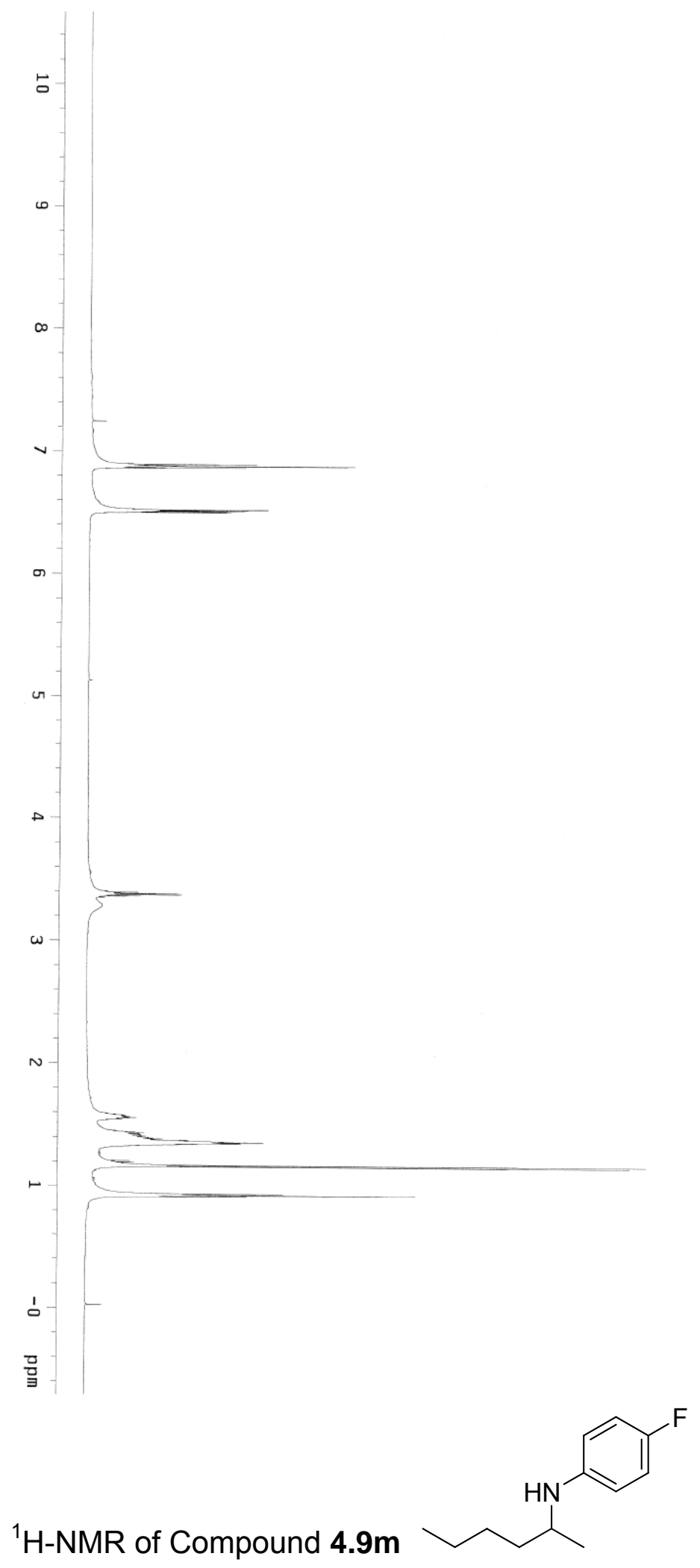

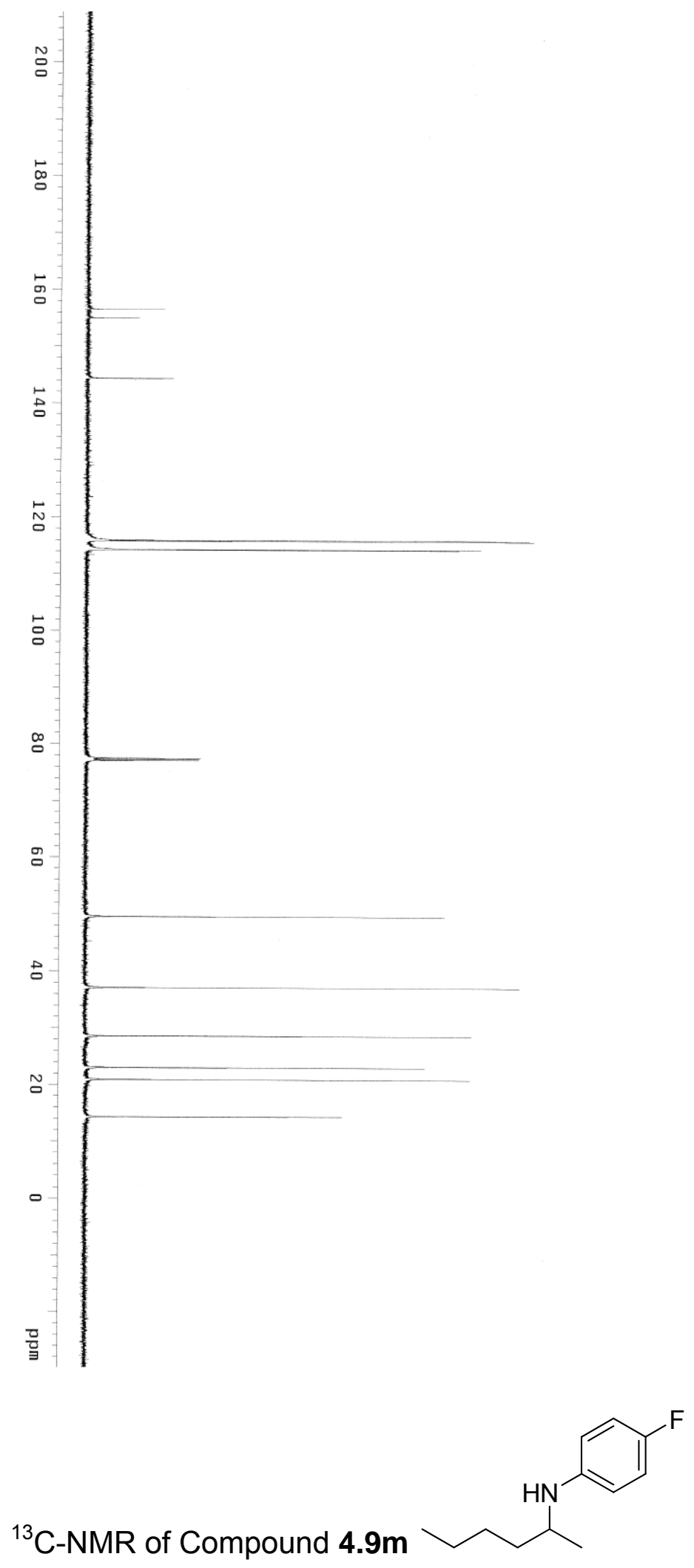


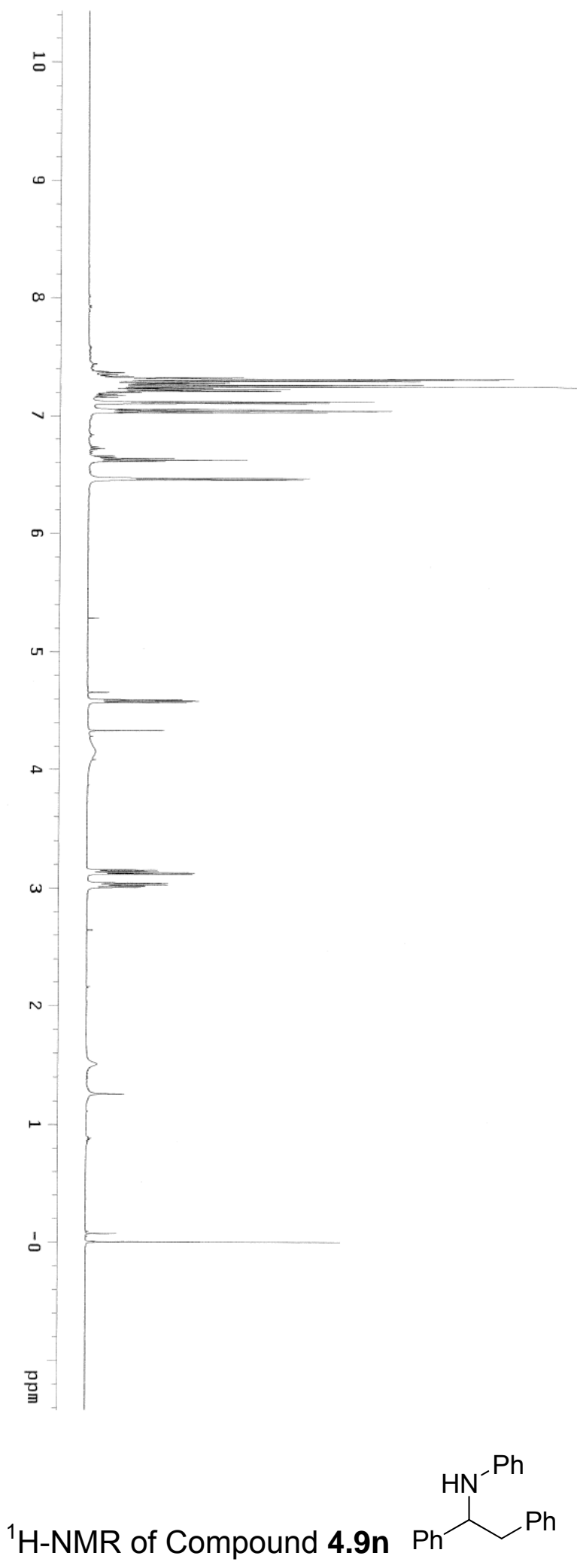



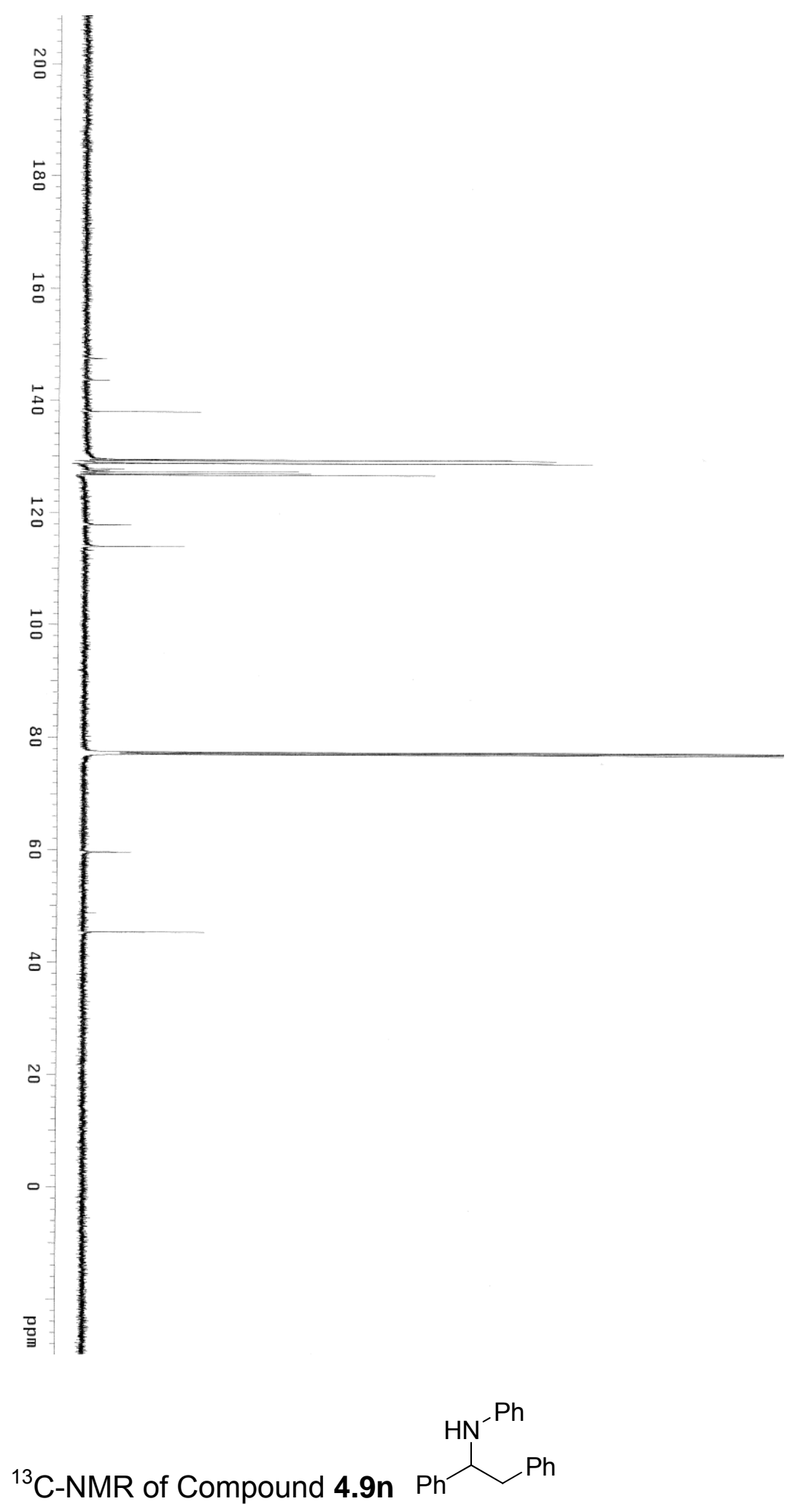

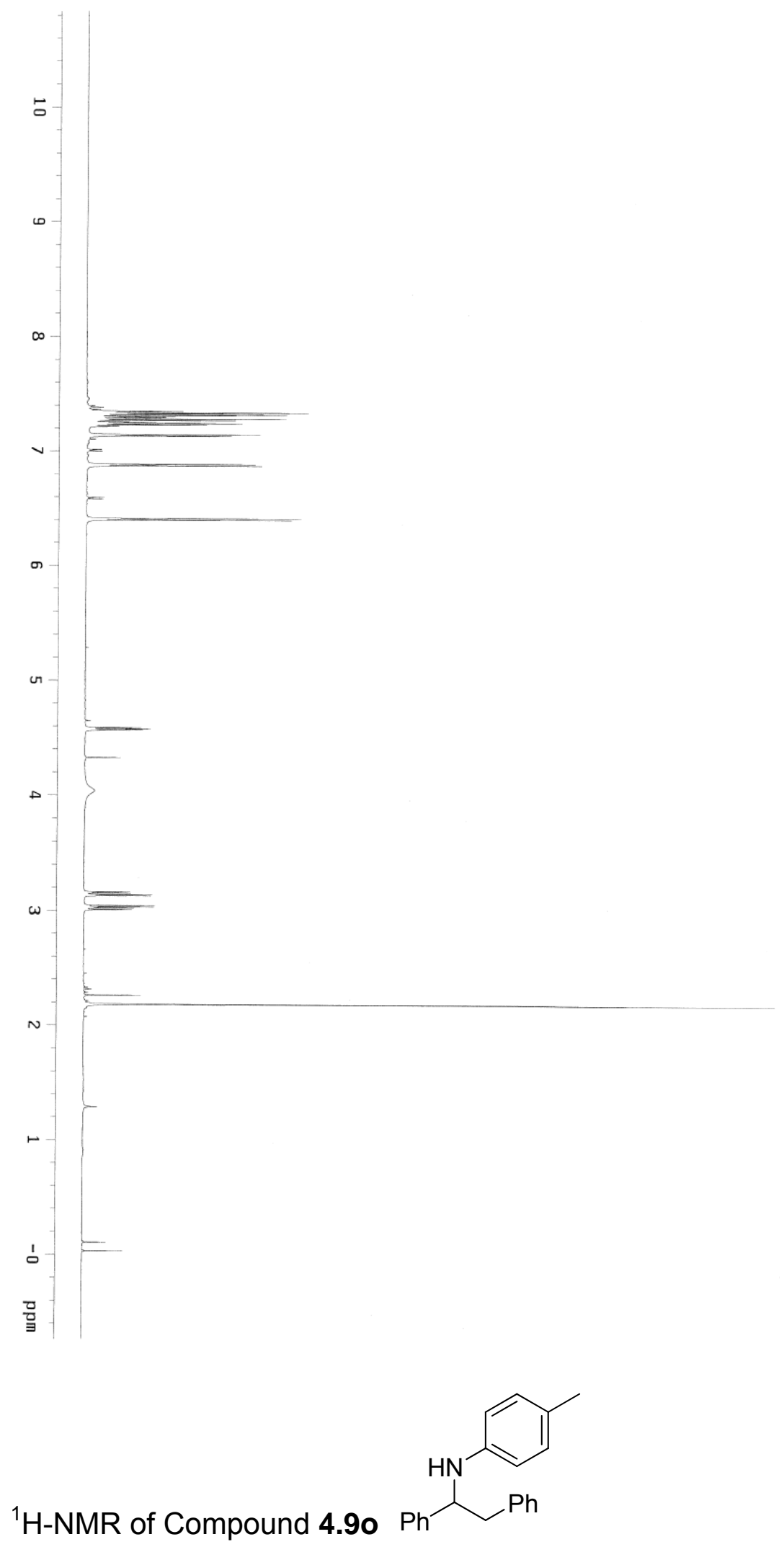

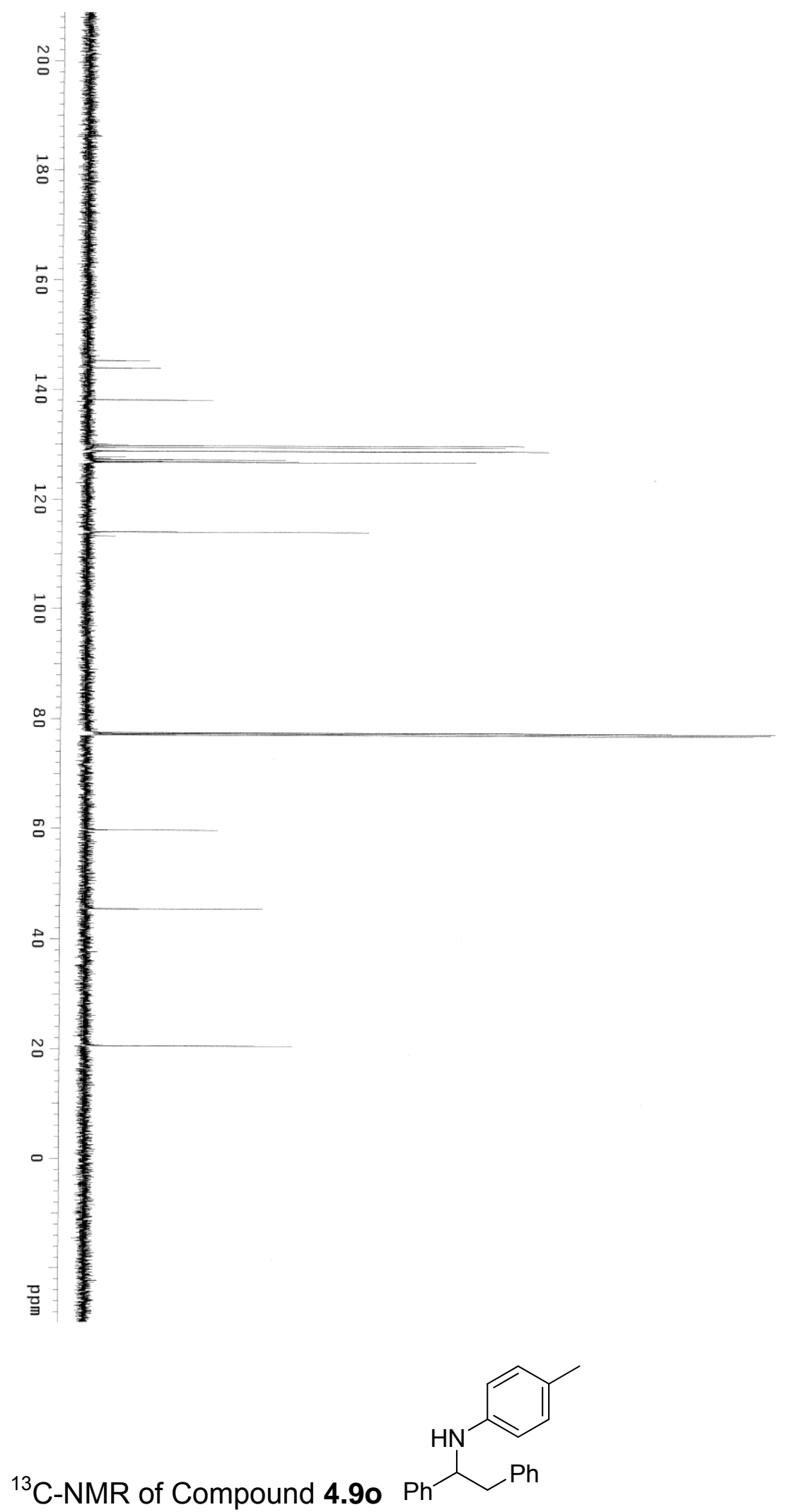


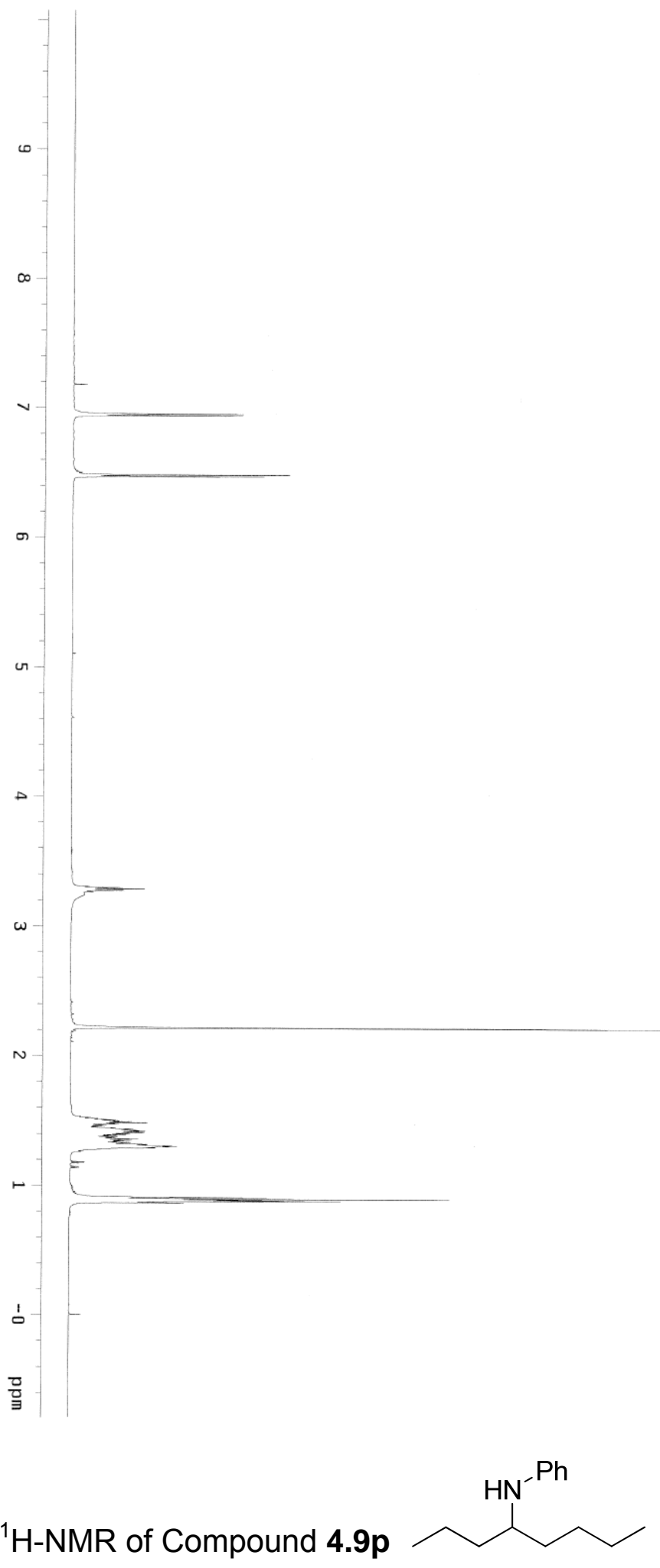




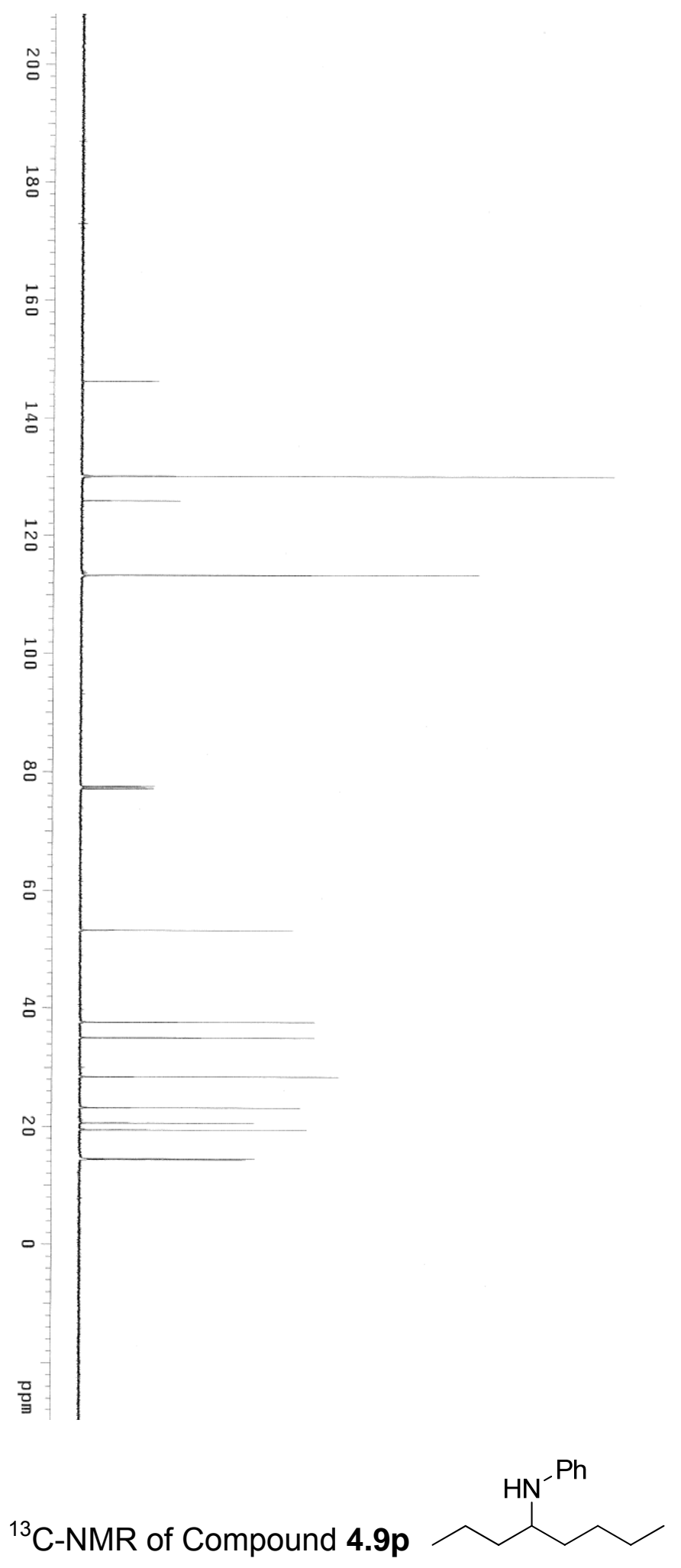




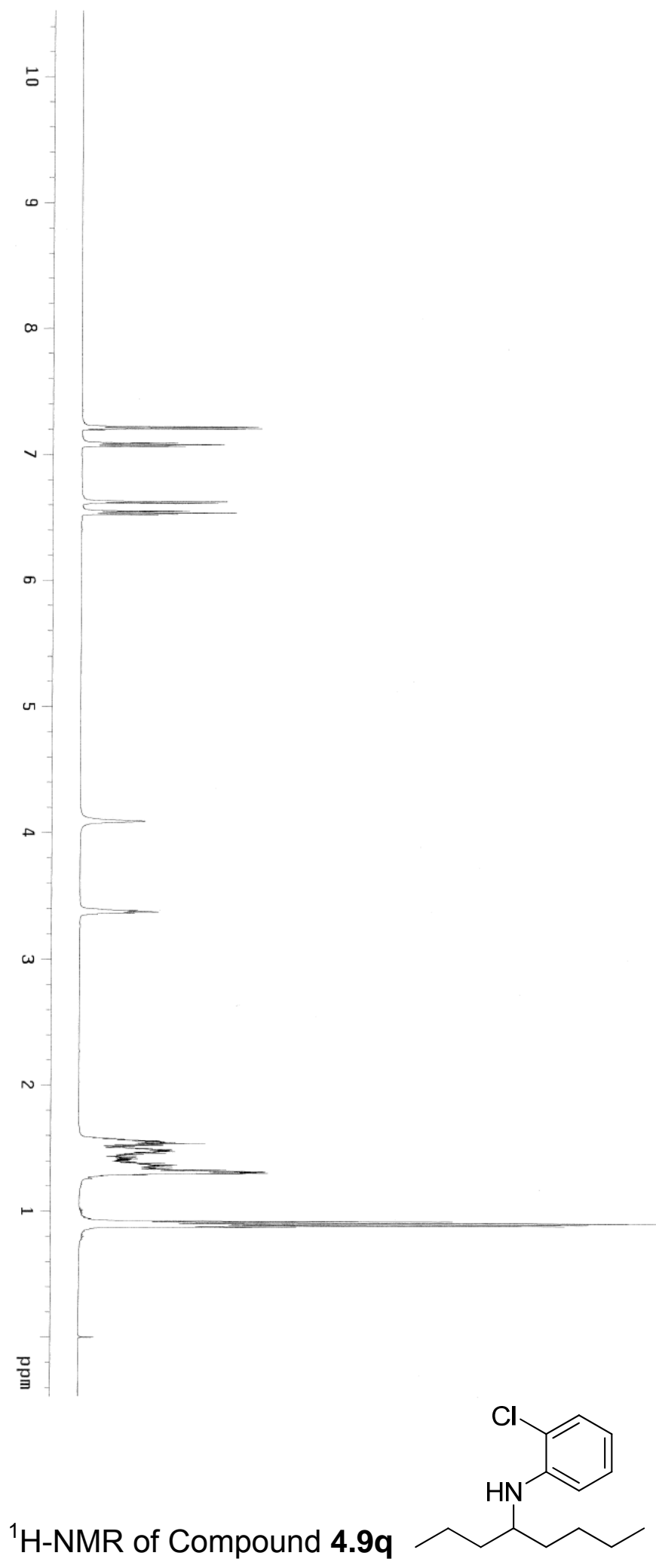



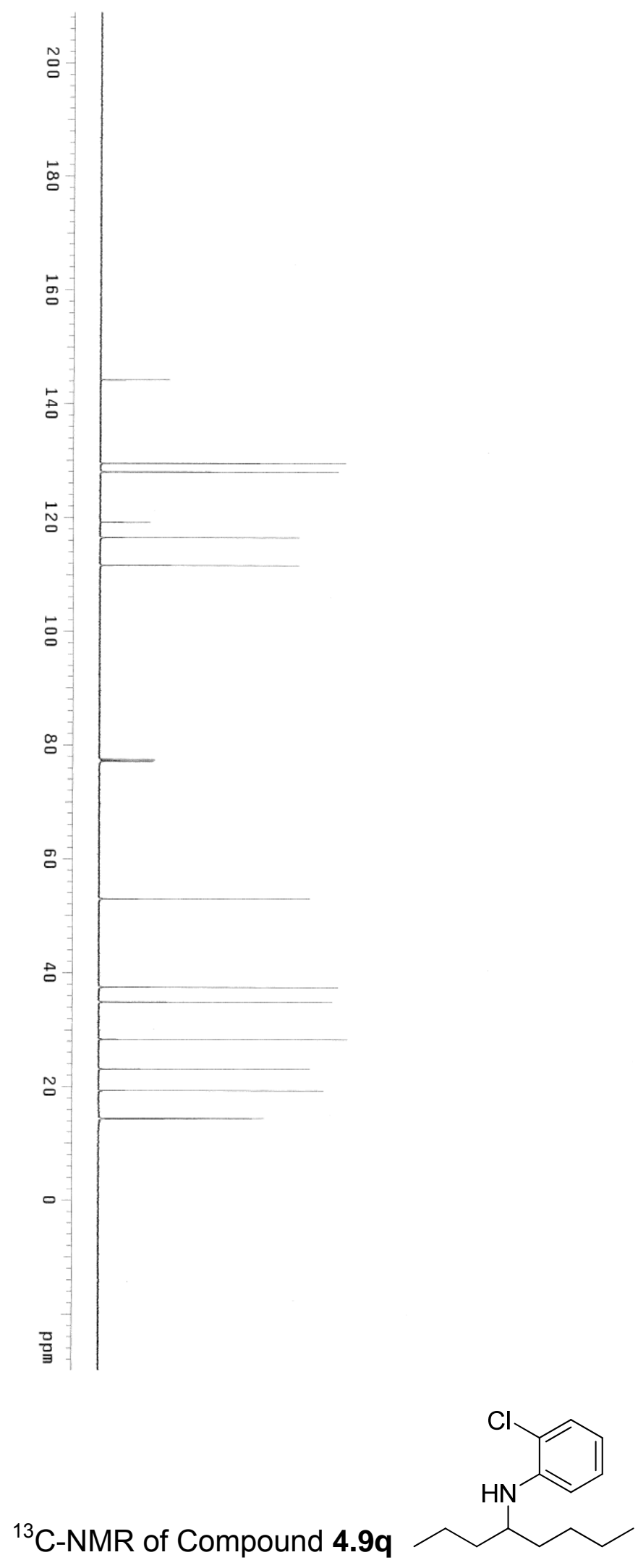


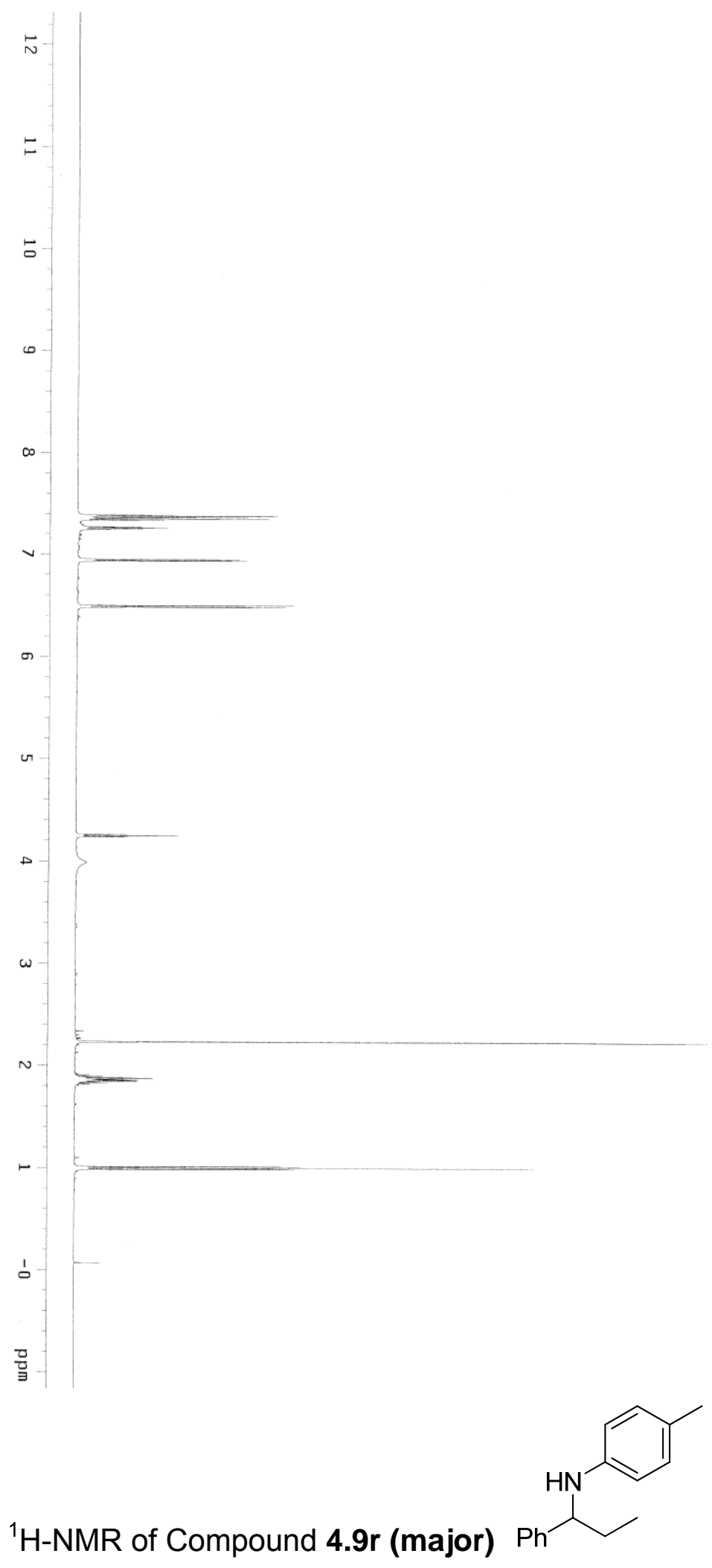



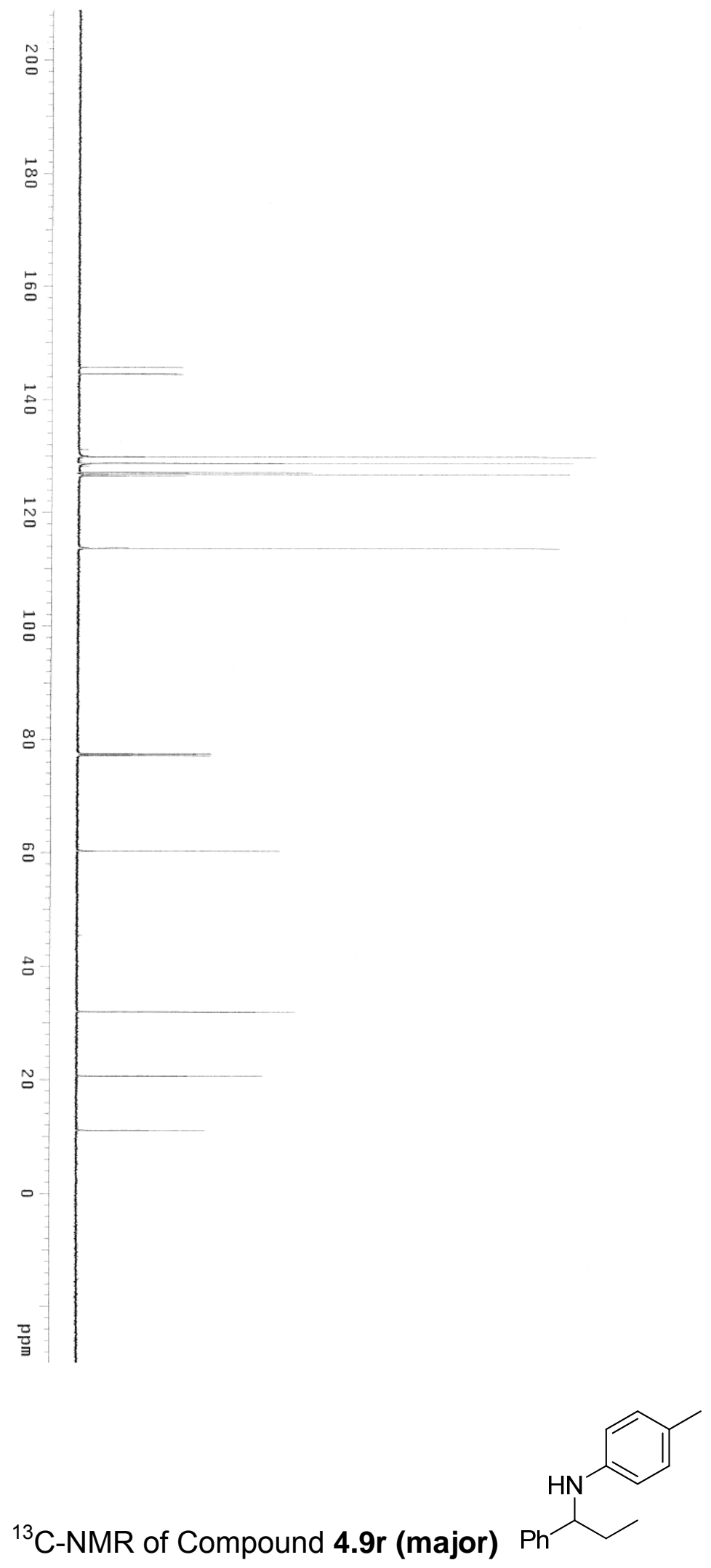

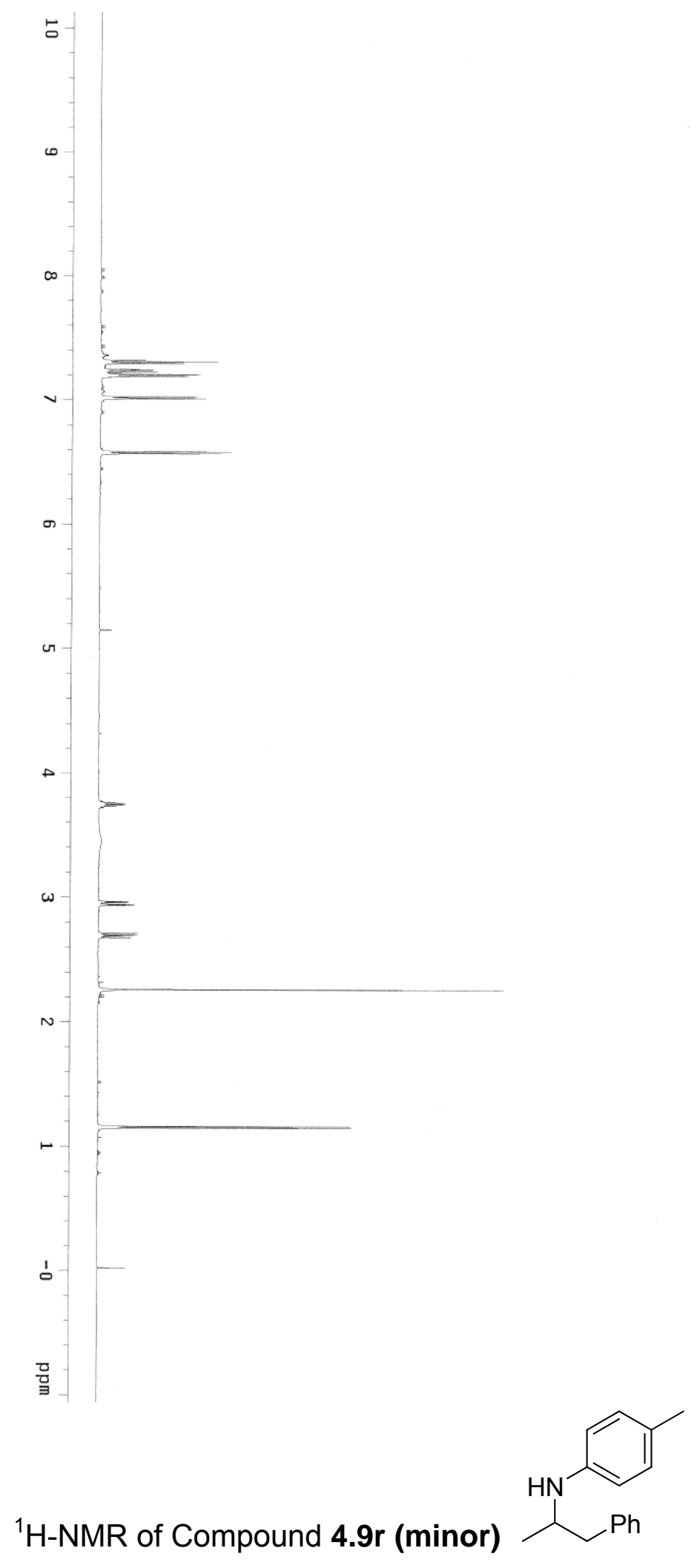


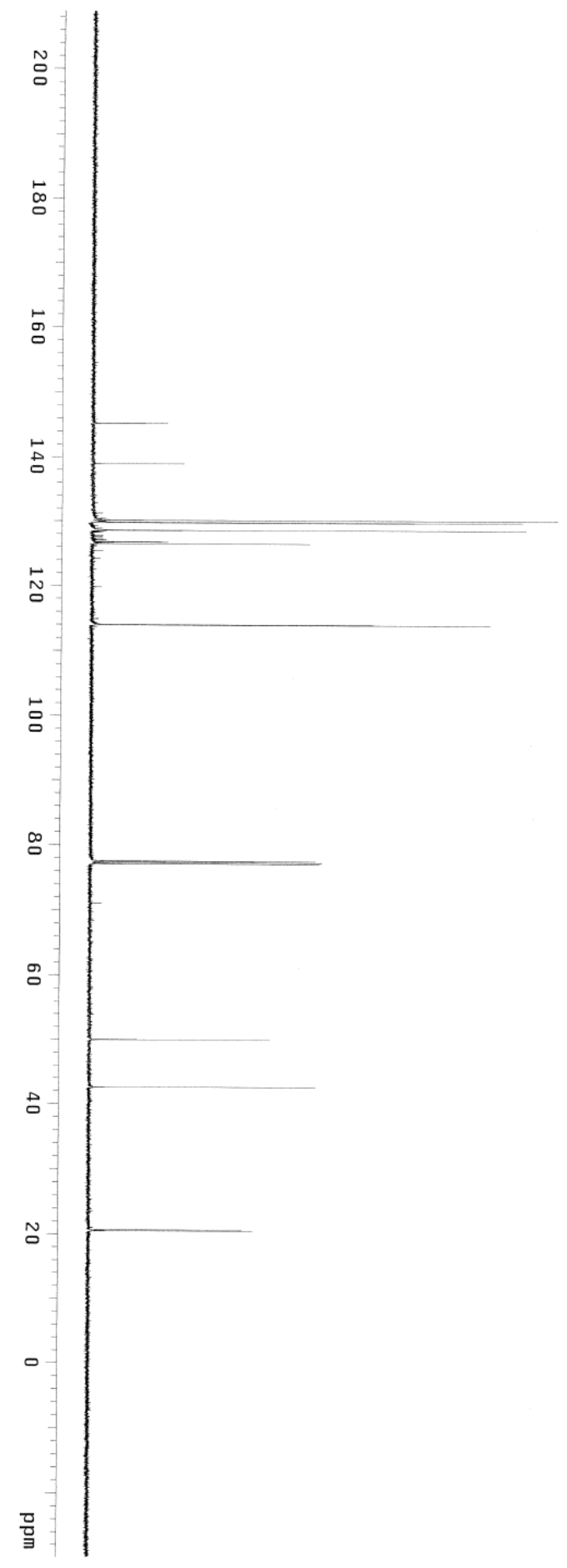

${ }^{13} \mathrm{C}-\mathrm{NMR}$ of Compound $4.9 \mathrm{r}$ (minor) 

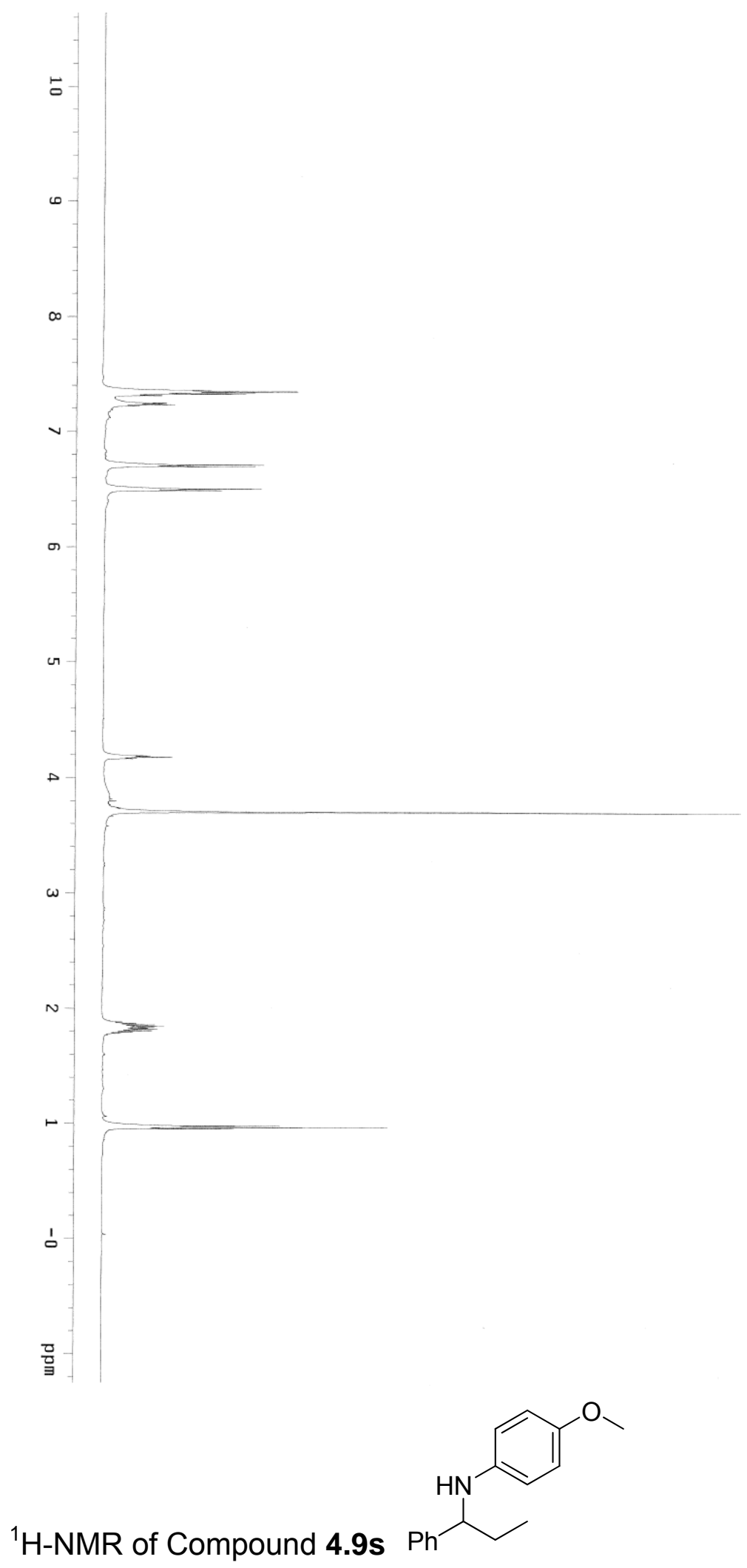


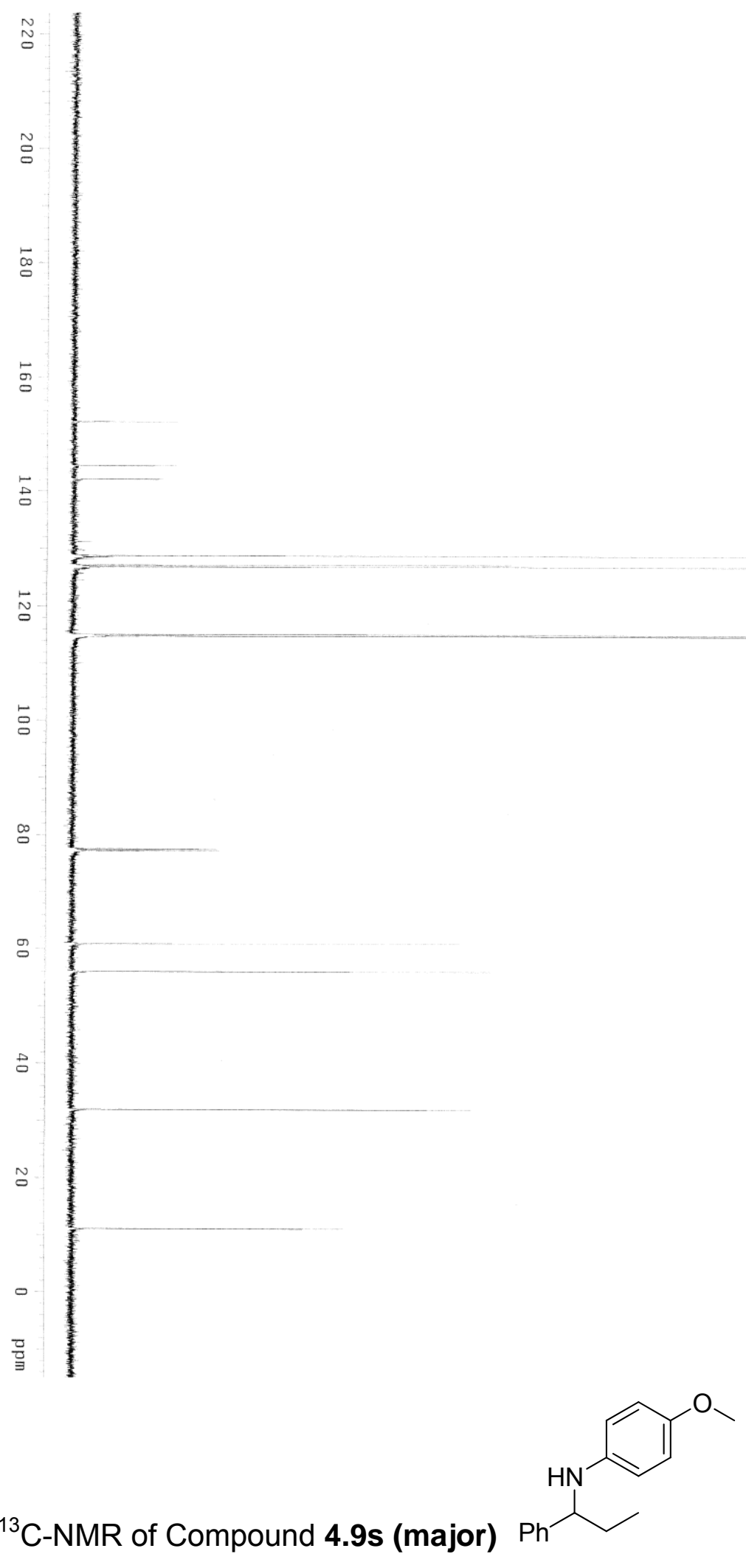




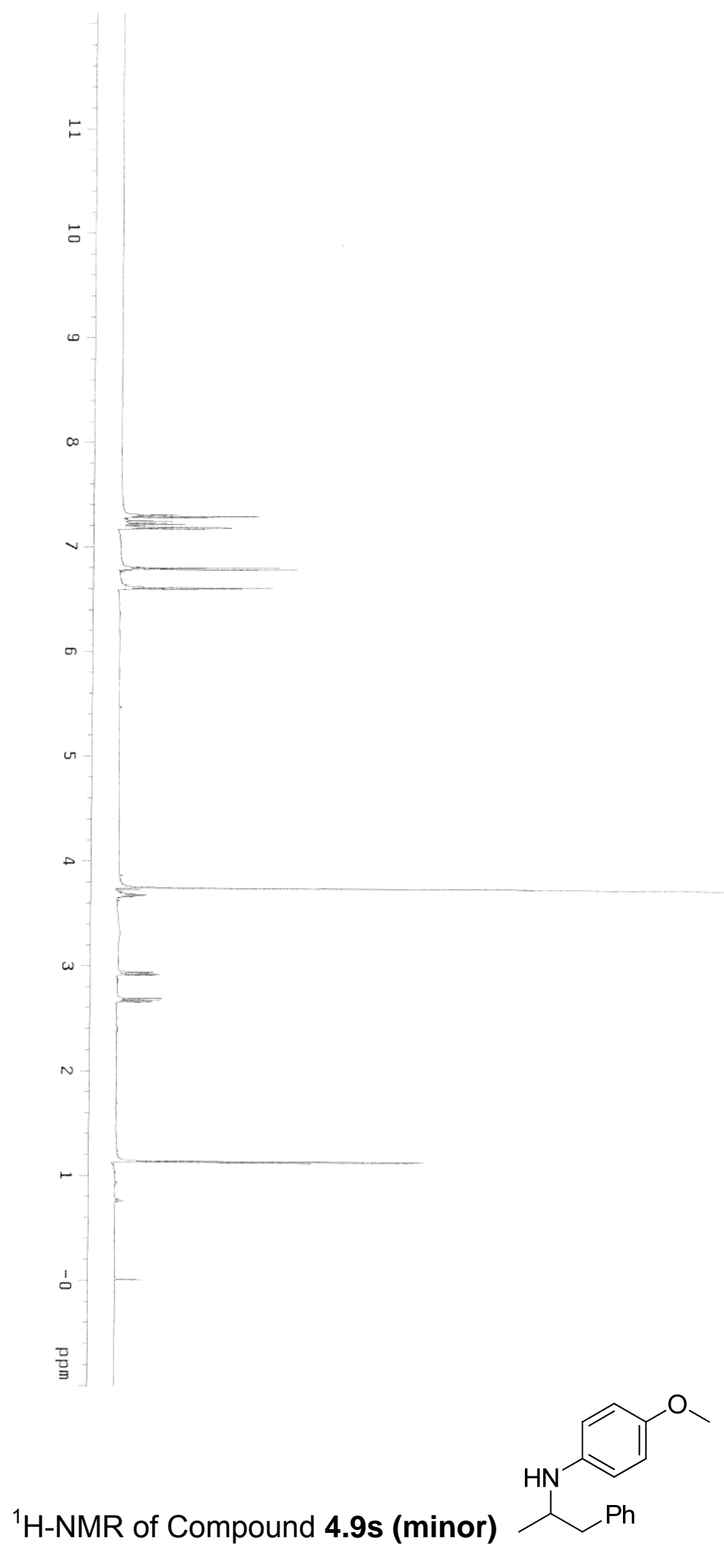



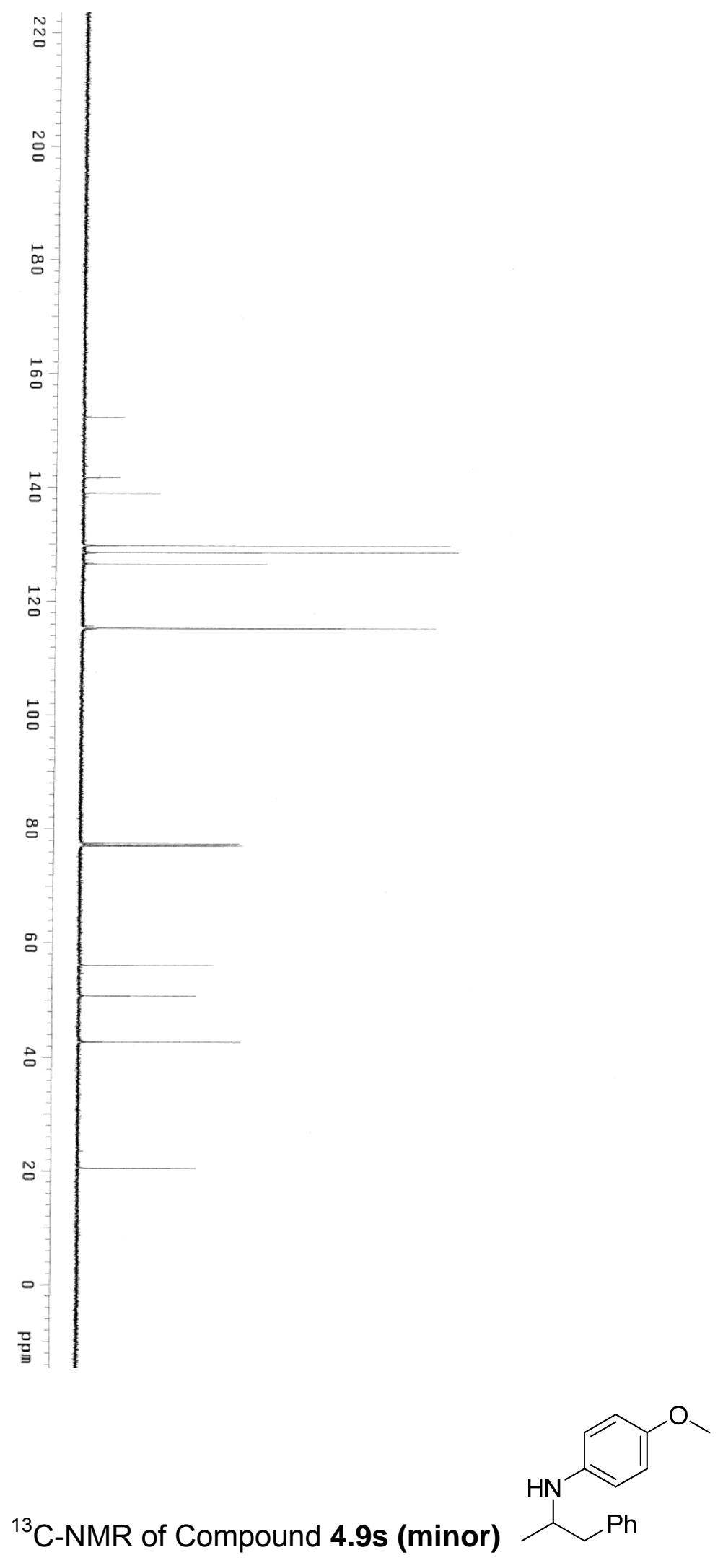


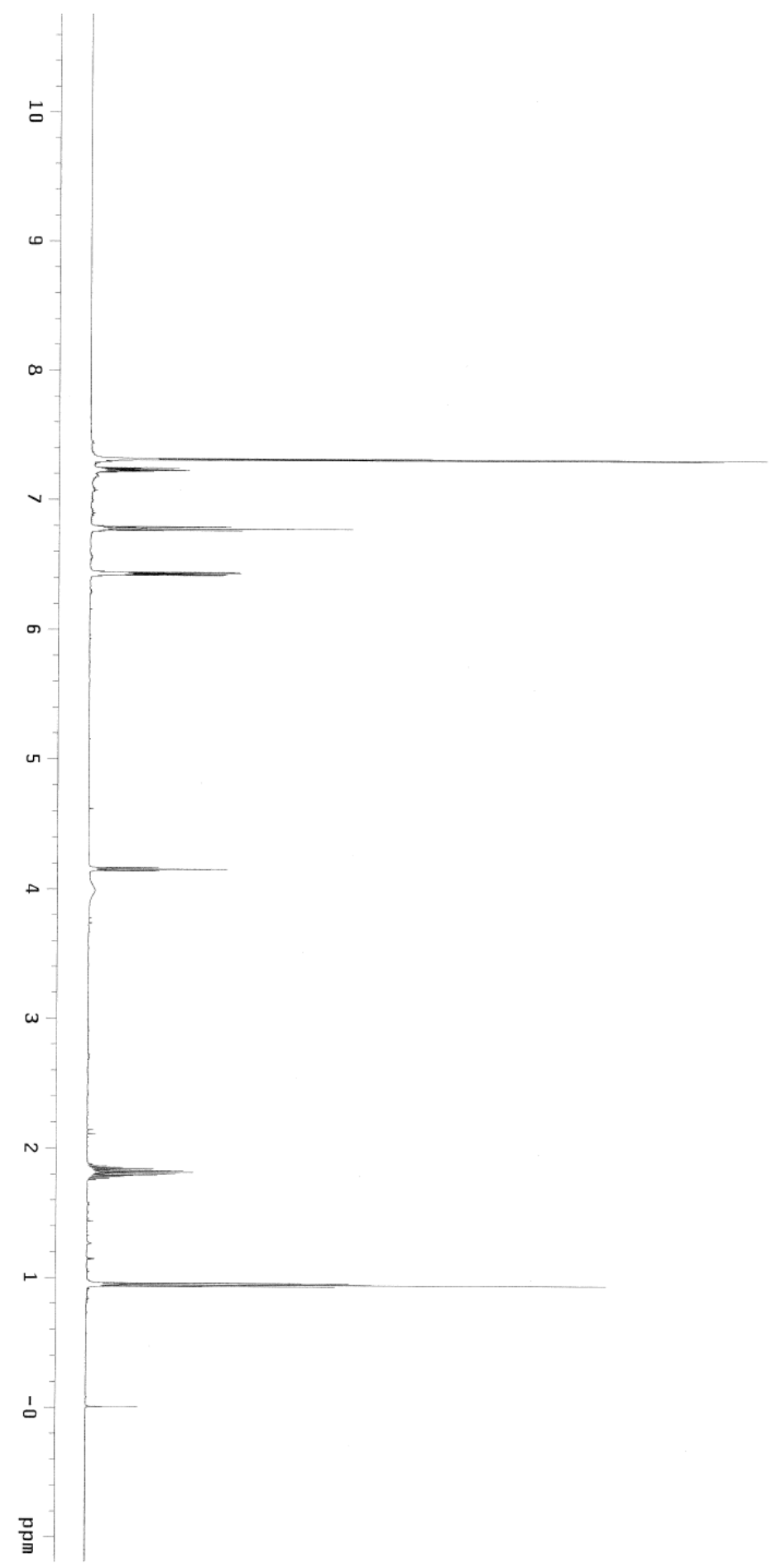

${ }^{1} \mathrm{H}-\mathrm{NMR}$ of Compound 4.9t (major) 


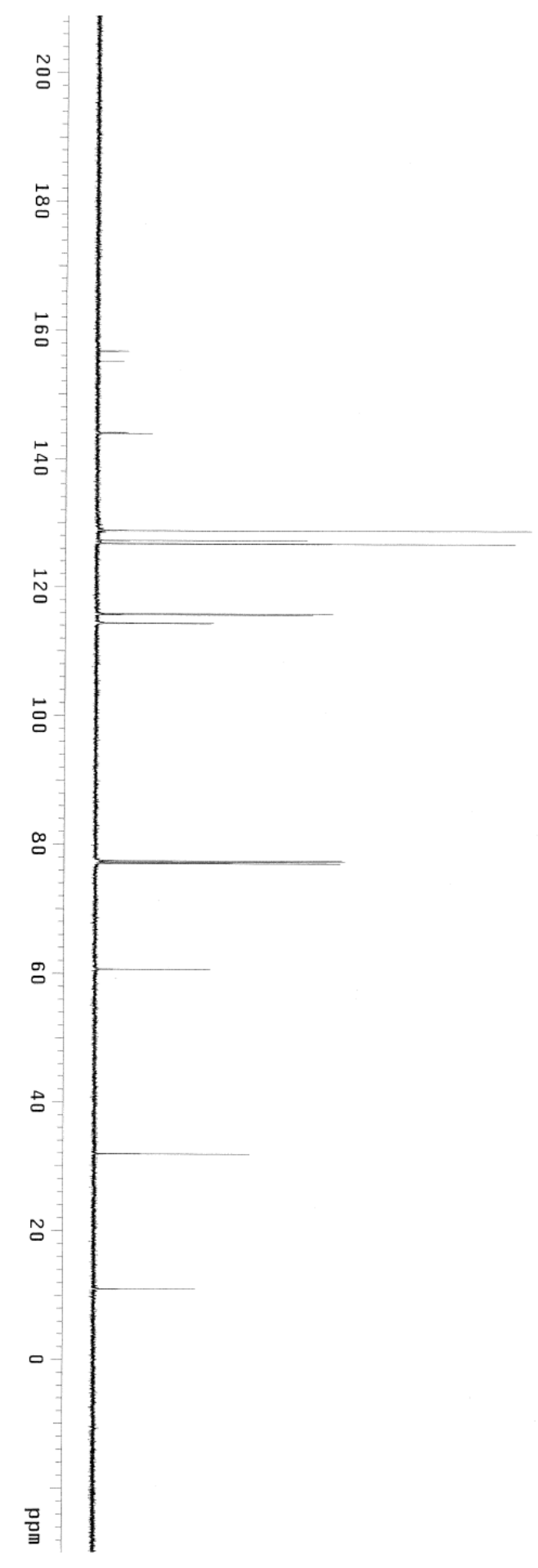

${ }^{13} \mathrm{C}-\mathrm{NMR}$ of Compound 4.9t (major) 


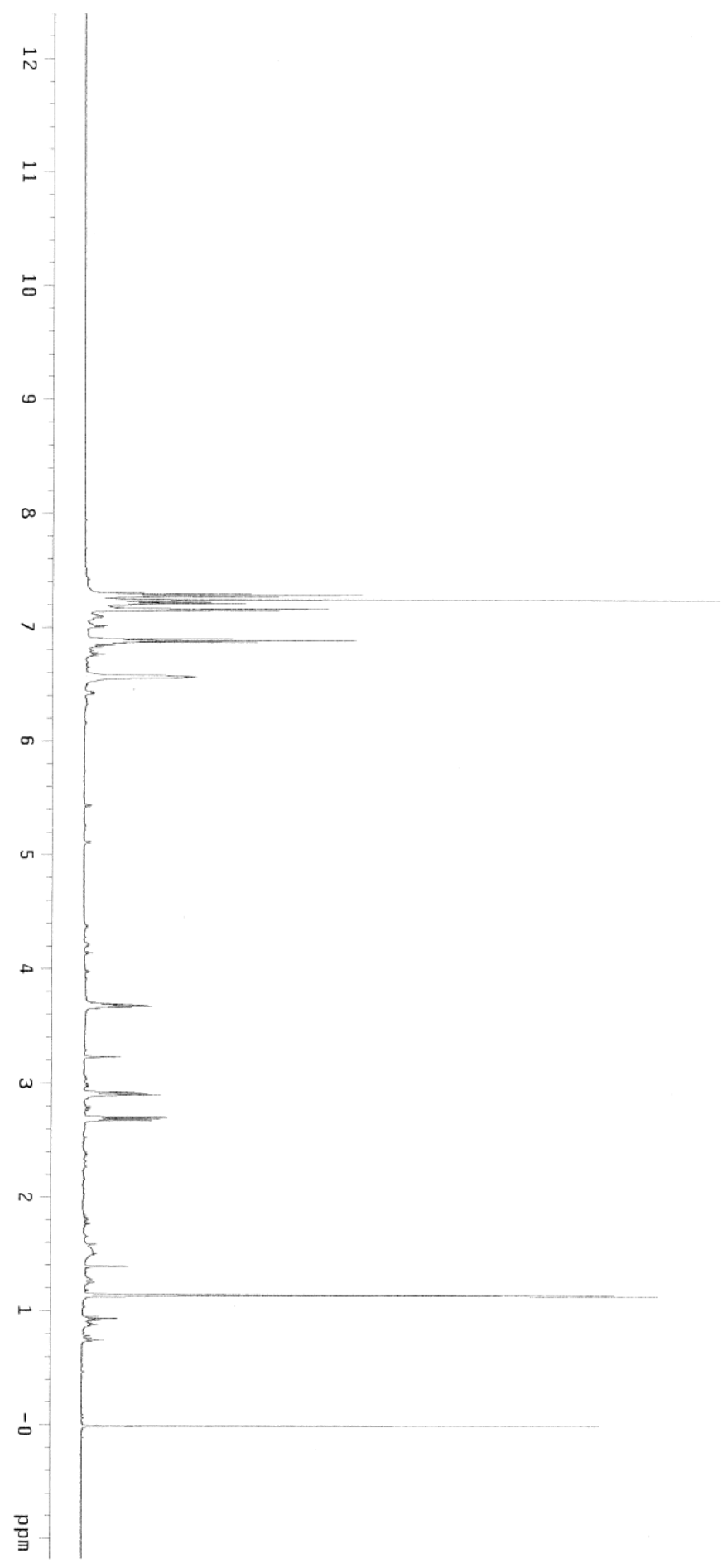

${ }^{1} \mathrm{H}-\mathrm{NMR}$ of Compound 4.9t (minor) 


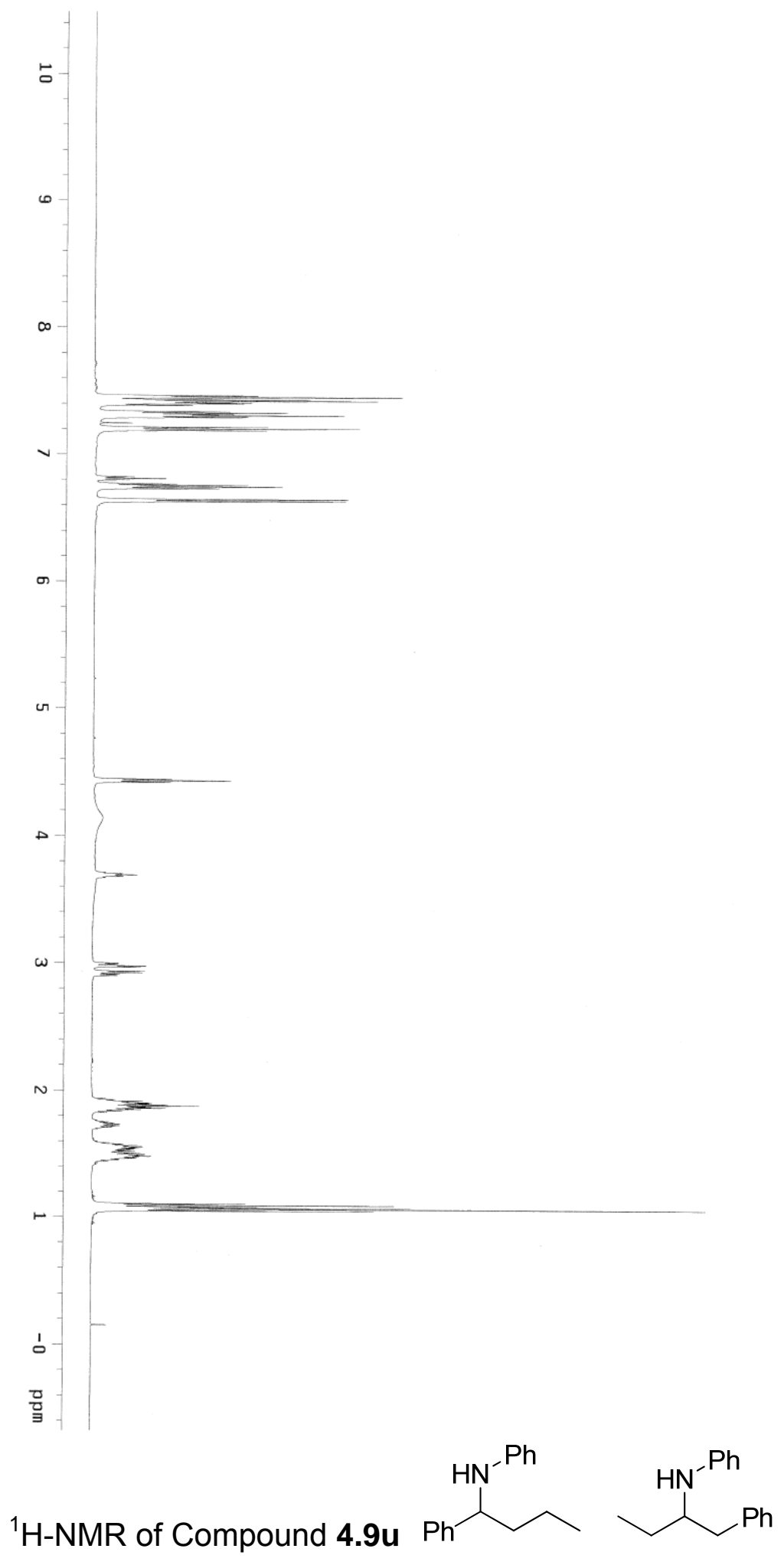




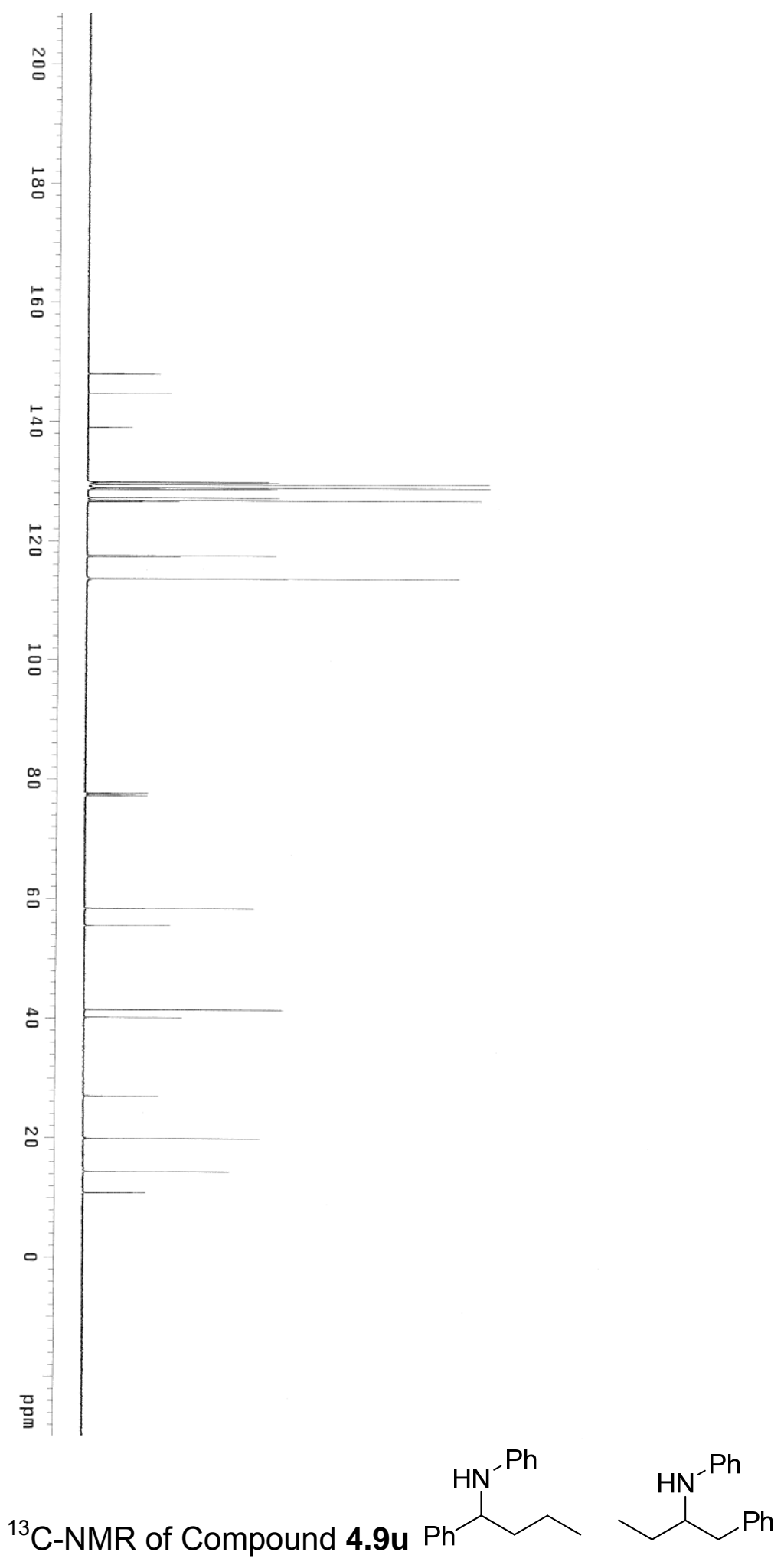




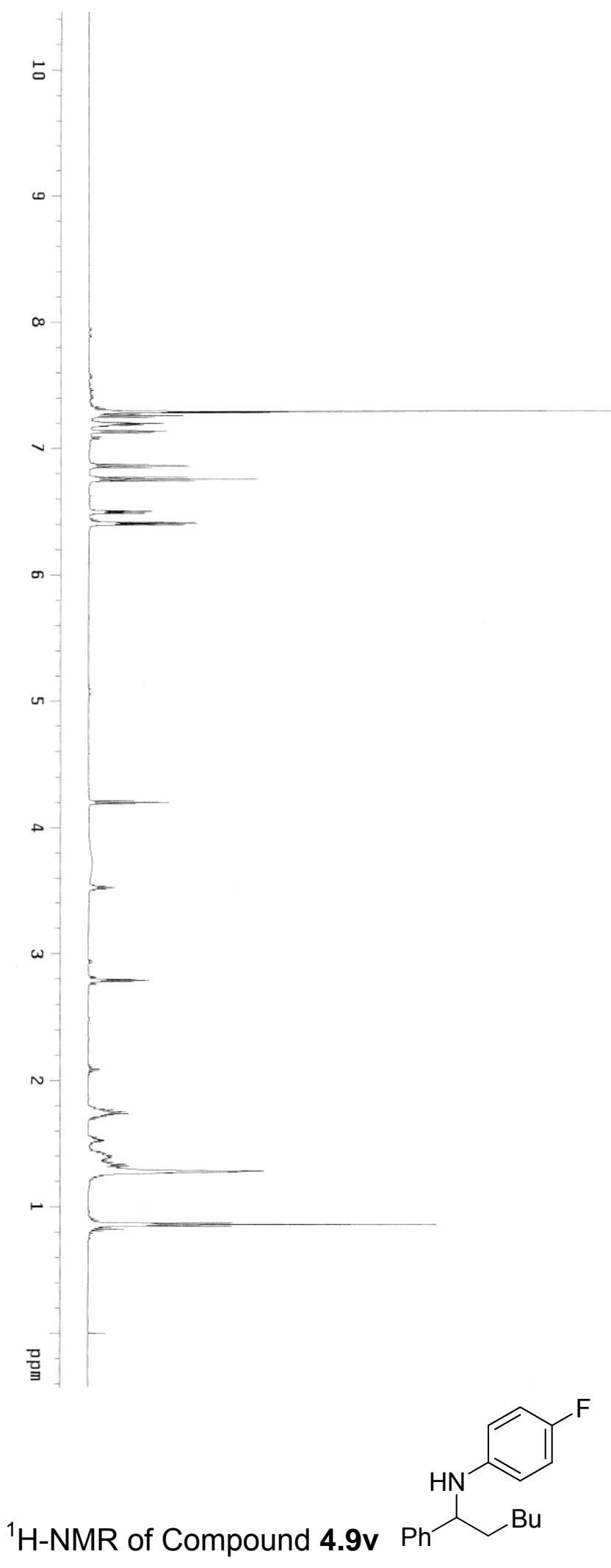



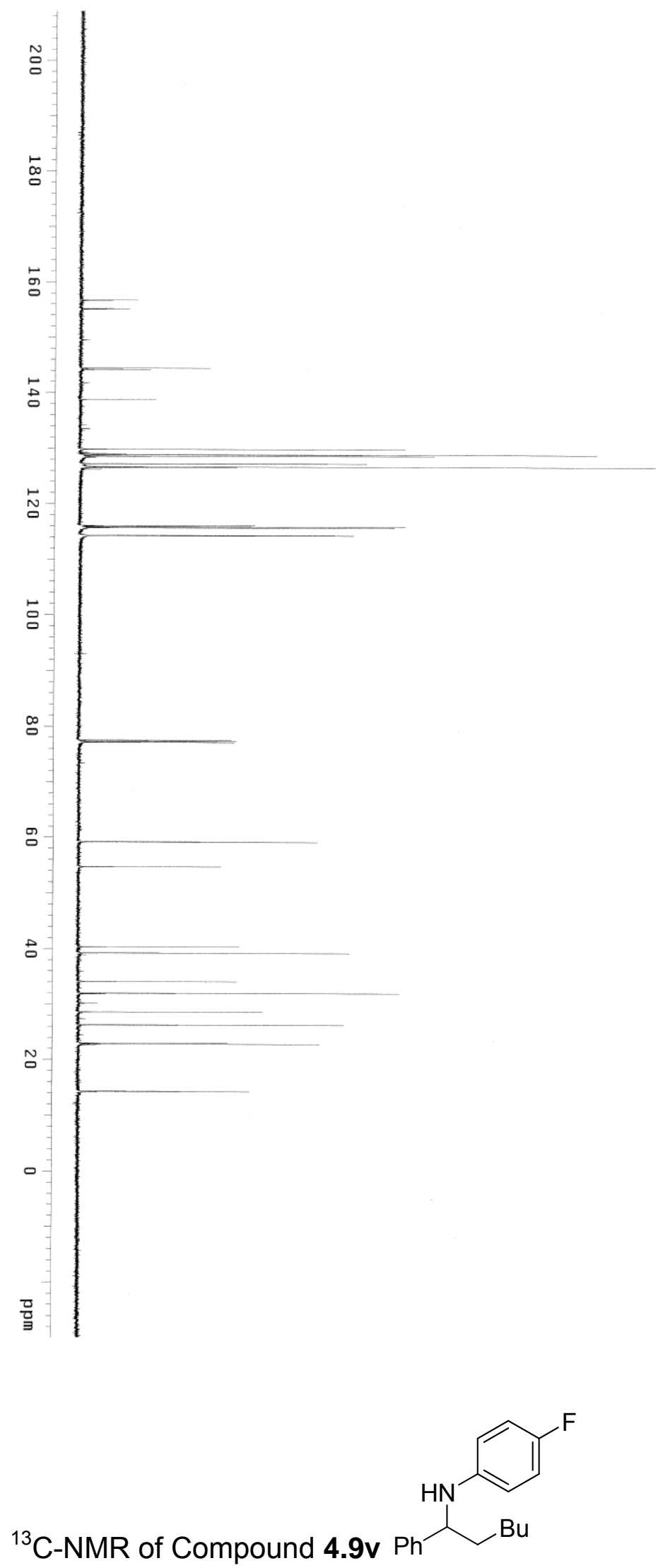


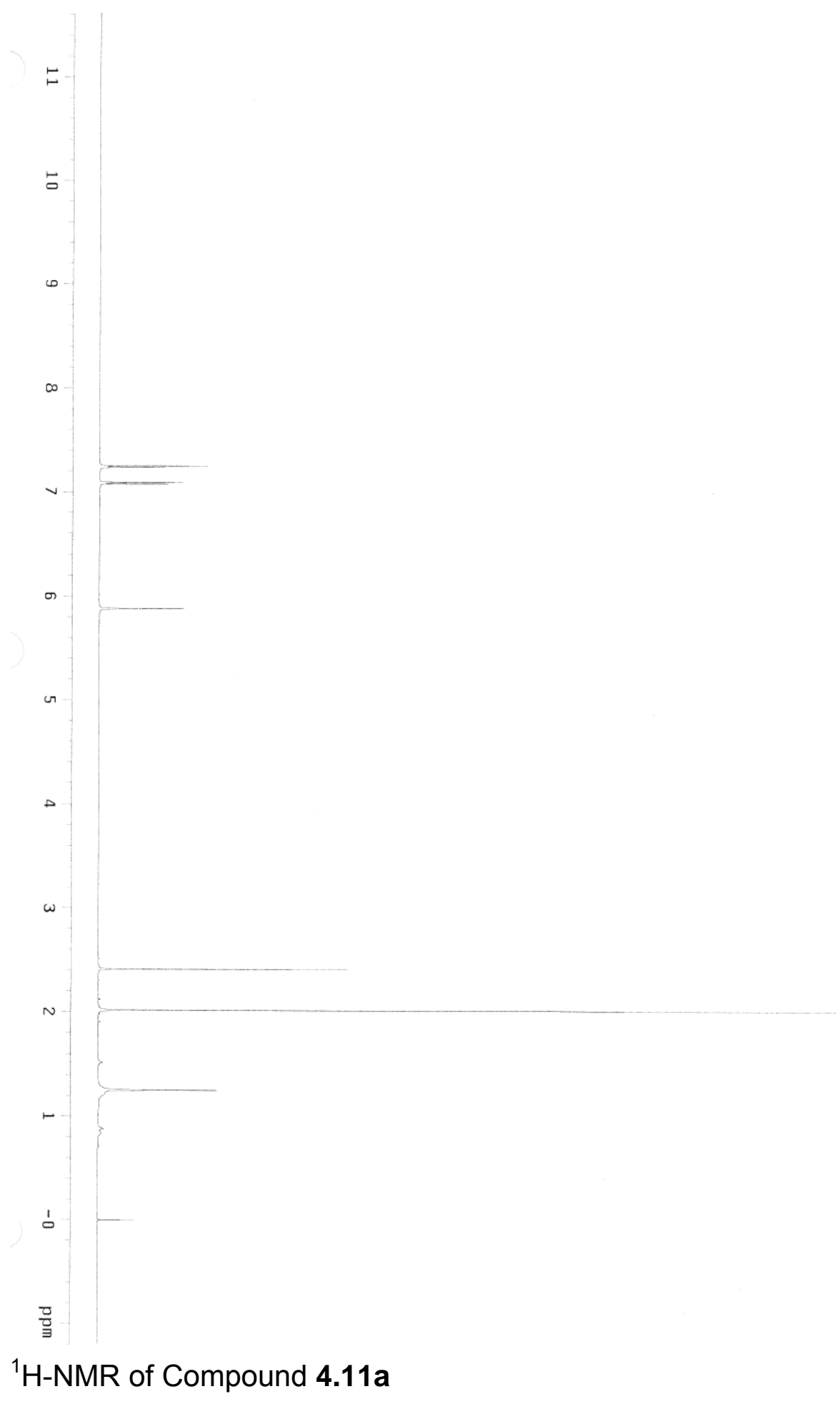




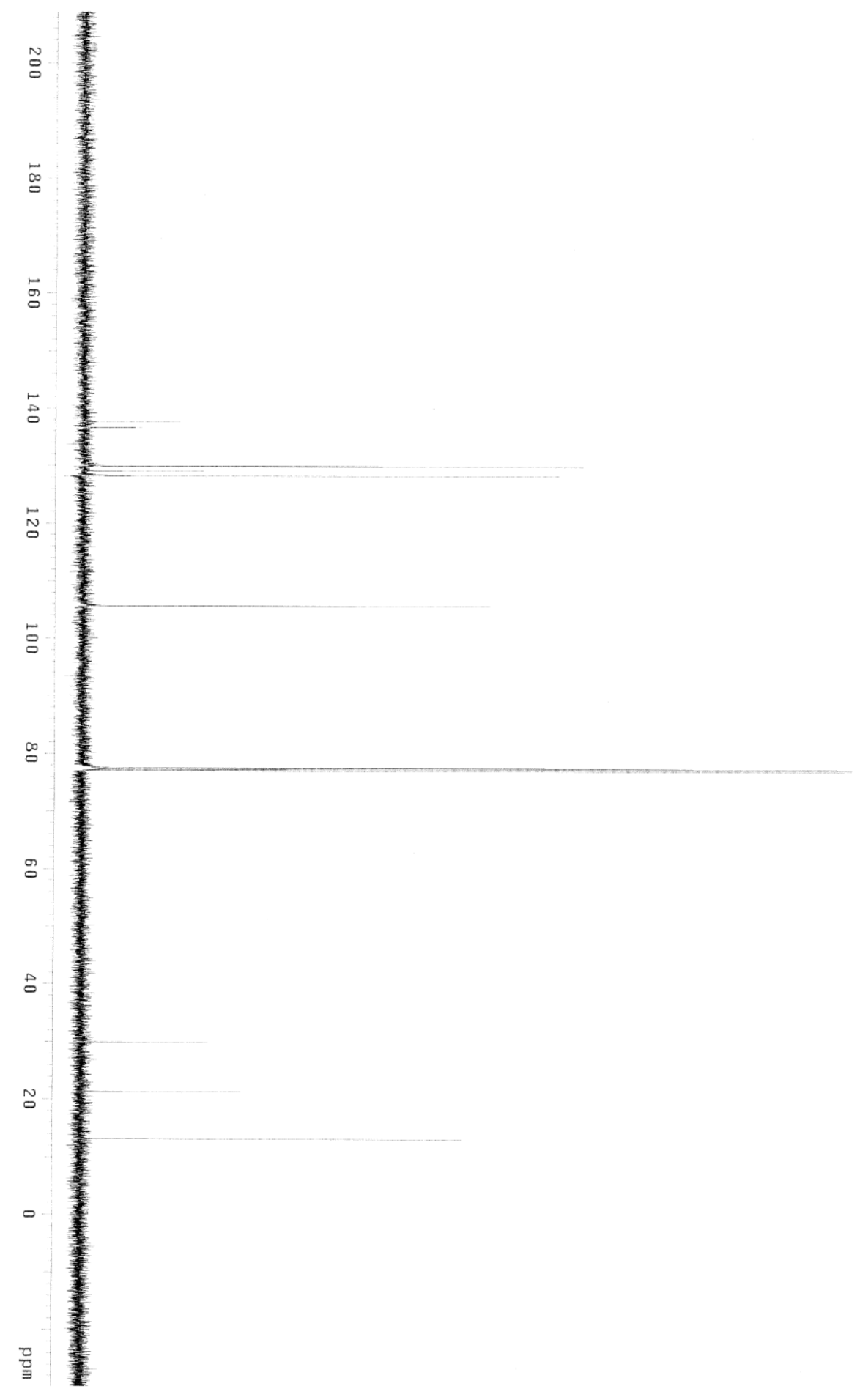

${ }^{13} \mathrm{C}-\mathrm{NMR}$ of Compound $4.11 \mathrm{a}$ 


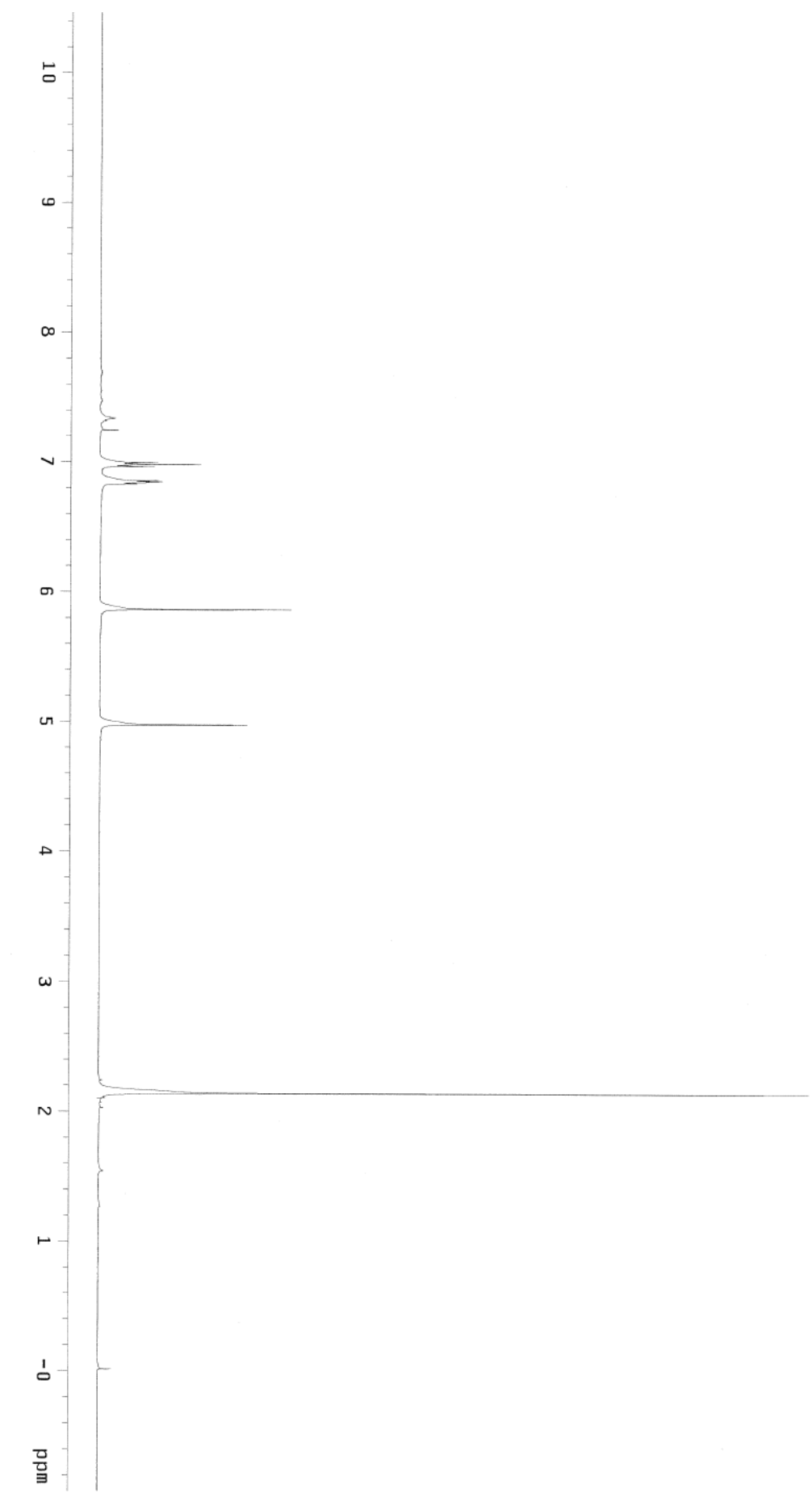

${ }^{1} \mathrm{H}-\mathrm{NMR}$ of Compound 4.11b 


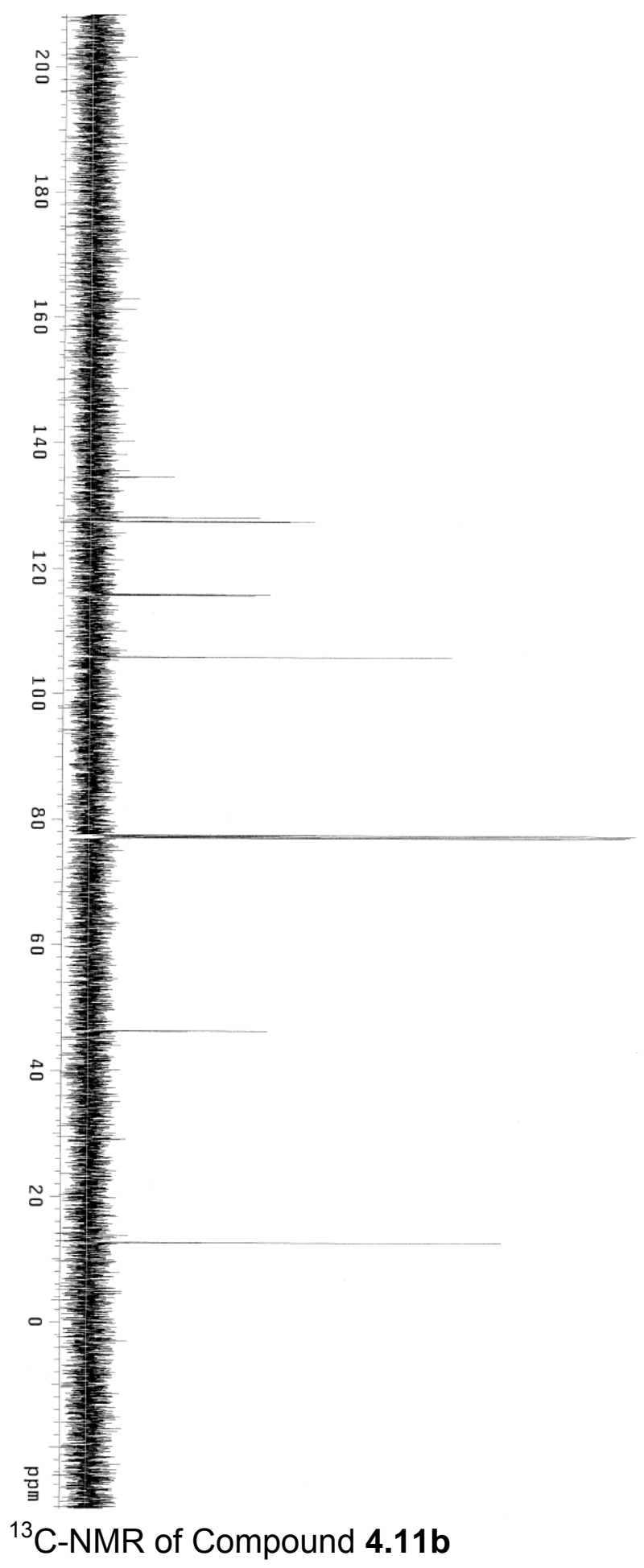




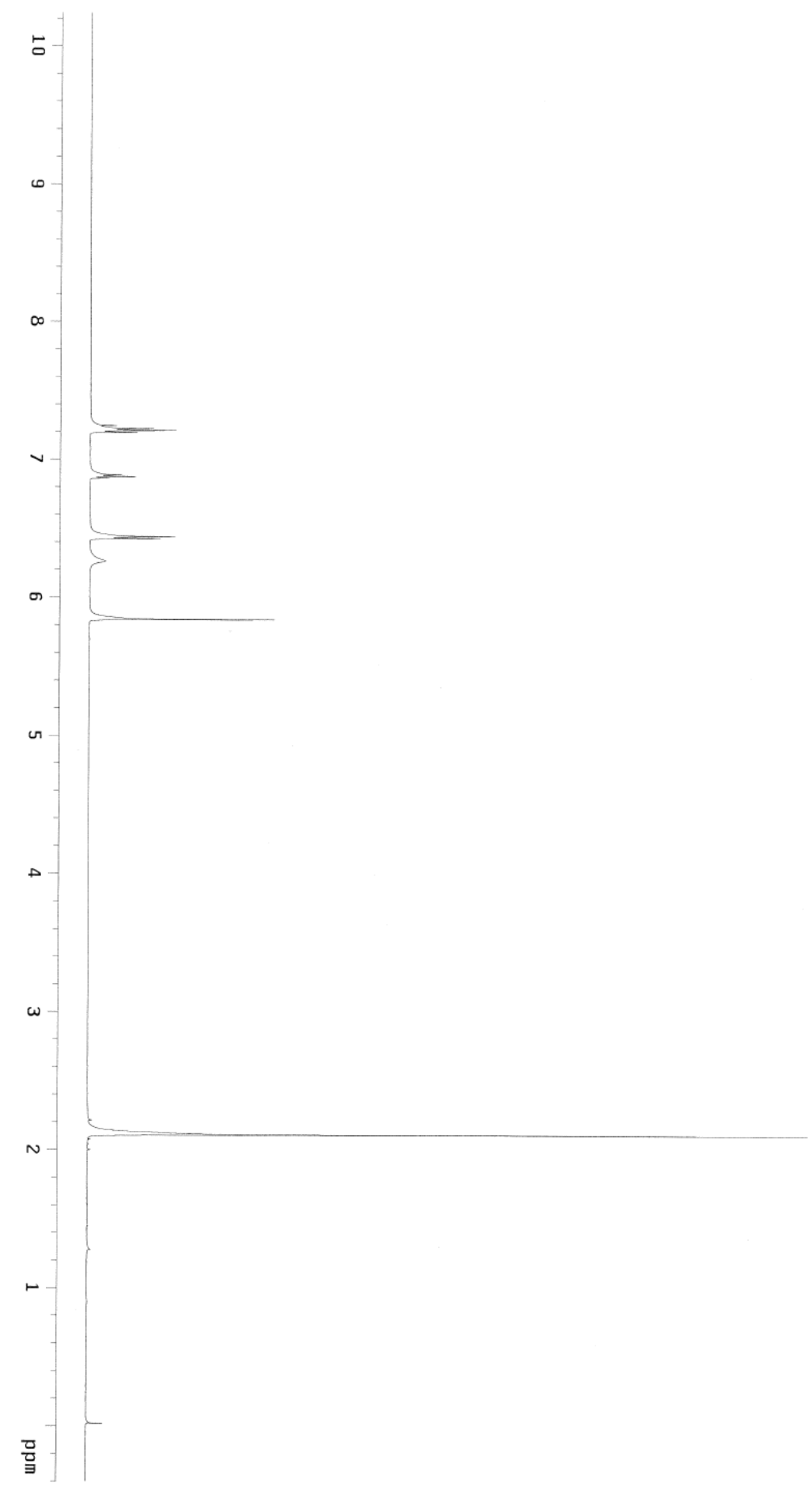

${ }^{1} \mathrm{H}-\mathrm{NMR}$ of Compound 4.11c 


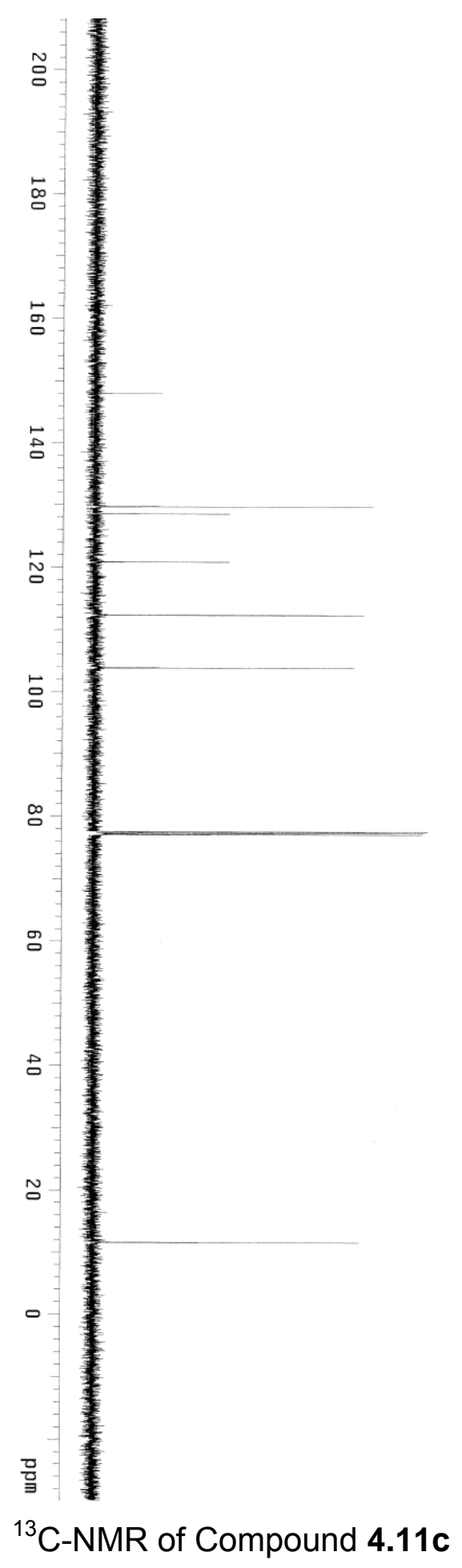

John $\mathrm{H}$. Hagen 